\title{
Entorno regional
}

y formación profesional:

los casos de Aragón, Asturias,

Cataluña, Madrid, Navarra y País Vasco

Mikel Olazaran, Ignasi Brunet (coords.)

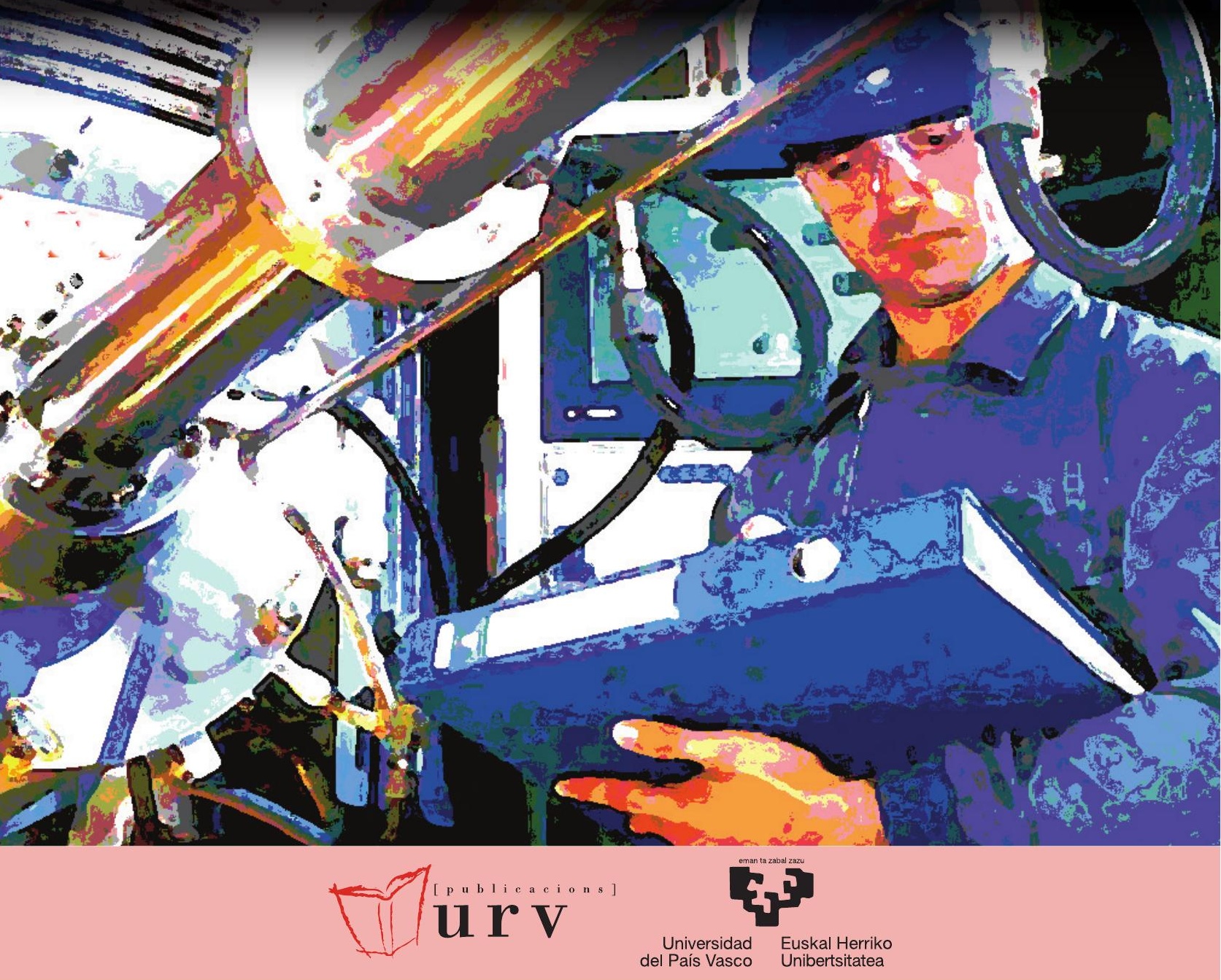





\title{
Entorno regional y formación profesional: los casos de Aragón, Asturias, Cataluña, Madrid, Navarra y País Vasco
}

\author{
Mikel Olazaran \\ Ignasi Brunet \\ (coords.)
}
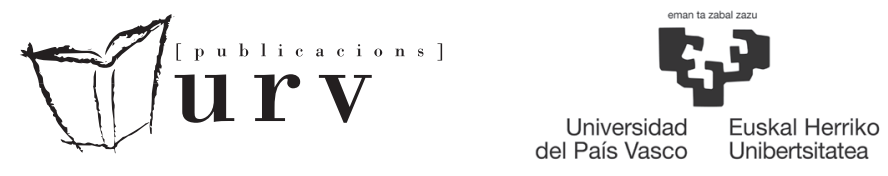

Tarragona, 2013 
Publicacions de la Universitat Rovira i Virgili

Av. Catalunya, 35 + 43002 Tarragona

Tel. 977558474 • publicacions@urv.cat

www.publicacions.urv.cat

\section{ه $y$ f}

1. a edición: septiembre de 2013

ISBN URV: 978-84-8424-243-7

ISBN UPV/EHU: 978-84-9860-899-1

Universidad del País Vasco (UPV/EHU):

Servicio Editorial

Apdo. 1397 - 48080 Bilbao (Bizkaia)

Tel. 946012227

http://www.ehu.es/argitalpenak

editorial@ehu.es

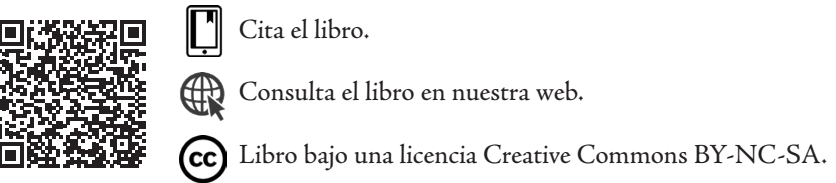

Publicacions de la Universitat Rovira i Virgili es miembro de la Unión de Editoriales

Universitarias Españolas y de la Xarxa Vives, lo que garantiza la difusión y comercialización de sus publicaciones a nivel nacional e internacional. 


\section{Índice}

$\begin{array}{ll}\text { INTRODUCCIÓN } & 7\end{array}$

$\begin{array}{ll}\text { COMUNIDAD DE ARAGÓN } & 21\end{array}$

PRINCIPADO DE ASTURIAS

$\begin{array}{ll}\text { CATALUNA } & 87\end{array}$

$\begin{array}{ll}\text { MADRID } & 129\end{array}$

COMUNIDAD FORAL DE NAVARRA (CFN) 161

COMUNIDAD AUTÓNOMA DEL PAÍS VASCO (CAPV) 189

$\begin{array}{ll}\text { CONCLUSIONES GENERALES } & 219\end{array}$

$\begin{array}{ll}\text { ANEXO } & 239\end{array}$

ÍNDICE SISTEMÁTICO 265 



\section{Introducción}

\section{Preguntas de investigación}

La formación profesional es un pilar, no suficientemente reconocido, del desarrollo económico y social. Los principales informes internacionales sobre desarrollo económico en los países industrializados ponen de manifiesto la importancia de la formación de la población y, en particular, de la formación profesional. Según un reciente estudio del centro europeo CEDEFOP (2010), la formación profesional puede convertirse en un motor de éxito y competitividad para las economías y sociedades europeas. El estudio confirma la centralidad de la formación profesional, entre otros aspectos, en el sostenimiento del desarrollo económico, en el estímulo de la capacidad de innovación empresarial y en la mejora de la productividad. En este sentido, la OCDE (2009) señala que la escasa centralidad de la formación profesional en España es una de las principales debilidades de la economía española, que se manifiesta, por ejemplo, en el bajo nivel de población activa con estudios de educación secundaria postobligatoria.

En este libro se presentan los resultados de la primera fase del proyecto de investigación «Formación profesional y sistema de innovación: el papel de los trabajadores intermedios en los procesos de innovación de las pymes industriales» (Ministerio de Ciencia e Innovación, hoy Ministerio de Economía y Competitividad, proyecto CSO2011-29410-C03, 2012-2014), donde participan investigadores de seis universidades o centros de investigación españoles.

En concreto, las principales preguntas de investigación a las que se pretende responder en esta primera fase son las siguientes:

- ¿Cómo se relacionan los centros de formación profesional (FP) y las empresas, y cuál es el alcance de los distintos tipos de relación?

- ¿Hasta qué punto realizan los centros de FP actividades como la formación continua y el apoyo a la innovación? ¿Qué potencialidades y dificultades existen al respecto?

- Y, en general, ¿cómo incide el entorno regional en la configuración del sistema de formación profesional y en la relación entre este y las empresas?

La estructura de esta introducción es la siguiente. En primer lugar, se expone el marco teórico desde el que se realiza la investigación. Posteriormente, se describe el marco normativo de la formación profesional y sus subsistemas. Finalmente, se presentan algunas magnitudes de interés de las regiones estudiadas. 


\section{Entorno regional, formación profesional e innovación‡ el marco teórico del estudio $^{1}$}

La perspectiva del sistema nacional de innovación (SNI) sostiene que las instituciones sociales condicionan o canalizan la acción económica, en general, y los procesos de innovación, en particular (Lundvall, 1992; Nelson, 1993; Edquist, 1997). Dentro de esta perspectiva, la aplicación a nivel regional («sistema regional de innovación», SRI) ha ganado una gran aceptación en años recientes (Braczyk et alii, 1996; Cooke y Morgan, 1998; Storper, 1997; Maskell y Malmberg, 1999; Cooke, Gómez y Etxeberria, 1997; Maskell, 2001; OCDE, 2001). La perspectiva del SRI enlaza con un creciente interés por la importancia del entorno regional de la innovación, especialmente para las pequeñas y medianas empresas (pymes).

Desde esta perspectiva, la innovación se concibe como un proceso de aprendizaje interactivo en el ámbito de la empresa (entre áreas funcionales, niveles jerárquicos y personas en la organización) y entre esta y otras organizaciones (clientes, proveedores, institutos de $\mathrm{I}+\mathrm{D}$, centros de formación, agencias públicas, etc.) dentro de un entorno institucional y cultural donde las relaciones entre el sector público y el privado y entre el sistema educativo y el productivo, así como otros factores como el marco de relaciones laborales, el sistema financiero o la cultura industrial tienen una gran importancia. El proceso no es lineal y se caracteriza por múltiples realimentaciones (por ejemplo, entre los clientes usuarios de una tecnología y los fabricantes de esta) y por procesos continuos de interacción entre agentes heterogéneos.

Las características institucionales de una región y sus infraestructuras de conocimiento se consideran importantes condiciones básicas que pueden servir de estímulo para promover las actividades innovadoras (Isaksen y Asheim, 2003). Diferentes estudios destacan que la región es especialmente importante para el intercambio de conocimiento tácito y para la provisión de mano de obra cualificada, ambos mecanismos muy importantes en los procesos de innovación de las empresas pequeñas (Asheim y Coenen, 2005; Kauffmann y Tödtling, 2003; Grotz y Braun, 1997; Doloreux 2003; Gebauer et alii, 2005). La proximidad geográfica adquiere una importancia esencial en el surgimiento de capacidades de innovación (Asheim y Gertler, 2005: 309-310). La confianza, la reciprocidad, los valores compartidos, las redes y las normas aceleran la transferencia de información y el desarrollo de nuevo conocimiento. En este sentido, las redes de colaboración interempresarial e interorganizacional son particularmente importantes en el caso de las pymes, que conforman la gran mayoría del tejido empresarial europeo.

La perspectiva del sistema de innovación ha señalado la importancia de las innovaciones incrementales ligadas a la actividad productiva habitual, a la adopción e implementación de tecnologías y a la interacción entre usuarios y productores de sistemas técnicos (Rosenberg, 1994; von Hippel, 1988). En esta línea, recientemente se ha señalado la existencia de dos «modos de innovación»: el basado más directamente en la ciencia y la tecnología (modo STI, Science, Technology and Innovation) y el basado en las actividades productivas habituales y el aprendizaje interactivo (modo DUI, Doing, Using and Interacting) (Jensen et alii, 2007; Lundvall y Lorenz, 2007). El modo de innovación STI, típico de sectores de alta tecnología, se caracteriza por la importancia del conocimiento codificado, del personal científico interno y de las relaciones con instituciones científico-tecnológicas externas. Por el contrario, en el modelo DUI, más relacionado con la innovación incremental, prima la interacción entre personas y entre departamentos,

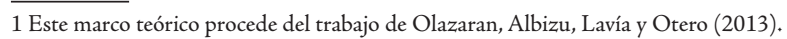


el intercambio de conocimiento tácito y la relación estrecha con usuarios o clientes ${ }^{2}$. No obstante, cabe señalar que se trata de dos «tipos ideales» o modelos que pueden coexistir en el mismo sector e incluso en la misma empresa.

Aunque se reconoce que el sistema de innovación está «enraizado» en el sistema de producción y en el «sistema de desarrollo de los recursos humanos» (Lundvall, 2002; Lundvall y Christensen, 2003), los estudios recientes realizados desde esta perspectiva se han centrado, en lo que al papel de las infraestructuras de conocimiento se refiere, en el estudio de centros tecnológicos y universidades, descuidando el papel que estructuras como los centros de formación profesional pueden jugar en relación con las pymes. El estudio del papel de los institutos técnicos de FP se retrotrae a los estudios sobre clústeres y distritos industriales, siendo una referencia central a este respecto los trabajos de Stuart Rosenfeld sobre el papel de algunas regiones de Estados Unidos (Rosenfeld 1998a, 1998b). Este autor sugirió que los institutos de educación y formación profesional técnica están en mejor posición que las universidades para dar servicio a las pymes, y que en algunos sectores industriales existe un problema de falta de técnicos y no tanto de ingenieros (Rosenfeld, 1998a, pp. 6 y 35). El papel que los institutos técnicos de FP pueden jugar en el desarrollo regional ha sido reconocido en trabajos más recientes (Curtain, 2004; Moodie, 2006; Veluzzi, 2010), aunque, como señala este último autor (ibidem, p. 205), dicho papel no ha sido suficientemente estudiado.

Como señaló Rosenfeld (1998a, p. 9 y ss.) en su informe para la OCDE, los centros de FP realizan distintas funciones en relación con el sistema económico, como son: la educación reglada (formación de capital humano), la formación continua de trabajadores y los servicios técnicos a las empresas (pudiendo llegar al apoyo a las pymes en los procesos de innovación). En relación con esta última función, se menciona también el posible papel de animador de la cooperación interempresarial y la importancia de las relaciones con las asociaciones empresariales y agencias de desarrollo local. Esta taxonomía de misiones sigue estando aceptada tanto en la literatura más reciente (véase, por ejemplo, Gurthie y Dawe, 2004) como en la práctica de los propios agentes educativos.

Respecto a la educación reglada (función más tradicional de los institutos de FP), se señala la necesidad de que los centros educativos adapten su programación o currículum a las necesidades de las empresas, de que dispongan de sistemas de prácticas y servicios de colocación de los egresados y de que el personal de los centros tenga experiencia en la industria (Rosenfeld, 1998a; Curtain, 2004, pp. 45-46 y 53).

Por su parte, la formación continua sería, en orden de importancia, la primera misión «no tradicional» que realizan los institutos de FP. En los casos de las regiones norteamericanas avanzadas estudiadas, Rosenfeld (1998b, p. 18) señaló que la formación continua se había convertido en un elemento central de los programas educativos de los institutos técnicos sobre la base de financiación proveniente de agencias gubernamentales del ámbito económico o del empleo. La implantación de nuevas tecnologías en las empresas exige frecuentemente cambios en los procesos y en los sistemas de gestión que generan necesidades formativas que van más allá de la formación proporcionada por los proveedores de las tecnologías. Por lo tanto, la inversión en nuevas tecnologías exigiría una inversión paralela en formación continua (Rosenfeld, 1998a, pp. 6 y 16).

La tercera misión (segunda misión «no tradicional») de los institutos de FP (los servicios técnicos a las empresas) está relacionada con la visión amplia de los procesos de innovación

2 Recientemente hemos mostrado la pertinencia del modelo DUI para comprender los procesos de innovación en pymes industriales españolas (Lavía et alii, 2011; Olazaran et alii, 2011). 
como procesos incrementales, de aprendizaje continuo, relacionados con las actividades productivas habituales y que afectan también a sectores de intensidad tecnológica media o baja, así como a empresas pequeñas y medianas. Este tipo de innovación se refiere a desarrollos, adaptaciones y recombinaciones de elementos técnicos existentes, así como a mejoras en los procesos, y no tanto a tareas de investigación básica o aplicada (Guthrie y Dawe, 2004, p. 12; Moodie, 2006, p. 6).

A este respecto, diversos estudios señalan la necesidad de coordinación entre los centros de FP y los centros tecnológicos. Tradicionalmente, los institutos técnicos han jugado un papel en la innovación y en el desarrollo local en momentos en los que las actividades de I+D formalizadas como tales apenas existían (Guthrie y Dawe, en su trabajo de 2004, señalan el caso australiano como ejemplo). El surgimiento de nuevos agentes de $\mathrm{I}+\mathrm{D}$ como son los centros tecnológicos («centros cooperativos» en Australia), que cubren nuevas necesidades, no debiera desligarse de los institutos de FP, que serían así «usuarios» de la investigación realizada por los centros tecnológicos, con los que colaborarían en el diseño y desarrollo de nuevos sistemas y procesos (Whittingham, Ferrier y Trood, 2004; Guthrie y Dawe, 2004). No obstante, estos autores reconocen que en el caso australiano no se han hecho los suficientes esfuerzos para relacionar estas dos estructuras. En general, como señalan estos estudios, la participación de los centros de FP en misiones diferentes de las tradicionales se ve obstaculizada a menudo por diversas barreras como la falta de autonomía o flexibilidad de los institutos, la falta de incentivos o de instrumentos públicos de fomento y la falta de relación con otros agentes de $\mathrm{I}+\mathrm{D}$ tales como los centros tecnológicos.

La falta de conexión entre la formación profesional y la innovación se retrotrae, en última instancia, a factores culturales e institucionales. Como han indicado Bosch y Charest (2008, p. 430), mientras que en algunos países (el ejemplo típico sería Alemania) la posesión de una credencial educativa en FP es una señal de que el egresado en cuestión tiene capacidad para realizar autónomamente tareas complejas en un ámbito ocupacional amplio, en otros países dicho título es una señal de fracaso académico y de capacidad de realizar únicamente tareas específicas de baja cualificación ${ }^{3}$.

En el ámbito de las empresas y la organización del trabajo se tiende a olvidar que los trabajadores técnicos con cualificaciones intermedias intervienen en el diseño, funcionamiento y mantenimiento de los productos y procesos, y, por lo tanto, contribuyen (o pueden contribuir) a la innovación en las empresas (Toner, 2009; Tether et alii, 2005). Las empresas innovadoras necesitan una plantilla cualificada e implicada en la mejora continua de procesos y productos. Es más, como han mostrado Toner, Turpin y Woolley (2010), buena parte del personal de I+D registrado por las estadísticas habituales (46\% del personal de I+D empresarial en Australia) está formado por trabajadores técnicos cualificados procedentes de la formación profesional que no solo realizan tareas de apoyo a los ingenieros o científicos, sino también tareas creativas y autónomas de resolución de problemas y de adaptación de las ideas propuestas por aquellos.

En este orden de cosas, Olazaran et alii (2013), en su análisis de las pymes industriales navarras, ponen de manifiesto que los trabajadores con perfil de FP desempeñan un papel activo en los procesos de innovación. El tipo de innovación para el que comparativamente se concede mayor importancia a la participación de los trabajadores es el desarrollo de nuevos procesos

\footnotetext{
3 La literatura institucionalista y de economía política muestra que los sistemas productivos, de relaciones laborales y de estatus nacionales, así como las políticas públicas, afectan de manera muy importante a la concepción y organización de la formación profesional (véanse, por ejemplo, Brinton, 2005; Brown, Green y Lauder, 2001; Estevez-Abe, Iversen y Soskice, 2001). Sin embargo, esta literatura apenas conecta con el estudio de los procesos de innovación en las empresas.
} 
y la implantación de nuevas tecnologías, y el aspecto en el que tienen menor consideración los trabajadores de FP es el relativo al desarrollo de nuevos productos. No obstante, a la vista de los datos recogidos en su trabajo, cabe afirmar que la aportación reconocida de los trabajadores técnicos a la innovación es en la actualidad relativamente baja. Por el contrario, tanto en este mismo trabajo como en el realizado por Albizu et alii (2011), en relación con la aportación de la FP a las pymes industriales en el País Vasco, se revela que la valoración que efectúan las empresas sobre los servicios prestados por la red de centros de FP en estas dos regiones es muy positiva.

Los obstáculos para una mayor participación de los trabajadores técnicos en los procesos de innovación pueden estar relacionados con la cultura y los sistemas organizativos de las empresas. Recientemente, se han realizado estudios que muestran un nivel de correlación importante entre las actividades de formación continua en las empresas europeas y la utilización de formas organizativas avanzadas o «aprendizaje discrecional», que sería vista como una dimensión de los procesos de innovación (Lundvall, Rasmussen y Lorenz, 2008; Lundvall, 2009). Estos trabajos apuntan la existencia de una divisoria norte-sur en Europa: las economías más avanzadas e innovadoras se caracterizarían por un mayor nivel de aprendizaje organizacional. Se indica que países como Portugal, España, Italia y Grecia, que han realizado importantes esfuerzos dirigidos a aumentar el número de graduados en ciencia e ingeniería, destacan por sus bajos niveles de actividades de formación continua y de aprendizaje organizativo (Lundvall, Rasmussen y Lorenz, 2008, p. 689).

En suma, aunque en distintas instancias y discursos se reconoce que una estructura de cualificaciones técnicas intermedias más distribuidas y de más nivel conceptual puede jugar un papel en los procesos de innovación, tal y como indica Toner (2009, p. 61), se han hecho pocos trabajos en el campo de los estudios de la innovación, o de otras disciplinas, que lleguen a operacionalizar esta influencia. Algunos casos pilotos analizados mostrarían que los sistemas de organización participativos posibilitan que los trabajadores cualificados procedentes de la FP realicen aportaciones dirigidas a la mejora de productos y procesos, y favorecen la satisfacción de las empresas con la formación (tanto reglada como continua) ofrecida por los centros de FP (Toner, Marceu, Hall y Considine, 2004, pp. 98 y 101).

\section{Marco normativo de la formación profesional}

En los últimos años se han llevado a cabo importantes reformas en el sistema español de formación profesional. Cabe mencionar a este respecto la implantación de los nuevos grados medio y superior a partir de la LOGSE, la institucionalización de los convenios con las empresas para la formación en centros de trabajo (FCT) y la revisión de los planes de estudios sobre la base de las competencias y los módulos profesionales. A partir de las leyes orgánicas 5/2002 y 2/2006 y sus desarrollos, siguen su curso en la actualidad los cambios dirigidos a la definición e implantación del sistema de cualificaciones y la integración de los distintos sistemas de formación (reglada, continua y ocupacional). Estos cambios responden a las directrices europeas (Lisboa 2000, Copenhague 2002 y Maastricht 2004), dirigidas a adaptar la formación y cualificación laboral a las demandas de los sectores productivos y a las necesidades de los trabajadores, dentro de una visión de «aprendizaje permanente» como elemento clave de innovación, competitividad y bienestar social en Europa.

El sistema de formación profesional español está regulado básicamente por la Ley Orgánica de las Cualificaciones y de la Formación Profesional (Ley Orgánica, 2002), la cual adop- 
ta una perspectiva integrada y trata de considerar a la formación como un sistema. La Ley se ha desarrollado posteriormente en dos reales decretos, que establecen, de hecho, dos subsistemas. Por una parte, el Real Decreto de 2006 regula la formación inicial en el marco del sistema educativo y depende del Ministerio de Educación. Por otra, el Real Decreto de 2007, que integra la antigua formación ocupacional y la formación continua, regula la formación para el empleo y depende del Ministerio de Trabajo e Inmigración. Así, aunque existe una voluntad integradora, en la práctica existe una subdivisión entre la formación inicial y la formación para el empleo, con una articulación incompleta entre ambos sistemas (Homs, 2008).

\section{Formación profesional inicial}

Desde la LOGSE, la formación profesional inicial está estructurada en torno a dos ciclos formativos: grado medio y grado superior.

Los ciclos formativos de grado medio dan lugar a la obtención de la titulación de técnico de la profesión correspondiente y están integrados en la educación secundaria postobligatoria. Estos ciclos constituyen la vía de especialización profesional para los jóvenes que, al finalizar los estudios obligatorios de la ESO, quieren incorporarse al mercado de trabajo. Están diseñados para ofrecer una mano de obra especializada y cualificada que permita ocupar puestos de trabajo de la producción directa en los sectores de la industria o de los servicios.

Los ciclos formativos de grado superior permiten la obtención de la titulación de técnico superior y están encuadrados dentro de la educación terciaria. Constituyen la oferta para la especialización de los jóvenes que, al finalizar el bachillerato, deciden incorporarse al mercado de trabajo. En contraste con el grado medio, el grado superior está pensado para formar futuros técnicos altamente especializados o los mandos intermedios de las empresas de cualquier sector económico.

Se puede acceder a los ciclos de grado medio una vez obtenido el graduado de educación secundaria obligatoria (ESO). Esta exigencia, que asegura un nivel mínimo homogéneo de conocimientos y capacidades, ha contribuido en gran medida a elevar el nivel de calidad de estos ciclos. Lo mismo ha ocurrido con el acceso a los ciclos superiores, para el que se requiere el título de bachillerato.

Una característica importante de los ciclos formativos es la introducción por parte de la LOGSE de la formación en centros de trabajo (FCT). Se trata de la realización de prácticas en una empresa, las cuales suponen un $25 \%$ del tiempo de enseñanza de un ciclo, entre 350 y 500 horas. La FCT constituye un módulo de formación evaluable que dispone de un tutor en el centro educativo y otro en el centro de trabajo, con un plan de trabajo establecido previamente y supervisado por ambos tutores. Las prácticas en empresas han contribuido a abrir los centros de formación profesional a las empresas, a mejorar la relación entre los centros y el mundo productivo, a habituar a los profesores a relacionarse con las empresas y, sobre todo, a facilitar la inserción laboral de los jóvenes una vez obtenida su titulación.

Otro aspecto relevante de la nueva normativa es la creación de los centros integrales de formación profesional, con una oferta formativa tanto inicial como ocupacional/continua (formación para el empleo) y con funciones complementarias de acreditación de competencias, formación de profesorado y excelencia. Estos centros deberían constituir la red de innovación de todo el sistema. 


\section{Formación para el empleo}

El subsistema de formación para el empleo ha integrado la formación ocupacional, dirigida al reciclaje de los trabajadores desempleados, y la formación continua, dirigida a los trabajadores ocupados. La formación para el empleo está tutelada por el Ministerio de Trabajo e Inmigración y su gestión se ha traspasado a las comunidades autónomas, con la excepción de Ceuta y Melilla.

El traspaso de la gestión de la formación a las comunidades autónomas está siendo bastante complejo, dado que no existe un consenso entre el Gobierno central y los agentes sociales de ámbito estatal sobre cuál tiene que ser el papel de cada uno en el subsistema (Homs, 2008). En el fondo del desacuerdo se halla el debate sobre dar la prioridad a la proximidad de las necesidades territoriales de formación $-y$ en este caso son las comunidades autónomas las que tendrían que asumir plenamente las competencias que los respectivos estatutos de autonomía les otorgan, tal como ha pasado con el subsistema de formación inicial- o bien a la dimensión sectorial y al marco de relaciones laborales - y en este caso los agentes sociales y las instituciones sectoriales estatales tendrían que mantener un importante papel regulador $u$ organizador de la oferta formativa-.

El subsistema de formación para el empleo depende del Ministerio de Empleo y Seguridad Social y está básicamente regulado por el Real Decreto 395/2007, de 23 de marzo, por medio del cual se integra la antigua formación ocupacional y la formación continua, pasándose a denominar formación para el empleo.

Dentro de la formación para el empleo se establecen cuatro iniciativas diferentes:

- La formación de demanda, referida a las acciones formativas de las empresas y a los permisos individuales de formación. En este caso son los beneficiarios directos (empresas y trabajadores) los que tienen que solicitar su financiación. La iniciativa de la organización de la formación de demanda recae en las propias empresas y se financia mediante un sistema de bonificación de las cuotas a la Seguridad Social que ingresan las empresas y que pagan trabajadores y empresas.

- La formación de oferta, que hace referencia tanto a las acciones formativas dirigidas prioritariamente a los trabajadores ocupados como a las acciones formativas orientadas principalmente a los trabajadores desempleados. En este tipo de formación la iniciativa ya no proviene de la empresa y/o el trabajador, sino que son los agentes sociales, las propias administraciones públicas o las entidades sociales y privadas colaboradoras quienes organizan una oferta formativa que someten a la aprobación de una subvención por parte del dispositivo. La organización de este tipo de formación se establece en dos ámbitos diferentes - el estatal y el autonómico-, ya que, aunque las competencias para la gestión de la formación están traspasadas a las comunidades autónomas, el Servicio Público de Empleo Estatal (SPEE) y los agentes sociales se reservan la organización de un conjunto de actividades en el ámbito estatal.

- La formación en alternancia, que integra las acciones formativas de los contratos de formación y los programas públicos de formación y ocupación en los que los trabajadores pueden compartir las actividades formativas y la práctica profesional en su puesto de trabajo. En España está poco desarrollada y engloba básicamente los programas de las escuelas-taller, las casas de oficios y los talleres de ocupación, así como las acciones formativas de los contratos de formación. 
- Las acciones de apoyo y acompañamiento, definidas como las destinadas a mejorar la eficacia del subsistema. Por medio de estas acciones se subvencionan estudios, programas, instrumentos y metodologías que se emplearán para la mejora de la calidad de las actividades formativas.

Las fuentes de financiación para la formación en el empleo son los fondos estructurales europeos y la cuota de formación profesional ${ }^{4}$. Las acciones destinadas prioritariamente a trabajadores ocupados (tanto de oferta como de demanda) son gestionadas por la Fundación Tripartita para la Formación en el Empleo ${ }^{5}$. Las acciones dirigidas prioritariamente a trabajadores desempleados son impartidas por el Servicio Público de Empleo Estatal (SPEE-INEM) directamente o a través de sus centros colaboradores, por otros centros homologados y por las comunidades autónomas que tienen funciones transferidas en esta materia (todas, con la excepción de Ceuta y Melilla).

\section{Regiones estudiadas}

El estudio realizado se refiere a regiones industriales españolas (Aragón, Asturias, Cataluña, Navarra y País Vasco), a las que se ha añadido el caso de Madrid. El objetivo es analizar la situación del sistema de formación profesional y su relación con el tejido productivo, con especial atención a la incidencia del entorno regional en dichos procesos.

Las CC. AA. estudiadas representan un 46\% de la población española, un 49,6\% del PIB y un 54,7\% del valor añadido bruto (VAB) industrial. En general, se trata (con la excepción de Madrid) de regiones industriales, en el sentido de que el peso de su sector industrial es muy superior a la media española. En cuanto al nivel tecnológico de la industria, las regiones estudiadas, con la excepción de Asturias, cuentan con niveles de VAB de los sectores de alta y mediaalta tecnología en su industria manufacturera notablemente superiores a la media española. El 60\% de la I+D española se concentra en cuatro de las comunidades autónomas estudiadas (Madrid, País Vasco, Navarra y Cataluña).

En las regiones analizadas el nivel de desempleo es inferior a la media española y el nivel educativo (medido por el nivel de población con estudios secundarios superiores y terciarios) superior a dicha media, destacando a este respecto el País Vasco, Madrid y Navarra. Son, asimismo, regiones más prósperas (en términos de PIB per cápita) que la media estatal, con la excepción de Asturias.

\footnotetext{
4 La cuota de formación profesional es la cantidad resultante de aplicar el tipo de 0,7\% sobre la base de cotización de contingencias comunes que aportan las empresas y los trabajadores a la Seguridad Social. De este tipo global, el 0,6\% lo aporta la empresa y el 0,1\% restante, el trabajador. Desde la Ley de Presupuestos Generales del Estado de 2005, del total de fondos recaudados por esta vía, el 60\% se destina a la formación de trabajadores ocupados y el $40 \%$, a la de trabajadores desempleados.

5 La Fundación Tripartita para la Formación en el Empleo tiene carácter tripartito y su patronato está constituido por la Administración general del Estado/Ministerio de Trabajo e Inmigración y por las organizaciones empresariales CEOE y CEPYME y las sindicales UGT, CC. OO. y CIG.
} 
Tabla 1.1. Indicadores socioeconómicos de España y de las seis regiones (2010)

\begin{tabular}{|l|c|c|c|c|c|c|c|}
\hline & Aragón & Asturias & Cataluña & Madrid & Navarra & País Vasco & España \\
\hline \% población española & 2,9 & 2,3 & 16,0 & 13,8 & 1,4 & 4,6 & 100,0 \\
\hline \% del PIB total español & 3,2 & 2,2 & 18,6 & 17,8 & 1,7 & 6,1 & 100,0 \\
\hline $\begin{array}{l}\text { PIB per cápita / media } \\
\text { nacional (=100) }\end{array}$ & 111,0 & 94,1 & 116,9 & 128,6 & 128,0 & 132,1 & 100,0 \\
\hline $\begin{array}{l}\text { \% VAB industrial / PIB } \\
\text { regional }\end{array}$ & 19,0 & 19,0 & 18,8 & 9,4 & 26,7 & 23,5 & 14,8 \\
\hline $\begin{array}{l}\text { \% sectores alta y media- } \\
\text { alta tecnología en industria } \\
\text { manufacturera }\end{array}$ & 36,3 & 13,7 & 33,6 & 33,7 & 36,7 & 31,7 & 26,6 \\
\hline Tasa de paro & 14,77 & 15,97 & 17,75 & 16,08 & 11,85 & 10,55 & 20,06 \\
\hline $\begin{array}{l}\text { Gasto I+D sobre el PIB } \\
\text { (\%) }\end{array}$ & 1,15 & 1,03 & 1,63 & 2,02 & 1,97 & 1,95 & 1,39 \\
\hline $\begin{array}{l}\text { \% del gasto I+D total } \\
\text { español }\end{array}$ & 2,6 & 1,6 & 22,1 & 16,4 & 2,5 & 8,9 & 100,0 \\
\hline
\end{tabular}

Fuente: INE

Las regiones analizadas están, con la excepción de Madrid, por encima de la media española de población ocupada con nivel de estudios de formación profesional (FP), que es del 19,5\%, destacando con claridad a este respecto los casos del País Vasco (30,1\%), Navarra $(27,3 \%)$ y Asturias $(25,3 \%)$, especialmente en lo que se refiere a la incidencia de la FP de grado superior (véase el gráfico 1.1). Las tablas 3.19 y 3.20 del anexo muestran el crecimiento de las tasas brutas de escolarización en ciclos de FP en España y en las regiones estudiadas en los últimos años, destacando la alta incidencia de los ciclos de grado superior en el País Vasco.

Gráfico 1.1. Porcentaje de personas con estudios de FP dentro de la población ocupada (2010)

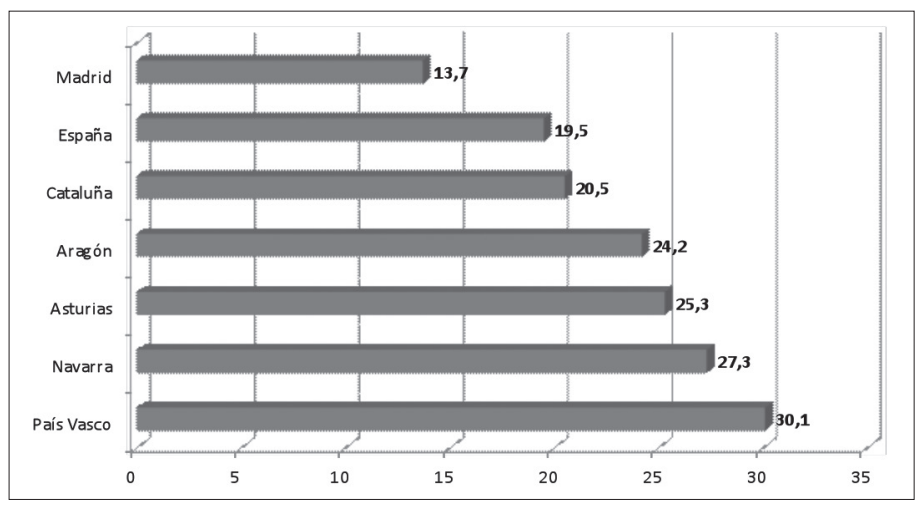

Fuente: Instituto Valenciano de Investigaciones Económicas

A partir de los indicadores revisados, cabe plantear algunas consideraciones interesantes respecto a la incidencia de los perfiles de FP en la industria y en las actividades de innova- 
ción. En cuanto a la incidencia de la FP en la industria, destaca el crecimiento en el porcentaje de personas con titulación de FP ocupadas en dicho sector, que, partiendo de un 4,9\% en 1985, ha llegado al 25,8\% en 2010 en España (véase el gráfico 1.2). De nuevo el País Vasco, Navarra y Asturias presentan los índices más destacados a este respecto, con un $44,2 \%$, un $39,1 \%$ y un $34,7 \%$, respectivamente.

Gráfico 1.2. Evolución del porcentaje de personas ocupadas en la industria con titulación de formación profesional (1985-2010)

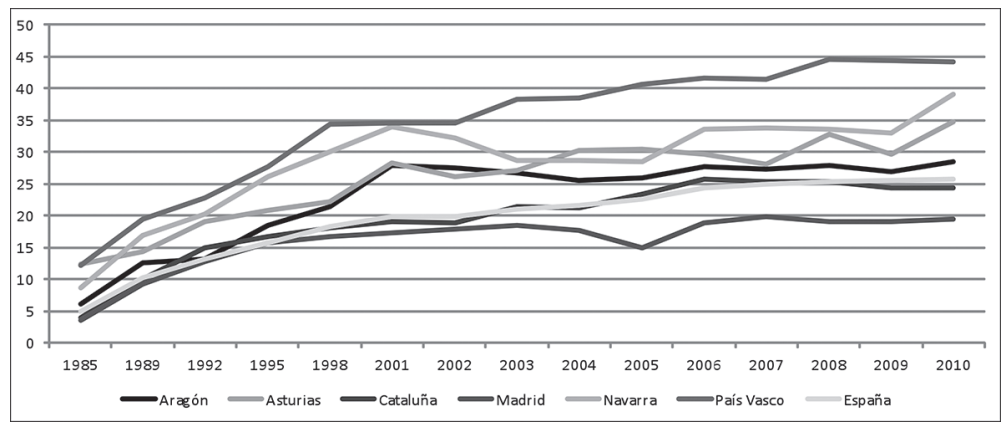

Fuente: Instituto Valenciano de Investigaciones Económicas

Un aspecto interesante de la década de crecimiento vivida en España con anterioridad a la actual crisis es el aumento de los recursos dedicados a $\mathrm{I}+\mathrm{D}$, que han pasado, en términos relativos al PIB, del 0,80\% en 1997 al 1,39\% en 2010. La actividad de I+D en España se haya altamente regionalizada (Cruz et alii, 2010). Destacan, a este respecto, como se ha indicado, cuatro de las CC. AA. analizadas en este informe (Madrid, Navarra, País Vasco y Cataluña), que juntas suman un $60 \%$ del gasto estatal en I+D. De entre las regiones estudiadas, Aragón y Asturias quedarían por debajo de la media estatal. Este patrón se reproduce en el gasto en $\mathrm{I}+\mathrm{D}$ en el sector empresas (como porcentaje del PIB), donde destacan de nuevo las cuatro CC. AA. mencionadas, siendo el nivel de Aragón y Asturias inferior a la media española (véase la tabla 3.6 del anexo).

Tal y como proponen Toner et alii (2010), el personal con perfil de FP puede jugar un papel relevante en los procesos de innovación, así como en su núcleo técnico: las actividades de $\mathrm{I}+\mathrm{D}$. Los datos revisados sobre personal de $\mathrm{I}+\mathrm{D}$ en España muestran que los técnicos y auxiliares (donde se ubican los profesionales con perfil de FP) suponen un 39,4\% del personal total (esto es, incluyendo todos los sectores: empresa, sector público y universidad).

En el sector industrial, los técnicos con perfil de FP suponen el 23,3\% del personal de $\mathrm{I}+\mathrm{D}$ de las empresas industriales españolas (tabla 3.10 del anexo). Si a este porcentaje le añadimos el de diplomados, la cifra alcanza el $44,6 \%$ del personal de I+D (frente a un 42,8\% de licenciados). En el País Vasco, región que presenta un gran desarrollo de la FP, dicho porcentaje alcanza un $52 \%$ del personal de $\mathrm{I}+\mathrm{D}$ de la industria. La visión frecuentemente dominante de que la $\mathrm{I}+\mathrm{D}$ es una cuestión «de ingenieros» queda refutada por esta constatación. 


\section{Gráfico 1.3. Personal EDP en el sector industrial dedicado a actividades} en $\mathrm{I}+\mathrm{D}$ por titulación y región $(2010)(\%)$

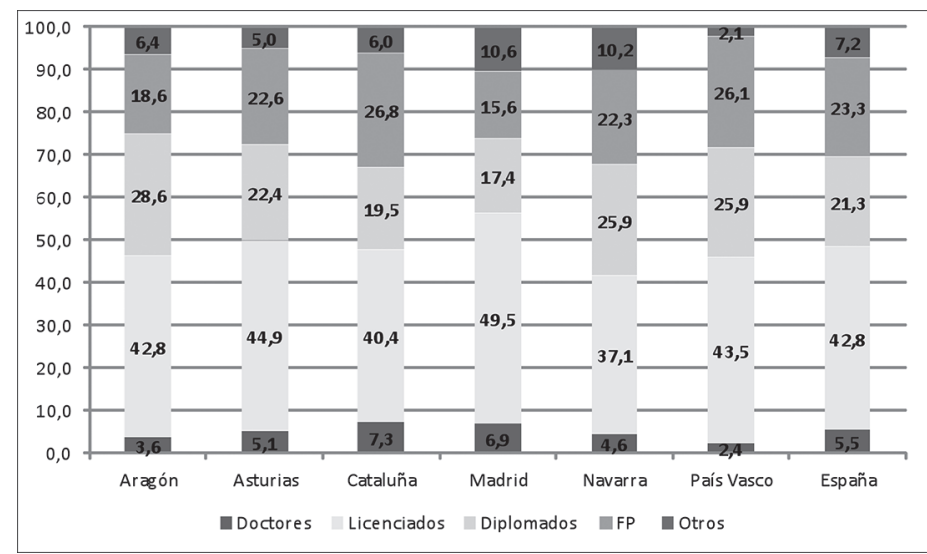

Fuente: INE

A continuación se incluyen los informes realizados por los equipos de las distintas regiones estudiadas. Los informes constan de tres partes principales. La primera se refiere al entorno regional e incluye una revisión de indicadores socioeconómicos y de innovación. En la segunda se revisa el estado de la formación profesional en cada una de las regiones y se incide, sobre la base de evidencia cualitativa propia, en los distintos tipos de relación entre los centros de FP y las empresas, así como en los obstáculos que impiden una mayor integración del sistema de formación y una mayor relación con el entorno empresarial. En la tercera parte de cada informe regional se presentan las conclusiones relativas al caso.

Finalmente, en el último capítulo del libro se ofrecen las conclusiones generales y comparativas derivadas de los estudios realizados en las seis regiones.

\section{Bibliografía}

Albizu, E.; Olazaran, M.; Lavía, C. y Otero, B. (2011): «Relationship between vocational training centres and industrial SMEs in the Basque Country: A regional innovation system approach», Intangible Capital 7(2), pp. 329-355.

Asheim, B. y Gertler, M. (2005): «The Geography of Innovation: Regional Innovation Systems», en Fageberg, J.; Mowery, D. y Nelson, R. (eds.), The Oxford Handbook of Innovation, Oxford, Oxford University Press, pp. 291-317.

Asheim, B.T. y Coenen, L. (2005): «Knowledge bases and regional innovation systems: comparing nordic clusters», Research policy, vol. 34, n. ${ }^{\circ}$ 8, pp. 173-1190.

Basterretxea, I.; González, A.; Saiz, M.y Simón, L. (2002): Colaboración entre los centros de Formación Profesional y las empresas en la Comunidad Autónoma Vasca, Leioa, Servicio Editorial de la UPV/EHU.

Bosch, G. y Charest, J. (2008): «Vocational training and the labour market in liberal and coordinated economies», Industrial Relations Journal, vol. 39, n. ${ }^{\circ}$ 5, pp. 428-447. 
Braczy , H.; Cooke, P. y Heidenreich, R. (eds.) (1996): Regional Innovation Systems. The Role of Governances in a Globalized World, Londres, University College Londres Press.

Brinton, M.C. (2005): «Education and the Economy», en Smelser, N.J. y Swedberg, R., Hanbook of Economic Sociology, Nueva York, Russel Sage Foundation, pp. 575-602.

Brown, P.; Green, A. y Lauder, H. (2001): High Skills: Globalisation, Competitiveness and Skill Formation, Oxford, Oxford University Press.

CEDEFOP (2010): «La modernización de la formación profesional», Luxemburgo, Oficina de Publicaciones de la Unión Europea. <http://www.cedefop.europa.eu/EN/Files/9013_es.pdf> (disponible en febrero de 2011).

Cooke, P.; Gomez, M. y Etxebarria, G. (1997)ः «Regional Innovation Systems: Institutional and Organizational Dimensions», Research Policy, vol. 26, n. ${ }^{\circ} 4-5, \mathrm{pp} .475-491$.

Cooke, P. y Morgan, K. (1998): The associational economy: Firms, regions and innovation, Oxford, Oxford University Press.

Cruz, L.; Molas, J. y Sanz, L. (2010): «Políticas de I+D e innovación», en Sanz, L. y Cruz, L. (comps.), Análisis sobre ciencia e innovación en España, Madrid, FECYT. Introducción a la sección IV, pp. 616-632.

Curtain, R. (2004): «Innovation and Vocational Education and Training», en Dawe, S. (ed), Vocational Education and Training and Innovation: Research Readings, Adelaida, SA, Australia, National Centre for Vocational Education Research (NCVER), pp. 42-58.

Doloreux, D. (2003): «Regional innovation systems in the periphery: the case of Beauce in Quebec (Canada)», International Journal of innovation management, vol. 7, n. ${ }^{\circ}$ 1, pp. 67-94.

Edquist, C. (1997): Systems of Innovation: Technologies, Institutions, and Organizations, Londres, Pinter.

Estevez-Abe, M.; Iversen, T. y Soskice, D.W. (2001): «Social protection and the formation of skills: a reinterpretation of the welfare state», en Hall, P.A. y Soskice, D.W. (eds.), Varieties of Capitalism: The institutional Foundations of Comparative Advantage, Oxford University Press, pp. 145-183.

Gebauer, A.; Woon Nam, C. y Parsche, R. (2005): «Regional technology policy and factors shaping local innovation networks in small German cities», European Planning Studies, vol. 13, n. ${ }^{\circ}$ 5, pp. 661-683.

Grotz, R. y Braun, B. (1997): «Territorial or transnational networking: spatial aspects of technology oriented cooperation within the German mechanical Engineering Industry», Regional Studies, vol. 31, n. ${ }^{\circ}$ 6, pp. 545-557.

Guthrie, H. y Dawe, S. (2004): «Overview», en Dawe, S. (ed.), Vocational Education and Training and Innovation: Research Readings, Adelaida, SA, Australia, NCVER, pp. 10-19.

Homs, O. (2008): La Formación Profesional en España. Hacia la sociedad del conocimiento, Barcelona, Fundación «la Caixa».

IsAKsen, B.T. y Asheim, A. (2003)ः «SMEs and the regional dimension of innovation», en Asheim, B. T.; Isaksen, A.; Nauwelaers, C. y Tödtling, F. (eds.), Regional innovation policy for small-medium enterprises, Cheltenham, Edwar Elgar, pp. 21-46.

Jensen, M.B.; Johnso, B.; Lorenz, E. y Lundvall, B.A. (2007): «Forms of knowledge and modes of innovation», Research Policy, vol. 36, n. ${ }^{\circ}$ 5, pp. 680-693. 
Kaufmann, A. y Todtling, F. (2003): «Innovation pattern of SMEs», en Asheim, B.; IsaKsen, A.; Nauwelaers, C. y Tödtling, F. (eds.), Regional innovation policy for smallmedium enterprises, Cheltenham, Edwar Elgar, pp. 78-115.

Lavía, C*; Otero, B.; Olazaran, M. y Albizu, E* (2011): «Innovación y territorio: una encuesta a pequeñas y medianas empresas (pymes) industriales», Revista Internacional de Sociología, 69 (2), pp. 461-486.

Lundvall, B.A. (ed.) (1992): National Systems of Innovation: Towards a Theory of Innovation and Interactive Learning, Londres, Pinter.

Lundvall, B.A. (2002): Innovation, Growth and Social Cohesion: The Danish Model, Cheltenham, Edward Elgar.

Lundvall, B.A. (2009): Innovation and Competence Building in the Learning Economy Implications for Innovation Policy, Aalborg Univ., Dep. of Business Studies, Working Paper Series $n *^{\circ} 2$.

Lundvall, B.A. y Christensen, J.L. (2003): «Broadening the Analysis of Innovation Systems - Competition, Organisational Change and Employment Dynamics in the Danish System», en Conceicao, P.; Heitor, M.V. y Lundvall, B.A., Innovation, Competence Building and Social Cohesion in Europe. Towards a Learning Society, Cheltenham, Edward Elgar, pp. 144-179.

Lundvall, B. A. y Lorenz, E. (2007): «Modes of Innovation and Knowledge Taxonomies in the Learning economy», CAS workshop on Innovation in Firms, Oslo.

Lundvall, B.A.; Rasmussen, P. y Lorenz, E. (2008): «Education in the Learning Economy: A European Perspective», Policy Futures in Education, vol. 6, n. ${ }^{\circ}$ 6, pp. 681-700.

Maskell, P. (2001): «Social capital, innovation and competitiveness», en Baron, S.; Field, J. y Schuller, T. (eds.), Social Capital: Critical perspectives, Oxford, Oxford University Press, pp. 111-123.

Maskell, P. y Malmberg, A. (1999): «Localised learning and industrial competitiveness», Cambridge Journal of Economics, vol. 23, n. ${ }^{\circ} 2,167-186$.

Moodie, G. (2006): «Vocational education institutions' role in national innovation», Research in Post-compulsory Education, vol 11, n. ${ }^{\circ}$ 2, pp. 131-140.

Nelson, R.R. (ed.) (1993): National Innovation Systems: A Comparative Analysis, Oxford, Oxford University Press.

OECD (2001): The Well-being of Nations, The Role of Human and Social Capital, París, OECD.

OECD (2009): Education at a Glance, París, OECD.

Olazaran, M.; Albizu, E* y Otero, B. (2011): «Cooperación y creación de conocimiento: innovación en las pequeñas y medianas empresas industriales», en GonzÁLEZ DE LA Fe, T. y López Peláez, A., Innovación, conocimiento científico y cambio social. Ensayos de sociología ibérica de la ciencia y la tecnología, Madrid, Centro de Investigaciones Sociológicas, pp. 131-162.

Olazaran, M.; Albizu, E; Lavía, C. y Otero, B. (2013): «Formación e innovación‡ el caso de la relación entre las pymes industriales y los centros de Formación Profesional en Navarra», Cuadernos de gestión, vol. 13, n. ${ }^{\circ}$ 1, pp. 15-40, DOI: 10.5295/cdg.110290mo. 
Rosenberg, N. (1994): Exploring the Black Box: Technology and Economics, Cambridge, Cambridge University Press.

Rosenfeld, S. (1998): Technical colleges, technology deployment and regional development, Modena, OECD.

Rosenfeld, S. (1998b): Community college/cluster connections: Specialization and competitiveness in the US and Europe, Nueva York, Community College Research Centre, Columbia University.

Storper, M. (1997): The regional economy, Nueva York, Guilford Press.

Tether, B.; Mina, A.; Consoli, D. y Gagliardi, D. (2005): A Literature Review on Skills and Innovation. How Does Successful Innovation Impact on the Demand of Skills and How Do Skills Drive Innovation?, Manchester: ESRC Centre for Research on Innovation and Competition (CRIC), Universidad de Manchester.

Toner, P. (2009): Workforce Skills and Innovation: An Overview of Major Themes in the Literature, París, OCDE.

Toner, P.; Marceau, J.; Hall, R. y Considine, G. (2004): «Innovation agents: Vocational education and training skills in the present and future Australian innovation system», en Dawe, S. (ed), Vocational Education and Training and Innovation: Research Readings, Adelaida, Australia, NCVER, pp. 84-105.

Toner, P.; Turpin, T.; Woolley, R. y Lloyd, C. (2010): The Role and Contribution of Tradespeople and Technicians in Australian Research E Development: An Exploratory Study, University of Western Sydney: Centre for Innovation Studies, 2010.

Velluzi, N.D. (2010): «Community colleges, clusters and competition: A case from Washington Wine Country», Regional Studies, vol. 44, n. 2 , pp. 201-214.

Von Hippel, E. (1988): The Sources of Innovation, Nueva York, Oxford University Press.

Whittingham, K.; Ferrier, F. y Trood, C. (2004): «Vocational education and training and the commercialisation of Australian research», en DAwe, S. (ed.), Vocational Education and Training and Innovation: Research Readings, Adelaida, Australia, NCVER, pp. 106-117. 


\section{COMUNIDAD DE ARAGÓN}

Ignasi Brunet, Juan Rodríguez y Esther Puyal 



\section{Entorno socioeconómico regional}

\subsection{Datos socioeconómicos básicos de referencia y características del tejido productivo}

Según los datos extraídos del INE (tabla 3.1), la Comunidad de Aragón cuenta con 1.346.300 habitantes, lo que supone un 2,9\% de la población española. Su PIB es de 33.252 millones de euros, que supone un 3,2\% del PIB estatal. El PIB per cápita es de 25.322 euros, lo que supone situar a la Comunidad de Aragón por encima de la media nacional (con un 111\%). Esto nos indica que estamos ante una región con un cierto nivel económico, aunque en comparación con las seis regiones estudiadas, la Comunidad de Aragón se sitúa como la segunda región con menos PIB per cápita, por encima solo de Asturias.

Los datos provenientes de la Encuesta de Población Activa de 2010 (tabla 3.3) reflejan unos niveles relativamente similares a la media estatal. Mientras que la tasa de actividad de la Comunidad de Aragón es ligeramente inferior a la tasa estatal (58,16\% frente al 60\%), la tasa de empleo es superior a la estatal (49,57\% frente al 47,96\%). Respecto al nivel de desempleo, la Comunidad de Aragón posee una tasa significativamente inferior a la del conjunto del Estado (14,77\% frente al 20,06\%). De hecho, de las seis regiones estudiadas, Aragón es la tercera región con menos nivel de desempleo, por detrás del País Vasco y de Navarra.

En relación con el tejido productivo en 2010 (tabla 3.1), cabe señalar que el VAB industrial de la Comunidad de Aragón es de 6.327,6 millones de euros, lo que supone un 4,1\% del VAB industrial estatal. Por otro lado, el VAB industrial de la Comunidad de Aragón en 2008 supone el 22,4\% del PIB regional y el 19,5\% del empleo.

Atendiendo a la especialización industrial de la región (2008, Contabilidad Regional de España, INE), cabe señalar que la Comunidad de Aragón destaca sobre la media española fundamentalmente en las siguientes industrias: maquinaria y equipo mecánico (2,4\% VAB y $2,4 \%$ empleo); equipo eléctrico, electrónico y óptico (1,8\% VAB y 1,5\% empleo); fabricación de material de transporte ( $3,1 \%$ VAB y $3,6 \%$ empleo); industrias manufactureras diversas $(1,5 \%$ VAB y $1,7 \%$ empleo).

La industria de la Comunidad de Aragón tiene un nivel tecnológico relativamente alto. Atendiendo al peso de los sectores manufactureros de alta y media-alta tecnología (Indicadores de Alta Tecnología, INE, 2009) (tabla 3.2), se puede observar que el 36,3\% del VAB industrial corresponde a actividades de tecnologías alta y media-alta. Un porcentaje similar al de Navarra $(36,7 \%)$ y significativamente superior al del conjunto del Estado (26,6\%). Ello sitúa a la Comu- 
nidad de Aragón como la segunda de las seis regiones estudiadas con mayor nivel tecnológico en su industria.

El nivel educativo de la población aragonesa entre 25 y 64 años en 2010 es más elevado que la media española (gráfico 3.1), caracterizándose por un menor porcentaje de población con nivel de estudios en educación secundaria inferior (41,5\% frente al 47,4\% de la media española) y un mayor porcentaje de población con nivel de estudios en educación secundaria superior (25,4\% frente al $22,0 \%)$ y con nivel de estudios en educación terciaria (33,1\% frente al $30,7 \%$ de la media española).

Si comparamos estos niveles de estudios con los datos de la UE15 y la UE27, observamos un cierto desequilibrio de la estructura de estudios de la población aragonesa. En los países miembros de la UE los niveles de población entre 25 y 64 años con niveles inferiores de formación son más bajos que los de la población aragonesa (30,5\% para la UE15 y 27,3\% para la UE27), mientras que los niveles de estudios de nivel intermedio son superiores a los de la Comunidad de Aragón (42,2\% para la UE15 y 46,8\% para la UE27). Finalmente, cabe señalar que para los niveles de estudios terciarios el porcentaje de población aragonesa es superior al de los países de la UE15 y la UE27 (27,4\% y 25,9\%, respectivamente), lo cual puede indicar tanto un elevado nivel de cualificación como un indicador de sobrecualificación de la población aragonesa.

En cuanto a la población ocupada según su nivel educativo en 2010 (tabla 3.4), a partir de los datos se observa la importancia de la formación profesional de grado medio (FPGM) y de grado superior (FPGS) respecto a la media española (para la FPGM, 12,1\% para Aragón y 8,9\% para España; para la FPGS, $12,1 \%$ para Aragón y 10,6\% para España). En cuanto a la población ocupada en la industria (tabla 3.5), las diferencias se acentúan para la FPGM $(13,25 \%$ frente a $10,5 \%)$ y para el bachiller superior $(16,27 \%$ frente a $12,9 \%)$.

En este sentido, el gráfico 3.2 muestra el crecimiento del porcentaje de personas ocupadas en la industria con cualificaciones de FP. Sobre la base de los datos se observa un crecimiento superior de la Comunidad de Aragón respecto al conjunto del Estado, al pasar de un $6 \%$ en 1985 a un $28,4 \%$ en 2010 , un crecimiento de más de 22 puntos porcentuales. Un crecimiento que, aunque no alcanza los niveles de otras regiones como el País Vasco o Navarra, sí que resulta significativo respecto al desarrollo de la industria y de la formación vinculada a los empleos generados en ella en los últimos 25 años.

\subsection{Indicadores de investigación, desarrollo e innovación}

En 2010, la Comunidad de Aragón dedica un 1,15\% de su PIB al gasto en I+D (tabla 3.6), cifra inferior a la media española $(1,39 \%)$ y muy alejada de la del conjunto de países de la UE27 (2\%). De las seis regiones estudiadas, solo Asturias posee un nivel de gasto inferior (1,03\%). Sin embargo, el crecimiento del gasto en $\mathrm{I}+\mathrm{D}$ experimentado por la Comunidad de Aragón entre 1997 y 2010 (gráfico 3.4) solo es superado por el País Vasco, Navarra y Cataluña.

La tabla 3.7 nos indica que en la Comunidad de Aragón el gasto en I+D es asumido por las empresas e IPSFL (56,5\%), porcentaje superior a la media española (51,6\%). La Administración pública también tiene un mayor protagonismo en la Comunidad de Aragón que en el conjunto del Estado (21\% frente a 20,1\%), mientras que la enseñanza superior tiene un menor peso en el gasto en I+D en la Comunidad de Aragón que en España (22,5\% frente a 28,3\%). 
En términos relativos al PIB (tabla 3.7), los tres sectores apuntados tienen un gasto inferior al del conjunto del Estado: el sector empresas e IPSFL, $0,65 \%$ frente a $0,71 \%$; el sector Administración pública, 0,24\% frente a 0,28\%; el sector enseñanza superior, 0,26\% frente a 0,39\%. Respecto a la evolución del gasto en I+D sobre el PIB en la Comunidad de Aragón entre 1997 y 2010, se observa un crecimiento superior al de España en el sector empresas e IPSFL, prácticamente idéntico en el sector Administración pública e inferior en el sector enseñanza superior.

En relación con los recursos humanos en I+D (tabla 3.8), la Comunidad de Aragón es la segunda región con un menor porcentaje de personal dedicado a $\mathrm{I}+\mathrm{D}$ sobre la población ocupada (12,9\%), solo superada por Asturias (9,36\%) y ligeramente por encima de la media española $(12,03 \%$ ). El crecimiento de este personal es ligeramente superior a la media española. En la misma línea, el porcentaje de investigadores sobre la población ocupada también supera al del conjunto del Estado (8,81\% frente a 7,3\%). Sin embargo, el volumen de personal técnico y auxiliar en I+D es inferior a la media estatal (31,7\% frente a 39,4\%).

La tabla 3.9 muestra la ubicación en los diferentes sectores de ejecución de $\mathrm{I}+\mathrm{D}$ de investigadores y técnicos y auxiliares. Cabe destacar que, en su conjunto, el sector de enseñanza superior aglutina a un mayor volumen de personal de $\mathrm{I}+\mathrm{D}$, siento este superior a la media española (43,8\% frente a 37,5\%). En el caso de los investigadores, el sector de enseñanza superior también es el sector que cuenta con un mayor porcentaje de personal $(60,9 \%)$, muy superior al del conjunto del Estado (48\%). Una cifra que supone el mayor porcentaje de investigadores respecto a las seis regiones estudiadas. Sin embargo, en el caso de técnicos y auxiliares, el sector empresas es el que cuenta con mayor volumen de personal (64,8\% frente al 43,8\% de la media española).

En relación con el sector industrial, cabe destacar el significativo peso de dicho sector, con un $65,8 \%$ del total de la I+D empresarial, muy superior a la media española y al del resto de regiones estudiadas. Por otro lado, respecto a la formación del personal de $\mathrm{I}+\mathrm{D}$ en el sector industrial (tabla 3.10), conviene señalar que el 18,6\% de este personal tiene titulación de FP, en mayor medida para el grado superior. Una cifra significativamente inferior a la media española $(23,3 \%)$. Por otro lado, tal y como muestra la tabla 3.11, el conjunto de cualificaciones intermedias de formación profesional es especialmente importante en las pymes del tramo 150-249 trabajadores $(24,4 \%)$.

Respecto a la distribución del gasto en innovación en el sector industrial (tabla 3.12), la Comunidad de Aragón se caracteriza por tener el porcentaje de $\mathrm{I}+\mathrm{D}$ interna más bajo de las seis regiones estudiadas (26,34\%), muy por debajo de la media estatal (46,51\%). En la misma línea, la adquisición de $\mathrm{I}+\mathrm{D}$ externa y de maquinaria también tiene un nivel inferior. En cambio, la adquisición de conocimientos externos (con un 55,81\%) es manifiestamente superior a la del resto de regiones y a la del conjunto del Estado. En cuanto a la formación, la Comunidad de Aragón es la segunda región con un mayor porcentaje de gasto (0,84\%). La adquisición de conocimientos externos solo es destacable en empresas de 250 o más trabajadores. La formación, en cambio, destaca en las empresas de 75-149 trabajadores y 0-24 trabajadores. La I+D interna y la adquisición de maquinaria resultan desiguales en función del tamaño de la empresa. En el primer caso, destacan de forma significativa las pymes de 25-74 y de 150-249 trabajadores. En el segundo caso, destacan las pymes de 0-24 y de 75-149 trabajadores.

En relación con la capacidad de las empresas innovadoras de la Comunidad de Aragón para obtener ayudas públicas a la innovación (tabla 3.13), cabe destacar que el porcentaje de empresas que acceden a ayudas públicas es ligeramente superior a la media española (30,3\% 
frente a 28,8\%). El nivel de acceso a ayudas del Gobierno central es superior a la media española. Sin embargo, el nivel de acceso a ayudas regionales o provenientes de la Unión Europea es inferior al nivel medio del conjunto del Estado.

Si atendemos al tamaño de las empresas, en la Comunidad de Aragón se observa que las empresas innovadoras de 0 a 24 trabajadores poseen unos destacados niveles de dinamismo: un $61,4 \%$ de ellas acceden a financiación pública de la Administración regional y un 22,7\% a financiación de la Unión Europea. Unos resultados que destacan por encima de los del resto de empresas.

Un último aspecto que destacar es la capacidad de las empresas para cooperar con otros actores del sistema de innovación. En este sentido, la tabla 3.14 muestra que las empresas de la Comunidad de Aragón tienden a cooperar relativamente más que la media estatal (25,2\% frente a $22,1 \%)$. Destaca la cooperación con empresas competidoras del sector, con universidades y con organismos públicos de investigación, todos ellos con niveles superiores de cooperación a la media española. El nivel de cooperación con centros tecnológicos también es importante, aunque ligeramente inferior al del conjunto del Estado. Sin embargo, la cooperación entre empresas del propio grupo y proveedores resulta muy inferior a la media española y a la del resto de regiones estudiadas. Si atendemos al tamaño de las empresas, destacan las empresas de 250 o más trabajadores (cooperación con empresas del mismo grupo, proveedores, clientes y centros tecnológicos) y las empresas de 150 a 249 trabajadores (cooperación con consultores e institutos privados de $\mathrm{I}+\mathrm{D}$, universidades y centros tecnológicos).

\subsection{Sistema institucional de agentes de $\mathrm{I}+\mathrm{D}+\mathrm{i}$}

De las entrevistas realizadas se deriva que la Comunidad de Aragón todavía tiene margen de desarrollo respecto de su sistema de innovación. Debido a las características del propio territorio, la mayoría de agentes se concentran en la conurbación de Zaragoza. El resto del territorio se considera medio rural, según algunos entrevistados, habiendo iniciativas puntuales vinculadas a actividades productivas muy concretas. La tipología de empresas pequeñas genera una serie de obstáculos, si bien el entorno facilita un mayor conocimiento e interacción por parte de los diferentes agentes.

Aquí, no sé si conoces Aragón, pero si somos un millón y medio de habitantes, casi 800.000 vivimos en Zaragoza. Y, por ejemplo, aquí, medio rural se considera todo menos Zaragoza capital. Teruel debe de tener 30.000 habitantes, Huesca 50.000. Y eso ya es... (AS1)

Yo creo que sí, porque al ser una comunidad pequeña en población sí que nos conocemos todos. Entonces es más fácil. Si tú no conoces a alguien, pues una persona próxima a ti seguro que tiene un contacto relacionado con esa persona. Entonces los contactos son más fáciles. Creo yo. También es cierto que, al ser empresas pequeñas, pues hay más resistencias que vencer porque les cuesta mucho el ver beneficios que pueden venir más tarde y no a corto o medio plazo. (AR1)

Según el Gobierno de Aragón, entre los agentes de innovación en el territorio destacan las dos universidades existentes (la Universidad de Zaragoza y la Universidad San Jorge, de reciente creación) y tres centros de la UNED; tres centros de innovación y tecnología (Instituto Tecnológico de Aragón, Fundación CIRCE y Fundación AITIIP); cuatro institutos universitarios de investigación; seis centros del CSIC; seis oficinas de transferencia de resultados de 
investigación; y tres parques tecnológicos ${ }^{1}$. Como se puede deducir, muchos de estos centros de innovación e investigación están vinculados a la Universidad de Zaragoza.

El desarrollo de parques tecnológicos en Aragón es muy limitado. Tal y como apuntan algunos entrevistados, los parques tecnológicos tienen un corto bagaje, con una escasa implantación de empresas en ellos. En los últimos años ha aumentado el número de empresas de innovación ubicadas en dichos parques. Algunos de estos parques han desarrollado una actividad continuada en el tiempo, adquiriendo un nivel de actividad importante. Entre ellos destaca el Parque Tecnológico Walqa y el Parque Tecnológico del Motor (Technopark - Motorland). Algunos entrevistados apuntan a la importancia de estos dos parques. También encontramos el Parque Tecnológico Campus Aula Dei, de menor importancia, dedicado al sector agroalimentario y medioambiental. En algunos de estos parques tecnológicos (PT) se ubican diferentes centros tecnológicos. En el PT de Walqa hay tres centros tecnológicos, destacando la Fundación del Hidrógeno, que mantiene contactos con el CPIFP Pirámide. En el caso de Motorland, hay diferentes centros tecnológicos vinculados a la automoción. La Universidad de Zaragoza tiene algunos laboratorios de investigación en ambos parques.

Estamos teniendo bastantes relaciones, que están yendo a más, con algunos parques tecnológicos que han empezado recientemente a funcionar. Por ejemplo, el Parque Tecnológico Walqa, en Huesca, está trabajando bastante con el Centro Integrado Pirámide. Estamos intentando plantear iniciativas conjuntas y yo creo que en el próximo futuro se materializarán más iniciativas. Y lo mismo ocurre en Alcañiz con la ciudad del motor y Motorland, donde se celebra un gran premio de motociclismo. También allí se están profundizando las relaciones entre este parque tecnológico y el centro integrado que tenemos allí en esa localidad, cuyo núcleo principal de actividad es la automoción. (AR1)

No es muy importante porque el parque lleva pocos años, pero sí que poquito a poco va incrementando su actividad. Digamos que va aumentando la concentración de industria. Empezó solamente el parque tecnológico, el circuito y tal, pero poco a poco van llegando más empresas. Están llegando empresas de fabricación, de mantenimiento, algunas que trabajan temas de innovación en el motor. Eso nos está viniendo muy bien, porque a partir de ahí surgen iniciativas de cambios, de mejoras en cuanto a la formación. Por ejemplo, han surgido propuestas de cursos de especialización sobre mecánicos de competición y algunos otros que hay por ahí. (AR1)

En los últimos años se ha producido un mayor contacto entre centros de FP e institutos tecnológicos como el Instituto Tecnológico de Aragón, la Fundación CIRCE o el Instituto Aragonés de Fomento, aunque con el segundo se ha mantenido un contacto más continuado en el tiempo. También en los últimos años la Universidad de Zaragoza, a partir del programa Universa de prácticas no laborales, está manteniendo contactos con el tejido empresarial.

Y Universa está también en las prácticas no laborales, junto con los cuatro agentes sociales, pero en este caso solamente para los cursos de los universitarios o de los últimos años de carrera, que les están formando en este caso en formación para el empleo, con lo cual esa oferta está cubierta. (AS1)

Y con respecto a acuerdos con universidad y demás, como te digo, estamos un poco empezando como centro integrado. Sí que existe contacto y se van firmando convenios. Hemos empezado un poco con asociaciones pequeñas de las familias profesionales donde nosotros estamos especializados. Pues asociaciones de audiovisuales, de transporte, de informática. Intentamos firmar esos acuerdos y ver en qué podemos plasmarlos luego. El primer paso ha sido con

1 Para un mayor detalle de todos los agentes del sistema regional de innovación, véase el anexo II. 
las asociaciones, para contactarlas y mostrarles y explicarles lo que somos. Ahora estamos hablando con CREA, con CEPYME. Darles una imagen más concreta de qué es lo que queremos y cómo queremos colaborar. Y el siguiente paso yo creo que va a ser intentar — porque además en las enseñanzas ahora viene el tema de la posible colaboración de prácticas en empresas con la universidad - poder hacer FCT en universidades y demás. El siguiente paso será la universidad. Hasta ahora hemos intentado colaborar, porque nosotros tenemos unos simuladores de conducción, con CIRCE, que es... una parte de la universidad que se dedica a cursos también de formación continua. Entonces hemos contactado con ellos este año para ver cómo podíamos colaborar y estamos empezando a tender puentes. (FP1)

\subsection{Política de $\mathrm{I}+\mathrm{D}+\mathrm{i}$ en el ámbito regional}

De las entrevistas y la documentación analizadas se deduce que la apuesta de la Administración regional por la potenciación y el desarrollo de la innovación y la investigación en la Comunidad de Aragón es relativamente limitada en el tiempo, lo que permite en la actualidad un importante margen de actuación. La mayoría de iniciativas, planes y/o programas vinculados a este ámbito son de reciente creación y tienen todavía un escaso recorrido (en algunos casos estamos hablando de un período de entre 5 y 10 años).

La política aragonesa de innovación y desarrollo se gestiona desde el Departamento de Industria e Innovación del Gobierno de Aragón. Existen dos planes regionales de impulso de la innovación y la investigación.

El I Plan Autonómico de Investigación, Desarrollo y Transferencia de Conocimientos de Aragón (PAID) abarca el período entre 2002 y 2004, dentro del cual se aprobó la Ley 9/2003, de 12 de marzo, de fomento y coordinación de la investigación, el desarrollo y la transferencia de conocimientos en Aragón («Ley de la Ciencia»). Este I PAID busca potenciar la mejora del sistema aragonés de ciencia-tecnología-empresa, así como la coordinación efectiva de las diferentes actuaciones en $\mathrm{I}+\mathrm{D}$ que se llevan a cabo por parte de los distintos departamentos del Gobierno de Aragón. Cabe destacar que este I PAID es la primera iniciativa en materia de fomento y coordinación de la investigación e innovación.

Las acciones propuestas en el I PAID se estructuraron en tres grandes áreas:

- Área 1: Incardinación del sistema de ciencia y tecnología en la sociedad aragonesa, donde destaca el esfuerzo realizado en materia de difusión de la actividad investigadora.

- Área 2: Estructuración del sistema de ciencia y tecnología, donde destacan, entre otras cuestiones, la creación de dos fundaciones en áreas estratégicas - la Fundación del Hidrógeno y la Fundación Zaragoza Logistics Center- y el apoyo al Parque Tecnológico Walqa, estableciéndose en él diversos laboratorios de investigación.

- Área 3: Potenciación y mejora de los recursos humanos y materiales del sistema, destacando la potenciación fundamentalmente de becas predoctorales, así como la mejora de las condiciones laborales de investigadores noveles.

El II PAID mantiene las mismas líneas de actuación y abarca el período entre 2005 y 2008, si bien tiene un desarrollo más elaborado. Comprende dos grandes tipos de actuaciones:

- Acciones generales de fomento de la investigación, el desarrollo tecnológico y la innovación.

+ Líneas estratégicas, líneas prioritarias y acciones relacionadas con temas específicos. 
Las acciones de tipo general se definen a continuación:

- Acciones en materia de recursos humanos.

- Acciones de apoyo a la I+D: financiación, técnicos, infraestructuras de investigación.

- Acciones de apoyo a la transferencia tecnológica y la innovación.

- Acciones de difusión de la investigación y la innovación.

Las líneas estratégicas comprenden grandes áreas que relacionan el territorio de Aragón con las acciones prioritarias del II PAID:

- Desarrollo del territorio aprovechando sus características específicas.

+ Conservación y puesta en valor del patrimonio natural y cultural.

- Seguridad y calidad de vida individual y colectiva.

+ Sostenibilidad del desarrollo social y económico.

+ Desarrollo tecnológico basado en nuevos materiales y procesos.

A partir de los datos disponibles no se tiene conocimiento de una continuidad de estas iniciativas. Durante la vigencia de este II PAID se crea la Fundación Agencia Aragonesa para la Investigación y el Desarrollo en junio de 2005, con el objetivo de impulsar la I+D+i en el territorio aragonés, aumentando el conjunto de recursos humanos y materiales vinculados a este ámbito. También se crean diferentes iniciativas vinculadas a la difusión y promoción de la investigación, tales como el portal Aragón Investiga (ya desde el I PAID) o el Observatorio Aragonés de Investigación y Desarrollo.

\section{La FP en el ámbito regional}

\subsection{Formación reglada: recursos del sistema}

En el curso 2009-2010, la Comunidad de Aragón cuenta con 88 centros que imparten ciclos formativos de grado medio (CFGM) y 69 centros que imparten ciclos formativos de grado superior (CFGS), lo que supone el 3,4\% y el 3,3\% del total de centros del conjunto del Estado, respectivamente (tabla 3.15).

Respecto a la titularidad (pública o privada) de los centros de formación profesional (tabla 3.15), cabe destacar que en la Comunidad de Aragón la formación profesional es fundamentalmente pública, aunque en un nivel menor a la media española. El $67 \%$ de los centros que imparten CFGM son públicos, ligeramente por debajo de la media del conjunto del Estado $(73,7 \%)$. De los centros que imparten CFGS, el 69,6\% son de titularidad pública, también por debajo de la media española $(76,1 \%)$.

En el curso 2009-2010, la Comunidad de Aragón cuenta con 8.066 alumnos matriculados en CFGM y 6.751 alumnos en CFGS, lo que supone el 3\% y el 2,7\% del total estatal, respectivamente (tabla 3.16). En cuanto a la distribución del alumnado entre centros públicos y privados, cabe destacar que la proporción aumenta a favor de los primeros respecto a los datos relativos de centros públicos y privados. Así, el 71,4\% del alumnado de CFGM y el 70,4\% del alumnado de CFGS están matriculados en centros públicos. Respecto a las tasas brutas de escolarización, se puede observar que son ligeramente superiores a la media española, especialmente la relativa a las enseñanzas de grado medio (35\% frente a 30,8\%). Esta supone la segunda 
tasa más elevada de las seis regiones estudiadas, ligeramente por detrás de Asturias (35,2\%). Sin embargo, la tasa para los CFGS, aun siendo superior a la media española, no es de las más elevadas.

Por otro lado, como se puede observar en el siguiente gráfico (tablas 3.17 y 3.18), la evolución de la formación profesional de grado medio (FP GM) en la Comunidad de Aragón ha mantenido una tendencia positiva en los últimos 10 años, mientras que la tendencia ha sido la contraria respecto a la formación profesional de grado superior (FP GS). En términos generales, la evolución del alumnado en enseñanzas profesionales en Aragón ha experimentado una evolución en forma de parábola invertida muy atenuada, teniendo en el curso 2009-2010 prácticamente el mismo número de alumnado que en el curso 1998-1999 (14.817 alumnos en 2009-2010 frente a 15.210 alumnos en 1998-1999). La diferencia estriba en que hace diez años estos alumnos mayoritariamente se ubicaban en las enseñanzas de grado superior y actualmente las enseñanzas de grado medio tienen un mayor protagonismo.

Gráfico 2.1. Evolución de las matriculaciones de FP en Aragón (1998-1999 y 2009-2010)

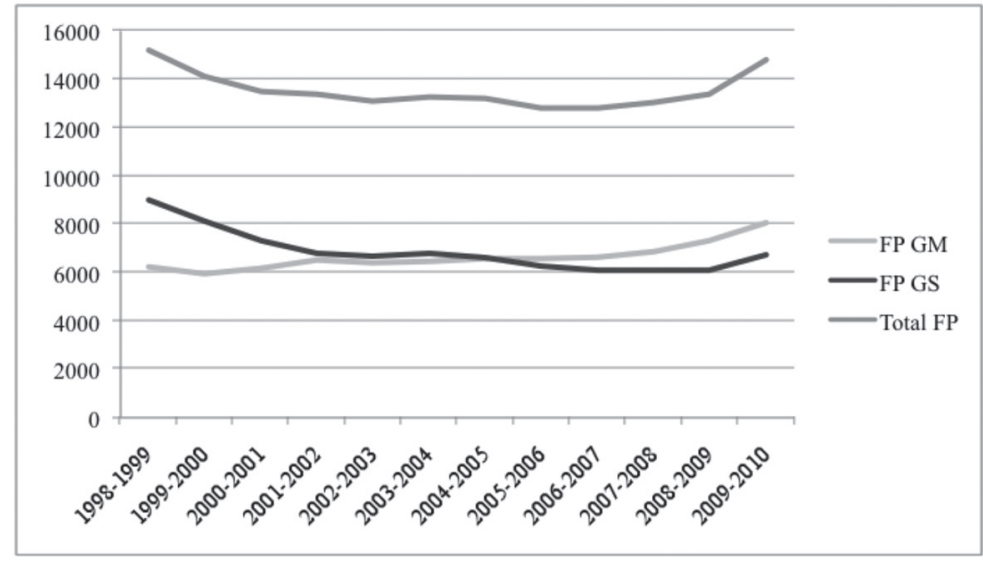

Fuente: elaboración propia a partir de «Las cifras de la Educación en España», Ministerio de Educación, Cultura y Deporte

Sin embargo, tal y como muestra el siguiente gráfico (tablas 3.23 y 3.24), la matriculación de alumnado en ramas industriales ha seguido una tendencia diferente de la evolución de la matriculación en general. La formación profesional de grado medio y de grado superior ha seguido una tendencia descendente y con ciertos altibajos. Esta tendencia resulta prácticamente idéntica a la sucedida en el conjunto del Estado y se debe, en parte, a la diversificación y creación de nuevas especialidades profesionales, muchas de ellas vinculadas al sector servicios. De hecho, en el conjunto del Estado el descenso en las matriculaciones en los últimos años es de 11 puntos porcentuales frente a los 10 puntos de la Comunidad de Aragón. 
Gráfico 2.2. Evolución del porcentaje de alumnos matriculados en familias del sector industrial respecto al total de alumnos FP (2000-2010). Aragón

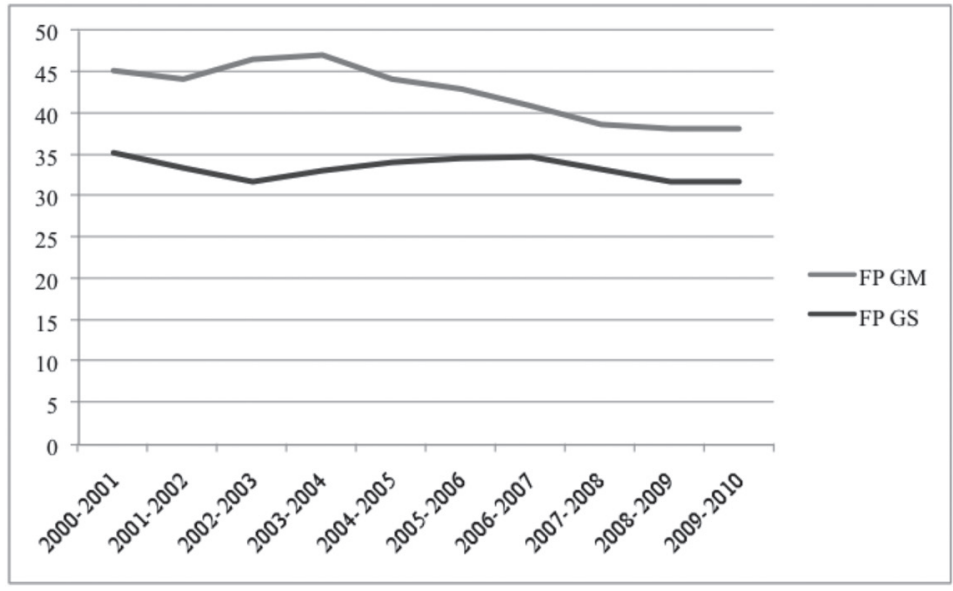

Fuente: elaboración propia a partir de «Las cifras de la Educación en España», Ministerio de Educación, Cultura y Deporte

Finalmente, respecto al peso de la formación profesional en los presupuestos del Gobierno de la Comunidad de Aragón (tabla 2.1), en los años 2008 y 2009 (últimos años disponibles) el gasto público relativo a la partida de educación secundaria y formación profesional suponía aproximadamente un $31 \%$ del gasto público total del Departamento de Educación de la Comunidad de Aragón.

Tabla 2.1. Evolución del gasto del Departamento de Educación, Universidad, Cultura y Deporte según actividad educativa. 2008-2009. Aragón

\begin{tabular}{|l|r|r|}
\hline (Miles de $€$ ) & 2008 & 2009 \\
\hline Gasto público total & $1.182 .565,80$ & $1.227 .369,80$ \\
\hline Educación no universitaria: & $869.594,60$ & $902.211,30$ \\
\hline - E. secundaria y f. profesional & $372.711,80$ & $392.063,80$ \\
\hline Educación universitaria (1) & $296.847,00$ & $312.268,10$ \\
\hline Formación ocupacional & $2.461,10$ & $2.183,40$ \\
\hline Becas y ayudas totales & $13.663,10$ & $10.707,00$ \\
\hline
\end{tabular}

(1) En 2008 incorpora 5.040.000 euros de becas del ME por exención de precios académicos y 43.543.000 euros de financiación de origen privado de las universidades.

(1) En 2009 incorpora 5.031.000 euros de becas del ME por exención de precios académicos y 47.523.000 euros de financiación de origen privado de las universidades.

Fuente: Ministerio de Educación, Cultura y Deporte 


\subsection{Formación reglada: ámbitos de especialización}

Según los datos sobre especialización (tabla 3.21), dentro de los ciclos formativos de grado medio las familias con más volumen de alumnado son la de Administración (20,9\%), Sanidad (14,9\%), Electricidad y Electrónica (13,2\%) y Mantenimiento de Vehículos Autopropulsados (9,5\%). El resto de familias profesionales no supera prácticamente el $5 \%$ de proporción de alumnado.

Atendiendo a los ámbitos de especialización industrial de los CFGM en la Comunidad de Aragón, en el siguiente gráfico (tabla 3.21) se puede observar que esta tiene una importante tasa de matriculación $(13,2 \%)$ en los grados medios de la familia de Electricidad y Electrónica, siendo la mayor diferencia con la media española ( 2 puntos porcentuales). Le siguen la familia de Fabricación Mecánica (1,6 puntos porcentuales) y, en menor medida, las familias de Mantenimiento y Servicios a la Producción (0,8 puntos porcentuales) y Mantenimiento de Vehículos Autopropulsados (0,7 puntos porcentuales). El mayor diferencial negativo lo encontramos en los grados medios de la familia de Informática ( $-2,4$ puntos porcentuales).

\section{Gráfico 2.3. Áreas de especialización industrial de la FPGM en Aragón}

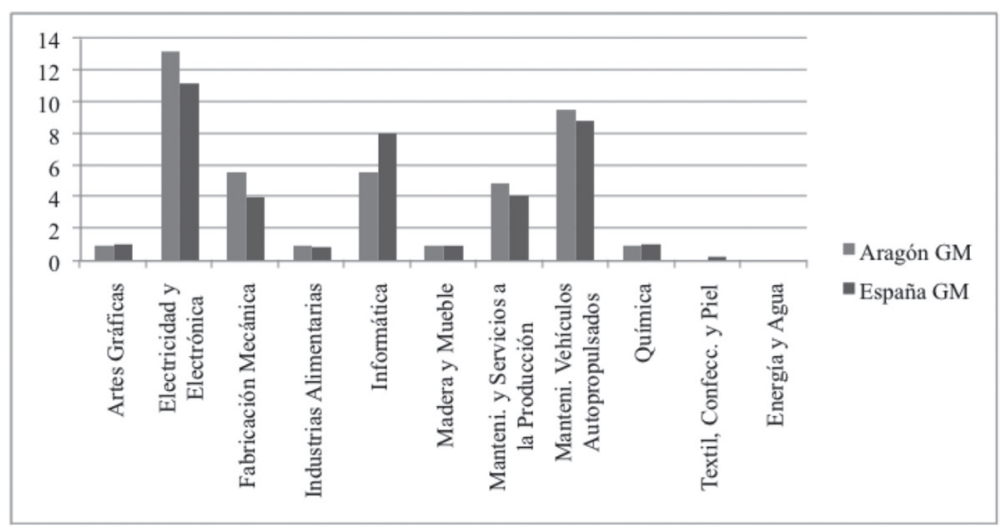

Fuente: elaboración propia a partir de «Las cifras de la Educación en España», Ministerio de Educación, Cultura y Deporte

En el caso de los ciclos formativos de grado superior, se mantienen las dos primeras familias con más volumen de alumnado, aunque aumenta la distancia entre ellas respecto a los CFGM: Administración (17,1\%) y Sanidad (12,4\%). A continuación le siguen las familias de Informática (10,2\%), Electricidad y Electrónica (8,7\%), Servicios Socioculturales y a la Comu$\operatorname{nidad}(7,8 \%)$ y Comercio y Marketing $(7,8 \%)$. El resto de familias profesionales no superan el $5 \%$ de proporción de alumnado.

Atendiendo a los ámbitos de especialización industrial de los CFGS, en el siguiente gráfico (tabla 3.22) se puede observar que, al igual que ocurre con los grados medios, Aragón tiene una importante tasa de matriculación $(8,7 \%)$ en los grados superiores de la familia de Electricidad y Electrónica, aunque es la familia de Informática la que aglutina un mayor porcentaje de matriculación en los grados superiores $(10,2 \%)$. La principal diferencia respecto a los grados medios es que en los grados superiores los diferenciales respecto a la media estatal de las ramas industriales son todos positivos, a excepción de la familia de Energía y Agua, que 
son igual a cero. El segundo rasgo importante es que, aunque positivos, estos diferenciales son mínimos, casi equiparados a las tasas estatales. De hecho, el principal diferencial se produce en la familia de Mantenimiento de Vehículos Autopropulsados (1,1 puntos porcentuales), seguida de Electricidad y Electrónica (0,9 puntos porcentuales) y Fabricación Mecánica (0,8 puntos porcentuales).

\section{Gráfico 2.4. Áreas de especialización industrial de la FPGS en Aragón}

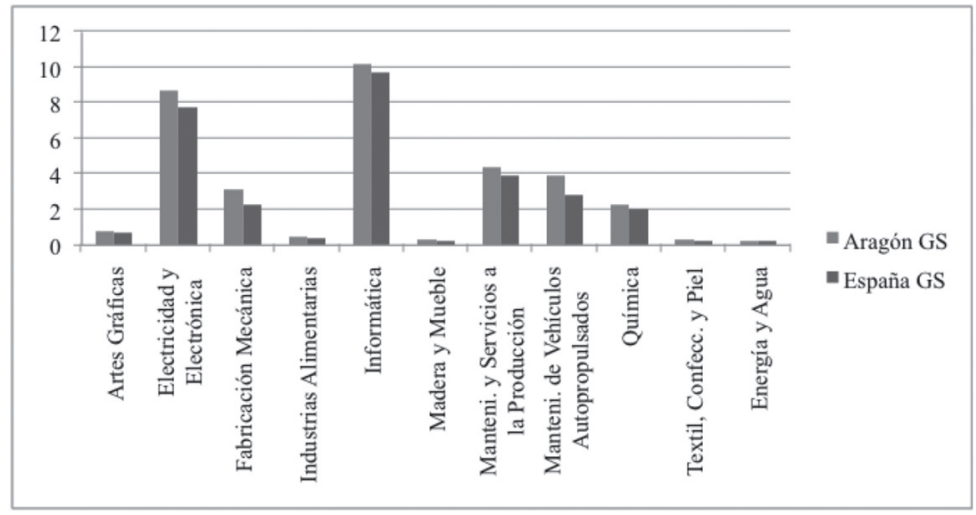

Fuente: elaboración propia a partir de «Las cifras de la Educación en España», Ministerio de Educación, Cultura y Deporte

Para finalizar, tal y como muestran las tablas 3.23 y 3.24, la Comunidad de Aragón ha experimentado una evolución similar a la del conjunto del Estado, manteniendo una mayor especialización en familias profesionales del sector industrial. En el curso 2009-2010, el porcentaje de alumnado matriculado en dichas familias es del 38,2\% en los CFGM y del 31,9\% en los CFGS, ambos superiores a la media española, que es del 33,3\% y del $28 \%$, respectivamente.

\subsection{Formación para el empleo: la formación de oferta}

En la Comunidad de Aragón y durante 2010, bajo la modalidad de oferta, han participado en la formación para el empleo un total de 33.498 personas, lo que supone un 4,3\% del total estatal (tabla 3.25). Dentro de esta formación para el empleo, un 26,8\% corresponde a formación vinculada al sector industrial, 4 puntos porcentuales por encima de la media española $(22,7 \%)$. Este porcentaje es el segundo más elevado de las seis regiones estudiadas, por detrás de Cataluña.

La fórmula presencial es la más utilizada en este tipo de formación en Aragón: un 58,1\% de las acciones formativas se desarrollan bajo esta modalidad, lo que supone una diferencia porcentual de casi 10 puntos por encima de la media española (48,5\%). Le siguen la teleformación (16\%), la formación a distancia $(14,1 \%)$ y la formación mixta $(11,9 \%)$. En este sentido, cabe destacar que el peso de la teleformación y de la formación a distancia es inferior al del conjunto del Estado, mientras que la formación mixta supera ligeramente a la media española.

Atendiendo al sexo y a la edad de los participantes (tabla 3.26), cabe apuntar que en la Comunidad de Aragón el 54,4\% de las personas formadas han sido hombres, una cifra prácticamente idéntica a la media española (54,2\%). Por otro lado, se puede observar que 6 de cada 10 
personas $(65,2 \%)$ se encuentran en la franja de edad $26-45$ y casi 2 de cada 10 personas $(19,5 \%)$ se encuentran en la franja de 46-55, siendo esta última la franja de edad donde se produce una mayor diferencia respecto a la media española $(16,7 \%)$.

Respecto al nivel de cualificación de las personas formadas (tabla 3.27), la formación de oferta en la Comunidad de Aragón se distribuye fundamentalmente entre personas con poca cualificación (43\%) y personas sin cualificación (30,3\%). Es con el primer colectivo donde se observan mayores diferencias respecto del conjunto del Estado (casi 5 puntos porcentuales). Ocurre lo contrario con las personas con más formación (técnicos, mandos intermedios y directivos), que reciben menos formación que en el conjunto del Estado.

Por otro lado, la formación de oferta de la Comunidad de Aragón se distribuye entre diferentes entidades formativas: centros de formación propios del Instituto Aragonés de Empleo (INAEM), organizaciones sindicales (CC. OO., UGT), organizaciones empresariales (CEPYME, CREA) y Ayuntamiento de Zaragoza. Asimismo, se establecen convenios de colaboración con diferentes instituciones y entidades formativas.

Tabla 2.2. Formación de oferta en Aragón.

Distribución del alumnado por tipo de entidad. 2010

\begin{tabular}{|l|c|c|c|}
\hline Tipo de entidad & Hombres & Mujeres & Total \\
\hline Agentes sociales & 2.667 & 4.080 & 6.747 \\
\hline Medios propios INAEM & 4.179 & 2.815 & 6.994 \\
\hline Convenios DGA & 1.574 & 1.505 & 3.079 \\
\hline Oferta desempleados & 5.099 & 4.374 & 9.473 \\
\hline Formación distancia & 482 & 700 & 1.182 \\
\hline Acuerdo con compromiso de contratación & 238 & 418 & 656 \\
\hline Total & 14.239 & 13.892 & 28.131 \\
\hline
\end{tabular}

Fuente: INAEM

Las familias profesionales con mayor número de cursos en 2010 son Informática y Comunicaciones (323 cursos) y Administración y Gestión (210 cursos). Según la memoria anual del INAEM 2010, el mayor volumen de cursos de estas dos familias profesionales se viene repitiendo en los dos últimos años. A continuación, destacan la Formación Complementaria (145 cursos) y Servicios Socioculturales y a la Comunidad (136 cursos). Según la misma fuente, el resto de familias han disminuido, siendo las familias de Transporte y Mantenimiento de Vehículos, Sanidad y Comercio y Marketing las que han experimentado un descenso más notable. 
Gráfico 2.5. Cursos finalizados por familia profesional en Aragón. 2010

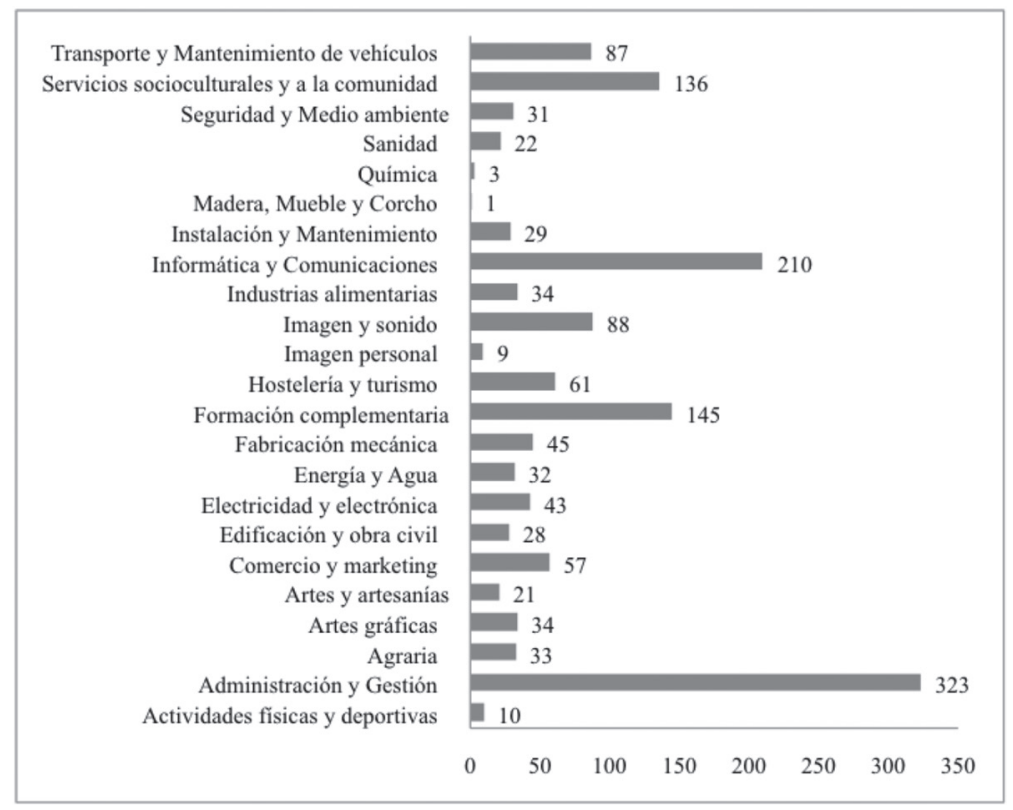

Fuente: INAEM

\subsection{Formación para el empleo: la formación de demanda}

En la Comunidad de Aragón, bajo la modalidad de formación de demanda y en 2010, se formaron un total de 74.107 trabajadores en las empresas aragonesas, lo que supone un 2,7\% de las personas formadas bajo la modalidad de demanda en España (tabla 3.29). El 21,6\% de las empresas de la Comunidad de Aragón participaron en dicha formación, una cifra inferior a la media española $(24,6 \%)$ (tabla 3.28).

Entre estas, las pymes de 50 a 249 son las que dedican más esfuerzo a dicha formación: el 74,2\% de las empresas de este tamaño han efectuado formación de demanda, una cifra prácticamente idéntica a la media española $(74,4 \%)$. El resto de pymes también han realizado un menor esfuerzo que el conjunto de empresas del Estado (tabla 3.28).

En este sentido, cabe destacar que la tasa de cobertura de la formación de demanda en la industria manufacturera (tabla 3.28) es del 31,9\%, casi un punto porcentual por debajo de la tasa estatal (32,8\%). En las empresas manufactureras, el 63,7\% de los participantes formados corresponde a empresas mayores de 100 trabajadores (tabla 3.29). En este sentido, según la distribución por sectores empresariales (tabla 3.30), el porcentaje de participantes formados en el sector industrial (26,6\%) es significativamente superior a la media española (18,7\%).

Respecto a la modalidad de la formación de demanda, cabe apuntar que en la Comunidad de Aragón dicha formación es fundamentalmente presencial: el 62,7\% de los participantes se han formado presencialmente, cifra que aumenta hasta el 72,4\% en el caso de las empresas manufactureras. En ambos casos la formación presencial en Aragón supera a la media española $(59,8 \%$ y $68,8 \%$, respectivamente). 
Atendiendo al sexo y a la edad de los participantes (tabla 3.31), casi 6 de cada 10 personas formadas bajo la modalidad de formación de demanda han sido hombres (59,8\%), una cifra ligeramente superior a la media estatal (57,6\%). Por otro lado, el 67,5\% tenían edades comprendidas entre los 26 y los 45 años y el 25,3\% de las personas formadas tenían 46 años o más.

Respecto al nivel de cualificación de las personas formadas (tabla 3.32), y en comparación con el conjunto del Estado, se puede observar que la formación de demanda en la industria aragonesa está ligeramente desplazada hacia las personas con responsabilidades de gestión. Así, un $40,6 \%$ de las personas formadas pertenecen a las categorías de directivos, mandos intermedios o técnicos, 2, 5 puntos porcentuales por encima de la media estatal, mientras que un 59,4\% de las personas formadas en esta modalidad son trabajadores cualificados o sin cualificación, 2,5 puntos porcentuales por debajo de la media estatal.

En cuanto al nivel de estudios de las personas formadas dentro del sector industrial de la Comunidad de Aragón (tabla 3.33), cabe destacar que el 35,5\% de los participantes cuentan con estudios universitarios, 6 puntos porcentuales por encima de la media estatal, una cifra solo superada por Navarra (36,6\%). Por el contrario, las personas con un perfil formativo bajomedio en Aragón reciben menos formación que en el conjunto del Estado.

Finalmente, si observamos los permisos individuales para la formación en la Comunidad de Aragón (tabla 3.34), vemos que estos se han formalizado mayoritariamente en las grandes empresas (59,6\%). Aun así, si comparamos el nivel de concesión de permisos en Aragón con el del conjunto del Estado, vemos que es en las micropymes y en las empresas medianas donde se da una mayor propensión a la concesión de este tipo de permisos con respecto al resto del Estado (en las micropymes, 9,6\% frente a 3,3\%; en las empresas medianas, 30,8\% frente a $23,3 \%)$. De hecho, el nivel de concesión de permisos en las micropymes aragonesas es el más elevado de las seis regiones estudiadas.

En la Comunidad de Aragón, al contrario que en otros territorios, una de las organizaciones empresariales, CEPYME, gestiona de manera importante la formación de demanda (sobre todo teleformación). La formación de demanda resulta muy complicada de gestionar para las pequeñas empresas, aunque se observa un cierto acercamiento de las empresas a esta formación, sobre todo en poblaciones pequeñas. Este tipo de formación, según algunos entrevistados, permite una mejor detección de las necesidades de las empresas que los mecanismos ordinarios existentes (observatorio del mercado de trabajo, jornadas del INAEM, CAFP, etc.).

CEPYME aquí, yo entiendo, es quien mejor trabaja la oferta de demanda. Al menos UGT no se había metido, CREA tampoco y CEPYME lleva varios años. Y X nos lo dice muchas veces: la oferta de demanda ha subido bastante, ha subido mucho. Y mucho quiero decir que muchas empresas la están utilizando y realmente yo creo que las empresas están con la de demanda. Y, cuando no es la de demanda, se dirigen sobre todo a CREA o CEPYME. A nosotros también, pero en menor proporción, claro. (AS1)

El gestionar formación de demanda te hace también estar todo el día hablando con las empresas del sector, con lo cual al final estás detectando perfectamente las necesidades y sabes lo que tienes que programar. (AS2)

La empresa suele atender a lo suyo, a su formación y a lo concreto, lo pequeño. Y, claro, a lo mejor tú planteas una formación y entre que se elabora el plan, se hacen las sesiones y se saca la formación pasan uno o dos años. Entonces esa formación igual ya se queda totalmente desfasada. Y yo creo que ese es el gran problema que tiene la formación de INAEM, en algunos casos. Salen cursos que ya no tienen sentido como formación continua. Yo creo que la idea tenía que ser ir por algo más ligero, más automático. Hay cosas demasiado rígidas, que entre que se hablan 
y se concretan, pasa demasiado tiempo para que eso se pueda hacer bien. Es complicado, muy complicado, y más en determinados sectores. Yo creo que ahí nosotros sí que podemos bastante, porque estamos en contacto con empresas, con muchas empresas del sector. Por ejemplo, alumnos de FCT solo en imagen y sonido, al año mandamos 100 o 120 alumnos pueden salir de aquí para hacer FCT. Solo de imagen: fotografía, de vídeo, productoras, televisiones, de todo. Entonces yo creo que la visión que podemos dar es muy buena. (FP1)

\subsection{Política regional en relación con la FP}

La política de la Administración aragonesa en materia de formación profesional se realiza desde el Departamento de Educación, Universidad, Cultura y Deporte junto con el Departamento de Hacienda, Economía y Empleo. La relación entre estos dos departamentos es, según la mayoría de los entrevistados, muy fluida, sobre todo si es comparada con otras comunidades autónomas. Aun así, se observan algunas discrepancias entre los dos departamentos que atienden, en algunos casos, a personalismos. En este sentido, la iniciativa de los centros integrados ha supuesto un mayor acercamiento entre ambos departamentos.

La relación entre ambos departamentos se incrementa a partir de las transferencias en educación, en 1998, y en empleo, en 2000. Desde entonces la colaboración es permanente.

En Aragón la verdad es que tenemos una trayectoria ya larga de relaciones con empresas y relaciones con el servicio público de empleo. En cuanto a la relación con empleo, la verdad es que yo creo que somos de las comunidades autónomas en las que mejor relación se mantiene entre educación y empleo. Llevamos desde el año 2000, desde que se recibieron las competencias en educación en el año 1998 y en empleo en el año 2000, una colaboración permanente. Estamos organizando jornadas conjuntas, estamos haciendo muchas actuaciones conjuntas. No todas las que nos gustaría llevar a cabo, pero hemos avanzado bastante. (AR1)

Yo creo que se están venciendo unas situaciones que eran complicadas. Y nosotros, por ejemplo, en el Consejo Social dependes mucho de las personas que tienes. Y yo, por ejemplo, lo bueno es que los representantes de INAEM que tenemos en el Consejo Social han sido gente receptiva y proactiva. Han entendido enseguida el concepto de que ellos estén en el centro integrado también representados. Y han entendido que eso implica colaboración. Y que tiene que ser por ambas partes. Lo complicado de eso a veces es que tú aquí lo tienes claro, pero cuando lo trasladas arriba, llega un momento que se atasca eso. Entonces estamos en esa fase un poco de desatascar y de ver que, o engrasamos y trabajamos juntos, o no vamos a ningún lado, sinceramente. Yo creo que la actitud es buena en ese sentido. Que la gente de Empleo y de Educación se están dando cuenta de que en otros aspectos puedes tener más diferencias, pero que si realmente quieres unos centros integrados que funcionen, necesitas trabajar juntos y trabajar bien juntos. Yo, en ese sentido, noto avances. Hay choques, porque su manera de trabajar y la nuestra es distinta. Y porque su manera de concebir la FP, la formación para el empleo ellos y la formación reglada nuestra es distinta. Ellos ven que el apartado pedagógico-educativo es bastante prescindible o no es lo importante, que lo importante es su formación, que es más puntual y específica. Y nosotros vemos que lo bueno de nuestra formación lo tendrían que recoger ellos para dar una formación mejor. Pero yo creo que el trabajo que estamos haciendo está siendo positivo y estamos tendiendo a avanzar, que es bastante más de lo que en un principio podíamos esperar. (FP1)

A ver, sabiendo lo que pasa en el resto de España, no nos podemos quejar. Obviamente, Educación y Empleo siempre van a ser Educación y Empleo. Aquí ha habido sus distancias. Pero, 
bueno, como tenemos mesas para estar juntos, yo creo que esas mesas favorecen también que las líneas vayan más o menos en paralelo. (AS2)

Pero eso también depende muchas veces de..., a ver, mira, como el Consejo de FP. Cuando se creó el Consejo Aragonés de Formación Profesional el pleno se reunía dos veces al año. Pues estuvimos dos años sin que se reuniese el pleno del Consejo Aragonés. Aquí, la Presidencia del Consejo Aragonés la ostenta la Consejería de Educación y la Consejería de Empleo. Pues estaban las peleas. Si los consejeros no se llevaban bien, que a veces pasaba, ojo, dentro del mismo partido político, como pasó, pues no lo convocaban. Le tocó a Educación y estuvo dos años sin que se convocase. Depende muchas veces de quién está en el Consejo, quién es el secretario, quién convoca. (AR1)

La formación profesional en Aragón se concreta en diferentes políticas, planes y programas. Entre ellos destacan el Plan de Formación e Inserción Profesional de Aragón y el Acuerdo Económico y Social para el Progreso de Aragón (AESPA) como marco general, los dos planes aragoneses de formación profesional ${ }^{2} \mathrm{y}$, en menor medida, los dos planes generales de educación permanente de Aragón.

Respecto a los planes de formación profesional, el I Plan Aragonés de Formación Profesional (PAFP) (2006-2008) destaca por iniciar algunos pasos importantes en la promoción y el desarrollo de la formación profesional, así como en la integración entre esta y los distintos subsistemas de formación. A continuación se apuntan algunos elementos importantes:

- Creación de la Agencia de las Cualificaciones Profesionales de Aragón, organismo que ha dirigido las etapas iniciales del procedimiento de evaluación, reconocimiento, acreditación y registro de las competencias profesionales adquiridas por la experiencia laboral o el aprendizaje no formal.

- Experimentación en el ámbito de los centros integrados: se ha desarrollado una experiencia en cinco IES que han ejercido las funciones de centros integrados de formación profesional. En ellos, además de crearse departamentos transversales para permitir desempeñar esas nuevas funciones, se han impartido numerosas acciones formativas de ambos subsistemas y se ha iniciado una estrecha colaboración con las empresas. Uno de los centros de FP entrevistados forma parte de estos cinco IES experimentales.

- Colaboración empresas y sistemas de formación: FCT y prácticas no laborales en empresas; participación de profesores especialistas, ajenos al sistema de formación; participación de empresas y trabajadores en la elaboración y revisión de los currículos de los ciclos formativos, así como en la identificación de cualificaciones relevantes para Aragón, en la elaboración de guías de evidencia y en actuaciones concretas del procedimiento de evaluación y acreditación de competencias. Numerosas empresas han participado asimismo en acciones formativas para profesorado de FP, como es el caso de las estancias formativas de profesores en empresas. 
Tabla 2.3. Participación de empresas en ámbitos FP. Período 2006-2008

\begin{tabular}{|l|c|}
\hline Actividad & Empresas participantes \\
\hline Elaboración de currículos de ciclos formativos & 27 \\
\hline Identificación de cualificaciones y elaboración de guías de evidencia & 45 \\
\hline Empresas que han acogido estancias formativas del profesorado & 180 \\
\hline
\end{tabular}

Fuente: DGFPEP

El II PAFP, que se corresponde con el período de 2009 a 2012, profundiza en estos y otros aspectos vinculados al fomento y la integración de la formación profesional y para el empleo. En este sentido, las directrices de este segundo plan se basan en cuatro líneas estratégicas:

1. El avance hacia un sistema integrado de cualificaciones y formación profesional.

2. La mejora continua en una formación profesional diferente.

3. Una formación profesional comprometida con el desarrollo de la innovación.

4. Impulso hacia una nueva cultura de la formación a través de las TIC.

A estas cuatro líneas estratégicas hay que añadir dos líneas transversales:

1. Difusión de la formación profesional.

2. Papel del Consejo Aragonés de Formación Profesional.

La iniciativa más importante es la apuesta por los centros integrados de formación profesional. En Aragón se inició en 2005 una fase experimental por la que se crearon cinco centros integrados experimentales: CPI Corona de Aragón y CPI Los Enlaces (Zaragoza), CPI Bajo Aragón (Teruel), y CPI San Lorenzo y CPI Pirámide (Huesca). Estos cinco centros experimentales se constituyen en septiembre de 2010 como centros públicos integrados de formación profesional, con distintas especialidades: CPI Bajo Aragón en automoción, CPI Los Enlaces en logística e imagen y sonido, CPI Corona de Aragón en mantenimiento industrial y química, CPI Pirámide en telecomunicaciones y CPI San Lorenzo en hostelería y turismo.

Por otro lado, existen dos planes generales de educación permanente. El I Plan General de Educación Permanente de Aragón (2006-2009) y el II Plan General de Educación Permanente de Aragón (2010-2013) aglutinan toda la formación realizada en el territorio aragonés e incluyen la formación reglada (estudios generales y profesionales), la formación para el empleo y otras formaciones realizadas por instituciones tales como el Instituto de la Mujer o el Instituto de la Juventud. De las entrevistas y la documentación analizada se deriva una menor incidencia de estos planes en la política aragonesa de formación profesional, siendo los dos PAFP los planes de referencia.

El I PAFP supone una sucesión de líneas maestras muy generales y, por lo tanto, bastante consensuadas entre todos los actores del territorio. El II PAFP incluye líneas de actuación más concretas, con indicadores y partida presupuestaria (véase la siguiente tabla). Actualmente se encuentra en fase de evaluación de dichos indicadores. 
Tabla 2.4. Presupuestos previstos II Plan Aragonés de Formación Profesional

\begin{tabular}{|l|c|}
\hline (Presupuesto de 2009 y propuestas para 2010, 2011 y 2012) & Total \\
\hline & 78.013 .944 \\
\hline Departamento de Economía, Hacienda y Empleo & 13.208 .800 \\
\hline Departamento de Educación, Universidad, Cultura y Deporte & 64.805 .144 \\
\hline
\end{tabular}

Fuente: Departamento de Educación, Universidad, Cultura y Deporte

Más allá de estos dos planes de formación profesional, en las entrevistas se destacan diferentes órganos institucionales tales como el Instituto Aragonés de Empleo (INAEM), el Consejo Aragonés de Formación Profesional (CAFP) y, en menor medida, el Consejo de Educación Permanente de Aragón (CEPA).

El INAEM, creado en 1999, es el responsable de planificar y gestionar las políticas de empleo en Aragón y, particularmente, la gestión de las políticas activas en el territorio. Su Consejo General lo constituyen representantes de la Administración regional (Departamento de Economía, Hacienda y Empleo) y representantes de los agentes sociales.

El máximo órgano consultivo en relación con la FP dentro de la Comunidad de Aragón es el Consejo Aragonés de la FP, cuyo Consejo y Comisión Permanente están formados por miembros de la Administración regional (Departamento de Economía, Hacienda y Empleo, INAEM y Departamento de Educación, Universidad, Cultura y Deporte) y representantes de las organizaciones sindicales (CC. OO. y UGT) y empresariales (CEPYME y CREA). No hay representantes de los centros de FP. La presidencia de este órgano se alterna entre las áreas de Empleo y Educación.

El Consejo de la Educación Permanente de Aragón es un órgano consultivo de la Comunidad Autónoma de Aragón adscrito al Departamento de Educación, Universidad, Cultura y Deporte con el fin de planificar, evaluar y coordinar todos los objetivos, las áreas de actuación y los programas de educación permanente, así como de garantizar el adecuado asesoramiento y la participación en esta materia. El CEPA lo constituyen miembros de la Administración regional (Departamento de Educación, Universidad, Cultura y Deporte, INAEM, Instituto Aragonés de la Mujer, Instituto Aragonés de la Juventud, Instituto Aragonés de Servicios Sociales, diputaciones provinciales), agentes sociales (CC. OO., UGT, CEPYME, CREA), instituciones educativas (Universidad de Zaragoza, Consejo Escolar de Aragón...) y otros agentes (cámaras de comercio).

Según las entrevistas realizadas, el CAFP ha estado poco activo desde su creación, aunque actualmente se está intentando reactivarlo. Sus funciones principales son de deliberación y asesoramiento. Hasta ahora la participación de los agentes sociales, a partir del CAFP, se ha limitado a aspectos muy concretos. Una de las actividades del CAFP es la detección de necesidades de formación, aunque, como admiten algunos entrevistados, dicha detección resulta poco dinámica y ágil para el mercado de trabajo, siendo los CPIFP actores más adecuados para detectar dichas necesidades.

Yo creo que sí, se ha avanzado algo [en la detección de necesidades]. El problema es que cuando empezamos todos y en el Consejo Aragonés de Formación Profesional decimos: «Bueno, vamos a hacer necesidades». Cuando hacemos análisis de necesidades, que lo último que ha salido es el Plan Detecta, pues cuando hacemos la foto, y ya ha habido muchísimos intentos de crear un observatorio de necesidades, etc., que lo hay. Pero, claro, detectar necesidades y con informantes 
clave, que están las empresas, los agentes sociales, y que aquí se hace cada dos años. El INAEM hace unas jornadas donde participan informantes clave. Además, se hacen reuniones allí. Claro, es que cada dos años realmente cambian muchas cosas. Entonces habría que buscar un método apropiado para que esas necesidades, cuando publiquen los resultados, es que el mercado ya te ha cambiado. Yo siempre digo: el mercado de trabajo se estudia con cámara de fotos, pero es que yo creo que el mercado es para estudiarlo con cámara de vídeo. (AS1)

Esta rigidez del CAFP también se observa en el caso del INAEM, muy criticado por algunos entrevistados por su excesivo nivel de burocratización. Los centros integrados, de hecho, suponen para algunos entrevistados una forma de romper dicha rigidez burocrática. Algunos entrevistados definen el INAEM como un simple gestor de subvenciones y con poca relación con algunos actores como los centros integrados.

Pues en el tema INAEM, las sesiones que organizaba INAEM cada año para detectar necesidades de formación, que eran con los sectores implicados, y dentro de los sectores incluía empresarios, organizaciones sindicales, centros de formación también, de FP..., para ver por dónde veíamos nosotros. Nosotros desde hace unos años hemos desaparecido de esas jornadas. Suponemos que obtendrán la información de otra manera. (FP1)

$Y$ que es difícil, que estudiar necesidades pues es difícil. $Y$ a veces pasa que una empresa tiene necesidades que en ese momento el INAEM no es capaz de..., yo insisto, creo que por problemas burocráticos. Porque a veces lo dicen los propios responsables del INAEM. Cuando una empresa tiene necesidad de contratar y de formar, a veces es que el INAEM no tiene recursos. (AS1)

Y yo creo que ese es el gran problema que tiene la formación del INAEM, en algunos casos. Salen cursos que ya no tienen sentido como formación continua. Yo creo que la idea tenía que ser ir por algo más ligero, más automático. Hay cosas demasiado rígidas que, entre que se hablan y se concretan, pasa demasiado tiempo para que eso se pueda hacer bien. Es complicado, muy complicado, y más en determinados sectores. Yo creo que ahí nosotros sí que podemos bastante, porque estamos en contacto con empresas, con muchas empresas del sector. (FP1)

Y yo creo que el INAEM, en este caso, es verdad, lo hace muy bien en gestionar subvenciones. Pero yo creo que no es eso. A ver, no es fácil. Tiene, a la vez, poco personal, aunque a la gente le parezca que lo tiene. La mayoría, en este caso, son personal interino, que supongo que ahora con la crisis y los recortes acabarán en la calle. Y realmente lo que hace con la formación es que tú hagas la formación de acuerdo con la normativa. Pero es la gestión del curso, no los contenidos. (AS1)

Tampoco se observa, según los entrevistados, una gran coordinación entre los diferentes órganos o espacios de actuación.

Tenemos, por supuesto, el Consejo Aragonés de Formación Profesional. La verdad es que ha estado un tiempo poco activo y ahora se está intentando reactivarlo. De hecho, anteayer tuvimos la última permanente del Consejo. El pleno se reunió en el mes..., a principios de febrero. Luego estamos retomando la iniciativa del Consejo. La verdad es que los agentes sociales nos piden que les demos participación en esto y en otras cosas, y yo creo que ahora estamos en un momento en el que vamos a intentar buscar consensos con todos ellos, porque tenemos que acometer algunas revisiones, algunos replanteamientos importantes, y es muy importante su visión. Digamos que hasta ahora su aportación no ha sido decisiva. Sí que ha sido tenida en cuenta, por supuesto. Pero han estado limitados a unos ámbitos muy concretos. Han estado limitados a dar su opinión sobre las modificaciones de la oferta formativa que se hacían, pero ya con un margen de 
maniobra muy escaso. Llegaban, pues, a hechos no consumados, pero sí ya muy muy avanzados. Ahora vamos a intentar que su participación sea previa a estos hechos consumados y que tengan un papel más decisivo. (AR1)

Al final el Plan Aragonés de Formación Profesional son más unas líneas maestras, unas tendencias a las que se quiere ir. Y yo creo que, como son consensuadas, todos vamos por esas líneas. El segundo se hizo con planes estratégicos, con medidas, con indicadores de esas medidas, pero no se han llegado a medir. Precisamente este año lo que se pretende es un poco medir para tener un punto de referencia. (AS2)

Tienen mala relación [educación y empleo]. Pero yo creo que pasa en toda España. Ha habido, aparte, verdaderas broncas. Yo creo que se vive un poco de espaldas, unos y otros. Lo hablo porque yo he estado en el Consejo de Educación Permanente y yo no formo parte, pero sí que formo parte de grupos de trabajo. Por ejemplo, para el Plan de Educación Permanente, yo formo parte del grupo de trabajo que elabora estudios sobre formación profesional $[\ldots]$ y veo que cada uno vamos a nuestra historia. Lo que hacemos nosotros les parece alucinante. Con alucinante me refiero a que no tienen ni idea. Y nosotros no tenemos ni idea de la otra parte. Yo creo que en ambos ámbitos se trabaja mucho, pero se trabaja de espaldas. (AS1)

En la Comunidad de Aragón existen determinados programas innovadores en materia de formación profesional, que se explican a continuación.

\section{Emprender en la Escuela}

El Departamento de Educación, Universidad, Cultura y Deporte del Gobierno de Aragón y el Instituto Aragonés de Fomento, con el objetivo de impulsar el espíritu emprendedor en el alumnado aragonés y su acercamiento al mundo empresarial, firmaron un convenio para implantar el Programa Emprender en la Escuela en los centros de educación secundaria de Aragón.

Este programa tiene el carácter de programa de innovación y su objetivo es la formación de emprendedores entre el alumnado que cursa estudios de formación profesional.

Se concreta principalmente en dos actuaciones:

+ Talleres de emprendedores.

- Premios a la realización de proyectos empresariales de creación de una empresa (véase edición de 2011).

\section{Simulación de Empresas}

El Programa Simulación de Empresas tiene por objeto el desarrollo de un proyecto innovador en el ámbito de la gestión comercial y los recursos humanos de las empresas a través de la metodología de la simulación de empresas, consistente en reproducir situaciones reales de trabajo.

Los alumnos «aprenden haciendo» en un contexto en el que se reproducen situaciones reales de trabajo, por lo que esta metodología permite adquirir no solo competencias técnicas, sino también una serie de competencias transversales como el trabajo en equipo, la toma de decisiones y la resolución de problemas, la comunicación efectiva, el trabajo en red y la transnacionalidad, entre otras.

Actualmente participan en este programa IES que imparten enseñanzas de formación profesional de las siguientes familias y ciclos formativos:

- Administración: cualquier ciclo formativo de la familia profesional. 
- Comercio y Marketing: ciclos formativos de Comercio Internacional y Gestión del Transporte.

- Hostelería y Turismo: ciclo formativo de Agencias de Viajes.

\section{Programas europeos}

Programas que fomentan la movilidad de alumnado y profesorado entre diferentes regiones del espacio europeo comunitario. Entre los programas de colaboración vigentes destacan los siguientes: Programa Academia, PIREFOP, SUDOEFOP, Programa de Aprendizaje Permanente (PAP), Programa de Estancias Formativas en UE.

\subsection{Prácticas de formación en centros de trabajo (FCT)}

Según algunos entrevistados, la Comunidad de Aragón es pionera en la firma de convenios con empresas de diversos sectores. Lo que aparece en todas las entrevistas es la importancia de las FCT para la conexión con el tejido empresarial y para la inserción de los alumnos que cursan dichas prácticas. De las entrevistas se deriva una cierta tradición de realización de prácticas, lo que se plasma en diferentes acuerdos con empresas.

Las prácticas en empresas aquí la verdad es que desde siempre se han realizado razonablemente bien. En los últimos tiempos sí que hay más dificultades, porque hay empresas que no se atreven o no quieren coger alumnos en prácticas porque están ajustando plantillas. Entonces, claro, queda mal. Y en los últimos tiempos sí que hay algunas dificultades, pero la verdad es que la experiencia nos ha ido demostrando que los alumnos que hacen prácticas en una empresa luego tienen muchísimas probabilidades de quedarse en esa empresa trabajando. (AR1)

Nosotros ya teníamos una relación muy estrecha con las empresas por el tema de la formación profesional por las FCT, la formación en centros de trabajo. Este siempre ha sido un centro que se ha caracterizado porque la relación con las empresas las cuida mucho. Entonces, además de llevar a alumnos a prácticas cuando toca, para que acaben sus módulos y sus ciclos, se ha intentado mantener una colaboración estrecha con las empresas y un cuidado de tener una relación durante todo el año. (FP1)

La consolidación de las FCT se ve plasmada en una serie de acuerdos firmados con empresas e instituciones para las siguientes familias profesionales:

- Servicio Aragonés de la Salud: acuerdo a nivel general.

- Asociación de Agencias de Viajes de Aragón: acuerdo a nivel general.

- Federación Aragonesa de Esquí: actividades físico-deportivas, deportes de invierno.

- Federación Aragonesa de Montañismo: actividades físico-deportivas, deportes de montaña y escalada.

- Federación Aragonesa de Piragüismo* actividades físico-deportivas.

- Real Aeroclub de Zaragoza: mantenimiento de vehículos autopropulsados (mantenimiento aeromecánico).

- Base Aérea del Ministerio de Defensa: mantenimiento de vehículos autopropulsados (mantenimiento aeromecánico). 
- Opel España: electricidad y electrónica, mantenimiento y servicios a la producción y administración.

+ Diputación Provincial de Zaragoza: hostelería y turismo.

- Ayuntamiento de Caspe: hostelería y turismo.

- Consejo Regulador Denominación de Origen y Ayuntamiento de Cariñena: industrias alimentarias.

- Federación Aragonesa de Vela: actividades físico-deportivas.

+ Endesa Generación: electricidad y electrónica.

- Casting Ros: mantenimiento y servicios a la producción.

+ Primayor: industrias alimentarias.

- Parador de Teruel: hostelería y turismo.

El Departamento de Educación, Universidad, Cultura y Deporte realizó en 2005, en colaboración con las cámaras de comercio e industria de Aragón, un informe de evaluación del módulo de FCT. De este informe se deriva una valoración muy positiva por parte de alumnos y empresas. Por otro lado, el 60\% de los alumnos que realizaron la FCT en el período 2003-2004 se encontraban trabajando en el momento de realizar el informe. El 24,8\% de los alumnos que iniciaron la FCT en una empresa continuaron trabajando en la misma empresa. Estos datos apuntan a la importancia de la FCT en la posterior inserción laboral de los egresados.

La evolución de la formación en centros de trabajo ha variado en los últimos cursos. Según algunos entrevistados, la crisis ha supuesto un descenso en el número de empresas dispuestas a mantener convenios de colaboración con los centros de formación profesional. Los datos disponibles así lo corroboran. A partir del curso 2009-2010 se observa una tendencia a la baja en el número de empresas colaboradoras. Sin embargo, el número de alumnos que han realizado dichas prácticas no ha dejado de aumentar ${ }^{3}$. Ello evidencia el esfuerzo por parte de los centros de FP para conseguir «recolocar» este volumen creciente de alumnado entre el cada vez menor número de empresas disponibles para admitir alumnos de formación profesional. Este mayor esfuerzo también aparece en algunas de las entrevistas realizadas.

Pues en FP reglada nosotros nos encontramos con cada vez más alumnado. Con más problemas para llevar alumnado a empresas también, porque nos cierran empresas, las empresas no pueden tener alumnos de prácticas tal y como es el programa. Y es complicado. Estamos poniendo a toda la gente en sus prácticas y en las empresas, pero está costando muchísimo. Mientras que antes casi te llamaban muchas veces y tenías casi que seleccionar, ahora tienes que ser tú el que esté llamando muchas veces a muchas puertas. (FP1)

Este esfuerzo también se observa en los resultados del informe de evaluación de la FCT para 2005. Según este informe, la iniciativa de participar en la FCT surgió en un 82,8\% de las ocasiones del centro de formación, con lo que se corrobora este esfuerzo por parte de los centros de formación profesional por acercarse al tejido empresarial.

\footnotetext{
3 En el curso 2011-2012 el número de alumnos ha bajado. No se tiene en cuenta este dato puesto que se considera un dato provisional; asimismo, todavía es posible conseguir colaboraciones con empresas para este curso y cabe señalar el hecho de que el número de alumnos en este curso ha aumentado con respecto al curso anterior.
} 
Gráfico 2.6. Prácticas FCT (varios años)

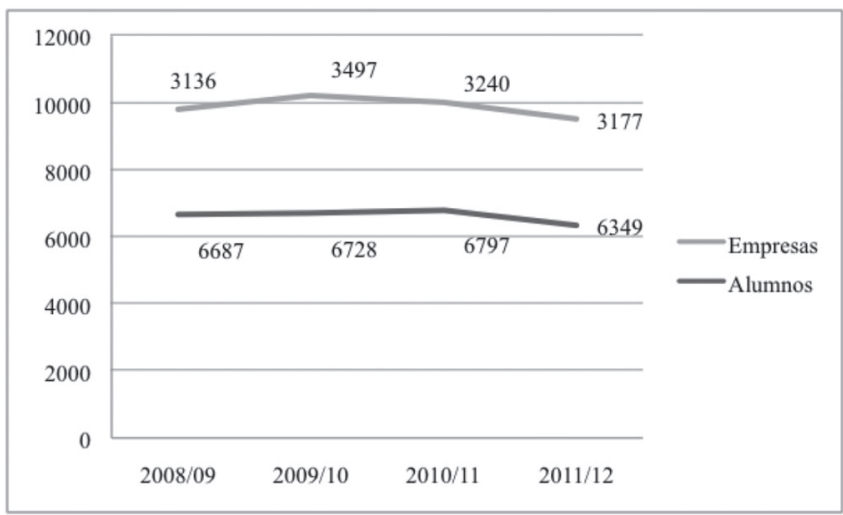

Fuente: elaboración propia. Servicio de Formación Profesional.

Departamento de Educación, Universidad, Cultura y Deporte

Todos los entrevistados destacan la importancia de las FCT para el desarrollo de relaciones entre los centros de formación y las empresas aragonesas. Las FCT han permitido acercar las empresas a la formación reglada. Este acercamiento también se ha dado en dos direcciones: entre alumno y mercado de trabajo y entre tutores de centro y empresas y mercado de trabajo. Ello ha permitido mejorar en aspectos tales como la detección de necesidades, la participación de empresas en currículos, etc. Además, las FCT han supuesto un antecedente importante en cuanto a relaciones entre los centros de FP y las empresas y han facilitado la comprensión por parte de las empresas de la concepción de los centros integrados.

Nosotros teníamos niveles, te hablo de hace cinco años, niveles de inserción de que el alumno que entraba, es que era una entrada a la empresa. Te conocían y esto. Es que es una manera de entrar a la empresa. (AS1)

Nosotros tenemos tutores en FCT, los tutores de prácticas. Y los tutores de prácticas trasladan al centro lo que hay. Y aparte de esos tutores de prácticas, los alumnos te trasladan también lo que hay. Y muchos tutores de FCT, de prácticas en las empresas, tienden puentes, ya sea por el tutor de FCT, a través de la bolsa de empleo del centro, a través de jornadas que hacemos en las que coincidimos. Lo importante es que te vean, que tú estés y que te intereses. Si las empresas ven que tampoco tienes interés y que no ofreces modificaciones y opciones a su formación, no tienes nada que hacer. (FP1)

Yo creo que uno de los grandes aciertos de los ciclos formativos fueron las FCT. Las FCT, la formación en centros de trabajo, acercaron muchísimo las empresas a la formación reglada, que era el gran fallo que había. Entonces la pregunta de siempre es: ¿los ciclos formativos dan al mercado lo que el mercado necesita? Y parece que por defecto hay que decir que no. Y yo en eso no estoy de acuerdo. Otra cosa es que no genere suficiente mano de obra para llenar. Pero lo que está claro es que cuando las cosas iban bien (ahora no, que nos sobra de todo), todos los que hacían formación en centros de trabajo se colocaban. Quieras que no, las FCT acercan la realidad de la formación reglada a la empresa. No solo para el chaval que hace las prácticas, sino también el propio tutor, el que se molesta, el que va a la empresa y el que llama «oye, que tengo un alumno»; pues al final si se molesta, ve por dónde va la empresa. Y ve que en fabricación mecánica o en instalaciones, pues ve lo que está haciendo, lo que necesita, si le falta, no le falta. 
La actualización de currículos es muy importante. La participación de las empresas en la actualización de esos currículos también me parece muy importante. (AS2)

\title{
2.7 Otros tipos de relaciones entre los centros de FP y las empresas. Papel de los centros de FP en la formación para el empleo
}

\author{
Servicios de innovación a las empresas
}

Las relaciones entre centros de FP y empresas, más allá de las FCT, se resumen según lo analizado en estancias de profesorado en empresas y realización de servicios y/o estudios a empresas. También existen los cursos de formación que los centros integrados ofrecen a las empresas.

El Departamento de Educación y Ciencia del Gobierno de Aragón impulsó en el curso 2000-2001 la realización de estancias de formación en empresas de Aragón del profesorado de formación profesional, e hizo una nueva convocatoria en 2001. El I PAFP también recogía el impulso de esta iniciativa. Las estancias de profesorado para el período comprendido dentro del I PAFP han sido 180. La información disponible en internet aparece muy desfasada. La información que tenemos se basa en las entrevistas realizadas.

Según algunos entrevistados, las estancias de profesores han resultado complicadas debido a las reticencias iniciales, sobre todo en entidades muy sindicalizadas (confusión entre formación y práctica laboral). Aun así, las estancias realizadas suponen un contacto y un acercamiento importante entre docentes y empresas.

Es complicado porque vas como un alumno. Tienes que tener un tutor en la empresa que se responsabilice de ti. Tienes que llevar un programa formativo o un proyecto de qué quieres hacer en esas prácticas. No es voy a una empresa para ver cómo funcionan. No. Qué es lo que quiero hacer en esa empresa, en qué quiero profundizar y qué es lo que voy a poder hacer allí. Y, luego, en determinadas empresas es complejo. Yo, por ejemplo, hice una estancia de empresas en $\mathrm{X}$. Pero me costó muchísimo explicarles y que entendieran que no eran unas prácticas laborales. En determinadas entidades están muy alerta de que tú no hagas un trabajo real dentro de tus prácticas. (FP1)

Se están haciendo y la verdad es que la gente, cuando vas a las prácticas, yo creo que lo ven como algo positivo. Porque ahí sí que se produce intercambio también. Ahí los profesionales primero te ven como un profesor que no tiene ni idea de lo que va a aprender, y luego ven que hay cosas que ellos no conocían o que no las veían así y que tú también les puedes aportar. Se han gestado muchos contactos para dejar de verte como un instituto y poder trabajar juntos en cosas. (FP1)

Este contacto ha permitido relaciones entre empresas y centros de FP más allá de estas estancias y de la oferta y realización de cursos de formación. En algunos casos, determinadas empresas han utilizado recursos de los propios centros de FP (como el caso del CPI Corona de Aragón). Otras veces se han compartido recursos (como el caso del CPI Pirámide y la Fundación Hidrógeno). En otros casos, los centros integrados ofrecen servicios a empresas, como el caso del CPI Los Enlaces, el cual, dentro del proyecto de innovación SiempreFP, plantea la realización de estudios a empresas para la mejora de algún producto o servicio de la propia empresa. 
Está pasando en los dos sentidos. Es cierto que hay empresas que ofertan sus instalaciones para determinadas actividades. Pero al revés también. Por ejemplo, en el centro integrado Corona de Aragón tenemos una máquina de fabricación mecánica. Es una máquina de fabricación de cinco ejes. Y hay empresas que están yendo allí para fabricar sus prototipos. Entonces, el instituto les cede las instalaciones y la empresa trabaja en el desarrollo de prototipos. Y en el sentido contrario se está planteando, por ejemplo, trabajar conjuntamente entre el centro integrado Pirámide y la Fundación del Hidrógeno para intentar implantar enseñanzas de energías alternativas, que una parte se haría en las instalaciones de la Fundación del Hidrógeno en Walqa, que tienen aerogeneradores, etc., y no haría falta instalarlos en el centro. (AR1)

Cada vez más lo que notamos es que no es una empresa que esté cerrada y que no se esté enterando de nada de lo que hay. Las empresas suelen estar muy bien informadas... Sí que estamos ahora, por ejemplo, en un proyecto de innovación que es el «SiempreFP», donde se les propone a las empresas que nosotros, lo que podamos, vamos a intentar contribuir para mejorar productos y servicios. Ese proyecto lo que hace es estudiar el tema de qué es lo que tiene la empresa y cómo se puede mejorar algún producto o servicio que tenga esa empresa. Entonces nosotros les ofrecemos la opción de hacerles el estudio. Que la empresa dice: «Oye, yo tengo este producto, pero me gustaría cómo podría mejorarlo». Nosotros nos comprometemos a estudiar cómo hacer ese desarrollo y ver cómo se puede mejorar. (FP1)

Por ejemplo, iniciativas que han surgido aquí como jornadas técnicas y demás son iniciativas que surgen a partir de que el profesorado se mueve y contacta con empresas, pero también asiste a jornadas, establece contactos..., cosas que ve nuevas o interesantes, intenta traerlas aquí a nuestros alumnos, pero también formación para profesores. (FP1)

\section{Formación para el empleo y centros integrados}

Como ya se ha apuntado, los dos PAFP incluyen el concepto de centros integrados y, por lo tanto, el progresivo protagonismo de los centros de FP en la formación para el empleo. Respecto a la formación de oferta para desempleados, según los presupuestos y algunos entrevistados, cabe destacar la partida propia de formación de oferta en centros integrados de formación profesional dentro de la formación de oferta dirigida prioritariamente a desempleados que establece el INAEM y que, en 2010, asciende a 504.315 euros, lo que supone un 2,8\% del presupuesto dirigido a dicha formación ${ }^{4}$. Esta partida presupuestaria se reparte entre los cinco centros integrados existentes en función de las propuestas de los centros y de los criterios de selección del INAEM. Esta partida presupuestaria diferenciada para los centros integrados existe desde hace dos años. Antes los centros integrados «competían» en las mismas condiciones que el resto de ofertantes de formación.

Desde hace dos años funcionamos con INAEM a través de un convenio aparte, los centros integrados. Hasta entonces entrábamos, digamos, en el mercado, en la subasta de cursos que INAEM ofrecía como cualquier centro colaborador: academias, centros privados, otros institutos de secundaria o FP. Y desde entonces vamos por convenio aparte. Entonces a los cinco centros integrados INAEM nos asigna una dotación igual para los cinco centros $y$, según esa dotación y la oferta que nosotros le planteamos de cursos que entendemos que podemos hacer, ellos nos dan esos cursos. (FP1)

Respecto a la formación de oferta para empleados, la situación es más compleja. La razón es estrictamente legal. Aunque, como ya se ha dicho, el INAEM tiene una partida presu-

4 Para más detalles, véase el anexo III. 
puestaria propia de formación de oferta a desempleados para los centros integrados, no permite a estos centros participar en la distribución de los cursos de formación para empleados. De hecho, el mecanismo que han buscado los centros integrados es ofrecerse a los agentes sociales (a los que sí que se les asignan dichos cursos de formación) como centros con recursos y docentes para la posible realización de sus cursos. Los centros integrados detectan necesidades a partir del contacto continuado con empresas y diseñan un curso que ofrecen a los agentes sociales, a la vez que se ofrecen para cualquier curso de formación planteado por los agentes sociales (siempre en relación con las familias profesionales del centro). Actualmente, hay reticencias por parte del INAEM y de los agentes sociales a la participación de los centros integrados en esta formación, si bien este acercamiento de los centros integrados también es reconocido por los propios agentes sociales, que ven a los IES como centros formativos más rígidos y burocratizados que los actuales centros integrados. En algunos centros integrados ya se han hecho cursos con sindicatos y se están manteniendo contactos con organizaciones empresariales.

[Dentro del convenio con INAEM] solamente entra la parte de desempleados. Entonces la parte de continua lo que estamos empezando a tejer ahora, que no teníamos nada, en continua lo único que teníamos es... La continua se reparte básicamente entre organizaciones sindicales, confederación de empresarios..., agentes sociales en definitiva. Entonces nosotros ahora hemos entrado ahí como una parte muy pequeñita, los centros integrados, y ellos no acaban de tener muy claro cuál es nuestro papel ahí. Entonces nosotros les estamos brindando lo que nosotros vemos o entendemos que debemos hacer. Que es que nosotros tenemos unas instalaciones para poder impartir unas clases y, primero damos reglada, pero tenemos unas horas donde se pueden dedicar esas instalaciones a esa formación continua de empresas. $Y$ tenemos gente preparada que puede darla y tenemos medios para poder darla. Entonces la idea es que los cursos que hasta ahora siempre había que hacer a través de academias o a través de aulas que ellos tienen, que sepan que aquí hay un lugar donde también pueden. ¿Cómo? Ellos solicitan su formación específica a INAEM. Si se la conceden, que sepan que, por un lado, hay instalaciones, profesorado y material para poder impartirla. Y, por otra parte, nosotros tenemos un profesorado activo que propone también cursos que no entran dentro del plan de desempleados. Cursos más innovadores: cosas para dispositivos móviles, cosas de más de dispositivos propios. Cursos cortos, como la formación a demanda que ofrecen las empresas. Nosotros también detectamos necesidades en las empresas cuando vamos. Entonces la idea es decir, bueno, si esa empresa no puede hacerlo. No puede solicitarlo por ella misma porque a lo mejor la única manera que tiene de hacerlo es a través de una formación con compromiso de contratación, por ejemplo, que la empresa no puede asumir. La idea es que si nosotros detectamos que en varias empresas hay esa necesidad, nosotros diseñamos un curso. Se lo ofrecemos a los agentes sociales para que sean ellos los que entren en ese sorteo en que nosotros no podemos entrar. (FP1)

Respecto a la formación de demanda, la relación con los centros integrados, según los entrevistados, todavía no está bien definida. Se está empezando a fomentar este tipo de formación, pero resulta complejo, ya que la pequeña empresa necesita agruparse para poder solicitar este tipo de cursos. Se están realizando algunos cursos de empresas en el propio centro, ofreciendo este los espacios y recursos para ello. Los centros integrados parecen estar todavía excesivamente burocratizados.

Pues supongo que también porque, al final, los centros integrados son muy burocráticos. Y si somos todos muy burocráticos, pues seguro que CEPYME es más flexible [respecto a la formación de demanda]. Dentro de la burocracia, es más flexible. Dentro de lo que tiene que es una 
normativa, y seguro que la cumple. Bueno, seguro no, la cumple. Seguro que se adapta más a las necesidades de las empresas. (AS1)

Hemos hablado con empresas, pero cuesta. Cuesta porque las opciones que tienen para sacar una formación a demanda es esa. Es a través de juntarse varias empresas. Con las pequeñas empresas sí que tenemos contactos y sí que nos dicen: «Tenemos necesidades de esto o lo otro». Y nosotros les planteamos: «Vale, vamos a diseñar cursos». Pero el camino, de momento, se les hace muy largo. (FP1)

Nosotros estamos intentando desde hace años ya apoyar el que pueda realizarse formación de demanda en nuestros centros. Es complejo en maquinarias tan rígidas como las del sistema educativo montar formación de demanda. Pero sí que es cierto que estamos haciendo experiencias, todavía a pequeña escala podríamos decir, de permitir a los centros que puedan realizar ofertas de módulos parciales, de tal manera que puedan ser pactados con empresas en un momento determinado. (AR1)

\section{Conclusiones}

Podemos definir a la Comunidad de Aragón como una región próspera atendiendo a sus niveles de $\mathrm{PIB}$, renta per cápita, VAB de su industria, empleo, etc., sobre todo en relación con el conjunto del Estado. Esto se debe, en parte, a un no desdeñable tejido industrial con un elevado nivel tecnológico. De hecho, de las seis regiones estudiadas Aragón es la segunda región con mayor nivel tecnológico dentro del sector industrial. Por otro lado, el nivel de cualificación general de su población resulta también elevado, relativamente superior a la media española. Cabe destacar también el importante peso de la formación profesional entre la población ocupada, especialmente los grados medios si hablamos del sector industrial.

Sin embargo, en términos de I+D la Comunidad de Aragón no destaca por su esfuerzo inversor, y ello a pesar del mayor protagonismo que tiene la Administración pública en la ejecución de dicho gasto, por encima de la media estatal. De hecho, son las empresas aragonesas las que realizan (en mayor medida que la media española) las acciones innovadoras dentro del territorio. Esta menor inversión general se nota en el menor volumen de personal dedicado a I + D sobre la población ocupada. De este personal, el sector de la enseñanza superior es el que presenta un mayor volumen. Aunque esto ha permitido un crecimiento mayor del personal dedicado a I+D sobre el conjunto del Estado.

Respecto al gasto en $\mathrm{I}+\mathrm{D}$, cabe destacar el protagonismo de las empresas industriales, muy superior a la media española, aunque este gasto responde menos al desarrollo interno de $\mathrm{I}+\mathrm{D}$ o a la adquisición externa de $\mathrm{I}+\mathrm{D}$ que a la adquisición de conocimientos externos de forma, por cierto, muy superior al resto de regiones estudiadas.

El acceso a ayudas a la I+D resulta capital para potenciar la innovación entre las empresas aragonesas. En este sentido, si bien el acceso a ayudas provenientes de la Administración central es superior a la media española, el acceso a ayudas regionales y provenientes de la Unión Europea es muy inferior. Esto quizás sea una de las razones por las que las empresas aragonesas cooperan en mayor medida que las del conjunto del Estado. Otra de las posibles razones puede ser el limitado territorio en el que las empresas aragonesas se ubican, así como su tipología.

El sistema de centros de formación e investigación parece estar dando una relativa cobertura a las necesidades tanto de capital humano como de innovación e investigación. Aun así, muchos de los agentes vinculados al fomento y desarrollo de la innovación son de reciente creación. 
Respecto de la formación, el fomento de la relación entre formación profesional inicial/reglada y formación para el empleo (sea esta de oferta o demanda) tiene un bagaje limitado en el tiempo. Esta relación se materializa (desde el punto de vista de los centros públicos) en la experiencia de los centros integrados de formación profesional (CPIFP), de reciente creación, partiendo de una experiencia piloto en 2005. Hasta la fecha se observa un relativo apoyo por parte del INAEM a estos centros a partir de la partida propia de formación de oferta dirigida prioritariamente a desempleados. Sin embargo, no parece desprenderse de ello avances en la participación de estos CPIFP en la formación de oferta dirigida a ocupados y/u otros programas de formación (por parte del INAEM en calidad de asignación presupuestaria propia o simplemente de participación en la asignación de los cursos de esta partida). En este sentido, la colaboración con los agentes sociales para coparticipar con los CPIFP (ofreciendo aulas y docentes) está en una situación prematura y poco consolidada. Actualmente se están realizando contactos de forma puntual e individualizada.

Otro elemento diferenciador es el contraste entre la conurbación de Zaragoza y el resto del territorio aragonés. Más allá del área de influencia de Zaragoza existen experiencias significativas en materia de relación entre CPIFP y empresas (CPI Bajo Aragón en Teruel y CPI Pirámide en Huesca). Estas iniciativas aparecen vinculadas a sectores muy concretos (entre otros, el caso del CPI Pirámide con la Fundación del Hidrógeno o el CPI Bajo Aragón con el sector de la automoción).

Respecto a la relación entre centros educativos y empresas, la relación que inician, desarrollan y consolidan los CPIFP con el tejido empresarial tiene tres consecuencias. La primera es una mejora en la inserción de los egresados de estos centros. La segunda es un acercamiento de las empresas a la formación reglada (tradicionalmente distanciadas), lo que, a su vez, provoca un aumento exponencial de los contactos entre ambos actores (vía jornadas, formación a demanda, prestación de servicios, estancias de profesorado, etc.). La tercera consecuencia es que se da una mejor detección de necesidades, al convertirse los CPIFP en «informantes clave» para una mejor detección de estas necesidades (formativas, de mejora de sistemas de producción o implementación de sistemas de innovación...), más allá de observatorios y jornadas técnicas planteados y organizados desde la Administración regional. Ello permite crear relaciones más allá de la impartición de formación por parte de los centros de formación profesional, generándose acciones vinculadas a la mejora de productos y/o servicios a las empresas o a la difusión del conocimiento y la innovación. 


\section{Anexos}

\section{Anexo I. Ficha técnica}

En el caso de la Comunidad de Aragón se han realizado un total de cuatro entrevistas de tipo exploratorio a representantes del Gobierno de Aragón (AR1), agentes sociales (AS1, AS2) y centros de formación profesional (FP1). Además, se han analizado los materiales recogidos como documentación sobre políticas, iniciativas y/o programas, así como datos estadísticos.

\section{Anexo II. Red de agentes de I+D+i de la Comunidad de Aragón}

A continuación se enumeran los agentes vinculados al sistema regional de innovación de la Comunidad de Aragón.

Centros de investigación propios del Gobierno de Aragón:

+ Instituto Tecnológico de Aragón (ITA)

- Centro de Investigación y Tecnología Agroalimentaria (CITA)

+ Instituto Aragonés de Ciencias de la Salud (I+CS)

Universidades e institutos universitarios de investigación:

+ Universidad de Zaragoza

- Tres centros UNED

- Universidad San Jorge (privada)

- Instituto Universitario de Investigación en Ingeniería de Aragón (I3A)

- Instituto Universitario de Nanociencia (INA)

- Instituto Universitario de Biocomputación y Física de Sistemas Complejos (BIFI)

- Instituto Universitario de Investigación en Catálisis Homogénea (IUCH)

Consejo Superior de Investigaciones Cientificas (CSIC). Centros propios:

- Estación experimental de Aula Dei (EEAD)

- Instituto de Carboquímica (ICB)

- Instituto Pirenaico de Ecología (IPE)

Consejo Superior de Investigaciones Cientificas (CSIC). Centros mixtos:

- Laboratorio de Investigaciones en Tecnologías de la Combustión (LITEC), con el Gobierno de Aragón y la Universidad de Zaragoza

+ Instituto de Estudios Islámicos y de Oriente Próximo (IEIOP), con las Cortes de Aragón y la Universidad de Zaragoza

+ Instituto de Ciencia de Materiales de Aragón (ICMA), con la Universidad de Zaragoza

Otros centros del sistema público de $I+D$ :

- Instituto Agronómico Mediterráneo de Zaragoza 
Centros de innovación y tecnología y parques tecnológicos:

+ Instituto Tecnológico de Aragón (ITA)

- Fundación CIRCE. Centro de Investigación del Rendimiento de Centrales Eléctricas

+ Zaragoza Logistics Center

- Parque Tecnológico Walqa

$+\quad$ Motorland

Oficinas de transferencia de resultados de investigación:

- OTRI de la Universidad de Zaragoza

- OTRI de la Escuela Universitaria Politécnica de La Almunia de Doña Godina

+ Fundación Empresa Universidad de Zaragoza (FEUZ)

- Confederación de Empresarios de Zaragoza (CEZ)

+ Instituto Tecnológico de Aragón (ITA)

+ OTT-CSIC en Aragón

$+\quad$ CIRCE

Otros organismos de apoyo a la innovación:

+ Instituto Aragonés de Fomento (IAF)

+ CEEI Aragón

+ ITA

$+\quad$ CITA

Entidades de origen empresarial:

+ Asociación de Investigación Taller de Inyección de la Industria de los Plásticos (AIITIP)

- Centro Zaragoza: Instituto de Investigación sobre Reparación de Vehículos

\section{Anexo III. Formación en Aragón 2010ः programación y presupuestos}

\begin{tabular}{|l|c|c|}
\hline Programa & Euros & Total \\
\hline Centros de formación propios INAEM & $2.089 .830,16$ & $\mathbf{2 . 0 8 9 . 8 3 0 , 1 6}$ \\
\hline $\begin{array}{l}\text { Formación de oferta dirigida prioritariamente a } \\
\text { desempleados: }\end{array}$ & $\mathbf{1 8 . 0 0 3 . 2 0 7 , 0 0}$ & \\
\hline${ }^{*}$ Cursos dirigidos a todo tipo de desempleados (Plan Gral.) & $15.973 .672,00$ & \\
\hline${ }^{*}$ Acuerdos con compromiso de contratación & $1.024 .870,00$ & \\
\hline${ }^{*}$ Centros integrados (IES) & $504.315,00$ & \\
\hline${ }^{*}$ Convenio Ayuntamiento Zaragoza & $500.350,00$ & \\
\hline Programas de escuelas taller y talleres de empleo & $9.300 .882,46$ & $\mathbf{9 . 3 0 0 . 8 8 2 , 4 6}$ \\
\hline Programa formativo propio de la Comunidad Autónoma & & \\
\hline
\end{tabular}




\begin{tabular}{|c|c|c|}
\hline Programa & Euros & Total \\
\hline *Agentes sociales (CC. OO., CEPYME, CREA, UGT): & $10.662 .514,89$ & \\
\hline - Acciones formativas & $5.749 .874,00$ & \\
\hline - Programas habilidades & $800.000,00$ & \\
\hline - Prácticas no laborales & $1.440 .000,00$ & \\
\hline - Acciones de orientación laboral (INFORIENTA) & $954.672,00$ & \\
\hline - Red de informantes (CREA) & $70.500,00$ & \\
\hline - Plan FIJA (agentes sociales) & $1.083 .535,00$ & \\
\hline - Infraestructuras formativas & $563.933,89$ & \\
\hline${ }^{*}$ Convenios de colaboración: & $3.311 .660,40$ & \\
\hline - Universidad de Zaragoza & $1.348 .010,32$ & \\
\hline - Convenio colaboración IASS-INAEM & $500.000,00$ & \\
\hline - Convenio diputaciones provinciales convocatoria TIC & $456.000,00$ & \\
\hline - Instituto Tecnológico de Aragón & $462.738,10$ & \\
\hline - Fundación Adunare & $194.559,44$ & \\
\hline - Secretariado General Gitano & $123.759,44$ & \\
\hline - Ministerio de Igualdad - Mujeres Emprendedoras Teruel & $70.000,00$ & \\
\hline - Fundación Santa María de Albarracín & $63.963,00$ & \\
\hline - Convenio prácticas no laborales centros integrados & $45.000,00$ & \\
\hline - Convenio a tu medida comarca Ribera Baja Ebro & $38.880,00$ & \\
\hline - Asociación de Malabaristas de Zaragoza & 8.750 & \\
\hline - Convenio Escuela Hostelería Topi & 0,00 & \\
\hline - Convenio Corporación Aragonesa Radio y Televisión & 0,00 & \\
\hline - Casa de la Mujer (Ayuntamiento) & 0,00 & \\
\hline${ }^{*}$ Convocatoria TIC zonas rurales & $3.485 .504,90$ & $3.485 .504,90$ \\
\hline $\begin{array}{l}\text { Planes nacionales de formación dirigidos } \\
\text { prioritariamente a ocupados: }\end{array}$ & $11.325 .038,51$ & \\
\hline - Planes de formación intersectorial & $5.333 .333,00$ & \\
\hline - Planes de formación sectorial & $5.642 .767,59$ & \\
\hline - Planes de formación de economía social & $199.999,99$ & \\
\hline - Planes de formación de autónomos & $148.937,93$ & \\
\hline Acciones de investigación, innovación y difusión & $610.000,00$ & $610.000,00$ \\
\hline Total & $58.788 .638,32$ & \\
\hline
\end{tabular}

Fuente: INAEM 



\title{
PRINCIPADO DE ASTURIAS
}

\author{
Ángel Alonso Domínguez, Isabel García Espejo \\ y Rodolfo Gutiérrez Palacios
}





\section{Entorno socioeconómico regional}

\subsection{Datos socioeconómicos básicos de referencia y características del tejido productivo}

El Principado de Asturias tiene una población de 1.081.500 habitantes en 2010, lo que supone el 2,3\% de la población total de España (tabla 3.1). Si consideramos la evolución mantenida por la población española y asturiana en la última década, la población española ha seguido una tendencia al alza, mientras que la asturiana se ha mantenido estable en torno a 1.080.000 habitantes. En términos de densidad de población, Asturias, con 102,3 habitantes por kilómetro cuadrado, se encuentra por encima de la media nacional, situándose en la décima posición entre las autonomías más densamente pobladas. Para el año 2020 se estima que Asturias contará con 1.023.971 habitantes, que suponen el 2,2\% de los 47,2 millones que se prevén para el conjunto del país (Consejo Económico y Social del Principado de Asturias ${ }^{1}$, 2010).

$\mathrm{Si}$ atendemos a algunos indicadores económicos, el PIB asturiano en 2010 es de 22.704,2 millones de euros, que representa el 2,2\% del PIB total español. El PIB per cápita es de 21.477 euros, cifra que sitúa al Principado en el 94,1\% de la media nacional, por debajo de comunidades como Aragón, Cataluña, Madrid, Navarra o País Vasco (tabla 3.1). El VAB industrial alcanza la cifra de 4.313,6 millones de euros, lo que representa un 2,8\% del VAB español y el 19,0\% del PIB regional, situándose por encima de la media española $(14,8 \%)$. La industria representa el $21,5 \%$ del VAB regional, con un porcentaje de empleo del $16 \%$, ambas cifras superiores a la media nacional. Destacan tres ramas de actividad industrial: metalurgia y fabricación de productos metálicos ( $8,5 \%$ VAB y $5,5 \%$ empleo), industrias extractivas ( $4,6 \%$ VAB y $1,7 \%$ empleo) e industria de alimentación, bebidas y tabaco (2,0\% VAB y 2,1\% empleo). La industria presenta un nivel tecnológico bajo si atendemos al peso de los sectores manufactureros de alta y media-alta tecnología (tabla 3.2). El 13,7\% del VAB de la industria pertenece a actividades de tecnologías alta y media-alta, una cifra inferior a la del conjunto del país $(26,6 \%)$.

Respecto a algunos indicadores del mercado de trabajo, según el INE en 2010 la tasa de actividad asturiana es el 51,65\%, inferior a la media española (60\%). También se sitúa por debajo de la media nacional la tasa de empleo, con valores del 43,4\% frente al 47,96\%. Sin embargo, el nivel de paro es inferior a la media nacional, un $15,97 \%$, mientras que en España alcanza la cifra del 20,06\% (tabla 3.3). Cabe destacar la incidencia del desempleo entre los jóvenes, un

1 consejo económico y social del principado de asturias (2010): Situación Económica y Social de Asturias 2010, CES de Asturias. 
$37,4 \%$ entre los menores de 25 años, si bien esta cifra sigue estando por debajo de la media nacional, que alcanza el 41,6\% (Consejo Económico y Social del Principado de Asturias, 2010).

La población asturiana con edades comprendidas entre 25 y 64 años presenta un nivel educativo ligeramente superior a la media española (gráfico 3.1). Las personas con un nivel de educación secundaria inferior suponen el 45,9\%, un 21,4\% cuenta con una educación secundaria superior y un $32,8 \%$ posee una educación terciaria (los valores para España son $47,4 \%, 22 \%$ y $30,7 \%$, respectivamente). Si comparamos estas cifras con la media de la UE15 y la UE27, se pone de manifiesto la existencia de una estructura educativa descompensada en la población de Asturias que es extensible al conjunto del país. En Europa los porcentajes de población con estudios de educación secundaria inferior son notablemente menores a los de Asturias (UE15 30,5\% y UE27 27,3\%), mientras que el porcentaje de personas con educación secundaria superior duplica al asturiano (UE15 42,2\% y UE27 46,8\%). Por su parte, la población de 25 a 64 años con estudios terciarios en Asturias supera a la media europea, tanto respecto a UE15 $(27,4 \%)$ como a UE27 (25,9\%). Cabe resaltar que el alto nivel educativo de la población asturiana y española en estudios terciarios, al no ir acompañado del suficiente crecimiento de empleos de alta cualificación, se ha venido traduciendo desde hace décadas en serios problemas de sobreeducación de la población ocupada asturiana y española.

Respecto a los niveles educativos de la población ocupada (tabla 3.4), Asturias destaca por el porcentaje de ocupados con estudios de formación profesional de grado medio $(10,3 \%)$ y, sobre todo, con estudios de formación profesional de grado superior (15\%). La población ocupada con estudios superiores es menor en términos relativos que la media nacional, un $12,5 \%$ frente a un $15,2 \%$. La importancia de los estudios de FP se refleja con más intensidad en la población ocupada en la industria, donde un $24,57 \%$ posee estudios de formación profesional de grado superior, unos datos acordes a la tradición industrial de la región. Así, si observamos la evolución del porcentaje de personas ocupadas en la industria con titulación de formación profesional desde 1985 hasta 2010, se observa como se ha pasado de un $12,3 \%$ en el año 1985 a un $34,7 \%$ en 2010, una cifra casi diez puntos por encima de la media española (tabla 3.5).

\subsection{Indicadores de investigación, desarrollo e innovación}

Si emprendemos ahora el análisis de la innovación en el Principado de Asturias, lo primero que se debe clarificar es qué se entiende por innovación. Una definición bastante aceptada es aquella que presenta la innovación como el resultado de un conjunto de actividades que transforman una idea o una invención en un producto, un servicio o un proceso que sea comercializable y que origine una mejora cualitativa de la oferta existente (Costa, Duch y Lladós ${ }^{2}, 2001$, pág.: 54). Ahora bien, la innovación no debe confundirse con la ciencia y la tecnología y no debe quedar limitada a la innovación tecnológica orientada a nuevos productos y procesos; a esta definición habría que añadir innovaciones organizativas e innovaciones comerciales (Esteban, Coll y Blasco ${ }^{3}$, 2005).

Tampoco se debe confundir la innovación con la I+D. Desde hace algunos años el propio Instituto Nacional de Estadística, siguiendo las directrices del Manual de Oslo, utiliza un

2 Costa, M. T.; Duch, N. y Lladós, J. (2001): «Determinantes de la innovación y efectos sobre la competitividad: el caso de las empresas textiles», Revista Asturiana de Economía, 20, 53-80.

3 Esteban García, J.; Coll Serrano, V. y Blasco Blasco, O. M. (2005). «¿Competitividad e innovación en la micro y pequeña empresa? Retos previos a superar», Estudios de Economía Aplicada, 23, 3, 559-581. 
concepto mucho más amplio de la innovación que el constreñido a la I+D. Así, junto a los gastos en $\mathrm{I}+\mathrm{D}$ se incluyen gastos en adquisición de maquinaria y en tecnología inmaterial y de software; gastos en diseño y en ingeniería industrial; desarrollo de instalaciones para producir experimentalmente y luego normalmente; gastos de formación y de comercialización; reorganización de los sistemas de gestión y de producción, así como los métodos — por ejemplo, nuevos métodos de gestión de stocks y de control de calidad- (INE, 2010).

Si nos referimos al estado de la innovación en Asturias, hay que decir que, a pesar de que se perciben signos de cambio, la propensión empresarial a la innovación es baja. Si atendemos a los gastos en I+D y en innovación del sector industrial según comunidades autónomas, se observa claramente que Asturias no figura a la cabeza de tales gastos. Su participación en $\mathrm{I}+\mathrm{D}$ y en innovación suponen respectivamente un 1,6\% y un 1,0\% de los gastos totales nacionales. De estos datos también se desprende la alta concentración de la innovación en unas pocas comunidades autónomas, así como las grandes disparidades regionales. Madrid es la comunidad autónoma más innovadora y que más gastos destina a $\mathrm{I}+\mathrm{D}$. Además de esta comunidad, destacan las inversiones de Cataluña, mientras que el resto de regiones tienen participaciones más reducidas. Las comunidades que se encuentran en la cola de la participación en el gasto total nacional son Extremadura, Islas Baleares, La Rioja, Ceuta y Melilla. En Asturias la intensidad de la innovación también es inferior a la media nacional $(0,52 \%$ y $1 \%$, respectivamente).

Tabla 2.5. Gastos en I+D y gastos en innovación por comunidades autónomas, 2010 (miles de euros)

\begin{tabular}{|l|c|c|c|c|c|}
\hline & $\begin{array}{c}\text { Gastos en } \\
\text { I+D }\end{array}$ & $\begin{array}{c}\text { Gastos en } \\
\text { I+D } \%)\end{array}$ & $\begin{array}{c}\text { Gastos en } \\
\text { innovación }\end{array}$ & $\begin{array}{c}\text { Gastos en } \\
\text { innovación (\%) }\end{array}$ & $\begin{array}{c}\text { Intensidad de } \\
\text { innovación* }\end{array}$ \\
\hline TOTAL & 14.588 .455 & 100,0 & 16.171 .218 & 100,0 & 1,00 \\
\hline Andalucía & 1.726 .765 & 11,8 & 1.042 .591 & 6,4 & 0,75 \\
\hline Aragón & 374.240 & 2,6 & 554.968 & 3,4 & 1,16 \\
\hline Principado de Asturias & 238.127 & 1,6 & 156.492 & 1,0 & 0,52 \\
\hline Islas Baleares & 110.385 & 0,8 & 52.707 & 0,3 & 0,19 \\
\hline Canarias & 255.402 & 1,8 & 136.651 & 0,8 & 0,47 \\
\hline Cantabria & 157.850 & 1,1 & 98.781 & 1,6 & 1,16 \\
\hline Castilla y León & 608.202 & 4,2 & 584.192 & 3,6 & 1,28 \\
\hline Castilla-La Mancha & 255.179 & 1,7 & 271.765 & 1,7 & 0,75 \\
\hline Cataluña & 3.227 .218 & 22,1 & 3.642 .187 & 22,5 & 1,10 \\
\hline Comunidad Valenciana & 1.080 .986 & 7,4 & 801.314 & 4,9 & 0,60 \\
\hline Extremadura & 151.779 & 1,0 & 87.145 & 0,5 & 0,64 \\
\hline Galicia & 531.601 & 3,6 & 626.353 & 3,9 & 0,88 \\
\hline Comunidad de Madrid & 3.854 .768 & 26,4 & 5.983 .287 & 37,0 & 1,10 \\
\hline Región de Murcia & 256.149 & 1,8 & 251.715 & 1,6 & 0,75 \\
\hline Navarra & 365.719 & 2,5 & 359.145 & 2,2 & 1,33 \\
\hline País Vasco & 1.305630 & 8,9 & 1.455 .457 & 9,0 & 1,32 \\
\hline
\end{tabular}




\begin{tabular}{|l|c|c|c|c|c|}
\hline & $\begin{array}{c}\text { Gastos en } \\
\text { I+D }\end{array}$ & $\begin{array}{c}\text { Gastos en } \\
\text { I+D (\%) }\end{array}$ & $\begin{array}{c}\text { Gastos en } \\
\text { innovación }\end{array}$ & $\begin{array}{c}\text { Gastos en } \\
\text { innovación (\%) }\end{array}$ & $\begin{array}{c}\text { Intensidad de } \\
\text { innovación* }\end{array}$ \\
\hline La Rioja & 84.885 & 0,6 & 66.038 & 0,4 & 0,92 \\
\hline Ceuta & 1.433 & 0,0 & 166 & 0,0 & 0,03 \\
\hline Melilla & 2.138 & 0,0 & 265 & 0,0 & 0,21 \\
\hline
\end{tabular}

$\left({ }^{*}\right)$ Intensidad de innovación $=$ (gasto actividades innovadoras/cifra de negocios) $\times 100$

Fuente: Estadística sobre actividades de I+D, 2010, INE.

Encuesta sobre innovación tecnológica en las empresas, 2010, elaboración propia.

Si nos referimos a los sectores de ejecución (tabla 3.7), el gasto en I+D es asumido fundamentalmente por la enseñanza superior y por las empresas e IPSFL con unos porcentajes similares ( $43,2 \%$ y $41,2 \%$, respectivamente). Es en enseñanza superior donde el Principado de Asturias destaca por encima de la media nacional, con un 28,3\%. La Administración pública tiene un menor peso $(15,5 \%)$ en la ejecución del gasto que en el ámbito nacional. En términos relativos al PIB, destaca el gasto en $\mathrm{I}+\mathrm{D}$ en la enseñanza superior, con seis puntos porcentuales por encima de la media estatal.

Si atendemos al personal dedicado a I+D sobre la población ocupada (tabla 3.8), Asturias se encuentra muy por debajo de la media española, pues en su caso esta cifra es del 9,36\%, mientras que en España es del 18,02\%. También se sitúa por debajo de la media nacional el porcentaje de técnicos y auxiliares (2,9\%). Solo destaca en el porcentaje de investigadores sobre el personal total en actividades de I+D, que representa el $68,5 \%$ frente al $62,5 \%$ del conjunto español.

Los gastos en $\mathrm{I}+\mathrm{D}$ en el sector empresarial por grandes ramas de actividad muestran que el peso relativo de la industria en Asturias es inferior a la media española, un 42,5\% frente a un $47,1 \%$. Sí destaca el sector servicios, con un porcentaje de gasto en I+D cinco puntos superior al conjunto del país $(55,4 \%$ frente a 50,1\%). Si analizamos el tipo de personal en el sector industrial por titulación, Asturias cuenta con un personal altamente cualificado (tabla 3.10). El porcentaje de licenciados representa casi el $45 \%$, el $22,4 \%$ son diplomados, el $16,5 \%$ son titulados de FP de grado superior y el 6,1\% son titulados de FP de grado medio. A excepción de este último grupo, todos los demás colectivos tienen una representación superior en Asturias que en el conjunto nacional. Por tamaño de la empresa, el número de personas con estudios de formación profesional es superior en las empresas de 25 a 74 trabajadores (tabla 3.11).

La distribución porcentual del gasto en innovación en el sector industrial según tipo de actividad sitúa la I+D interna a un mismo nivel que la de España (46,19\% y 46,51\%, respectivamente). Destacan sobre la media nacional la adquisición de maquinaria, equipos y software (26,01\%), la introducción de innovaciones en el mercado (9,31\%) y diseño, otros preparativos para producción y/o distribución (tabla 3.12). Por tamaño de la empresa, la adquisición de $\mathrm{I}+\mathrm{D}$ interna se concentra en las empresas de 150 a 249 trabajadores $(70,4 \%)$, mientras que la adquisición de maquinaria, equipos y software es superior en términos relativos en las empresas de pequeño tamaño, de 0 a 24 trabajadores, al igual que el gasto en diseño, otros preparativos para producción y/o distribución.

En cuanto a la obtención de ayudas públicas a la innovación por parte de las empresas industriales según la Administración financiadora, el porcentaje de empresas asturianas que han recibido financiación pública es muy superior a la media nacional, casi un $40 \%$ frente a un 
$28,8 \%$. También es superior el acceso a ayudas procedentes de las administraciones locales. Por el contrario, las empresas asturianas consiguen menos fondos de la Administración del Estado, mientras que presentan un nivel similar al alcanzado por la media nacional en cuanto a las ayudas que provienen de la Unión Europea (tabla 3.13). Según el tamaño de las empresas, el acceso a las ayudas públicas es superior en las empresas de mayor tamaño, de más de 249 trabajadores, aunque destacan las empresas de entre 75 y 149 trabajadores en las ayudas procedentes de las administraciones locales.

Un aspecto importante a analizar es el sistema regional de innovación. Se puede definir un sistema regional de innovación «como un conjunto de redes entre agentes públicos y privados que interactúan y se retroalimentan en un territorio específico, aprovechando una infraestructura propia para los propósitos de adaptar, generar y difundir conocimientos e innovaciones» (Buesa et alii ${ }^{4}, 2002$, pág. 16). Si abordamos la cooperación con agentes externos por parte de las empresas del sector industrial según partner de cooperación (tabla 3.14), Asturias se sitúa a un nivel similar al español en cuanto al porcentaje de empresas que han cooperado en innovación (23,7\%). Destacan sobre todo la cooperación con universidades u otros centros de enseñanza superior (un 50,8\% frente al 34,3\% nacional) y la colaboración con centros tecnológicos. Son las empresas de mayor tamaño, de más de 250 trabajadores, las que más establecen líneas de cooperación con los distintos partners. Únicamente sobresale la cooperación de las empresas más pequeñas con los proveedores de equipo, material o software.

\subsection{Sistema institucional y agentes de $\mathrm{I}+\mathrm{D}+\mathrm{i}$}

El sistema asturiano de ciencia, tecnología e innovación está constituido por cinco tipos de agentes: la sociedad asturiana, la Administración, la oferta científica, la tecnológica y la de innovación, las infraestructuras de apoyo a la innovación y las empresas. En al anexo II se realiza una breve descripción de estos agentes.

\subsection{Política de $\mathrm{I}+\mathrm{D}$ en el ámbito regional}

$\mathrm{Al}$ igual que los gobiernos de otras comunidades analizadas en este estudio, el Gobierno asturiano ha desempeñado un papel central en la implantación de políticas que potencien la innovación empresarial. Actualmente sigue vigente el Plan de Ciencia, Tecnología e Innovación 20062009 (PCTI), que ha estado precedido en años anteriores por sucesivos planes y estrategias relacionados con la mejora de la posición del Principado en el ámbito de la ciencia, la tecnología y la innovación. Entre ellos cabe citar el proyecto RITTS (Regional Innovation and Transfer of Technology Strategy), el Plan de Investigación, Desarrollo Tecnológico e Innovación 20012004 y la Política de Innovación en Asturias 2003-2006.

El PCTI 2006-2009 persigue entre sus objetivos renovar y diversificar el tejido industrial; consolidar el sistema asturiano de ciencia, tecnología e innovación, racionalizando las infraestructuras científico-tecnológicas, fomentando el trabajo en red e impulsando la interfaz con el tejido empresarial; y promover la creación de empresas innovadoras, sobre todo aquellas capaces de operar con alto valor añadido en la sociedad del conocimiento.

4 Buesa, M.; Baumert, T.; Heijs, J. y Martínez, M. (2002b): «Los factores determinantes de la innovación: un análisis econométrico sobre las regiones españolas», Economía Industrial, 347, 67-84. 
En PCTI 2006-2009 se ha estructurado en cuatro áreas de actuación relacionadas con los objetivos del Plan. La primera área se centra en la generación y aplicación del conocimiento que integran el Programa Severo Ochoa y el Programa Clarín de ayudas posdoctorales: ayudas para la ejecución de proyectos de investigación con perspectiva de género, para la adquisición de equipamiento científico-tecnológico y para proyectos de investigación básica. La segunda línea de actuación se dirige a la constitución de plataformas de cooperación e innovación entre los diferentes agentes e instituciones que incentiven los proyectos de colaboración entre empresas y entre empresas y universidad, centros tecnológicos $u$ organismos públicos de investigación (OPI). La tercera área de actuación se denomina «Empresa y competitividad» y se concreta en ayudas a empresas para la realización de proyectos de $\mathrm{I}+\mathrm{D}+\mathrm{i}$, para la incorporación de titulados universitarios para estas actividades, para la transferencia de tecnología y para la participación de las empresas y los centros de investigación en programas internacionales de $\mathrm{I}+\mathrm{D}+\mathrm{i}$. Por último, la cuarta línea de actuación se ha dirigido a la creación y consolidación de empresas innovadoras de base tecnológica (EIBT).

Los recursos económicos del PCTI 2006-2009 provienen de las administraciones regional y nacional, de la Unión Europea y de las inversiones directas de las empresas en programas de $\mathrm{I}+\mathrm{D}+\mathrm{i}$ o de las coparticipaciones de fondos privados. Los recursos aportados por la Administración central proceden sobre todo de la participación del sistema regional de innovación en los programas PCCP y CDTI y en el Plan Nacional de Investigación Científica, Desarrollo e Innovación Tecnológica. Por su parte, la contribución de la Unión Europea se deriva de la participación del sistema regional de innovación en el VI y VII Programa Marco, de los fondos FEDER y del FSE. El PCTI 2006-2009 preveía movilizar 322 millones de euros de recursos públicos entre las distintas administraciones entre los años 2006 y 2009, y ha logrado canalizar unos 352 millones de euros, 30 millones de euros más de los previstos, lo que equivale a un grado de ejecución del 19,1\% para la globalidad del Plan.

Entre los logros obtenidos en el marco del PCTI 2006-2009, cabe destacar la consolidación de una red de centros tecnológicos, tres de los cuales han sido reconocidos por el anterior Ministerio de Ciencia e Innovación: el Centro Tecnológico para el Diseño y la Producción Industrial de Asturias (Fundación PRODINTEC), el Instituto Tecnológico de Materiales (Fundación ITMA) y el Centro Tecnológico de la Información y Comunicación (Fundación CTIC). Asimismo, se han creado agrupaciones empresariales innovadoras y la Red Empresarial de Innovación (REI), que surge, por iniciativa de la Federación Asturiana de Empresarios, durante el proceso de negociación que dio lugar al Acuerdo para la Competitividad, el Empleo y el Bienestar en Asturias (ACEBA) 2008-2010. Cabe mencionar también la construcción de infraestructuras como el Bioterio de la Universidad de Oviedo, el Centro de Investigación Campus de Mieres, el Centro de Investigación de Tecnologías e Innovación (CITI) de la Universidad Laboral, el Campus de Excelencia Internacional (CEI) y el Centro de Biotecnología Animal de Deva.

El Gobierno del Principado ha elaborado un nuevo plan, denominado PCTI 2015, que todavía no ha entrado en vigor, y centrado en la consecución de las siguientes metas para ese año: lograr que 1.300 empresas sean innovadoras frente a las 742 de 2009, corresponsabilizándose el Principado con el objetivo fijado en la Estrategia Estatal de Innovación de incrementar en 40.000 empresas innovadoras el tejido empresarial español; posicionar la investigación asturiana en el mapa de la excelencia en el Espacio Europeo de Investigación; desarrollar una oferta de infraestructuras de innovación dedicadas a la innovación social; destinar el 10\% de la compra pública a compra pública de tecnología innovadora en 2015; y alcanzar la tasa de éxito escolar de la UE. En su diseño, este plan pretende dinamizar más de 1.500 millones de euros. 


\section{La FP en el ámbito regional}

En 2003, una vez que se aprueba el Plan Regional de Formación Profesional 2003-2006, se inicia el proceso de integración de la formación profesional en Asturias al quedar adscrita la Dirección General de Formación (hasta entonces dependiente de la Consejería de Trabajo y Promoción de Empleo) a la Consejería de Educación y Ciencia con el nombre de Dirección General de Formación Profesional. Desde ese momento, Educación asume todas las competencias en formación profesional reglada, un hito muy importante para el proceso de integración de los tres subsistemas formativos. La Dirección General de Formación Profesional también tendrá competencias en materia de formación ocupacional y continua, que pasa a denominarse formación profesional para el empleo. En 2009, sin embargo, la formación ocupacional pasó de nuevo a depender de la Consejería de Industria y Empleo del Principado de Asturias, siguiendo adscrita la FP reglada a Educación, lo que ha provocado situaciones de descoordinación y competencia entre esta consejería y la de Empleo.

A continuación se describen y se aportan datos de los distintos tipos de formación profesional existentes en Asturias.

\subsection{Formación reglada: recursos del sistema}

La formación profesional reglada agrupa en 22 familias profesionales una variedad de ciclos formativos de grado superior y medio que tienen su correspondencia en determinadas profesiones. A la finalización de estos ciclos se obtiene el título de «Técnico/a superior en...»o «Técnico/a en...».

Si atendemos al número de centros que imparten enseñanzas de formación profesional por ciclos formativos para el curso 2009-2010, Asturias cuenta con 70 centros que imparten FP de grado medio, de los cuales el 68,6\% son centros públicos y el 31,4\% privados. En FP de grado superior el número de centros es de 61; el 75,4\% públicos y el 24,6\% privados (tabla 3.15).

En el curso 2009-2010 estaban matriculados en Asturias en FP de grado medio un total de 5.418 alumnos (tabla 3.16), un 75\% de los cuales cursaban sus estudios en centros públicos y un $24,7 \%$ en centros privados. En FP de grado superior la matrícula alcanzó los 5.555 alumnos, con una concentración aún mayor en centros públicos, el 82,8\%. La evolución del número de alumnos de grado medio seguida desde el curso 1998-1999 hasta el curso 2009-2010 muestra un incremento hasta el curso 2002-2003, para luego ir descendiendo progresivamente hasta el curso 2008-2009. En el curso 2009-2010 tiene lugar un crecimiento importante de más de 400 alumnos (tabla 3.17). Si nos referimos a la evolución de los alumnos en el grado superior (tabla 3.18), se observa un continuado descenso en el alumnado desde 1998-1999 hasta el curso 2008-2009. Es en el último curso considerado, 2009-2010, cuando comienza a repuntar de nuevo la matrícula en este tipo de estudios. En la interpretación de estos datos no hay que olvidar que a partir del año 2000 desaparece totalmente la antigua FPI y en 2003, la antigua FPII.

\subsection{Formación reglada: ámbitos de especialización}

Atendiendo a las familias profesionales industriales de la FPGM, se observa una concentración del alumnado en cuatro ramas industriales: Electricidad y Electrónica (10,5\%), Mantenimiento de Vehículos Autopropulsados (9,1\%), Fabricación Mecánica (8,8\%) y 
Mantenimiento y Servicios a la Producción (8,4\%). En el resto de familias industriales la matriculación es muy reducida o inexistente (tabla 3.21). Esta misma especialización se observa en la FPGS, con un porcentaje de alumnos superior a la media nacional, a excepción de la matrícula en Mantenimiento de Vehículos Autopropulsados, que presenta un porcentaje de alumnos similar al del conjunto del Estado (tabla 3.22). A pesar de la fuerte concentración en las familias citadas, Asturias cuenta con un importante porcentaje de alumnos matriculados en familias del sector industrial; en FPGM el porcentaje es del 44,5\%, mientras que la media nacional se sitúa en un 33,3\%. Lo mismo ocurre en los estudios de grado superior, con un $34,1 \%$ de alumnos matriculados en estudios dirigidos al sector industrial, mientras que en el conjunto de España el porcentaje es del 28\% (tablas 3.23 y 3.24).

Si analizamos la inserción laboral de los titulados, el Servicio de Formación Profesional Inicial y Aprendizaje Permanente ha tenido acceso a los datos de 2.906 alumnos del curso 2009-2010, a los que se les ha realizado un seguimiento mediante la herramienta informática WEB-FCT. Las familias profesionales con una mayor tasa de inserción laboral son las de Textil, Confección y Piel (100\%), Actividades Marítimo-Pesqueras (78\%) y Madera y Mueble (70\%). Hay que destacar que se trata de familias profesionales con un reducido número de alumnos matriculados. En el lado opuesto, las familias que presentan unas tasas de inserción menores son las de Comunicación, Imagen y Sonido (37\%), Informática (40\%) y Artes Gráficas (42\%).

Tabla 2.6. Inserción laboral del alumnado titulado en ciclos formativos en el curso 2009-2010

\begin{tabular}{|l|c|c|c|}
\hline Familia profesional & Trabajan \% & $\begin{array}{c}\text { Demandan } \\
\text { empleo } \%\end{array}$ & $\begin{array}{c}\text { Continúan } \\
\text { estudiando \% }\end{array}$ \\
\hline Actividades Agrarias & 48 & 18 & 34 \\
\hline Administración & 47 & 24 & 29 \\
\hline Actividades Físicas y Deportivas & 43 & 8 & 49 \\
\hline Actividades Marítimo-Pesqueras & 78 & 6 & 16 \\
\hline Artes Gráficas & 42 & 39 & 19 \\
\hline Comunicación Imagen y Sonido & 37 & 38 & 25 \\
\hline Comercio y Marketing & 56 & 16 & 28 \\
\hline Electricidad y Electrónica & 61 & 18 & 21 \\
\hline Edificación y Obra Civil & 43 & 15 & 42 \\
\hline Fabricación Mecánica & 55 & 21 & 24 \\
\hline Hostelería y Turismo & 67 & 13 & 20 \\
\hline Imagen Personal & 46 & 28 & 26 \\
\hline Industrias Alimentarias & 70 & 10 & 20 \\
\hline Informática & 40 & 29 & 31 \\
\hline Madera y Mueble & 70 & 26 & 4 \\
\hline Mantenimiento y Servicios a la Producción & 51 & 19 & 30 \\
\hline Mantenimiento de Vehículos Autopropulsados & 50 & 29 & 21 \\
\hline Química & 43 & 29 & 28 \\
\hline
\end{tabular}




\begin{tabular}{|l|c|c|c|}
\hline Familia profesional & Trabajan \% & $\begin{array}{c}\text { Demandan } \\
\text { empleo \% }\end{array}$ & $\begin{array}{c}\text { Continúan } \\
\text { estudiando \% }\end{array}$ \\
\hline Servicios Socioculturales a la Comunidad & 46 & 18 & 36 \\
\hline Sanidad & 58 & 16 & 26 \\
\hline Textil Confección y Piel & 100 & - & - \\
\hline & 52 & 21 & 27 \\
\hline
\end{tabular}

Fuente: Servicio de Formación Profesional Inicial y Aprendizaje Permanente.

Memoria 2010

La resolución de 18 de junio de 2009, de la Consejería de Educación y Ciencia, fue la reguladora de la organización y evaluación de la formación profesional del sistema educativo en el Principado de Asturias. En su contenido se recogen los cambios producidos con relación a la nomenclatura de los subsistemas de la formación profesional anteriores. Así, lo que a partir de 2008 se llaman programas de cualificación profesional inicial (PCPI) es lo que en datos de 2007 figuraban como programas de garantía social.

Los programas de garantía social estaban orientados a la obtención por parte de los alumnos de los objetivos de la educación secundaria obligatoria, es decir, a la adquisición de una formación profesional básica necesaria para la incorporación a la vida profesional, máxime en un entorno como el actual, de gran exigencia formativa por parte de las empresas industriales.

Tabla 2.7. Programas de cualificación profesional inicial ${ }^{5}$. Asturias (2007-2011)

\begin{tabular}{|c|c|c|c|}
\hline Curso & $\begin{array}{c}\text { N.o alumnos que cursan } \\
\text { programas de cualificación } \\
\text { profesional }\end{array}$ & $\begin{array}{c}\text { Alumnado en } \\
\text { prácticas formativas } \\
\text { en empresas }\end{array}$ & Porcentaje \\
\hline $\mathbf{2 0 1 0 - 2 0 1 1}$ & 818 & 405 & 49,50 \\
\hline $\mathbf{2 0 0 9 - 2 0 1 0}$ & 692 & 324 & 46,80 \\
\hline $\mathbf{2 0 0 8 - 2 0 0 9}$ & 692 & 70 & 10,11 \\
\hline $\mathbf{2 0 0 7 - 2 0 0 8}$ & 707 & 80 & 8,90 \\
\hline
\end{tabular}

Fuente: memorias del Consejo de la FP de Asturias

La obligatoriedad de las prácticas en los nuevos PCPI posibilita una mejor inserción laboral de los estudiantes de FP, mientras que los centros, por su parte, están trabajando para realizar adaptaciones en el currículum, de manera que tengan una mayor vinculación con las necesidades de las empresas. Por supuesto, siempre que esto sea posible, ya que la titularidad pública del centro impone muchas más rigideces al sistema.

\subsection{Formación para el empleo: la formación de oferta}

La formación profesional para el empleo (Real Decreto 395/2007, de 23 de marzo) en España integra en un solo modelo la formación ocupacional dirigida a desempleados y la continua

5 A partir de 2009-2010 se introducen los nuevos programas de cualificación profesional inicial, en los que las prácticas son de carácter obligatorio. De ahí las diferencias en los porcentajes. 
orientada a los ocupados. Distingue tres modelos de formación: de demanda, que son las acciones formativas de las empresas y los permisos individuales de formación; de oferta, integrada por los planes de formación dirigidos principalmente a ocupados y las acciones formativas orientadas a desempleados; y en alternancia con el empleo, que son las acciones formativas de contratos para la formación y los programas públicos de empleo formación. A ellas hay que añadir las acciones de apoyo y acompañamiento a la formación. En este apartado se analiza la formación de oferta, para abordar en el siguiente la formación de demanda.

En Asturias, en el año 2010 el número de personas formadas en esta modalidad formativa fue de 17.664 , una cifra que supone el 2,25\% del total nacional (tabla 3.25). Por sector de actividad, la cifra más alta corresponde al sector servicios, con un 31,4\% de los formados, mientras que en la industria el porcentaje es del $23 \%$, ambas cifras superiores a la media estatal.

La modalidad formativa mayoritaria es la presencial (50,7\%), le sigue la teleformación $(19,1 \%)$, la formación a distancia $(15,2 \%)$ y la formación mixta $(15,0)$. Cabe destacar la duración media de los cursos, que en Asturias es de 69,1 horas, una cifra superior a la media nacional y a la alcanzada por las otras comunidades contempladas en esta investigación: Aragón, Cataluña, Madrid, Navarra y País Vasco.

Un $54,5 \%$ de las personas formadas son hombres y el $45,5 \%$, mujeres, unos porcentajes casi idénticos a los que presenta el conjunto del país. El 38,4\% de estas personas se encuentran en la franja de edad de 26 a 35 años, y un 32,5\% tienen entre 36 y 45 años (tabla 3.26). La suma de estos dos grupos de edad supone el $71 \%$ del total de los formados. Si atendemos a la categoría profesional de los participantes, este tipo de formación está dirigida a los niveles de cualificación más bajos. Así, los trabajadores cualificados representan el 37,2\% y los no cualificados, un $30,3 \%$, unos porcentajes inferiores a la media nacional. Un 13,4\% son técnicos y el 12,8\% directivos. Estos dos últimos colectivos reciben más formación de oferta que en el conjunto nacional (tabla 3.27).

\subsection{Formación para el empleo: la formación de demanda}

Comprende la formación continua en las empresas y los permisos individuales de formación. Para esta formación las empresas disponen de un crédito que pueden hacer efectivo a través de la aplicación de bonificaciones en las cotizaciones a la Seguridad Social.

Según los datos del Consejo Económico y Social del Principado de Asturias, en el año 2010 el número de trabajadores formados fue de 60.108, que representan el 2,2\% de los formados en España. La tasa de cobertura formativa se situó en el 23,3\%, 0,7 puntos por encima de la media española. El número de empresas que proporcionaron formación en Asturias creció menos que en España, ascendiendo a 9.511 y 380.548, respectivamente. Estos datos representan el 13,5\% del tejido empresarial asturiano y el 11,6\% del español. La tasa de cobertura se situó en el $27,7 \%$, un nivel superior al registrado por España $(24,6 \%)$.

Tabla 2.8. Formación continua en las empresas. Asturias-España, 2010

\begin{tabular}{|l|c|c|}
\hline & Asturias & España \\
\hline Participantes formados & 60.108 & 2.771 .069 \\
\hline Tasa de cobertura & 23,3 & 22,6 \\
\hline Duración media (horas) & 29,6 & 26,8 \\
\hline
\end{tabular}




\begin{tabular}{|l|c|c|}
\hline & Asturias & España \\
\hline Empresas formadoras & 9.511 & 380.548 \\
\hline Tasa de cobertura & 27,7 & 24,6 \\
\hline Financiación & & \\
\hline Crédito asignado & 13,9 & 722,6 \\
\hline Crédito dispuesto & 9,6 & 516,1 \\
\hline
\end{tabular}

Fuente: «Situación Económica y Social de Asturias», 2010,

Consejo Económico y Social del Principado de Asturias

El mayor número de alumnos formados pertenece a las grandes empresas $(51,1 \%)$ y en torno al 30\% a empresas de menos de 50 trabajadores, unos porcentajes que son similares a la media nacional. En cuanto a la industria manufacturera, en torno al 66\% de los trabajadores formados están empleados en industrias mayores de 100 trabajadores (tabla 3.29). Atendiendo a la distribución sectorial (tabla 3.30), el $24 \%$ de los formados corresponde al sector industrial, una cifra por encima de la media nacional $(18,7 \%)$.

Este tipo de formación de demanda es fundamentalmente presencial $(50,8 \%)$, sobre todo en el caso de las empresas industriales $(62,4 \%)$. En el resto de modalidades formativas, el Principado destaca por encima del conjunto del Estado en la formación mixta —un 16,5\% en el total de formados y un $20 \%$ en los que pertenecen al sector industrial-.

Los hombres superan a las mujeres en casi diez puntos (54,6\% frente al 45,4\%), una diferencia que se acentúa en casi cuarenta puntos porcentuales a favor de los hombres en el caso de las industrias manufactureras (tabla 3.31). Las edades centrales de los trabajadores que más formación reciben se sitúan entre 26 y 45 años.

La formación está dirigida en un 46,1\% a trabajadores cualificados del total de trabajadores (tabla 3.32). Dentro de las industrias manufactureras el $44,5 \%$ son también trabajadores cualificados y un $24,9 \%$ sin cualificar. En total estos dos grupos representan casi el $70 \%$ de los formados (en España la cifra es del 62\%). Los datos de ocupación están muy relacionados con los niveles educativos de los formados (tabla 3.33). Así, la mayor proporción tiene estudios secundarios postobligatorios tanto en el conjunto de sectores productivos como en el sector industrial ( $43,7 \%$ y $45,6 \%$, respectivamente).

En Asturias, en el año 2010 se concedieron 38 permisos individuales de formación, la cantidad más pequeña de las comunidades que integran este estudio (tabla 3.34). La concentración de estos permisos en las grandes empresas asturianas es abrumadora, el 86,6\%, cifra dieciséis puntos más alta que la que registran las empresas nacionales.

\subsection{Política regional en relación con la FP}

En este apartado se destacan las principales medidas que se han puesto en práctica en el Principado de Asturias durante la última década, orientadas fundamentalmente a poner las bases de un sistema integrado de formación profesional.

1. En noviembre de 2002, el Consejo de Formación Profesional envía al Gobierno del Principado el I Plan Regional de Formación Profesional (2003-2006), que se aprobó en abril de 2003. Este plan recoge las principales propuestas del Pacto Institucional por el 
Empleo firmado por el Gobierno regional y los agentes sociales (Federación Asturiana de Empresarios, UGT y CC. OO.). En él se establecen las bases del sistema integrado de formación profesional, en el que se unificarán los tres subsistemas de formación: reglada, ocupacional y continua.

2. En 2003 se realiza la puesta en marcha de la Red de Centros Integrados: 4 IES y 7 centros de adultos que impartieron cursos de formación continua.

3. En 2005 se culmina el proceso de transferencias en materia de educación/formación al Principado de Asturias iniciado en el año 2000.

4. Desde el año 2005 y según el Real Decreto 1506/2003 del Ministerio de Trabajo y Asuntos Sociales, se está desarrollando la acreditación, mediante la expedición del certificado de profesionalidad, de las competencias adquiridas mediante la formación ocupacional, siempre que se haya completado el itinerario formativo de una especialidad con evaluación positiva.

5. Se crean departamentos de formación y orientación laboral como departamentos didácticos en los IES que imparten FP reglada.

6. Decretos 42, 43, 44, 45 y 46/2006, en los que se establece el desarrollo de la Red de Centros Integrados de Formación Profesional (CIFP): se crean cinco en Asturias, tres de ellos IES reconvertidos.

7. Plan Regional de Formación Profesional 2007-2010. Dentro de este plan cabe destacar las siguientes metas:

- Avance en la puesta en marcha de un sistema integrado de cualificaciones y consolidación del sistema integrado de formación profesional (SIFP).

- Mejora continua de la calidad del sistema: a) evaluación ISO y EFQM en centros educativos y en la Dirección General de Formación Profesional; b) evaluación del Plan Nacional de Formación e Inserción Profesional (FIP) y del Plan de Formación Ocupacional y Continua (FOC).

- Innovación y uso de nuevas TIC: portales de educación (Educastur), empleo (Trabajastur) y HOLA (Herramienta para la Orientación Laboral de Asturias).

- Fomento de la formación permanente de los ciudadanos.

- Facilitación de la obtención de cualificaciones y organización de itinerarios formativos personalizados.

- Acceso a la acreditación para quienes tengan cualificaciones obtenidas fuera de los sistemas formales.

8. Medidas complementarias. Se trata de actualizaciones o mejoras del sistema de formación profesional que no estaban en los planes anteriores y que han ido surgiendo como respuesta a necesidades concretas:

- Fomento de programas de formación a la carta, con compromiso de contratación.

- Puesta en marcha y ampliación de la oferta de formación profesional a distancia.

- Incremento de los convenios de colaboración con empresas para la realización de prácticas de FP reglada y ocupacional, y firma del Convenio de Colaboración con las cámaras de comercio. 
- Convenios de colaboración con agentes sociales en materia de formación continua.

- Desarrollo de herramientas informáticas de gestión de sistemas (SINTRAFOR), estancias de alumnos en empresas (WEB FCT), gestión de acceso de alumnos a ciclos formativos (WEB ADMISIÓN) y gestión de iniciativas comunitarias EQUAL (EQUALASTURIAS).

9. El 4 de enero de 2008, el Gobierno regional y los principales agentes económicos y sociales de la región suscribieron el Acuerdo para la Competitividad, el Empleo y el Bienestar de Asturias (ACEBA) 2008-2011, que se estructura en cinco ejes de actuación‡ promoción económica, sociedad y economía del conocimiento, empleo y formación, prevención de riesgos y salud laboral, y cohesión social. Este acuerdo impulsa el desarrollo de la formación profesional para el empleo en el eje empleo y formación. En 2010 los fondos económicos destinados a acciones formativas alcanzaron los 56 millones de euros, de los cuales el $82 \%$ se destinó a formación de desempleados.

\subsection{Prácticas de formación en centros de trabajo (FCT)}

La resolución de 18 de junio de 2009, de la Consejería de Educación y Ciencia, fue la reguladora de la organización y evaluación de la formación profesional del sistema educativo en el Principado de Asturias. Y, concretamente, la disposición adicional novena establecía la «Regulación del módulo de Formación en centros de trabajo» de los ciclos formativos de la formación profesional específica que se imparten en centros docentes del Principado de Asturias (BOPA de 9 de marzo de 2006).

La formación en centros de trabajo (FCT) del alumnado de formación profesional inicial se incluye con carácter obligatorio en todos los ciclos formativos. Es una formación práctica que realizan en empresas del sector los alumnos que han finalizado la formación teórico-práctica y condición necesaria superarla para obtener el título correspondiente. Aunque la FCT es una de las partes integrantes de la formación profesional inicial, ha adquirido gran importancia tanto por la formación integral del alumnado como por su capacidad para incrementar las posibilidades de inserción laboral.

La FCT se ha convertido en una de las mejores opciones de inserción laboral de los titulados de FP. O al menos así era durante los años de bonanza económica. Según los datos del Servicio de Formación Profesional Inicial y Aprendizaje Permanente, el nivel de inserción ha descendido de manera constante durante los años de crisis. En el curso 2006-2007 consiguieron acceder al empleo más de siete de cada diez alumnos (73\%), pero las posibilidades de inserción se redujeron ya de forma dramática en los alumnos matriculados en 2009-2010 a los que se hizo seguimiento, ya que apenas la mitad de los titulados en algún grado de FP (52\%) consiguió encontrar trabajo.

Las FCT también han conseguido estrechar los vínculos entre los centros de FP y las empresas, dando lugar en muchas ocasiones a nuevas oportunidades de colaboración.

Pues el año pasado..., sí, el año pasado, dentro del Seminario Regional de Formación de Sanidad, trajimos..., vinieron aquí, para darnos formación a los profesores de Sanidad, los responsables de la implantación de la historia clínica digital que va a ir para el nuevo hospital [... ] y eso tenemos que transmitirlo a los alumnos que tenemos aquí. Porque después van a ir allí a 
hacer su FCT, entonces, no pueden encontrarse con un sistema del que no saben nada, ¿no?, entonces, tenemos que avanzar. [...] La relación con la empresa es fundamental. (Director CIPF)

Sin embargo, junto a esta relación tan fluida, también nos han relatado que se producen algunas disfuncionalidades en el sistema que derivan en abusos laborales hacia los estudiantes de FP que realizan sus prácticas.

[...] Bueno, pues porque la empresa..., era a lo mejor la primera vez que participaba, y el alumno se quejaba de que... Puede darse esa circunstancia, ¿no? [...] Sí, en FCT, pero en realidad trabajadores. Porque afeaba, incluso, el hecho de que alguno no..., hubiese que dedicarle mucho tiempo y todo eso... Claro..., que las cosas son como son. Es decir... Yo tuve... Vamos a ver... Las vacaciones de las secretarias del mayor empresario que tenemos en Asturias de [...] y del hijo, pues..., ¿cómo las sustituía?: con alumnas de aquí. Es decir, a la primera semana querían dejarlo ya. Porque es que la formación era desde el primer día la agenda de ese señor, y del segundo de abordo, que era su hijo [...]. Te puedo dar el nombre de una empresa [...] y que el alumno tuvimos que sacarlo de ahí, porque se debía de quejar de que se tenía que llevar hasta el destornillador. (Director IES)

La intensidad de las FCT depende de los contactos que se tengan con las empresas del entorno más que del volumen y el desarrollo empresarial. Y las dificultades económicas por las que atraviesan las empresas han obligado a los centros de FP a redoblar sus esfuerzos para poder captar firmas que participen en las FCT, cuyo número se ha reducido considerablemente como consecuencia de la crisis.

Actualmente participan entre sesenta y cien empresas, dependiendo del número de alumnos que hagan... En estos momentos, dada la situación económica, pues hay algunas empresas que han tenido dificultades, algunos [...] manifestaron el grado de dificultad que tenían para buscar nuevas empresas. Como están con ERES y con cosas de estas, que hay alguna dificultad este año. Básicamente casi siempre son las mismas. (Director IES)

Los directores de los centros entrevistados se muestran especialmente críticos con nuevas experiencias como la FP dual, la FP en alternancia o la recuperación de la figura del aprendiz. También hay quejas sobre la poca importancia que tradicionalmente se ha dado a los estudios de FP y la escasa consideración que tienen los estudiantes de FP en España. Se trata de un problema cultural que se transmite a la estructura de las empresas y a la forma de pensar de los directivos.

Yo vi la experiencia en Suiza y me pareció que estaba..., si es verdad lo que nos contó aquella chica allí..., me pareció que estaba muy ordenado. Sí. La alemana me pareció un batiburrillo imposible de llevar a cabo aquí... Lógicamente, aquí... ¡Por favor...! ¡En España...! El modelo alemán, si yo no entendí mal y por lo que leí, selecciona los alumnos desde los doce años. Ya les dicen a muchos alumnos a los doce años: «Tú vas para la...». Y algunos incluso hasta los condenan... (Director IES)

[... ] nosotros mandamos alumnos en Erasmus a hacer la FCT en Alemania y hay un porcentaje que puede quedarse allí con contrato de trabajo. Entonces, yo me pregunto: si un alumno es lo suficientemente interesante para competir en Alemania..., me cuesta un poquito creer que no sea igual de competitivo, pero en una empresa en Asturias. Sobre todo si comparamos unas empresas (las empresas alemanas) y las de aquí. [...] Entonces, ahora vienen con la figura esta 
del aprendiz, que yo creo que es como volver casi al siglo xix. Entonces, historias pasadas, nunca se pueden trasladar al presente... (Director CIFP)

Los empresarios de Asturias también ven problemas para la implantación de la formación dual. $\mathrm{O}$ al menos en el modelo que se ha elegido implementar en Asturias. Como el resto de agentes intervinientes, consideran difícil la adaptación a las peculiaridades españolas de algunos de estos modelos aplicados en otros países europeos. Y menos su replicación sin más.

[...] ya se anunció por parte de [...], por lo menos, el secretario del Consejo de Asturias de Formación Profesional..., que en la Consejería el modelo que gustaba era el francés [...], nuestra organización dijo que no era el modelo francés el que le gustaba, precisamente. Y yo creo que los resultados están ahí. Yo cojo los modelos de Alemania y Austria, o Suiza, incluso, y cojo el modelo francés, $y$, bueno... Salvo que se llaman «en alternancia» y que, efectivamente, los alumnos pasan determinadas horas en la empresa, el parecido es casi como un huevo a una castaña..., me temo que cometeríamos un error si fuésemos al modelo francés. Pero... (Organización de empresarios)

\subsection{Otros tipos de relaciones entre los centros de FP y las empresas. Papel de los centros de FP en la formación para el empleo}

\section{Relación entre centros formativos y empresas}

Como los cambios introducidos en la normativa sobre la FP son muy recientes, para poder evaluar mejor su evolución se ha acudido a las entrevistas cualitativas realizadas a algunos de los actores que integran el sistema de FP.

Los directores de los centros valoran de forma positiva su relación con las empresas del entorno:

Aspectos positivos, para nosotros, todos, porque, realmente, nos hace estar justo dentro de lo que son las necesidades del mercado laboral. Esto ya no se trata de un observatorio de ocupaciones y tal, que es más genérico y demás, sino que esto es la propia empresa, en este caso una empresa potente y otras empresas, las que nos dicen: «Bueno, es que nosotros necesitamos tal cosa; entonces, queremos formar en esto, en eso y en aquello del más allá» ¿ ¿De acuerdo? Entonces, para nosotros eso es muy positivo. (Director CIFP)

Los centros de FP aprecian la fluidez de las relaciones que se establecen con las empresas, lo que favorece la especialización de los alumnos en las áreas más demandadas, una especialización que facilita la inserción laboral futura, a la vez que obliga al centro educativo a una constante revisión y actualización de los contenidos curriculares y de los itinerarios. La siguiente cita refleja el tipo de relación que los centros mantienen con las empresas y cómo se plantea la posibilidad de introducir cambios en la formación en repuesta a la demanda.

Suele ser bastante fluida. Por ejemplo, mira, ahora mismo... Para que veas, me acaban de pasar una llamada, que es del Instituto X, del centro de Oftalmología, y entonces, «Posibilidad para implantar estudios relacionados...», [...] porque ellos contratan a alumnos nuestros, de diagnóstico por la imagen, y entonces, ahora sería dar un paso más allá. Sería, sobre estos alumnos que nosotros formamos aquí, en una especie de convenio con ellos, darles un reciclaje específico 
para el tipo de aparatos de resonancia de retina, y demás, que ellos están utilizando allí. O sea, intentamos estar los más metidos e implantados posible. (Director CIFP)

Sin embargo, en algunos centros no parece que exista una planificación específica para realizar adaptaciones en el currículum, o al menos era así hasta épocas recientes. Las empresas que colaboran con los centros de FP suelen ser siempre las mismas y son ellas las que acuden para buscar trabajadores cualificados. De hecho, hasta la actual crisis económica los alumnos no tenían ningún problema de inserción laboral porque la demanda era muy superior a la oferta.

Si te refieres a si hay un plan específico para eso, no. No. Sí absorbían hasta ahora a la mayor parte del alumnado porque había un índice de ocupación..., de inserción laboral, alto, pero ahora eso no [...]; se produce justamente el fenómeno contrario... que aumenta la demanda de estos estudios por la gente que abandona el mercado laboral, ¿eh?, por la crisis económica... En las cuencas, los que impartimos la formación profesional prácticamente somos nosotros, entonces, hay empresas que tradicionalmente, desde hace años, pues todos los trabajadores han pasado por aquí. ¿Eh? Pero no porque haya una planificación concreta en ese sentido. (Director IES)

\section{A) FPE}

Resulta difícil concretar el nivel de actividad actual de la FPE en los centros de FP asturianos. Los últimos datos disponibles son los que ofrecen las memorias del Consejo de Asturias de la FP, pero la última publicada corresponde al ejercicio 2010. Además, los datos agregados solo reflejan la FPE dirigida preferentemente a trabajadores desempleados e incluyen la programación impartida por centros públicos de formación ocupacional, CIFP, centros colaboradores (IES y centros de educación de personas adultas homologados para ocupacional), organizaciones sindicales y empresariales y acciones a la carta con compromiso de contratación.

A falta de datos más actualizados, se dispone de los ofrecidos por los propios centros en las entrevistas mantenidas con ellos a lo largo de este proyecto. Y estos difieren mucho entre los CIFP y los centros tradicionales de FP. Así, en uno de los IES entrevistados no se impartió ningún curso de FPE durante el ejercicio 2011-2012 y en los años 2009 y 2010 solamente «un par de cursos» (IES), en palabras textuales de su director, lo que refleja la escasa importancia que le otorgan a este tipo de formación en el centro.

Distinta es la situación de los CIFP, mucho más activos a la hora de ofrecer FPE ${ }^{6}$.

Sí, sí, sí... Y hacemos actividades tanto para desempleados como para empleados. El año pasado (2011) digamos que ejecutamos prácticamente por valor de unos trescientos ochenta mil euros [...] del Servicio Público de Empleo. (CIFP)

Lo que sí que existe es coincidencia en que falta desarrollar adecuadamente la FPE en el Principado de Asturias y en que el sistema aún está en vías de consolidación. Sobre todo en relación con los CIFP.

[... ] cada centro funciona por libre, no es algo que funcione con..., no hay un reglamento..., que los venimos demandando desde hace años..., de centros integrados, en el que puedan tener unas

\footnotetext{
6 Los datos ofrecidos por uno de los CIFP que más FPE realiza en Asturias son los siguientes: número de horas impartidas en (total): 7.060; número de docentes implicados: 95; número de alumnos: 325; número de cursos (total): 20, divididos en 18 cursos de ocupacional y 2 de continua (oferta).
} 
normas mínimas de gestión, sino ahí depende un poco de la dirección de cada centro. (Experto Empleo)

Bueno, los centros integrados... Yo creo que no están en pleno desarrollo todavía. (Sindicato).

Pues mira, yo creo que ahora mismo aporta muchas cosas [la formación para el empleo], pero yo creo que es un sistema que se tiene que consolidar mucho más. (CIFP)

El primer problema que ha dificultado un mejor funcionamiento de la FPE ha sido de orden político, a decir de los actores intervinientes. Y en esto ha tenido mucho que ver la diferente lógica administrativa, burocrática y de gestión consecuencia de los constantes cambios sufridos por la FP en Asturias en su paso por las consejerías de Industria (Empleo) o de Educación. Tampoco aquí hay acuerdo entre los actores, pero lo cierto es que los IES han dejado en gran medida de ofrecer este tipo de formación desde que volvieron a la Consejería de Industria...

Bueno, ya sabes que, de la misma que se integraron, y fue el «gran avance» de la educación asturiana..., creo que fue en 2004, o por ahí..., la integración de los tres subsistemas, de la noche a la mañana, pues de un plumazo, la ocupacional y la continua se fueron otra vez a Industria. Estuvimos impartiendo aquí hasta el año pasado, durante tres años, un curso de formación ocupacional. De verdad que la presión era tan grande para que se..., que nos metimos ahí. Nos metimos. Estaba un director general que me ofrecía confianza, y yo le dije «oye, ¿̇esto...?». Y nos metimos. Pasó a Industria, y dejamos de darlo, porque no sabemos en qué situación va a estar. (IES)

... mientras que desde el Servicio Público de Empleo del Principado de Asturias se considera que el tiempo que la FP pasó integrada en la Consejería de Educación fue perjudicial para su desarrollo e implantación porque se perdió la vinculación que tiene que tener la formación con el empleo.

Yo creo que es profundamente negativo. Y creo que en Asturias eso ha sido un ejemplo. Después de pasar formación para el empleo a Educación, se consiguió que hubiera cero cursos en la región y cero convocatorias... Pero si la formación profesional se confunde, y no hacen el reciclaje interno que tienen que hacer, y solo identifica a la entrada en la formación continua como ser un proveedor más de la formación para el empleo, o quedarse con una cuota presupuestaria de los recursos de formación, se convierte en un actor más. En vez de dedicarse a potenciar el suyo. Entonces, sí me parece muy bien que los centros de formación profesional, los centros integrados, hagan actividad de formación para el empleo, pero la decisión de formación para el empleo tiene que estar ligada al mundo del empleo. (Experto Empleo)

El segundo obstáculo ha surgido de la indefinición de los sistemas, de la escasa diferenciación entre ellos, lo que ha generado confusión. Se ha terminado por equiparar la FPE con la FP reglada, al introducirse en aquella un sistema modular equiparable al de esta. Por eso, a los centros les está costando adaptarse a la FPE, siguen en clave docente y viendo la formación ocupacional simplemente como una oportunidad para completar sus horarios de clases y los de su profesorado.

Pero en la formación para el empleo, a mi modo de ver, sería lo otro, lo que puede cambiar, lo distinto, lo diferente, lo que es adaptado a unos colectivos concretos, a unos territorios concre- 
tos, a unas empresas concretas, con unos proyectos y con unos problemas. Lo que me permita abordar la diferencia, la variedad. Creo que se han confundido las cosas. Porque lo que es muy interesante, en términos de módulos, para la formación profesional, se ha utilizado para dar más rigor teórico — rigor entre comillas — a la formación para el empleo, pero a costa de perder flexibilidad. (Experto Empleo)

Porque uno de los problemas que tienen, y eso ha pasado también, es que no puedes mantener, o no puedes desarrollar, una formación para el empleo con una metodología que venían utilizando en la formación inicial, en la reglada. iPorque es que la gente que te va a esos cursos han salido rebotados de ese sistema! Es decir, ¿los vuelves a traer al sistema, pero para utilizar o seguir queriendo hacer lo mismo? ¡No...! La gente busca un aprovechamiento más del tiempo, una rentabilidad... (Estudios sociales)

Pero en el trasfondo de todo parece que está la competencia por recursos escasos. Los decretos 42, 43, 44, 45 y 46/2006 establecieron el desarrollo de la red de CIFP, creándose inicialmente cinco en Asturias (hoy hay seis), tres de ellos IES reconvertidos. La creación de los CIFP ha generado competencia entre las funciones de estos y los IES, algo que ha terminado por perjudicar a todo el sistema, a decir de los agentes. Los IES estaban poco interesados por este tipo de formación, pero en un momento dado se vieron obligados a entrar en ella, abandonándola con prontitud. Por su parte, los agentes sociales han visto que les perjudicaba el reparto de las subvenciones.

No están funcionando porque yo creo que se crearon, más que nada, con una filosofía. Y es intervenir en unos recursos públicos donde no intervenían anteriormente. Fundamentalmente. Pues eso ha llevado a problemas lógicos. Primero, de competencia entre ellos mismos, de formación para el empleo con ciclos formativos. No es de recibo que un centro integrado esté impartiendo un ciclo formativo de grado medio y a la vez ofrezca un certificado de profesionalidad de nivel de cualificación 3, que es el mismo curso, que desde el punto de vista del empleo te cualifica igual. (Estudios sociales)

O sea, significa, en este caso, que desde hace dos años no vamos en régimen competitivo, ¿eh?, con el resto de instituciones privadas que intentan ir a ejecutar este tipo de formación, sino que tenemos una partida..., pequeña, pero bueno..., una partida para ejecutar nosotros. (CIFP)

No. No ha habido integración de ningún tipo... Los centros integrados no son ni más ni menos que antiguos centros de formación profesional... ¡ o nuevos...! en los que se mete a profesores que ya había, se imparten ciclos que ya había de formación profesional reglada, y, a la vez, se ceden o se ponen las instalaciones para que las fundaciones, por ahí, que nacen al albur de todas estas subvenciones, y de todas estas cosas, tengan sitio para dar esos cursos. $ॄ$ Eh? Captando todos esos recursos. Y esas subvenciones. ¡ Es la puñetera realidad...! Y se nos dijo, básicamente, que teníamos que ofertar cursos de ocupacional. Y que esa era la manera de financiarse. Que no había dinero para formación profesional reglada y que si queríamos captar fondos... (IES)

Creo que se han confundido las cosas. Siguen como estaban. Los mismos profesores, en horario de mañana, y las mismas instalaciones poco utilizadas. Se ha intentado un poco corregir esto, lo de las instalaciones, permitiendo a los centros de FP y los centros integrados hacer cursos del FIP. Lo que han hecho es algo que ambicionan todos los actores en este sistema: meter un bocado grande al presupuesto allí donde hay dinero. (Experto Empleo)

Para algunos de los actores consultados, la formación de oferta requiere un proceso muy burocratizado para su implantación. Se necesita que el sistema sea menos rígido, como han apuntado el resto de agentes entrevistados, pero también actualizar contenidos y hacer más cortos los cursos y más operativos. 
Hombre, yo, lo que veo en los cursos del Plan Nacional de Inserción y Formación Profesional (FIP) es que me parece que tienen muchísimas horas..., muchísimas horas..., y que están, en cierto modo, un poco desactualizados en cuanto a contenidos, ¿eh? Yo creo que les faltan aspectos... Por ejemplo, en temas de gestión..., un poco..., la vanguardia de la gestión, no la tienen... Pues porque son programas que están hechos ya desde hace tiempo. Y ahí sí que creo que habría que darle una vuelta de tuerca, ¿eh? Y los certificados de profesionalidad, lo mismo. (Empresa formadora)

[...] necesitamos que los jóvenes, en los períodos de paro, en las distintas transacciones, puedan ir a los cursos. Entonces, estos tienen que ser cortos. ${ }_{\uparrow}$ No largos! Porque la prioridad de una persona en desempleo es buscar trabajo. Si le ofrecen un trabajo, de lo que sea, va a dejar el curso. Si tú eres camionero y lo estás pasando mal, y ves que puedes hacer un curso, pero el curso dura 600 horas, y a la hora cien te ofrecen un trabajo, aunque sepas que es muy temprano, vas a dejar el curso. En cambio, si el curso es pequeño, puedes hacer uno y arriesgar con otro. Pero te llevas uno en la mochila. (Experto Empleo)

La formación de oferta debe responder a las necesidades de los actores que participan. Especialmente la de oferta a empleados, la más compleja, ya que está gestionada por los agentes sociales, a los que los CIPF se ofrecen, pero también debe responder a las necesidades de las empresas. Por eso, los CIPF intentan realizar, en la medida de sus posibilidades, adaptaciones en el currículo de educación reglada en respuesta a demandas expresadas por las empresas.

Una propuesta formativa en la que, evidentemente, ahí sí que tenemos que mirar lo que dice el Observatorio Ocupacional, cuáles son, digamos, las líneas prioritarias, y a partir de ahí, pues nada, hacemos una oferta... Nosotros aquí hacemos una oferta que suele ir fundamentalmente a las cuatro familias profesionales que tenemos. Y después, en segunda programación, que es un poco así, digamos, más flexible, pues ahí ya intentamos hacer ofertas de cursos un poquito más específicos, más de especialización, más a la carta, ¿no? Un poco también lo que demandan las empresas: «Pues mira, nosotros aquí necesitamos» [...]. Hombre, nos vendría bien que en esto vendrían más fuertes, y tal, ¿no? Entonces, bueno, nosotros intentamos orientar la formación de los alumnos a lo que realmente..., a lo que pensamos. Acercarnos a lo que sería la necesidad de la empresa. (Director CIPF)

[...] Porque eso también se traslada, por ejemplo, a la formación de oferta. Lo que pasa es que la formación de oferta sí es cierto que normalmente se hace fuera de los horarios de trabajo. Que esa es otra. Yo creo que funciona. Que se tiene que mejorar, por supuesto. Y que sigue siendo, en muchos casos, un sistema bastante farragoso para que la propia empresa lo gestione, también. No hay más que mirar que incluso las que tienen estructura para gestionarlo normalmente lo externalizan porque..., «no quiero líos, que estos son papeles por todos los lados». (Organización empresarios)

Por lo que se refiere a la formación de demanda, se desprende de las opiniones de los entrevistados que nos encontramos ante una modalidad de gran complejidad para su desarrollo por sus problemas de adaptación al tejido industrial regional, conformado casi en su totalidad por empresas de muy pequeño tamaño. Para los empresarios, la formación de demanda tiene algunos problemas graves que resolver, dificultades que son imputables, más que al modelo, a su falta de adaptabilidad al tejido empresarial en el que se desarrolla.

El problema que tiene la formación de demanda, desde que se creó, es que no llega adecuadamente a un tamaño de empresa determinado: la pyme y la micropyme [...]. Las micropymes, en 
muchos casos, no es tanto por el propio sistema, sino por la imposibilidad... Pero yo creo que no es tanto el modelo en sí. (Organización empresarios)

\section{B) Estancias}

El Pacto Institucional por el Empleo (2000-2003), suscrito en noviembre de 1999 por el Gobierno del Principado de Asturias, la Federación Asturiana de Empresarios y las centrales sindicales Unión General de Trabajadores y Comisiones Obreras, fue el encargado de sentar las bases para el desarrollo del sistema de formación profesional en la Comunidad Autónoma. En este pacto se propone la creación del Consejo de Asturias de la Formación Profesional (Decreto 78/2000) como órgano consultivo y de participación social e institucional.

Como culminación a todo el proceso, las transferencias en materia educativa supusieron nuevos retos para la formación del profesorado asturiano, concretándose para la FP en un programa de formación continua del profesorado de formación profesional específica, en el que se incluyó la posibilidad de realizar estancias formativas del profesorado en empresas ubicadas en el Principado de Asturias.

En la convocatoria de 2011, podían realizar dichas estancias los profesores de enseñanza secundaria y los profesores técnicos de formación profesional que estuvieran impartiendo docencia en ciclos formativos de los centros sostenidos con fondos públicos dependientes de la Consejería de Educación y Ciencia del Principado de Asturias. En esta última convocatoria, se podía optar a:

+ 50 plazas de la modalidad A (a realizar en períodos y horarios lectivos), estancias formativas propuestas por la Consejería de Educación y Ciencia.

+ 50 plazas de la modalidad B (a realizar en períodos y horarios coincidentes con el horario lectivo), estancias formativas en empresas e instituciones, propuestas por el profesorado, con un proyecto de trabajo ratificado por la empresa o entidad colaboradora en la que se pretendía desarrollar dicho proyecto.

La relación con la empresa es fundamental para los centros de FP, que no pueden vivir de espaldas a la empresa. Sus dos grandes clientes son el alumno, claro, pero también la empresa. Por eso, una FP que no tenga implantación en el mercado, en la empresa, no tiene sentido. El valor añadido que adquieren los centros con las estancias del profesorado resulta fundamental a la hora de diseñar las FCT, pues permiten completar la adquisición de competencias profesionales y evaluar aquellas otras que requieren un entorno real de trabajo y, por lo tanto, no pueden comprobarse en el centro educativo.

Sin embargo, según la información recabada de los centros entrevistados, el modelo está lejos de haber completado su desarrollo, por lo que la formación del profesorado se complementa con seminarios especializados.

[...] No, no... Ha habido un programa de la Consejería..., en el sentido de que se sacan prácticas, de..., períodos de estancia..., programas, para que los profesores puedan ir a una empresa, pues..., no sé después en qué se concreta. Y algún profesor de aquí, alguna profesora, evidentemente fue a una empresa... Sí, en el mes de julio, y este tipo de cosas. Pero bueno, yo creo que eso era algo experimental, que no cuajó... Y fuera de ahí, pues... (Director IES)

[...] Sí. Realizan estancias formativas en empresas, entre otras cosas..., además, vienen reguladas y gestionadas por la propia Consejería de Educación [...]. Pero, además de esto, mediante los seminarios regionales de formación de familias profesionales también se aprovecha para potenciar este tipo de cosas [...]. Es decir, para nosotros, eso..., en formación profesional 
es fundamental. El profesor, todos los años..., no sé,.., o cada dos años, o más tiempo..., pero debería darse una vuelta importante, una estancia, por la empresa y ver cómo se está avanzando para realmente darse cuenta de por dónde van los tiros en el mercado laboral. (Director CIPF)

\section{C) Otros SERVicios a LAS EMPRESAS}

De las entrevistas mantenidas se deduce que esta es la parte menos desarrollada de las relaciones entre centros de FP y empresas. Los vínculos formados apenas han generado demanda por parte de las empresas para el diseño de cursos de formación continua a la carta, asesoramiento tecnológico, ensayos u otros usos de instalaciones de centros de FP. Las nuevas demandas se han limitado fundamentalmente a mejoras en los convenios de colaboración y contrataciones a través de bolsa de empleo.

[...] el convenio con alguna empresa, dentro de la formación, para hacer parte de la formación interna que tienen ellos para sus trabajadores. Por ejemplo, con la empresa $Y$ tenemos algo. De hecho, ellos incluso vienen aquí a hacer sus pruebas de selección para nuevos trabajadores, nos piden las instalaciones, el profesorado nuestro es el que suele hacer ese tipo de exámenes y pruebas..., y ponemos en marcha cursos, de lo que ellos necesitan, de reciclaje interno, y lo vamos haciendo... Y entonces, los alumnos ahí pueden dejar currículos, nos llaman las empresas, y dicen «oye, necesitamos contratar, o hacer una selección, con este perfil profesional». Y nosotros, pues los ponemos en contacto, $y$ demás. (Director CIFP)

\section{D) Formación e inNovación}

A pesar de algunos problemas que circunstancialmente puedan aparecer, los entrevistados nos hablan de una relación consolidada en el tiempo entre los centros formativos y las empresas asturianas. De sus respuestas se desprende, además, que esta vinculación depende fundamentalmente de la especialización sectorial del centro y del área de influencia de las empresas radicadas en la comarca.

Entonces, fundamentalmente, por ejemplo en sanidad, prácticamente yo te diría que un porcentaje muy significativo, posiblemente más del $80 \%$ de nuestros alumnos, hacen la FCT en el [... ] SESPA..., pero sí tenemos mucha relación, y fluida, y muy buena, creo que es muy satisfactoria por ambas partes, con la empresa Z. Z es la empresa que gestiona prácticamente el $95 \%$ de todas las ambulancias y el servicio de transporte sanitario del Principado de Asturias. De hecho, hacemos cursos conjuntos. Del Servicio Público de Empleo. Los ponemos en marcha... Algunos de estos profesionales, [...] es a lo que se dedican, bien a dar formación en estos cursos, y, por otra parte, nosotros mandamos alumnos allí a que hagan prácticas no laborales en empresas, y demás. O sea, que la relación es muy fluida. (Director CIPF)

Sí. Hay algunos. Hay autónomos. Hay autónomos. Relación con el centro... Sí, pues... Pero, vamos a ver..., circunstancial. Es decir, que algún alumno vaya a hacer prácticas con ellos. Ya te digo que las empresas casi siempre se repiten las mismas, y siempre, digamos, que nos absorben a todo ese alumnado. Salvo este año, que, por aquella circunstancia que te expliqué, casi todas las... Bueno, pues mira, hay un chaval que estudió aquí, que tiene una empresa de instalaciones eléctricas, de instalación de alarmas..., y que no teníamos convenio con él, y me lo encontré y...

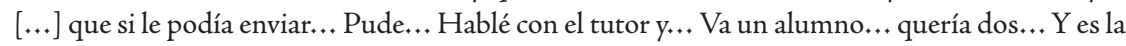
primera vez que firmamos un convenio con él. Pero son cosas así, meramente circunstanciales... (Director IES) 
La cultura individual de las empresas se considera decisiva en la introducción de la innovación en el entorno empresarial. La ausencia o presencia de este impulso innovador repercute en las políticas de recursos humanos. Como también lo hacen otros factores, entre los cuales destaca la tipología del tejido empresarial de Asturias, en el que predominan de forma abrumadora las micropymes, o la equivocada percepción social que se tiene del emprendedor, identificado casi siempre con la figura del empresario. Estos son, a su entender, algunos de los problemas fundamentales a los que se enfrentan la formación y la innovación en el Principado.

Y luego está la cultura interna de cada empresa. Que si no apuesta por la innovación, pues no apuesta por la innovación, indistintamente de que tenga gente joven o gente mayor... No la ve..., es que no la siente. $\mathrm{Y}$ eso depende mucho del sector, pero también del tamaño. $\mathrm{Y}$, a mi modo de ver, uno de los puntos críticos de nuestra economía es el excesivo pequeño tamaño de las empresas... Con lo cual también tenemos una rigidez en la percepción social. Que llamamos emprendedor, o empresario, a cualquiera que se busca la vida. Que es heroico. Pero que no tiene por qué ser un empresario en el sentido riguroso, que sabe de la importancia de la innovación, del desarrollo, de la inversión en recursos humanos, del mantenimiento, de la comercialización, del marketing..., y de la internacionalización. No, sabe de sobrevivir. Entonces, nos liamos. (Experto Empleo)

Para los sindicatos, los problemas culturales y organizativos de las empresas también resultan determinantes a la hora de apostar por la formación y la innovación. Existen muchas reticencias, casi resistencias, a implementar políticas de innovación y de mejora en la formación de los trabajadores. Persiste también, en muchas ocasiones, la idea de que una mayor formación equivale a la búsqueda de nuevos horizontes para los empleados que la han recibido. Así, junto al escaso interés que muestran las empresas por realizar acciones formativas, las organizaciones sindicales consideran que las que se llevan a la práctica suelen estar más relacionadas con el puesto de trabajo actual y menos con la posibilidad de conseguir promocionarse en la empresa.

Bueno, a las empresas les va costando entender que emplear tiempo en formación es luego ganar tiempo en ganar en competitividad y productividad... Es que aquí hay que distinguir [...]. No todo el mundo es empresario [...]. Hay negocio en no sé qué, y yo tengo dinero, cojo ese negocio, lo exploto mientras dura, y cuando acaba el negocio, cierro y se acabó. Esos son empleadores, no son empresarios... Ese empresario es el que sí se preocupa de formar..., son los menos, pero los hay..., sí se preocupan de formar e ir actualizando a los trabajadores en conocimientos y nuevas tecnologías y tal... Pero luego está el resto... (Sindicato)

[... L La empresa, en lugar de valorar que una persona está formada, muchas veces lo ve como un impedimento. Es decir, el discurso que muchas veces: «Es que yo formo al trabajador, para que luego se me vaya, $y$ ¿quién me paga la formación del trabajador?». Eso es algo donde hay que cambiar la mentalidad. Y mientras no cambiemos esa mentalidad, es muy complicado. Es muy complicado. Al final, si tú mejoras la cualificación del factor fundamental, que son los recursos humanos de la empresa... Es que si no, estás abocado al fracaso. (Estudios sociales)

Sin embargo, los empresarios tienen otra visión muy distinta sobre la formación y la innovación. Para ellos, el problema reside en el desinterés político, ya que se han puesto en marcha iniciativas en este sentido que no han sido secundadas por la Administración regional. En opinión de los empresarios asturianos, debería haber más sensibilidad política hacia estas propuestas, que provienen de organizaciones que conocen perfectamente cómo funciona el mercado laboral y sus necesidades. 
[...] por ejemplo, una organización como la nuestra innova y pone en marcha un proyecto que saca a la luz el que podría ser el..., digamos, el perfil del gestor de innovación, se hace el esfuerzo de adaptarlo al sistema educativo..., por un lado, se innova, y, por otro, el sistema dice que «bueno, muy bien, pero eso no va conmigo». Pues si queremos apostar por la innovación, o apostamos o no apostamos... Pero bueno, luego hay cosas que van quedando en la cuneta, y uno no se explica por qué. La verdad es que es de una torpeza supina invertir incluso recursos públicos en hacer eso, algo que las propias empresas avalan, y luego mirar para otro lado. (Organización de empresarios)

\subsection{Cultura y sociedad}

\section{a) Entorno regional y cultura empresarial}

Todos los actores entrevistados coinciden en que el entorno regional condiciona en gran medida la apuesta por la innovación en el Principado de Asturias. En lo que no coinciden es en el origen de los problemas y en quiénes recae la responsabilidad de las dificultades que existen sobre el sistema de FP y la innovación. Los directores de los centros de FP consultados culpan en mayor medida a la cultura organizativa de las empresas y al entorno empresarial.

[... Cultura empresarial... Yo creo que... Pero es que lo condiciona todo. Es decir, el tema, digamos, cultural te va a condicionar hasta cómo se organizan las empresas, sobre todo empresas que sean propias, de aquí, de la región. No estamos hablando de multinacionales que vienen con sus propios sistemas organizativos [...]. Pero empresas que se están haciendo aquí o que son propias nuestras, pues lo cultural se va a transmitir a la estructura de la empresa y en la manera de pensar, ¿no? (Director CIPF)

Lo dificulta totalmente. [...] Yo, cuando oigo al presidente de la Federación de Empresarios decir que la solución para la formación es recuperar la figura de aprendiz. Yo no sé si esa es la solución o no. Probablemente lo sea. Yo no lo sé, y tendrá muchos [...]. Ahora, yo lo que no me creo es que ese señor esté siendo sincero con lo que dice. No me lo creo. Porque aquí, lo que se está haciendo... Claro, cuando lees después en el periódico que el $50 \%$ de las subvenciones, de esas millonadas que vienen, se las lleva esa Federación..., pues..., y que el $40 \%$ restante se lo lleva los agentes sociales..., ¿̇eh...? (Director IES)

Otros entrevistados prefieren acudir en general a la cultura de la sociedad asturiana como causa del escaso empuje innovador del Principado, una visión que es compartida desde el ámbito empresarial, que reclama mayor proactividad, cooperación y diálogo entre las partes involucradas.

Bueno, todas las partes que intervienen... Formamos parte de una cultura muy conservadora, no innovadora, una sociedad no innovadora..., entonces, pues son todos. El centro no provee de las competencias, el mercado laboral no permite que ese joven esté aportando a un proyecto empresarial, en el momento más creativo de su vida intelectual, el jefe de ese joven no va a invertir mucho tiempo en él, porque, con la temporalidad, volverá con otro, cambiará, se marchará, volverá alguien..., y la dirección de la empresa no está atenta a la innovación, en una sociedad que tampoco le presta mucha atención a estas cosas. No... (Experto Empleo)

Asturias no está, precisamente, entre las comunidades autónomas con mayor intensidad de gasto en $\mathrm{I}+\mathrm{D}$, ni con mayor presencia relativa de empresas innovadoras ni con una potencia destacada en el ámbito de la inversión tecnológica [...]. Se ha ido tejiendo un sistema regional de 
innovación con muchos elementos destacables [...]. Pero queda un amplio camino por recorrer [...]. Esto supone invertir cada año un $48 \%$ más de lo que se ha venido haciendo en los últimos años. El reto, por lo tanto, es notable. (Organización de empresarios)

[...] Bueno, cultural, yo creo que también, ¿̇eh? Yo creo que cultural, también. Puede ser. Que no estamos acostumbrados a tirar..., bueno, pues eso, de las investigaciones o un proyecto [...]. Por ejemplo, ese proyecto que se está haciendo en la universidad. Nosotros nos enteramos porque llamas para hacer una entrevista, pero si no... ¿Dónde queda eso? (Empresa formadora)

\section{b) Administración autonómica y situación política}

Como se ha visto anteriormente, en 2003 se produjo el proceso de integración de la formación profesional en Asturias. Toda la formación profesional, hasta entonces dependiente de la Consejería de Trabajo y Promoción de Empleo, quedó adscrita a la Consejería de Educación y Ciencia. Pero en 2009 la formación ocupacional pasó de nuevo a depender de la Consejería de Industria y Empleo del Principado de Asturias. Esto provocó, a juicio de los responsables sindicales, no pocos problemas entre ambas consejerías pues la FP reglada siguió adscrita a Educación. Los ritmos de ambas consejerías son distintos, mucho menos ágil Educación, como también su funcionamiento interno. El problema no es tanto la definición del sistema, que ya está hecha, como su coordinación, que tiene que funcionar como un todo.

Se coordinan muy mal las consejerías. Muy poca coordinación. Porque de hecho, nosotros..., en un principio estaba todo en Educación. Lo que es la formación para el empleo dependía de Educación. Entonces estaba la parte inicial, o reglada, y estaba la parte práctica de empleo, de reciclaje, de... Bueno, porque, como nosotros entendemos la formación para toda la vida..., o sea, como algo para toda la vida, desde muy temprana edad, hasta que una persona se jubile o incluso más allá... (Sindicato)

Porque la formación para el empleo, la formación ocupacional, siempre estuvo en el ámbito del empleo... Aquí, en un momento determinado, se hizo una apuesta en Asturias de ser los más innovadores de toda España, y lo que hicimos es coger y meterlo todo en Educación. Mira, yo... Al final, lo mismo da que esté todo en Educación que esté todo en Empleo. Si el problema no es dónde esté, sino que es cómo se gestiona. Porque son dos sistemas que tienen que incardinarse uno con el otro. El problema es cuando intentas solapar, o supeditar, uno a otro. ¿Problemas que ha habido en Educación? La burocracia. (Estudios sociales)

También se han apuntado otras debilidades del sistema. Así, se deberían abordar urgentemente los problemas derivados de las diferentes lógicas administrativas existentes en ambas consejerías, así como la necesidad de vincular más la FP al entorno laboral. Una cuestión esta última en la que inciden también desde el ámbito empresarial.

Yo creo que es profundamente negativo. Y creo que en Asturias eso ha sido un ejemplo. Después de pasar formación para el empleo a Educación, se consiguió que hubiera cero cursos en la región y cero convocatorias. Y eso es porque la lógica administrativa de la administración de Educación y la lógica administrativa de Empleo son diferentes..., me parece muy bien que los centros de formación profesional, los centros integrados, hagan actividad de formación para el empleo, pero la decisión de formación para el empleo tiene que estar ligada al mundo del empleo y de la actividad económica. Si no, hemos visto aquí que es un error. (Experto Empleo)

Bueno, el Plan Nacional de Inserción y Formación Profesional (FIP) está regulado. O sea, el programa es el que es. Y, probablemente, pues ahí hay cosas que sobren, cosas que falten, en programación... Por ejemplo, hay cosas transversales que..., a veces te cuestionas si realmente 
eso sirve para algo..., y, a lo mejor, más especialización en la parte de contenido de la materia, ¿no? Hombre, yo creo que son temas que están un poco rígidos, pero que están cambiando, ¿no?, con el tema de certificados. (Empresa formadora)

Finalmente, un tema recurrente en todas las entrevistas fue la situación política de Asturias y la paralización de todas las convocatorias de formación como consecuencia de la interinidad del Gobierno regional (en el momento de realizar las entrevistas) y de la celebración de elecciones al parlamento regional del Principado por segunda vez en menos de un año.

[... entonces, ahora mismo la situación en la que estamos es que no hay convocatoria. Debería haber salido ya la convocatoria. De hecho, el año pasado, en el mes de abril ya estaban los cursos planificados; o sea, ya estaba la resolución del programa [...] formativas que se iban a poner en marcha. Ahora mismo, a día de hoy, de momento no hay ni siquiera convocatoria. Que es un poco paradójico, teniendo en cuenta el nivel de desempleados, la tasa de desempleo que hay, que precisamente en estos momentos, pues bueno, las convocatorias..., en este caso, por la coyuntura política y la situación en que estamos ahora mismo [...]. Se está hablando de que pueda salir algo en junio..., no, miento..., o en agosto». (Empresa formadora)

Menos optimistas con los plazos se mostraban las organizaciones sindicales consultadas, que hablaban, probablemente, de un año perdido en materia de formación para el empleo y ocupacional, con las graves consecuencias que esto puede tener en un contexto de desempleo galopante.

[... pero claro, en septiembre..., habría una gran concentración de formación en unos meses..., en meses finales del año, cuando tendríamos los seis primeros meses del año sin nada de nada. Y luego tendríamos la formación de ocupados, la formación para los trabajadores que están empleados [...]. Y esa formación, pues está igual que la del Fondo Social Europeo: parada del todo, del todo. (Sindicato)

[...] sobre la formación para el empleo..., hay una cuestión y es clara: es la incertidumbre. Pero incertidumbre, ¿en qué sentido? No es una incertidumbre desde el punto de vista de que no existe un marco normativo donde se regule la formación para el empleo. Yo creo que existe, que está claramente definido [...]. La incertidumbre, lógicamente, viene, pues..., las convocatorias están paradas, y están paradas ¿por qué? Pues nada más y nada menos que por la falta de recursos económicos. Los presupuestos están definiéndose ahora, las comunidades autónomas no conocen la parte de esos presupuestos que se van a gestionar... (Estudios sociales)

Para otros entrevistados, incluso la parálisis política estaba influyendo en la situación crítica de muchas empresas, inmersas en expedientes de regulación de empleo o incluso abocadas al cierre por los impagos de la Administración.

Tenemos clientes que están cerrando, que están con ERES, que están todo el día diciendo «oye, no...», con problemas de cobro... Y ves que los que tienen que tomar decisiones en la región no las están tomando. Pero, además, yo creo que ahora ya estamos en un extremo [...]. Mira, no salió convocatoria del FIP, no salieron convocatorias de Medio Ambiente..., no salen convocatorias de nada. El Instituto de Desarrollo Económico del Principado de Asturias (IDEPA) está paralizado. Que el IDEPA, al final, es una fuente [...]. Yo creo que el entorno regional ahora mismo es un desastre. Entonces, o se toman decisiones ya o esto va a explotar. (Empresa formadora) 


\section{Conclusiones}

Mientras que la población española ha mantenido una tendencia al alza en las últimas décadas, la población asturiana se ha mantenido estable. Su PIB per cápita se sitúa por debajo de comunidades como Aragón, Madrid, Navarra o País Vasco, si bien el VAB industrial se sitúa por encima de la media nacional. En la estructura productiva industrial destacan tres ramas de actividad de gran tradición en la región: metalurgia y fabricación de productos metálicos; industrias extractivas; e industria de alimentación, bebidas y tabaco. La industria presenta un nivel tecnológico bajo si atendemos al peso de los sectores manufactureros de alta-media tecnología. Respecto a algunos indicadores del mercado de trabajo, el Principado tiene unas tasas de actividad y de empleo inferiores a la media nacional, aunque la tasa de paro está por debajo de los niveles alcanzados en el conjunto del país.

La población asturiana con edades comprendidas entre 25 y 64 años posee un nivel educativo ligeramente superior a la media española, aunque comparada con UE15 y UE27 su estructura educativa está descompensada. Así, en Europa el porcentaje de personas con educación secundaria superior duplica al asturiano, mientras que en estudios terciarios la región supera a la media europea. Respecto a los niveles educativos de la población ocupada, Asturias destaca por el porcentaje de ocupados con estudios de formación profesional de grado medio y sobre todo con estudios de grado superior. Esta importancia de los estudios de FP se refleja con más intensidad en la población ocupada en la industria.

La propensión de las empresas regionales a la innovación es baja. Asturias no figura a la cabeza de las regiones españolas en gastos en $\mathrm{I}+\mathrm{D}$ e innovación. También se sitúa por debajo de la media española en personal dedicado a I+D. Solo destaca en el porcentaje de investigadores sobre el personal total dedicado a estas actividades. Este resultado está relacionado con la importancia que tiene en la región la institución de educación superior como ejecutor del gasto en I+D. En la distribución porcentual del gasto en innovación en el sector industrial según tipo de actividad destacan la adquisición de maquinaria, equipos y software; la introducción de innovaciones en el mercado; y diseño, otros preparativos para producción y/o distribución.

Asturias presenta ciertas particularidades en cuanto al tipo de empresas más innovadoras. En la región asturiana se estima que más del 70\% de las empresas involucradas en actividades de I+D tienen menos de 250 trabajadores, en contraste con el total nacional. En cuanto a la obtención de ayudas públicas, el porcentaje de empresas asturianas que han obtenido financiación pública es muy superior a la media española.

Si nos referimos a la cooperación con agentes externos por parte de las empresas del sector industrial, en el Principado destacan la cooperación con universidades y otros centros de enseñanza superior y la colaboración con centros tecnológicos. Son las empresas más grandes las que establecen en mayor medida líneas de cooperación con los distintos partners.

$\mathrm{Al}$ igual que los gobiernos de otras comunidades que integran este estudio, el Gobierno asturiano ha desempeñado un papel central en la implantación de políticas que potencien la innovación empresarial. Actualmente sigue vigente el PCTI 2006-2009, que ha perseguido diversificar el tejido industrial, consolidar el sistema asturiano de ciencia, tecnología e innovación implantando infraestructuras científico-tecnológicas, fomentar el trabajo en red y promover la creación de empresas innovadoras. Entre sus logros cabe destacar la consolidación de una red de centros tecnológicos, la creación de agrupaciones empresariales innovadoras y la construcción de infraestructuras de apoyo a la investigación. Todavía no se ha puesto en marcha el PCTI 
2015, entre cuyos objetivos se persigue que 1.300 empresas de la región sean innovadoras. La actual crisis económica puede afectar sobremanera el logro de los objetivos de este nuevo plan.

La mayoría de los centros de la región que imparten FP son de titularidad pública. La evolución seguida por la matrícula en este tipo de estudios ha tenido altibajos, aunque se ha producido un aumento significativo de los alumnos en el último curso 2009-2010 en FP de grado medio y en FP de grado superior. Asturias cuenta con un importante porcentaje de alumnos matriculados en familias del sector industrial. Atendiendo a los ámbitos de especialización de este sector, en los dos grados se produce una concentración del alumnado en cuatro ramas industriales: Electricidad y Electrónica; Mantenimiento de Vehículos Autopropulsados; Fabricación Mecánica; y Mantenimiento y Servicios a la Producción.

En cuanto a la política regional en relación con la FP, en los últimos años ha estado orientada fundamentalmente a poner las bases de un sistema integrado de formación profesional. En esta línea se enmarcan el I Plan Regional de Formación Profesional 2003-2006 y el Plan Regional de Formación Profesional 2007-2010, si bien este último estaba paralizado en el momento de realización de este estudio por desacuerdos entre los agentes sociales, con las consiguientes consecuencias negativas para la integración del sistema de formación profesional.

La formación en centros de trabajo (FCT) es una formación práctica que realizan los alumnos en empresas y su superación una condición necesaria para obtener el título correspondiente. Este tipo de formación ha adquirido gran importancia porque se ha convertido en una de las mejores opciones de inserción laboral de los titulados de FP, si bien el nivel de inserción ha descendido de manera constante a partir del inicio de la crisis económica. Antes de la actual crisis los titulados no tenían dificultades de empleo ya que la demanda era muy superior a la oferta, eran las empresas las que acudían a los centros en busca de personal cualificado.

Todos los centros de FP entrevistados coinciden en una valoración muy positiva de la relación que mantienen con las empresas del entorno, que ha permitido cerrar convenios de colaboración y efectuar contrataciones de titulados. No obstante, la intensidad de las prácticas de los alumnos depende en gran medida de los contactos personales con dichas empresas más que del volumen y desarrollo empresarial de la región. Los centros valoran asimismo la fluidez de estas relaciones, que favorece la especialización de los alumnos en las áreas más demandadas y que facilita la inserción laboral futura, a la vez que obliga al centro educativo a una revisión permanente de los contenidos curriculares y de los itinerarios.

Tanto los centros como los empresarios consultados se muestran muy críticos con nuevas experiencias como la FP dual, la FP en alternancia o la recuperación de la figura del aprendiz. Se considera difícil la aplicación de alguno de estos modelos existentes en otros países debido a las peculiaridades españolas. También se quejan de la escasa consideración que tiene la FP en España. Se trata de un problema cultural que se transmite a la forma de pensar de los directivos de las empresas.

Son muy bien valoradas las estancias formativas del profesorado en empresas ubicadas en la región. Se considera que el valor añadido que adquieren los centros con las estancias del profesorado es fundamental para el diseño de las FCT, para completar la adquisición de competencias profesionales y para evaluar cuáles son las que requieren un entorno real de trabajo y no pueden adquirirse en el centro educativo.

Para los agentes consultados, la cultura de la empresa se considera decisiva a la hora de introducir innovaciones. Es un factor que repercute en la política de recursos humanos y en la introducción de innovaciones. También ejerce gran influencia el entorno empresarial, la cultura de la sociedad asturiana como causa del escaso impulso innovador del Principado, una visión 
que es compartida también desde el ámbito empresarial, que reclama mayor cooperación y diálogo entre las partes involucradas. Junto a este factor se señalan las características del tejido empresarial asturiano, en el que predominan de forma abrumadora las micropymes, o la equivocada percepción social que se tiene del emprendedor.

Por último, respecto a la formación de demanda, para los entrevistados se trata de una formación de gran complejidad para su desarrollo por sus problemas de adaptación al tejido empresarial de la región, formado en casi su totalidad por empresas de tamaño muy pequeño. En cuanto a la formación de oferta, se encuentra excesivamente burocratizada. Se necesitaría un sistema menos rígido, con cursos más cortos y más operativos.

\section{Anexos}

\section{Anexo I. Ficha técnica}

La parte de análisis cualitativo de este informe se ha basado en una serie de entrevistas realizadas a responsables de centros de formación que operan en el Principado de Asturias, a personas responsables de la formación profesional en la Administración regional y a agentes del sistema de formación para el empleo.

Los actores seleccionados han sido los siguientes:

+ Director de IES (IES)

+ Director de centro integrado de formación profesional (CFIP)

+ Responsable sindical (Sindicato)

+ Responsable de instituto de estudios sociales (Estudios sociales)

+ Experto del Departamento de Empleo (Experto Empleo).

- Responsable de organización de empresarios (Organización empresarios)

+ Gerente de empresa formadora (Empresa formadora)

\section{Anexo II. Agentes del sistema asturiano de ciencia, tecnología e innovación}

A continuación exponemos la composición del sistema asturiano de ciencia, tecnología e innovación.

- La Administración regional cuenta con diversos organismos. Entre ellos destacan la Consejería de Educación y Ciencia, que actúa principalmente a través de la Fundación para el Fomento en Asturias de la Investigación Científica Aplicada y la Tecnología (FICYT), y el Instituto de Desarrollo Económico del Principado de Asturias (IDEPA). Además, existen convenios de colaboración público-privada con las siguientes empresas: ThyssenKrupp Elevador, Arcelor-Mittal, Duro Felguera, HC Energía, Grupo Temper, IDESA, Saint-Gobain, FEVECAF, TSK, Aleastur y MBA.

La FICYT tiene por objeto promover, incentivar y promocionar las actividades de investigación, desarrollo tecnológico e innovación. Es la encargada de la gestión de los planes orientados a $\mathrm{I}+\mathrm{D}+\mathrm{i}$ del Principado de Asturias. 
El IDEPA se configura como una entidad pública adscrita a la Consejería que en cada momento tenga atribuidas las competencias de promoción económica e industrial. Lleva a cabo acciones orientadas a materializar la política de promoción empresarial del Gobierno regional.

- La oferta cientifica procede sobre todo de la Universidad de Oviedo, que se complementa con cinco centros de investigación: Centro Oceanográfico de Gijón, Instituto de Productos Lácteos, Instituto Nacional del Carbón, Servicio Regional de Investigación y Desarrollo Agroalimentario (SERIDA) y Centro de Investigación en Nanomateriales y Nanotecnología (CINN). El sistema público de I+D muestra una mayor especialización hacia las áreas de ingeniería y tecnología y agroalimentación, siendo reducida su actividad en el ámbito de las TIC.

La Universidad de Oviedo cuenta con los siguientes institutos universitarios:

- Instituto Universitario de Química Organometálica Enrique Moles

+ Instituto Universitario de Oncología

+ Instituto Universitario de Biotecnología

- Instituto Universitario de Tecnología Industrial

+ Instituto Feijoo de Estudios del Siglo xvirI

- Instituto Universitario de la Empresa

- Instituto de Recursos Naturales y Ordenación del Territorio (INDUROT)

+ Centro de Cooperación y Desarrollo Territorial (CECODET)

- Centro de Inteligencia Artificial

- Instituto de Ciencias de la Educación

- Por su parte, la oferta tecnológica y de innovación tiene como misión fundamental generar y difundir el conocimiento y las tecnologías utilizables por los demás agentes del sistema asturiano de ciencia, tecnología e innovación. Su actividad se dirige fundamentalmente a la realización de investigación y al desarrollo tecnológico, sobre todo en lo relativo a tareas de transferencia de tecnología, realización de labores de vigilancia tecnológica, asesoramiento técnico y difusión, con vistas a prestar servicios y promover la innovación en las pymes y micropymes de la región.

Dentro de la oferta tecnológica y de innovación están los centros tecnológicos:

- Instituto Tecnológico de Materiales (ITMA)

+ Centro Tecnológico del Acero y Materiales Metálicos (CEAMET)

+ Centro Tecnológico del Diseño y Promoción Industrial (PRODINTEC)

+ Centro Tecnológico de la Información y las Comunicaciones (CTIC)

- Centro Tecnológico Fundación Barredo

Además de los centros tecnológicos, existen en el Principado otros organismos que proporcionan servicios tecnológicos a las empresas o a la Administración:

- Centro de Experimentación Pesquera

+ Laboratorio Interprofesional Lechero (LILA)

- Laboratorio de la Asociación de Investigación de las Industrias Cárnicas

- Laboratorio del Servicio de Geología de Materiales

- Además, están los centros de I+D de grandes empresas: Arcelor-Mittal, Empresa Nacional de Celulosa y Centro Tecnológico de Esmena 
- Finalmente, las infraestructuras de apoyo a la innovación están formadas por una serie de organismos que realizan actividades de intermediación entre los centros de la oferta científica, tecnológica y de innovación y el sector empresarial, a la vez que sirven de apoyo a la actividad innovadora:

- Las oficinas de transferencia de los resultados de investigación (OTRI). Su misión fundacional consiste en identificar las necesidades de las empresas y contribuir a convertir los resultados de I+D en nuevos productos y servicios. Los OTRI del Principado de Asturias son: OTRI de la Universidad de Oviedo, OTRI de la FICYT, OTRI del ITMA.

- Centro de Enlace para la Innovación Galantea, ubicado en la FICYT, que tiene el objetivo de fomentar la cooperación tecnológica entre empresas y centros de investigación de Asturias y sus homólogos en 32 países europeos, a través de la transferencia de tecnología transnacional, y contribuir a la consolidación de la infraestructura europea de apoyo profesional a la innovación.

- Las fundaciones universidad-empresa (FUO), que buscan formas de colaboración y la creación de colaboraciones entre la universidad y las empresas.

- Los centros europeos de empresas e innovación (CEEI) aparecen en 1984 como resultado de un programa de la Dirección General de Política Regional (DGXVI) de la Comisión Europea. Su objetivo es dinamizar los recursos regionales para fomentar la aparición y expansión de empresas innovadoras, tanto mediante el apoyo a la creación como mediante la diversificación de las existentes. La región cuenta con el CEEI del Principado de Asturias.

- Los parques científicos y tecnológicos. Consisten en amplias zonas puestas a disposición de empresas y centros tecnológicos. En el Principado hay el Parque Tecnológico de Asturias y el Parque Científico-Tecnológico de Gijón.

- Otros agentes que actúan como infraestructuras de apoyo a la innovación, cuya aportación principal está basada en la prestación de servicios de formación, así como organismos de la Administración directamente relacionados con la investigación científica y el apoyo a la innovación: Federación Asturiana de Empresarios (FADE); Asociación Asturiana de Jóvenes Empresarios; asociaciones empresariales, cámaras de comercio, industria y navegación; Club Asturiano de la Innovación; Club Asturiano de la Calidad; Fundación Asturiana de la Energía (FAEN); Fundación Asturiana de Medio Ambiente (FAMA); clústeres sectoriales.

- Organismos de interfaz para dar o complementar el apoyo financiero a los agentes del sistema de ciencia, tecnología e innovación: Sociedad de Garantía Recíproca de Asturias (ASTURGAR); Sociedad Regional de Promoción (SRP); Sociedad para el Desarrollo de las Comarcas Mineras (SODECO).

- - De todos los elementos del sistema regional de innovación, las empresas son el subsistema de mayor importancia, sobre todo las que son innovadoras, al facilitar la conexión entre el sistema productivo y el de innovación. Asturias presenta ciertas particularidades en cuanto al tipo de empresas más innovadoras. En la región asturiana se estima que el $75 \%$ de las empresas involucradas en actividades de I+D interna tienen menos de 250 trabajadores, en contraste con el total nacional, donde las pymes solo realizan el 46\% del gasto (PCTI Asturias 2006-2009). 


\section{CATALUÑA}

Ignasi Brunet y JuAn Rodríguez 



\section{Entorno socioeconómico regional}

\subsection{Datos socioeconómicos básicos de referencia y características del tejido productivo}

Según los datos extraídos del INE (tabla 3.1), Cataluña posee 7.539.600 habitantes, lo que supone el 16\% de la población española. Su PIB es de 195.286,9 millones de euros, que suponen el 18,6\% del PIB estatal. El PIB per cápita es de 26.675 euros, lo que sitúa a Cataluña en el $116,9 \%$ de la media estatal, una posición intermedia respecto al resto de las regiones estudiadas (por encima de Aragón y Asturias, pero lejos de Madrid, Navarra y País Vasco).

Los datos provenientes de la Encuesta de Población Activa para 2010 (tabla 3.3) reflejan unos niveles superiores a la media estatal. Tanto la tasa de actividad como la tasa de empleo son superiores a los niveles estatales. Respecto a la primera, un $62,81 \%$ frente al $60 \%$ del Estado. En cuanto a la tasa de empleo, un $51,66 \%$ frente al $47,96 \%$ de la media estatal. Respecto al nivel de desempleo, Cataluña posee una tasa inferior a la del conjunto del Estado (17,75\% frente a 20,06\%), siendo esta la tasa de desempleo más elevada de las seis regiones estudiadas.

En cuanto al tejido productivo en 2010 (tabla 3.1), cabe señalar que el VAB industrial de Cataluña es de 36.688,7 millones de euros, lo que supone el 23,6\% del VAB industrial estatal. Por otro lado, el VAB industrial de Cataluña en 2008 supone el 21,4\% del PIB regional y el $19,7 \%$ del empleo.

Atendiendo a la especialización industrial de la región (Contabilidad Regional de España, INE, 2008), cabe señalar que Cataluña destaca sobre la media española fundamentalmente en las siguientes industrias: industria textil y de la confección, cuero y calzado $(1,2 \% \mathrm{VAB}$ y $1,9 \%$ empleo); e industria química (3,2\% VAB y $2 \%$ empleo).

La industria de Cataluña tiene un nivel tecnológico relativamente alto respecto al conjunto del Estado, aunque relativamente medio respecto al resto de regiones estudiadas. Atendiendo al peso de los sectores manufactureros de alta y media-alta tecnología (Indicadores de Alta Tecnología, INE, 2009) (tabla 3.2), se puede observar que el 33,6\% del VAB industrial corresponde a actividades de tecnologías alta y media-alta. Un porcentaje inferior a Navarra (36,7\%), Aragón (36,3\%) y Madrid (33,7\%), aunque significativamente superior al del conjunto del Estado (26,6\%).

El nivel educativo de la población catalana entre 25 y 64 años en 2010 es prácticamente el mismo que el de la media española (gráfico 3.1), caracterizándose por un idéntico porcentaje de población con nivel de estudios en educación secundaria inferior $(47,4 \%)$ y con un porcen- 
taje ligeramente inferior de población con nivel de estudios en educación secundaria superior (21,9\% frente a $22,0 \%)$, y con un nivel de estudios ligeramente superior en educación terciaria (30,8\% frente a $30,7 \%$ de la media española).

Si comparamos estos niveles de estudios con los datos de la UE15 y la UE27, observamos un cierto desequilibrio de la estructura de estudios de la población catalana, al igual que ocurre con la media española. En los países miembros de la UE los niveles de población entre 25 y 64 años con niveles inferiores de formación son más bajos que los de la población catalana (30,5\% para la UE15 y 27,3\% para la UE27), mientras que los niveles de estudios de nivel intermedio son superiores a los de Cataluña (42,2\% para la UE15 y 46,8\% para la UE27). Finalmente, cabe señalar que en cuanto a los niveles de estudios terciarios, el porcentaje de población catalana es superior al de los países de la UE15 y la UE27 (27,4\% y 25,9\%, respectivamente), lo cual puede indicar tanto un elevado nivel de cualificación como una posible sobrecualificación de la población catalana.

En cuanto a la población ocupada según su nivel educativo en 2010 (tabla 3.4), según los datos se observan dos cuestiones. En primer lugar, el significativo peso de la población analfabeta sin estudios acabados (un 17\% frente al 12,8\% de la media española). En segundo lugar, el peso ligeramente superior de la formación profesional de grado superior (FPGS) respecto del conjunto del Estado (11,6\% frente a 10,6\%). En cuanto a la población ocupada en la industria (tabla 3.5), las diferencias se mantienen para la población analfabeta, sin estudios y con estudios primarios $(17,33 \%$ frente a $13,2 \%)$, aumentan para el bachiller superior $(15,41 \%$ frente a $12,9 \%)$ y estudios superiores $(10,73 \%$ frente a $9,8 \%)$ y se invierten para la FPGS $(14,71 \%$ frente a $15,4 \%)$.

En este sentido, el gráfico 3.2 muestra el crecimiento del porcentaje de personas ocupadas en la industria con cualificaciones de FP. Según los datos, se observa que Cataluña es, de las seis regiones estudiadas, la que menos crecimiento tiene en los últimos 25 años, solo superada por la Comunidad de Madrid. Entre 1985 y 2010 la población catalana con cualificaciones de FP y ocupada en la industria pasó del $4 \%$ al $24,3 \%$. Este crecimiento resulta prácticamente idéntico al del conjunto del Estado. Estos datos sugieren una cierta debilidad de la formación profesional en el sector industrial, donde se ha utilizado personal, por una parte, poco o nada cualificado y, por otra, personal muy cualificado. Esta situación apunta a un uso menor que en otras regiones industrializadas del personal con cualificaciones profesionales de grado mediosuperior, lo que puede indicar un débil ajuste entre las necesidades del tejido industrial catalán y las formaciones profesionales intermedias, tal y como ocurre en algunas regiones españolas.

\subsection{Indicadores de investigación, desarrollo e innovación}

En 2010, Cataluña dedica un 1,63\% de su PIB al gasto en I+D (tabla 3.6), una cifra que es superior a la media española (1,39\%), pero inferior a la del conjunto de países de la UE27 (2\%). De las seis regiones estudiadas, Cataluña es la cuarta región por nivel de gasto, por detrás de Madrid (2,02\%), Navarra (1,97\%) y País Vasco (1,95\%). Respecto al crecimiento del gasto en I+D experimentado entre 1997 y 2010 (gráfico 3.4), Cataluña solo es superada por el País Vasco y Navarra.

La tabla 3.7 nos indica que en Cataluña el gasto en $\mathrm{I}+\mathrm{D}$ es ejecutado principalmente por las empresas e IPSFL (56,8\%), porcentaje superior a la media española (51,6\%). La Administración pública y la enseñanza superior en Cataluña tienen un menor peso en la ejecución del gasto en I+D que en el conjunto del Estado: $19,8 \%$ frente a $20,2 \%$ y $23,4 \%$ frente a $28,3 \%$, respectivamente. 
En términos relativos al PIB (tabla 3.7), los tres sectores apuntados igualan o superan a la media española. El gasto en $\mathrm{I}+\mathrm{D}$ en los sectores de empresas y Administración pública es significativamente superior al del conjunto del Estado: 0,93\% frente a 0,71\% y 0,39\% frente a $0,28 \%$, respectivamente. Respecto al sector de la enseñanza superior, el gasto en Cataluña es ligeramente inferior al de España (0,38\% frente a 0,39\%). En cuanto a la evolución del gasto en I+D sobre el PIB en Cataluña entre 1997 y 2010, se observa en los tres sectores un crecimiento superior al del conjunto del Estado, destacando especialmente el crecimiento en la ejecución del gasto en el sector de la Administración pública.

En relación con los recursos humanos en I+D (tabla 3.8), Cataluña ocupa una posición intermedia entre las regiones estudiadas, si bien el nivel de personal dedicado a $\mathrm{I}+\mathrm{D}$ sobre la población ocupada $(16,12 \%$ ) está claramente por encima de la media española (12,03\%o). El crecimiento de este personal es superior al del conjunto del Estado gracias a un crecimiento más acusado entre 2009 y 2010 (del 14,8\% al 17,4\%). En la misma línea, el porcentaje de investigadores sobre la población ocupada también supera al del conjunto del Estado $(9,41 \%$ frente a $7,3 \%)$, al igual que ocurre con el personal técnico y auxiliar en $\mathrm{I}+\mathrm{D}$ (41,6\% frente a 39,4\%). Sin embargo, el volumen de investigadores dentro del personal de $\mathrm{I}+\mathrm{D}$ es inferior a la media estatal $(58,4 \%$ frente a $60,6 \%)$.

La tabla 3.9 muestra la ubicación en los diferentes sectores de ejecución de $\mathrm{I}+\mathrm{D}$ de investigadores y técnicos y auxiliares. Cabe destacar, en general, el mayor peso de empresas seguido del de la enseñanza superior. En el caso de los investigadores, destaca el sector enseñanza superior $(40,7 \%)$ y el sector empresas $(37,9 \%)$, siendo este porcentaje superior al conjunto del estado. En el caso de técnicos y auxiliares, destaca el peso del sector empresas (59,3\%), también superior a la media española.

En relación con el sector industrial, cabe destacar el significativo peso de dicho sector, con un 59\% del total de la I+D empresarial, muy superior a la media española y al del resto de regiones estudiadas, solo superado por la Comunidad Autónoma de Aragón (65,8\%). Por otro lado, respecto a la formación del personal de I+D en el sector industrial (tabla 3.10), conviene señalar que el $26,8 \%$ de este personal tiene titulación de FP, en mayor medida para el grado superior. Una cifra que es superior a la media española $(23,3 \%)$ y a la del resto de regiones estudiadas. Por otro lado, tal y como muestra la tabla 3.11, el conjunto de cualificaciones intermedias de formación profesional es especialmente importante en las pymes del tramo 75-149 trabajadores $(28,1 \%)$ y del tramo $150-249$ trabajadores $(27,4 \%)$.

Respecto a la distribución del gasto en innovación en el sector industrial (tabla 3.12), Cataluña se caracteriza por tener el porcentaje de adquisición de I+D externa más alto de las seis regiones estudiadas (29,66 \%), muy por encima de la media estatal (20,62\%). En cambio, la $\mathrm{I}+\mathrm{D}$ interna y la adquisición de maquinaria sitúan a Cataluña en una posición intermedia. Si atendemos al tamaño de las empresas industriales, se observa que el gasto en $\mathrm{I}+\mathrm{D}$ interna y en $\mathrm{I}+\mathrm{D}$ externa crece a medida que aumenta el tamaño de la pyme. En el caso de la adquisición de maquinaria se produce la tendencia contraria.

En relación con la capacidad de las empresas innovadoras de Cataluña para la obtención de ayudas públicas para la innovación (tabla 3.13), cabe destacar que el porcentaje de empresas que acceden a ayudas públicas en Cataluña es inferior a la media española $(23,3 \%$ frente a $28,8 \%$ ) y al del resto de regiones estudiadas, a excepción de la Comunidad de Madrid. El nivel de acceso a ayudas por parte del Gobierno central es muy superior a la media española y al del resto de regiones. Sin embargo, el nivel de acceso a ayudas regionales o provenientes de la Unión Europea es significativamente inferior al nivel medio del conjunto del Estado y al del resto de 
regiones estudiadas, lo que refleja una situación con grandes desequilibrios respecto a la capacidad de las empresas catalanas para acceder a unas ayudas u otras.

Si observamos el tamaño de las empresas, en Cataluña destacan las empresas de 150 a 249 trabajadores como aquellas con más capacidad para obtener financiación para la innovación: un 84,5\% de estas acceden a financiación pública de la Administración central y un 6,9\% a financiación de la Unión Europea.

Un último aspecto a destacar es la capacidad de las empresas para cooperar con otros actores del sistema de innovación. En este sentido, la tabla 3.14 muestra como las empresas de Cataluña tienden a cooperar relativamente menos que la media estatal (21,1\% frente a $22,1 \%)$. Destaca la cooperación con agentes de la cadena de valor (empresas del mismo grupo, proveedores y clientes). La cooperación con universidades también es importante, al igual que con los centros tecnológicos, aunque en este último caso el nivel de cooperación es inferior a la media española. Si atendemos al tamaño de las empresas, destacan las empresas de 250 o más trabajadores (cooperación con empresas del mismo grupo, proveedores, clientes, universidades, organismos públicos de investigación y centros tecnológicos) y, en menor medida, las empresas de 150 a 249 trabajadores (cooperación con proveedores y universidades).

\subsection{Sistema institucional de agentes de $\mathrm{I}+\mathrm{D}+\mathrm{i}$}

De las entrevistas realizadas y la documentación analizada se deriva un vasto y complejo sistema de innovación, condicionado por un tejido productivo más o menos desarrollado en el territorio y por una serie de actores e instituciones vinculados a la investigación y a la innovación. Cabe destacar que predominan los agentes públicos especialmente vinculados a la investigación (entre otros, las universidades catalanas y sus derivados), aunque la transferencia de tecnología tiene un cierto protagonismo (centros tecnológicos, red TECNIO, entre otros).

El sistema catalán de investigación e innovación está integrado fundamentalmente por las universidades, los centros de investigación, las instituciones hospitalarias, las grandes infraestructuras de apoyo a la investigación, los parques científicos y tecnológicos, y las redes y los grupos de investigación.

De forma sintética ${ }^{1}$, el sistema catalán de innovación estaría compuesto por los siguientes actores:

+ Universidades: 12 universidades, 7 públicas y 5 privadas.

+ Centros de investigación en Cataluña (CERCA): más de 40 centros vinculados al Programa CERCA.

- Parques científicos y tecnológicos: 22 parques entre socios y asociados a la Red de Parques Tecnológicos de Cataluña (XPCAT).

+ Fundaciones hospitalarias.

+ Clústeres: bios, media, diseño, energía y TIC, entre otros.

+ Grandes infraestructuras de I+D

- Redes de referencia de I+D+i: en Cataluña hay 8 redes de transferencia.

- Centros TECNIO: más de 100 unidades, entre centros y agentes del programa ACC1Ó.

\footnotetext{
1 Para un mayor detalle, véase el anexo II.
} 
+ Instituciones públicas de investigación (CSIC): más de 20 centros del CSIC, junto con centros de investigación vinculados a diferentes departamentos de la Generalitat.

- Grupos de investigación reconocidos.

Entre estos actores destacan, entre otros, CERCA, TECNIO y BIOCAT. El primero coordina y apoya la acción del Gobierno de Cataluña entre los centros de investigación catalanes que el Gobierno ha creado y que tienen entidad jurídica propia. El segundo consiste en un consorcio que coordina los centros de la Red Tecnológica de Cataluña (centros TECNIO). BIOCAT, por su parte, es una entidad que coordina y fomenta la biotecnología, la biomedicina y las tecnologías médicas en Cataluña. Es impulsada por la Generalitat de Catalunya y el Ayuntamiento de Barcelona, e integra empresas y entidades del sector.

\subsection{Política de $\mathrm{I}+\mathrm{D}+\mathrm{i}$ en el ámbito regional}

La apuesta del Gobierno catalán por el desarrollo y fomento de la innovación se manifiesta en la sucesión de planes y acuerdos generales relacionados con ello. Entre ellos destaca como marco general el Pacte Nacional per a la Recerca i la Innovació (PNRI) (2008), que supone la hoja de ruta en materia de investigación e innovación para los próximos 15 años. Este pacto está firmado por el Gobierno catalán, los partidos políticos con representación parlamentaria, Foment del Treball, PIMEC, UGT y todas las universidades catalanas. Otros agentes vinculados a este ámbito (parques tecnológicos, centros de investigación, centros tecnológicos, administraciones locales, cámaras de comercio, escuelas de negocio...) se han ido adhiriendo progresivamente.

Entre los planes que marcan las directrices de la política catalana de investigación e innovación destacan, además, los sucesivos planes de investigación e innovación (2005-2008 y 2010-2013). Previamente, entre 1993 y 2004 en Cataluña se aprueban tres sucesivos planes de investigación. Cada uno de ellos marca las políticas del Gobierno catalán en materia de I+D estableciendo los ámbitos de actuación, los programas prioritarios y las diferentes áreas de gestión y potenciando la creación de grupos de investigación consolidados, las redes temáticas y los centros de referencia en I+D. Cabe apuntar que los tres primeros planes están más enfocados al sistema de investigación catalán. Tras el tercer plan se da una convergencia entre el fomento del sistema de investigación y el fomento del sistema de innovación.

El I Pla de Recerca de Catalunya (1993-1996) focaliza la mayoría de esfuerzos y recursos en la consolidación de grupos de investigación mediante el apoyo de una infraestructura de ciencia y tecnología física, humana y organizativa en universidades y centros de investigación.

El II Pla de Recerca de Catalunya (1997-2000) mantiene la importancia del desarrollo de infraestructuras de investigación y capital humano, si bien se inician actuaciones vinculadas a la innovación.

El III Pla de Recerca de Catalunya (2001-2004) coincide con el I Pla d'Innovació (20012004). Esta situación permitió realizar actuaciones conjuntas en materia de transferencia de conocimientos y tecnologías. El I Pla d'Innovació es elaborado por el Departamento de Trabajo e Industria y es gestionado por el Centro de Innovación y Desarrollo Empresarial (CIDEM).

Tras tres planes de investigación y un plan de innovación, en 2004 se firma el I Pla de Recerca i Innovació de Catalunya (2005-2008), el cual refuerza y potencia el carácter integral de las políticas en materia de investigación e innovación, iniciado con la coincidencia en el tiempo del III Pla de Recerca de Catalunya y el I Pla d'Innovació. Este nuevo plan es elaborado por el Consejo Interdepartamental de Investigación e Innovación Tecnológica (CIRIT) en colaboración con el 
Departamento de Universidades, Investigación y Sociedad de la Información (DURSI) y el Departamento de Trabajo e Industria. De los diez objetivos que comprende el plan, tres se refieren al sistema de investigación y tres al sistema de innovación, incidiendo en la mejora de la articulación y la interacción de los agentes públicos y privados. Cabe destacar que, del resto de objetivos, dos de ellos inciden en el fomento de la innovación dentro del tejido empresarial.

En 2008 se firma el Pacte Nacional per a la Recerca i la Innovació (PNRI), impulsado por el Gobierno de la Generalitat de Catalunya y refrendado con un amplio consenso social y político, que establece un marco a largo plazo (2020 como horizonte) para el desarrollo del sistema de innovación catalán. Cabe destacar el reconocimiento del papel y la capacidad de mejora de la formación profesional dentro de este sistema, que apuesta por un sistema integrado de formación profesional. Otro de los elementos interesantes es la apuesta por la potenciación de las relaciones entre la formación profesional, las empresas y la universidad.

El II Pla de Recerca i Innovació de Catalunya (2010-2013) recoge los compromisos adoptados en el pacto de 2008 y establece 10 objetivos que inciden en el fomento de la innovación, el desarrollo de los diferentes agentes públicos y privados y la interacción de todos estos agentes en el territorio y dentro del sistema regional de innovación. Entre estos destaca el objetivo 6, que potencia la cooperación entre los diferentes agentes del sistema de $\mathrm{I}+\mathrm{D}+\mathrm{i}$.

\section{La FP en el ámbito regional}

\subsection{Formación reglada: recursos del sistema}

En el curso 2009-2010 Cataluña cuenta con 351 centros que imparten ciclos formativos de grado medio (CFGM) y 286 centros que imparten ciclos formativos de grado superior (CFGS), lo que supone el $13,5 \%$ y el $13,7 \%$ del total de centros del conjunto del Estado, respectivamente (tabla 3.15). Sin duda, de las seis regiones estudiadas Cataluña es la que aglutina con diferencia un mayor número de centros que imparten estudios de formación profesional.

Respecto a la titularidad (pública o privada) de los centros de formación profesional (tabla 3.15), cabe destacar que en Cataluña la formación profesional es fundamentalmente pública, aunque en un nivel menor a la media española. El $67 \%$ de los centros que imparten CFGM son públicos, ligeramente por debajo de la media del conjunto del Estado (73,7\%). De los centros que imparten CFGS, el $67,1 \%$ son de titularidad pública, también por debajo de la media española $(76,1 \%)$.

En el curso 2009-2010 Cataluña cuenta con 45.597 alumnos matriculados en CFGM y 43.563 alumnos en CFGS, lo que supone el $16,8 \%$ y el $17,8 \%$ del total estatal, respectivamente (tabla 3.16). Al igual que ocurre con el número de centros, Cataluña es la región con más alumnado matriculado en formación profesional. Respecto a la distribución del alumnado entre centros públicos y privados, cabe destacar que la proporción aumenta a favor de los primeros respecto a los datos relativos de centros públicos y privados, especialmente en el caso de las enseñanzas de grado medio. El 74,1\% del alumnado de CFGM y el 70,5\% del alumnado de CFGS están matriculados en centros públicos. Aun así, no dejan de ser porcentajes inferiores a la media española. Respecto a las tasas brutas de escolarización, se puede observar que son superiores a la media española, especialmente la relativa a las enseñanzas de grado superior (31,8\% frente a $26,4 \%)$. 
Por otro lado, en Cataluña la formación profesional a distancia cuenta con un volumen considerable de alumnado (5,4\%), superando incluso a la media española (4,4\%). En relación con la formación profesional presencial impartida en Cataluña, la formación de grado superior a distancia tiene una mayor presencia que la formación de grado medio (8,5\% frente a 2,5\%). Esta última mantiene la media del conjunto del Estado (2,7\%), mientras que la formación a distancia de grado superior es significativamente superior a la media española.

Tabla 2.9. Alumnado FP a distancia. Cataluña-España. Curso 2009-2010

\begin{tabular}{|l|c|c|c|c|c|c|}
\hline Cataluña-España & CFGM & CFGS & Total FP & CFGM & CFGS & Total FP \\
\hline FP a distancia & 1.144 & 3.709 & 4.853 & 5.935 & 14.292 & 20.227 \\
\hline Total FP* & 45.597 & 43.563 & 89.160 & 217.990 & 245.354 & 463.344 \\
\hline FP a distancia/Total FP & 2,5 & 8,5 & 5,4 & 2,7 & 5,8 & 4,4 \\
\hline
\end{tabular}

* Enseñanza presencial: régimen ordinario y adultos.

Fuente: elaboración propia a partir de la Estadística de Enseñanzas no Universitarias. Ministerio de Educación, Cultura y Deporte

Por otro lado, como se puede observar en el siguiente gráfico (tablas 3.17 y 3.18), la evolución de la formación profesional de grado medio (FP GM) y la de grado superior (FP GS) en Cataluña han seguido una tendencia muy similar, a excepción del período comprendido entre los cursos 1998-1999 y 2001-2002. El gráfico recoge el mayor peso de las enseñanzas de grado superior en el período citado, con una tendencia negativa. Las enseñanzas de grado medio siguen una tendencia positiva hasta llegar a converger en el curso 2001-2002. A partir de ese curso ambos estudios siguen una tendencia positiva, con un aumento mayor a partir del curso 2005-2006, dos años antes de la crisis económica actual.

Gráfico 2.7. Evolución de las matriculaciones de FP en Cataluña (1998-1999 / 2009-2010)

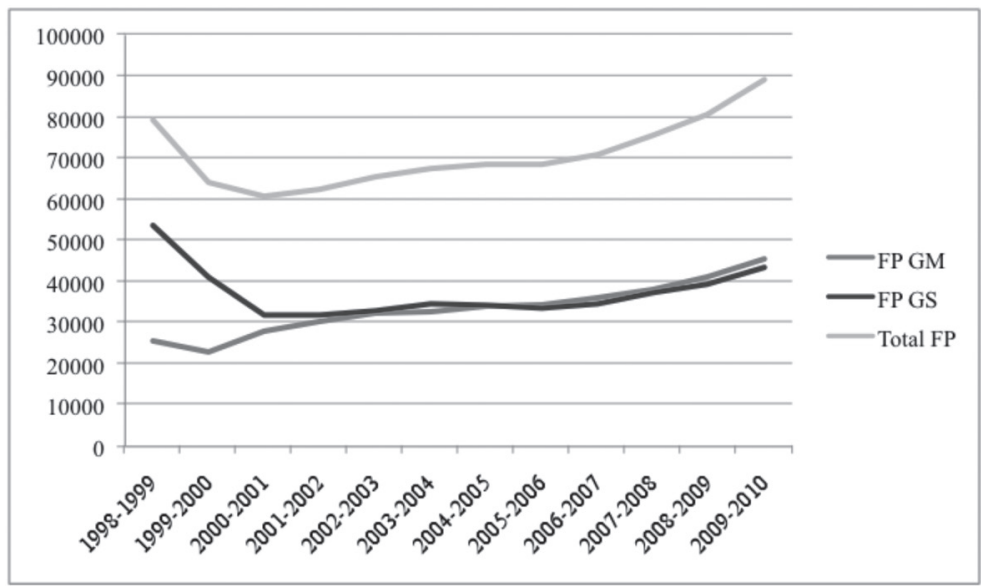

Fuente: elaboración propia a partir de «Las cifras de la educación en España», Ministerio de Educación, Cultura y Deporte 
Sin embargo, tal y como muestra el siguiente gráfico (tablas 3.23 y 3.24), la matriculación de alumnado en ramas industriales ha seguido una tendencia diferente de la evolución de la matriculación en general. La formación profesional de grado medio y de grado superior ha seguido una tendencia negativa muy acusada. Esta tendencia descendente es superior a la experimentada por el conjunto del Estado y se debe, en parte, a la diversificación y creación de nuevas especialidades profesionales, muchas de ellas vinculadas al sector servicios. De hecho, en el conjunto del Estado el descenso en las matriculaciones en los últimos años es de 11 puntos porcentuales, mientras que en Cataluña el descenso es de 21 puntos. Este acusado descenso ha equiparado en 2010 el nivel de matriculaciones en ramas industriales en Cataluña con la media española.

Gráfico 2.8. Evolución del porcentaje de alumnos matriculados en familias del sector industrial respecto al total de alumnos FP (2000-2010). Cataluña

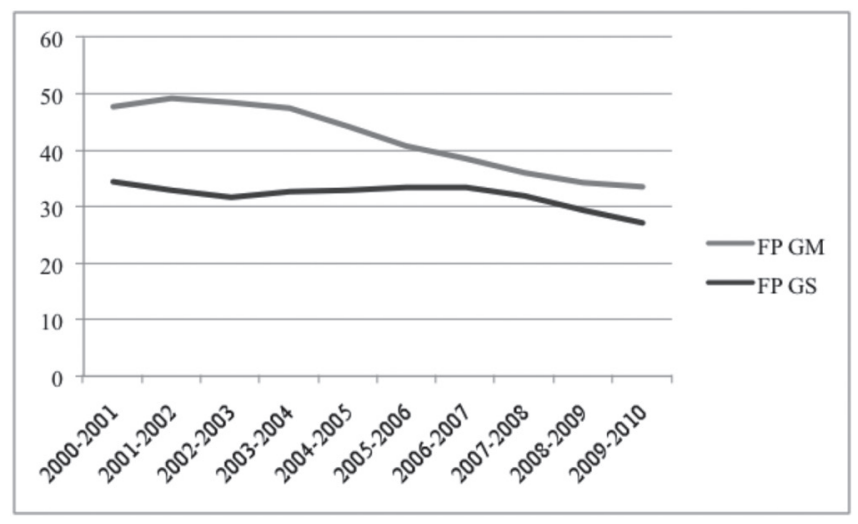

Fuente: elaboración propia a partir de «Las cifras de la educación en España», Ministerio de Educación, Cultura y Deporte

Finalmente, respecto al peso de la formación profesional en los presupuestos del Gobierno de Cataluña (tabla 2.10), en 2009 (último año disponible) el gasto público relativo a la partida de educación secundaria y formación profesional suponía el 38,8\% del gasto público del Departamento de Enseñanza en educación no universitaria y el 30\% del gasto público total del Departamento de Enseñanza de Cataluña.

Tabla 2.10. Gasto Departamento de Enseñanza. Cataluña. 2009

\begin{tabular}{|l|c|}
\hline (Miles de $€$ ) & $\mathbf{2 0 0 9}$ \\
\hline GASTO PÚBLICO TOTAL & $\mathbf{6 . 9 3 1 . 8 4 8 , 8}$ \\
\hline Educación no universitaria: & $5.357 .787,7$ \\
\hline - E. secundaria y f. profesional & $2.079 .672,4$ \\
\hline Educación universitaria (1) & $1.538 .728,3$ \\
\hline Formación ocupacional & 0 \\
\hline Becas y ayudas totales & $35.332,8$ \\
\hline & \\
\hline
\end{tabular}




\begin{tabular}{|l|c|}
\hline (Miles de $€$ ) & $\mathbf{2 0 0 9}$ \\
\hline ACTIVIDADES EDUCATIVAS (TOTAL) & $\mathbf{1 0 4 . 1 8 9 , 8}$ \\
\hline Educación no universitaria: & $3.753,6$ \\
\hline - E. secundaria y f. profesional & $3.753,6$ \\
\hline Educación universitaria (1) & $11.676,7$ \\
\hline Formación ocupacional & $88.759,5$ \\
\hline Becas y ayudas totales & 0,0 \\
\hline
\end{tabular}

(1) Incorpora 24.445.000 euros de becas del ME por exención de precios académicos y 296.351.000 euros de financiación de origen privado de las universidades.

(2) Incorpora las partidas transferidas por el SEPE para formación de desempleados. Departamentos: Trabajo, Cultura, Interior y Ganadería y Pesca.

Fuente: Ministerio de Educación, Cultura y Deporte

\subsection{Formación reglada: ámbitos de especialización}

Según se desprende de los datos sobre especialización (tabla 3.21), dentro de los ciclos formativos de grado medio las familias con más volumen de alumnado son las de Sanidad $(14,2 \%)$, Administración (13,6\%), Informática (11,1\%), Electricidad y Electrónica (10,2\%) y Mantenimiento de Vehículos Autopropulsados (9,3\%). El resto de familias profesionales, a excepción de Imagen Personal (6,2\%), no supera el 5\% de proporción de alumnado.

Atendiendo a los ámbitos de especialización industrial de los CFGM, en el siguiente gráfico (tabla 3.21) se puede observar que Cataluña tiene una importante tasa de matriculación $(11,1 \%)$ en los grados medios de la familia de Informática, siendo la mayor diferencia con la media española (3,1 puntos porcentuales). El resto de diferenciales no superan el punto porcentual. De hecho, la segunda y la tercera familia con mayor tasa de matriculación en Cataluña son Electricidad y Electrónica (10,2\%) y Mantenimiento de Vehículos Autopropulsados $(9,3 \%)$. Respecto al segundo caso, el diferencial con España es mínimo (0,5 puntos porcentuales), mientras que en el primer caso el diferencial es incluso negativo (-1 punto porcentual).

Gráfico 2.9. Áreas de especialización industrial de la FPGM en Cataluña

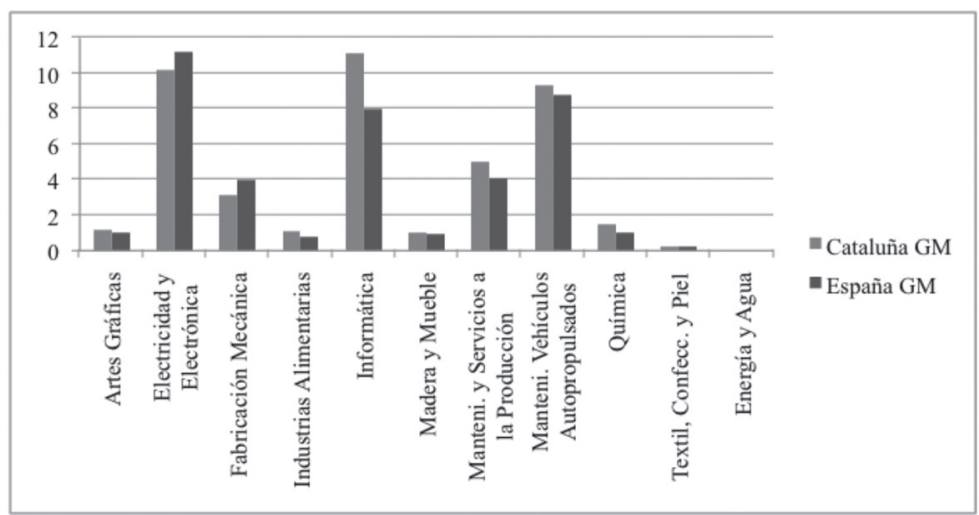

Fuente: elaboración propia a partir de «Las cifras de la educación en España», Ministerio de Educación, Cultura y Deporte 
En el caso de los ciclos formativos de grado superior, la familia de Servicios Socioculturales y a la Comunidad (15,8\%) supera a las dos primeras familias de los CFGM, que cambian su posición: Administración (12,9\%) y Sanidad (10,9\%). Les siguen Informática (8,4\%), Electricidad y Electrónica (6,9\%) y Comercio y Marketing (5,5\%). El resto de familias profesionales no superan el $5 \%$ de proporción de alumnado.

Atendiendo a los ámbitos de especialización industrial de los CFGS, en el siguiente gráfico (tabla 3.22) se puede observar que, al igual que en los grados medios, la familia de Informática posee la mayor tasa de matriculación $(8,4 \%)$ de todos los grados superiores, aunque en este caso el diferencial con España resulta negativo ( $-1,3$ puntos porcentuales). De hecho, esta es la característica principal de las especializaciones industriales de grado superior en Cataluña: la mayor presencia de diferenciales negativos respecto a la media española. También cabe destacar el aumento del peso de la familia de Química (3,4\%), que supone el mayor diferencial de todos los grados superiores en Cataluña (1,4 puntos porcentuales).

\section{Gráfico 2.10. Áreas de especialización industrial de la FPGS en Cataluña}

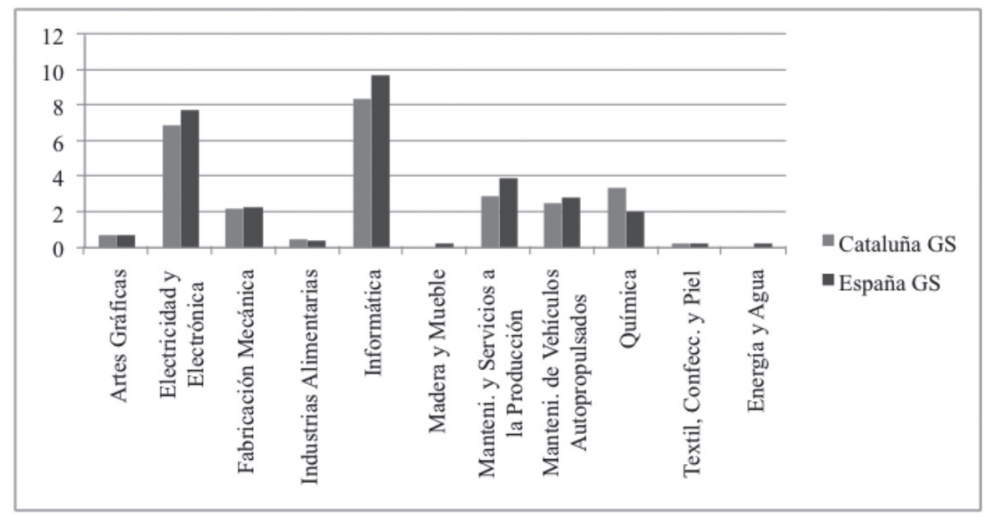

Fuente: elaboración propia a partir de «Las cifras de la educación en España», Ministerio de Educación, Cultura y Deporte

Para finalizar, tal y como reflejan las tablas 3.23 y 3.24, Cataluña ha experimentado un importante descenso de los estudios profesionales en las ramas industriales, mostrando ciertas carencias en la mayoría de especializaciones industriales. En el curso 2009-2010, el porcentaje de alumnado matriculado en dichas especializaciones es del 33,6\% para los CFGM y del 27,3\% para los CFGS, similares o incluso inferiores a la media española, que es del 33,3\% y del 28\%, respectivamente.

\subsection{Formación para el empleo: la formación de oferta}

En Cataluña y durante 2010, bajo la modalidad de oferta, han participado en la formación para el empleo un total de 100.534 personas, lo que supone un 12,8\% del total estatal (tabla 3.25). Es la segunda región, por detrás de Madrid, con mayor número de participantes en cursos de formación de oferta en 2010. Dentro de esta formación para el empleo, un 33,4\% corresponde a formación vinculada al sector industrial, más de 10 puntos porcentuales por encima de la media española (22,7\%). Este porcentaje es el más elevado de las seis regiones estudiadas con diferencia. 
La fórmula presencial es la más utilizada en este tipo de formación en Cataluña, más incluso que en el resto de regiones estudiadas: un 69,3\% de las acciones formativas se desarrollan bajo esta modalidad, lo que supone una diferencia porcentual de más de 20 puntos por encima de la media española (48,5\%). Le siguen la teleformación (12,9\%), la formación mixta $(9,7 \%)$ y la formación a distancia $(8,1 \%)$. En este sentido, cabe destacar que estas tres últimas modalidades tienen un peso inferior al que tienen en el conjunto del Estado, especialmente la formación a distancia y, en menor medida, la teleformación.

Atendiendo al sexo y a la edad de los participantes (tabla 3.26), cabe apuntar que en Cataluña solo el $35,5 \%$ de las personas formadas han sido mujeres, una cifra significativamente inferior a la del resto de regiones estudiadas y a la media española (45,8\%). Por otro lado, se puede observar que 6 de cada 10 personas (66\%) se encuentran en la franja de edad 26-45, y casi 2 de cada 10 personas (19,7\%) se encuentran en la franja de 46-55, siendo esta última la franja de edad donde se produce una mayor diferencia respecto a la media española (16,7\%). Le sigue la franja de edad de más de 55 años (6\% frente al 4,1\% de la media estatal).

Respecto al nivel de cualificación de las personas formadas (tabla 3.27), la formación de oferta en Cataluña se dirige fundamentalmente a personas con poca cualificación $(44,5 \%) y$, en menor medida, a personas sin cualificación (20,4\%). En cuanto al primer colectivo, el diferencial con el Estado es positivo (6,3 puntos porcentuales), mientras que, en cuanto al segundo colectivo, el diferencial es negativo (-12,1 puntos porcentuales), siendo la categoría de cualificación con mayores diferencias respecto al conjunto del Estado. También cabe destacar que las personas con más formación (técnicos, mandos intermedios y directivos) participan en mayor medida que en el conjunto del Estado.

Por otro lado, la formación de oferta realizada en Cataluña se canaliza a través del Servei d'Ocupació de Catalunya (SOC). A continuación se enumeran los tipos de programas que actualmente ofrece.

Tabla 2.11. Programas de formación del Servei d’Ocupació de Catalunya. 2010

\begin{tabular}{|l|l|}
\hline Ámbito: cualificación profesional & $\begin{array}{l}\text { Formación de oferta mediante planes formativos } \\
\text { en áreas profesionales prioritarias }\end{array}$ \\
\hline & $\begin{array}{l}\text { Formación de oferta mediante planes formativos } \\
\text { en entidades locales }\end{array}$ \\
\hline & $\begin{array}{l}\text { Programa de Cualificación Profesional Inicial } \\
\text { (PCPI) }\end{array}$ \\
\hline & Programa Forma y Contrata \\
\hline & Crédito formación para el trabajo \\
\hline & $\begin{array}{l}\text { Centros de innovación y formación ocupacional } \\
\text { (CIFO) }\end{array}$ \\
\hline & FP.CAT \\
\hline & Formación virtual a distancia e-formación \\
\hline & Connecta't \\
\hline & Convenios interdepartamentales \\
\hline \multirow{2}{*}{ Ámbito: promoción del empleo } & Planes de empleo \\
\hline & Nuevas casas para nuevos oficios \\
\hline
\end{tabular}




\begin{tabular}{|c|c|}
\hline \multirow[t]{4}{*}{ Ámbito: cohesión social y desarrollo territorial } & Treball als Barris \\
\hline & Treball a les 7 Comarques \\
\hline & Fomento del desarrollo local y territorial \\
\hline & $\begin{array}{l}\text { Prórroga de los agentes de empleo y desarrollo } \\
\text { local (AEDL) }\end{array}$ \\
\hline \multirow{8}{*}{$\begin{array}{l}\text { Ámbito: actuaciones innovadoras y } \\
\text { experimentales }\end{array}$} & Proyectos innovadores \\
\hline & $\begin{array}{l}\text { Programa de experiencia profesional para el } \\
\text { empleo juvenil en Cataluña (Programa Suma't) }\end{array}$ \\
\hline & $\begin{array}{l}\text { Convocatoria de acciones para el empleo con } \\
\text { entidades locales }\end{array}$ \\
\hline & Programa de igualdad de oportunidades \\
\hline & $\begin{array}{l}\text { Programas innovadores para impulsar cambios } \\
\text { estructurales hacia la igualdad de oportunidades } \\
\text { en el ámbito laboral }\end{array}$ \\
\hline & $\begin{array}{l}\text { Programas de orientación y apoyo a la inserción } \\
\text { laboral de mujeres en situación de vulnerabilidad } \\
\text { por el desempleo }\end{array}$ \\
\hline & Red catalana de agentes locales de igualdad \\
\hline & Colectivos especiales \\
\hline
\end{tabular}

Fuente: SOC

Además del SOC, el Gobierno de Cataluña posee la competencia de la formación profesional continua desde 2004, por lo que se creó el Consorci per a la Formació Contínua de Catalunya (CFCC), compuesto por la Administración regional y los agentes sociales más representativos del territorio. Las funciones del CFCC son las de gestionar y ejecutar los programas de formación profesional continua. Actualmente se están desarrollando tres programas formativos:

- Planes de formación intersectoriales (conocimientos y habilidades que se pueden aplicar en cualquier sector productivo).

+ Planes de formación dirigidos a trabajadores de entidades de economía social.

+ Planes de formación sectoriales (conocimientos y habilidades que se pueden aplicar en diferentes sectores productivos).

Estos cursos están totalmente subvencionados y algunas especialidades se pueden cursar a distancia o mediante teleformación (Programa e-formació). Entre los planes de formación sectoriales vinculados a la industria, destaca el sector del metal, seguido por el sector de la construcción (en volumen de acciones, grupos y participantes aprobados). 
Tabla 2.12. Planes de formación sectoriales en Cataluña. 2011

\begin{tabular}{|l|c|c|c|c|}
\hline Ámbitos sectoriales & $\begin{array}{c}\text { Acciones } \\
\text { aprobadas }\end{array}$ & $\begin{array}{c}\text { Grupos } \\
\text { aprobados }\end{array}$ & $\begin{array}{c}\text { Participantes } \\
\text { aprobados }\end{array}$ & $\begin{array}{c}\text { Financiación } \\
\text { aprobada }\end{array}$ \\
\hline Agroalimentaria & 168 & 229 & 3.429 & 1.298 .700 \\
\hline Otros servicios e industrias afines & 103 & 79 & 1.191 & 726.708 \\
\hline Comercio & 198 & 675 & 10.121 & 4.440 .809 \\
\hline Construcción & 333 & 477 & 7.149 & 3.401 .784 \\
\hline Educación y formación & 232 & 324 & 4.856 & 1.478 .353 \\
\hline Metal & 338 & 508 & 7.621 & 3.064 .087 \\
\hline Químico & 105 & 127 & 1.902 & 689.156 \\
\hline Sanidad & 346 & 360 & 5.401 & 1.633 .719 \\
\hline $\begin{array}{l}\text { Servicios colectivos y a las } \\
\text { personas }\end{array}$ & 420 & 493 & 7.393 & 2.862 .675 \\
\hline $\begin{array}{l}\text { Servicios financieros, } \\
\text { administrativos y de seguros }\end{array}$ & 300 & 425 & 6.381 & 3.554 .797 \\
\hline Textil, calzado y piel & 64 & 55 & 823 & 340.651 \\
\hline $\begin{array}{l}\text { Transportes, comunicaciones y } \\
\text { mar }\end{array}$ & 151 & 176 & 2.641 & 1.556 .962 \\
\hline Turismo, hostelería y juego & 387 & 386 & 5.783 & 2.064 .956 \\
\hline TOTAL & 3.145 & 4.313 & 64.691 & 27.113 .356 \\
\hline
\end{tabular}

Fuente: CFCC

Estas acciones se desarrollan a través de los centros de innovación y formación ocupacional (CIFO) 2 del SOC y de los centros colaboradores en materia de formación profesional ocupacional, públicos o privados. Los CIFO tienen asignadas las funciones siguientes:

- Llevar a cabo acciones formativas de experimentación en nuevas cualificaciones.

- Desarrollar acciones de innovación metodológica para conseguir competencias y capacidades profesionales.

- Programar, de forma continua, acciones formativas dirigidas a personas trabajadoras en situación de desempleo.

La actividad formativa que los CIFO llevan a cabo se basa fundamentalmente en la impartición de acciones de formación para el empleo adaptadas a las necesidades de las personas, las empresas y los territorios ${ }^{3}$. Por ello, los CIFO centran su actividad formativa en aquellas especialidades que corresponden a ocupaciones altamente demandadas por los sectores económicos y que, sin embargo, cuentan con una escasa oferta formativa en el conjunto del territorio de

2 Creados a partir del Decreto 288/1995, de 11 de octubre, de creación de los centros de innovación y formación ocupacional del Departamento de Trabajo, ampliados por sucesivos decretos hasta el número de CIFO actuales.

3 Los CIFO se ubican en el ámbito de cualificación profesional dentro de los programas de formación del SOC con un presupuesto en 2010 de 9 millones de euros, lo que supone un 4,5\% del presupuesto destinado al ámbito de cualificación profesional del SOC (véanse cuadro «Programas de formación del Servei d'Ocupació de Cataluña. 2010» y el anexo III). 
Cataluña. Así, cada unos de los ocho CIFO existentes desarrolla su oferta formativa atendiendo a las demandas que empresas y organizaciones empresariales y sindicales territoriales realizan. Actualmente, las áreas de referencia de los CIFO son:

+ Área de diseño dentro artes gráficas (CIFO l'Hospitalet de Llobregat)

- Automoción (CIFO Sant Feliu de Llobregat)

+ Energías renovables (CIFO Santa Coloma de Gramenet y CIFO Lleida)

+ Fabricación y construcciones metálicas (CIFO Salt, CIFO Lleida y CIFO Sabadell)

+ Fabricación mecánica (CIFO Sant Feliu de Llobregat)

+ Frío industrial (CIFO Lleida)

- Imagen y sonido (CIFO l'Hospitalet de Llobregat)

+ Industria química (CIFO Tarragona)

+ Industrias alimentarias (CIFO Salt)

- Informática y comunicaciones (CIFO La Violeta, Barcelona)

- Jardinería urbana (CIFO Santa Coloma de Gramenet)

- Metodología docente (todos los CIFO)

- Montaje e instalación (CIFO Sabadell)

- Servicios integrales para la rehabilitación y el mantenimiento de viviendas (CIFO Santa Coloma de Gramenet)

Muchos de estos cursos incluyen la posibilidad de hacer prácticas en empresas del territorio. También cabe destacar que los contenidos de estos cursos están vinculados a los programas de certificados de profesionalidad.

Tabla 2.13, Cursos realizados y alumnos CIFO en Cataluña. 2010

\begin{tabular}{|l|c|c|}
\hline CIFO & Cursos & Alumnos \\
\hline L'Hospitalet de Llobregat & 63 & 945 \\
\hline La Violeta & 66 & 990 \\
\hline Lleida & 76 & 1.281 \\
\hline Salt & 47 & 593 \\
\hline Sant Feliu de Llobregat & 94 & 1.410 \\
\hline Santa Coloma de Gramenet & 67 & 920 \\
\hline Tarragona & 50 & 860 \\
\hline Vallès & 150 & 331 \\
\hline Total Cataluña & 613 & 9.330 \\
\hline
\end{tabular}

Fuente: SOC 
Actualmente, son ocho los CIFO repartidos por el territorio catalán:

+ Barcelona: La Violeta

+ L’Hospitalet de Llobregat

+ Sabadell: Vallès

- Sant Feliu de Llobregat de Llobregat

+ Santa Coloma de Gramenet

$+\quad$ Salt

+ Tarragona

$+\quad$ Lleida

Por otro lado, los CIFO se integran en dos redes de formación a nivel estatal: la Red de Centros de Excelencia FP.CAT y la Red de Centros de Referencia Nacional (CNR). El proyecto FP.CAT integra en un mismo plan de estudio el alumnado de formación profesional independientemente de si estudia FP inicial, FP ocupacional o FP continua, gracias a que las tres modalidades comparten materias y/o unidades formativas.

En la actualidad, ya son cinco los CIFO que forman parte de la red FP.CAT como centros de excelencia en la formación de trabajadores de diferentes áreas profesionales:

- CIFO Sant Feliu de Llobregat, centro de excelencia de la Red FP.CAT en la familia profesional de automoción.

- CIFO Santa Coloma de Gramenet, centro de excelencia de la Red FP.CAT en la familia profesional de sostenibilidad ambiental.

- CIFO Tarragona, centro de excelencia de la Red FP.CAT en la familia profesional de química industrial.

- CIFO l'Hospitalet de Llobregat, centro de excelencia de la Red FP.CAT en la familia profesional de artes gráficas.

- CIFO Lleida, centro de excelencia de la Red FP.CAT en la familia profesional de agroalimentario.

La Red de CNR, que tiene como objetivo detectar las necesidades de cualificación existentes en el actual sistema productivo para elaborar guías didácticas y los certificados de competencias y profesionalidad adecuados, está formada por centros que son referentes (a nivel estatal) en la formación de determinadas familias profesionales.

Actualmente, Cataluña cuenta con dos CNR:

- CIFO Sant Feliu de Llobregat, centro nacional de referencia en el área de operaciones mecánicas de la familia de fabricación mecánica. Este, además, actúa (hasta que finalice la construcción del nuevo Centro de Excelencia para la Formación de Profesionales de Automoción en Martorell) como CNR en el área de carrocería de la familia de transporte y mantenimiento de vehículos.

- CIFO l'Hospitalet de Llobregat, centro nacional de referencia en el área de artes gráficas. 


\subsection{Formación para el empleo: la formación de demanda}

En Cataluña, bajo la modalidad de formación de demanda y en 2010, se formaron un total de 515.171 trabajadores en las empresas catalanas, lo que supone un 18,6\% de las personas formadas bajo la modalidad de demanda en España (tabla 3.29). Una cifra que convierte a Cataluña en la segunda de las seis regiones estudiadas (por detrás de la Comunidad de Madrid) con mayor número de participantes bajo esta modalidad de formación. En cambio, solo el 18,1\% de las empresas de Cataluña han participado en dicha formación, una cifra significativamente inferior a la del resto de regiones estudiadas y a la media española (24,6\%) (tabla 3.28).

Entre estas, las pymes de 50 a 249 son las que dedican más esfuerzo a dicha formación: el 72,9\% de las empresas de este tamaño han efectuado formación de demanda, una cifra ligeramente inferior a la media española $(74,4 \%)$. El resto de pymes también han realizado un menor esfuerzo que el del conjunto de empresas del Estado.

De hecho, la tasa de cobertura en la industria manufacturera catalana es la menor de las seis regiones estudiadas $(25,4 \%)$ y está muy por debajo de la media del Estado $(32,8 \%)$ (tabla 3.28). En las empresas manufactureras, poco más de la mitad (50,8\%) de los participantes formados corresponden a empresas mayores de 249 trabajadores (tabla 3.29), 5 puntos porcentuales por encima de la media española $(45,7 \%)$. En este sentido, según la distribución por sectores empresariales (tabla 3.30), el porcentaje de participantes formados en el sector industrial $(21,8 \%)$ es el segundo más bajo de las seis regiones estudiadas (solo superado por la Comunidad de Madrid) y ligeramente superior a la media española $(18,7 \%)$.

Respecto a la modalidad de la formación de demanda, cabe apuntar que en Cataluña dicha formación es fundamentalmente presencial: el $67,9 \%$ de los participantes se han formado presencialmente, cifra que aumenta hasta el $78,1 \%$ en el caso de las empresas manufactureras. En ambos casos la formación presencial en Cataluña supera de forma significativa a la media española $(59,8 \%$ y $68,8 \%$, respectivamente).

Atendiendo al sexo y a la edad de los participantes (tabla 3.31), el 45,4\% de las personas formadas bajo la modalidad de formación de demanda han sido mujeres, una cifra superior a la media estatal $(42,4 \%)$. Por otro lado, el $67,4 \%$ tenían edades comprendidas entre los 26 y los 45 años y el $24,7 \%$ de las personas formadas tenían 46 años o más.

Respecto al nivel de cualificación de las personas formadas (tabla 3.32), y en comparación con el conjunto del Estado, se puede observar que la formación de demanda en la industria catalana está ligeramente desplazada hacia las personas con responsabilidades de gestión. Así, un $41,6 \%$ de las personas formadas pertenecen a las categorías de directivos, mandos intermedios o técnicos, 3,5 puntos porcentuales por encima de la media estatal, mientras que un $58,4 \%$ de las personas formadas en esta modalidad son trabajadores cualificados o sin cualificación, 3,5 puntos porcentuales por debajo de la media estatal.

En cuanto al nivel de estudios de las personas formadas dentro del sector industrial de Cataluña (tabla 3.33), cabe destacar que el $43,1 \%$ de los participantes cuentan con estudios secundarios postobligatorios, 3,3 puntos porcentuales por encima de la media estatal. Por el contrario, las personas con un perfil formativo bajo-medio en Cataluña reciben menos formación que en el conjunto del Estado. También cabe destacar que solo el 28,7\% de los participantes cuentan con estudios universitarios, lo que supone la segunda región con menor volumen de participantes universitarios (solo superada por Asturias) y sitúa Cataluña por debajo de la media estatal $(29,2 \%)$. 
Además, si observamos los permisos individuales para la formación en Cataluña (tabla 3.34), vemos que estos se han formalizado mayoritariamente en las grandes empresas $(73,6 \%)$. Si comparamos el nivel de concesión de permisos en Cataluña con el del conjunto del Estado, vemos que siguen prácticamente la misma distribución, con la diferencia de que es en las empresas medianas donde se da una mayor propensión (aunque mínima) a la concesión de este tipo de permisos con respecto al resto del Estado (24,9\% frente a 23,3\%).

\subsection{Política regional en relación con la FP}

En el caso catalán, y desde un punto de vista general, habría que apuntar los diferentes planes generales de empleo, los cuales recogen una cierta sinergia entre la formación profesional futura y las necesidades del mercado de trabajo. De hecho, la referencia actual más importante en formación para el empleo, el Pla de Desenvolupament de les Polítiques Actives d'Ocupació de Catalunya (2010-2011), se define a sí mismo como un plan abierto y flexible — a fin de atender a los posibles cambios futuros en el mercado de trabajo-, una de cuyas acciones consiste en avanzar en la integración de la formación profesional impulsando el modelo catalán de formación profesional.

En el caso de Cataluña, un elemento importante es la progresiva importancia de los niveles regional y local en las políticas activas de empleo y su relación con la formación profesional. Los niveles regional y local aparecen desde hace años como un factor importante dentro de estas políticas. En 1997 se traspasa la gestión de la formación ocupacional a la Generalitat de Catalunya, con lo que se inicia la gestión regional de dicha formación. Se crean, entre otros, los primeros CIFO (1995), el Consell Català de Formació Professional (1999), el Institut Català de les Qualificacions Professionals (2003) y el Servei d'Ocupació de Catalunya y sus respectivas ordenaciones posteriores (Ley 17/2002 y D69/2004, D160/2006, respectivamente).

Desde un punto de vista más estricto, en Cataluña existen dos tipos de acuerdos o planes generales vinculados al impulso de la formación profesional en el territorio: los dos planes generales de formación profesional (2004-2006 y 2007-2010) y el Acord Estratègic per a la Internacionalització, la Qualitat de l'Ocupació i la Competitivitat de l'Economia Catalana (2005-2008) (de ahora en adelante, Acuerdo estratégico).

El Acuerdo Estratégico supone una hoja de ruta entre las organizaciones empresariales, los sindicatos y el Gobierno de Cataluña. Incluye 86 medidas concretas, cuantificadas con indicadores y presupuesto (4.470,11 millones de euros) y estructuradas en 7 bloques temáticos: investigación, desarrollo e innovación; capital humano; infraestructuras; ámbito empresarial; internacionalización; calidad del empleo; y cohesión social.

El Acuerdo Estratégico (2008-2011) supone la revisión y el impulso de la mayoría de medidas incluidas en el primer acuerdo. El presupuesto aumenta hasta un total de 33.169,10 millones de euros, poniendo el acento en diez grandes ámbitos. Entre ellos destaca el ámbito número 1, «Pacto por la formación profesional», con el que se busca transformar el modelo de FP, reforzar la gobernanza, integrar los tres subsistemas y dotar de mayor flexibilidad los estudios de FP y acercarlos al mundo de la empresa. Este ámbito se materializa en la línea 4, «Formación profesional (impulso estratégico)».

El II Pla General de Formació Professional de Catalunya (2007-2010) establece las bases para crear un sistema integrado de formación profesional, incidiendo en dos elementos: la consolidación del sistema integrado de formación y la adaptación de esta a las necesidades 
de la economía catalana. Sus líneas prioritarias son: adaptación e innovación de los dispositivos y recursos de la formación profesional a las nuevas necesidades de la economía catalana; consolidación del sistema integrado de cualificación y formación profesional; y potenciación del reconocimiento y del valor social de la formación profesional.

Paralelamente al período de ejecución del II Pla General de Formació Professional se desarrollan una serie de acuerdos y programas con especial incidencia en el sistema catalán de formación profesional. En primer lugar, el inicio, el desarrollo y la finalización del Programa Interdepartamental de la Generalitat de Catalunya per a la Integració de la Formació Professional. En segundo lugar, la revisión y el impulso del Acuerdo Estratégico (2008-2011). Y en tercer lugar, la creación de la Comissió del Sistema de Formació i Qualificació Professional a partir de la sexta medida de los «30 compromisos per a l'ocupació, el teixit econòmic i el desenvolupament social a Catalunya» de 2009, acuerdo de amplio consenso cuya medida número 6 se refiere específicamente a la integración de la formación profesional.

Más allá de estos planes generales, a partir de las entrevistas y la documentación analizada destacan diferentes órganos institucionales con incidencia en la formación profesional de Cataluña. Algunos de estos órganos son el Consell Català de Formació Professional (CCFP), el Servei d'Ocupació de Catalunya (SOC) y, en menor medida, el Consell Superior d'Avaluació del Sistema Educatiu (CSASE).

El CCFP, creado en 1999, es el órgano de consulta y asesoramiento en materia de formación profesional del Gobierno de Cataluña, con carácter no vinculante. La Comisión Permanente está compuesta por miembros de la Administración regional (Departamento de Enseñanza y Departamento de Empresa y Empleo), organizaciones empresariales (FTN y PIMEC), organizaciones sindicales (CC. OO. y UGT) y diversas entidades públicas (Federació de Municipis de Catalunya y Associació Catalana de Municipis i Comarques). Este órgano se complementa con el Consell de Treball, Econòmic i Social de Catalunya (CTESC) y el Consell Escolar de Catalunya. Sus funciones son, entre otras, la elaboración, el seguimiento y la evaluación del Pla General de la Formació Professional de Catalunya; el fomento de la integración de los tres subsistemas de formación profesional (inicial/reglada, ocupacional y continua); la detección de necesidades de formación profesional en el territorio; y el fomento de la formación en centros de trabajo y la colaboración de los diferentes agentes implicados (empresas, escuelas $y$ agentes sociales).

El SOC se crea en 2002 y es un organismo autónomo de carácter administrativo adscrito al Departamento de Trabajo (hoy Departamento de Empresa y Empleo). Las funciones principales del SOC son las de ofrecer y prestar servicios a todas las personas que busquen empleo, independientemente de que su situación laboral sea en activo o en paro, y a las empresas. El SOC, junto con el Consorci per a la Formació Contínua de Catalunya (CFCC), es el responsable de la formación para el empleo en el territorio catalán. El SOC tiene diferentes niveles de actuación. Además de estar distribuido en el territorio a partir de los Servicios Territoriales, también actúa a partir de las oficinas de trabajo de la Generalitat (OTG) y de los centros de innovación y formación ocupacional (CIFO), que son centros de referencia de formación profesional.

El CSASE es un órgano consultivo del Departamento de Enseñanza, creado en 1993, que está compuesto por personal de la Administración y representantes del profesorado universitario, de secundaria y de primaria. Su función es analizar y evaluar el sistema educativo no universitario de Cataluña, elaborando y difundiendo estudios sobre dicho sistema. 
En cuanto a los programas o iniciativas vinculados a la formación profesional, destacan por encima del resto el plan FP.CAT y el Institut Obert de Catalunya.

El plan FP.CAT es un programa impulsado por el Gobierno de Cataluña con la participación de los departamentos de Educación y Empleo (actualmente, Departamento de Enseñanza y Departamento de Empresa y Empleo) y que surge de dos planes políticos: el Acuerdo Estratégico y el Programa Interdepartamental de la Generalitat de Catalunya per a la Integració de la Formació Professional.

El objetivo de este programa es crear una red de centros de formación que ofrezcan formación profesional de los diferentes tipos de subsistemas de formación (inicial/reglada, dirigida a estudiantes de ciclos formativos; y formación para el empleo, dirigida a trabajadores en activo o en situación de desempleo).

También se pretende incorporar la posible formación solicitada desde las empresas ofreciendo un sistema funcional de evaluación y acreditación de competencias profesionales. Ello comportará que los conocimientos profesionales que las personas adquieran a través de cualquiera de estas vías, así como de la experiencia laboral o de sistemas de formación no formal, sean reconocidos por todo el sistema, con la consiguiente posibilidad de pasar de un sistema de formación a otro.

Según algunos entrevistados, este programa es la base de la integración de la formación profesional y la coordinación de las áreas de Educación y Empleo, tradicionalmente alejadas. La demanda de los agentes sociales de la integración de la formación profesional - a partir de los sucesivos planes de formación profesional y formalizada en el Acuerdo Estratégico- inicia este programa que permite poner las bases de una red de centros formativos para su posterior integración, aportando, entre otras cuestiones, presupuestos propios para la puesta en marcha del programa ${ }^{4}$. De las entrevistas se desprende que las relaciones entre las áreas de educación y empleo no son excesivamente fluidas. Programas como el plan FP.CAT o los recientes planes, acuerdos y compromisos adquiridos inciden en una apuesta por la integración de los tres subsistemas de formación profesional (muchas veces desde los propios agentes sociales, más que desde la propia Administración regional) que «obliga» de alguna forma a que ambas áreas intenten converger en intereses y esfuerzos. De hecho, una de las debilidades de la formación profesional en Cataluña que se desprenden del informe «Avaluació de la formació professional reglada a Catalunya 2001-2008», de septiembre de 2010, elaborado por el CSASE, es la existencia de obstáculos para la integración de los subsistemas de FP y el desarrollo de los centros integrados. Entre estos obstáculos destaca el bajo nivel de relación entre las administraciones educativa y laboral. Una de las propuestas para superar esta limitación es la creación de un organismo que integre la gestión de los subsistemas de FP (y, por lo tanto, supere las barreras de ambas administraciones).

[Educación y Empleo] S'han posat d'acord forçats. Forçats pels agents socials. Així de clar. Jo crec que els agents socials vam fer una declaració de principis en què exigíem una coordinació dels dos. Inclús exigíem una governança única. Com a conseqüència d’això es va fer un pla d'integració $i$ en l'Acord Estratègic això es va insistir molt. I va aparèixer aquest model amb centres que teníem consell social, en què eren participats per tots nosaltres, $i$ un consell rector que, d'alguna manera, organitzava o anava facilitant, autoritzant, recomanant, marcant directrius i condicionants per poder pertànyer a la xarxa o no. L'interès d'aquest model està i estava, i jo crec que a la llarga serà així, és que preveu que hi hagi una xarxa de centres integrats entre

4 La revisión del Acuerdo Estratégico (2008-2011) contiene, dentro de la línea 4, «Formación profesional (impulso estratégico)», la medida de «Impulsar el plan FP.cat». 
si, però que aquesta xarxa estigui vinculada no solament entre els centres integrats, sinó que també hi hagi una xarxa amb tots els altres operadors del sistema. A tots els altres centres que són operadors del sistema, siguin només de contínua o ocupacional, siguin només de formació reglada o siguin del que siguin; que puguin estar dins d'aquesta estratègia, que puguin recollir les directrius i l'experiència i que puguin aportar l'especialització en alguns casos; o, de vegades, la generalització; o, de vegades, loferta territorial més àmplia. (AS1)

Jo et diria que aquesta fricció [entre Educación y Empleo] és una fricció universal. (FP1)

Que les necessitats de la formació professional són unes i les del sistema educatiu són unes altres. Clar, això és un procés i s'ha de modular. Nosaltres el que demanem és sectorialització dels centres de formació. Clar, si en un centre et conviu el batxillerat i la FP, «bueno», hi ha molts temes aquí al darrere. (AS2)

En este sentido, los objetivos de la red de centros FP.CAT van dirigidos a esta idea de integración, coordinación y cooperación entre subsistemas, instituciones y agentes involucrados. Estos objetivos son:

- Impartir una oferta formativa integrada.

- Vincularse al entorno sectorial y territorial.

+ Implementar un sistema de información-orientación y asesoramiento tanto a trabajadores como a empresas.

+ Impulsar proyectos de innovación (por ejemplo, formación detectada desde el territorio, etc.).

- Incorporar a las empresas al sistema integrado.

Actualmente, la red de centros FP.CAT la integran los centros de innovación y formación ocupacional (CIFO) del SOC y algunos IES, teniendo en cuenta su experiencia en oferta integral de formación profesional. Los centros FP.CAT se distinguen entre centros de ámbito sectorial y centros de ámbito territorial. Según algunos entrevistados, la experiencia de los centros sectoriales ha sido exitosa, yendo en la línea de la integración de la formación, mientras que el éxito de los centros territoriales, desde el punto de vista de la integración, ha sido menor. Este último tipo de CIFO territoriales no parecen haber respondido a las demandas de formación por parte de sus ámbitos territoriales correspondientes. El hecho de no configurarse de forma sectorial ( $y$, por lo tanto, funcionar de forma más integrada y conectada con el tejido empresarial) ha generado un tipo de centros que, según algunos entrevistados, programaban una formación no excesivamente vinculada a las necesidades formativas del entorno.

Lexperiència dels centres FP.CAT que van vinculats a sectors ha sigut un centre integrat. $\mathrm{Ha}$ sigut el que en un futur hauria de ser un centre integrat. La resta ha sigut una cosa com, «bueno», per donar sortida i per donar programació bàsicament a determinats centres, i, per mi, no respon al que hauria de ser. Per exemple, tenim l'experiència de tot el que era l'atenció a persones, que era amb l'Institut Bonanova, que era la part nostra més els IES que estaven vinculats a aquest sector, que ha sigut molt enriquidor. La part de química també molt enriquidora. Però, per exemple, hi ha hagut centres de FP.CAT, de Lleida i així, que era una mica, «bueno», ha sigut un mica, per mi, no l'experiència que responia als centres integrats. (AR2) 
Tabla 2.14. Red de centros FP.CAT en Cataluña. 2010

\begin{tabular}{|l|}
\hline Centros de ámbito sectorial \\
\hline FP.CAT Atención sanitaria y sociosanitaria \\
\hline FP.CAT Automoción \\
\hline FP.CAT Industrias gráficas \\
\hline FP.CAT Logística \\
\hline FP.CAT Mecatrónica \\
\hline FP.CAT Multimedia y comunicación \\
\hline FP.CAT Química farmacéutica \\
\hline FP.CAT Química industrial \\
\hline FP.CAT Sostenibilidad ambiental \\
\hline Centros de ámbito territorial \\
\hline FP.CAT Bages \\
\hline FP.CAT Garrotxa \\
\hline FP.CAT Girona \\
\hline FP.CAT Granollers \\
\hline FP.CAT Lleida \\
\hline FP.CAT Tarragona \\
\hline FP.CAT Terres de l'Ebre \\
\hline
\end{tabular}

Fuente: SOC

Por otro lado, un órgano importante en el desarrollo de la formación profesional en Cataluña es la creación y consolidación de la formación a distancia (o teleformación) a través de la creación del Institut Obert de Catalunya (IOC). El IOC se creó en el curso 2007-2008 a partir de la integración en un único centro de tres iniciativas ya existentes en materia de formación no presencial gestionadas desde el Departamento de Enseñanza: el Institut Català d'Ensenyament Secundari a Distància (ICESD), creado en el curso 1990-1991 a partir de la transferencia a la Generalitat de Catalunya del Instituto Nacional de Bachillerato a Distancia (INBAD); el Graduado en Educación Secundaria para personas adultas (GES), creado en 2003 y con un recorrido previo iniciado en 1989; y el instituto virtual de formación profesional FPOberta (creado en 2004 por la Dirección General de FP para impulsar la formación profesional no presencial). Todos ellos desembocan, después de una prueba piloto en 2006, en la creación del IOC en el curso 2007-2008, que integra los tres sistemas no presenciales de formación profesional.

El ámbito fundamental del IOC es el de la formación reglada a través del desarrollo de los ciclos formativos de grado medio y superior, aunque se están incorporando cursos de formación no reglada. De hecho, este es uno de los objetivos del IOC en los próximos años.

Algunos entrevistados apuntan la importancia del IOC como pieza fundamental de la estrategia catalana de integración de la formación profesional. En este sentido, la formación a distancia ha tenido un impulso muy significativo en los últimos años. De los 5.864 alumnos del primer curso, durante el curso 2009-2010 se ha pasado a atender a 23.925 alumnos. La creación del IOC, en cuanto centro de formación a distancia de ciclos formativos, ha supuesto 
un revulsivo para este tipo de formación dentro del territorio catalán, de la misma manera que la UOC (Universitat Oberta de Catalunya) lo supuso en su momento para la formación universitaria.

L’altre, evidentment, és la creació de l'IOC. La creació d'un institut obert i, per tant, posar la formació a distància. Igual que la UOC va suposar un revulsiu per tota la formació universitària, perquè les persones que no podien fer una formació presencial també podien fer estudis universitaris. (AR1)

Otras experiencias interesantes en el caso catalán son los diferentes programas experimentales que han aparecido en los últimos años, vinculados a la certificación y homologación de las competencias profesionales (Qualifica't, Acredita't), los programas de formación vinculados al territorio (Treball als Barris, Treball a les 7 Comarques), los programas que relacionan formación y contratación laboral (Forma i Contracta, Suma't) y los programas que fomentan la teleformación y/o el uso de nuevas tecnologías de la información (e-formació, Connecta't).

\subsection{Prácticas de formación en centros de trabajo (FCT)}

El Departamento de Enseñanza inició en 1984 el Plan de Formación en Centros de Trabajo. Actualmente esta formación está integrada dentro de los ciclos formativos, tal y como establece la normativa.

Para formalizar un convenio individual entre el centro formativo y la empresa, esta ha de estar afiliada a alguna cámara de comercio o colectivo empresarial que haya firmado con el Departamento de Enseñanza un convenio-marco de colaboración para la realización de prácticas. El volumen de convenios, tal y como se observa en la tabla, ha sido muy significativo en los últimos diez años.

Tabla 2.15. Convenios en alternancia hechos entre escuela y empresa. Cataluña

\begin{tabular}{|c|c|c|}
\hline Año & Alumnado en prácticas & Empresas con convenios \\
\hline $\mathbf{2 0 0 1}$ & 36.252 & 18.246 \\
\hline $\mathbf{2 0 0 2}$ & 37.739 & 18.737 \\
\hline $\mathbf{2 0 0 3}$ & 38.786 & 19.729 \\
\hline $\mathbf{2 0 0 4}$ & 38.677 & 19.595 \\
\hline $\mathbf{2 0 0 5}$ & 38.438 & 19.857 \\
\hline $\mathbf{2 0 0 6}$ & 38.725 & 20.211 \\
\hline $\mathbf{2 0 0 7}$ & 37.003 & 19.424 \\
\hline $\mathbf{2 0 0 8}$ & 41.293 & 20.405 \\
\hline $\mathbf{2 0 0 9}$ & 48.647 & 23.819 \\
\hline $\mathbf{2 0 1 0}$ & 52.400 & 22.184 \\
\hline $\mathbf{2 0 1 1}$ & 56.865 & 21.554 \\
\hline
\end{tabular}

Fuente: Departamento de Enseñanza 
Según las entrevistas realizadas, aunque los últimos cambios normativos son muy recientes, las FCT tienen una consolidada tradición en el territorio catalán, sea por su duración continuada en el tiempo, sea por el volumen de convenios realizados. La intensidad de las FCT, tal y como apuntan algunos entrevistados, depende del nivel de desarrollo y organización del tejido empresarial en el territorio catalán y de los contactos con las empresas del entorno. Así, las FCT en el territorio catalán tienen su versión anterior en las prácticas en empresas, consolidadas desde hace más de dos décadas y creadas de forma experimental antes de su normalización por la legislación educativa. En otras palabras, en Cataluña se han dado procesos de relación entre centros formativos y empresas antes de que la legislación educativa estatal los institucionalizara. Estos acuerdos consolidados en el tiempo han permitido crear y asentar relaciones entre centros de FP y empresas y/o organizaciones empresariales (sean estas sectoriales o generalistas). Este nivel de relación se ha plasmado, en algunos casos (donde, además, existía un cierto nivel de cohesión territorial), en fundaciones donde tienen cabida organizaciones empresariales y sindicales, Administración local y centros formativos. Algunas de estas fundaciones hoy forman parte del sistema integrado de formación profesional de Cataluña.

A Catalunya estan més organitzades. Hi ha una relació més estreta amb el món empresarial que en altres llocs. Et posaré un exemple. Fa 25 anys van començar les pràctiques en empreses, el que ara és la formació en centres de treball. Doncs a Catalunya es van fer primer experimentalment. Abans que la LOGSE les instituís com a matèria curricular, doncs es van fer experimentalment. I llavors el Govern, la Generalitat, va signar uns acords. Es van mobilitzar per signar uns acords amb els gremis. Però a la vegada es va proveir que a cada institut hi hagués un tutor, que era el que, en aquells acords, se n'anava a visitar les empreses del voltant, del seu municipi, de la seva comarca, del sector en què treballava. I era el que concretava els acords, els contractes per fer les pràctiques. Contractes formatius per fer les pràctiques. (AR1)

El gran avantatge també del tema de les pràctiques, i per molts altres aspectes, és que al llarg d'aquests 20 anys la relació de l'Institut amb el sector empresarial del Bages, que no deixa de ser una comarca, entre cometes, petita, és molt forta. I, per tant, el fet de comptar en el patronat de la fundació que et presideixi la Cambra, que hi hagi PIMEC, que hi hagi la Patronal Metal.lúrgica, que hi hagi els sindicats, etc., això, vulguis o no, és un valor que aporta molt a l'Institut. Per què? Ens vénen alumnes estrangers a fer pràctiques al Bages. Què ens costa trobar empreses? Doncs, quatre trucades, per dir-ho d'alguna manera. Per què? Perquè parles amb la Cambra i li dius: «Escolta». Ara, si el president de la Cambra presideix la Fundació i et diu: «Què necessiteu?». «Doncs, mira, que ens donis un cop de mà, que ens facis tres gestions per no sé què». Doncs ja hi pots comptar. Clar, això al llarg de 20 anys, amb centenars de convenis cada any, amb 40 o 50 empreses que han posat uns recursos aquí, que són les més importants del Bages, que hi ha una relació no només podríem dir comercial, sinó que formen part del Patronat, que formen part de la Comissió Executiva d'allà, que pots parlar de tu a tu; doncs això facilita molt. (FP1)

Per ells és una assignatura més a superar per l'obtenció de la titulació i que, per una altra banda, els hi obre la porta al que és el món laboral real. Dins de l'FCT movem molts alumnes. Tenim una gran quantitat d'empreses colllaboradores. Podem estar parlant de l'entorn de 80100 empreses. Dins d'aquest entorn podem estar parlant d'empreses que ja estan fidelitzades de fa molts anys, amb les quals hi ha una estreta col-laboració. Empreses amb les quals, a més, fruit d'aquesta colllaboració, ja hi ha molts exalumnes que són treballadors, alguns dels quals també tenen càrrecs. I això fa un cercle que s'autoalimenta. (FP2)

Les fundacions aquestes tenen el seu origen en l'organització de l'FCT, que van començar a Catalunya abans de la LOGSE. O sigui, l'FCT s'estableix per la LOGSE el 1990, però les experiències comencen abans, a la primera meitat dels vuitanta a Catalunya... I què és això? És posar en contacte, perquè per anar a buscar les pràctiques has d'anar a veure les empreses. Per 
tant, treball per dalt està bé, però després treball per baix. Centre per centre, institut per institut, empresa per empresa, municipi per municipi. (AR1)

Para el sector industrial y para los centros formativos, las FCT son fundamentales para una mayor inserción laboral de los egresados debido al nivel de exigencia formativa de las empresas industriales. En comparación con determinadas familias profesionales del sector servicios, la mayor especialización que requieren las empresas industriales hace más necesaria la puesta en práctica de estas FCT para facilitar una mayor probabilidad de inserción futura del alumno. Además, de alguna manera, los centros de FP, a través de las FCT, se configuran como una especie de intermediadores laborales, en el sentido de que consiguen que las empresas conozcan a sus alumnos, con lo que facilitan unos primeros contactos que, en caso de no existir tales prácticas, los egresados deberían hacer una vez finalizados sus estudios. Así pues, los centros formativos permiten acercar a sus alumnos al «mundo real» de las empresas, pero también permiten un mayor contacto entre ellos, facilitando el contacto y dirigiendo a su alumnado a las empresas del entorno en función de las características formativas y las expectativas laborales de los estudiantes y en función de las demandas y exigencias de las empresas.

Potser per la pròpia tradició que té l'institut i després també pels sectors econòmics on nosaltres treballàvem. Nosaltres, tots els sectors econòmics són industrials. I als sectors econòmics industrials la seva mà d’obra ha de ser qualificada per força i amb un mínim de qualificació. I la manera que té l’empresari de tenir la mínima garantia o la garantia inicial és que aquesta sigui acreditada. O sigui, que tingui la titulació, que estigui en un centre. Per tant, vindran a buscar-te el treballador aquí. Què passa? Nosaltres teníem Administració. Gestió Administrativa. I teníem Administració i Finances. Teníem la branca aquesta. Això és més versàtil. I llavors aquí podem tenir competència, perquè no és una qualificació tan específica com seria quan et demanen un «tio» de manteniment industrial que sàpiga automatismes. Clar, això no śaprèn d'un dia per l'altre. En canvi, si és per cobrir una plaça d’auxiliar d'oficina en no sé quines hores amb no sé quines tasques. Clar, potser la formació i el període d’adaptació és molt més curt. Per això jo penso que les nostres pràctiques sempre han tingut èxit. I, per una altra banda, una de les coses que sempre s'ha vigilat molt és també com es fa l'FCT, el seguiment i, sobretot, el pla d'activitats, que és una qüestió també important. El pla d'activitats, que és la manera com es desenvolupen les pràctiques, sobretot des de les especialitats, sempre que s'intenti complir, que serveixin de formació. La qual cosa significa que si una empresa ja fa l'esforç de formar aquell alumne, si posa per la seva part un mínim per intentar formar-lo, doncs potser un cop el té format, se'l queda. (FP1)

Però, realment, l'FCT, a part de per a l'alumne és obrir-li una porta a conèixer què és el món real del treball, també és una molt bona eina de l'empresa per conèixer aquests alumnes de cara a futures incorporacions. (FP2)

\subsection{Otros tipos de relaciones entre los centros de FP y las empresas. Papel de los centros de FP en la formación para el empleo}

\section{Relación entre centros formativos y empresas}

El Departamento de Educación reguló en 2005 (Orden EDC/458/2005, de 30 de noviembre) las estancias de formación en empresas de Cataluña del profesorado de formación profesional. Las estancias de formación del profesorado de formación profesional son una de las actividades del plan de formación permanente. Las estancias pueden ser de tipo A o de tipo B. Las primeras se llevan a cabo en períodos y horarios no lectivos y las segundas se realizan en períodos y 
horarios total o parcialmente coincidentes con el horario lectivo del profesorado. El Departamento de Enseñanza convoca cada año un concurso público para la concesión de 80 estancias de formación de tipo B. No existe información disponible sobre el balance de estas estancias. El I PAFP también recogía el impulso de esta iniciativa. Las estancias de profesorado en el período comprendido dentro del I PAFP han sido 180.

Como ya se ha apuntado, las FCT, al igual que las estancias de profesorado, permiten acercar las empresas a los centros formativos, y viceversa. La cesión de espacios y materiales (aulas, maquinarias, programas de software...) también es una forma de acercar ambos ámbitos. Este acercamiento, más allá de la posible oferta de formación para el empleo (de la que hablaremos en el siguiente punto), se ha plasmado en colaboraciones que inciden en la mejora de productos y procesos de producción. Esta colaboración necesita una constante interacción entre los centros formativos y las empresas. Las necesidades de las empresas, especialmente de las pymes, convergen con las necesidades de los centros formativos a la hora de compartir recursos (espacios, maquinarias, etc.). Esta convergencia en el caso de las pymes permite un acercamiento entre unos y otros que facilita los contactos y la emergencia de manera informal de estrategias que facilitan la innovación.

Jo crec que el model d'innovació tecnològica, a nivell estatal, es vol centrar en els centres de referència nacional. [...] No necessàriament això promourà la innovació, sinó que segurament la innovació, el que cal, és promoure-la des de la base. És a dir, fer aliances que permetin que els centres de formació facilitin a les empreses innovació i formació, i a la inversa. (AS1)

Hem tingut colllaboracions amb empreses. Per exemple, una de les més recents per a una empresa, X. Hem estat colllaborant alguns anys en el cicle de desenvolupament de productes electrònics. Organitzem un concurs anomenat «Electrònica sobre rodes», pel qual els alumnes proposen innovacions que després aquesta empresa aplica als nous productes que treu al mercat. I nosaltres, una manera de motivar-los és fer-ho en forma de concurs, però realment ens hem sorprès de les solucions imaginatives que han aportat els alumnes i que després l'empresa aplica a la producció. (FP2)

O tu tofereixes com a espai per fer innovació a les empreses i les empreses vénen a fer innovació al teu espai, les petites (això ho fan a Lacetània), i paral-lelament les empreses taporten valor afegit en el centre, o fas un model d'innovació modèlic i l'intentes traslladar a les empreses. Això és més complicat. (AS1)

De las entrevistas realizadas se deriva una relación entre centros formativos y tejido empresarial continuada en el tiempo. Esta relación depende de muchos factores, entre ellos: el nivel de desarrollo productivo en el territorio, el nivel de organización del sector o gremio y el nivel de fragmentación (o, al contrario, de cohesión) del territorio. Estos factores hacen referencia al nivel de organización de las empresas de un determinado territorio o sector y a su relación con los diferentes agentes del territorio (Administración local, organizaciones sindicales y patronales territoriales, centros formativos, cámaras de comercio....). Los casos más significativos en Cataluña se caracterizan por poseer unos niveles elevados de estos tres factores. Estos casos también tienen una característica común: en la mayoría de casos estas experiencias escapan al área de influencia de la conurbación urbana de Barcelona (por ejemplo, el Centre Integral de Formació Professional de la Garrotxa junto al IES Garrotxa de Olot, o el complejo definido por la Fundació Lacetània, el IES Lacetània y el Centre de Formació Pràctica de Manresa), presentándonos unos territorios relativamente cohesionados y alejados de la dinámica del área metropolitana de Barcelona. En estos territorios, tal y como se ha apuntado anteriormente, el 
elevado nivel de cohesión y relación entre sus agentes ha permitido converger intereses en la creación y consolidación de este tipo de casos.

La formació professional no es pot entendre, no es pot dir que és que està poc lligada a l'empresa. A veure, com és l'empresa d'un país? Estan organitzats els sectors? El sector hostaleria està organitzat? El sector turístic està organitzat? Si no tenim organitzats els sectors econòmics, com anem a organitzar la relació amb els centres. És el primer. (AR1)

En la Fundació qui estava des de bon començament eren els patrons fundadors, que van ser la Cambra de Comerç, la Patronal Metal-lúrgica del Bages i l'Institut. A partir que es constituís la Fundació, això sámplia i entren no després de molt temps els sindicats. I, llavors, els que aposten són tots. Aposta fonamentalment la Patronal, que és la que no vol perdre l'oportunitat de fer formació. Segurament que això és perquè coincideix que qui està davant d'aquestes patronals i tal és gent o empreses que tenen molt clar la importància de la formació contínua per als seus treballadors i busquen els recursos. I això s' ha mantingut. Perquè una experiència d'aquest tipus durant 20 anys en què ha anat sempre funcionant bé $\mathrm{i}$ ha anat a més. «Bueno», ara tenim un període de crisi com tothom. Doncs, i que s'ha mantingut, només és per això, perquè tothom que hi és no hi és formalment únicament, sinó que en determinats moment, que vols que et digui, «arriman el hombro». I tenen una participació activa. Perquè si no, durant 20 anys, una cosa com aquesta no es manté. (FP1)

El fet de conèixer-nos també pot servir per dir, mira, doncs a nosaltres potser ens interessaria un curset, o veiem que els nostres treballadors els hi estaria bé tal tipus de formació, o hi ha un dia que potser necessiten incorporar un treballador nou a l'empresa $i$, com que coneix el tutor, diu: «Escoltám, teniu algun exalumne a la borsa de treball que pugui encaixar amb el perfil que nosaltres necessitaríem?». I dóna peu a una colllaboració mútua entre l'escola i l'empresa. (FP2)

Per què la formació professional catalana ha tingut menys connexió que altres europees $\mathrm{i}$ més dintre del context ibèric? Perquè si anem al context ibèric, és molt més gran la relació que hi ha amb l'empresa de la formació professional a Catalunya, a excepció del País Basc, on encara és superior a la catalana, però a la resta per descomptat és menor. Per un motiu elemental, és un tema que la formació professional va totalment lligada al sistema productiu d'un país. En un país com l'espanyol, que s'ha caracteritzat per la seva feble tradició industrial, és normal que la formació professional hagi sigut raquítica. (AR1)

Las experiencias recogidas en las diferentes entrevistas apuntan a la importancia de determinados sectores (como el sector industrial y, dentro de él, el sector mecánico o electromecánico, el sector químico, etc.). Estos sectores necesitan de recursos importantes (instalaciones, maquinaria) que obligan al acercamiento ente centros de formación profesional especializados en estas familias y empresas o universidades y/o centros tecnológicos. Las razones son varias. La primera es el elevado coste de este tipo de espacios e instrumentos. La segunda razón es la continua necesidad de actualización tecnológica tanto de empresas como de centros formativos (estos en cuanto a los contenidos a trasmitir a sus estudiantes). Cuando existen estas necesidades, el intercambio de profesores y alumnos resulta más fluido. Los primeros a partir de las estancias de profesorado y la realización puntual de formación de demanda para empresas como prestación de servicios a empresas. Los segundos aprovechan las instalaciones de empresas o fundaciones para realizar módulos específicos de los ciclos formativos. Los centros formativos aprovechan las instalaciones y la maquinaria más actualizadas de las empresas para realizar determinados módulos. Las empresas, por su parte, aprovechan este trasvase de estudiantes para captar futuros estudiantes en prácticas (FCT), además de futuros trabajadores. Por otro lado, esta relación continuada en el tiempo entre empresas y centros formativos ha permitido, 
en algunos casos, donaciones de maquinaria por parte de empresas con vistas a promover la formación de los estudiantes de FP en ese tipo de maquinaria.

Considero que és un factor molt interessant. Molt del professorat que sol.licita ha pogut fer. I ara, actualment, encara hi ha professors que estan fent estades a l'empresa. Són estades entre $2 \mathrm{i}$ 3 setmanes i el professor està a dedicació completa a l'empresa, formant-se, reciclant-se i, a més, en principi va a l'empresa que el professor demana. Crec que és una eina molt interessant per posar-se al dia i adaptar-nos al que seria la realitat. (FP2)

Aquí fem dos cicles superiors i cada vegada el nivell tecnològic de la maquinària que tenim a l'institut no està a l'altura del que tenim allà dalt, que l'han comprat les empreses. Per tant, com suplim això? Doncs a través de la col-laboració; els nostres alumnes van allà dalt i fan les classes allà dalt. (FP1)

Per exemple, el curs que fem amb $\mathrm{X}$, algunes de les classes s'imparteixen a les seves installlacions. Per posar un exemple d'utilització de recursos externs a nosaltres. (FP2)

Una de les maneres de colllaborar és fer pràctiques i una altra manera..., per exemple, no fa molt el Centre de Tecnologia necessita incorporar tècnics per a alguns dels seus projectes. Doncs molts cops acudeix a nosaltres i facilitem en borsa de treball alumnes amb perfils adequats per participar en aquests projectes. Altres coses que fem? Per exemple, anem al servei de microscòpia electrònica de la URV perquè nosaltres no tenim això. Nosaltres anem a formar els alumnes en aquest servei. (FP2)

\section{Formación para el empleo y centros de formación profesional}

En cuanto a la relación entre los centros de formación profesional y la formación para el empleo, los primeros cada vez más realizan cursos de formación para el empleo, sea esta de oferta o de demanda. Sin embargo, la peculiaridad del caso catalán reside en dos cuestiones. La primera es la concepción amplia de la idea de integración de la formación profesional, entendida esta como una formación que puede ser ofertada por una multiplicidad de agentes: IES, CIFO, centros homologados (ayuntamientos, agentes sociales, centros privados...), entre otros; pero sobre todo porque la integración parece entenderse como la complementariedad entre centros formativos, de tal manera que la integración de la formación no pasa necesariamente por un solo centro formativo ${ }^{5}$. La segunda cuestión es la existencia anterior en el tiempo de los centros de innovación y formación ocupacional (CIFO), que aglutinan parte de la formación para el empleo actual, sea esta de oferta o de demanda.

Sí que es fan bastants cursos per l'ocupació. S'han fet cursos d'automatismes, cursos de disseny en Autocad. Han tingut força èxit. Alguns es fan entre setmana i altres es fan el dissabte. I els dissabtes hi ha una quantitat important de persones de l'empresa que vénen a formar-se. (FP2)

La nostra prioritat sempre són els CIFO. De fet, és l’oferta que sempre surt primer. És la que ja està aprovada i funcionant, la dels nostres centres propis. Després és colllateral, per dir-ho d'alguna manera. No donem preferència als centres de formació. Però, bàsicament, perquè també la nostra població no sempre és carn d'instituts. Nosaltres ara tenim un volum de joves molt important demandants de la nostra formació. Però això és una mica a remolc del fracàs escolar que arrossega Ensenyament. (AR2)

Un CIFO pot ser un centre integrat. En un futur podrà ser un centre integrat, si cal. Aquesta, la idea. Ara hem de definir què serà un centre integrat, però no té per què ser només un IES.

5 Esta concepción no está a día de hoy completamente definida. De hecho, uno de los puntos del III Pla General de Formació Professional, actualmente en fase de elaboración, consiste en la definición de la posición de los IES dentro del sistema de integración de la formación profesional. 
$\mathrm{O}$ tots els IES no seran centres integrats. Aquí és on hem de trobar qui serà què i què serà un centre integrat. Tampoc té sentit que tots els IES siguin centres integrats i que tots el CIFO ho siguin. (AR2)

De hecho, según algunos entrevistados, los centros de formación profesional resultan más rígidos y menos atractivos (para los jóvenes que realizan formación para el empleo) que los CIFO, los cuales poseen una estructura más flexible y una formación más práctica y cercana al mundo de la empresa, sobre todo cuando la formación aparece vinculada al ámbito de los certificados de profesionalidad. La estructura más rígida y más académica de los centros de FP puede resultar un obstáculo para la demanda de determinados tipos de formación muy específicos (desde el punto de vista del contenido y del tiempo de formación). De hecho, actualmente los CIFO han notado un considerable aumento de jóvenes dentro del perfil de su alumnado. Un perfil que anteriormente era, en su gran mayoría, adultos de entre 35 y 45 años. Hoy el porcentaje de jóvenes alcanza el $25 \%$ del alumnado de este tipo de centros.

Flexibilitat, flexibilitat. Pensa que els centres educatius, que els instituts que fan formació professional estan molt limitats per l'organització del sistema educatiu. És més permeable, però és molt poc més permeable. Clar, des del sistema educatiu es veu que és molt permeable, per al que és el sistema educatiu. Però continua sent poc permeable. I et poso un exemple en la contractació d'experts. A formació professional ja es pot contractar experts que no siguin funcionaris, professors per impartir, però és com la cosa rara. M'entens. Llavors, des del sistema educatiu ja es veu que això és un avenç, però faria falta molt més, molt més. (AS2)

Linterès d'aquest model està i estava, i jo crec que a la llarga serà així, és que preveu que hi hagi una xarxa de centres integrats entre si, però que aquesta xarxa estigui vinculada no solament entre els centres integrats, sinó que també hi hagi una xarxa amb tots els altres operadors del sistema. A tots els altres centres que són operadors del sistema, siguin només de contínua o ocupacional, siguin només de formació reglada o siguin del que siguin; que puguin estar dins d'aquesta estratègia, que puguin recollir les directrius i l'experiència i que puguin aportar l'especialització en alguns casos; o, de vegades, la generalització; o, de vegades, l’oferta territorial més àmplia. (AS1)

Nosaltres sempre hem tingut una franja d'edat molt entre els 35 i els 45 anys, que era el nostre gruix. De fet, era més del $70 \%$ del nostre públic. I actualment estem en un $25 \%$ en joves, però que no l'havíem tingut mai. Perquè nosaltres érem de $35 \mathrm{a} 45 \mathrm{i}$ després pràcticament de 45 a 55. Actualment estem absorbint aquests joves. Però, fins i tot es detecta en programes com els PQPI. Tu saps que nosaltres financem PQPI a Ensenyament i PQPI en els nostres. L'abandonament a Ensenyament era superior al 25\%. En els nostres no superava el $5 \%$. Per tant, l'entorn en què es fa és important. Jo crec que, en paral.lel amb tot el tema de la integració, ha d'haver-hi una adaptació. Si han de colllaborar els instituts en formació per l'ocupació, han de fer un canvi de xip del model. Del model, del formador i de tot plegat. (AR2)

También hay que tener en cuenta que experiencias como el programa FP.CAT han hecho aumentar exponencialmente la oferta de formación en aquellos centros que ya tenían cierta tradición formativa $y$, por lo tanto, los mecanismos necesarios para desplegarla con cierto éxito en el territorio. En cualquier caso, hay que tener en cuenta que la existencia de los CIFO extendidos por todo el territorio catalán ha moderado (y puede atenuar en el futuro) el posible aumento de los centros integrados vinculados a centros de formación profesional, por cuanto, en función del territorio y del tipo de familia profesional, la oferta formativa de los CIFO ha dificultado la implantación de determinados cursos de formación en determinados IES tradicionales. En cualquier caso, la oferta de los CIFO no parece tener una excesiva presencia ni 
importancia en aquellos territorios donde las relaciones entre centros de FP y empresas (con la creación, en algunos casos, de fundaciones) aparecen consolidadas en el tiempo.

Hi havia centres de formació públics, hi havia algun centre concertat $i_{\ldots}, \ldots$, «bueno», això serien els nuclis, que jo entenc que haurien de ser centres integrats i després hi havien CIFO, que jo interpreto que en la pràctica han estat així alguns ( 3 dels 8 o 10 que hi ha) centres de referència nacional. $\mathrm{O}$, si més no, de referència en l’àmbit català: 3 que són de referència estatal i 2 que eren d'àmbit estrictament català. I van fer coses amb empreses, vinculades amb la pròpia Administració. Van fer formació. S'han fet coses interessants. (AS1)

Laparició del Centre de Formació Pràctica, perquè l'institut no donava l'abast a fer tota la formació que exigia en aquell moment. I per què no donava l'abast? Perquè nosaltres érem fonamentalment un institut del Departament d'Ensenyament o Educació, depèn de l’època per la que passis, i, clar, el que hem de fer és atendre la formació reglada. Malgrat que aquesta és la prioritat fonamental, sempre també hem atès $i$ hem buscat atendre formació contínua i formació ocupacional. El que passa és que l'institut té la dimensió que té i les hores del dia són les que són. Què passa? Llavors els empresaris van veure que hi havia un moment en què aquí estava impossible. La capacitat ja estava sobrepassada, la capacitat que tenia el centre d'oferir formació $i$, aprofitant la Fundació, vam dir: «'Bueno', intentem fer un centre en aquest cas més especialitzat, perquè qui va apostar va ser la patronal metal.lúrgica, un centre per completar aquesta formació. I, llavors, treballem conjuntament. I què va fer l'institut? L'institut va dir, guaita, així com altres instituts fan tota l'oferta, la formació reglada i la formació contínua i ocupacional o al llarg de la vida, aquí a partir d'un moment determinat vam dir que l'institut se n'ocupi directament de la formació reglada i tota la formació que no és reglada la canalitzem a través de la Fundació Lacetània, a través de la qual nosaltres també hi som. (FP1)

A partir de l'experiència FP.CAT, i dic el que va ser perquè en aquests moments que serà, el que sí que hi ha hagut és un augment de l'oferta per l'ocupació molt gran en els centres d'aquesta xarxa. L'experiència aquesta m'ha demostrat que centres que eren molt potents que ja feien formació per l'ocupació a través de fundacions o a través de l'organisme que tinguessin per poder-la contractar o per poder pactar quan es tractava de formació contínua amb nosaltres o quan es tractava de formació ocupacional directament amb el SOC, llavors van passar de 2 cursos a 50. Olot, Manresa, Lleida, Tarragona el Comte Rius. Tots els centres aquests d'aquesta xarxa. Aquí va haver-hi un salt. Hi ha hagut un salt qualitatiu molt gran. (AS1)

Nosaltres sí que ens hem adonat que, quan fem les enquestes de satisfacció, prefereixen la metodologia dels nostres centres a les dels instituts. Perquè no deixen de ser estructures molt, molt determinades. Per dir-ho suaument. Ho prefereixen perquè és molt més pràctic. No són aules, no és teoria d'hores i hores, sinó que és un ensenyament molt més pràctic i molt més proper a l'empresa. Però, fins i tot ens està passant amb els joves, que prefereixen anar a un CIFO que tornar a un institut, encara que sigui en l'entorn de la formació per l'ocupació. (AR2)

En cuanto a la formación de demanda, según los entrevistados esta es el tipo de formación más complejo para el tejido empresarial de pequeña y mediana empresa, sobre todo para aquellos tipos de empresas de menor volumen. Ello obliga a la agrupación y/u organización temporal de este tipo de empresas con el objetivo de poder reunir recursos suficientes para poner en marcha cursos de formación. Sin embargo, resulta difícil poder conseguir que estas empresas se agrupen para solicitar formación. Los centros integrados de formación profesional podrían permitir una mayor flexibilidad a la hora de gestionar este tipo de formación. En Cataluña existe un cierto bagaje en la integración de la formación para el empleo. Muchas de estas experiencias que integran los diferentes subsistemas de formación profesional tienen detrás una relación entre empresas y centros de formación continuada en el tiempo que, en algunos 
casos, se materializa en forma de fundaciones o similares. Como ya se ha apuntado, en algunos casos este tipo de fundaciones están compuestas por empresas, organizaciones empresariales y sindicales, Administración local y centros de FP del territorio, lo que facilita los canales de comunicación y gestión a la hora de proponer, aprobar y crear este tipo de formación de demanda, que necesita de una mayor agilidad en su gestión.

Tenim un sistema de demanda que ja sabíem tots, quan es va instaurar, que tindria un gran problema, que és l'accés a les pimes. Perquè és un sistema que no està pensat ni dissenyat per facilitar l'accés a les pimes. (AS2)

Com es configura l'oferta formativa? L'oferta formativa moltes vegades és molt repetitiva perquè és una oferta formativa bàsica i perquè es tracta a través de la formació contínua de formar inicialment uns treballadors, sobretot aquells que contracten al llarg de tot el temps. I què es fa? Com que hi ha una relació directa del centre amb les empreses, doncs la mateixa oferta que fa el centre la configura a partir del que li demanen les empreses. El que passa és que es fa a través d'una formació d’oferta. Per què? Perquè és com si van a la patronal els empresaris i diuen: «Des de la patronal per què no organitzeu un curs de 3D o no sé què?» Que les poden recollir i com que la patronal tiba del catàleg, perquè té la possibilitat aquesta, és un agent. Doncs això és el que fa el Centre de Formació Pràctica. És el mateix. Recull aquestes coses. (FP1)

$\mathrm{O}$, des del punt de vista de formació per l'ocupació, almenys no tenim dades de com es pot estar invertint, perquè en molt casos la lectura que faig és que passa per via de la formació de demanda. És a dir, quan hi ha alguna inversió en un canvi tecnològic l'empresa per adaptar-la ràpidament la formació que demanen és justament ajustar-la amb aquell canvi tecnològic. Vull dir que la decisió prèvia ja l'ha pres l'empresa, no relacionada a priori amb la formació, sinó la formació és l'ajust que necessita l'empresa per aplicar aquell canvi tecnològic. Llavors, pel que fa a l'oferta, té a veure que hi hagi una bona prospecció de necessitats formatives perquè l'oferta doni resposta als canvis tecnològics dels sectors. Llavors, sempre és difícil tenir tota la informació prèvia necessària. Entre altres coses perquè, per exemple, en el moment que demanes un pla de formació i realitzes l'acció formativa pot passar un any. Llavors, l'ajust en el moment concret, qui dóna més resposta és la demanda, no l'oferta, per com està establert el sistema. (AS1)

El sistema d'aquí tenia una cobertura per dalt, però era un sistema des de baix. I es que, clar, la relació amb l'empresa no es decreta. Es construeix des de baix. Per tant..., Lacetània o Garrotxa han creat fundacions fa molts anys. Fa 30 anys que tenen fundacions. $\mathrm{O} 25$ anys que tenen fundacions. Qui hi ha a aquestes fundacions? Hi ha els instituts, hi ha la patronal, hi ha els sindicats, hi ha l'Ajuntament, hi ha el Consell Comarcal. A la del Bages, doncs, està el Consell Comarcal del Bages, però està la Unió Patronal Metal-lúrgica del Bages, està la Cambra de Comerç. És a dir, estan en definitiva els actors locals de la formació professional. A Tarragona? Què han fet? Han fet treball amb l'Associació d’Empreses Químiques de Tarragona. Ara. L'Associació d'Empreses Químiques és una associació potent i organitzada. El sector de l'hostaleria? Doncs sí que hi ha gremis, però hi ha gremis i gremiets. Insisteixo. Molt sovint el problema no és que la formació professional no sadreci, sinó que és que l'atomització i la poca regulació patronal dificulta. (AR1)

La formació de demanda? La formació de demanda es comença a fer. Algunes empreses sí que van i poden enviar algú a fer algun tipus de, no mòdul sencer, sinó una unitat formativa d'un mòdul. Home, apunta que l'estructura sigui aquesta, modular i després amb unitats formatives corresponents a unitats de competència. Sembla que està ben orientada. Dóna major flexibilitat. I permet d'alguna manera al propi treballador, el que es forma, capitalitzar i rendibilitzar de cara al futur i al currículum professional i personal millor la seva formació. I això és important. (FP1) 


\section{Conclusiones}

Cataluña se caracteriza por ser una región con una capacidad de desarrollo importante debido en parte a unos elevados niveles de PIB, una relativa renta per cápita (es la cuarta región de las seis estudiadas, pero supera la media nacional), un VAB industrial importante, así como los niveles de empleo dentro del sector industrial, siempre respecto a la media española. Esto es debido a la existencia de un importante tejido industrial extendido por todo el territorio catalán y con unos elevados niveles tecnológicos (en comparación con el conjunto del Estado). Si la comparamos con el resto de regiones estudiadas, Cataluña ocuparía una posición intermedia. En este sentido, el nivel de cualificación general de su población ocupa también una posición media, con proporciones similares a la media del conjunto del Estado. El peso de los estudios profesionales en el sector industrial es limitado. De hecho, Cataluña es, después de Madrid, la región cuya población ocupada en la industria con estudios profesionales ha crecido menos en los últimos 25 años. Esta situación apunta a un uso menor que en otras regiones industrializadas del personal con cualificaciones profesionales de grado medio-superior, lo que puede indicar un débil ajuste entre las necesidades del tejido industrial catalán y las formaciones profesionales intermedias.

En cuanto al gasto en I+D, Cataluña supera a la media estatal, pero ocupa una posición intermedia entre las seis regiones estudiadas. En este sentido, son las empresas catalanas las que realizan (en mayor medida que la media española) las acciones innovadoras dentro del territorio. Esta menor inversión general se nota en el menor volumen de personal dedicado a $\mathrm{I}+\mathrm{D}$ sobre la población ocupada. Respecto a este personal, cabe destacar, además del peso del sector empresarial, el significativo peso de la Administración pública.

En cambio, si nos limitamos al sector industrial, respecto al gasto en $\mathrm{I}+\mathrm{D}$ destaca el protagonismo de las empresas industriales, muy superior a la media española y al del resto de regiones estudiadas. Este gasto responde sobre todo a la adquisición externa de $\mathrm{I}+\mathrm{D}$ y no tanto al desarrollo interno de $\mathrm{I}+\mathrm{D}$.

El acceso a ayudas a la I+D resulta fundamental para entender la capacidad de innovación de las empresas catalanas. Aunque, si bien el acceso a ayudas provenientes de la Administración central es superior a la media española y al del resto de regiones, con el acceso a ayudas regionales y provenientes de la Unión Europea ocurre la situación contraria: es el menor de las seis regiones estudiadas.

En cuanto al nivel de cooperación de las empresas catalanas, cabe decir que, en términos generales, este es limitado, destacando especialmente la cooperación con empresas del mismo grupo, proveedores, clientes $y$, especialmente, con universidades $y$, en menor medida, centros tecnológicos.

Esta última característica enlaza con la política de $\mathrm{I}+\mathrm{D}+\mathrm{i}$ catalana, que posee cierto recorrido en el tiempo. Aunque cabe destacar que hasta hace poco dicha política se ha centrado más en desarrollar y articular las estructuras del sistema de investigación de Cataluña. La transferencia de tecnología y la cooperación entre agentes del sistema de formación-investigación y el tejido empresarial, sobre todo el de pymes, resultan más recientes.

En cuanto a la política de formación profesional impulsada en Cataluña, cabe destacar el protagonismo de la Administración regional, pero, sobre todo, el de los agentes sociales, especialmente en el tema de la integración de la formación profesional y sus subsistemas. Dicha integración, aunque en la práctica se ha dado en mayor o menor medida en el territorio, desde el punto de vista normativo existe de forma experimental. En los últimos años se han dado 
grandes avances en el desarrollo de un modelo catalán de integración de los subsistemas de formación profesional.

Más allá de las políticas, acuerdos y/o programas, Cataluña se caracteriza por tres elementos importantes. El primero es la importancia de la articulación del territorio. El segundo es el elevado recorrido que tienen las empresas y los centros formativos (en cuanto a prácticas en centros de trabajo y otros). El tercero se refiere al protagonismo que actualmente tienen los CIFO respecto a la política de integración de los diferentes subsistemas de formación profesional.

Respecto al primer elemento, del análisis realizado se deriva la importancia que desde la Administración regional (tanto Educación como Empleo) se otorga a los diferentes niveles territoriales (provincial, comarcal, local, mancomunado).

La articulación de los diferentes programas de formación para el empleo o experiencias como el plan FP.CAT se corresponden con un intento importante de articulación (organización y relación entre actores clave) del territorio catalán. De hecho, es esta mayor o menor articulación la que marca el nivel de importancia de las experiencias en centros integrales de formación profesional. Casos como la Fundació Lacetània de Manresa o el IES Garrotxa de Olot responden a territorios muy articulados y autónomos (respecto a la dinámica del área metropolitana de Barcelona) donde los actores que participan (Administración local, agentes sociales territoriales, empresarios) tienen una relación entre ellos consolidada en el tiempo. Esta situación conlleva que este tipo de experiencias creadas escapen a la lógica más formal de los centros integrados o, si se quiere, de la formación inicial/reglada.

Otro elemento significativo en el caso de Cataluña es el hecho de que las experiencias en integración de la formación profesional y para el empleo no están relacionadas exclusivamente con los tradicionales centros de formación profesional. En Cataluña, paralelamente, se ha apostado por el fomento y desarrollo de la red de centros de innovación y formación ocupacional (CIFO) (creados en 1995), que integran gran parte de la formación para el empleo y parte de la formación profesional vinculada a los certificados de profesionalidad. En este sentido, el plan FP.CAT se desarrolla en IES, pero fundamentalmente en centros CIFO. Este tipo de centros aglutina parte de esta formación, estableciendo vínculos con el tejido empresarial del territorio, aunque la tendencia de este tipo de centros (hasta ahora al menos) era desarrollar en mayor medida la parte de la formación para el empleo que la formación profesional inicial/reglada.

En Cataluña, actualmente la integración de los diferentes subsistemas de formación pasa por crear «itinerarios de formación profesional», los cuales buscan integrar la formación inicial/reglada en los IES con la formación para el empleo en CIFO y otros centros existentes. Esta complementariedad entre centros de formación genera tensiones entre ellos y limita la posibilidad de que los IES o centros de FP puedan ir aumentando progresivamente su oferta formativa y, por lo tanto, sus posibilidades de relación con el tejido empresarial. Actualmente, Cataluña se encuentra en plena fase de reflexión sobre el papel que desarrollarán unos y otros (pero, especialmente, los IES) dentro del sistema integrado de formación profesional. 


\section{Anexos}

\section{Anexo I. Ficha técnica}

Para el caso de Cataluña se han realizado un total de seis entrevistas de tipo exploratorio, distribuidas entre representantes de la Generalitat de Catalunya (AR1, AR2), agentes sociales (AS1, AS2) y centros de formación profesional (FP1, FP2). También se han analizado materiales como documentación sobre políticas, iniciativas y/o programas, así como datos estadísticos.

\section{Anexo II. Red de agentes de I+D+I de Cataluña}

A continuación se mencionan de forma exhaustiva los agentes más destacados dentro del sistema de investigación e innovación catalán. Cada uno de los agentes va acompañado del número de unidades. En algunos casos, debido al elevado número de estas, no se ha entrado en detalles. Aquellos agentes específicos del territorio van acompañados por una pequeña descripción.

\section{Estructuras universitarias (223)}

a) Universidades (12): 7 públicas y 5 privadas.

- Universitat de Barcelona, UB

+ Universitat Autònoma de Barcelona, UAB

+ Universitat Politècnica de Catalunya, UPC

+ Universitat Pompeu Fabra, UPF

- Universitat Ramon Llull, URL

+ Universitat de Lleida, UdL

- Universitat de Girona, UdG

+ Universitat Rovira i Virgili, URV

- Universitat Oberta de Catalunya, UOC

+ Universitat de Vic, UVic

- Universitat Internacional de Catalunya, UIC

+ Universitat Abat Oliba CEU, UAO

b) Institutos universitarios de investigación (40): centros dedicados a la investigación científica y técnica. Pueden desarrollar programas docentes de tercer ciclo.

c) Facultades y escuelas universitarias (171).

2. Centros de investigación (77)

a) Centros CERCA (47): centros de investigación participados por la Generalitat de Catalunya.

+ Centre d'Estudis Demogràfics, CED

- Centre de Medicina Regenerativa de Barcelona, CMRB

- Centre de Recerca Ecològica i Aplicacions Forestals, CREAF

- Centre de Recerca en Agrigenòmica, CRAG 
+ Centre de Recerca en Economia Internacional, CREI

+ Centre de Recerca en Epidemiologia Ambiental, CREAL

- Centre de Recerca en Salut Internacional de Barcelona, CRESIB

+ Centre de Recerca en Sanitat Animal, CReSA

+ Centre de Recerca Matemàtica, CRM

+ Centre de Regulació Genòmica, CRG

+ Centre de Visió per Computador, CVC

- Centre Internacional de Mètodes Numèrics en Enginyeria, CIMNE

- Centre Tecnològic de Telecomunicacions de Catalunya, CTTC

- Centre Tecnològic Forestal de Catalunya, CTFC

+ Consorci Markets Organizations and Votes in Economics, MOVE

+ Fundació IRSI-CAIXA, IRSI-CAIXA

+ $\quad$ Fundació UdL-IRTA, Fun. UdL-IRTA

- Hospital Universitari Vall d'Hebron - Institut de Recerca, HUVHIR

+ Institut Català d'Arqueologia Clàssica, ICAC

- Institut Català d'Investigació Química, ICIQ

- Institut Català de Ciències Cardiovasculars, ICCC

+ Institut Català de Ciències del Clima, IC3

+ Institut Català de Nanotecnologia, ICN

+ Institut Català de Paleoecologia Humana i Evolució Social, IPHES

- Institut Català de Paleontologia Miquel Crusafont, ICP

- Institut Català de Recerca de l'Aigua, ICRA

- Institut Català de Recerca en Patrimoni Cultural, ICRPC

+ Institut d'Estudis Espacials de Catalunya, IEEC

+ Institut d'Investigació Biomèdica de Bellvitge, IDIBELL

- Institut d'Investigació Biomèdica de Girona Dr. Josep Trueta, IDIBGI

- Institut d'Investigació en Ciències de la Salut Germans Trias i Pujol, IGTP

- Institut d'Investigació Oncològica de Vall-Hebrón, VHIO

+ Institut d'Investigació Sanitària Pere Virgili, IISPV

- Institut d'Investigacions Biomèdiques August Pi i Sunyer, IDIBAPS

+ Institut de Bioenginyeria de Catalunya, IBEC

- Institut de Ciències Fotòniques, ICFO

+ Institut de Física d'Altes Energies, IFAE

+ Institut de Geomàtica, IG

- Institut de Medicina Predictiva i Personalitzada del Càncer, IMPPC

+ Institut de Recerca Biomèdica, IRB

- Institut de Recerca Biomèdica de Lleida Fundació Dr. Pifarré, IRBLleida

+ Institut de Recerca contra la Leucèmia Josep Carreras, IRFJC

- Institut de Recerca de l'Energia de Catalunya, IREC

- Institut de Recerca de l'Hospital de la Santa Creu i Sant Pau, IRHSCSP

- Institut Hospital del Mar d'Investigacions Mèdiques, IMIM

+ Institut per a la Recerca i Tecnologia Agroalimentàries, IRTA

- Internet i Innovació Digital a Catalunya, i2CAT

b) Centros CSIC (21): red de centros propios y experimentales del Consejo Superior de Investigaciones Científicas en Cataluña. 
+ Centre d'Estudis Avançats de Blanes, CEAB

+ Centre d'Investigació Cardiovascular, CIC

- Centre d'Investigació en Nanociència i Nanotecnologia, CIN2

- Centre Mediterrani d'Investigacions Marines i Ambientals, CMIMA

+ Institució Milà i Fontanals, IMF

+ Institut Botànic de Barcelona, IBB

+ Institut d'Anàlisi Econòmica, IAE

+ Institut d'Investigació en Intel-ligència Artificial, IIIA

- Institut d'Investigacions Biomèdiques de Barcelona, IIBB

- Institut de Biologia Evolutiva, IBE

- Institut de Biologia Molecular de Barcelona, IBMB

- Institut de Ciència de Materials de Barcelona, ICMAB

- Institut de Ciències de l'Espai, ICE

+ Institut de Ciències de la Terra Jaume Almera, ICTJA

+ Institut de Ciències del Mar, ICM

- Institut de Diagnosi Ambiental i Estudis de l'Aigua, IDAEA

- Institut de Microelectrònica de Barcelona, IMB-CNM

- Institut de Química Avançada de Catalunya, IQAC

+ Institut de Robòtica i Informàtica Industrial, IRII

+ Observatori de Física Còsmica de l'Ebre

+ Unitat de Tecnologia Marina, UTM

c) Centros IRTA (9): red de centros propios y experimentales del Institut per a la Recerca i Tecnologia Agroalimentàries (IRTA).

$+\quad$ Centre de Cabrils, IRTA-CA

- Centre de Tecnologia dels Aliments i Avaluació del Porcí, IRTA-TA

+ Centre Mas de Bover, IRTA-MB

+ Centre Torre Marimon, IRTA-TM

+ Estació Experimental d'Alcarràs

+ Estació Experimental de l'Ebre

+ Lleida (1)

+ Lleida (2) Estació Experimental de Lleida

+ Sant Carles de la Ràpita

\section{Instituciones hospitalarias (9)}

Instituciones que dan apoyo a instalaciones sanitarias en docencia, investigación y formación científico-médica.

+ Hospital Universitari Vall d'Hebron - Institut de Recerca, HUVHIR

+ Institut d'Investigació Biomèdica de Bellvitge, IDIBELL

+ Institut d'Investigació Biomèdica de Girona Dr. Josep Trueta, IDIBGI

- Institut d'Investigació en Ciències de la Salut Germans Trias i Pujol, IGTP

- Institut d'Investigació Sanitària Pere Virgili, IISPV

- Institut d'Investigacions Biomèdiques August Pi i Sunyer, IDIBAPS

+ Institut de Recerca Biomèdica de Lleida Fundació Dr. Pifarré, IRBLleida 
+ Institut de Recerca de l'Hospital de la Santa Creu i Sant Pau, IRHSCSP

+ Institut Hospital del Mar d'Investigacions Mèdiques, IMIM

\section{Instalaciones científicas y tecnológicas singulares (12)}

Infraestructura de I+D de carácter singular, sea por coste, ubicación geográfica o por sus resultados. Generalmente tienen carácter internacional.

- Centre de Biotecnologia Animal i de Teràpia Gènica, CBATEG

- Centre de Serveis Científics i Acadèmics de Catalunya, CESCA

- Centre Internacional d'Investigació dels Recursos Costaners, CIIRC

+ Centre Nacional d'Anàlisi Genòmica, CNAG

+ Centre Nacional de Supercomputació, BSC-CNS

- Consorci de Biblioteques Universitàries de Catalunya, CBUC

- Consorci per a l'Explotació del Laboratori de Llum Sincrotró, CELLS

- Laboratori de Ressonància Magnètica Nuclear de Barcelona, LRMN

- Observatori Astronòmic del Montsec, OAdM

- Observatori de l'Ebre, OE

+ Observatori Fabra, OF

+ Sala Blanca del Centre Nacional de Microelectrònica, CNM-Sala Blanca

\section{Parques científicos y tecnológicos (23)}

Espacio de desarrollo industrial y empresarial en colaboración con instituciones de enseñanza superior y centros de investigación. La mayoría de estos parques forman parte de la Xarxa de Parcs Científics de Catalunya (XPCAT).

+22@Barcelona,22@

+ Barcelona Innovació Tecnològica, b-TEC

+ Consorci Biopol de l'Hospitalet, BIOPOL

+ Consorci Zona Franca, CZF

+ ESADE CREAPOLIS, CREAPOLIS

+ Fundació Parc d'Innovació La Salle, PILS

- Parc Aeroespacial de Viladecans, PAMV

+ Parc Audiovisual de Catalunya, PAC

+ Parc Científic de Barcelona, PCB

- Parc Científic i Tecnològic Agroalimentari de Lleida, PCiTAL

- Parc Científic i Tecnològic de la Indústria Enològica, PCT IE

- Parc Científic i Tecnològic de la UdG, PCTUdG

- Parc Científic i Tecnològic de Tarragona, PCTT

- Parc Científic i Tecnològic del Turisme i l’Oci, TCT TiO

- Parc de Negocis de Viladecans, PNV

+ Parc de Recerca UAB, PRUAB

- Parc de Recerca Barcelona Media, PBM

- Parc de Recerca Biomèdica de Barcelona, PRBB

+ Parc Mediterrani de la Tecnologia (UPC), PMT

- Parc Tecnològic Barcelona Nord, PTBN

- Parc Tecnològic del Camp - Tecnoparc 
+ Parc Tecnològic del Vallès, PTV

+ Tecnocampus Mataró-Maresme, Tecnocampus

\section{Centros tecnológicos (24)}

a) Centros tecnológicos (2): centros especializados en transferencia de tecnología en entornos locales.

+ $\quad$ Fundació Centre CIM, CIM

+ Laboratori General d’Assaigs i Investigacions, LGAI

b) Red TECNIO (22): creada por ACC1Ó, aglutina a los principales agentes expertos en investigación aplicada y transferencia tecnológica en Cataluña. El objetivo pasa por estructurar el mercado tecnológico, acercando la tecnología a las empresas. Distingue entre centros tecnológicos ordinarios y centros tecnológicos avanzados. Estos últimos poseen una elevada masa crítica, con capacidad efectiva de gestionar grandes proyectos y de expansión internacional.

b.1) Centros tecnológicos. Redes TECNIO (16).

- Asociación de Investigación de las Industrias del Curtido y Anexas, AIICA

- Centre d’Aplicacions TIC de Manresa, fundación privada, CATIC

- Centre de Difusió Tecnològica de la Fusta i el Moble de Catalunya, fundación privada, CENFIM

+ Centre de Noves Tecnologies i Processos Alimentaris, fundación privada, CENTA

- Centre de Tecnologia Aeroespacial, fundación privada, CTAE

- Centre Tecnològic de la Construcció, fundación privada, IMAT

- Centre Tecnològic de la Química de Catalunya, fundación privada, CTQC

- Centre Tecnològic en Tecnologies de la Nutrició i Salut, fundación privada, CTNS

+ Fundació Institut Tecnològic de Lleida, ITL

- Fundació Privada Cecot Innovació, FCI

+ Fundació Privada Eduard Soler, FES

- Fundació Privada Indústries Gràfiques, CENTIC

- Fundació Privada per la Innovació Tèxtil d'Igualada, FITEX

- Fundació TCM Audiovisual, fundación privada, TCM Audiovisual

+ Fundación Privada Centro de Difusión Tecnológica del Sector Panadero, INNOPAN

+ Institut Català de la Vinya i el Vi, INCAVI

b. 2) Centros tecnológicos avanzados. Redes TECNIO (6).

+ Barcelona Media - Centre d'Innovació, BM-CI

+ Centre Tecnològic LEITAT, LEITAT

+ Fundació Privada ASCAMM, ASCAMM

- Fundació Privada Barcelona Digital Centre Tecnològic, bDIGITAL

+ Fundació Privada CETEMMSA, CETEMMSA

+ Fundació Privada CTM Centre Tecnològic, CTM 
7. Redes y grupos de investigación (1.388)

a) Redes de referencia (8): redes de colaboración entre grupos de investigación (centros IT. Tecnio).

- Xarxa de Referència d'R+D+I en Aqüicultura, XRAq

- Xarxa de Referència d'R+D+I en Biotecnologia, XRB

- Xarxa de Referència d'R+D+I en Economia Aplicada, XREAP

- Xarxa de Referència d'R+D+I en Economia i Polítiques Públiques, XREPP

+ Xarxa de Referència d'R+D+I en Materials Avançats per a l'Energia, XARMAE

- Xarxa de Referència d'R+D+I en Química Teòrica i Computacional, XRQTC

- Xarxa de Referència d'R+D+I en Tècniques Avançades de Producció, XaRTAP

- Xarxa de Referència d'R+D+I en Tecnologia dels Aliments, XARTA

b) Centros IT. Redes TECNIO (83): grupos de investigación universitarios con vocación de transferencia de tecnología.

c) Grupos de investigación reconocidos (1.297).

8. Agentes de interfaz con entidades empresariales

a) ACC1Ó: adscrita al Departamento de Empresa y Empleo, es la agencia de apoyo a la innovación y la internacionalización de empresas en Cataluña. Cuenta con una red de 34 oficinas internacionales. Hereda el testigo del CIDEM (Centre d'Innovació i Desenvolupament Empresarial) y del COPCA (Consorci de Promoció Comercial de Catalunya).

b) Clústeres: conjunto de actuaciones y colaboraciones entre empresas, centros tecnológicos y de investigación y ACC1Ó. Esta línea de actuación ha dado lugar a 8 clústeres.

+ Agua y energía

- Alimentación

+ Energía

+ Manufacturas del diseño

+ Movilidad

$+\quad$ Salud

+ Sistemas industriales

$+\quad$ Transversales

c) Redes de transferencia tecnológicas: agrupaciones de expertos y entidades de investigación e innovación que tienen como objetivo la difusión de la transferencia de conocimiento y tecnología.

- Xarxa d'Innovació Tecnològica (XIT)

- Xarxa de Trampolins Tecnològics (XTT)

- Xarxa de Centres d'Innovació (XPIC)

+ Xarxa d'Assessors Tecnològics (XAT)

+ Business Angels Network (xarxa d'inversors privats o XIP)

- Xarxa de Centres Tecnològics (XCT) 


\section{Anexo III. Programas de políticas activas de empleo en Cataluña. 2010}

\begin{tabular}{|c|c|c|c|}
\hline Programas & $\begin{array}{l}\text { Acciones/ } \\
\text { Proyectos }\end{array}$ & $\begin{array}{l}\text { Presupuesto } \\
\text { aprobado }\end{array}$ & $\begin{array}{c}\text { Personas } \\
\text { beneficiarias }\end{array}$ \\
\hline Cohesión social y desarrollo territorial & 768 & $48.235 .493,3$ & 17.715 \\
\hline $\begin{array}{l}\text { Prórroga de los agentes de empleo y desarrollo } \\
\text { local (AEDL) }\end{array}$ & n.d. & $8.547 .655,88$ & 324 \\
\hline Fomento del desarrollo local (FDL) & 84 & 1.140 .795 & n.d. \\
\hline Treball als Barris (1) & 601 & $29.182 .944,9$ & 8.507 \\
\hline Treball a les 7 Comarques & 60 & $1.507 .923,26$ & 8.507 \\
\hline Proyectos innovadores 2010-2011 (2) & 23 & $7.856 .174,27$ & 6.988 \\
\hline Cualificación profesional & 15.740 & 200.328 .237 & 366.890 \\
\hline $\begin{array}{l}\text { Formación de oferta mediante planes formativos } \\
\text { en áreas profesionales prioritarias }\end{array}$ & 7.582 & 82.711 .959 & 130.356 \\
\hline $\begin{array}{l}\text { Formación de oferta mediante planes formativos } \\
\text { en entidades locales }\end{array}$ & 1.851 & 19.994 .823 & 30.842 \\
\hline $\begin{array}{l}\text { Programas de cualificación profesional inicial } \\
\text { (PCPI) }\end{array}$ & 138 & 7.059 .696 & 2.247 \\
\hline Forma i Contracta & 81 & 2.295 .423 & 1.144 \\
\hline Crédito formación para el trabajo & - & $6.612 .887,19$ & 2.654 \\
\hline CIFO & 613 & 9.000 .000 & 9.330 \\
\hline FP.CAT & n.d. & 1.500 .000 & 1.900 \\
\hline e-formació & 1.473 & 1.648 .998 & 36.831 \\
\hline Connecta't & n.d. & $182.650,44$ & 3.512 \\
\hline $\begin{array}{l}\text { Convenios interdepartamentales (FIAP, Depto. } \\
\text { Agricultura, CIRE) }\end{array}$ & n.d. & 3.352 .080 & 3.287 \\
\hline $\begin{array}{l}\text { Formación de oferta prioritariamente para } \\
\text { personas ocupadas }\end{array}$ & 4.002 & $65.969 .720,7$ & 144.787 \\
\hline Promoción del empleo & 2.740 & 141.158 .145 & 21.694 \\
\hline $\begin{array}{l}\text { Planes de empleo convocatoria ESAL y } \\
\text { universidades públicas }\end{array}$ & 293 & 4.650 .695 & 715 \\
\hline Planes de empleo EELL & 1.603 & $40.266 .972,5$ & 5.956 \\
\hline Planes extraordinarios de empleo local (PEOL) & 550 & $90.760 .568,5$ & 12.651 \\
\hline $\begin{array}{l}\text { Planes de empleo campañas agrarias de } \\
\text { temporada }\end{array}$ & 53 & $667.318,88$ & 141 \\
\hline $\begin{array}{l}\text { Planes de empleo para la limpieza de bosques } \\
\text { (efectos temporal de nieve) }\end{array}$ & 165 & $4.812 .589,73$ & 1.100 \\
\hline Planes de empleo Treball als Barris & 76 & n.d. & 1.128 \\
\hline Programas de orientación profesional & 114.455 & 11.181 .324 & 141.198 \\
\hline Orientación desde las oficinas de trabajo & 114.243 & n.d. & 105.154 \\
\hline
\end{tabular}




\begin{tabular}{|l|c|c|c|}
\hline Aulas activas & & & \\
\hline Itinerarios personales de inserción (IPI) & 202 & 9.836 .895 & 31.161 \\
\hline Reiniciát & 10 & 1.344 .429 & 1.200 \\
\hline Empleo y formación & 153 & 44.020 .350 & 5.941 \\
\hline Nuevas casas para nuevos oficios & 92 & 29.668 .600 & 2.466 \\
\hline SUMA'T & 61 & 14.351 .750 & 3.475 \\
\hline Programas de igualdad de oportunidades & 141 & $12.425 .669,3$ & 35.227 \\
\hline $\begin{array}{l}\text { Programas innovadores para impulsar cambios } \\
\text { estructurales hacia la igualdad de oportunidades } \\
\text { en el ámbito laboral }\end{array}$ & 2 & n.d. & 28.000 \\
\hline $\begin{array}{l}\text { Programas de orientación y apoyo a la inserción } \\
\text { laboral de mujeres en situación de vulnerabilidad } \\
\text { por el paro }\end{array}$ & 31 & $1.850 .758,84$ & 1.586 \\
\hline Red catalana de agentes locales de igualdad & 3 & $1.200 .310,25$ & 84 \\
\hline Colectivos especiales & 105 & 7.949 .369 & 4.975 \\
\hline $\begin{array}{l}\text { Fomento de la contratación de personas } \\
\text { trabajadoras con discapacidad }\end{array}$ & n.d. & $1.425 .231,19$ & 582 \\
\hline Medidas contra la crisis & n.d. & $1.974 .452,77$ & 971 \\
\hline $\begin{array}{l}\text { Proyecto de recolocación de personas despedidas } \\
\text { del sector textil }\end{array}$ & n.d. & $1.974 .452,77$ & $\mathbf{2 3 3 . 9 9 7}$ \\
\hline Total general & $\mathbf{4 5 9 . 3 2 3 . 6 7 1}$ & $\mathbf{5 8 9 . 0 9 6}$ \\
\hline
\end{tabular}

(1) Los planes de empleo dentro del proyecto Treball als Barris se contabilizan en el apartado de Treball als barris.

(2) Proyectos Innovadores es un programa plurianual. n.d.: no disponible

Fuente: SOC 


\section{MADRID}

María Asunción Candela, Celia Díaz, Reyes Maroto, Gustavo Nombela, Irene Ramos, Loredana Stan 



\section{Entorno socioeconómico regional}

\subsection{Datos económicos básicos de referencia}

Según el Instituto Nacional de Estadística, la Comunidad de Madrid (CM) contaba en el año 2010 con aproximadamente 6.500 .000 habitantes, lo que representaba el 13,8\% del total de la población nacional. Su PIB, en el mismo año, fue de 186.630,3 millones de euros, lo que representaba el 17,8\% del nacional. Y el PIB per cápita registró en 2010 un valor de 29.351 euros, un 128,6 de la media nacional (tabla 3.1).

De acuerdo con los datos proporcionados por la Encuesta de la Población Activa (INE, 2010), la tasa de actividad en la Comunidad de Madrid era, en el año 2010, del 65,1\%, la segunda más alta después de Islas Baleares $(66,01 \%)$ y por encima de la media nacional del $60 \%$ (tabla 3.3). En cuanto a la tasa de empleo, la situación en la Comunidad de Madrid era en 2010 sensiblemente mejor que la media nacional (47,96\%), al registrar un valor de $54,63 \%$, mientras que la tasa de paro $(16,08 \%)$ estaba muy por debajo de la media $(20,06 \%)$.

Por lo que al tejido productivo se refiere, el valor añadido bruto total de la Comunidad de Madrid es de 176.707 millones de euros, lo que representa el 17,74\% del VAB total nacional. Asimismo, en términos relativos, el VAB industrial tiene un peso menor en el PIB regional $(12,9 \%)$ y también en el empleo (10\%), muy por debajo de sectores como servicios, con un VAB del $77 \%$ y el $80,2 \%$ de los puestos de trabajo regionales, los niveles más altos de los 6 casos de estudio, lo que supone que la CM es la región menos industrial de los 6 casos de estudio.

No obstante, atendiendo a los sectores de especialización industrial en la región (Contabilidad Regional de España, INE, 2008), es importante señalar que la CM iguala o supera la media nacional en las siguientes ramas industriales: industrias extractivas y energías $(2,8 \%$ VAB y $0,6 \%$ empleo); industria del papel, edición y artes gráficas (2\% VAB y $1,8 \%$ empleo); industria química (1,4\% VAB y $0,8 \%$ empleo); y equipos eléctrico, electrónico y óptico $(1,2 \%$ VAB y $1,2 \%$ empleo).

El nivel tecnológico de la industria madrileña es relativamente alto. Si se considera el peso de los sectores manufactureros de alta y media-alta tecnología (Indicadores de Alta Tecnología, INE, 2009), se observa que el 33,7\% del VAT de la industria manufacturera de la CM corresponde a sectores de alta y media-alta tecnología, con un 31,9\% del total de los ocupados en los sectores industriales, mientras que la media de España registra valores del 26,6\%, con un $27,9 \%$ del empleo. 
La CM destaca en el caso de los sectores manufactureros de tecnología alta, donde registra el segundo porcentaje más alto del VAB de la industria regional $(9,5 \%)$ después de Cataluña $(13,7 \%)$, pero el primer puesto en la tasa de empleo que estos sectores generan $(12,7 \%$ del total del empleo industrial regional). En las dos variables los valores son superiores a la media nacional (5,6\% del VAB de la industria manufacturera y 5,2\% del empleo industrial).

La población residente en la CM tiene, por lo general, un nivel educativo superior a la media española (gráfico 3.1), con mayor representación que a nivel nacional en cuanto a la educación secundaria superior (26,5\% en la CM frente al $22 \%$ de la media nacional) y sobre todo la educación terciaria, donde supera la media española en 10 puntos porcentuales $(40,9 \%$ en la CM frente al 30,7 de la media nacional). En cambio, el porcentaje de población con niveles de educación secundaria inferior registra valores más bajos en aproximadamente 15 puntos porcentuales que a nivel nacional (32,6\% en la CM frente al 47,4\% de la media española).

Sin embargo, en comparación con las medias de la UE15 y la UE27, la Comunidad de Madrid muestra una descompensación de la estructura de estudios de la población (más acusada que en el caso general español). Asimismo, si a nivel europeo la proporción de los niveles de estudios intermedios son mayoritarios (46,8\% UE27 y 42,2\% UE15) con respecto a los niveles de educación secundaria inferior (27,3\% UE27 y 30,5\% UE15). El desajuste es aún mayor en el caso de la educación superior, donde la CM supera las medias europeas en aproximadamente 15 puntos porcentuales. Aunque esto puede indicar un nivel de cualificación mejor de la población madrileña con respecto a la media nacional y la europea, también puede producir ciertos desequilibrios y una sobrecualificación de la población activa en la Comunidad de Madrid.

Respecto al nivel de estudios de la población ocupada, se observa que (tabla 3.4), en comparación con otras comunidades autónomas (País Vasco, Navarra, Asturias), así como con la media nacional, la Comunidad de Madrid registra niveles inferiores en cuanto a los titulados de formación profesional de grado medio (6\% del total de los ocupados) y superior (7,7\% del total de los ocupados) y es puntera en el caso de los titulados de educación superior, tendencia determinada en parte por la estructura del tejido empresarial madrileño, con una acentuada orientación al sector servicios, así como por la importante concentración de instituciones universitarias, ya que la CM cuenta con seis universidades públicas y ocho privadas (véase apartado 1.3).

Aunque a la hora de referirnos específicamente al sector industrial el número de los ocupados con titulaciones de FP de grado medio y superior refleja un cierto incremento, sigue muy por debajo de los valores que registran las otras comunidades autónomas objeto de estudio y también de la media nacional (tabla 3.5). También en este caso la CM sobresale en cuanto al número de ocupados con estudios terciarios, superando la media nacional en casi 13 puntos porcentuales. El gráfico 3.2 muestra que esta ha sido también la pauta general que la Comunidad de Madrid ha seguido durante los últimos 25 años, pues, con excepciones puntuales, ha registrado constantemente valores inferiores a la media nacional.

\subsection{Indicadores de investigación, desarrollo e innovación}

La Comunidad de Madrid destinaba en 2010 el 2,02\% de su PIB al gasto en I+D, valor superior a la media nacional $(1,39 \%)$ - ocupando junto con el País Vasco y Navarra los primeros puestos en I+D dentro del ranking de las CC. AA.—, y similar a la media de la UE27 (2\%) (tabla 3.6). Por lo que se refiere a la evolución en el tiempo del gasto en $\mathrm{I}+\mathrm{D}$, este ha experimentado un crecimiento sostenido (su valor ha aumentado en 0,50 puntos desde 1997), pero 
con una tendencia de contención en los últimos tres años, pudiendo ser la crisis económica la causa de ello (gráfico 3.4).

En Madrid el gasto en I+D en el año 2010 era fundamentalmente realizado por empresas e IPSFL (Instituciones Privadas Sin Fines de Lucro (54,6\% del total), registrando un porcentaje superior a la media nacional (51,6\%). La CM destaca en cuanto a la inversión de la Administración pública $(27,6 \%)$, cuyos valores son netamente superiores a la media española $(20,1 \%)$. No obstante, comparando con la media nacional $(28,3 \%)$ y los otros casos de estudio (Asturias, 43,2\%; Cataluña, 23,4\%; Navarra y Aragón, 22,5\%; o el País Vasco, 18,5\%), en la CM el sector de la enseñanza superior tiene un menor peso en la ejecución del gasto en $\mathrm{I}+\mathrm{D}(17,8 \%)$ (tabla 3.7).

En lo relativo al porcentaje que representa el gasto en $\mathrm{I}+\mathrm{D}$ del PIB regional, se observa una pauta similar a la anterior, registrándose unos valores muy superiores a la media en cuanto a los sectores de las empresas e IPSFL (1,11\% en la CM frente al 0,71 de la media nacional) y la Administración pública $(0,56 \%$ frente a $0,28 \%)$, pero inferiores en cuanto al sector de las enseñanzas superiores se refiere (0,36\% frente a $0,39 \%)$.

Desde el punto de vista de los recursos humanos, en la Comunidad de Madrid, en el año 2010, el personal de I+D representaba el 17,44\% de la población ocupada, muy por encima de la media nacional (12,03\%). El porcentaje de población ocupada en el ámbito ha seguido una senda de crecimiento desde 1997 hasta 2009, aumentando en 4,5 puntos, interrumpida en 2010 por una importante contracción, de 2,5 puntos, que situaba la CM al nivel del año 2006.

Con una tasa del 10,19\% del total de la población ocupada, el número de investigadores y técnicos auxiliares dedicados al sector de I+D en la CM (10,19\% del total de la población ocupada) es superior a la media nacional (7,3\%) (tabla 3.8). Sin embargo, si se observan las ponderaciones del personal investigador sobre el total del personal de I+D, los valores en la CM están por debajo de la media nacional $(60,6)$ u otras comunidades autónomas (Aragón, 68,3\%, o Asturias, $68,5 \%)$. Pasa lo contrario con los técnicos y auxiliares, que representan el $41,6 \%$ del total de personal I+D en la Comunidad de Madrid, un valor superior a la media nacional (39,4\%).

En cuanto a la distribución del personal I+D por sectores de ejecución (tabla 3.9), en la CM las empresas ocupan el primer puesto, ya que un 42,9\% del total dedicado a actividades de I $+\mathrm{D}$ que es personal de empresa. Siguen a continuación el sector de la administración pública, con un $29,4 \%$, y la enseñanza superior, con un $27,7 \%$.

Desde el punto de vista del estudio, es importante señalar que la Comunidad de Madrid es diferente de los demás casos de referencia ya que el sector servicios del tejido empresarial madrileño es el que más gasto en I+D tuvo en el año 2010, pues representaba el 52,3\% del total y superaba la media nacional (50,1\%). El comportamiento de gasto en I+D de las empresas madrileñas por sector de actividad es similar al de Asturias y al del País Vasco, pues las tres comunidades destacan por un menor peso del sector industrial frente al sector servicios (43,8\% frente a 50,1\% en el caso de Madrid; 42,5\% frente a 55,4\% en el caso de Asturias; y 44,3\% frente a 54,9\% en el caso del País Vasco). La adquisición de maquinaria ocupa la mayor parte del gasto en $\mathrm{I}+\mathrm{D}$ en las empresas pequeñas, mientras que la actividad innovadora de las pymes de más de 75 trabajadores se concentra en I+D interna. Destaca en el caso de la Comunidad de Madrid, en comparación con los demás casos de referencia, el importante nivel de gasto en diseño y otros preparativos para producción y/o distribución (28,54\%) en las empresas con entre 150-249 trabajadores.

Las empresas industriales madrileñas han accedido en menor medida a financiación pública que la media española (17,9\% frente a $28,8 \%$ ). Aun así, en términos relativos el nivel de acceso a ayudas estatales es del $72,7 \%$, superando en 20 puntos la media nacional, mientras que las ayudas locales tienen un peso menor (39,0\%), muy por debajo de la media $(63,5 \%)$. En el 
caso de la Comunidad de Madrid es importante destacar que el 14,7\% de las empresas industriales acceden a financiación europea, lo que duplica la media española (14,7\%) (tabla 3.13). Por número de trabajadores, las empresas de más de 250 trabajadores son las que acceden, en términos generales, a más ayudas públicas ( $45,7 \%$ de las empresas innovadoras) y en particular a financiación de la UE (23,2\%), mientras que las empresas con 150-249 trabajadores acceden en un porcentaje del $100 \%$ a ayudas estatales. En el acceso a ayudas públicas de la Administración local destacan las pymes con entre 25 y 74 trabajadores.

En cuanto a la cooperación con otros actores del sistema de innovación, las empresas industriales de la Comunidad de Madrid tienen un nivel inferior de colaboración a la media española (19,9\% del total de las empresas madrileñas frente al 22,1\% de la media nacional). No obstante, destacan los casos de la cooperación con otras empresas del mismo grupo (43\%); clientes $(34,4 \%)$; consultores laboratorios comerciales o institutos privados de I+D $(31,6 \%)$; universidades u otros centros de enseñanza superior (43,8\%); y organismos públicos de investigación (28,9\%) (tabla 3.14). Destacan las empresas con 250 o más trabajadores, que registran los mayores niveles de cooperación $(59,6 \%)$ en términos generales, así como en cuanto a la cooperación horizontal y vertical. Las pymes con hasta 25 trabajadores colaboran más con los clientes (46\%), las de entre 25 y 75 colaboran en mayor medida con los proveedores de equipos y las universidades (47,8\%), y las empresas con más de 150 trabajadores colaboran más con otras empresas de su mismo grupo y las universidades u otros centros de enseñanza superior.

\subsection{Sistema institucional de agentes de $\mathrm{I}+\mathrm{D}+\mathrm{i}$}

Se presentan los agentes de $\mathrm{I}+\mathrm{D}+\mathrm{i}$ en tres categorías distintas ${ }^{1}$.

\section{Los organismos regionales con competencias en materia de $I+D$}

Componen el entramado institucional de la región, encabezados por la Comisión Interdepartamental de Ciencia y Tecnología, un órgano encargado de la programación y la coordinación, y la Dirección General de Universidades e Investigación, dependiente de la Consejería de Educación y Empleo. Su principal competencia es la de diseñar y gestionar el instrumento principal de I+D, el Plan Regional de Investigación Científica e Innovación Tecnológica (PRICIT).

Desde esta dirección se han creado varios organismos para informar a los distintos agentes, como el sistema madri+d o las oficinas de apoyo. Entre estas últimas se encuentran la red de oficinas de apoyo a los investigadores, a jóvenes investigadores, al emprendedor de base tecnológica, la de coordinación de infraestructuras de investigación, la del espacio europeo de investigación, la de información científica y la de comercialización de la investigación. Esta última proporciona asistencia especializada a grupos de investigación y empresas de la CM para la comercialización de tecnología.

\section{Las infraestructuras cientifico-tecnológicas}

Esta comunidad presenta la mayor concentración universitaria en España. En el territorio madrileño están ubicadas seis universidades públicas (Alcalá de Henares, Autónoma de Madrid, Carlos III, Complutense de Madrid, Politécnica de Madrid y Rey Juan Carlos) y ocho privadas (Alfonso X el Sabio, Antonio de Nebrija, Europea de Madrid, Francisco de Vitoria, Pontificia

1 Para mayor detalle, ver el anexo II. 
de Comillas, Pontificia de Salamanca en Madrid, San Pablo CEU y la Universidad a Distancia de Madrid). Además, se encuentra la sede central de la UNED, la única universidad española que sigue siendo competencia de la AGE. En total, están recibiendo enseñanza en estas instituciones 308.546 alumnos.

En la CM tienen la sede muchos centros de investigación dependientes de la AGE. En el anexo se recoge el listado de todos ellos ordenados en función de los ministerios a los que están vinculados: Ministerio de Defensa, Ministerio de Industria, Energía y Turismo, Ministerio de Fomento, Ministerio de Hacienda y Administraciones Públicas, Ministerio de Justicia, Ministerio de Agricultura, Alimentación y Medio Ambiente, Ministerio de la Presidencia, Ministerio de Empleo y Seguridad Social y Ministerio de Sanidad, Servicios Sociales e Igualdad.

Por otro lado, también se hallan en la CM diversos centros de innovación y tecnología. En este sentido, destacan los centros madrileños asociados a la Federación Española de Entidades de Innovación y Tecnología, fundamentalmente sectoriales (en anexo II).

Además, se cuenta con los 46 centros de difusión tecnológica, promovidos por la Dirección General de Economía, Estadística e Innovación Tecnológica de la Consejería de Economía y Hacienda de la Comunidad de Madrid. Comparten la misión de detectar las necesidades de las empresas y dar asesoramiento preliminar en la adopción de planes y medidas de innovación o de incorporación a la sociedad de la información. Dos de ellos son del Gobierno regional: el Instituto Madrileño de Investigación y Desarrollo Rural, Agrario y Alimentario (IMIDRA) y el Instituto Madrileño de Estudios Avanzados (IMDEA).

Una de las grandes apuestas por la innovación de la CM es Madrid Network, una plataforma público-privada con 580 asociados creada para posicionar a la región entre las 10 más avanzadas del mundo. Tiene un modelo económico basado en una red de clústeres y parques científicos y tecnológicos, a la vez que trata de potenciar la capacidad investigadora de los institutos madrileños de estudios avanzados (IMDEA) y de las universidades madrileñas en áreas estratégicas para las empresas. Esta red ha identificado cinco clústeres: financiero, audiovisual, de logística, artes gráficas y automoción. La Comunidad de Madrid ha identificado, además, otros siete por su carácter estratégico: aeroespacial, biotecnología, salud, seguridad y TIC, energías renovables, turismo e idioma español.

Las universidades son artífices, junto con la Administración, de los parques científicos y tecnológicos de la CM, tales como el Parque Científico de Madrid, Tecnoleganés, Tecnogetafe o Tecnomóstoles.

Asimismo, se encuentran otros centros vinculados al Ministerio de Economía y Competitividad, tales como el Centro para el Desarrollo Tecnológico Industrial (CDTI), la Fundación para el Fomento de la Innovación Industrial (F212), la Asociación de Investigación Técnica de las Industrias de la Madera y Corcho (AITIM) y la Fundación Jiménez Díaz.

\section{Infraestructura de apoyo a la transferencia y la innovación}

Como estructuras de interfaz destacan tanto las OTRI universitarias como los parques tecnológicos. Además, entre las estructuras de interfaz también se consideran las siguientes fundaciones universidad-empresa ubicadas en la CM: Red de Fundaciones Universidad Empresa, Fundación Universidad-Empresa (FUE) y Fundación General de la UNED.

Por último, cabe mencionar la Unidad de Innovación Internacional (UII). Es un departamento que presta apoyo para la presentación de proyectos de I+D en el VII Programa 
Marco de la UE, fomentando la participación de las empresas madrileñas, en colaboración con el Programa del CDTI Tecnoeuropa.

\subsection{Política de I+D en el ámbito regional}

La política regional de investigación se ha estructurado en diferentes planes desde que se aprobó el Primer Plan Regional de Investigación en 1990. El Segundo Plan, aprobado en 1993, se fundamentó en el «Libro blanco sobre la política científica en la Comunidad de Madrid». En 1995 se creó la Dirección General de Investigación, actualmente Dirección General de Universidades e Investigación, con la responsabilidad de coordinar la planificación y la ejecución de la política regional. En el año 2000 se publicó el III Plan Regional de Investigación, Ciencia y Tecnología (PRICIT), con la voluntad de integrar la innovación y reforzar la competitividad, en la línea del Plan Nacional.

El IV PRICIT (2005-2008) se estructuró en siete grandes áreas de intervención, manteniendo la división por paneles que se utilizó durante su proceso de elaboración. En ese proceso participaron una gran diversidad de grupos de interés y es, sin duda, la mayor apuesta que ha asumido la CM en esta materia. En cada una de las áreas se introdujeron una serie de actuaciones, resumidas en el anexo III, a las que se les asignó un marco presupuestario.

Posteriormente, esta política se ha redirigido hacia la innovación, a través del Plan Regional de Investigación, Desarrollo e Innovación (PRIDI) (2009-2012). Este plan ha perdido en su diseño la voluntad participativa del anterior, relegándose a una empresa consultora. Aglutina los recursos incluidos en el PRICIT, así como el resto de actividades de investigación, desarrollo e innovación de las consejerías sectoriales de la Comunidad.

El principal objetivo del PRIDI es la canalización de la I+D hacia un mayor avance en la competitividad para consolidar la posición internacional de la Comunidad de Madrid. Sin embargo, este plan ha perdido la visibilidad del antiguo PRICIT, mientras que la localización de los programas diseñados para implantarlo es bastante complicada. No se ha conseguido elaborar un instrumento en el que se encuentren clasificados de forma clara todos ellos.

La actuación del PRIDI se plantea sobre ocho ejes de actuación diferentes: organización de la I+D; capital humano; recursos e infraestructuras; resultados de la investigación; ciencia para la productividad; apoyo a la creación y el desarrollo de empresas innovadoras; apoyo a la innovación en empresas y sociedad; y mejora de la competitividad en empresas.

Uno de los principales objetivos del PRIDI es la consolidación de la red de parques y clústeres encuadrados en la iniciativa Madrid Network, en línea con el propósito de mejora de la competitividad de la región. Esta estrategia para mejorar la interacción entre los agentes de la región no se ve, sin embargo, materializada en actuaciones concretas. En todo este diseño reticular de clústeres los centros públicos de investigación ocupan un segundo plano. Son presentados como un foco de atracción para empresas extranjeras, pero tienen un limitado papel en las actuaciones de Madrid Network. Las actividades tienen un carácter de asesoramiento, fundamentalmente en materia de innovación y emprendimiento.

Por otro lado, aunque el apoyo a universidades y centros de investigación se considera una de las prioridades, la realidad es que los grupos de investigación de la Comunidad han perdido casi todas las convocatorias de apoyo a la investigación. La mayoría de ellas han desaparecido y en los últimos años se han visto reducidas a becas y premios. Han desaparecido también los trabajos que analizaban la $\mathrm{I}+\mathrm{D}$ de la región y el resultado de los planes, dirigidos desde la 
Fundación madri+d. De este modo se ha perdido una herramienta que permitía evaluar los avances en esta política.

La dotación económica en los presupuestos del año 2012 para innovación y tecnología es de 57,92 millones y de 63,10 millones para investigación. Este dato supone una bajada del $10 \%$ para todas las partidas de investigación con respecto a la anualidad del PRICIT de 2008.

\section{La FP en el ámbito regional}

\subsection{Formación reglada: recursos del sistema}

En términos absolutos, durante el curso 2009-2010 un número de 376 centros escolares de la Comunidad de Madrid impartían cursos de formación profesional reglada, 190 de grado medio y 186 de grado superior, lo que representaba el 7,3\% y el 8,9\% respectivamente del total de centros a nivel nacional (tabla 3.15). Aunque en la Comunidad de Madrid la FP se imparte mayoritariamente en centros públicos (67\% de los centros tanto de FPGM como de FPGS), su número es bastante inferior a la media nacional (73,7\% y $76,1 \%$, respectivamente).

En el mismo curso la Comunidad de Madrid contaba con 25.743 alumnos matriculados en FPGM y 30.016 en FPGS, lo que representaba el 9,46\% y el 12,23\% respectivamente del total nacional. En cuanto a la distribución del alumnado entre los centros públicos y los privados, cabe destacar que, si bien la tasa bruta de escolarización en los centros públicos $(72,6 \%$ en FPGM y 73,4\% en FPGS) es menor que la media nacional, es muy superior a la distribución de los centros expuesta anteriormente. No ocurre lo mismo en el caso de la distribución del alumnado en los centros privados, ya que, aunque se supera la media nacional tanto en la FPGM como en la FPGS, la distribución del alumnado en centros privados es inferior a la de los centros públicos.

Gráfico 2.11. Evolución de las matrículas de FP en la CM (1999-2000 / 2009-2010)

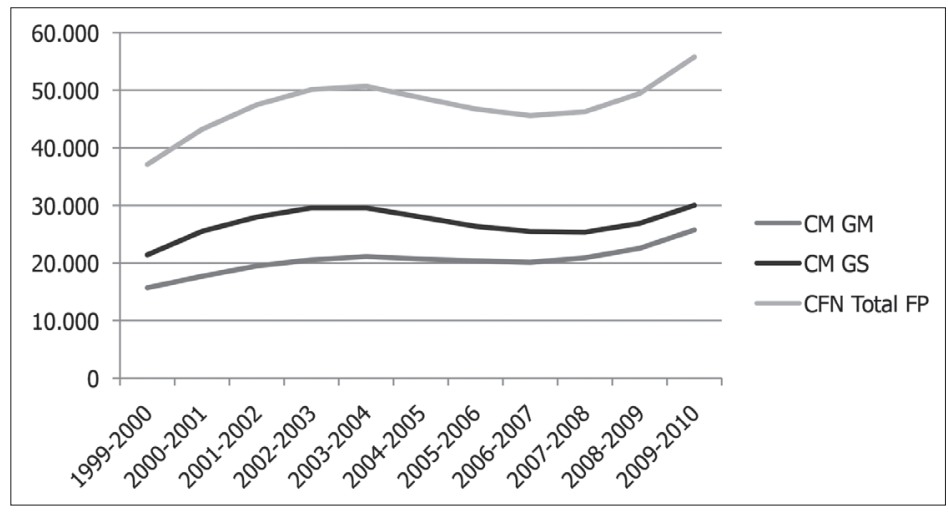

El gráfico muestra la evolución del alumnado matriculado en enseñanzas de FP de grado medio y superior. Se observa que a principios de la década el número de matriculaciones 
mantiene un nivel constante hasta el curso 2008-2009, lo que coincide también con el estallido de la crisis económica, cuando se observa un incremento notable.

Finalmente, el número de alumnos matriculados en las ramas industriales de la $\mathrm{FP}$ en la Comunidad de Madrid registra una tendencia de descenso en la última década, mucho más acentuada en el caso de la formación profesional de grado medio (un descenso de aproximadamente 10 puntos entre 1999 y 2010). Ello se debe, por una parte, al importante peso de la enseñanza superior en la región y, con ello, a la pujanza de los estudios de ESO y bachillerato, y, por otra, a la importancia del sector servicios en el tejido empresarial madrileño, que determina mayores niveles de matriculación en las familias profesionales asociadas a este sector.

En cuanto al profesorado, 5.674 docentes impartían cursos de formación profesional en el año 2010. La siguiente tabla muestra una tendencia a la baja del número de profesores que imparten cursos en dos niveles de formación. No obstante, la disminución importante se produce en los centros públicos, cuyo número baja en tres años en un $54,4 \%$, lo contrario a lo que pasa en los centros privados, donde presenta un incremento del $14,9 \%$.

En términos relativos, en la CM, durante el curso 2009-2010, cada docente impartía cursos de formación profesional, tanto de grado medio como superior, a una media de 11,8 alumnos. En los últimos dos cursos la media de alumnos por profesor se ha incrementado en 1,3 puntos porcentuales, desde 10,5 en el curso 2007-2008.

Tabla 2.16. Situación del profesorado de formación profesional en la Comunidad de Madrid

\begin{tabular}{|l|r|r|r|r|r|r|}
\hline \multirow{2}{*}{$\begin{array}{l}\text { Tipo de } \\
\text { Centro }\end{array}$} & \multicolumn{2}{|c|}{$\mathbf{2 0 0 7 - 2 0 0 8}$} & \multicolumn{2}{c|}{$\mathbf{2 0 0 8 - 2 0 0 9}$} & \multicolumn{2}{c|}{$\mathbf{2 0 0 9 - 2 0 1 0}$} \\
\cline { 2 - 7 } & $\begin{array}{l}\text { Profesorado } \\
\text { exclusivo FP }\end{array}$ & $\begin{array}{l}\text { Profesorado FP } \\
\text { y otros niveles }\end{array}$ & $\begin{array}{l}\text { Profesorado } \\
\text { exclusivo FP }\end{array}$ & $\begin{array}{l}\text { Profesorado FP } \\
\text { Y otros niveles }\end{array}$ & $\begin{array}{l}\text { Profesorado } \\
\text { exclusivo FP }\end{array}$ & $\begin{array}{l}\text { Profesorado } \\
\text { FP otros } \\
\text { niveles }\end{array}$ \\
\hline $\begin{array}{l}\text { Centros } \\
\text { Públicos }\end{array}$ & 3.178 & 1.188 & 3.300 & 869 & 3.462 & 542 \\
\hline $\begin{array}{l}\text { Centros } \\
\text { Privados }\end{array}$ & 1.232 & 303 & 1.298 & 289 & 1.312 & 356 \\
\hline Total & $\mathbf{4 . 4 1 0}$ & $\mathbf{1 . 4 9 3}$ & $\mathbf{4 . 5 9 8}$ & $\mathbf{1 1 5 8}$ & $\mathbf{4 . 7 7 6}$ & $\mathbf{8 9 8}$ \\
\hline
\end{tabular}

\subsection{Formación regladał ámbitos de especialización}

De las 26 familias profesionales aprobadas por el Ministerio de Educación a nivel nacional, en la Comunidad de Madrid no se imparten cursos de formación profesional en seis de estas familias (Artes y Artesanías; Energía y Agua; Industrias Extractivas; Seguridad y Medio Ambiente; Vidrio y Cerámica; Marítimo-Pesquera). Asimismo, en la Comunidad de Madrid se ofertan 96 títulos profesionales ( 60 de grado superior y 36 de grado medio) de los aproximadamente 150 títulos ofertados a nivel nacional. 
Gráfico 2.12. Áreas de especialización industrial de la FPGM en la CM

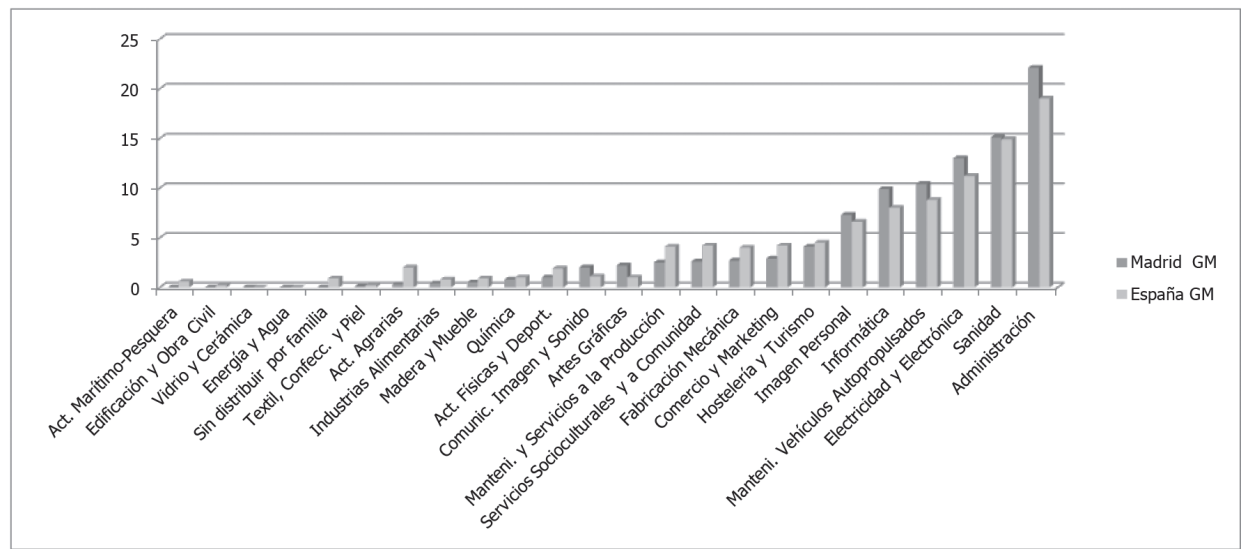

Gráfico 2.13. Áreas de especialización industrial de la FPGS en la CM

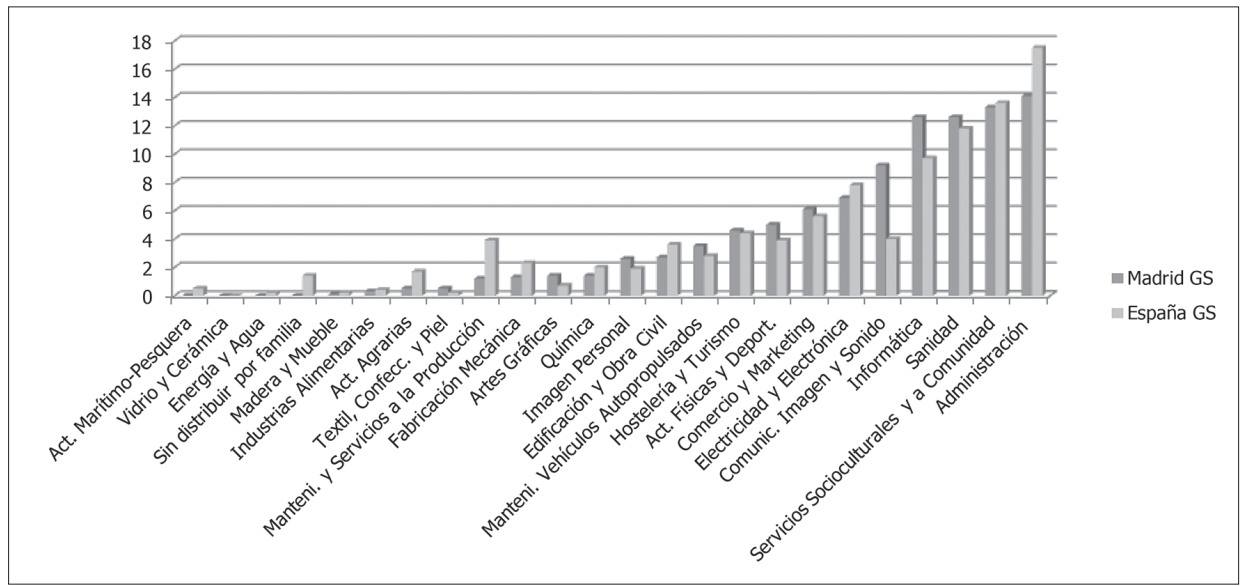

Si miramos la distribución de los alumnos matriculados en las diferentes familias profesionales por ciclo formativo en los últimos dos cursos - tanto en los cursos de grado medio como en los de grado superior-, las titulaciones más demandadas son las de Administración (que representan el 22,1\% del alumnado matriculado en ciclos de grado medio y el 14,1\% en el caso de los matriculados en ciclos de grado superior).

En el caso de la FP de grado medio, completan el podio las familias de Sanidad (15,1\%) y Electricidad y Electrónica (13,0\%), mientras que en la FP de grado superior las siguientes familias más demandadas son Servicios Socioculturales (13,3\%), Informática y Sanidad (12,6\%).

En términos comparados, en el caso de la FP de grado medio no hay una variación importante con respecto a la media nacional, consiguiendo valores superiores a esta última en las tres familias más demandadas (3 puntos en el caso de la Administración, 2 puntos en Electricidad y Electrónica y 0,3 puntos en Sanidad). También superan la media nacional las familias Mantenimiento de Vehículos Autopropulsados e Informática en 1,6 y 2 puntos porcentuales respectivamente (tabla 3.21). 
En la FP de grado superior se mantiene la misma pauta, con la diferencia de que las primeras dos familias profesionales más demandadas en la CM registran niveles inferiores a la media nacional en 3,6 puntos para la Administración y 0,3 puntos para los Servicios Socioculturales y a la Comunidad. En Sanidad se supera la media estatal en 0,8 puntos, mientras que en Informática la diferencia es de 2,9 puntos. Es destacable el caso de Comunicación, Imagen y Sonido, en el que la CM supera la media nacional en 5,2 puntos (tabla 3.22).

\subsection{Formación para el empleo: la formación de oferta}

En la CM han participado durante 2010 en la formación para el empleo, en la modalidad de oferta, un total de 128.175 personas, lo que supone un 16,33\% del total estatal (tabla 3.25).

Cabe destacar que la CM refleja el porcentaje menor de personas formadas en la industria entre las comunidades estudiadas, alcanzando un 20,3\%; es decir, 2,4 puntos inferior al nivel estatal $(22,7 \%)$.

La fórmula presencial es la más utilizada en la CM, llegando a un 43,9\% de las acciones, aunque a pesar de ello se encuentra 4,6 puntos porcentuales por debajo de la media estatal. La segunda modalidad más utilizada es la teleformación, con un $27,9 \%$ de las acciones, lo que implica 8 puntos porcentuales por encima de la media estatal. La formación a distancia (17,4\%) y la formación mixta (10,9\%) son fórmulas mucho menos utilizadas, situándose por debajo de los resultados medios estatales.

Un 47,8\% de las personas formadas han sido mujeres, dos puntos porcentuales por encima de la media del Estado (tabla 3.26). Por franjas de edad, un $41,2 \%$ de las personas formadas se sitúa entre los 26 y los 35 años, colectivo que supera a la media estatal en 3,6 puntos porcentuales, seguido del grupo de personas entre los 36 y los 45 años $(31,3 \%)$.

La formación de oferta en la CM tiene un perfil algo diferente de lo que ocurre en el Estado en su conjunto respecto a la categoría profesional de sus participantes (tabla 3.27). Mientras que el porcentaje de trabajadores cualificados que participan en esta formación es similar, un $38,5 \%$ para la CM y un 38,2\% para la media del Estado, los resultados difieren en el caso de los técnicos, con un $22 \%$ en el caso de la CM (9,3 puntos superior a la media del Estado) y en el caso de los trabajadores no cualificados, por lo que el dato de la CM, con un 24,9\%, es 7,6 puntos inferior a la media de España.

\subsection{Formación para el empleo: la formación de demanda}

De acuerdo con los datos que facilita la Fundación Tripartita para la Formación en el Empleo (tabla 3.29), durante 2010 se formaron 556.840 trabajadores en las empresas de la CM. Esto representa el 20,1\% de las personas formadas en la modalidad de demanda en el Estado español, siendo el 19,6\% de las empresas de la CM las que hacen formación de demanda, una media un poco por debajo de la media estatal (24,6\% de las empresas), según se recoge en la tabla 3.28.

Las pymes con un tamaño comprendido entre 50 y 249 trabajadores son las que dedican, relativamente, más esfuerzo a esta actividad. Así, el 68,3\% de las empresas situadas en esta franja de tamaño han efectuado formación de demanda. Un porcentaje que, no obstante, es menor al resto de las regiones de referencia y menor también a la media del Estado, situada en un $74,4 \%$ (tabla 3.28 ). 
Cabe señalar que la tasa de cobertura de la formación de demanda en la industria manufacturera (tabla 3.28) es del 25,5\%, la tasa menor después de la de Cataluña (25,4\%) entre las regiones estudiadas y 7,3 puntos porcentuales inferior a la media estatal (32,8\%). Como se puede observar en la tabla 3.29, el 67,7\% de los participantes formados en empresas manufactureras corresponde a empresas mayores de 249 trabajadores, porcentaje superior al resto de las regiones, en las que la participación de las empresas de entre 100 y 249 trabajadores es mayor que en el caso de la CM. Atendiendo a la distribución por sectores empresariales (tabla 3.30), el porcentaje de participantes formados en el sector industrial es uno de los menores $(11,6 \%)$ respecto al resto de regiones y a la media española (18,7\%). Sin embargo, la CM refleja el mayor porcentaje en el segmento de Otros servicios (58,7\%).

En la CM, como en las demás regiones, la formación de demanda es fundamentalmente presencial; un $65,5 \%$ de las personas formadas han realizado esta modalidad de formación. Esta tasa alcanza el 73,9\% en el caso de las empresas industriales, sensiblemente por encima de la media estatal, situada en $59,8 \%$ y $68,8 \%$, respectivamente.

Si observamos el perfil de los participantes formados dentro de la modalidad de demanda en la industria (tabla 3.31), un 67,1\% han sido hombres. Por grupos de edad, el más numeroso es el comprendido entre los 26 y los 45 años $(71,4 \%)$.

La formación de demanda en la industria de la CM (tabla 3.32) está dirigida sobre todo a las categorías de técnicos y trabajadores cualificados. Así, un 33,4\% de las personas formadas pertenecen a la categoría de técnicos, porcentaje casi 13 puntos superior a la media española. El $36,5 \%$ se ha dirigido a la formación de trabajadores cualificados, que en este caso es inferior a la media del Estado en casi 7 puntos porcentuales. Los directivos y mandos intermedios representan un $17,8 \%$ del total de trabajadores formados en la industria. Dentro de la mano de obra no cualificada, un $12,2 \%$ ha recibido formación de demanda en la CM, porcentaje ligeramente por debajo de la media estatal $(18,6 \%)$.

En relación con el perfil profesional de las personas formadas en la industria de la CM (dentro de la fórmula de demanda) y con la estructura de estudios de la población en esta región (tabla 3.33), el perfil académico de los participantes en la formación es de un 45,5\% de universitarios, porcentaje superior tanto a la media española $(29,2 \%)$ como a la del resto de regiones. La segunda categoría que acumula un porcentaje mayor corresponde a la de estudios secundarios postobligatorios, con un 35,9\%, cifra cercana a la media del Estado (39,8\%). Respecto a los participantes con estudios primarios y secundarios, en la CM hubo un 17,3\% de participantes, cifra muy inferior a la media española, que casi duplica el porcentaje con un $29,8 \%$.

Los permisos individuales para la formación en la CM (1.069 en 2010) se acumulan prácticamente en su totalidad en la gran empresa, con un 91,4\% (tabla 3.34), lo que muestra una elevada concentración de la concesión en este tipo de empresas (la media del Estado es de $73,4 \%)$. La mediana empresa solo obtiene el 8,2\%.

\subsection{Política regional en relación con la FP}

\subsubsection{Formación profesional reglada}

En la actualidad, el sistema de formación profesional en la Comunidad de Madrid se rige por un conjunto de decretos, órdenes y resoluciones que actualizan y adaptan la ordenación madrileña a las reformas nacionales del sistema de formación profesional, regulando los currículos, el proceso de acceso, el funcionamiento de la FP en la Comunidad de Madrid — en todas sus 
formas, presencial y/o a distancia-, el proceso de formación y selección del profesorado, o la evaluación de los alumnos.

Esta normativa se completa con un sistema de equivalencias y convalidaciones. Por una parte, de todo lo relativo a la sustitución progresiva de las titulaciones de formación profesional de la LOSGE (1990) por las nuevas de la LOE (2006) y la implementación de las creadas por esta; y, por otra, de las convalidaciones de módulos de determinados ciclos formativos, en especial de grado superior, mediante una serie de convenios que la Consejería de Educación de la Comunidad de Madrid firma con las universidades madrileñas. Este sistema pretende dar respuesta a la necesidad reflejada tanto por los centros de FP y los estudiantes como por las universidades de crear un sistema integrado que facilite el acceso de los titulados de grado superior y potencie así la excelencia y la innovación. Asimismo, es un mecanismo mediante el cual se pretende incidir en la conciliación entre la formación y la vida laboral.

Desde el punto de vista de la organización institucional autonómica, la formación profesional está incluida entre las atribuciones de la Viceconsejería de Empleo y depende directamente de la Dirección General de Formación, que aglutina:

- Subdirección General de Formación Profesional

- Subdirección General de Formación Continua y Emprendedores

Varios órganos consultivos completan el panorama institucional de la formación profesional:

+ Consejo de Madrid para el Desarrollo, el Empleo y la Formación

- Consejo de Formación Profesional, encargado de elaborar el Plan Regional de Formación Profesional

- Consejo de Ciencia y Tecnología

- Instituto Regional de Cualificaciones (creado en 2006), eliminado por medio de la Ley 9/2010, de 23 de diciembre, de Medidas Fiscales, Administrativas y Racionalización del Sector Público

Pese a la existencia de la base institucional en la Administración regional, en la actualidad la Comunidad de Madrid carece de un plan de formación profesional, habiendo finalizado el último en el año 2008. Según la información publicada por el Gobierno regional, existen otros planes cuyos ámbitos de actuación tocan de manera indirecta el campo de la formación profesional. Ninguno de ellos, sin embargo, presenta un desarrollo claro del contenido en la versión abierta a la consulta pública:

+ Plan para el Empleo

- Plan de Empleo y Formación

- Plan de Orientación para el Empleo

- Plan de Emprendedores de la CM

Si bien a raíz de ello se echa en falta la existencia de un plan de actuación que encamine la política regional hacia la potenciación de la formación profesional en la Comunidad de Madrid, los proyectos más recientes impulsados desde la Administración madrileña en este ámbito van dirigidos $\mathrm{a}$ :

- La promoción del modelo de FP dual, siguiendo el modelo alemán, que supone básicamente que el alumno pase dos terceras partes del tiempo de su formación en la empresa y el otro tercio en su centro educativo. Los alumnos reciben durante los 24 meses que dura su ciclo formativo una beca salario de 450 euros/mes y a su vez deben cumplir el horario que le fijen en la empresa. Aquí reside la principal diferencia 
con el modelo ordinario de FP, en el que solo se contempla una estancia limitada de tres meses (módulo obligatorio de Formación en Centros de Trabajo) en la empresa una vez que el alumno ha concluido su ciclo formativo en el centro educativo. Este modelo se puso en marcha en la CM en octubre del año pasado mediante un proyecto piloto con 60 estudiantes. Se pretende ampliar su número hasta 500 para el curso 2012-2013 en diferentes familias profesionales: Administración, Comercio y Marketing, Informática y Comunicaciones, Hostelería y Turismo, Sanidad, Electricidad y Electrónica, Transporte y Mantenimiento de Vehículos o Química.

- La creación de los centros integrados de FP. Actualmente hay tres en la CM, un número muy escaso comparado con el caso del País Vasco, donde 46 de los 110 centros de FP son integrados. A finales de 2005 se ponen las bases normativas de los centros (Real Decreto 1558/2005, de 23 de diciembre, por el que se regulan los requisitos básicos de los Centros integrados de formación profesional). En el año 2007 se crea el Centro Integrado de Formación Profesional Profesor Raúl Vázquez, el primero de este tipo (Decreto 32/2007, de 14 de junio, del Consejo de Gobierno de la Comunidad de Madrid, por el que se aprobó su creación). Ese centro está incluido en el proyecto piloto de formación dual.

\subsubsection{Formación profesional para el empleo}

El Real Decreto 395/2007, de 23 de marzo, regula el subsistema de formación profesional para el empleo. Bajo esta nueva regulación se integran las dos modalidades hasta entonces existentes, la formación ocupacional y la formación continua.

En la Comunidad de Madrid se distingue, por una parte, la oferta de formación para el empleo dirigida prioritariamente a trabajadores desempleados, que incluye:

- Las acciones formativas en el marco del Programa Operativo Plurirregional titularidad del Servicio Público de Empleo Estatal: programas de formación en centros de formación para el empleo de la Comunidad de Madrid y programas de formación con centros o entidades acreditadas o inscritas.

- Las acciones formativas en el marco del Programa Operativo Regional titularidad de la Comunidad de Madrid: programas de formación con ayuntamientos y programas de formación de carácter sectorial o territorial con entidades de acreditada solvencia.

Por otra, la formación dirigida prioritariamente a trabajadores ocupados, que pretende proporcionar la capacitación profesional que puedan necesitar a lo largo de su vida laboral, de forma que obtengan los conocimientos y las competencias requeridos en cada momento por las empresas.

La CM cuenta también con una red de centros de formación para el empleo (formada por cinco centros) cuya misión es mejorar la capacitación profesional de los trabajadores a través de actuaciones que integran la formación especializada y el apoyo activo en la búsqueda de empleo. La especialización de los centros está orientada a los siguientes sectores productivos: Informática, Administración de Empresas, Aeronáutica, Mecánica de Fluidos, Frío y Climatización, y Edificación y Obras Públicas.

Respecto a la financiación de este subsistema, en el artículo 6 del Real Decreto 395/2007 se establecen las siguientes fuentes de financiación: los fondos procedentes de la cuota de forma- 
ción profesional que aportan las empresas y los trabajadores, las ayudas procedentes del Fondo Social Europeo y las aportaciones específicas establecidas en el presupuesto del Servicio Público de Empleo Estatal. Por otro lado, las comunidades autónomas podrán, en ejercicio de su competencia, destinar fondos propios para financiar la gestión de las iniciativas de formación.

Tanto la formación de demanda como la formación de oferta disponen de regulación propia y de sistemas de financiación diferentes. La formación de demanda se financiará mediante la aplicación de un sistema de bonificaciones en las cuotas de la Seguridad Social que ingresan las empresas. Las empresas, según establece la norma, dispondrán de un crédito para la formación de sus trabajadores cuyo importe resultará de aplicar a la cuantía ingresada por cada empresa el año anterior, en concepto de cuota de formación profesional. La cuota dependerá del tamaño de la empresa.

La regulación y planificación de la formación de oferta debe tener en cuenta la transferencia de competencias en la materia, que viene recogida en el Real Decreto 2534/1998, de 27 de noviembre. No obstante, el Ministerio de Trabajo (actualmente Ministerio de Empleo y Seguridad Social) realizará una planificación plurianual de la formación de oferta a partir de las propuestas realizadas por las CC. AA. y las organizaciones empresariales y sindicales.

Del subsistema de la formación profesional para el empleo, considerando las figuras correspondientes a la formación de demanda y a la formación de oferta, la categoría en la que las comunidades autónomas tienen una mayor discrecionalidad en la toma de decisiones es en la formación de oferta.

Respecto a la financiación con cargo a los Presupuestos Generales del Estado de la formación profesional para el empleo en materia de formación de oferta, la Orden TIN/887/2011, de 5 de abril, es la norma por la que se procede a distribuir territorialmente, para el ejercicio 2011, las subvenciones con cargo a los Presupuestos Generales del Estado, de las que la CM recibió 50 millones de euros para acciones de formación profesional dirigida prioritariamente a trabajadores ocupados y 83 millones para acciones de formación dirigida prioritariamente a trabajadores desempleados.

Finalmente, la regulación específica de la $\mathrm{CM}$ en esta materia viene recogida en dos órdenes. En primer lugar, en la Orden 4608/2010, de 29 de diciembre, de la Consejería de Empleo, Mujer e Inmigración, se recoge la convocatoria de subvenciones, así como su regulación, para la financiación de acciones de formación de oferta dirigidas prioritariamente a trabajadores desempleados. Se asignan un total de 84,5 millones de euros, de los cuales 54,5 millones para el ejercicio presupuestario 2011 y 30 millones para el ejercicio 2012. En segundo lugar, en la Orden 3727/2011, de 21 de septiembre, de la Consejería de Educación y Empleo de la Comunidad de Madrid, se establecen las disposiciones generales para la financiación de planes de formación dirigidos prioritariamente a trabajadores ocupados y también se regula la convocatoria de subvenciones para el año 2011, cuyo importe máximo de los fondos presupuestarios ascendía a 100 millones de euros (presupuesto inicial de unos 50 millones de euros y fondos adicionales previstos de otros 50 millones de euros).

\subsection{Prácticas de formación en centros de trabajo (FCT)}

Las prácticas en los centros de trabajo representan un aspecto fundamental para el éxito del sistema de formación profesional, ya que son imprescindibles para fomentar y reforzar la conexión de los estudiantes matriculados en cursos de FP con las empresas y el mercado laboral. Para 
ello, los módulos de prácticas son obligatorios en todos los centros educativos que imparten ciclos formativos de grado medio y superior. Asimismo, los centros suscriben convenios de colaboración con empresas u otras organizaciones (solicitando la autorización previa de la Dirección General de Enseñanza Secundaria y Enseñanzas Profesionales) que permitan el desarrollo de los programas formativos atendiendo a la normativa correspondiente.

Durante el curso 2009-2010, 12.188 alumnos matriculados en ciclos de FPGM y FPGS en la CM realizaron 4.953 .522 horas de prácticas en 4.458 empresas ( Situación de la enseñanza en la Comunidad de Madrid», 2011). Sin embargo, en la tabla 2.17 se puede observar como en términos relativos tanto el porcentaje de empresas como el de los alumnos que participan en el módulo de prácticas en los centros de trabajo es menor en el curso 2009-2010 que en el 2005-2006. Se debe señalar, no obstante, el repunte de las empresas participantes en este último año, recuperando $1,65 \%$ con respecto al curso anterior.

Tabla 2.17. Evolución del módulo profesional de Formación en Centros de Trabajo en la CM. Cursos 2005-2006 a 2009-2010

\begin{tabular}{|l|r|r|}
\hline & $\begin{array}{l}\text { \% de empresas en FCT del total de } \\
\text { empresas con 10 o más trabajadores }\end{array}$ & $\begin{array}{l}\text { \% de alumnos en FCT del total } \\
\text { de alumnos matriculados en FP }\end{array}$ \\
\hline $\mathbf{2 0 0 5 - 2 0 0 6}$ & 15,48 & 24,18 \\
\hline $\mathbf{2 0 0 6 - 2 0 0 7}$ & 14,19 & 23,64 \\
\hline $\mathbf{2 0 0 7 - 2 0 0 8}$ & 13,27 & 22,33 \\
\hline $\mathbf{2 0 0 8 - 2 0 0 9}$ & 13,21 & 21,76 \\
\hline $\mathbf{2 0 0 9 - 2 0 1 0}$ & 14,86 & 21,36 \\
\hline
\end{tabular}

Siempre hay cosas que no vas a aprender en un curso, por muy largo que sea. Porque luego la realidad del trabajo posiblemente sea otra. Aunque nuestros cursos están muy adaptados. Sin embargo, así, una vez en el puesto de trabajo, saben cómo funciona una empresa, cómo tienen que trabajar..., y luego se adaptan mejor a la disciplina, la puntualidad, el trabajo continuo [...]. El aprender a trabajar en la organización, seguir la política de la empresa [...]. Es muy interesante. (Director FPE)

Es fundamentalmente la Administración regional quien impulsa este módulo, lo que por parte de los centros se percibe como una falta de implicación de las empresas en las estrategias formativas de los sectores. La implicación empresarial se considera, además, crucial para mejorar el seguimiento de las prácticas, con un mejor aprovechamiento de estas en lo que se refiere a la adquisición de competencias por parte de los alumnos.

Ahora que se habla tanto del «sistema dual», de Alemania, [... ] aquí, en España, las consejerías educativas pagan a las empresas por tener alumnos... Es decir, no es el proceso inverso... En Alemania son las empresas las que pagan a los alumnos para hacer esas prácticas en las empresas y, además, hacen un seguimiento exhaustivo. (Director IES)

Es más, el mundo empresarial debería invertir en la formación profesional. No debería ser solo una inversión pública del Ministerio de Educación y Empleo o de las consejerías..., sino también de las propias empresas. (Director IES)

En el período actual, los centros de FP tienen que hacer mayores esfuerzos para involucrar a empresas en la formación que antes de que comenzara la crisis. Sin embargo, no todos los sectores se encuentran en la misma situación. En este sentido destaca la actividad del sector 
aeronáutico en la Comunidad de Madrid. Antes de la crisis eran las empresas las que solicitaban alumnos en prácticas con la intención fundamental de contratarlos al finalizarlas.

Las empresas las buscamos nosotros. Al ser un centro de formación profesional desde hace mucho tiempo, tenemos muchas empresas en nuestra agenda, en nuestra bolsa, para establecer vínculos de relación... Ahora ya menos... Hubo un tiempo en que eran muchas las empresas que se ponían en contacto con nosotros para intentar conseguir alumnos que hicieran las prácticas. (Director IES)

Formación en Centro de Trabajo (FCT), bolsas de trabajo y estancias de profesorado en empresas

$\mathrm{Al}$ convertirse en un nexo importante, el único en muchos casos, entre los alumnos de FP y el tejido empresarial, el módulo de Prácticas de Formación en Centros de Trabajo tiene un impacto muy positivo sobre la inserción laboral de los titulados de formación profesional. Asimismo, según datos de la Comunidad de Madrid, en 2010 casi siete de cada diez alumnos que terminan los estudios de FP en la región encuentran trabajo durante los seis meses posteriores. En concreto, el 67,5\% de los alumnos madrileños de grado medio y el 66,4\% de los de grado superior encuentran un puesto de trabajo en los seis primeros meses tras la obtención del título. Entre los ciclos de formación profesional con mayor inserción laboral en la Comunidad de Madrid destacan Higiene Bucodental (87\%), Cocina (83,60\%), Administración de Sistemas Informáticos (82,68\%), Carrocería (75\%) o Administración y Finanzas (73\%) (Comunidad de Madrid, 2011).

Además, la demanda y la necesidad de mano de obra formada del tejido empresarial de la región y la valoración que hacen las empresas del módulo de Prácticas de FCT y de la FP en su conjunto son variables importantes en este apartado. En este sentido, Madrid era en 2010 la tercera comunidad con más oferta de empleo dirigida a titulados de FP, después de Cataluña y País Vasco, aunque con un ligero descenso con respecto a 2009, cuando lideraba el ranking. Entre las tres comunidades autónomas reúnen el 45,95\% de esta oferta en el ámbito nacional. En la Comunidad de Madrid, más específicamente, el 14,85\% del total de la oferta de empleo $(18,45 \%)$ está dirigida a titulados de FP. (Adecco e Infoempleo, 2011).

Sin embargo, según la información cualitativa recogida, la contratación de los jóvenes estudiantes de FP en las empresas en las que realizan el módulo de FCT ha bajado considerablemente desde el inicio de la crisis. Si antes las empresas consideraban la FCT como un importante instrumento de contratación, en el contexto actual son muy pocas las empresas que acuden a los centros.

2008, 2009... Hasta ese momento eran muchas las empresas que se ponían en contacto con nosotros porque, al haber una situación, además, boyante de empleo, las empresas veían que era el principal recurso para formar y contratar. De hecho, era uno de los criterios que nosotros establecimos como más interesantes para mandar alumnos a empresas, es decir, aquellas que sabíamos que su tendencia era contratar a los alumnos una vez que los formaban. Era uno de los criterios más importantes. Ahora mismo, no. Ahora no se da. Sin embargo, es verdad que todavía sigue habiendo alumnos que, en la empresa en que hacen las prácticas, terminan quedándose a trabajar. Pero ya es muy difícil que una empresa te llame para decir «quiero alumnos» para realizar prácticas. (Director IES) 
En muchos casos, los buenos resultados en términos de contratación de la FP se deben, además de a las prácticas en los centros de trabajo, a las bolsas de empleo de los propios centros de formación profesional. Sin embargo, según las entrevistas realizadas, esta práctica ha experimentado un importante retroceso en los últimos años como consecuencia del efecto de la crisis económica sobre la creación de empleo en España.

Nosotros también tenemos otras vías, ¿̇no? Tenemos también una bolsa de trabajo en la página web... Y recibimos muchas... Cuando recibíamos... Todavía seguimos recibiendo alguna..., alguna oferta de trabajo..., pues se tramita a través de una persona que se encarga de esa bolsa de empleo, que es el profesor de Formación y Orientación Laboral, y a través de los tutores correspondientes, que pueden conocer no a los alumnos que tienen ahora estudiando, sino a alumnos de años anteriores..., su situación laboral..., alumnos que puedan estar en paro o alumnos que quieran mejorar de trabajo... Entonces se les tramita la oferta de empleo. (Director IES)

Otra forma de relación entre los centros de FP y las empresas son las estancias de los profesores en estas. Sin embargo, en la Comunidad de Madrid, según las entrevistas realizadas, no es una experiencia habitual. La infrautilización de esta posibilidad está determinada, según los profesores, por las trabas burocráticas que supone la consecución de este tipo de contractos.

Pero existen desde un punto de vista muy institucional, ¿no?, esa formación para estancias profesionales, en determinados lugares..., pero ya es como si fuese un proyecto Leonardo, pero no para alumnos, sino para titulados..., y en ese caso se incluye también a los profesores. Entonces, eso implica muchos trámites burocráticos. Por eso, las dificultades de cualquier proyecto, ¿̇no?, como este que estamos comentando, un Comenius, que sería prácticamente lo mismo que un Leonardo, pero para otros ámbitos que no son del ámbito profesional... Y por eso no se suelen solicitar... (Director IES)

Tampoco existe ningún programa específico en este sentido impulsado desde el Gobierno regional, salvo lo que se recoge en el sistema educativo a nivel nacional, que, en la mayoría de los casos, se concreta en las relaciones que el profesor pueda establecer con el tejido empresarial mediante las FCT que supervisa.

¿Sobre las estancias de profesores? Un programa específico no hay, salvo en el sistema educativo. En el sistema educativo, los profesores que se dedican durante un período de tiempo, normalmente un año, a facilitar las prácticas en centros de trabajo su práctica actividad o prácticamente todo su tiempo lo dedican no solo a poner en contacto a los alumnos con el sistema productivo, sino a..., un poco, pues a sumergirse, ¿no?, en el propio sistema. (Responsable, Gobierno regional)

\subsection{Otros tipos de relaciones entre los centros de FP y las empresas. Papel de los centros de FP en la formación para el empleo}

La relación de los centros de FP y las empresas madrileñas se basa fundamentalmente en las FCT; más allá de este módulo, el mundo educativo y el mundo empresarial funcionan bastante en paralelo (director IES). Existe, por lo tanto, un gran margen para mejorar la relación que establecen actualmente los centros de FP y las empresas en la Comunidad de Madrid para potenciar el papel de los primeros en la formación continua y la innovación empresarial. 
[...] Es más, el mundo empresarial debería invertir en la formación profesional. No debería ser solo una inversión pública del Ministerio de Educación y Empleo o de las consejerías..., sino que debería ser una inversión de las propias empresas... (Director IES)

Asimismo, desde los centros de FP se considera que la cultura empresarial mayoritaria se encuentra alejada de posiciones innovadoras y emprendedoras interesadas por una mejor formación.

Si fuesen empresas realmente innovadoras y emprendedoras, lo que querrían es tener a los mejores trabajadores formándose para poder contratarlos luego, ¿no? Y por eso creo que debería haber una gran inversión... Pero una gran inversión que se notara hasta en los propios recursos de los centros educativos de formación profesional..., que es una de las carencias que más notamos. (Director IES)

Pero además de la necesidad de un cambio en la cultura empresarial, la limitada relación entre los dos sectores es también consecuencia del escaso papel que los centros de FP tienen en la prestación de servicios de formación profesional para el empleo. Ello se debe a que los centros de FP han sido sustituidos en esta labor por otros actores:

+ Los centros de formación profesional para el empleo (FPE).

+ Las empresas privadas de formación.

- Los actores sociales, aunque en menor medida, ya que su papel también ha disminuido en los últimos años por el auge de las empresas formadoras.

Los centros de formación para el empleo colaboran con las empresas de una manera más estrecha. Muchas veces las empresas participan activamente en el desarrollo de los cursos aportando su know-how en cuestiones relacionadas, por ejemplo, con procesos tecnológicos determinados. Se producen, por lo tanto, intercambios más frecuentes. De esta forma los centros consiguen materiales y asesoramiento que benefician y mejoran la calidad formativa del centro.

Nosotros, aparte de decir «bueno, necesito tal curso para insertarles...», que es a lo que vamos: yo te doy este curso, pero me lo insertas. O sea, a ver qué... Vale. Pero nosotros necesitamos material, y las empresas nos lo dan. Que necesitamos normativa, o documentación o contenidos de algo..., y las empresas nos lo dan. Que tenemos que elaborar ese programa que tú necesitas..., tú me das los contenidos y yo te elaboro metodológicamente los objetivos y los medios que necesitas, y demás, ¿¿no? Todo eso es un ten con ten con las empresas. Luego también, a cambio..., vienen y les asesoran técnicamente a los alumnos de cualquier cosa, les dan charlas de cómo está el sector, nos dejan visitar las empresas y les dicen cómo funciona todo... O sea, todo eso hay... Y hay muy buena colaboración [...]. Pero esto es trabajar mucho con las empresas, insistir... (Director FPE)

Mira, lo bueno que tenemos también es que, como también licitamos y se presentan empresas del sector, pues luego seguimos en contacto con esas empresas... Ya nos imparten los cursos... Colaboran voluntariamente... Simplemente que les interesa. Por ejemplo, una asociación de fontaneros y de calefactores colabora mucho con nosotros porque es una empresa que funciona muy bien y nos está dando cosas muy buenas... Eso también nos viene bien, que sean las empresas las que impartan los cursos. Porque nos están asesorando continuamente. (Director FPE)

En el caso particular de los centros de formación para el empleo, y en comparación con los centros de FP, las prácticas realizadas son voluntarias, tanto por parte de las empresas como 
por parte de los alumnos. Estas prácticas no laborales están vinculadas normalmente a certificados de profesionalidad, a la formación profesional para el empleo o a cualquier otro curso, como aclara un responsables del gobierno de la $\mathrm{CM}$ y no son remuneradas. Los estudiantes que las realizan tienen una probabilidad algo más elevada de inserción a corto plazo (10\% a los 3 meses). Sin embargo, esta diferencia disminuye a la mitad en un año. La inserción se produce en 115 de las 175 empresas con las que se colabora por esta vía. En el caso de la formación para el empleo, los resultados han variado de un $75 \%$ a unos mínimos esperables del $20 \%$. Si no se cumple este mínimo, se efectúa la extinción de esos programas para intentar garantizarlo.

Los resultados han variado mucho. Hace unos cuatro años nos estábamos moviendo en un $75 \%$ de media de inserción en cualquiera de los tipos de contrato que son habituales en el Estado español... A día de hoy no hay que ocultar que esto no es tan fácil. Los últimos datos de inserción que tenemos nos llevan a poder afirmar que estamos por encima del 20\%. (Responsable Gobierno CM)

Si excluimos aquellas especialidades que no han acreditado en otros períodos un mínimo del $20 \%$ en los contratos alcanzados, creemos que tenemos garantizado un $20 \%$ de suelo de inserción laboral. Si no cambian mucho las circunstancias, ese suelo se va a mantener, como mínimo. (Responsable Gobierno CM)

En la actualidad hay centros de formación para el empleo que mantienen relaciones continuadas con empresas extranjeras, ejecutando las prácticas en otros países europeos. Se realiza formación complementaria, como la enseñanza del idioma, para favorecer la inserción al finalizar las prácticas allí.

Ahora vamos a mandar a cuatro alumnos a una empresa alemana con la que colaboramos, dentro de un proyecto Leonardo... Tenemos todas las esperanzas de que incluso les contraten, porque están seleccionados..., van a estar cuatro meses allí haciendo prácticas no laborales, les damos cursos de alemán... (Director FPE)

Es importante señalar aquí el protagonismo que han cobrado las empresas formadoras privadas (que se han duplicado entre 2008 y 2010) en detrimento de otros actores sociales, cuya participación se ha visto sustancialmente reducida. Según el Anuario de Estadísticas del Ministerio de Empleo y Seguridad Social, si en el año 2008 había registradas 19.397 empresas formadoras en la Comunidad de Madrid, dos años después su número llegaba a 40.570.

Desde los actores sociales se critica la actuación del Gobierno regional tanto respecto a los compromisos financieros en torno al reparto de FPE, registrándose un grave retraso (de un año) en el pago de esta, como respecto a su participación en el proceso de consulta sobre las decisiones que afectan a la FPE. Actualmente, simplemente les facilitan los borradores de las órdenes por las que se derivan los fondos públicos y su papel se reduce a aportaciones a estos.

Creo que son los quintos acuerdos de formación continua, que hay un parón... Todo, además, va con retraso, porque nosotros estamos ahora ejecutando, hasta el 30 de noviembre de 2012, fondos del año 2011... Igual que a nivel estatal... Y aquí estamos en un parón, que no sabemos cómo se va a quedar el tema de formación. (Responsable sindicato)

En la Comunidad de Madrid, mientras que en otras comunidades..., en cuanto a la elaboración de las órdenes que promulga la Comunidad de Madrid, había un papel participativo de los agentes sociales...; en las dos últimas convocatorias se nos quitó la participación. Ten en cuenta que el Servicio Regional de Empleo, que era donde teníamos la participación los agentes socia- 
les, se disolvió. Eso, ahí. Y en la anterior convocatoria se derivaba simplemente a un borrador, que hiciéramos aportaciones, que luego prácticamente ninguna de ellas era tenida en cuenta a la hora de sacar la orden que regulaba los fondos públicos. Y esa es la que regula tanto la formación para el empleo como la formación ocupacional. Por lo tanto, por concluir, no hay ninguna participación, en el ámbito de la Comunidad de Madrid, con la Administración pública en cuanto a formación. (Responsable sindicato)

Con la creación de los centros integrados se ha querido introducir un cambio sustancial en el papel de los centros de FP en la impartición de la formación para el empleo y mejorar así su relación con el tejido empresarial madrileño, dada la vinculación más cercana de esta con las empresas.

Otro efecto positivo de la puesta en marcha de los centros integrados ha sido el acercamiento entre los centros de FP y los de FPE, ya que los primeros se han visto obligados a acudir a servicios de asesoramiento de los segundos.

[...] la formación reglada no sabe cómo funcionaba formación para el empleo. Entonces, el centro de formación para el empleo colabora con el Raúl Vázquez para asesorarles [sobre] cómo se seleccionan los alumnos, todo el papeleo que hay que hacer, cómo hay que hacer el seguimiento de los cursos... Bueno, en todos los procedimientos, tanto de selección de alumnos como de administración. (Director FPE)

Vínculos que, a juzgar por el caso concreto, no parecen ser tan frecuentes y se ven reducidos a la propia localidad. Mayoritariamente informales, están determinados por los traslados de profesores, que han adquirido experiencia en el desarrollo de proyectos distintos. Los profesores se constituyen así como impulsores de dinámicas nuevas en el centro que permiten una mayor apertura exterior.

Con los centros de otras localidades, no. Sí existe relación con los centros de la propia localidad. Pero de otras localidades, no. No suele ser frecuente... En algún caso estamos estableciendo ahora más vínculos por proyectos que puedas querer desarrollar, ¿no? Pero no, no es frecuente ese intercambio de relaciones. (Director IES)

\section{Conclusiones}

La Comunidad de Madrid destaca en el contexto nacional por registrar buenos niveles en los indicadores que miden la situación socioeconómica regional. El PIB representa el 17\% del PIB nacional, mientras que el nivel del PIB per cápita supera la media nacional en 128\%. Además, la tasa de ocupación es superior a la nacional. Ello se debe en parte a la cultura y el desarrollo empresarial y al alto nivel de cualificación de la población activa.

Desde la perspectiva del estudio es importante subrayar la peculiaridad del caso de estudio de la Comunidad de Madrid en cuanto a la FP, ya que es preeminente el peso del gasto en actividades de $\mathrm{I}+\mathrm{D}$ que se realiza desde el sector servicios. No obstante, aun cuando el sector industrial no tiene un peso tan significativo en la economía regional como el sector de los servicios, la actividad industrial de la Comunidad de Madrid destaca por su alto nivel tecnológico, donde registra el segundo porcentaje más alto del VAT de la industria regional $(9,5 \%)$ después de Cata- 
luña $(13,7 \%)$, a la vez que el primer puesto en la tasa de empleo que estos sectores generan $(12,7 \%$ del total del empleo industrial regional) y la alta cualificación del personal empleado en este sector.

Actualmente, la política regional en I+D está plasmada a través del Plan Regional de Investigación, Desarrollo e Innovación (PRIDI) (2009-2012) y, desde el punto de vista específico de la innovación en el sector industrial, a través del Plan de Fomento e Impulso de la Industria (FICAM) 2009-2012, para consolidar y mejorar la competitividad de la industria madrileña.

La inversión pública en $\mathrm{I}+\mathrm{D}$ juega un papel determinante en este cometido y en la $\mathrm{CM}$ es superior a la media nacional y se ejerce especialmente desde el tejido empresarial y la Administración regional. Respecto a las ayudas públicas a la $\mathrm{I}+\mathrm{D}$, factor decisivo en la creación de capacidades internas de I+D, en la CM es importante resaltar el peso que tienen la financiación estatal y europea, con un menor peso de las ayudas locales. Estas ayudas han posibilitado la cooperación entre una multiplicidad de actores públicos y privados, que en su conjunto forman Madrid Network, y al que pertenecen los centros de formación e investigación.

La formación profesional reglada es fundamentalmente pública, aunque en los últimos años se puede observar un mayor impulso desde la Administración regional a la enseñanza privada y concertada. En este sentido se observa un cierto desajuste con la demanda social, que está dirigida fundamentalmente a los centros públicos de FP, ya que las matriculaciones en centros públicos de formación profesional reglada registran una tendencia ascendente (véase apartado 2.1). En términos de matriculación, es destacable el incremento de alumnos matriculados en ciclos de FP a partir de 2008-2009, especialmente en el caso de la FP de grado superior, coincidiendo con el estallido de la crisis económica. Ello se debe en parte a los niveles más altos de empleabilidad de los titulados de FP y, por lo tanto, a una mayor demanda de este tipo de cualificaciones por parte de las empresas. En este sentido, los centros de FP desarrollan relaciones con el entorno empresarial regional, y el principal nexo son las prácticas formativas en los centros de trabajo. Sin embargo, según las entrevistas realizadas a los centros de FP, la FCT no solo es el principal nexo con las empresas, sino, en muchos casos, el único. Otros tipos de relaciones (visitas de profesores de FP, uso de las instalaciones de los centros por parte de las empresas, etc.) son muy escasas o inexistentes.

Ello se debe en buena medida al papel marginal que los centros de FP tienen en la impartición de cursos de formación para el empleo, ya que en la Comunidad de Madrid otros actores han tomado protagonismo en este sector formativo. Se trata, en primer lugar, de una red de centros de formación para el empleo que pertenecen a la Administración regional, cuyos currículos están dirigidos tanto a trabajadores como a desempleados. Aunque en este tipo de centros la implicación en prácticas formativas es totalmente voluntaria (tanto por parte de las empresas como de los propios estudiantes), las relaciones que establecen estos centros con el tejido empresarial madrileño son más intensas y habitualmente se desarrollan en doble sentido: los centros proporcionan formación a las empresas, pero también son las propias empresas las que se ofrecen a impartir cursos en los centros.

Con la creación de los centros integrados de formación profesional, que combinan dentro de un mismo centro la formación reglada y la formación para el empleo, se pretende dar un vuelco a esta situación e intensificar, por una parte, la influencia de los centros de FP en la impartición de cursos de formación para el empleo y, por otra, la relación de estos con las empresas, mejorando así la calidad de la enseñanza y adaptándola a las demandas del mercado laboral.

Sin embargo, en esta ecuación intervienen también otros actores como los sindicatos o las empresas formativas privadas. Estas últimas han cobrado un papel protagónico en los 
últimos años, en detrimento de los primeros, ya que, según datos del Ministerio de Empleo y Seguridad Social, han duplicado su número entre 2008 y 2010.

De manera concomitante con el incremento del número de empresas formadoras, desde los sindicatos se percibe un malestar causado por la disminución de su participación en la formación para el empleo, pero también por los agentes sociales y sindicales echan en falta la existencia de un plan de actuación en este ámbito puesto que el último finalizó en 2008. Todo ello, unido al impulso a la educación reglada concertada y privada, pone de manifiesto el giro del Gobierno regional hacia la externalización de servicios en el ámbito de la formación profesional.

Destaca aquí el interés de los centros de FP en internacionalizar las relaciones con las empresas, cobrando cada vez más peso los programas de intercambios a nivel europeo.

Para la formación profesional para el empleo, varias son las conclusiones que se pueden extraer: por una parte, la disminución de la participación de los agentes sociales y los centros de formación profesional (en la CM existen solo 3 centros integrados de FP), cuyo protagonismo ha sido reemplazado por una multiplicidad de empresas privadas (las empresas formadoras han duplicado su número entre 2008 y 2010); por otra, un importante aumento de la demanda de FP para el empleo (tanto de formación de demanda como de oferta).

\section{Anexos}

\section{Ficha técnica}

Para la realización de este estudio exploratorio se han realizado cuatro entrevistas con actores del sistema regional:

- Director de un instituto de educación secundaria con especialidades de electrónica industrial de un municipio madrileño.

- Director de un centro de formación en electricidad, electrónica y aeronáutica.

+ Responsable de la formación continua en una organización sindical.

- Cargo de responsabilidad de la Dirección General de Formación y Empleo de la Comunidad de Madrid.

Las entrevistas semidirigidas se han realizado entre los meses de marzo y mayo de 2012 para profundizar en la comprensión de la visión de estos actores sobre el sistema, así como de las relaciones que establecen con otros agentes de la misma región o en otros entornos.

\section{Agentes de I+D+i en la CM}

\section{Ministerio de Economía y Competitividad}

Centro de Investigaciones Energéticas Medioambientales y Tecnológicas (CIEMAT); Consejo Superior de Investigaciones Científicas (CSIC); Centro de Biología Molecular; Centro de Investigaciones Biológicas; Centro Nacional de Biotecnología; Instituto de Biología Molecular; Instituto de Bioquímica; Instituto de Farmacología y Toxicología; Instituto de Investigaciones Biomédicas Alberto Sols; Instituto de Neurobiología Ramón y Cajal; Instituto de Fermentaciones Industriales; Instituto de Nutrición y Bromatología; Instituto del Frío; Centro Nacional de Investigacio- 
nes Metalúrgicas; Instituto de Cerámica y Vidrio; Instituto de Ciencia de Materiales de Madrid; Instituto de Ciencia y Tecnología de Polímeros; Instituto de Ciencias de la Construcción Eduardo Torroja; Centro de Astrobiología; Centro de Comunicaciones CSIC-REDIRIS; Centro de Física Miguel A. Catalán; Centro de Tecnologías Físicas L. Torres Quevedo; Centro Técnico de Informática; Instituto de Acústica; Instituto de Astronomía y Geodesia; Instituto de Automática Industrial; Instituto de Estructura de la Materia; Instituto de Física Aplicada; Instituto de Matemática y Física Fundamental; Instituto de Microelectrónica de Madrid; Instituto de Óptica Daza de Valdés; Centro de Química Orgánica M. Lora Tamayo; Instituto de Catálisis y Petroleoquímica; Instituto de Química Física Rocasolano; Instituto de Química Médica; Instituto de Química Orgánica General; Centro de Ciencias Medioambientales; Centro de Humanidades y Ciencias Sociales; Museo Nacional de Ciencias Naturales; Real Jardín Botánico; Instituto Español de Oceanografía (IEO); Instituto Nacional de Investigación de Tecnología Agraria y Alimentaria (INIA); Instituto Geológico y Minero de España (IGME); Centro de Investigación y Documentación Educativa (CIDE); Centro Nacional de Investigaciones Oncológicas (CNIO); Centro Nacional de Investigaciones Cardiovasculares (CNIC); Instituto de Salud Carlos III (ISCIII).

\section{Ministerio de Defensa}

Instituto Nacional de Técnica Aeroespacial (INTA); Canal de Experiencias Hidrodinámicas de El Pardo (CEHIPAR); Laboratorios de Ingenieros del Ejército (LIE); Centro de Investigación y Desarrollo de la Armada (CIDA).

Ministerio de Industria, Energía y Turismo

Instituto para la Diversificación y Ahorro de la Energía (IDAE); Centro Español de Meteorología (CEM).

\section{Ministerio de Fomento}

Centro de Estudios y Experimentación de Obras Públicas (CEDEX); Instituto Geográfico Nacional (IGN).

\section{Ministerio de Hacienda y Administraciones Públicas}

Instituto de Estudios Fiscales (IEF).

Ministerio de Justicia

Centro de Estudios Jurídicos (CEJ).

Ministerio de Agricultura, Alimentación y Medio Ambiente

Agencia Estatal de Meteorología (AEMET).

\section{Ministerio de la Presidencia}

Centro de Estudios Políticos y Constitucionales (CEPCO); Centro de Investigaciones Sociológicas (CIS). 
Ministerio de Empleo y Seguridad Social

Instituto Nacional de Seguridad e Higiene en el Trabajo (INSHT).

\title{
Centros de innovación y tecnología de la Comunidad de Madrid
}

\author{
Asociados a la Federación Española de Entidades de Innovación y Tecnología
}

Asociación para la Investigación y Desarrollo Industrial de los Recursos Naturales (ATEMIN); Asociación Española de Constructores de Material Aeroespacial (ATECMA); Asociación Española de Soldadura y Tecnologías de Unión (CESOL); Asociación de Investigación Técnica de la Industria Papelera Española (IPE); Asociación Española de Bioempresas (ASEBIO); Asociación Española de Fabricantes de Equipos y Componentes para Automoción (SERNAUTO); Asociación Española del Hidrógeno (AEH); Asociación Multisectorial de Empresas de Tecnologías de la Información Comunicaciones y Electrónica (ASIMELEC); Asociación de Empresas de Electrónica, Tecnologías de la Información y Telecomunicaciones de España (AETIC); Federación Empresarial de la Industria Química Española (FEIQUE); Federación Española de Empresas de Tecnología Sanitaria (FENIN).

\section{Estructuras de interfaz de la Comunidad de Madrid}

Las principales estructuras de interfaz son las oficinas de transferencia de resultados de la investigación (OTRI). Las oficinas adscritas al registro de OTRI del Ministerio localizadas en la Comunidad de Madrid son:

Universidad Complutense; UNED; Universidad Politécnica de Madrid; Centro de Estudios y Experimentación de Obras Públicas (CEDEX); Centro de Investigaciones Energéticas, Medioambientales y Tecnológicas; Consejo Superior de Investigaciones Científicas; Instituto Nacional de Técnica Aeroespacial Esteban Terradas MDE (INTA); Instituto Nacional de Investigación y Tecnología Agraria y Alimentaria (INIA); Instituto Español de Oceanografía (IEO); Instituto de Salud Carlos III (ISCIII); Universidad Pontificia de Comillas; Centro Español de Metrología; Ministerio de Industria, Turismo y Comercio; Instituto Geológico y Minero de España; Asociación de Investigación Técnica de la Industria Papelera Española; Universidad de Alcalá; Fundación Universitaria San Pablo CEU; Fundación General de la Universidad Autónoma de Madrid; Fundación CONFEMETAL; Instituto Nacional de Seguridad e Higiene en el Trabajo; Asociación para la Investigación y Desarrollo Industrial de Recursos Naturales; Asociación Técnica Española de Fundición; Federación Española de Industrias de la Alimentación y Bebidas; Federación Española de Entidades de Innovación y Tecnología; Universidad Europea de Madrid SL; Asociación de Investigación Técnica de las Industrias de la Madera y el Corcho; Fundación Centro Nacional de Investigaciones Oncológicas Carlos III; Fundación Centro Nacional de Investigaciones Cardiovasculares Carlos III; Fundación Universidad Rey Juan Carlos; Fundación para la Investigación Biomédica del Hospital G. Marañón; Fundación Antonio de Nebrija; Asociación de Empresas de Electrónica, Tecnología de la Información y Telecomunicaciones; Fundación para la Investigación Biomédica Hospital Clínico San Carlos; Fundación Instituto Tecnológico para el Desarrollo de las Industrias Marítimas; Fundación FIDES; Instituto de Investigación La Paz. 


\section{Programas, instrumentos y beneficiarios del PRICIT}

\begin{tabular}{|c|c|c|c|c|c|}
\hline Áreas & Programa & Objetivos & Instrumentos & Beneficiarios & Presupuesto \\
\hline \multirow{2}{*}{$\begin{array}{l}\text { Creación de } \\
\text { capital } \\
\text { humano }\end{array}$} & $\begin{array}{l}\text { Formación y } \\
\text { movilidad de } \\
\text { investigadores }\end{array}$ & $\begin{array}{l}\text { Formación de } \\
\text { investigadores de calidad, } \\
\text { fomento de su movilidad } \\
\text { e incorporación de } \\
\text { investigadores de } \\
\text { prestigio a los centros de } \\
\text { investigación de la } \\
\text { comunidad. }\end{array}$ & $\begin{array}{l}\text { Becas-contrato } \\
\text { por } 2+2 \text { afios }\end{array}$ & Doctorandos & \multirow[b]{2}{*}{$30 \%$} \\
\hline & $\begin{array}{l}\text { Formación de } \\
\text { técnicos de } \\
\text { labor atorio }\end{array}$ & $\begin{array}{l}\text { Capacitación de técnicos } \\
\text { especialistas de grado } \\
\text { medio y superior para el } \\
\text { manejo y mantenimiento } \\
\text { de los equipos de } \\
\text { laboratorios de I+D de } \\
\text { universidades y OPI. }\end{array}$ & $\begin{array}{l}\text { Contratos- } \\
\text { programa } \\
\text { y becas }\end{array}$ & $\begin{array}{l}\text { Técnicos } \\
\text { especialistas de } \\
\text { grado medio y } \\
\text { superior }\end{array}$ & \\
\hline \multirow[t]{2}{*}{$\begin{array}{l}\text { Grupos de } \\
\text { investigación }\end{array}$} & $\begin{array}{l}\text { Apoyo a grupos } \\
\text { de investigación }\end{array}$ & $\begin{array}{l}\text { Mejorar la posición } \\
\text { competitiva, favorecer } \\
\text { su participación en } \\
\text { convocatorias nadionales } \\
\text { e internacionales, y } \\
\text { fomentar que sus } \\
\text { miembros acerquen sus } \\
\text { trabajos a la sociedad. }\end{array}$ & $\begin{array}{l}\text { Programas } \\
\text { competitivos de } \\
\text { trabajo para } 2+2 \\
\text { an̂́os }\end{array}$ & $\begin{array}{l}\text { Grupos de } \\
\text { investigación }\end{array}$ & \multirow[t]{2}{*}{$25 \%$} \\
\hline & $\begin{array}{l}\text { Creación y } \\
\text { consolidación } \\
\text { de grupos }\end{array}$ & $\begin{array}{l}\text { Favorecer la creación, } \\
\text { consolidación de grupos } \\
\text { y la actividad de jóvenes } \\
\text { investigadores }\end{array}$ & $\begin{array}{l}\text { Contrato } \\
\text { programa con } \\
\text { universidades }\end{array}$ & $\begin{array}{l}\text { Jóvenes e } \\
\text { investigadores }\end{array}$ & \\
\hline
\end{tabular}




\section{Programas, instrumentos y beneficiarios del PRICIT (2)}

\begin{tabular}{|c|c|c|c|c|c|}
\hline Áreas & Programa & Objetivos & Instrumentos & Beneficiarios & Presupuesto \\
\hline \multirow{3}{*}{$\begin{array}{l}\text { Coor dinación } \\
\text { y dotación de } \\
\text { infraestruc- } \\
\text { turas de } \\
\text { interés } \\
\text { regional }\end{array}$} & $\begin{array}{l}\text { Confección de un } \\
\text { mapa de } \\
\text { capacidades } \\
\text { cientifico } \\
\text { tecnológicas de la } \\
\text { Comunidad de } \\
\text { Madrid y creación } \\
\text { de la Oficina de } \\
\text { Coordinación de } \\
\text { Infraestructuras de } \\
\text { I+D+l (OCIDI) }\end{array}$ & $\begin{array}{l}\text { Confeccionar un mapa } \\
\text { de capacidades de I+D } \\
\text { de la CM. Creación } \\
\text { de la OCIDI } \\
\end{array}$ & $\begin{array}{l}\text { Financiación } \\
\text { directa }\end{array}$ & OCIDI & \multirow{3}{*}{$25 \%$} \\
\hline & $\begin{array}{l}\text { Red de } \\
\text { laboratorios, red } \\
\text { de bibliotecas } \\
\text { y red de institutos } \\
\text { madrilefios de } \\
\text { investigación }\end{array}$ & $\begin{array}{l}\text { Potenciar la } \\
\text { cooperación entre los } \\
\text { laboratorios }\end{array}$ & $\begin{array}{l}\text { Contrato } \\
\text { programa con } \\
\text { instituciones } \\
\text { sobre una } \\
\text { planificación } \\
\text { plurianual }\end{array}$ & $\begin{array}{l}\text { Laboratorios y } \\
\text { bibliotecas } \\
\text { independientes o } \\
\text { dependientes de } \\
\text { Universidades } \\
\text { u otros centros de } \\
\text { investigación }\end{array}$ & \\
\hline & $\begin{array}{l}\text { Red telemática } \\
\text { de alta velocidad }\end{array}$ & $\begin{array}{l}\text { Mejorar la comunicación } \\
\text { entre los investigadores } \\
\text { de la } \mathrm{CM} \text { y entre estos y } \\
\text { los investigadores que } \\
\text { desar rollan sus tareas } \\
\text { fuera de nuestra región }\end{array}$ & $\begin{array}{l}\text { Acuerdos para la } \\
\text { conexión de la } \\
\text { red de alta } \\
\text { velocidad }\end{array}$ & $\begin{array}{l}\text { Organismos de } \\
\text { investigación }\end{array}$ & \\
\hline \multirow{3}{*}{$\begin{array}{l}\text { Fomento de la } \\
\text { cooperación } \\
y \text { de la } 1+D \\
\text { empresarial }\end{array}$} & $\begin{array}{l}\text { Creación de } \\
\text { nuevas empresas } \\
\text { de base } \\
\text { tecnológica } \\
\text { (NEBT) }\end{array}$ & $\begin{array}{l}\text { Explotar los resultados } \\
\text { dela investigación a } \\
\text { través de la creación } \\
\text { de NEBT }\end{array}$ & $\begin{array}{l}\text { Contratos } \\
\text { programa con } \\
\text { instituciones que } \\
\text { desarrollen } \\
\text { estrategias propias } \\
\text { sobre NEBT. } \\
\text { Prestación de } \\
\text { servicios generales } \\
\text { y de coordinación }\end{array}$ & $\begin{array}{l}\text { Nuevas empresas } \\
\text { de base } \\
\text { tecnológica }\end{array}$ & \multirow{3}{*}{$10 \%$} \\
\hline & $\begin{array}{l}\text { Comercialización } \\
\text { e internaciona- } \\
\text { lización de los } \\
\text { resultados de } \\
\text { investigación }\end{array}$ & $\begin{array}{l}\text { Intentar dar un valor } \\
\text { económico real, exacto } \\
\text { y pronto a los } \\
\text { trabajos de centros de } \\
\text { investigación y } \\
\text { empresas innovadoras }\end{array}$ & $\begin{array}{l}\text { Contratos } \\
\text { programa }\end{array}$ & $\begin{array}{l}\text { Instituciones de } \\
\text { investigación }\end{array}$ & \\
\hline & $\begin{array}{l}\text { Subvenciones a } \\
\text { proyectos de } 1+D \\
\text { en empresas }\end{array}$ & $\begin{array}{l}\text { Crear empleo y } \\
\text { potenciar la innovación } \\
\text { tecnológica a través de } \\
\text { la investigación }\end{array}$ & Subvenciones & PYME & \\
\hline
\end{tabular}




\section{Programas, instrumentos y beneficiarios del PRICIT (3)}

\begin{tabular}{|c|c|c|c|c|c|}
\hline Áreas & Programa & Objetivos & Instrumentos & Beneficiarios & Presupuesto \\
\hline $\begin{array}{l}\text { Cooperación } \\
\text { Interregional }\end{array}$ & $\begin{array}{l}\text { Oficina del } \\
\text { espacio europeo } \\
\text { de investigación } \\
\text { y movilidad } \\
\text { PROERA }\end{array}$ & $\begin{array}{l}\text { Promover la participación } \\
\text { de investigadores y } \\
\text { empresas innovadoras } \\
\text { de la } \mathrm{CM} \text { en programas } \\
\text { europeos de } \mathrm{I}+\mathrm{D}+\mathrm{i}\end{array}$ & $\begin{array}{l}\text { Servicios de } \\
\text { asesoramiento, } \\
\text { apoyoy } \\
\text { seguimiento } \\
\text { a los proyectos } \\
\text { presentados al PM }\end{array}$ & $\begin{array}{l}\text { Instituciones que } \\
\text { se presenten a } \\
\text { conwocatorias } \\
\text { europeas }\end{array}$ & $2 \%$ \\
\hline \multirow{2}{*}{$\begin{array}{l}\text { La ciencia en } \\
\text { la sociedad }\end{array}$} & $\begin{array}{l}\text { Feria } \alpha \text { Madrid por } \\
\text { la ciencia } \$\end{array}$ & $\begin{array}{l}\text { Presentación de los } \\
\text { resultados de } \\
\text { investigación a la } \\
\text { sociedad }\end{array}$ & $\begin{array}{l}\text { Contratos } \\
\text { programa }\end{array}$ & $\begin{array}{l}\text { Instituciones } \\
\text { educativas y de } \\
\text { investigación }\end{array}$ & \multirow{2}{*}{$5 \%$} \\
\hline & $\begin{array}{l}\text { Semana Europea } \\
\text { de la ciencia }\end{array}$ & $\begin{array}{l}\text { Promocionar los valores } \\
\text { cientificos } \\
\text { entre la sociedad }\end{array}$ & $\begin{array}{l}\text { Contratos } \\
\text { programa }\end{array}$ & $\begin{array}{l}\text { Instituciones de } \\
\text { investigación }\end{array}$ & \\
\hline \multirow{3}{*}{$\begin{array}{l}\text { Gestión, } \\
\text { seguimiento y } \\
\text { evaluación }\end{array}$} & $\begin{array}{l}\text { Secretaría del IV } \\
\text { PRICIT }\end{array}$ & $\begin{array}{l}\text { Coordinar informes de } \\
\text { seguimiento y realizar } \\
\text { prospectiva }\end{array}$ & $\begin{array}{l}\text { Secretaria con } \\
10 \text { comités } \\
\text { sectoriales }\end{array}$ & $\begin{array}{l}\text { Instituciones de } \\
\text { investigación }\end{array}$ & \multirow{3}{*}{$3 \%$} \\
\hline & Madrid 2010 & $\begin{array}{l}\text { Dar a conocer a la } \\
\text { sociedad las } \\
\text { oportunidades } \\
\text { que para la CM ofrecen } \\
\text { sus recursos en ciencia y } \\
\text { tecnología }\end{array}$ & $\begin{array}{l}\text { Convocatorias } \\
\text { de premios }\end{array}$ & $\begin{array}{l}\text { Investigadores e } \\
\text { instituciones de } \\
\text { investigación }\end{array}$ & \\
\hline & $\begin{array}{l}\text { Fundación para el } \\
\text { conocimiento } \\
\text { madritd }\end{array}$ & $\begin{array}{l}\text { Prestación de servicios a } \\
\text { investigadores }\end{array}$ & Convenios & $\begin{array}{l}\text { Investigadores e } \\
\text { instituciones de } \\
\text { investigación }\end{array}$ & \\
\hline
\end{tabular}

Fuente: Elaboración propia a partir de IV PRICIT. 
Programas, instrumentos y beneficiarios del PRICIT (4)

\begin{tabular}{|c|c|c|c|c|c|}
\hline Áreas & Programa & Objetivos & Instrumentos & Beneficiarios & Presupuesto \\
\hline $\begin{array}{l}\text { Cooperación } \\
\text { Interregional }\end{array}$ & $\begin{array}{l}\text { Oficina del } \\
\text { espacio europeo } \\
\text { de investigación } \\
\text { y movilidad } \\
\text { PROERA }\end{array}$ & $\begin{array}{l}\text { Promover la participación } \\
\text { de investigadores y } \\
\text { empresas innovadoras } \\
\text { de la CM en programas } \\
\text { europeos de } 1+D+i\end{array}$ & $\begin{array}{l}\text { Servicios de } \\
\text { asesoramiento, } \\
\text { apoyo y } \\
\text { seguimiento } \\
\text { a los proyectos } \\
\text { presentados al PM }\end{array}$ & $\begin{array}{l}\text { Instituciones que } \\
\text { se presenten a } \\
\text { convocatorias } \\
\text { europeas }\end{array}$ & $2 \%$ \\
\hline \multirow{2}{*}{$\begin{array}{l}\text { La ciencia en } \\
\text { la sociedad }\end{array}$} & $\begin{array}{l}\text { Feria «Madrid por } \\
\text { la ciencia» }\end{array}$ & $\begin{array}{l}\text { Presentación de los } \\
\text { resultados de } \\
\text { investigación a la } \\
\text { sociedad }\end{array}$ & $\begin{array}{l}\text { Contratos } \\
\text { programa }\end{array}$ & $\begin{array}{l}\text { Instituciones } \\
\text { educativas y de } \\
\text { investigación }\end{array}$ & \multirow{2}{*}{$5 \%$} \\
\hline & $\begin{array}{l}\text { Semana Europea } \\
\text { de la ciencia }\end{array}$ & $\begin{array}{l}\text { Promocionar los valores } \\
\text { cientificos } \\
\text { entre la sociedad }\end{array}$ & $\begin{array}{l}\text { Contratos } \\
\text { programa }\end{array}$ & $\begin{array}{l}\text { Instituciones de } \\
\text { investigación }\end{array}$ & \\
\hline \multirow{3}{*}{$\begin{array}{l}\text { Gestión, } \\
\text { seguimiento y } \\
\text { evaluación }\end{array}$} & $\begin{array}{l}\text { Secretaría del IV } \\
\text { PRICIT }\end{array}$ & $\begin{array}{l}\text { Coordinar informes de } \\
\text { seguimiento y realizar } \\
\text { prospectiva }\end{array}$ & $\begin{array}{l}\text { Secretaría con } \\
10 \text { comités } \\
\text { sectoriales }\end{array}$ & $\begin{array}{l}\text { Instituciones de } \\
\text { investigación }\end{array}$ & \multirow{3}{*}{$3 \%$} \\
\hline & Madrid 2010 & $\begin{array}{l}\text { Dar a conocer a la } \\
\text { sociedad las } \\
\text { oportunidades } \\
\text { que para la CM ofrecen } \\
\text { sus recursos en cienciay } \\
\text { tecnología }\end{array}$ & $\begin{array}{l}\text { Convocatorias } \\
\text { de premios }\end{array}$ & $\begin{array}{l}\text { Investigadores e } \\
\text { instituciones de } \\
\text { investigación }\end{array}$ & \\
\hline & $\begin{array}{l}\text { Fundación para el } \\
\text { conocimiento } \\
\text { madritd }\end{array}$ & $\begin{array}{l}\text { Prestación de servicios a } \\
\text { investigadores }\end{array}$ & Convenios & $\begin{array}{l}\text { Investigadores e } \\
\text { instituciones de } \\
\text { investigación }\end{array}$ & \\
\hline
\end{tabular}

Fuente: Elaboración propia a partir de IV PRICIT.

\section{Bibliografía}

Adecco e Infoempleo (2011): Informe Infoempleo.com 2010, Madrid.

Consejería de Educación (2005): IV PRICIT 2005-2008. Plan de Ciencia y Tecnología de la Comunidad de Madrid, Comunidad de Madrid.

Consejería de Educación y Empleo (2011): Informe 2011 sobre la situación de la enseñanza no universitaria en la Comunidad de Madrid, Comunidad de Madrid.

Dirección General de Medios de Comunicación (2011). Comunidad de Madrid. Disponible en: <http://www.madrid.org/prensa>

Panorama Laboral (2010). Dirección General de Ordenación y Acreditación Profesional. Comunidad de Madrid. Disponible en: < http://www.madrid.org/cs/Satellite?c=CM_ Publicaciones_FA\&cid $=1142657521605 \&$ idConsejeria $=1109266187254 \&$ idListCo $\mathrm{nsj}=1109265444710 \&$ idOrganismo $=1142652621644 \&$ language $=\mathrm{es} \&$ pagename $=C$ omunidadMadrid\%2FEstructura\&sm $=1109266101003>$

Instituto de Estadística de la Comunidad de Madrid (2011): Anuario de Estadística. Disponible en: <http://www.madrid.org/iestadis/fijas/estructu/general/anuario/ ianu.htm.>

Instituto Nacional de Estadística <www.ine.es>

Portal de Formación Profesional de la Comunidad de Madrid < http://www.madrid. org/fp/>

PORTAL MADRI+D <WwW.madrimasd.org $>$ 


\section{Legislación y normativa}

Decreto 32/2007, de 14 de junio, del Consejo de Gobierno, por el que se crea el Centro Integrado de Formación Profesional en Transporte y Logística «Profesor Raúl Vázquez», de Madrid. Disponible en: <http://gestiona.madrid.org/pdf/UBKSZVW.pdf>

Real Decreto 1558/2005, de 23 de diciembre, por el que se regulan los requisitos básicos de los Centros integrados de formación profesional. Disponible en: <http://www.boe.es/ boe/dias/2005/12/30/pdfs/A43141-43146.pdf>

Decreto 65/2003, de 8 de mayo, por el que se regula la colaboración entre el Servicio Regional de Empleo y los Centros Integrados de Empleo. Disponible en: <http://www.madrid.org/cs/Satellite?blobtable=CM_Seccion_BOCM\&blobcol=seccionpdf\&blobkey=id\&b lobwhere $=1114173617921 \&$ ssbinary $=$ true\&blobheader $=$ application $/ \mathrm{pdf}>$

Orden TAS/718/2008, de 7 de marzo, por la que se desarrolla el Real Decreto $395 / 2007$, de 23 de marzo, por el que se regula el subsistema de formación profesional para el empleo, en materia de formación de oferta y se establecen las bases reguladoras para la concesión de subvenciones públicas destinadas a su financiación. Disponible en: <http://www.boe. es/boe/dias/2008/03/18/pdfs/A16051-16067.pdf>

Orden TAS/2307/2007, de 27 de julio, por la que se desarrolla parcialmente el Real Decreto 395/2007, de 23 de marzo, por el que se regula el subsistema de formación profesional para el empleo en materia de formación de demanda y su financiación, y se crea el correspondiente sistema telemático, así como los ficheros de datos personales de titularidad del Servicio Público de Empleo Estatal. Disponible en: < http://www.boe.es/boe/dias/2007/07/31/pdfs/ A33036-33049.pdf>

Orden TIN/887/2011 de 5 de abril, por la que se distribuyen territorialmente para el ejercicio económico de 2011, para su gestión por las comunidades autónomas con competencias asumidas, subvenciones del ámbito laboral financiado con cargo a los Presupuestos Generales del Estado. Disponible en: http://www.boe.es/boe/dias/2011/04/12/pdfs/BOEA-2011-6613.pdf

Orden 4608/2010, de 29 de diciembre, por la que se convocan subvenciones para la financiación de acciones de formación de oferta dirigidas prioritariamente a trabajadores desempleados en el marco del subsistema de formación para el empleo para el año 2011. Disponible en: <http://www.madrid.org/boletin/CM_Orden_BOCM/2011/01/13/BOCM20110113-17.PDF>

Orden 3727/2011, de 21 de septiembre, por la que se dictan disposiciones generales para la financiación de planes de formación, dirigidos prioritariamente a trabajadores ocupados y se convocan subvenciones para el año 2011. Disponible en: <http://www.sepe.es/Legislati$\mathrm{vaWeb} /$ verFichero,do?fichero $=09017$ edb800bd749>

Real Decreto 395/2007, de 23 de marzo, por el que se regula el subsistema de Formación Profesional para el Empleo. Disponible en: <http://www.boe.es/boe/dias/2007/04/11/ pdfs/A15582-15598.pdf>

Real Decreto 2534/1998, de 27 de noviembre, sobre traspaso de funciones y servicios de la Administración del Estado a la Comunidad de Madrid, en materia de gestión de la formación profesional ocupacional. Disponible en: <http://www.boe.es/aeboe/consultas/bases_datos/doc.php?id=BOE-A-1999-3619> 



\section{COMUNIDAD FORAL DE NAVARRA (CFN)}

Mikel Olazaran, Eneka Albizu, Cristina lavía, Beatriz Otero 



\section{Entorno socioeconómico regional}

\subsection{Datos socioeconómicos básicos de referencia y características del tejido productivo}

De acuerdo con los datos facilitados por el INE (tabla 3.1), la CFN cuenta en 2010 con 642.100 habitantes, que suponen el 1,4\% de la población española. Su PIB es de 18.121,7 millones de euros, un 1,7\% del PIB estatal. El PIB per cápita es de 29.197 euros, hecho que sitúa a esta comunidad en el $128 \%$ de la media nacional, lo que refleja que se trata una de las regiones más prósperas del país.

La Encuesta de Población Activa (INE, 2010) refleja una tasa de actividad similar para la CFN y el Estado - aproximadamente del 60\%-, mientras que las tasas de empleo y paro son sensiblemente mejores en la CFN (tabla 3.3): 54,63\% frente a 47,96\% para el empleo y $11,85 \%$ frente a $20,06 \%$ para el paro, respectivamente. De hecho, la CFN se encuentra entre las regiones con menos desempleo en España.

En referencia al tejido productivo, cabe señalar que el VAB industrial de la CFN es de 4.839,8 millones de euros, lo que supone un 3,1\% del VAB estatal. Así las cosas, la CFN es, en términos relativos, la región más industrial del Estado — junto con la CAPV—, con un VAB industrial que representa el 26,7\% del PIB regional y el 24,8\% del empleo.

Atendiendo a la especialización industrial de la región (Contabilidad Regional de España, INE, 2008), cabe señalar que la CFN destaca sobre la media española fundamentalmente en las siguientes industrias: industrias de la alimentación, bebidas y tabaco (3,1\% VAB y 3,9\% empleo); metalurgia y fabricación de productos metálicos (5,4\% VAB y 4,1\% empleo); maquinaria y equipo mecánico (3,5\% VAB y 3,2\% empleo); equipo eléctrico, electrónico y óptico (1,8\% VAB y 1,5\% empleo); y fabricación de material de transporte (4,9\% VAB y $4,8 \%$ empleo).

La industria de la CFN tiene un nivel tecnológico relativamente alto. Considerando el peso de los sectores manufactureros de alta y media-alta tecnología (Indicadores de Alta Tecnología, INE, 2009) (tabla 3.2), se observa que el 36,7\% del VAB de la industria de la CFN corresponde a actividades de tecnologías alta y media-alta, mientras que en el conjunto del Estado el porcentaje de VAB industrial dentro de estas categorías se reduce al $26,6 \%$, diez puntos porcentuales por debajo de la CFN.

El nivel educativo de la población navarra entre 25 y 64 años es más elevado que la media española (gráfico 3.1), caracterizándose por un menor porcentaje de población con techo 
de estudios en educación secundaria inferior (37,7\% en CFN frente a 47,4\% en España) y un mayor porcentaje de población con techo de estudios en educación secundaria superior $(23,7 \%$ en CFN frente a 22,0\% en España) y sobre todo en educación terciaria (38,6\% frente a 30,7\%).

No obstante, los datos de la UE15 y de la UE27 ponen de manifiesto la existencia de una descompensación de la estructura de estudios de la población en la CFN (más acusada en el caso general español). En los países de la UE los porcentajes de población activa con niveles inferiores de formación son netamente más bajos (UE15, 30,5\%, y UE27, 27,3\%), mientras que el porcentaje de la población activa con estudios de nivel intermedio es mucho más elevado (UE15, 42,2\%, y UE27, 46,8\%). Por su parte, los altos niveles relativos de población con estudios terciarios, superiores a los de los países de referencia (UE15, 27,4\%, y UE27, 25,9\%), si bien son un indicador del alto nivel de cualificación de la población navarra respecto a la media española, pueden generar, al igual que en el caso general español, ciertos desequilibrios y sobrecualificación en el mercado de trabajo.

En cuanto a la población ocupada según el nivel educativo, la tabla 3.4, elaborada con datos del Instituto Valenciano de Investigaciones Económicas, muestra las fortalezas relativas de la CFN (junto con otras regiones como el País Vasco o Asturias), respecto a la media española, en cualificaciones intermedias e intermedias-altas como la formación profesional (FP) de grado medio y superior, y en el nivel anterior al superior (diplomaturas e ingenierías técnicas). Esto se refleja específicamente en cuanto al ámbito industrial, objeto de este estudio, en la tabla 3.5.

El gráfico 3.2 refleja el espectacular crecimiento del porcentaje de personas ocupadas en la industria con cualificaciones de FP en la CFN, que pasó del 8,6\% en 1985 al 39,1\% en 2010. Este dato sugiere que el empleo de personal con cualificaciones intermedias en la industria, que ha experimentado un importante crecimiento en España y particularmente en regiones industriales específicas, es un proceso que cuenta todavía con un margen de mejora debido a las crecientes exigencias competitivas a las que está sujeta la industria.

\subsection{Indicadores de investigación, desarrollo e innovación}

La CFN dedica un 1,97\% de su PIB al gasto en I+D en 2010 (tabla 3.6), cifra bastante superior a la media española (1,39\%) y similar a la que se dedica en la UE27 (2\%). Junto con Madrid y el País Vasco, Navarra ocupa las primeras posiciones en I+D dentro de las regiones españolas. El crecimiento del gasto en I+D experimentado en la CFN entre 1997 y 2010 ha sido sostenido y en estos últimos 12 años esta región casi ha triplicado su gasto en $\mathrm{I}+\mathrm{D}$ como porcentaje del PIB.

La tabla 3.7 nos permite afirmar que en la CFN el gasto en $\mathrm{I}+\mathrm{D}$ es asumido fundamentalmente por las empresas e IPSFL $(69,4 \%)$, porcentaje muy superior a la media española (51,6\%). Por el contrario, en el ámbito estatal los sectores de la enseñanza superior $(28,3 \%$ frente a $17,8 \%)$ y la Administración pública $(20,1 \%$ frente a $8,1 \%)$ tienen un mayor peso en la ejecución del gasto en $\mathrm{I}+\mathrm{D}$ que en la CFN.

En términos relativos al PIB, destaca el gasto en $\mathrm{I}+\mathrm{D}$ en el sector empresas $(1,36 \%)$, que casi dobla la media española $(0,71 \%)$. El gasto en el sector enseñanza superior es superior a la media española $(0,44 \%$ frente a $0,39 \%)$, siendo el gasto realizado en el sector público $(0,16 \%$ del PIB) inferior a la media española $(0,28 \%)$.

En relación con el personal dedicado a I+D por 1.000 unidades de población ocupada (tabla 3.8), en 2010 la CFN se encuentra a la cabeza de las regiones españolas con un 19,25\%o 
de la población, muy por encima de la media estatal $(12,03 \%){ }^{1}$. El crecimiento de este colectivo ha sido del 241,2\% entre 1997 y 2010 (INE). Asimismo, la CFN dedica más investigadores a la $\mathrm{I}+\mathrm{D}(12,2 \%$ de la población ocupada) que el Estado (7,3\%o). Sin embargo, la participación de personal técnico y auxiliares en la $\mathrm{I}+\mathrm{D}$ (36,6\% sobre el personal de $\mathrm{I}+\mathrm{D}$ total) es ligeramente inferior a la media estatal $(39,4 \%)$.

En cuanto al sector industrial, es interesante el peso relativo de dicho sector, superior a la media española, con un $51,2 \%$ del total de la I+D empresarial. Desde el punto de vista de este estudio, es interesante señalar que el 22,3\% del personal de I+D de la industria de Navarra tiene titulación de FP, sobre todo de grado superior (tabla 3.10). Otro 25,9\% corresponde a diplomados (categoría que incluye al personal de ingenierías técnicas). Si sumamos ambas categorías, considerando a los diplomados como personal con cualificación intermedia-alta, se llega al 48,2\% del personal de I+D (en el conjunto del Estado esta suma asciende al 44,6\%). Como muestra la tabla 3.11, el conjunto de cualificaciones intermedias es especialmente importante en las pymes del tramo 150-249 empleados, ascendiendo al 67,4\%.

Una de las características distintivas de la actividad innovadora en la CFN es que esta, más que en ninguna otra región española, descansa sobre la I+D interna (tabla 3.12). Así, el $63,39 \%$ del gasto en innovación se concentra en este concepto, que en el conjunto del Estado alcanza únicamente el 46,51\% del gasto. En términos relativos, la adquisición de I+D externa y de maquinaria tienen un nivel inferior. En las pymes de menor tamaño la adquisición de maquinaria tiene una importancia mayor en la I+D, mientras que las de 75-249 empleados presentan mayores niveles de adquisición de I+D externa. En general, la actividad innovadora de las pymes de 75-249 se concentra en la I+D interna y externa, siendo, en términos relativos, el gasto en adquisición de maquinaria, equipos y software mucho menor.

En relación con la capacidad de las empresas innovadoras de la CFN para la obtención de ayudas públicas para la innovación (tabla 3.13), cabe señalar que el porcentaje de empresas que accede a ayudas públicas en 2010 es muy superior a la media española: el $40 \%$ de las empresas innovadoras reciben ayudas públicas frente al $28,8 \%$ de media para el conjunto del Estado. El nivel de acceso a ayudas regionales es superior a la media estatal, como también lo es el nivel de acceso a ayudas del Gobierno central, lo que muestra la capacidad de las empresas para competir por estas ayudas. La asignatura pendiente serían las ayudas europeas, donde las empresas innovadoras navarras consiguen menos fondos que la media estatal.

De nuevo las empresas innovadoras de entre 75 y 149 empleados muestran un interesante dinamismo: un 87,6\% de ellas acceden a financiación pública de la Administración regional y un $83,3 \%$, a financiación de la Administración del Estado. Estos datos muestran, a nuestro entender, una muy importante actividad innovadora.

Un importante aspecto que favorece la innovación en las empresas es su capacidad de cooperar con otros actores del sistema de innovación. Como muestra la tabla 3.14, las empresas de la CFN tienden a colaborar en innovación algo más que la media estatal (24,8\% frente a $22,1 \%)$. Destaca la cooperación con agentes de la cadena de valor (empresas del grupo, proveedores y clientes). El nivel de cooperación con centros tecnológicos es también importante, aunque algo inferior a la media española, y la cooperación con universidades es netamente inferior a dicha media. Destacan los niveles de cooperación de las empresas grandes (250 empleados o más), tanto en cooperación horizontal como vertical, así como tecnológica.

1 Como ha indicado en algunas ocasiones Mikel Navarro, investigador de la Universidad de Deusto, hay que recelar de una comparación con la UE en este indicador que puede verse afectada por la diferente valoración de los costes de personal. 


\subsection{Sistema institucional de agentes de $\mathrm{I}+\mathrm{D}+\mathrm{i}$}

La red de agentes de oferta de ciencia y tecnología de la Comunidad Foral de Navarra está formada por tres universidades, 14 centros tecnológicos - la gran mayoría de ellos de carácter sectorial- $y$ algunos agentes de interfaz. En muchos casos se trata de agentes creados recientemente con todavía un escaso recorrido histórico. En el anexo II se recoge una breve descripción de estos.

\subsection{Política de $\mathrm{I}+\mathrm{D}+\mathrm{i}$ en el ámbito regional}

Una característica distintiva del sistema de innovación de la Comunidad Foral de Navarra (CFN) es el papel central del Gobierno regional como «animador» de la innovación empresarial. A partir del año 2000 el Gobierno regional formaliza en mayor medida su apuesta por la I+D y define el primer Plan Tecnológico de Navarra (2000-2003), impulsado a través del Departamento de Innovación, Empresa y Empleo (antes Industria y Tecnología, Comercio y Trabajo) ${ }^{2}$. El Plan supuso una mayor estructuración de las actuaciones públicas regionales en materia de $\mathrm{I}+\mathrm{D}$, con dos objetivos principales: incrementar la actividad de $\mathrm{I}+\mathrm{D}+\mathrm{i}$ de las empresas (de manera que se fuera extendiendo en la región una cultura empresarial de la innovación) y sentar las bases de una infraestructura tecnológica que diera servicio y apoyo en materia de $\mathrm{I}+\mathrm{D}$ e innovación a las empresas (principalmente, los centros tecnológicos).

El II Plan Tecnológico (2004-2007) da continuidad a este primer plan y ya pone el énfasis en la consolidación de las actividades de I+D+i del sector empresarial, buscando que las empresas asuman una planificación y una estabilidad en dichas actividades. Por otro lado, se pretende estimular la cooperación entre la «oferta de tecnología» (universidades e infraestructura tecnológica creada) y la «demanda de tecnología» (empresas).

El III Plan Tecnológico (2008-2011) busca, sin olvidar los objetivos anteriores, propiciar un impulso mayor a la $\mathrm{I}+\mathrm{D}+\mathrm{i}$ a través de la cooperación entre los diversos agentes, tanto en el ámbito regional como en el nacional y en el internacional. Este plan supone un importante aumento de los recursos destinados a la I+D.

Así, el Plan Tecnológico de Navarra pasa de contar con una asignación de 55.206.400 euros en 2006 a contar con un presupuesto de 67.443.500 euros en 2011. En ambos casos el porcentaje del Plan Tecnológico sobre el total del presupuesto de la CFN es similar, el 1,6\%, si bien la participación del Plan en el presupuesto específico del Departamento de Industria, de quien depende, ha aumentado ligeramente, pasando del 19\% en 2006 al 20,2\% en 2011.

Dentro del III Plan Tecnológico de Navarra (2008-2011), la estimulación y el apoyo a proyectos de $\mathrm{I}+\mathrm{D}+\mathrm{i}$ empresarial (incluyendo los análisis individualizados previos) suponen la principal partida del presupuesto, concentrando el $41 \%$ de los recursos, seguida por la dedicada al desarrollo de la infraestructura tecnológica regional (22,7\%). Cobran también cierto peso la financiación de actividades de cooperación entre agentes $(8,3 \%$ para la cooperación en $\mathrm{I}+\mathrm{D}+\mathrm{i})$ $y$, en menor medida, las ayudas a la competitividad (7,1\%). El resto de las partidas cuentan con asignaciones menos cuantiosas en el presupuesto ${ }^{3}$.

\footnotetext{
2 A partir de 2011 el Departamento pasa a denominarse Departamento de Desarrollo Rural, Industria, Empleo y Medio Ambiente. Para simplificar, en este informe emplearemos el término Industria, por ser esta el área gubernamental donde se concentran los recursos de apoyo a la I+D.

3 Apoyo a solicitud de patentes (0,7\%); apoyo a incorporación de TIC en las empresas (3,7\%); apoyo a las NEBT (3,7\%); reforzamiento de la colaboración entre centros tecnológicos y agentes (1,1\%); ayudas a la contratación y movilidad de tecnólogos y doctores en empresas y centros tecnológicos (2,3\%); apoyo a la incorporación de titulados en empresas y centros tecnológicos (4,8\%); creación de comisiones mixtas para la adecuación de la oferta formativa a las demandas de las empresas $(0,1 \%)$; apoyo para la creación de propues-
} 
Durante los últimos años ha aumentado progresivamente el peso de los centros tecnológicos en la recepción de las ayudas, en detrimento de las ayudas directas a los proyectos empresariales. Así, en 1999 las empresas recibían un 96,1\% del total de las ayudas a la I+D+i, frente al 3,9\% que recibían los centros tecnológicos. En 2009 los centros superaron por primera vez a las empresas en percepción de ayudas a la $\mathrm{I}+\mathrm{D}+\mathrm{i}$, con un $50,6 \%$ de las ayudas, frente al $49,4 \%$ recibido por las empresas.

Como se ha comentado anteriormente, una característica definitoria de las políticas de I $+\mathrm{D}$ en la CFN es el papel central del Departamento de Industria, lo que reduce a otras áreas como Educación a un actor casi testimonial por su volumen en el conjunto del sistema.

El Departamento de Educación gestiona el Plan de Formación y de I+D, destinado al apoyo a cursos de doctorado para la adquisición de la suficiencia investigadora, la elaboración de tesis doctorales, el perfeccionamiento técnico, metodológico y científico de doctores y, por último, el desarrollo de proyectos de investigación de interés preferente para Navarra. Asimismo, contribuye a la investigación desarrollada en las universidades navarras a través de su aportación a los fondos generales universitarios mediante los convenios de financiación establecidos entre el Gobierno de Navarra y la Universidad Pública de Navarra y la UNED.

No obstante, la mayoría de las ayudas del Plan van destinadas a la Universidad de Navarra, habiendo aumentado durante los últimos años el peso de esta universidad. En 2009 recibió 1.338.700 euros, el 52\% de este plan, mientras que en 1999 recibió el 41\%. Por el contrario, la UPNA recibió en 2009458.000 euros, que suponen el 18\% del presupuesto, mientras que en 1999 recibió el 33,2\% de este.

\section{La FP en el ámbito regional}

\subsection{Formación reglada: recursos del sistema}

La CFN cuenta en el curso 2009-2010 con 25 centros que imparten titulaciones de FP de grado medio y 23 centros que imparten grados superiores, lo que supone un $0,96 \%$ y un $1,1 \%$ del total de centros del Estado, respectivamente (tabla 3.15).

En la CFN la FP es eminentemente pública. El 76\% de los centros que imparten enseñanzas de grado medio son públicos, 2,3 puntos porcentuales por encima de la media estatal, mientras que entre los centros que imparten grados superiores hay una -ligeramente- mayor penetración de los centros privados, siendo en este grupo el 73,9\% públicos, 2,2 puntos porcentuales por debajo de la media estatal.

La CFN cuenta en el curso estudiado con 3.380 alumnos matriculados en enseñanzas de grado medio y 3.035 en enseñanzas de grado superior (tabla 3.16), lo que supone un 1,24\% y un 1,23\% del total estatal, respectivamente. La distribución del alumnado entre centros públicos y privados es muy similar a la distribución de centros comentada anteriormente. Las tasas brutas de escolarización en FPGM y FPGS son similares a la media española.

Tal y como se puede observar en la siguiente figura (tablas 3.17 y 3.18), la evolución de la FPGM en la CFN ha mantenido un curso tendencialmente ascendente durante los últimos años, mientras que la evolución de la FPGS es más desigual. A finales de los noventa se produce una fuer-

tas europeas e internacionales (1,5\%); internacionalización de la $\mathrm{I}+\mathrm{D}+\mathrm{i}$ empresarial $(1,5 \%)$; internacionalización de la I+D+i de los centros tecnológicos $(0,1 \%)$; otras acciones de difusión $(1,1 \%)$. 
te caída relacionada con los cambios en las titulaciones de las matriculaciones, produciéndose una cierta estabilización a partir del curso 2000-2001 ${ }^{4}$. Desde la llegada de la crisis financiera de 2008 se produce un repunte de las matriculaciones en el sistema educativo que afecta también a la FP.

\section{Gráfico 2.14. Evolución de las matriculaciones de FP en la CFN} (1998-1999 / 2009-2010)

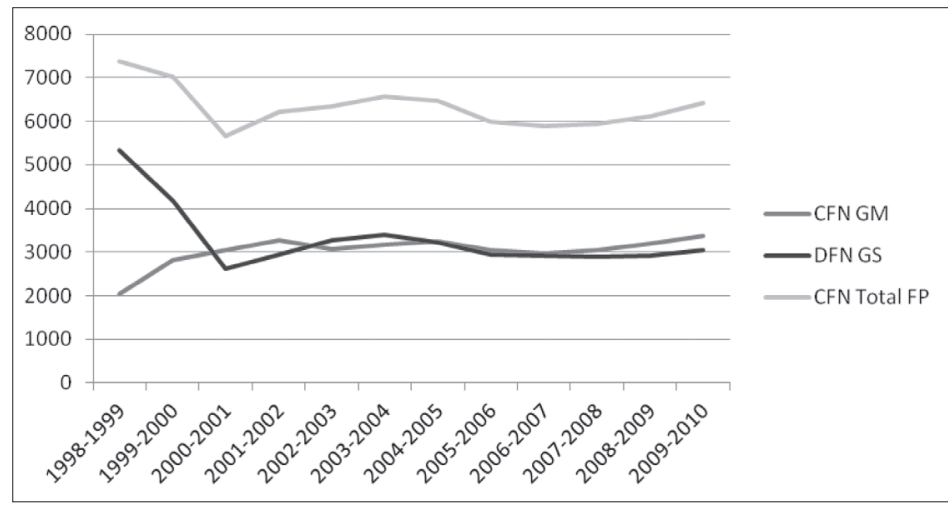

Finalmente, apuntaremos que la matriculación en las ramas industriales de la FP sigue una tendencia negativa debido, por una parte, a la diversificación y creación de nuevos estudios de FP — más asociados a la nueva sociedad de servicios - y, por otra, a la pujanza de los estudios de ESO y bachillerato. Así las cosas, en el Estado la disminución de la matrícula en las ramas industriales ha sido del $9 \%$ en FPGM y del 1,9\% en FPGS durante los últimos diez cursos académicos (tablas 3.23 y 3.24). Cabe señalar, sin embargo, que en la CFN este descenso ha sido menos acusado en $\operatorname{FPGM}(4,5 \%)$, mientras que la FPGS ha experimentado un notable crecimiento de 9,7 puntos porcentuales, probablemente por la fuerte impronta industrial de la región y el buen comportamiento comercial de los sectores industriales de la CFN y, subsiguientemente, del empleo industrial.

\subsection{Formación reglada: ámbitos de especialización}

Atendiendo a los ámbitos de especialización industrial de la FPGM en la CFN, en la siguiente figura (basada en la tabla 3.21) podemos observar que la CFN tiene una importante tasa de matriculación (12\%) en los grados medios de la familia de Electricidad y Electrónica, si bien la diferencia con la media estatal, aunque existente, es pequeña. Por el contrario, se observa un importante diferencial de especialización en Fabricación Mecánica (8 puntos porcentuales) y en Mantenimiento y Servicios a la Producción (5,8 puntos porcentuales). Existe también cierto diferencial de especialización, si bien reducido, en Madera y Mueble (1,3 p.p.), Química (0,6 p. p.) y Artes Gráficas (0,7 p. p.). En Mantenimiento de Vehículos Autopropulsados, la CFN muestra una tasa de matriculación del $8,7 \%$, muy pareja a la media estatal (8,8\%). La principal carencia relativa de la FP se sitúa en los grados medios en informática.

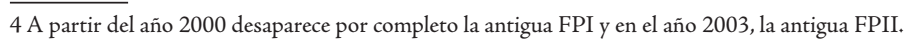


Gráfico 2.15. Áreas de especialización industrial de la FPGM en la CFN

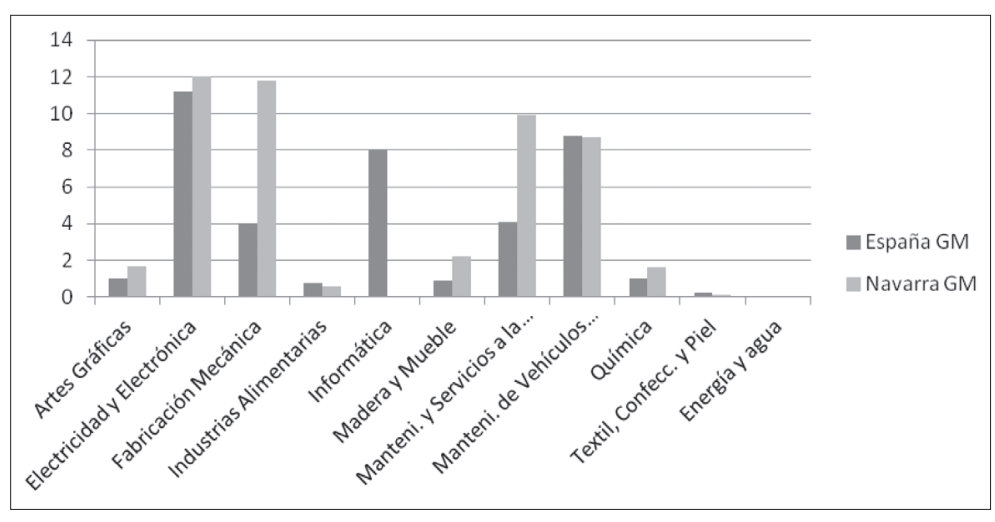

Atendiendo a los ámbitos de especialización industrial de la FPGS, en la siguiente figura (basada en la tabla 3.22) podemos observar que la CFN tiene, al igual que en los GM, una importante tasa de matriculación (12,7\%) en los grados superiores de la familia de Electricidad y Electrónica, con una diferencia con la media estatal de cerca de cinco puntos porcentuales. El principal diferencial de especialización en FPGS se produce, no obstante, en Mantenimiento y Servicios a la Producción (7,5 puntos porcentuales) y, en menor medida, en Fabricación Mecánica (2,9 puntos porcentuales). Existe también cierto diferencial de especialización, aunque pequeño, en Energía y Agua (1,2 p.p.), Madera y Mueble (0,5 p.p.) y Artes Gráficas (0,3 p.p.). La principal carencia relativa de la FP se sitúa en los grados superiores en Informática $(1,4 \mathrm{p}$. p.), Mantenimiento de Vehículos Autopropulsados (1,4 p.p.) y Química (0,6 p.p.).

\section{Gráfico 2.16. Áreas de especialización industrial de la FPGS en la CFN}

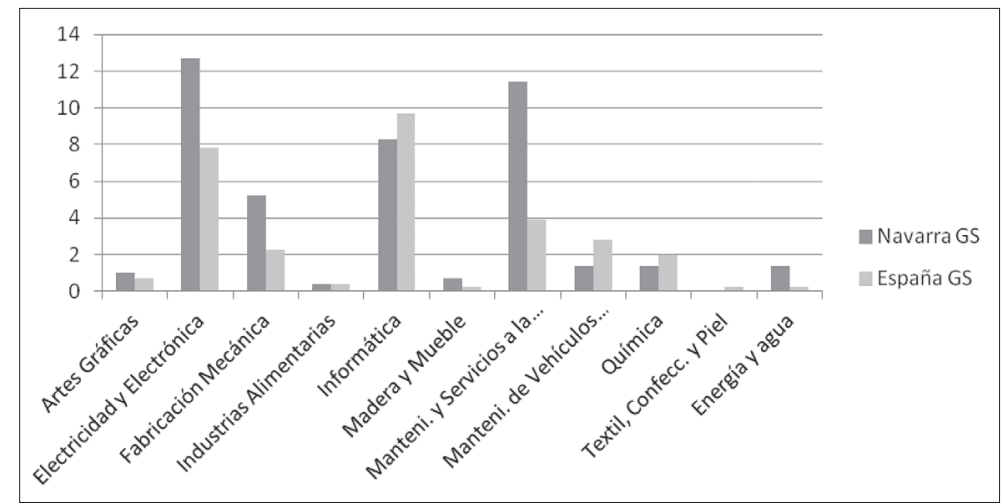

En conjunto, como muestran las tablas 3.23 y 3.24, Navarra cuenta con una especialización muy importante en familias de estudios de FP del sector industrial. El porcentaje de alumnos matriculados en dichas familias es 49,1 para FPGM y 37,3 para FPGS, siendo la media española del 33,3 y del 28,0, respectivamente. 


\subsection{Formación para el empleo: la formación de oferta}

En la CFN han participado en la formación para el empleo, en la modalidad de oferta, durante 2010, un total de 7.710 personas, lo que supone un $0,98 \%$ del total estatal (tabla 3.25).

Dentro de esta modalidad de formación para el empleo, señalaremos que en la CFN corresponden a la industria el $22,9 \%$ de las personas formadas, en la línea de lo que sucede a nivel estatal $(22,7 \%)$.

La fórmula presencial es la más utilizada en la CFN, abarcando a un 52,8\% de las acciones, 4,3 puntos porcentuales por encima de la media estatal. La formación a distancia (19,9\%), la formación mixta (13\%) y la teleformación $(14,3 \%)$ son fórmulas mucho menos utilizadas. Entre estas, señalaremos que la teleformación se sitúa a 5,6 puntos porcentuales por debajo de la media estatal, estando la formación a distancia y la formación mixta en línea con las prácticas estatales.

La mitad de las personas formadas han sido mujeres (50,5\%), casi cinco puntos porcentuales por encima de la media del Estado y por delante del resto de regiones de referencia (tabla 3.26). Asimismo, cabe señalar que más de la mitad de las personas formadas se encuentran en la franja de edad 36-55, siendo en este colectivo donde se produce una mayor diferencia con la media del Estado, 4,4 puntos porcentuales a favor de la CFN.

La formación de oferta en la CFN, al igual que ocurre en el Estado, se dirige a personas con menores niveles de cualificación (tabla 3.27). Más concretamente, el 34,3\% de las personas formadas no tenían cualificación y otras tantas (34\%) tenían poca cualificación. La diferencia más notable, si se compara con el Estado, estriba en que en la CFN los mandos intermedios reciben más formación de oferta (12,9\% frente a 6,4\%). En sentido contrario, en la CFN los técnicos y directivos reciben menos formación de oferta que en el Estado (9,9\% frente a 12,7\% y $8,9 \%$ frente a $10,2 \%$, respectivamente).

\subsection{Formación para el empleo: la formación de demanda}

De acuerdo con los datos que facilita la Fundación Tripartita para la Formación en el Empleo (tabla 3.29), durante 2010 se formaron 40.986 trabajadores en las empresas de la CFN, el $1,47 \%$ de las personas formadas en la modalidad de demanda en el Estado español, siendo el $22,4 \%$ de las empresas de la CFN las que hacen formación de demanda, un poco menos que la media estatal (24,6\% de las empresas).

Entre estas, las pymes con mayor tamaño (aquellas empresas comprendidas entre 50 y 249 trabajadores) son las que relativamente dedican más esfuerzo a esta actividad. Así, el 83\% de las empresas situadas en esta franja de tamaño han efectuado formación de demanda; 8,6 puntos porcentuales por encima de la media estatal y también sensiblemente por encima del resto de las regiones de referencia.

Cabe señalar que la tasa de cobertura de la formación de demanda en la industria manufacturera (tabla 3.28) es del 37,3\%, superior a la media estatal (32,8\%). Como se puede observar en la tabla 3.29, el 70,7\% de los participantes formados en empresas manufactureras corresponde a empresas mayores de 100 trabajadores. Atendiendo a la distribución por sectores empresariales (tabla 3.30), el porcentaje de participantes formados en el sector industrial $(36,9 \%)$ dobla la media española $(18,7 \%)$. La CFN, junto con Asturias, tiene las mayores tasas de cobertura en formación de demanda en la industria manufacturera (en torno al 37\%; tabla 3.28). 
La formación de demanda es fundamentalmente presencial en la CFN; tres cuartas partes de las personas formadas lo han sido dentro de esta modalidad de formación, índice que, en el caso de las empresas industriales, sube al $84,7 \%$, sensiblemente por encima de la media estatal $(59,8 \%$ y $68,8 \%$, respectivamente) y del resto de regiones de referencia.

Cerca de tres cuartas partes de las personas formadas dentro de la modalidad de demanda en la industria han sido hombres y de edades comprendidas entre los 26 y 45 años.

La formación de demanda en la industria de la CFN (tabla 3.32) está dirigida, en mayor medida, a las personas con responsabilidades de gestión. Así, un 45,2\% de las personas formadas pertenecen a las categorías de directivos, mandos intermedios o técnicos, 6,9 puntos porcentuales por encima de la media estatal, mientras que un $35,1 \%$ de las personas formadas en esta modalidad han sido trabajadores cualificados, 8,2 puntos porcentuales por debajo de la media estatal. Dentro de la mano de obra no cualificada, un $19,7 \%$ ha recibido formación de demanda en la CFN, ligeramente por encima de la media estatal $(18,6 \%)$.

En relación con el perfil profesional de las personas formadas (dentro de la fórmula de demanda) en la industria de la CFN y con la estructura de estudios de la población en esta región, el perfil académico de los participantes en la formación es medio-alto (tabla 3.33). El $40,6 \%$ de las personas cuentan con estudios secundarios postobligatorios y un $36,6 \%$ con estudios universitarios. Especialmente, las personas con estudios universitarios que reciben este tipo de formación reflejan la mayor diferencia con la media española, existiendo 7,4 puntos porcentuales de diferencia en este colectivo. Como consecuencia de lo anterior, las personas con bajos niveles de estudios reciben proporcionalmente menos formación de demanda en la CFN (por ejemplo, las personas con estudios primarios y secundarios obligatorios representan un $20,6 \%$ de los formados frente al 29,1\% de la media estatal).

Los permisos individuales para la formación en la CFN ( 52 permisos en 2010) se distribuyen al $50 \%$ entre las medianas y las grandes empresas (tabla 3.34), mostrando mucha mayor propensión a la concesión de este tipo de permisos en las empresas medianas navarras que en las españolas (26,7 puntos porcentuales de diferencia). Lo contrario ocurre en el caso de las grandes empresas. No obstante, hay que destacar el bajo nivel general de extensión de esta práctica.

\subsection{Política regional en relación con la FP}

La actuación regional sobre la FP en la CFN parte del Plan de Formación Profesional 2001-2004, continúa con el Acuerdo de 4 de abril de 2005 del Gobierno de Navarra, por el que se establecen las directrices para el desarrollo del Sistema de Cualificaciones y Formación Profesional en Navarra, y, subsiguientemente, sigue con el Decreto Foral 54/2008, de 26 de mayo, por el que se regula la ordenación y el desarrollo de la formación profesional en el sistema educativo de la Comunidad Foral. Entre los objetivos de este decreto están: el desarrollo del currículo educativo, la potenciación de las relaciones con la empresa (a través de la oferta de formación para trabajadores y la participación de profesionales del sector productivo como docentes) y el desarrollo de los centros integrados, que serían, según la nueva normativa, referentes en sus especialidades tanto para formación reglada como para ocupacional y continua. Navarra fue pionera en su regulación en 2006, así como en el impulso a la innovación tecnológica y didáctica y a la internacionalización de los centros de FP.

Dentro de este proceso de cambio del sistema de formación y cualificaciones, un aspecto clave es la relación entre los distintos sistemas de formación (reglada, ocupacional y continua), donde intervienen dos ámbitos de la Administración (Educación, por una parte, y Empleo, por otra) y donde desempeña un importante papel el Consejo Navarro de Formación Profesional, 
órgano consultivo y asesor en el que participan, además de los departamentos mencionados, los agentes sociales ${ }^{5}$. En 2011 los presupuestos para formación ocupacional (preferentemente para desocupados) y continua (preferentemente para ocupados) en Navarra fueron, respectivamente, 5 y 9 millones de euros (Presupuestos de Navarra 2011) ${ }^{6}$. Sobre la base de un convenio entre el Departamento de Empleo y el Departamento de Educación, los centros de FP recibieron 766.710 euros en 2011 para su oferta de cursos de formación ocupacional y continua.

\subsection{Prácticas de formación en centros de trabajo (FCT)}

De acuerdo con el trabajo empírico de Olazaran et alii (véase ficha técnica en el anexo I), el 73\% de las pymes industriales tiene o ha tenido alguna relación con centros de FP. La existencia de relaciones con centros de FP es significativamente más frecuente entre las empresas de mayor tamaño (a partir de 50 empleados el porcentaje asciende al 85,7\%) y entre las empresas de metalmecánica (86,5\%). Sin llegar a ser diferencias estadísticamente significativas, la detección de relaciones es también más frecuente entre las que se consideran innovadoras $(74,1 \%)$ y entre las que tienen un plan de formación $(76,8 \%)$. Este nivel de relación entre las empresas y los centros de $\mathrm{FP}$ es un hecho altamente significativo que sugiere un grado importante de interacción entre las empresas y el sistema educativo de FP.

Otro aspecto importante sobre las relaciones de las empresas con los centros de FP es que son geográficamente cercanas: el $73 \%$ de las empresas se relacionan principalmente con centros de FP radicados en la misma comarca y el 19\% con un centro de otra comarca pero radicado en Navarra (por lo tanto, el 92\% de las relaciones se refieren a centros ubicados dentro de la propia Comunidad Foral, un indicador de su contribución al desarrollo regional).

De acuerdo con la evidencia cualitativa, recogida tanto en las empresas como en los centros de FP, se manifiesta una buena valoración de la capacitación del alumnado de FP, muy notablemente del nuevo grado superior surgido de la LOGSE, que compite con los ingenieros por su alto nivel de adaptación a las necesidades de las pymes y por sus inferiores costes ${ }^{8}$.

En las empresas nos dicen que para ellos, desde la perspectiva del mando intermedio y de ser gente que tenga un feedback con la empresa, tienen más confianza en este tipo de técnicos [de grado superior] que en los que vienen de la universidad, que tienen, lógicamente, unos perfiles muchísimo más amplios en cuanto a lo que sería la especialización... Llevamos ya diez años con antiguos alumnos y muchos de ellos están ocupando cargos relevantes en las empresas. (FP3, pp. 16-17) ${ }^{9}$

En una oficina técnica prefieren muchas veces un delineante industrial antes que un ingeniero. (FP5, p. 17)

Mientras que un técnico de grado medio se ocupa de la conducción de una línea, el de grado superior es gestión en sí de toda la planta. Serían los responsables de la calidad, los responsables

\footnotetext{
5 En Navarra participan en este organismo la Confederación de Empresarios de Navarra (CEN) y los sindicatos UGT y CC. OO. No participan sindicatos con un nivel importante de representación como son ELA y LAB.

6 En los presupuestos hay otras partidas relacionadas con la formación. Hay que destacar, por ejemplo, una partida de 5,56 millones de euros para escuelas-taller (programas mixtos de formación y empleo para jóvenes desempleados).

7 Olazaran, M.; Albizu, E.; Lavía, C. y Otero, B.: «Formación profesional, pymes e innovación en Navarra», Cuadernos de Gestión. Aceptada publicación en vol. 13, núm. 1.2013.

8 En relación con la alta valoración de la FPGS, hay que mencionar que existe un riesgo de que crezcan las distancias respecto al grado medio, bajando los estándares de calidad y alumnado de este.

9 Las entrevistas con la numeración FPx corresponden a las realizadas a directores de centros de formación profesional o responsables de relaciones con la empresa. Las entrevistas con la numeración Ex corresponden a las realizadas en empresas a directores gerentes y directivos de oficinas técnicas o de departamentos de $\mathrm{I}+\mathrm{D}$, o a personas con responsabilidades en innovación.
} 
de la logística, qué hacemos, a quién compramos, controlar la calidad, cómo te vienen los productos, calidad con la que salen. Muchos de nuestros alumnos se colocan en calidad. Muchos. (FP7, pp. 20-21)

La tendencia es a coger gente de grado superior [frente al grado medio]. En muchas ocasiones huyen un poco del ingeniero, aunque lo utilizan a veces para hacer ese desempeño de un profesional, digamos, cualificado y demás. Las empresas buenas, competitivas, de la zona están pensando en coger solo a técnicos de grado superior. Y también quieren, lógicamente, pagarles cuanto menos mejor. Tienen que ajustar costes, tienen que ser competitivos, y eso no sé si es justo o no, pero es una necesidad que tienen, el ser competitivos. Y si no lo son, al final se quedan sin trabajo. Y conjugar todo eso no es tarea fácil. (FP13, p. 15)

Los directivos no son ingenieros, ¿eh? El director general era un FP instalador de neumática y X lo mismo. Buenos técnicos. Esos han nacido de buenos técnicos de FP. Increíblemente. Y se nota en la naturaleza de la empresa y la gente. (E9, p. 18)

\section{Formación en Centro de Trabajo (FCT), Bolsas de Trabajo y Estancias de Profesorado en Empresas}

La forma más generalizada y básica de relación de las pymes con los centros de FP es la de recibir alumnado en prácticas: de las empresas que declaran mantener relaciones con los centros, el $90 \%$ recibe alumnado en prácticas de FCT. Se trata, por lo tanto, de un tipo de relación ampliamente extendida y aceptada. Además, la recepción de alumnado en prácticas se valora con un elevado grado de satisfacción, y de manera homogénea, por parte de las empresas: 7,54 puntos en una escala de 0 a 10.

Frecuentemente, las prácticas de FCT, que se realizan en el último trimestre del segundo año del ciclo de formación reglada (de grado medio o superior), suelen estar relacionadas con la posterior contratación de los estudiantes. La contratación de trabajadores a través de las bolsas de trabajo de los centros es la segunda forma de relación más frecuente entre centros de FP y pymes industriales navarras. La mayoría de las empresas relacionadas con centros de FP (56\%) manifiestan que contratan trabajadores recurriendo directamente a los propios centros, lo cual supone una incidencia del $41 \%$ sobre el total de pymes encuestadas. Con una valoración media de 7,5 (escala 0-10), se deduce que también el grado de satisfacción de las empresas que recurren a este servicio es alto.

De las relaciones regulares entre los tutores de los centros y los instructores de las empresas (no hay que olvidar, además, que estos son en ocasiones antiguos alumnos de los centros) surgen relaciones de cercanía y confianza que derivan en la articulación de un canal de comunicación a través del cual los centros de FP reciben gran cantidad de información y detectan necesidades de las empresas.

Así, en las entrevistas cualitativas realizadas, hemos podido comprobar que el sistema de prácticas FCT es el nexo principal de relación entre el sistema educativo de FP y las empresas. De la relación entre pymes industriales y centros de FP en torno a las prácticas se derivan resultados como la contratación de estudiantes egresados, adaptaciones en el currículo de la formación regla$\mathrm{da}^{10} \mathrm{y}$ detección de necesidades de formación continua y de necesidades tecnológicas.

El profesor previamente ha ido a acordar un programa formativo con la empresa. Han llegado a un acuerdo en las tareas que van a realizar durante ese tiempo los alumnos que van a ir allí, hace un seguimiento quincenal, in situ, para ver cómo se va desarrollando todo este proceso,

10 Esta posibilidad, contemplada en la normativa legal (Decreto Foral 54/2008), supone un importante mecanismo de ajuste a las demandas de las empresas y se ha visto reflejada con profusión en las entrevistas realizadas. 
tiene contacto con los encargados de la empresa, etc., etc. Todo eso es una fuente de información directísima y tremenda. (FP11 p. 3)

Aquí, en el centro X, participan como tutores de prácticas FCT todos los profesores que imparten clase en el curso. Hay unos que llevan a dos alumnos, otros a tres, otros... De tal forma que todo el equipo está en contacto con la empresa... Con lo cual quiere decir que todos se enriquecen de ir hacia el exterior y visualizar qué es lo nuclear, qué es lo fundamental, para luego aquí no quedarte con lo accesorio. Y luego, pues ese intercambio, esa puesta en común... (FP3, pp. 5-6)

Conozco mucho a su director y a la gente que trabaja allí, y vienen aquí a visitarnos, y traen a los chavales, y tal... Y siempre me intentan vender que ellos también desarrollan [tecnología] y que ellos también hacen, y que les gustaría [participar en proyectos]. (E10, p. 9)

Y estos módulos formativos atienden a estas actividades, a este perfil, que nosotros tenemos aquí en el centro. Claro, a partir de ahí, sí que es cierto que el perfil después hay que circunscribirlo a la tipología de industria que haya en cada comarca o en cada zona... [Por otro lado,] en cuanto a lo que serían inversiones en material para las prácticas y demás, pues sí que se tiene muy en cuenta también qué es lo que se está haciendo alrededor en las empresas. (FP3, pp. 3-4)

Hicimos un estudio, me encargué yo mismo de ver, antes de poner el ciclo formativo, qué necesidades tenía la zona. E, invariablemente, en todas las empresas del sector se decía: necesitamos aquí una persona que no solo sepa conducir las líneas de $\mathrm{X}$, sino que sepa mantenerlas. Porque en cualquier momento hay un fallo, y no se puede esperar a que el taller auxiliar venga, porque se ha perdido mucho tiempo, porque igual es una tontería y un trabajador puede arreglar la máquina, ¿no? Y nosotros lo incorporamos y lo hicimos. Entonces, es un ciclo especial. No hay en toda España el ciclo que hay aquí. Es X más mantenimiento. Aumenta un año más los estudios. (FP7, p. 4)

Tenemos una serie de equipos docentes, tenemos una serie de antenas diseminadas por todo el entorno productivo de $\mathrm{X}$ y su comarca, y eso nos permite captar cuáles son las tendencias, qué necesidades está teniendo ahora mismo la empresa, y ver y contrastar si realmente aquello que estamos intentando desarrollar en el propio alumnado es útil a la empresa, encaja, cumple con las expectativas. (FP13, p. 10)

En consecuencia, las relaciones entre centros de FP y empresas que se establecen a través de las prácticas de FCT son la base de formas más «avanzadas» de relación, entre las que destaca, en el caso de la CFN, la formación continua.

A través de esos contactos [FCT] se derivan también, muchas veces, peticiones de las empresas, que te dicen: «Oye, ¿vosotros dais formación [continua]?». (FP4, p. 6)

Las necesidades de formación continua de las empresas se detectan a partir de las prácticas $y$, sobre todo, de las estancias [de profesores en las empresas]. Y son las dos fuentes, básicamente. (FP10, p. 15)

Cuando hacemos las prácticas, pasamos sistemáticamente a las empresas una encuesta en la que detectamos, entre otras cosas, qué necesidades formativas serían interesantes para sus propios trabajadores y, en la medida de lo posible, canalizamos esa propuesta de actividades formativas a la Unidad Técnica de Formación Profesional [del Departamento de Educación] para que nos facilite el que podamos impartir algún curso a las empresas a la carta y/o haciendo un compendio de las distintas organizaciones. (FP13, p. 1)

Otra forma de relación entre los centros de FP y las empresas son las estancias de profesores en estas. Este instrumento, apoyado por el Gobierno regional, es bien valorado como forma de profundizar en el conocimiento de las tecnologías y las necesidades de las empresas, pero se reconoce mayoritariamente que su extensión es, a día de hoy, limitada. Como en el caso 
de otras actividades consideradas «extras» del profesorado (formación continua, innovación), existen inercias en contra de su desarrollo, que depende más bien de iniciativas personales.

En esto, lo que te he dicho, estamos dos profesores de estancias en empresa. De los 20, es un $10 \%$. El resto no está. Y bueno, aunque vamos pasando a lo largo de los años, pues en los últimos cuatro años igual hemos pasado pues dos, cuatro, seis o siete. Pero claro, el resto aún no ha pasado. (FP10, p. 24)

Ha estado puntualmente algún profesor, no es significativo. (FP12, p. 12)

¿Innovación? Casi prefiero que nos dejen ir a la empresa a trabajar para ver qué está aplicando la empresa. (FP12, p. 15)

\subsection{Otros tipos de relaciones entre los centros de FP y las empresas. Papel de los centros de FP en la formación para el empleo}

\section{Formación continua}

Los centros de FP aparecen como proveedores de considerable importancia en servicios de formación continua para las empresas con las que se relacionan: el 30,5\% de las pymes industriales navarras que tienen relaciones con los centros de FP envía a sus trabajadores a recibir formación continua reglada en los centros, lo que supone un $22,2 \%$ del total de empresas encuestadas. Además, el 24\% de las empresas ha desarrollado formación continua bajo demanda con centros de FP. Si bien la combinación de ambos formatos no es muy frecuente (19\%), un 36\% de las empresas que tienen relaciones con centros de FP ha recurrido a sus servicios de formación para trabajadores de una u otra forma.

Los cursos de formación que imparten los centros de FP para los trabajadores de pymes son muy bien valorados por las empresas: cuando se ha detectado este tipo de relación, las valoraciones resultantes nunca son negativas, de manera que como imagen global tenemos un notable. La media de valoración de esta relación es de 7,6, subiendo hasta el 8 (sobre 10) en el caso de la formación a medida, una forma de relación y servicio menos frecuente pero más intensa: prácticamente todas las empresas (el 93\%) que realizan este tipo de formación continua tiene ya otros dos o más tipos de relaciones diferentes con los centros, incluyendo recibir prácticas, contratar, etc.

Las entrevistas cualitativas realizadas nos permiten profundizar en la problemática de la formación continua para los centros de formación profesional. La conclusión principal que se obtiene de esta evidencia empírica es que existen importantes obstáculos, tanto internos al sistema de FP como externos a este, para alcanzar la integración entre la formación reglada y la formación para el empleo, un objetivo clave de las reformas y normativas recientes (en el caso de Navarra, el Decreto Foral 54/2008).

En el momento de la realización del trabajo de campo en Navarra (entre abril y noviembre de 2010), existía una percepción unánime entre los agentes de FP entrevistados sobre la insuficiencia de los fondos asignados por el Servicio Navarro de Empleo (SNE) para cursos de formación continua en los centros de FP. De hecho, estos fondos fueron eliminados en 2009 debido a las desavenencias entre el Departamento de Educación y los agentes sociales del Consejo de Formación Profesional. Los agentes de FP entrevistados manifiestan que, en comparación con los centros formativos creados al albur de las organizaciones sindicales, su oferta formativa y sus instalaciones se adaptan mejor a las necesidades de las empresas, y que podrían impartir 
mucha más formación continua de la que imparten en la actualidad (los centros entrevistados imparten por término medio entre 5 y 10 cursos anuales subvencionados por el SNE).

A diferencia de la C. A. del País Vasco, aquí en Navarra tienen mucho protagonismo los sindicatos y las organizaciones empresariales. Entonces, de hecho, prácticamente la totalidad de la formación continua va por ese conducto. Y una pequeñísima parte - mínima diría yo- es la que se deriva a los centros de formación profesional. (FP3, p. 6)

No nos cabe la menor duda de que realmente los que tendríamos la clientela seríamos nosotros, por la especificidad de cada una de las familias profesionales. Merecería la pena que los medios que tenemos estuviesen utilizándose desde las ocho de la mañana hasta las diez de la noche, y cuanto antes se amortizasen y se renovasen, pues todo el mundo saldría beneficiado. Y el hecho de estar en esos mismos centros, pululando los trabajadores y nosotros, pues habría esa ósmosis entre un sistema y el otro que favorecería a todo el mundo. (FP3, pp. 7-8)

El problema es quién es el que administra eso [el sistema de formación continua]. Ese es el problema. Quién es el que administra y a quién se le adjudica. (FP4, p. 10)

Formación continua se hacía antes más. ¿Por qué? Porque siempre había empresas que nos solicitaban o nosotros ofertábamos cursos. Pero ahora los sindicatos son los que absorben. Todo el tema se ha ido para los sindicatos. Los sindicatos han asumido esas funciones, que no son propias de ellos. Y a nosotros nos han quitado el dinero. (FP6, p. 6)

No podíamos impartir un curso de soldadura porque no nos lo concedían, y luego venía el sindicato X con el curso de soldadura a ver si lo podían impartir en nuestras aulas. (FP8, pp. 29-30)

En los años ochenta se llamaba educación para adultos (EPA), y desde este centro se organizaba formación continua para 1.800 trabajadores y trabajadoras. Educación para adultos estaba insertado en el organigrama del centro, y se organizaban por todas las localidades cursos... En la comarca antes teníamos la exclusividad, no había otro centro de formación profesional. La realidad de hoy es que, de diez años a esta parte, han emergido otros centros paralelos en materia de formación profesional, y tenemos una concurrencia competitiva yo entiendo que desleal... Nos está ocurriendo que algún curso de formación para el empleo que estamos ofertando nosotros también lo están ofertando esas tres o cuatro entidades formativas de los sindicatos que existen en la zona. Y unos u otros nos vemos sin alumnos, porque no es tanto el potencial de gente dispuesta a formarse. Entonces, todo eso se tiene que coordinar. (FP13, pp. 2-5)

Además de las dificultades relacionadas con los procesos de asignación de los fondos de formación continua, existen otros problemas de carácter más interno al sistema educativo de FP como son la falta de autonomía de los centros, la falta de incentivos, los límites legales a la dedicación del profesorado funcionario a estas actividades o la imposibilidad de planificar e integrar la formación continua en los horarios y en la carga lectiva del profesorado titular. Incluso en el centro nacional integrado entrevistado, con programas de formación para el empleo de ámbito estatal, se constata una rigidez en la separación entre formación reglada y formación continua.

En estos momentos, lo que sería la estructura de centros integrados, que fundamentalmente daría un poco de respuesta a todo eso, con esas dimensiones, pues está muy poco desarrollada. Quiero decir, en el IMH [Instituto de Máquina-Herramienta, Elgoibar] hay gente que su jornada laboral la dedica a eso. Aquí eso es impensable. La formación continua siempre es como una cosa extra. (FP3, pp. 10-11)

Los cursos de 2010, solicitados en abril del año pasado, nos los han comunicado la semana pasada [abril de 2010]. Como comprenderán, nos quedan mayo y junio para este trimestre, y luego, septiembre, octubre, noviembre y diciembre para el que viene. Para intentar encajar los once cursos que nos han concedido. Entonces, es muy difícil, y además la única posibilidad de 
ajustarlo ahí, en el centro, es hacer horas extraordinarias los profesores. Es decir, es el profe el que tiene que coger y decir: «Yo doy ese curso». Entonces, un trabajo extraordinario, cosa que no es lo ideal. Lo ideal sería saber desde el principio la planificación, decir: «Tenéis estos cursos», y te puedes planificar desde los propios departamentos..., puedes tener la planificación de los cursos reglados y los cursos de formación continua u ocupacional. (FP4, pp. 7-8)

El centro integrado se ve de alguna manera con las manos atadas a la hora de hacer una oferta autónoma. ¿Por qué? Porque las partidas económicas dependen de Trabajo o, en todo caso, del Departamento de Educación, que hace una redistribución entre todos los centros de su red pública... No tenemos capacidad para hacer una oferta directa en formación ocupacional y continua. (FP10, pp. 3 y 6 )

Nosotros, al final, siempre lo que se ha intentado luchar es por que te den medio profesor más, o te den algo, para que des esas horas. O cogerte y decir: «Bueno, pues vas a tener dos horas menos todos los días, y en la temporada que había que dar el curso, pues das el curso, y ya está». (FP8, p. 17)

A juicio del agente social entrevistado, un problema clave que obstaculiza una mayor financiación para formación continua en los centros de FP, principalmente en los centros integrados, es la falta de autonomía de los centros y su subordinación excesiva al Departamento de Educación. Este problema se refleja en la falta de operatividad de los consejos sociales de dichos centros, donde están representados los agentes empresariales y sindicales. Estos agentes exigen una mayor participación como condición para vehicular más recursos económicos hacia la formación continua en centros de FP.

En cuanto a la formación de demanda desde las empresas, según el sistema de deducción de las cuotas de formación por parte de estas, gestionado desde la Fundación Tripartita (bonificaciones), está menos extendida debido también, en parte, a las rigideces internas de funcionamiento de los centros públicos de FP. Algunas asociaciones empresariales comarcales están tratando de fomentar este tipo de formación entre las pymes de sus zonas.

La otra [opción] es que la empresa nos pague a nosotros. Que nos paguen a nosotros el costo de ese curso y ellos se lo deduzcan, nosotros tampoco tenemos problemas. Pero nosotros tenemos una limitación ahí, entre comillas, a la hora de facturar. Por esa pega, porque si yo tuviera aquí la artillería del centro privado X, ¿me explico? Llama a las empresas: «¿Qué cursos...? Sí, tenga. Pues yo te facturo tal, y tú te lo descuentas de tal». (FP4, p. 9)

Claro, nosotros, toda esa colaboración tenemos, pero lo bonito sería que fuese el centro el que facturara, y que luego, bueno, pues cobrase el profesor, o lo que fuese, pero que saliera del centro, que figurara Educación. Y al final, simplemente es una relación a título personal entre el profesor y la empresa. Aunque se realiza todo a través del centro... Al final, pues las personas no pueden facturar, pero siendo profesor, pues hasta unos 3.000 euros o así, cantidades pequeñas, puedes llegar a facturar con el DNI. Pero lo bueno sería que entrase Educación ahí. Porque estás dando un curso, y tienes relación o una colaboración con una empresa... Se podría llegar a un cauce o alguna vía... (FP8, pp. 8-9)

Hemos empezado ahora. La asociación empresarial comarcal X ha empezado [a fomentar] ese modelo de formación y se lo está enseñando a las empresas, y las empresas lo están utilizando. Desde septiembre hasta mitad, el primer curso... Lo que nos parece, bueno, no nos parece mal, pero nosotros estamos limitados a ese número de horas... Y luego tampoco podemos facturar. (FP8, p. 28) 


\section{Servicios de apoyo a la innovación en las empresas}

Además de las principales misiones de los centros de FP (la cualificación de los estudiantes y la recualificación de los trabajadores), una tercera misión, «no tradicional», de los centros sería el apoyo (más explícito) a la innovación en las pymes. El Decreto Foral 54/2008, en su artículo 26, señala el carácter estratégico de la innovación tecnológica (además de la puramente didáctica) e indica que se constituirá un sistema de vigilancia tecnológica y se fomentarán los proyectos de innovación ${ }^{11}$.

A la luz de los resultados obtenidos en la encuesta realizada, se desprende, no obstante, que el papel de los centros de FP en proyectos formales de innovación con las empresas es realmente reducido en este momento en Navarra. Un 5\% de las empresas tienen algún centro de FP como colaborador en programas de mejora de gestión/organización y tan solo un 1,7\% ha realizado con este tipo de centros algún proyecto (formal) de innovación técnica.

Los contactos entre centros de FP y pymes que pueden redundar en mejoras e innovaciones en estas pueden tomar distintas formas. Así, cabe señalar que un $10 \%$ de las empresas han utilizado las infraestructuras técnicas de los centros de FP para pruebas o ensayos y que manifiestan una alta satisfacción $(7,7)$ con este servicio.

Las entrevistas nos han permitido corroborar la extensión, a día de hoy limitada, de los proyectos formales de innovación, apoyados por una línea incipiente de la Administración regional. Sin lugar a dudas, la crisis ha frenado algunas de estas posibles iniciativas entre las empresas. No obstante, se dan casos exitosos (por ejemplo, el desarrollo de un sistema de visión artificial para una importante empresa de naipes) que pueden servir de modelo de la potencialidad de este tipo de colaboración.

En los centros de FP hay un material con el que nadie cuenta, y es el material humano de los profesores. Hay personas muy, muy válidas, con muchas ganas de hacer algo, que podrían participar en proyectos... (E7, p. 14)

Sí que podríamos colaborar y no lo hacemos. Culpa de ambos. (E10, p. 9)

¿Servicios a la empresa? Hay pequeñas pruebas, que suelen hacer con empresas que no tienen recursos técnicos como para hacer algunos ensayos. Alguna cosilla sí que se ha hecho. Pero, más allá, el planteamiento sería entrar... Claro, las empresas, ya sabes, lo que quieren es hacer una cosa rápida. Y a nosotros más nos interesaría entrar en temas de colaboración en proyectos de innovación. (FP10, p. 25)

Contactamos con una empresa que se dedicaba a hacer algo de visión. Entonces vino uno, el representante, un poco, el técnico, y yo le dije: «Bueno, a ver, algún problema que tengáis en vista que no se pueda resolver». Y entonces dijo: «Pues tengo este tema de las cartas». Y así empezó el tema. Presentamos un proyecto de innovación y nos lo aceptaron... En la cadena de esta empresa tienen puesto el sistema [que desarrollamos] en dos o tres sitios. (FP12, pp. 17 y 22)

11 En el momento de la realización del trabajo de campo de este estudio se habían realizado cuatro convocatorias anuales de proyectos de innovación. 


\section{Conclusiones}

La CFN es una región próspera (PIB, renta per cápita, empleo) dentro del contexto español gracias en buena medida (aunque no únicamente) a tres elementos: cultura y desarrollo industrial, Gobierno regional activo en la política tecnológico-industrial y alto nivel de cualificación de la población.

En relación con la primera cuestión, cabe señalar que la tradición industrial de la CFN viene de lejos y que en la actualidad es la región más industrial del Estado, estando su actividad industrial fundamentalmente orientada hacia las diferentes ramas industriales de la metalmecánica. Asimismo, cabe señalar que el nivel tecnológico de esta industria, aunque con una representación importante de pymes, es relativamente alto.

En relación con la actuación del Gobierno regional, cabe señalar que ha jugado un papel decisivo en la promoción de la $\mathrm{I}+\mathrm{D}$ y en la movilización de los recursos propios de $\mathrm{I}+\mathrm{D}$ de las empresas. La cercanía y el papel «animador» del Gobierno regional, así como sus instrumentos de apoyo económico continuado a los proyectos de $\mathrm{I}+\mathrm{D}$ de las empresas (en coordinación con los del Estado) y a la creación de una infraestructura de centros tecnológicos en la región (donde ha conseguido situar distintos centros tecnológicos de ámbito estatal), han tenido un impacto decisivo en el surgimiento de un sistema robusto de $\mathrm{I}+\mathrm{D}$ e innovación en Navarra.

Las ayudas a la I+D son una palanca que facilita la generación de capacidades internas de $\mathrm{I}+\mathrm{D}$, la formalización y planificación de dichas actividades y el establecimiento de ámbitos de cooperación entre los diferentes actores del sistema, donde se encuentran los centros de formación e investigación.

La existencia de una importante red de centros de educación e investigación públicos y privados ha posibilitado el poder dar cobertura a las necesidades de capital humano adecuadamente formado en ámbitos científico-tecnológicos en relación con las necesidades industriales. Este hecho supone una condición preexistente y necesaria para comprender el desarrollo reciente de la CFN. Dentro de esta red de centros se encuentran los dedicados a la formación profesional, cuya relación con las pymes industriales es objeto de nuestro análisis.

La FP en la CFN es básicamente pública. Aunque se ha producido una regresión a nivel estatal en la matriculación de FP en sus ramas industriales, la CFN se ha visto menos afectada por este descenso debido a su sólida tradición industrial. La FP en la CFN tiene como principales ámbitos de especialización (de acuerdo con su tejido industrial), en relación con la FP estatal, las familias de Fabricación Mecánica y Mantenimiento y Servicios a la Producción.

Los centros de FP de la CFN tienen un nivel muy importante de relación con el entorno empresarial regional. El principal nexo a este respecto son las relaciones continuas, en un contexto de cercanía, reciprocidad y confianza, entre los tutores de los centros y los tutores de las empresas. Estas relaciones posibilitan la inserción del capital humano en las empresas y la adaptación del currículo educativo de los centros a las necesidades empresariales.

Los centros de FP de Navarra son, por lo tanto, una estructura clave en la provisión de mano de obra cualificada en la región, siendo muy bien valorados a este respecto por las empresas. El principal punto de mejora en este ámbito sería la extensión, a día de hoy limitada, del programa de estancias de los profesores en las empresas, lo que posibilitaría un mayor contacto de los docentes en general (y no solo de los tutores de prácticas) con la realidad empresarial.

En relación con la formación para al empleo, la CFN se caracteriza especialmente por la amplia implantación de las fórmulas que implican presencialidad en la docencia y porque la 
formación para personas con cargos de responsabilidad y niveles medio-altos de cualificación tiene una repercusión alta en la región.

Los centros navarros de FP efectúan una labor considerable y bien valorada por las empresas en el área de formación para el empleo. En el caso específico de la formación de demanda, se demuestra una manera de relación con los centros de FP menos frecuente pero más intensa y con unos niveles de satisfacción por parte de las empresas muy altos.

Con todo, cabe señalar que existen importantes barreras en el desarrollo de la formación continua en los centros de FP, tanto internas como externas a ellos. Entre las internas hay que mencionar la falta de autonomía de los centros, las limitaciones en la normativa vigente y la falta de incentivos para los docentes. Entre las externas están la falta de coordinación entre los departamentos de Educación y Empleo del Gobierno regional y el bajo nivel de financiación a los centros de FP desde el Servicio Navarro de Empleo. El desarrollo del modelo de «centro integrado de $\mathrm{FP}$ » que atienda a las diferentes funciones, previsto por la normativa reciente tanto estatal como autonómica, se halla, por lo tanto, ralentizado.

La prestación de servicios de asistencia técnica a las empresas se encuentra, a la luz de la evidencia aportada en este trabajo, poco desarrollada en la CFN. Algunas empresas utilizan las instalaciones y la maquinaria de los centros para hacer pruebas y ensayos, pero, en general, el papel de los centros como facilitadores de la innovación en las empresas es, hoy por hoy, reducido. A este respecto, la convocatoria de proyectos de innovación que ha lanzado en los últimos años el Gobierno regional ha tenido hasta el momento un alcance limitado.

Desde el punto de vista de las empresas, se detecta un reconocimiento incipiente, si bien insuficiente, de las aportaciones que los trabajadores técnicos realizan o pueden realizar en los procesos de innovación, aunque la evidencia cualitativa recogida muestra interesantes ejemplos al respecto. Es este un aspecto que debe ser estudiado en profundidad en investigaciones futuras, tal y como se señala también en el ámbito internacional.

En general, a pesar de que la FP ha jugado un papel importante en el desarrollo económico de la CFN, en la actualidad se encuentra desligada de las infraestructuras de $\mathrm{I}+\mathrm{D}$ (centros tecnológicos y universitarios) potenciadas en los últimos años por el Gobierno regional.

La relación entre el sistema de FP y el universitario es, según las entrevistas realizadas, inexistente, no habiendo coordinación entre estas dos instituciones, que constituyen dos mundos diferentes. La inclusión de ambas parcelas bajo una única dirección general en el Gobierno de Navarra (Formación Profesional y Universidades) no parece haber generado sinergias transversales $^{12}$. En cuanto a los centros tecnológicos, la relación es, asimismo, inexistente, por lo que, al igual que en otros países, quedan sin aprovechar posibles sinergias señaladas por la literatura internacional.

Como conclusión general, cabe señalar que de las relaciones entre empresas y centros de FP se derivan importantes beneficios para empresas y centros formativos y, en última instancia, para el desarrollo regional. En el futuro es necesario un mayor reconocimiento de la interrelación entre el sistema de formación y el sistema regional de innovación, un nexo frecuentemente olvidado por las políticas de innovación (y por algunos de sus actores). Es necesario también ampliar el concepto de innovación imperante, excesivamente lineal y jerárquico, y profundizar en el papel que los trabajadores técnicos cualificados pueden tener en los procesos de innovación de las empresas.

$12 \mathrm{El}$ problema principal es también de ámbito estatal y se manifiesta en aspectos como las dificultades en las convalidaciones de asignaturas de alumnos que acceden a la universidad desde los grados superiores de FP. 


\section{Anexos}

\section{Anexo I. Ficha técnica}

El estudio de carácter exploratorio efectuado se basa en la combinación y triangulación de evidencia cualitativa y cuantitativa. Por una parte, se cuenta con evidencia procedente de 14 entrevistas con actores del sistema de $\mathrm{FP}^{13}$ y 20 entrevistas con responsables empresariales en pymes industriales de entre 50 y 175 empleados en sectores de media-alta tecnología ${ }^{14}$. Estas entrevistas cualitativas (semiestructuradas en profundidad) se realizaron presencialmente entre abril de 2010 y marzo de 2011 a fin de conocer cuál es la visión de los actores del sistema regional sobre las relaciones que se vienen desarrollando entre los centros de FP y las empresas en Navarra.

Por otra, se ha encuestado a 81 pymes industriales navarras de entre 25 y 249 trabajadores (códigos CNAE93 entre 15 y 41). La encuesta se realizó a lo largo del mes de junio de 2010 de modo telefónico, entrevistando fundamentalmente a responsables de recursos humanos y formación (85\%) o, secundariamente, a gerentes o directores de las empresas.

Las encuestas realizadas constituyen la parte proporcional correspondiente a Navarra de una muestra de empresas de ámbito territorial mayor. Por lo tanto, aunque en cuanto a tamaño es una muestra estadística con limitaciones ${ }^{15}$, la selección de las empresas, de modo totalmente aleatorio y además proporcional a tamaños, contribuye a su representatividad y a la relevancia de los hallazgos empíricos.

\section{Anexo II. Red de agentes institucionales de I+D+i de la CFN}

\section{A) Universidades}

\section{Universidad Pública de Navarra}

En 1987 se creó la Universidad Pública de Navarra con el fin de que ampliara la oferta de titulaciones existentes y de que reuniera las enseñanzas universitarias impartidas en centros públicos. En la actualidad cuenta con 8.635 alumnos y 932 profesores (año 2010).

La Universidad Pública de Navarra cuenta con 104 grupos de investigación (año 2010). Durante los años 2005 y 2009 la facturación por actividades de transferencia de conocimiento a la sociedad (contratos art. 83) ha pasado de 1.412 .686 euros a 2.950 .421 euros (Bayona y González, 2010), lo que refleja una evolución positiva de la actividad de transferencia. Dos terceras partes de esta cifra se deben a proyectos de $\mathrm{I}+\mathrm{D}$, un 6,9\% a servicios de asistencia técnica, un $11,5 \%$ a servicios de asesoramiento tecnológico y el resto a acuerdos, convenios y formación.

\section{Universidad de Navarra}

La Universidad de Navarra, fundada en el año 1952, cuenta con 9.245 alumnos y 691 profesores y 586 investigadores. En 1986 se constituyó el Instituto Científico y Tecnológico (ICT),

1312 directores de centros de formación profesional o responsables de relaciones con la empresa, un responsable del Departamento de Educación del Gobierno de Navarra y el responsable de formación de un sindicato.

14 Directores gerentes y directivos de oficinas técnicas o de departamento de I+D, o personas con responsabilidades en innovación en las empresas entrevistadas.

15 El error muestral máximo es del 9,8\% para estimaciones a un nivel de confianza del 95,5\%, en el supuesto de diversidad más desfavorable $(\mathrm{p}=\mathrm{q}=0,5)$. 
cuya función es impulsar la transferencia de los conocimientos y resultados de investigación generados en la Universidad. En el curso 2009-2010, el ICT firmó 140 contratos con empresas, con un volumen de contratación cercano a los 3 millones de euros.

\section{UNED}

Los centros asociados de la UNED en Pamplona y Tudela cuentan con 4.404 alumnos y 157 profesores.

\section{B) Centros Tecnológicos}

\section{AIN}

AIN (Asociación de la Industria Navarra) es un centro de innovación y tecnología fundado en 1963, propiedad de las empresas asociadas (en la actualidad 142, que suponen el 80\% de la actividad empresarial de Navarra), que presta servicios tecnológicos y de asistencia técnica a las empresas con el objetivo de que incrementen su competitividad.

En esta organización trabajan 150 personas, de las cuales el 77\% son titulados universitarios. El 83,1\% de su facturación proviene de la facturación de servicios, el 15\% del desarrollo de proyectos y un $1,9 \%$ de las cuotas de sus asociados. Respecto a su facturación por tipo de actividad, casi un $40 \%$ de sus ingresos $(38,8 \%)$ se deben a actividades de consultoría y asesoramiento técnico, un $25,1 \%$ a actividades de I+D, un $19 \%$ a actividades de ingeniería y un $17 \%$ a actividades de formación (datos recogidos de la página web de la AIN en el año 2011)

\section{CEMITEC}

CEMITEC, Centro Multidisciplinar de Innovación y Tecnología de Navarra, es un centro tecnológico especializado en cuatro disciplinas: electrónica, mecánica de fluidos e ingeniería térmica, materiales metálicos y materiales poliméricos, que tiene por misión contribuir a la mejora de la competitividad de las empresas a través del desarrollo de proyectos de $\mathrm{I}+\mathrm{D}$, servicios tecnológicos y otras actividades de fomento de la innovación. En junio de 2008 CEMITEC contaba en plantilla con 53 personas.

CEMITEC busca ser el socio tecnológico de sus clientes. Así, utiliza el concepto de «clientes estratégicos», con los que se busca la realización de acuerdos formales que persiguen su fidelización.

Este centro busca mantener un equilibrio entre sus funciones de captación y transferencia de conocimiento. Para la primera de estas funciones acuden a los programas tecnológicos de las administraciones. Por otro lado, en esta labor de transferencia de tecnología desarrollan proyectos y servicios de $\mathrm{I}+\mathrm{D}+\mathrm{i}$ para empresas. CEMITEC persigue que la cifra de negocio de transferencia tecnológica a empresas suponga entre el $50 \%$ y el $70 \%$ de la cifra de negocio total, y las actividades de captación de conocimientos, el resto (entre el 50\% y el 30\%). Esto se ha venido cumpliendo y el porcentaje de ingresos bajo contrato se mantiene por encima del $60 \%$.

En la actualidad uno de los retos del centro es el desarrollo, la protección y la explotación de productos propios a través de empresas innovadoras de base tecnológica (EIBT), para lo que colaboran con el CEIN.

Para la adquisición de nuevos conocimientos y para el desarrollo de productos propios, CEMITEC colabora con otros centros tecnológicos (CNTA, CITEAN, IDEKO, CIDETEC). 
Los principales competidores de CEMITEC son centros tecnológicos de regiones limítrofes, como los del País Vasco, que cuentan con una dilatada experiencia y, en general, son de mayor volumen que CEMITEC.

\section{CENER}

El Centro Nacional de Energías Renovables (CENER) es un centro tecnológico especializado en la investigación aplicada, el desarrollo y el fomento de las energías renovables. Se trata de una fundación que inició su actividad en 2002 y cuyo patronato está compuesto por el Ministerio de Industria, el Ministerio de Ciencia e Innovación, Ciemat y el Gobierno de Navarra. En la actualidad cuenta con una plantilla de casi 200 profesionales. Este centro presta servicios y realiza trabajos de investigación en 6 áreas en el campo de las energías renovables: 1) energía eólica; 2) energía solar térmica; 3) energía solar fotovoltaica; 4) energía de la biomasa; 5) arquitectura bioclimática; y 6 ) integración en red de energías renovables. Su función es apoyar la actividad de $\mathrm{I}+\mathrm{D}+\mathrm{i}$ de las empresas mediante la prestación de servicios tecnológicos, la realización de proyectos de $\mathrm{I}+\mathrm{D}$ bajo contrato y la consultoría.

\section{CIMA}

El Centro Internacional de Medicina Avanzada (CIMA) fue inaugurado en el año 2004, promovido por la Universidad de Navarra a través de la Fundación para la Investigación Médica Aplicada. El CIMA busca aproximar la investigación básica a la aplicación clínica y colabora con la industria farmacéutica y biotecnológica en el desarrollo de productos para diagnóstico y tratamiento. En el CIMA trabajan cerca de 400 profesionales de 25 países de Europa. Las áreas de especialización del centro son: 1) terapia génica y hepatología; 2) ciencias cardiovasculares; 3) neurociencias; y 4) oncología. El presupuesto del CIMA para el año 2009-2010 superaba los 21 millones de euros, con una ratio de financiación privada sobre gasto del $66 \%$.

\section{CITEAN}

El Centro de Innovación Tecnológica de Automoción de Navarra (CITEAN) fue creado en 2001 en el marco del I Plan Tecnológico de Navarra, impulsado por el Gobierno de Navarra para potenciar, mediante la aportación de tecnología e investigación aplicada, la competitividad del tejido industrial de la región, fuertemente vinculado a la industria del automóvil. La iniciativa contó con un acuerdo de colaboración entre DANA Automoción, AP Amortiguadores (actualmente KYBSE), la Universidad Pública de Navarra y la Fundación CETENA.

El Centro de Innovación Tecnológica de Automoción de Navarra, que inició su actividad en 2003 y en el que trabajan 34 personas (datos recogidos de la página web de CITEAN en el año 2011), pretende ayudar a las empresas del sector a ser más competitivas, aumentando su capacidad de investigación, desarrollo e innovación tecnológica $(\mathrm{I}+\mathrm{D}+\mathrm{i})$.

CITEAN focaliza su actividad en cuatro áreas: 1) simulación y análisis estructural; 2) fatiga y durabilidad; 3) ruido y vibraciones; y 4) cinemática y dinámica. CITEAN aborda todas las fases del desarrollo de nuevos productos e incide en la optimización del diseño conceptual, la simulación virtual y la verificación y validación mediante ensayos. En definitiva, CITEAN pretende ser un socio tecnológico, consultor y colaborador de referencia de empresas del sector, esto es, fabricantes de vehículos y proveedores de componentes, así como empresas de otros sectores con necesidades análogas al de automoción: ferroviario, energías renovables, etc. 


\section{CNTA}

El Centro Nacional de Tecnología y Seguridad Alimentaria es una entidad privada sin ánimo de lucro creada en 1981 por iniciativa del sector industrial conservero del Valle del Ebro. El CNTA presta servicios analíticos, de asistencia técnica (asesoramiento, consultoría y formación) y de I+D+i a más de 500 empresas del sector agroalimentario. En la actualidad cuenta con 200 empresas asociadas, además de 300 empresas clientes. Su presupuesto es de 5 millones de euros (2007). En la actualidad cuenta con una plantilla de 111 personas, de las cuales el $45 \%$ son licenciados y el $20 \%$, doctores.

Dentro de sus actividades de $\mathrm{I}+\mathrm{D}$, el Centro desarrolla proyectos de investigación de carácter aplicado, tanto de interés general para el sector (promovidos por el Centro y/o en colaboración con universidades, centros públicos de investigación o empresas) como proyectos concertados con empresas. Dentro de la labor de soporte técnico, el centro realiza labores de asesoramiento, consultoría y formación (nuevos procesos y tecnologías, instalaciones industriales, legislación y normativa, tramitación de expedientes sancionadores, seguridad e higiene, implantación de sistemas APPCC, trazabilidad).

\section{EVENA}

La Estación de Viticultura y Enología de Navarra (EVENA) es un organismo autónomo adscrito al Departamento de Desarrollo Rural y Medio Ambiente creado para impulsar el sector vitivinícola navarro. Este organismo tiene como misiones principales la investigación, experimentación y divulgación de las técnicas más adecuadas para el cultivo de la vid y la elaboración del vino, y la gestión del catastro oficial vitícola del Gobierno de Navarra, y actúa como centro de consulta y asesoramiento de viticultores, bodegas y enólogos.

\section{FIDENA}

Se trata de un centro de reciente creación en el área de la nanotecnología. Sus órganos de gobierno son SODENA (Sociedad para el Desarrollo de Navarra), la Universidad Pública de Navarra y Principia Technology Group, spin-off americana del MIT fundada en 2005.

\section{IDAB}

El Instituto de Agrobiotecnología y Recursos Naturales, creado en julio de 1999, es un centro de investigación en los ámbitos de la agroproductividad y la agrosanidad en el que trabajan unas 60 personas. El IDAB es un centro mixto de la Universidad Pública de Navarra, el Consejo Superior de Investigaciones Científicas y el Gobierno de Navarra. Las principales líneas de investigación están relacionadas con aspectos tales como la bioquímica y biología molecular de procesos infecciosos y la respuesta inmune, la utilización de organismos como biofactorías o el metabolismo y la genética de plantas.

\section{IDIMA}

El Centro Tecnológico Medioambiental IDIMA es una fundación con sede en Estella constituida por treinta empresas y el Gobierno de Navarra cuya finalidad es impulsar la $\mathrm{I}+\mathrm{D}+\mathrm{i}$ medioambiental para mejorar la competitividad de las empresas en este ámbito de gestión. Trabaja fundamentalmente en dos áreas: 1) reutilización, reciclado y valorización energética de los residuos industriales; y 2) minimización del residuo producido en los procesos industriales. 


\section{ILL}

El Instituto Lactológico de Lekunberri nació de un acuerdo de los gobiernos navarro y vasco y fue el primer centro creado en España (1984) especializado en leche y productos lácteos. En la actualidad el ILL está compuesto por un equipo humano de más de 20 personas que presta sus servicios a casi 2.000 empresas del sector. El Instituto está gestionado por la Asociación Lechera de Vacuno y Ovino del País Vasco y Navarra (ALVO), asociación sin ánimo de lucro formada por las organizaciones y empresas del sector de Navarra, el País Vasco y La Rioja. El ILL presta servicios analíticos, de asistencia técnica y de $\mathrm{I}+\mathrm{D}+\mathrm{i}$ a explotaciones ganaderas e industrias lácteas. Dentro de las actividades de I+D, el Instituto está realizando proyectos de interés general para el sector, así como otros más específicos concertados con empresas privadas. Se trata de líneas de investigación que mejoren las técnicas, faciliten los procesos de fabricación y ayuden a los elaboradores a mejorar la calidad de sus productos.

\section{ITGA}

El Instituto Técnico y de Gestión Agrícola (ITGA) se dedica a la experimentación e investigación en todas aquellas materias relacionadas con la producción de cultivos extensivos, hortofrutícolas y de invernadero. Asimismo, realiza una importante labor de formación en el sector y de divulgación de sus resultados. La plantilla del ITGA consta de un total de 70 empleados (2006).

\section{ITGG}

El Instituto Técnico y de Gestión Ganadero (ITGG) es una organización sin ánimo de lucro que busca la mejora de las explotaciones y del sector ganadero de Navarra mediante la formación, la realización de estudios, la prestación de servicios y la divulgación de técnicas y sistemas de producción. Está formado por 39 personas.

\section{L'UREDERRA}

La fundación L’Urederra es una entidad sin ánimo de lucro que está reconocida como centro tecnológico por el Ministerio de Educación y Ciencia y que realiza actividades de investigación y desarrollo tecnológico aplicado en los campos de nuevos materiales y medio ambiente avanzado.

\section{C) Agentes de interfaz entre actores del sistema de innovación}

En este apartado haremos referencia a algunos agentes cuya finalidad principal es la de promover la cooperación entre los actores del sistema a través de diferentes medios.

\section{RED RETECNA}

En 2006 nació la red de centros tecnológicos RETECNA para fomentar la cooperación entre centros tecnológicos. En la actualidad están integrados en la red los siguientes centros tecnológicos: AIN, CEMITEC, CENER, CIMA, CITEAN, CNTA, IDAB, ILL y L'UREDERRA. 
Indicadores de la red RETECNA (2006-2010)

\begin{tabular}{|l|r|r|r|r|r|}
\hline & 2006 & 2007 & 2008 & 2009 & 2010 \\
\hline N. ${ }^{\circ}$ de proyectos de I+D iniciados en el año & 144 & 222 & 292 & 228 & 240 \\
\hline Ingresos I+D (miles de euros) & $47.648,3$ & $53.754,6$ & $59.472,08$ & $57.351,5$ & $66.517,3$ \\
\hline Plantilla I+D (sin admón. y becarios) & 537 & 665 & 775 & 743 & 728 \\
\hline Doctores en plantilla & 205 & 212 & 250 & 242 & 228 \\
\hline Empresas receptoras de servicios & 827 & 3348 & 3088 & 2810 & 3045 \\
\hline
\end{tabular}

Fuente: Red Tecnológica de Navarra (RETECNA)

\section{CLÚSTERES}

El Gobierno de Navarra está tratando de articular la demanda empresarial en torno a clústeres. En la actualidad existen 4 clústeres: agroalimentación, automoción, logística y TIC.

- Clúster Agroalimentario: el Gobierno de Navarra, a través del Departamento de Innovación, Empresa y Empleo, ha impulsado la realización de un mapa-inventario con las principales demandas y ofertas tecnológicas de empresas, universidades y centros tecnológicos de Navarra.

- Clúster de Automoción: la sociedad pública Centro Europeo de Empresas e Innovación de Navarra (CEIN, S. A.) es la entidad encargada de dinamizar este clúster a través de la puesta en marcha de los proyectos estratégicos que se recogen en el Plan Estratégico del Sector de la Automoción en Navarra (2007).

- Clúster de la Logística y el Transporte de Mercancías: es una iniciativa impulsada por el Gobierno de Navarra, a través del Departamento de Obras Públicas, Transportes y Comunicaciones, en la que participan las asociaciones, las empresas, los profesionales y las entidades relacionados con el sector. Dentro del clúster se han creado distintos foros de trabajo.

- Clúster de TIC: este clúster, que busca la mejora de la competitividad del sector TIC mediante la cooperación y la innovación, es gestionado por el CEIN. Se han creado distintos foros de trabajo para la realización de proyectos estratégicos dentro del clúster.

La estructura de funcionamiento general de los clústeres es la siguiente: existe una asamblea del clúster en la que participan todos sus miembros y a partir de la cual se forman grupos de trabajo para abordar iniciativas y/o proyectos estratégicos. Por otro lado, se crea una «mesa de desarrollo», que es el grupo encargado de definir los objetivos a cumplir por el clúster, de velar por su buena marcha y de dar coherencia a los proyectos e iniciativas abordados en los grupos de trabajo. Asimismo, existe un equipo técnico/gerente, que es el responsable de llevar adelante el clúster y sus proyectos. Realiza la labor operativa de puesta en marcha de los grupos de trabajo, así como de los servicios comunes (comunicación y marketing, formación, vigilancia, etc.) del clúster. Se encarga de gestionar la operativa de convocatoria a la mesa de desarrollo.

Por otro lado, los grupos de trabajo y proyectos temáticos se proponen en la mesa de desarrollo, mientras que el equipo técnico es el encargado de convocarlos y coordinarlos. Su duración es temporal. 


\section{ANAIN}

En 1999 se crea la Agencia Navarra de Innovación (ANAIN) como una sociedad anónima perteneciente al Gobierno de Navarra con el objeto de promover el incremento cuantitativo y cualitativo de la innovación de la Comunidad Foral. 



\section{COMUNIDAD AUTÓNOMA DEL PAÍS VASCO (CAPV)}

Eneka Albizu, Mikel Olazaran, Cristina lavía, Beatriz Otero 



\section{Entorno socioeconómico regional}

\subsection{Datos socioeconómicos básicos de referencia y características del tejido productivo}

De acuerdo con los datos facilitados por el INE (tabla 3.1), la CAPV cuenta en 2010 con 2.184.600 habitantes, que suponen el 4,6\% de la población española. Su PIB es de 64.464,2 millones de euros, un 6,1\% del PIB estatal. El PIB per cápita es de 30.152 euros, hecho que sitúa a esta comunidad en el 132,1\% de la media nacional, lo que refleja que se trata de la región más próspera del país.

La Encuesta de Población Activa (INE, 2010) refleja una tasa de actividad del 57,59\%, algo inferior a la media del Estado - 60\%-, mientras que las tasas de empleo y paro son mejores en la CAPV (tabla 3.3):51,52\% frente a 47,96\% para el empleo y, especialmente, $10,55 \%$ frente a $20,06 \%$ para el paro, respectivamente. De hecho, la CAPV es la región con menos desempleo dentro de España.

Respecto al tejido productivo, cabe señalar que el VAB industrial de la CAPV es de 17.702.724 millones de euros. Así las cosas, la CAPV es, en términos relativos y junto con la Comunidad Foral de Navarra (CFN), la región más industrial del Estado, con un VAB industrial que representa el 28,5\% del PIB regional y el 24,1\% del empleo.

Atendiendo a la especialización industrial de la región (Contabilidad Regional de España, INE, 2008), cabe señalar que la CAPV destaca sobre la media española, y de manera muy pronunciada, en Metalurgia y Fabricación de Productos Metálicos (9,7\% VAB y 8,1\% empleo). También muestra cierta especialización productiva en Maquinaria y Equipo Mecánico (3,6\% VAB y 3,6\% empleo), y en Fabricación de Material de Transporte (2,4\% VAB y 2,4\% empleo). Cabe mencionar, asimismo, que si bien no es una industria intensiva en mano de obra en la CAPV (0,6\% del empleo), la Industria Extractiva y de Energía supone un 3,5\% del VAB.

La industria de la CAPV tiene un nivel tecnológico moderadamente alto. Considerando el peso de los sectores manufactureros de alta y media-alta tecnología (Indicadores de Alta Tecnología, INE, 2009) (tabla 3.2), se observa que el 31,7\% del VAB de la industria de la CAPV corresponde a actividades de tecnologías alta y media-alta, mientras que en el conjunto del Estado el porcentaje del VAB industrial dentro de estas categorías se reduce al 26,6\%, cerca de cinco puntos porcentuales por debajo de la CAPV. No obstante, cabe señalar que, salvo en el caso de Asturias, el resto de las regiones analizadas cuentan con una industria de mayor nivel tecnológico.

El nivel educativo de la población vasca entre 25 y 64 años es más elevado que la media española (gráfico 3.1), caracterizándose por un mucho menor porcentaje de población con 
techo de estudios en educación secundaria inferior (33,5\% en CAPV frente a 47,4\% en España), parecido porcentaje de población con techo de estudios en educación secundaria superior (22,4\% en CAPV frente a 22,0\% en España) y mucho mayor porcentaje de población que ha culminado estudios de educación terciaria (44,1\% frente a 30,7\%).

No obstante, los datos de la UE15 y de la UE27 ponen de manifiesto la existencia de una descompensación de la estructura de estudios de la población en la CAPV (más acusada en el caso general español). En los países de la UE los porcentajes de población activa con niveles de formación inferiores son algo más bajos que los vascos (UE15, 30,5\%, y UE27, 27,3\%), mientras que el porcentaje de población activa con estudios de nivel intermedio es el doble (UE15, 42,2\%, y UE27, 46,8\%) que en la CAPV y en España. Así también, los altos niveles relativos de población con estudios terciarios de la CAPV, muy superiores a los de los países de referencia (UE15, 27,4\%, y UE27, 25,9\%), si bien representan un indicador del alto nivel de cualificación de la población vasca, pueden generar, al igual que en el caso general español, ciertos desequilibrios y sobrecualificación/subocupación en el mercado de trabajo.

En cuanto a la población ocupada según el nivel educativo, la tabla 3.4, elaborada con datos del Instituto Valenciano de Investigaciones Económicas, muestra las fortalezas relativas de la CAPV, respecto a la media española, en cualificaciones intermedias, intermedias-altas y altas. Destacan, especialmente, la formación profesional (FP) de grado superior (18,3\% frente a 10,6\% en el Estado) y, en menor medida, los estudios superiores (19,5\% frente a 15,2\%), la FPGM (11,8\% frente a 8,9\%) y las diplomaturas e ingenierías técnicas (12,9\% frente a $10,9 \%)$. Esto se refleja específicamente en el ámbito industrial, objeto de este estudio (cfr. tabla 3.5).

El gráfico 3.2 refleja el espectacular crecimiento del porcentaje de personas ocupadas en la industria con cualificaciones de FP, pasando en el caso de la CAPV del 12,1\% en 1985 al $44,2 \%$ en 2010, cifra muy superior a la media del Estado y del resto de las regiones de referencia. Este crecimiento gradual de la inserción de personas con cualificaciones de FP en la industria es un proceso que cuenta todavía con un margen de mejora debido a las crecientes exigencias competitivas a las que está sujeta la industria.

\subsection{Indicadores de investigación, desarrollo e innovación}

La CAPV dedica un 1,95\% de su PIB al gasto en I+D en 2010 (tabla 3.6), cifra bastante superior a la media española $(1,39 \%)$ y próxima a la que se dedica en la UE27 (2\%). Junto con Madrid y la CFN, el País Vasco ocupa las primeras posiciones en gasto en I+D dentro de las regiones españolas. El crecimiento del gasto en I+D experimentado en la CAPV entre 1997 y 2010 ha sido sostenido y en estos últimos 12 años esta región ha aumentado un 72,5\% su gasto en I+D como porcentaje del PIB.

La tabla 3.7 nos permite afirmar que en la CAPV el gasto en $\mathrm{I}+\mathrm{D}$ es asumido en sus tres cuartas partes por las empresas e $\operatorname{IPSFL}^{1}(75,5 \%)$, porcentaje muy superior a la media española $(51,6 \%)$ y bastante superior que el de la CFN, región que más se aproxima a la CAPV en este concepto $(69,4 \%)$. Por el contrario, en el ámbito estatal los sectores de la enseñanza superior (28,3\% frente a 18,5\%) y, especialmente, la Administración pública ${ }^{2}$ (20,1\% frente a $6 \%)$ tienen, como contraparte, un mayor peso que en la CAPV en la ejecución del gasto en I+D.

\footnotetext{
1 En el caso de la CAPV se incluye el gasto ejecutado por los centros tecnológicos.

2 Hasta 1999 el Gobierno del Estado no había habilitado ningún centro de investigación público en la CAPV. En ese año se crean dos centros mixtos CSIC-UPV/EHU: (la Unidad de Biofísica, en Leioa, y el Centro de Física de los Materiales, en Donostia).
} 
En términos relativos al PIB, destaca el gasto en $\mathrm{I}+\mathrm{D}$ efectuado en el sector de empresas $(1,47 \%)$, que dobla la media española $(0,71 \%)$ y se sitúa muy por encima del resto de las regiones de referencia, incluida la CFN (1,36\%), que es la más próxima en este concepto. El gasto en el sector enseñanza superior es ligeramente inferior a la media española $(0,36 \%$ frente a $0,39 \%)$ y claramente inferior al del resto de las regiones de referencia, salvo Aragón, siendo el gasto ejecutado en el sector público (0,12\% del PIB) manifiestamente inferior a la media española $(0,28 \%)$ y al del resto de regiones de referencia.

En relación con el personal dedicado a $\mathrm{I}+\mathrm{D}$ (en tanto por mil) sobre la población ocupada en 2010 (tabla 3.8), la CAPV dedica un 16,12\% de la población a actividades de I+D, cuatro puntos porcentuales por encima de la media estatal (12,03\%o), únicamente superada entre las regiones españolas por la CFN, con un 19,25\% de la población ${ }^{3}$. El crecimiento de este colectivo ha sido del 216,8\% entre 1997 y 2010 (INE). Asimismo, la CAPV dedica más investigadores a la I+D (11,27\% de la población ocupada) que el Estado (7,3\%o). Sin embargo, la participación de personal técnico y auxiliares en la $\mathrm{I}+\mathrm{D}$ (36,6\% sobre el personal de I+D total) es ligeramente inferior a la media estatal $(39,4 \%$ ) y cuatro puntos porcentuales menor a la de regiones como Madrid y Cataluña.

El peso relativo del sector industrial en la $\mathrm{I}+\mathrm{D}$ es ligeramente inferior a la media española $(47,1 \%)^{4}$, con un $44,3 \%$ del total de la I+D empresarial y solo por delante de Madrid entre las regiones de referencia. Desde el punto de vista de este estudio, es interesante señalar que el $26,1 \%$ del personal de I+D de la industria de la CAPV tiene titulación de FP, sobre todo de grado superior (tabla 3.11). Otro 25,9\% corresponde a diplomados (categoría que incluye al personal de ingenierías técnicas). Si sumamos ambas categorías, considerando a los diplomados como personal con cualificación intermedia-alta, suman el 52\% del personal de $\mathrm{I}+\mathrm{D}$ (para el conjunto del Estado esta suma asciende al 44,6\%). Asimismo, la participación en la I+D del personal con cualificaciones intermedias es claramente superior en la CAPV que en el resto de las regiones de referencia.

Una de las características distintivas de la actividad innovadora en la CAPV es que descansa sobre la I+D interna (tabla 3.12). Así, el 58,13\% del gasto en innovación se concentra en este concepto, que para el conjunto del Estado alcanza el 46,51\% del gasto. En términos relativos, la adquisición de $\mathrm{I}+\mathrm{D}$ externa y de maquinaria tiene un nivel inferior (algo menos de un tercio del gasto). En las pymes de menor tamaño la adquisición de maquinaria tiene una importancia mayor en la $\mathrm{I}+\mathrm{D}$, mientras que las de 75-249 empleados presentan mayores niveles de adquisición de I+D externa. En general, la actividad innovadora de las pymes de 75-249 se concentra en la I+D interna y externa, siendo, en términos relativos, el gasto en adquisición de maquinaria, equipos y software muy reducido.

En relación con la capacidad de las empresas innovadoras de la CAPV para la obtención de ayudas públicas para la innovación (tabla 3.13), cabe señalar que el porcentaje de empresas que acceden a ayudas públicas en 2010 es muy superior a la media española (el 43,7\% de las empresas innovadoras reciben ayudas públicas frente al $28,8 \%$ de media para el conjunto del Estado) y superior al de las empresas radicadas en las regiones de referencia.

Un elemento idiosincrático dentro del ámbito estatal estriba en que las EIN vascas están muy apoyadas por las administraciones regionales. El nivel de acceso a ayudas regionales

\footnotetext{
3 Como ha indicado en algunas ocasiones Mikel Navarro, investigador de la Universidad de Deusto, hay que recelar de una comparación con la UE en este indicador que puede verse afectada por la diferente valoración de los costes de personal.

4 La importante actividad de I+D para las empresas industriales efectuada por parte de los centros tecnológicos está computada como actividad de servicios.
} 
es muy superior a la media estatal (83,6\% CAPV frente a 63,5\% Estado español) y también superior al de las regiones de referencia. Las empresas innovadoras que obtienen ayudas europeas son el 8,2\%, ligeramente por encima de la media estatal, aunque alejadas del 14,7\% de Madrid, región puntera en este concepto. Por el contrario, el nivel de acceso a ayudas del Gobierno central es más bajo en la CAPV (46,1\% CAPV frente a 52,6\% Estado español).

El porcentaje de empresas subvencionadas en innovación aumenta con el tamaño en el ámbito regional de la CAPV. Se observa que no existe una discriminación negativa por motivo de tamaño empresarial en las ayudas regionales, si bien estas diferencias se observan con más claridad en relación con la percepción de ayudas estatales y europeas.

Un importante aspecto que favorece la innovación en las empresas es su capacidad de cooperar con otros actores del sistema de innovación. Como muestra la tabla 3.14, las empresas de la CAPV tienden a colaborar en innovación mucho más que la media estatal (34,4\% frente a $22,1 \%)$ y que en las regiones analizadas.

Destaca la cooperación con agentes de la cadena de valor (proveedores y clientes). Así también, en el caso de la CAPV el nivel de cooperación con centros tecnológicos es muy importante (51,5\% frente a $38,5 \%$ a nivel estatal) y sensiblemente superior al del resto de las regiones de este análisis. También se tiende a colaborar más con empresas del mismo grupo en la CAPV que en el Estado (31,3\% frente a 25,9\%). El recurso a consultores, laboratorios comerciales o institutos privados de I+D, aunque bastante utilizado en la CAPV (29,4\% de las EIN), refleja porcentajes similares a los del ámbito estatal (28,4\%).

Por el contrario, la cooperación con agentes dedicados a la generación de conocimiento tecnológico como universidades y OPI es netamente inferior a dicha media (24,3\% en la CAPV frente a 34,3\% en el Estado español y 13,8\% en la CAPV frente a 17,6\% en el Estado español, respectivamente). La cooperación horizontal, con competidores u otras empresas del sector, a su vez, es ligeramente inferior a la media del Estado (15,3\% frente a 16,6\%).

En la CAPV los niveles de cooperación en innovación aumentan con el tamaño empresarial: el 25,7\% de las empresas innovadoras de menos de 25 empleados coopera en innovación, frente al $53,1 \%$ de las grandes empresas.

\subsection{Política de $\mathrm{I}+\mathrm{D}+\mathrm{i}$ en el ámbito regional}

Desde la década de los ochenta las políticas de I+D en la Comunidad Autónoma del País Vasco (CAPV) se han dirigido a la creación de una infraestructura de $\mathrm{I}+\mathrm{D}$ (inexistente en el contexto de la transición democrática) y al fomento de su relación con las empresas de la región. En un contexto de grave crisis económica y tensión social, el Gobierno Vasco utilizó su capacidad de autogobierno, posibilitada por el Estatuto de Gernika de 1979, para fomentar la incorporación de nuevas tecnologías a las empresas del país, principalmente pymes de sectores maduros.

Un rasgo de las políticas de I+D en la C. A. del País Vasco es el liderazgo de la política tecnológica frente a la política científica. El mayor peso de la política tecnológica frente a la científica se puede observar en los presupuestos del Gobierno Vasco. Así, el Programa Tecnología (política tecnológica) supone un 32,0\% del Departamento de Industria y un 1,2\% del presupuesto total, mientras que el Programa Investigación (que engloba los instrumentos en materia de política científica) supone un 1,5\% del Departamento de Educación, Universidades e Investigación y un 0,4\% del total. Como se puede observar en la siguiente tabla, la relación $1 / 3$ entre estas políticas (científica e industrial) se ha mantenido invariable a lo largo de los quince 
últimos años en la CAPV, si bien el presupuesto total de la CAPV se ha triplicado a lo largo de este período.

Tabla 2.18. Presupuestos de la política científica y tecnológica de la CAPV (1995-2011)

\begin{tabular}{|l|r|r|r|r|}
\hline & 1995 & 2000 & 2005 & 2011 \\
\hline Política científica & 7.927 & 11.299 & 12.797 & 39.541 \\
\hline Departamento Educación & 1.029 .393 & 1.396 .908 & 1.897 .700 & 2.669 .844 \\
\hline Política tecnológica & 26.534 & 42.088 & 84.867 & 128.823 \\
\hline Departamento Industria & 224.388 & 216.322 & 285.645 & 402.576 \\
\hline Total presupuesto & 3.979 .902 & 5.173 .761 & 7.117 .102 & 10.549 .489 \\
\hline \% Política científica / Total & 0,2 & 0,2 & 0,2 & 0,4 \\
\hline \% Política tecnol. / Total & 0,6 & 0,8 & 1,1 & 1,2 \\
\hline
\end{tabular}

Fuente: Presupuestos Generales de la CAPV

Ante la inexistencia de estructuras de I+D en la región, los agentes decisores del Gobierno regional, en contacto con intereses industriales, optaron por un modelo de captación y difusión de conocimiento tecnológico basado en centros de investigación privados pero financiados y tutelados por el Gobierno regional.

El background profesional, las ideas sobre la ciencia y la tecnología, la ideología política y las conexiones con la industria y sus incipientes laboratorios de ensayos hicieron que los agentes decisores, en interrelación con los agentes movilizados en este campo de políticas, se decantaran por un modelo «tecnológico», cercano a la industria, y desecharan el modelo "científico», cercano a los intereses académicos y organismos públicos de investigación, imperante en aquel momento en el Estado español.

La falta de desarrollo de la universidad y la reducida posibilidad de control de esta desde el Gobierno regional reforzaron la opción a favor de centros de investigación privados sin ánimo de lucro (los centros tecnológicos), siguiendo el «modelo alemán» (Fraunhofer) ya adoptado entonces por el incipiente centro Ikerlan.

Hasta mediados de los noventa, siguiendo unas políticas de «oferta», las políticas regionales impulsaron un proceso de creación de capacidades tecnológicas «horizontales» (nuevas tecnologías dirigidas a los distintos sectores de la economía). A partir de entonces se comenzó a atender más a la demanda tecnológica (clústeres) y a la relación entre oferta y demanda, y se reforzaron otros actores como los centros sectoriales o las unidades de $\mathrm{I}+\mathrm{D}$ empresariales.

En los últimos años se han creado nuevos instrumentos para la coordinación y agregación de actores (investigación estratégica, centros de investigación cooperativa CIC) y se ha activado algo más el papel del Departamento de Educación, Universidades e Investigación del Gobierno Vasco (centros de investigación básica de excelencia BERC, Ikerbasque). También se han desarrollado algunas plataformas de colaboración público-privada como Innobasque, aunque esta iniciativa ha sido posteriormente rebajada. A la vez que se busca potenciar las capacidades científicas del sistema, se quiere prestar una mayor atención a las empresas como usuarios finales de estas políticas (Red Innovanet y programa Agendas de Innovación, que buscan fomentar la innovación en todo el tejido empresarial, especialmente pymes). 
Principales instrumentos de financiación para los agentes de la Red Vasca de Ciencia, Tecnología e Innovación (RVCTI)

En este apartado vamos a tratar los principales instrumentos de financiación para los agentes de la Red Vasca de Ciencia, Tecnología e Innovación (RVCTI) del Gobierno Vasco, tanto aquellos dirigidos a la oferta científico-tecnológica (programas Saiotek, Emaitek y Etortek) como a las empresas (programas Intek, Agendas de Innovación y Aldatu).

Las ayudas que reciben los agentes de la RVCTI para acometer sus actividades de investigación y generación de tecnología se articulan en la actualidad en torno a los programas Saiotek y Etortek. Se trata de que los agentes de la oferta tecnológica, mediante la realización de proyectos de investigación, se especialicen en áreas que pueden ser de interés para el sector empresarial de la región.

Los proyectos genéricos Saiotek son aquellos proyectos realizados por los agentes de la red con el objetivo de asimilar y generar tecnologías genéricas para posteriormente transferirlas y difundirlas al sector industrial. Los centros tecnológicos han sido históricamente los principales beneficiarios de este programa hasta el año 2007. A partir de ese año surge un programa específico para los centros tecnológicos $\left(\right.$ Emaitek $\left.^{5}\right)$, con lo que estos agentes dejan de concurrir al programa Saiotek.

Etortek es el programa para la investigación estratégica. En él se potencia la cooperación entre los diferentes agentes de I+D. Desde su puesta en marcha en el año 2002, se han aprobado 90 proyectos Etortek, siendo la gran mayoría (84) consorcios compuestos por diferentes agentes del sistema: centros tecnológicos, CIC, grupos de investigación universitarios, unidades I $+\mathrm{D}$ empresariales, centros sectoriales, etc. Los principales beneficiarios de este programa son los CIC, seguidos de los centros tecnológicos.

El programa Intek ha sido un instrumento central de la política tecnológica de la CAPV. Estos proyectos van dirigidos a las empresas y buscan la realización de desarrollos tecnológicos a través de la colaboración entre estas y los agentes de I+D. Las relaciones entre centros tecnológicos y empresas se han articulado en gran medida a través de este instrumento ya que, hasta hace poco, la cooperación con agentes de la red vasca era un requisito para poder acceder a la convocatoria. A partir del año 2005 los proyectos Intek se transforman y pasan a denominarse Intek-Berri. Aparecen nuevas modalidades: Gaitek está dirigido al desarrollo de nuevos productos, Innotek apoya proyectos orientados a la mejora de productos ya existentes y/o a la mejora o desarrollo tecnológico de nuevos procesos y Nets va dirigido a la creación de nuevas empresas.

Agrupando en clústeres las empresas subvencionadas (Intekberri y Etortek), cabe señalar que los clústeres más apoyados son máquina herramienta, energía, electrónica y telecomunicaciones y automoción. Se ha producido también un aumento del peso del sector biociencias en los últimos años.

Recientemente, el Plan de Competitividad Social y el Plan de Ciencia, Tecnología e Innovación señalan la necesidad de prestar mayor atención a las empresas, especialmente pymes: «La incorporación de las pymes, especialmente de los sectores tradicionales, al sistema de innovación es una necesidad que requiere el establecimiento de los mecanismos específicos necesarios para facilitar la transferencia a dicho segmento de empresas». Así, el programa Berrikuntza Agendak ${ }^{6}$ contempla ayudas para la definición, el desarrollo y la revisión de Agendas de Innovación por las pymes de la CAPV.

\footnotetext{
5 Emaitek es un nuevo instrumento que busca la orientación a resultados de los centros tecnológicos. La subvención obtenida por cada centro tecnológico no puede exceder el $25 \%$ de sus ingresos totales por $\mathrm{I}+\mathrm{D}+\mathrm{i}$.

$6 \mathrm{El}$ objeto de este programa es propiciar que las empresas desarrollen la capacidad de innovar de forma sistemática. Se trata de que el equipo de dirección de la pyme realice una reflexión estratégica de innovación que aborde la situación actual de la empresa y, en función
} 
Por otro lado, se ha puesto en marcha el programa Aldatu para fomentar la innovación en marketing y organización, y en particular en todas las dimensiones aptas para la creación de valor que se encuentran más alejadas de la tecnología. A su vez, se entiende que esta tipología de proyectos es fruto de una reflexión estratégica de innovación, por lo que deberán identificarse previamente en la Agenda de Innovación de la empresa que la haya realizado bien a través de la Iniciativa Innova y/o que así conste en su Plan Estratégico. Se contemplan proyectos en los siguientes ámbitos de actuación: replanteamiento de la estrategia de la empresa, innovación de mercado y organización y desarrollo de la capacidad de innovación (organización y cultura de la innovación).

\subsection{Sistema institucional de agentes de $\mathrm{I}+\mathrm{D}+\mathrm{i}$}

El principal objetivo de las políticas regionales en la CAPV ha sido la creación de una infraestructura de agentes de I+D propia (principalmente, los centros tecnológicos). Una vez consolidada esta estructura, el énfasis se ha puesto en fomentar la relaciones entre esta y el resto de agentes (principalmente con las empresas, pero también, más tarde, con otros agentes de $\mathrm{I}+\mathrm{D}$ del sistema como la universidad). En los siguientes apartados daremos cuenta de las características generales de los principales actores del sistema de innovación, englobados en la Red Vasca de Ciencia, Tecnología e Innovación (RVCTI).

\section{Centros tecnológicos}

Como se ha comentado anteriormente, los centros tecnológicos han supuesto la base sobre la que se ha construido la oferta tecnológica en la CAPV. En 2007 los centros tecnológicos, con 286 millones de euros, aglutinaron el $26 \%$ de todo el gasto interno en I+D realizado en la CAPV, lo que supuso el 0,43\% del PIB. La gran mayoría de dicho gasto se realiza en el campo de la ingeniería y tecnología (71\%, 204 millones de euros). En cuanto a su financiación, casi la mitad de sus fondos (un 48\%) procede de diferentes administraciones públicas y un $45 \%$ de proyectos y servicios tecnológicos realizados con empresas. El personal (EDP) de los centros tecnológicos asciende a 3.024 personas (2007), de las cuales $2.180(72,1 \%)$ son investigadores, $582(19,3 \%)$ técnicos y 261 (8,6\%) auxiliares. Respecto al nivel de formación del personal, el $85 \%$ posee estudios universitarios, siendo doctores el $13,7 \%$, licenciados el $58,9 \%$ y diplomados el 12,9\%. El resto del personal tiene una titulación a nivel de bachiller o formación profesional $(14,3 \%)$ y otros estudios $(0,3 \%)$.

En la actualidad se está llevando a cabo un proceso de mayor coordinación e integración entre los centros tecnológicos que ha llevado al surgimiento de las plataformas Tecnalia e IK4.

\section{Universidades}

En la CAPV existen cuatro universidades ${ }^{7}$ la UPV/EHU, universidad pública y generalista, que recibe cerca del $85 \%$ de la matrícula universitaria y en la que descansa más del $90 \%$ del I+D básica de la CAPV; la Universidad de Deusto, universidad de la Iglesia orientada a las escuelas de negocios y los servicios a las empresas y la Administración; la Universidad de Mondragon, perteneciente a MCC y muy focalizada en las necesidades de cualificación del entramado coo-

del estado de maduración de sus capacidades de innovación, pueda detectar las áreas a desarrollar y sus oportunidades de futuro. Se han organizado foros y redes de agentes para difundir esta iniciativa dentro del sector empresarial.

$7 \mathrm{Y}$ dos centros adscritos a la UNED en Portugalete y Bergara. 
perativo, así como en los proyectos en empresas del grupo; y Tecnun, ETS Ingeniería de la Universidad de Navarra, en San Sebastián, que posee un centro tecnológico. Las cuatro cubren ampliamente el campo de las enseñanzas técnicas, y la UPV/EHU, además, posee varios centros encuadrados en distintas áreas de ciencias.

En los últimos años se ha producido un aumento importante de recursos y una reorientación del sector universitario hacia el área de ingeniería y tecnología (que pasa del 15,1\% en 1994 al 26,2\% del gasto en 2008). Este cambio se refleja también en los fondos específicos de investigación, que han pasado del 15,2\% en 1994 al 28,3\% en $2008^{8}$. En paralelo, se ha producido una disminución del tamaño del área de ciencias sociales y humanidades, aunque esta área mantiene un nivel importante de fondos específicos de I+D. El área principal, por volumen de gasto general y fondos específicos, sigue siendo ciencias exactas y naturales.

La evolución mencionada se observa también si se atiende al personal de I+D por áreas. Las ciencias exactas y naturales crecen notablemente y mantienen su posición como área principal por nivel de recursos; ingeniería y tecnología crece espectacularmente; y las ciencias sociales y humanidades sufren una fuerte disminución (de un 48\% del personal en 1994 pasan a suponer un $25,5 \%$ en el año 2008).

En cuanto al tipo de investigación, es significativo el aumento del peso de la investigación aplicada (del 33,2\% en el año 2000 al 49,2\% en el año 2008), lo que la coloca a niveles similares a los de la investigación básica.

Atendiendo a los fondos específicos por organismos financiadores (solo disponemos de datos hasta el año 2004), se observa, en primer lugar, el aumento relativo de la financiación procedente de la Administración central, que llega a aportar el 26,1\% de los fondos en 2004, lo cual puede verse como un indicador positivo de la capacidad de los grupos de la universidad pública para obtener fondos competitivos de nivel estatal. Por su parte, la Administración vasca aporta el 41,9\% en dicho año, si bien es necesario hacer algunas consideraciones al respecto.

Dentro de la financiación autonómica se recogen tres fuentes de financiación diferentes: el Departamento de Educación del Gobierno Vasco, dentro de cuyas competencias se recoge la política científica; la propia UPV/EHU, que a través de su Vicerrectorado de Investigación lleva a cabo distintas acciones de apoyo a la investigación; y el Departamento de Industria del Gobierno Vasco, que ha abierto una vía importante de financiación al sistema universitario a través de los programas Saiotek (investigación genérica) y Etortek (investigación estratégica).

\section{Centros de investigación básica y de excelencia (BERC)}

Dentro del sistema científico se han puesto en marcha recientemente los denominados centros de investigación básica y de excelencia (BERC), que persiguen los siguientes objetivos: elevar el nivel y la calidad de la investigación científica en la CAPV; atraer investigadores de referencia de fuera del sistema científico vasco que catalicen la excelencia y la internacionalización de la investigación realizada; y crear nuevos grupos de investigación de referencia en sus áreas de conocimiento, apoyados en torno a investigadores de excelencia. En la actualidad existen los siguientes BERC: Fundación Donostia International Physics Center (DIPC), Fundación Biofísica Bizkaia, Basque

8 Los fondos específicos de $\mathrm{I}+\mathrm{D}$ son un indicador más preciso que los fondos generales puesto que no incluyen la imputación que las estadísticas habituales realizan del valor de una parte de la dedicación de los profesores universitarios. Los gastos realizados en un año a cargo de actividades de I+D contabilizados como fondos específicos son los siguientes: el gasto realizado en el desarrollo de proyectos de investigación propiamente dichos; la inversión en formación de personal investigador (becas y movilidad del personal); las subvenciones para inversiones en infraestructuras; $y$ otras subvenciones o ayudas específicas al mantenimiento de tareas de investigación. Otro capítulo importante son los gastos provenientes de los contratos externos (de prestación de servicios de I+D y/o colaboraciones con otros agentes en proyectos conjuntos). 
Centre for Climate Change (BC3), Basque Center for Applied Mathematics (BCAM), Basque Center on Cognition, Brain and Language (BCBL) y Materials Physics Center (MPC).

\section{Centros de investigación cooperativa (CIC)}

Los CIC son la última apuesta de la política de I+D e innovación de la CAPV para fomentar la integración del ámbito científico (universidad) y el tecnológico (centros y empresas). Con estas estructuras se busca avanzar en la investigación en áreas consideradas de interés estratégico, y entre sus funciones se encuentran: la generación de nuevo conocimiento, la transferencia tecnológica, la formación de alto nivel y la explotación comercial de los resultados de la investigación. En la actualidad existen siete CIC.

\section{Unidades de I+D empresarial}

Las unidades empresariales de tecnología e innovación se definen como estructuras encargadas de impulsar la innovación tecnológica dentro de las empresas, planificando y llevando a cabo proyectos de desarrollo que posteriormente puedan ser implantados en las propias empresas. Estas estructuras tienen como objetivo la consecución de nuevos productos, servicios y procesos innovadores que mejoren la competitividad de las empresas.

\section{Clústeres}

A partir de los años noventa se puso en marcha en la CAPV la política de clústeres con el principal objetivo de articular la demanda de las empresas. Diferentes sectores industriales se agruparon en clústeres y se inició un proceso de reflexión en torno a las posibilidades de mejorar su competitividad. Los clústeres de electrodomésticos, automoción y máquina herramienta tienen gran peso por la tracción que ejercen sobre el tejido industrial y su implicación importante en las comunidades socioempresariales de las cooperativas de Mondragón y de las pymes. También están representados en los clústeres sectores más incipientes que suponen una diversificación del tejido industrial vasco, como la aeronáutica.

\section{CEI y parques tecnológicos}

Los centros de empresa e innovación (CEI) coordinan las actividades dirigidas al fomento del emprendizaje a través de la promoción y tutorización de nuevos proyectos empresariales. Con este objetivo se han puesto en marcha los programas Ekintzaile y Barnekintzaile. Ambos programas están dirigidos a apoyar el desarrollo y la maduración de una idea de empresa, siempre que pertenezca al ámbito industrial o de servicios conexos a la industria y que reciba la consideración de idea innovadora y/o tecnológica. En el caso de Barnekintzaile, la idea tiene que haber nacido en el seno de una pyme con el objetivo de crear una empresa independiente.

En cuanto a la Red de Parques Tecnológicos de la CAPV, esta tiene como función facilitar los espacios de encuentro y de interacción entre los diferentes agentes científico-tecnológicos y empresariales en el desempeño de sus actividades innovadoras. Los parques tecnológicos de Álava, Bizkaia y Donostia-San Sebastián cerraron el ejercicio 2009 con un total de 397 empresas instaladas, dando empleo a 13.440 personas y facturando 3.464 millones de euros. Las actividades que desarrollan las empresas ubicadas en estos parques están relacionadas en un $32 \%$ con las TIC y en un $14 \%$ con la aeronáutica. El 16\% de la plantilla total de los parques pertenece a los centros tecnológicos, y el 10\% trabaja en el sector de las biociencias. 


\section{La FP en el ámbito regional}

\subsection{Formación reglada: recursos del sistema}

La CAPV cuenta en el curso 2009-2010 con 120 centros que imparten titulaciones de FP de grado medio y otros tantos que imparten grados superiores, lo que supone un 4,63\% y un 5,74\% del total de centros del Estado, respectivamente (tabla 3.15).

En la CAPV, a diferencia de en otras regiones del Estado, la FP tiene una alta penetración del sector privado (mayoritariamente concertado). Únicamente el 52,5\% de los centros que imparten enseñanzas de grado medio son públicos, 21,2 puntos porcentuales por debajo de la media estatal, mientras que, entre los centros que imparten grados superiores, el 54,2\% de los centros son públicos, 21,9 puntos porcentuales por debajo de la media estatal. Este hecho condiciona las relaciones que los centros mantienen con las empresas, ya que los centros privados cuentan con una mayor presencia de las empresas en sus órganos de dirección, control o consultivos, según los casos.

La CAPV cuenta en el curso referenciado con 11.068 alumnos matriculados en enseñanzas de grado medio y 16.579 en enseñanzas de grado superior (tabla 3.16), lo que supone un $4,06 \%$ y un $6,7 \%$ del total estatal, respectivamente. La distribución del alumnado entre centros públicos y privados es muy similar a la distribución de centros comentada anteriormente.

Las tasas brutas de escolarización en FPGM $(33,1 \%)$ son algo superiores a la media española $(30,8 \%)$ y ligeramente inferiores a las de regiones como Aragón (35,0\%), Asturias $(35,2 \%)$ y Cataluña $(34,4 \%)$, mientras que en FPGS $(47,7 \%)$ son notablemente superiores tanto a la media española $(26,4 \%)$ como a las del resto de las regiones analizadas en este informe. Por ello, cabe afirmar que la FPGS vasca es muy destacada dentro del ámbito del Estado español en términos de impacto en la estructura de los estudios de la población.

Tal y como se puede observar en las siguientes figuras (tablas 3.17 y 3.18), la evolución de la FPGM en la CAPV ha mantenido un curso relativamente estable durante los últimos años, mientras que la evolución de la FPGS es claramente descendente. Dado su elevado peso en la FP vasca, el conjunto de la FP se ha visto afectado por esta tendencia negativa de la FPGS. Desde la llegada de la crisis financiera de 2008 se produce un repunte de las matriculaciones en el sistema educativo que afecta también a los dos niveles de la FP.

\section{Gráfico 2.16. Evolución de las matriculaciones de FP en la CAPV}

$(1998 / 1999-2009 / 2010)$

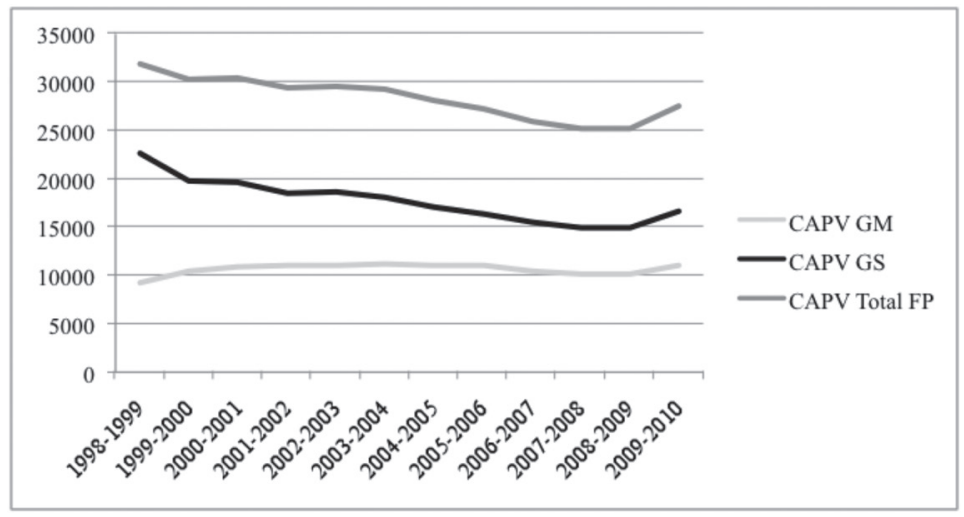


Finalmente, apuntaremos que la matriculación en las ramas industriales de la FP sigue una tendencia negativa debido, por una parte, a la diversificación y creación de nuevos estudios de FP — más asociados a la nueva sociedad de servicios - y, por otra, a la pujanza de los estudios de ESO y bachillerato. Así las cosas, en el Estado la disminución de la matrícula en las ramas industriales ha sido del 9\% en FPGM y del 1,9\% en FPGS durante los últimos diez cursos académicos (tablas 3.23 y 3.24). Cabe señalar, sin embargo, que en la CAPV este descenso ha sido algo menos acusado (7,7\% en FPGM y 1,6\% en FPGS), probablemente por la fuerte impronta industrial de la región y por el atractivo del empleo asociado a este sector, que está obteniendo buenos resultados económicos gracias a la actividad de innovación e internacionalización.

\subsection{Formación reglada: ámbitos de especialización}

Atendiendo a los ámbitos de especialización industrial de la FPGM, en la siguiente figura, basada en la tabla 3.21, podemos observar que la CAPV tiene una importante tasa de matriculación (16,5\%) en los grados medios de la familia de Fabricación Mecánica, 12,5 puntos porcentuales por encima de la media estatal y notablemente por encima del resto de las regiones analizadas. Electricidad y Electrónica recibe el 11,4\% de las matrículas de FPGM, si bien las diferencias con la media estatal y con el resto de las regiones son muy pequeñas. Ocurre lo mismo con Mantenimiento de Vehículos Autopropulsados, que cuenta con el 8,9\% de las matrículas de FPGM.

Existe, aunque con unos niveles de matriculación más bajos, un cierto diferencial de especialización en relación con el Estado en Mantenimiento y Servicios a la Producción (7,6\% CAPV frente a 4,1\% EE), así como en Madera y Mueble (2,2\% CAPV frente a 0,9\% EE).

La principal carencia relativa de la FPGM en la CAPV se sitúa en los grados medios en Informática $(5,3 \%$ CAPV frente a 8,0\% EE).

\section{Gráfico 2.17. Áreas de especialización industrial de la FPGM en la CAPV}

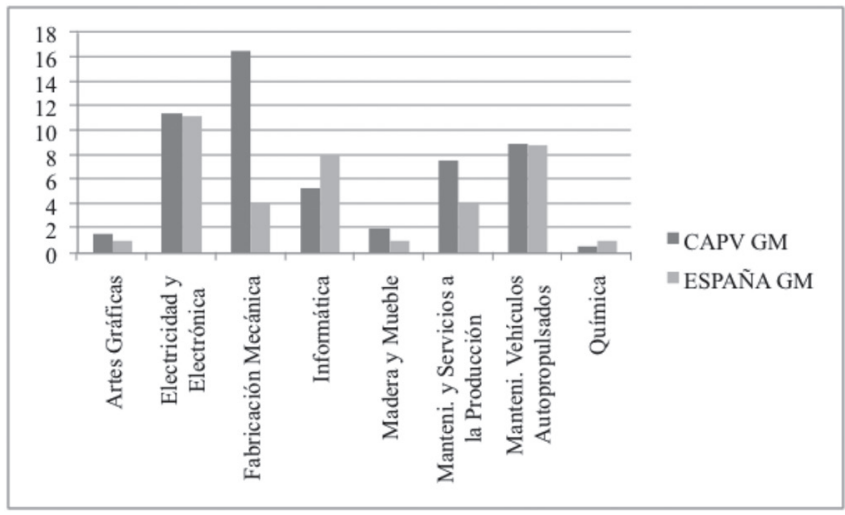

Atendiendo a los ámbitos de especialización industrial de la FPGS, en la siguiente figura, basada en la tabla 3.22, podemos observar que la CAPV tiene, al igual que en los GM, una importante tasa de matriculación (12,7\%) en los grados superiores de la familia de Electricidad y Electrónica, con una diferencia con la media estatal de cerca de cinco puntos porcentuales $y$, 
salvo en el caso de la CFN, que cuenta con las mismas tasas de matriculación, muy por encima del resto de las regiones analizadas.

Con todo, el principal diferencial de especialización en FPGS de la CAPV se produce — también en los grados superiores - en Fabricación Mecánica ( 9,1 puntos porcentuales sobre la media estatal) y, en menor medida, en Mantenimiento y Servicios a la Producción (3 puntos porcentuales), ámbito de mayor especialización de la CFN.

Como ocurría en los GM, el principal déficit relativo de la FP en la CAPV se sitúa en la Informática (2,6 puntos porcentuales por debajo del EE y por detrás de todas las regiones objeto de este análisis).

\section{Gráfico 2.18, Áreas de especialización industrial de la FPGS en la CAPV}

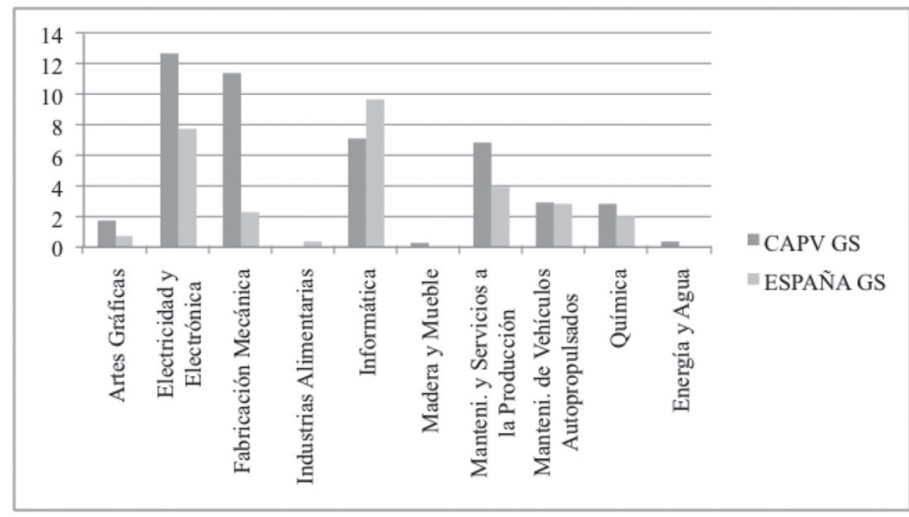

En conjunto, como muestran las tablas 3.23 y 3.24, la CAPV cuenta con una especialización muy importante en familias de estudios de FP del sector industrial. El porcentaje de alumnos matriculados en dichas familias es del 50,7\% en FPGM y 45,9\% en FPGS, siendo la media española del 33,3\% y 28,0\%, respectivamente. Asimismo, cabe señalar que estos porcentajes de matriculaciones en ramas industriales son sensiblemente superiores a los del resto de las regiones analizadas.

\subsection{Formación para el empleo: la formación de oferta}

En la CAPV han participado en la formación para el empleo, en la modalidad de oferta, durante 2010 un total de 25.585 personas, lo que supone un 3,25\% del total estatal (tabla 3.25).

Dentro de esta modalidad de formación para el empleo, señalaremos que en la CAPV corresponden a la industria el $22,4 \%$ de las personas formadas, en la línea de lo que sucede a nivel estatal $(22,7 \%)$.

La fórmula presencial es la más utilizada en la CAPV, abarcando un 55,3\% de las acciones, 6,8 puntos porcentuales por encima de la media estatal. La formación a distancia $(12,1 \%)$, la formación mixta $(11,7 \%)$ y la teleformación $(20,8 \%)$ son fórmulas mucho menos utilizadas. Entre estas, señalaremos que la formación a distancia se sitúa 7,8 puntos porcentuales por debajo de la media estatal, estando la formación mixta y la teleformación en línea con las prácticas estatales.

Más de la mitad de las personas formadas en esta modalidad de la formación para el empleo han sido mujeres $(48,5 \%)$, casi tres puntos porcentuales por encima de la media del 
Estado (tabla 3.26). Asimismo, cabe señalar que más de la mitad de las personas formadas se encuentran en la franja de edad de 36-55 años, siendo en este colectivo donde se produce una mayor diferencia con la media del Estado (8 puntos porcentuales a favor de la CAPV) y con el resto de las regiones analizadas.

La formación de oferta en la CAPV (tabla 3.27) se dirige más a personas con cualificación (33,3\% de los participantes) que a personas sin cualificación (26,4\%). Los porcentajes de personas con y sin cualificación formadas en oferta en la CAPV están cinco y seis puntos porcentuales por debajo de la media del Estado, respectivamente.

Por el contrario, en la CAPV el colectivo de directivos y técnicos, así como - muy especialmente - los mandos intermedios (7,1 p.p. de diferencia con la media estatal y claramente por encima del resto de las regiones analizadas), reciben mucha más formación de oferta.

\subsection{Formación para el empleo: la formación de demanda}

De acuerdo con los datos que facilita la Fundación Tripartita para la Formación en el Empleo (tabla 3.29), durante 2010 se formaron 149.816 trabajadores en las empresas de la CAPV, el $5,4 \%$ de las personas formadas en la modalidad de demanda en el Estado español, siendo el $24,1 \%$ de las empresas de la CAPV las que hacen formación de demanda, en línea con la media estatal (24,6\% de las empresas).

El esfuerzo en formación de demanda crece con el tamaño de las empresas tanto en el Estado como en la CAPV (tabla 3.28), si bien las empresas vascas de mayor tamaño (especialmente las del tramo 50-249 empleados) hacen un mayor esfuerzo - comparado con la media del Estado - en este tipo de formación, mientras que las de menor tamaño (menos de 50 trabajadores) muestran índices ligeramente inferiores de participación.

Cabe señalar que la tasa de cobertura de la formación de demanda en la industria manufacturera (tabla 3.28 ) es del $33,8 \%$, ligeramente superior a la media estatal (32,8\%), pero inferior a la de regiones como CFN y Asturias.

Como se puede observar en la tabla 3.29, cerca del $60 \%$ de los participantes formados en empresas manufactureras corresponde a empresas mayores de 100 trabajadores, porcentaje inferior a los del resto del Estado en este tramo de tamaño empresarial. Las empresas de la CAPV que muestran un diferencial positivo de formación de demanda tanto con el Estado como con el resto de las regiones analizadas son aquellas encuadradas en el tramo 10-49 trabajadores (representan el 22,7\% de los participantes formados en la CAPV).

Atendiendo a la distribución por sectores empresariales (tabla 3.30), el porcentaje de participantes formados en el sector industrial $(26,2 \%)$ es claramente superior a la media española $(18,7 \%)$.

La formación de demanda en la CAPV es fundamentalmente presencial. Dos terceras partes de las personas formadas lo han sido dentro de esta modalidad de formación, índice que, en el caso de las empresas industriales, sube a tres cuartas partes por encima de la media estatal ( $59,8 \%$ y $68,8 \%$, respectivamente).

Casi el $80 \%$ de las personas formadas dentro de la modalidad de demanda en la industria han sido hombres, y tres cuartas partes, de edades comprendidas entre los 26 y 45 años.

La formación de demanda en la industria manufacturera de la CAPV (tabla 3.32) está dirigida, en mayor medida, a trabajadores cualificados (40,1\%). Un 44,4\% de las personas for- 
madas pertenecen a las categorías profesionales con responsabilidades de gestión (directivos, mandos intermedios o técnicos), 6,3 puntos porcentuales por encima de la media estatal.

En relación con el perfil profesional de las personas formadas (dentro de la fórmula de demanda) en la industria de la CAPV y con la estructura de estudios de la población en esta región, el perfil académico de los participantes en la formación es medio-alto (tabla 3.33).

Un $47,1 \%$ de las personas cuentan con estudios secundarios postobligatorios y un $33,3 \%$ con estudios universitarios. Las personas con estudios secundarios postobligatorios que reciben este tipo de formación reflejan la mayor diferencia con la media española, existiendo 7,3 puntos porcentuales de diferencia en este colectivo. Los universitarios también reciben más formación que la media estatal (33,3\% frente a 29,2\%). Como consecuencia de lo anterior, las personas con bajos niveles de estudios reciben proporcionalmente menos formación de demanda en la CAPV (por ejemplo, las personas con estudios primarios y secundarios obligatorios representan el 17,1\% de los formados, frente al 29,1\% de media estatal).

Los permisos individuales para la formación en la CAPV (132 permisos en 2010) se conceden prácticamente en sus dos terceras partes a trabajadores de grandes empresas (tabla 3.34). Destaca, en términos relativos, que en las medianas empresas de la CAPV se han concedido casi un tercio de los permisos, muy por encima de la media estatal $(23,3 \%)$.

\subsection{Política regional en relación con la FP}

La formación profesional es una parcela de gran importancia dentro del sistema educativo del País Vasco puesto que se encarga de relacionar unas enseñanzas específicas relativas a áreas de especialización profesional con las necesidades de la industria regional. De esta manera, cumple una función clave de provisión de trabajadores cualificados al tejido empresarial.

Así, el Plan Vasco de Formación Profesional (1997) supuso una ruptura con una concepción estanca de los fines y los procedimientos formativos para buscar la integración y concatenación de las distintas ofertas y actividades formativas a fin de satisfacer las diversas necesidades de cualificación de las personas de la CAPV. El Plan supuso un importante esfuerzo de carácter organizativo y económico que permitió una mejor ubicación de la formación profesional en el marco de una sociedad cambiante.

El II Plan Vasco de Formación Profesional (2004-2007) se concibió como «la adaptación de las estructuras y actividades ya en marcha a los nuevos cambios detectados, acomodando planes y procesos ya existentes a la transformación de las tecnologías, mercados, competidores y valores, y tratando también de penetrar por medio de nuevos instrumentos y herramientas en otros campos emergentes». Este plan establece un presupuesto de 806,7 millones de euros a realizar en 4 años y tiene como objetivo el desarrollo de 4 ámbitos estratégicos: completar, actualizar y mejorar el sistema integrado de cualificaciones y formación profesional; fomentar la calidad en la formación profesional del País Vasco; impulsar la innovación en la formación profesional del País Vasco como un proceso de mejora continua; y promover las nuevas tecnologías en la formación profesional del País Vasco.

Fruto de la implantación de estos dos primeros planes, cabe señalar que han cobrado forma tres características distintivas del desarrollo de la FP en la CAPV.

a) La atención prestada por el Gobierno Vasco y las diputaciones forales (Basterretxea et alii, 2002) de manera ininterrumpida a esta parcela de la educación. Así, más allá del importante aporte económico efectuado desde mediados de los años 
noventa, se han creado diferentes estructuras, pioneras en el ámbito estatal, que han permitido robustecer e institucionalizar progresivamente la formación profesional ${ }^{9}$.

b) El impulso por parte de la Administración ${ }^{10}$ de la adopción de enfoques de calidad homologables con los utilizados comúnmente por la industria y los servicios (Plan Vasco de Formación Profesional, 1997).

En apoyo de esta estrategia se desarrolló el programa SAREka para los centros públicos cuyo objetivo fue el implantar un sistema de calidad basado en la ISO 9.001, tal como ya habían implantado con éxito algunos centros públicos. También se canalizaron ayudas económicas a las asociaciones de los centros concertados para desarrollar sus sistemas de gestión y para poder integrarse en los programas que desarrolló Euskalit (Fundación Vasca para la Excelencia) para el sector educativo y cuyo referente era el modelo EFQM de excelencia. Aquella estrategia ha contribuido, sin duda, a la mejora de los resultados generales de la formación profesional. El Plan Vasco de Formación Profesional 2004-2007 destacó la aplicación de estándares como las normas ISO 9.001 y el modelo de excelencia EFQM.

Así las cosas, entre los centros de FP se extendió la implantación de diferentes certificaciones y sistemas de gestión y obtención de distinciones con notables resultados11: 46 centros poseen la acreditación ISO 9.001; 18 centros la Q de Oro 500 EFQM; 50 centros la Q de Plata 400 EFQM; 10 centros la ISO 14.001; 16 centros la distinción Ecoskan; 14 centros la liP; 1 centro la ISO 27.001; y otro la UNE 166.002. Este impulso ha favorecido, sin lugar a dudas, una notable transformación de las estructuras de gestión, la modernización de los equipamientos, la transición de la oferta formativa reglada y el desarrollo de la formación para el empleo.

c) Creciente compromiso con el desarrollo de la formación profesional continua y ocupacional (actualmente, formación para el empleo).

A diferencia de lo que ha venido ocurriendo en el resto del Estado español, donde la formación de oferta ha estado gestionada fundamentalmente a través de contratos programa con los agentes sociales, en la CAPV la Red de Centros Integrales de FP ha desempeñado un importante papel en la cobertura de este tipo de formación, notablemente a través del Catálogo Modular, así como con una oferta a la medida de las demandas de las empresas.

En la tabla 2.19, elaborada sobre la base de los datos que nos ha facilitado Hobetuz (Fundación Vasca para la Formación Profesional Continua) ${ }^{12}$, se pueden apreciar el número de horas impartidas por los centros integrales de FP, el número de personas formadas y la subvención recibida por los cursos impartidos, que han ido creciendo durante los últimos años. En 2009 han supuesto el 50,36\% del total de

\footnotetext{
9 Consejo Vasco de Formación Profesional (1994); Fundación Vasca para la Formación Profesional Continua, Hobetuz, gestada tras el Acuerdo Interprofesional y Tripartito (1996); Observatorio del Sistema Vasco de Formación Profesional (1998); Instituto Vasco de Cualificaciones Profesionales y Formación Profesional (1998); Red de Centros Integrales de Formación Profesional (1998); Agencia Vasca para la Evaluación de la Competencia y la Calidad de la Formación Profesional (2000); Viceconsejería de Formación Profesional y Aprendizaje Permanente (2001).

10 Plan Vasco de Formación Profesional (1997).

11 Viceconsejería de Formación Profesional y Aprendizaje Permanente. Anuario Estadístico 2008-2009.

12 La firma del Acuerdo Interprofesional y el Acuerdo Tripartito sobre Formación Continua en la CAPV, en septiembre de 1995, entre la Confederación Empresarial Vasca Confebask, las centrales sindicales ELA, CC. OO., UGT y LAB y el Gobierno Vasco, supuso la gestación de Hobetuz como entidad tripartita que promueve y gestiona la formación profesional continua en la CAPV.
} 
horas impartidas dentro del sistema, el $51,9 \%$ de las personas formadas y el $46,3 \%$ de la subvención otorgada para este concepto.

Tabla 2.19. Evolución de la participación de los centros de FP en la formación continua

\begin{tabular}{|l|c|c|c|c|c|c|}
\cline { 2 - 7 } \multicolumn{1}{c|}{} & $2004(1)$ & $2005(1)$ & $2006(3)$ & 2007 & 2008 & 2009 \\
\hline $\begin{array}{l}\text { N. de horas } \\
\text { impartidas en } \\
\text { centros FP (2) }\end{array}$ & 73.622 & 50.743 & $\mathrm{xxx}$ & 85.180 & 90.691 & 92.874 \\
\hline $\begin{array}{l}\text { N. de personas } \\
\text { formadas en } \\
\text { centros FP }\end{array}$ & 14.076 & 9.780 & $\mathrm{xxx}$ & 19.725 & 20.648 & 22.181 \\
\hline $\begin{array}{l}\text { Subvención cursos } \\
\text { centros FP }\end{array}$ & $5.565 .560,10$ & $3.208 .973,61$ & $\mathrm{xxx}$ & $7.917 .891,05$ & $9.284 .874,35$ & $9.536 .062,93$ \\
\hline
\end{tabular}

(1) En estos dos años la convocatoria de trabajadores solo era para planes del Catálogo Modular - Sistema Vasco de Cualificaciones

(2) Número de horas = horas de la acción formativa * número de grupos de la acción

(3) Convocatoria gestionada directamente por el Gobierno Vasco. Hobetuz no dispone de datos.

Fuente: Hobetuz (Fundación Vasca para la Formación Profesional Continua)

La modernización de la formación profesional incide en los profesores y formadores. Entre las preocupaciones comunes relativas al desarrollo de competencias de los profesionales de formación profesional, cabe citar un enfoque centrado en el alumnado; la relevancia de la formación para el mercado laboral (tanto en relación con las aptitudes técnicas como con la empleabilidad); las TIC y los métodos docentes flexibles; los enfoques que responden a las necesidades de los clientes y los principales interesados, impulsando colaboraciones y adaptando la formación a los requisitos de la industria; la evaluación y el seguimiento de los resultados del aprendizaje; los conocimientos técnicos relativos al sistema de formación; y el desarrollo de aptitudes y competencias transversales como la orientación, la gestión y la administración.

Sin embargo, el análisis de la formación del profesorado muestra que las horas de formación en empresa decrecen del 30\% al 16\% entre 2003 y 2007. El total de horas de formación representan alrededor (según los años) de 1,3 horas a 2,5 horas de media por profesor. Sin duda, un volumen bajo si se atiende a la necesidad de transformación de las competencias del profesorado. Por otro lado, se observa que la creación de $\mathrm{Tknika}^{13}$ repercute favorablemente en el incremento de horas de formación a partir de 2007.

Tabla 2.20. Número de horas de formación del profesorado de FP

\begin{tabular}{|c|c|c|c|c|c|}
\hline CURSO & $\begin{array}{c}\text { Cursos de } \\
\text { perfeccionamiento }\end{array}$ & $\begin{array}{c}\text { Formación en } \\
\text { centros }\end{array}$ & Empresas & $\begin{array}{c}\text { Tknika / IVAC } \\
\text { multilingüe }\end{array}$ & Total \\
\hline 2002 & 1.596 & 3.057 & & & 4.653 \\
\hline 2003 & 1.473 & 3.056 & 2.800 & & 7.329 \\
\hline 2004 & 1.587 & 4.446 & 2.106 & & 8.139 \\
\hline
\end{tabular}

13 Tknika es un centro impulsado por la Viceconsejería de Formación Profesional y Aprendizaje Permanente del Departamento de Educación, Universidades e Investigación del Gobierno Vasco. A través del trabajo en red, y con la implicación del profesorado de formación profesional, este centro, que tiene como referente los modelos avanzados del mundo, desarrolla proyectos de innovación relacionados con los ámbitos tecnológicos, formativos y de gestión. 


\begin{tabular}{|c|c|c|c|c|c|}
\hline CURSO & $\begin{array}{c}\text { Cursos de } \\
\text { perfeccionamiento }\end{array}$ & $\begin{array}{c}\text { Formación en } \\
\text { centros }\end{array}$ & Empresas & $\begin{array}{c}\text { Tknika / IVAC } \\
\text { multilingüe }\end{array}$ & Total \\
\hline 2005 & 1.380 & 3.338 & 2.017 & & 6.735 \\
\hline 2006 & 2.007 & 2.986 & $2.384,5$ & & $7.377,5$ \\
\hline 2007 & 1.546 & 4.205 & 1.448 & 1.769 & 8.968 \\
\hline
\end{tabular}

Fuente: Viceconsejería de Formación Profesional y Aprendizaje Permanente.

Anuario Estadístico 2008-2009

El profesorado, en general, es un colectivo de trabajadores de edad elevada en un porcentaje alto. De ello deriva el riesgo de que sus competencias profesionales queden obsoletas y que el número de docentes cualificados sea insuficiente a medio plazo. Otro riesgo es la escasez de profesores y formadores si la demanda de reemplazo generada por las jubilaciones o la movilidad profesional no queda satisfecha adecuadamente.

Con las jubilaciones pueden producirse carencias cualitativas de competencias si no se crean las condiciones para una transferencia de conocimientos, aptitudes y experiencias por parte de los profesionales mayores en el momento de su jubilación. A la vez, a causa de la obsolescencia de las competencias docentes, los conocimientos técnicos y profesionales de los profesores y formadores mayores pueden perder relevancia para el mercado laboral, lo que acentuaría la necesidad de formación continua.

En la situación actual, los centros y el profesorado necesitan desarrollar sus competencias pedagógicas para elaborar y experimentar métodos de enseñanza y evaluación adaptados al enfoque basado en competencias. La enseñanza no solo debe transmitir conocimientos, sino también dotar al alumnado de las actitudes y aptitudes pertinentes. En particular, es necesario realizar esfuerzos en lo que respecta a las competencias transversales clave, esenciales para mejorar la creatividad y la innovación, así como para el éxito laboral y social en general.

En este sentido, es significativo el empuje realizado para favorecer la participación del profesorado en proyectos de innovación. Alrededor de un $15 \%$ del profesorado de los centros públicos han participado en ellos a través de los programas de innovación de Tknika. 
Gráfico 2.19. Proyectos desarrollados por Tknika en los cursos 2006-2007 y 2007-2008

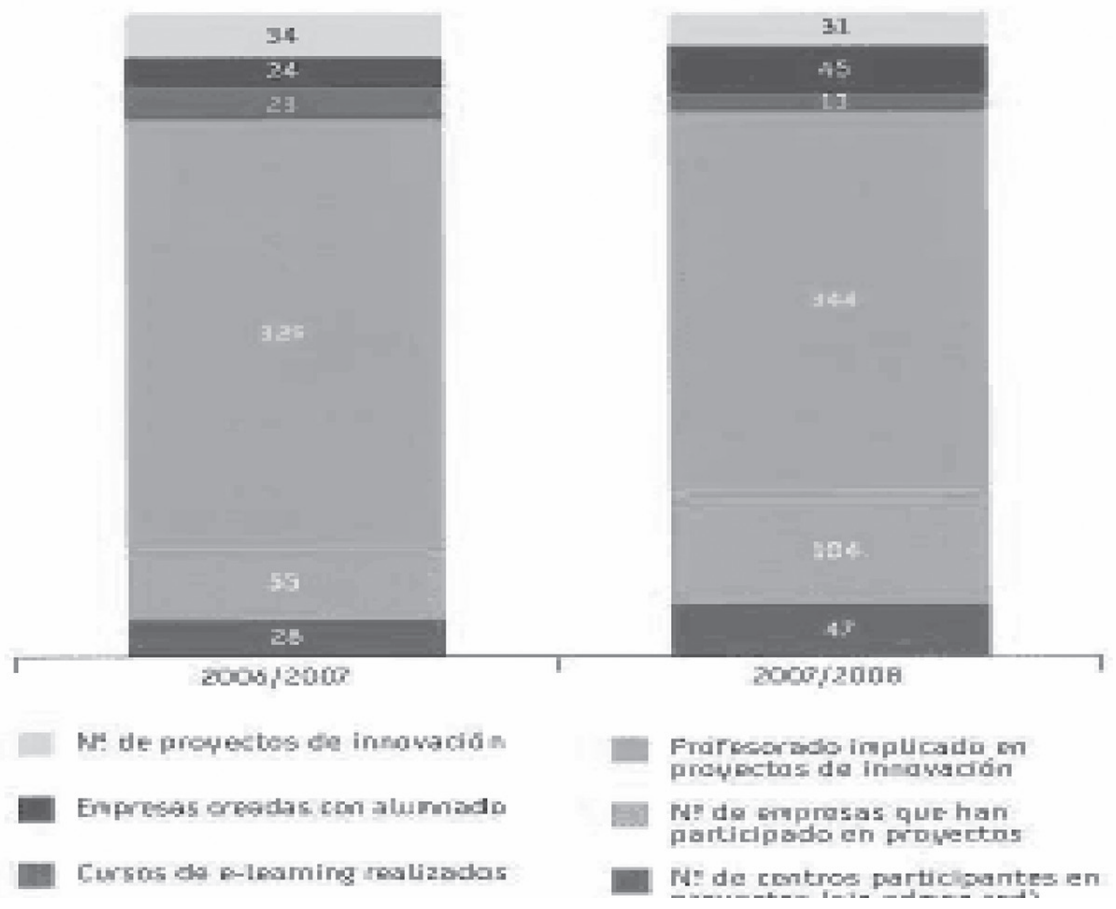

Fuente: Viceconsejería de Formación Profesional y Aprendizaje Permanente.

Anuario Estadístico 2008-2009

A nivel presupuestario, el Gobierno regional ha dedicado recursos de manera creciente a la FP hasta 2010, cuando los recursos destinados a esta área del sistema educativo se reducen. Las líneas estratégicas que desarrolla el actual plan (III Plan de Formación Profesional, 20112013) son cuatro (aprendizaje permanente y movilidad; calidad y eficacia de la FP; promoción de la equidad, cohesión social y ciudadanía activa; creatividad, innovación y emprendizaje), y el detalle del gasto en las actividades asociadas al desarrollo del Plan en el período 2011-2013 aparece reflejado en la siguiente tabla. 
Tabla 2.20. III Plan de FP Gobierno Vasco (miles de euros)

\begin{tabular}{|c|c|c|c|c|c|c|}
\hline & $\begin{array}{c}2011 \\
\text { Dpto. } \\
\text { Educación }\end{array}$ & $\begin{array}{c}2011 \\
\text { Lanbide } \\
\text { Dpto. } \\
\text { Trabajo y } \\
\text { AASS }\end{array}$ & $\begin{array}{c}2012 \\
\text { Dpto. } \\
\text { Educación }\end{array}$ & $\begin{array}{c}2012 \\
\text { Lanbide } \\
\text { Dpto. } \\
\text { Trabajo y } \\
\text { aass }\end{array}$ & $\begin{array}{c}2013 \\
\text { Dpto. } \\
\text { Educación }\end{array}$ & $\begin{array}{c}2013 \\
\text { Lanbide } \\
\text { Dpto. } \\
\text { Trabajo y } \\
\text { AASS }\end{array}$ \\
\hline Ciclos LOE & 453,6 & & 453,6 & & 453,6 & \\
\hline $\begin{array}{l}\text { Certificados - } \\
\text { Catálogo Modular }\end{array}$ & $5.000,0$ & 200,0 & $5.000,0$ & 200,0 & $5.000,0$ & 200,0 \\
\hline Enseñanza on line & $1.083,5$ & & $1.083,5$ & & $1.083,5$ & \\
\hline $\begin{array}{l}\text { PCPI - Atajar } \\
\text { abandono escolar } \\
\text { temprano }\end{array}$ & $19.000,0$ & 50,0 & $19.000,0$ & 80,0 & $19.000,0$ & 150,0 \\
\hline Internacionalización & $1.793,8$ & 300,0 & $1.793,8$ & 300,0 & $1.793,8$ & 300,0 \\
\hline $\begin{array}{l}\text { Reconocimiento } \\
\text { experiencia laboral }\end{array}$ & 885,2 & 500,0 & 885,2 & 500,0 & 885,2 & 500,0 \\
\hline $\begin{array}{l}\text { Asesoramiento y } \\
\text { orientación }\end{array}$ & 755,2 & 200,0 & 755,2 & 200,0 & 755,2 & 200,0 \\
\hline Centros integrados & $6.019,5$ & 300,0 & $6.019,5$ & 300,0 & $6.019,5$ & 300,0 \\
\hline Infraestructuras & $4.900,0$ & & $19.600,0$ & & $24.500,0$ & \\
\hline $\begin{array}{l}\text { Modernización } \\
\text { equipamientos }\end{array}$ & $6.576,0$ & & $6.576,0$ & & $6.576,0$ & \\
\hline Modelos de gestión & 94,6 & 150,0 & 94,6 & 150,0 & 94,6 & 150,0 \\
\hline $\begin{array}{l}\text { Gestión de la } \\
\text { información }\end{array}$ & 100,0 & & 100,0 & & 100,0 & \\
\hline $\begin{array}{l}\text { Innovación } \\
\text { emprendizaje }\end{array}$ & $3.204,4$ & 500,0 & $3.204,4$ & 500,0 & $3.204,4$ & 500,0 \\
\hline $\begin{array}{l}\text { Relación empresas- } \\
\text { FP }\end{array}$ & 250,0 & 300,0 & 250,0 & 300,0 & 250,0 & 300,0 \\
\hline $\begin{array}{l}\text { Plataforma } \\
\text { cualificaciones }\end{array}$ & 100,0 & 200,0 & 100,0 & 200,0 & 100,0 & 200,0 \\
\hline $\begin{array}{l}\text { Formación } \\
\text { profesorado }\end{array}$ & $1.077,4$ & 50,0 & $1.077,4$ & 50,0 & $1.077,4$ & 50,0 \\
\hline $\begin{array}{l}\text { Plan de rescate } \\
\text { (segunda } \\
\text { oportunidad } \\
\text { población 25-29 } \\
\text { años) }\end{array}$ & 0,0 & 400,0 & 0,0 & 500,0 & 0,0 & 560,0 \\
\hline $\begin{array}{l}\text { Participación diseño } \\
\text { FP }\end{array}$ & 200,0 & & 200,0 & & 200,0 & \\
\hline Difusión & 633,4 & 120,0 & 633,4 & 110,0 & 633,4 & 100,0 \\
\hline
\end{tabular}

Fuente: III Plan Vasco de Formación Profesional 


\subsection{Relaciones entre los centros de FP y las empresas}

De acuerdo con los trabajos empíricos de Albizu et alii ${ }^{14}$ (véase ficha técnica en el anexo I), del total de empresas encuestadas, el $82 \%$ afirma que tiene o ha tenido alguna relación con centros de FP. Se trata de una tendencia mayoritaria en todo el ámbito analizado, siendo en Gipuzkoa donde la existencia de estas relaciones se ha detectado en el mayor porcentaje de empresas $(88,3 \%)$.

Aunque la mayoría de las empresas son pequeñas (78\% de hasta 50 empleados), las relaciones con centros de FP son significativamente más frecuentes entre las empresas de mayor tamaño (a partir de 50 empleados el porcentaje asciende al 89,8\% en el total de las empresas y al 94,4\% entre las empresas guipuzcoanas).

Las empresas se relacionan con centros geográficamente próximos: el 69\% de las empresas se relacionan principalmente con centros de FP radicados en la misma comarca, y hasta en un $89,5 \%$, en su propia provincia o territorio.

\section{Formación en Centro de Trabajo (FCT)}

Cerca del $86 \%$ de las empresas que mantienen relaciones con los centros de FP en la CAPV reciben alumnado en prácticas. Creemos que este hecho es altamente significativo e indica un grado importante de relación entre las empresas y el sistema educativo de FP. Las empresas innovadoras están ligeramente por encima de la media en esta actividad y las diferencias entre empresas innovadoras y no innovadoras no son importantes ( 3,8 puntos porcentuales). La valoración por parte de las empresas de esta experiencia es realmente alta $(7,69 / 10)$, destacando el muy escaso porcentaje $(2,2 \%)$ de empresas que han tenido experiencias insatisfactorias y un $22,2 \%$ de empresas que valoran las prácticas como una herramienta excelente (9-10).

La formación en centros de trabajo $(\mathrm{FCT})^{15}$ es un mecanismo fundamental para que las empresas y los centros se conozcan y desarrollen relaciones de confianza. Así las cosas, los tutores del centro de FP visitan las empresas y conocen de cerca su actividad, sus necesidades en materia de formación, así como los niveles de adecuación de los conocimientos de los estudiantes a las necesidades de las empresas. Subsiguientemente, los centros de FP pueden, a través de este mecanismo, captar y canalizar información relativa a los cambios que están sucediendo en el ámbito tecnológico en las empresas.

A la vez que hacen el seguimiento del alumno, van conociendo, pues bueno, los entresijos de la empresa, la tecnología con la que está trabajando actualmente, los programas, las máquinas y tal... Y, entonces, pues ahí es donde se ven las necesidades... (E4, p. 36)

Sendotzen joan dira harremanak enpresekin, ba beno, tutoreek segimentua egiten dute eta ikasleen seguimentua egiteko orduan joaten dira baita ere, enpresak bisitatu eta batekin eta besteekin hitz egiten dute. Gero, normalean, enpresetan ba ikasleak izandakoak daude eta orduan harreman bat sortzen da eta urteen poderioz harreman hori asko sakondu da. (E11, p. 1)

14 Albizu, E.; Olazaran, M.; Lavía, C. у Otero, B. (2011): «Relationships between vocational training centres and industrial SMEs in the Basque Country: a Regional Innovation System approach», Intangible Capital, vol. 7, n. ${ }^{\circ}$, pp. 329-355. Ed. UPC. Online ISSN: 1697-9818 - Print ISSN: 2014-321. <http://dx.doi.org/10.3926/ic.2011.v7n2.p329-355>.

Albizu, E.; Olazaran, M. y Otero, B. (2012): «El papel de la formación profesional en la innovación de las PYMEs de la Comunidad Autónoma del País Vasco: un estudio cualitativo», en Merino, L. (ed.), Contextos y usos de la innovación social, ed. Servicio Editorial de la Universidad del País Vasco, Leioa, pp. 243-268. ISBN: 978-84-9860-634-8.

$15 \mathrm{La}$ formación en el centro de trabajo se refiere a las prácticas que deben realizar los alumnos de los ciclos medio y superior de manera obligatoria para obtener el título de Formación Profesional. 
Hemengo tutore bat egoten da heurekin kontaktuan, ikusten zelan dihoan guzti hori, eta aldi berean, urtean zehar enpresetara joaten gara ere, ikusten ditugu beraien beharrak zeintzuk diren. Orain dela urte batzuk, ikusi zen, adibidez, ba behar zirela aldaketa batzuk. Nahiz eta teknologikoki oso ondo prestatuta egon, nolabait, beste arlo batzuk oso zakar zeudela ohartu ginen. Konpetentzia transbersalen behar hori ikusi zen empresetan, Komunikazioa, talde lana, planifikazioa, arazoen konponketa... Guzti hori hasi gara lantzen jada. (E6, p. 4)

Adicionalmente, las estadísticas demuestran que este es un poderoso instrumento para la inserción laboral ya que, en la mayoría de los casos, las personas que denotan un perfil actitudinal satisfactorio terminan siendo contratadas en las empresas. El 58\% de las empresas encuestadas recurren a las bolsas de trabajo de los centros de FP.

Por otro lado, las FCT ofrecen a las empresas la posibilidad de conocer de cerca la actividad efectuada en los centros (por ejemplo, la oferta de formación continua) y el equipamiento del que disponen. Los tutores de las FCT son, por lo tanto, una figura destacada a través de la cual se canalizan las relaciones y los intercambios de información entre los centros de FP y las empresas.

\section{Formación continua}

Los cursos de formación continua son una fuente importante de relación entre centro y empresa. Los técnicos de las empresas que acuden a estos cursos tienen la oportunidad de conocer de cerca los centros, los profesores y el equipamiento de que disponen. Asimismo, a través de los técnicos, los profesores conocen los problemas a los que se enfrentan las empresas en su actividad diaria y actualizan su conocimiento de la realidad empresarial. Algunos entrevistados señalan que la formación continua ha contribuido a elevar el prestigio de la FP entre las empresas del entorno, a la vez que a estrechar lazos con ellas.

Desde los centros se señala que las necesidades en formación que plantean las empresas del entorno frecuentemente se insertan dentro de la formación continua, si bien estos contenidos van pasando a formar parte del currículo de la formación reglada progresivamente. Asimismo, las demandas recibidas desde las empresas marcan las prioridades en la adquisición de equipamientos que permitan dar soporte a la formación ofrecida.

Yo creo que ha hecho mucho el tema de los cursos de la no reglada, el prestigio de la FP y, además, que han venido trabajadores de empresas... (E4, p. 32)

Esperientzia ona da ikastetxeentzako. Harreman zuzena daukate langile horiekin edo tekniko horiekin. Gero langileek ere ikusten dute batzuetan: «kontxo, honek soluzionatu ahal du...» Asko etortzen dira problema batekin, batzuetan «lantegian ez dugu lortzen hau egitea», batzuetan soluzionatzen zaizkie gauza batzuk. Badago harreman bat nahiko aberatsa, irakasleek, eurek ere, asko ikasten dute, benetako problemak ikusten dituzte, nondik datozten problemak. Orduan horrek ematen die feed back bat oso importantea. (E8, p. 16)

Eta irakasle bat baldin badago bere bizitzako urte guztietan hemen, Ez arautuan parte hartzeke, Arautuan bakarrik, atzeratuta geratzen da. (E3, p. 20)

\section{Formación continua del Catálogo Modular (FCCM)}

Los centros de FP aparecen como proveedores de considerable importancia en servicios de formación continua para las empresas con las que se relacionan: el 44,3\% de las empresas encuestadas envía a sus trabajadores a recibir formación ofertada dentro del Catálogo Modular en la red de centros de FP. 
Respecto a la formación continua que las empresas obtienen de los centros a través de cursos del Catálogo Modular, se detecta que las innovadoras recurren en mucha mayor medida a esta solución de formación que las no innovadoras (47,6 frente a 36,9\%), si bien no lo hacen de forma netamente superior a la media de las empresas encuestadas.

La formación que imparten los centros de FP para los trabajadores de pymes está muy bien valorada por las empresas: como imagen global tenemos un notable $(7,38 / 10)$. Ninguna empresa tiene una apreciación insatisfactoria sobre esta modalidad de formación en los centros de FP. El posicionamiento de las empresas es tan claro y generalizado en esta dimensión que no se han observado diferencias significativas de valoración media en relación con las empresas innovadoras.

\section{Formación continua a medida (FCaM)}

Algunos centros con más recursos y capacidades y mayor nivel de orientación al cliente se están convirtiendo en proveedores de soluciones de formación a medida de las empresas. Es decir, están constituyéndose en agentes que, una vez recibidas las necesidades de formación de las empresas de su entorno, canalizan y gestionan una oferta formativa que incluye formadores propios y ajenos, a los que coordinan sobre la base de la demanda formativa específica efectuada por las empresas.

Un 23,8\% de las empresas que se relacionan con centros FP ha declarado que recurre a ellos para obtener FCaM. Además, la inmensa mayoría de estas empresas (80,0\%) también envían a sus trabajadores a cursos reglados de reciclaje. Las empresas innovadoras recurren en mucha mayor medida a los centros de FP para la realización de formación continua «a la carta» (29,7\% frente a $10,8 \%$ en el caso de las empresas no innovadoras). Existe una relación significativa (ji cuadrado sig. $=0,003$ ) entre realizar formación continua a la carta y ser una empresa innovadora.

La valoración media de los centros de FP como proveedores de formación continua a medida es de 7,48/10 puntos, subiendo a 7,63/10 en el caso de las empresas innovadoras. El recurso de las pymes industriales a la formación continua a medida denota una alta intensidad en las relaciones - y en la confianza con el centro-, ya que el $88 \%$ de las empresas que realizan este tipo de formación continua tienen ya otros 3 o más tipos de relaciones diferentes con los centros (por ejemplo, recibir prácticas, contratar de bolsas de empleo, obtener formación del Catálogo Modular, utilizar las instalaciones, etc.).

\section{Servicios de apoyo a la innovación en las empresas}

Los centros de FP de la CAPV manifiestan poner a disposición de las empresas equipamiento y personal del que disponen para la solución de problemas tecnológicos de diferente naturaleza (por ejemplo, nuevos elementos de diseño, fabricación de utillajes, mejoras de procesos, metrologías, pruebas y ensayos de materiales, etc.).

Lo que sí se ha mantenido es la colaboración desde el punto de vista de apoyo técnico, de asesoramiento técnico y de resolución de problemas de la propia empresa. (E9, p. 4)

Hori dela eta, enpresaren betebeharrak gerturatzen zaizkigu. Ez formazio beharra bakarrik, baizik eta beste zerbitzuak, ba aholkularitza teknologikoa edo... Ez dakit ba, agian ba pieza konplikatuak, ba nola bideratu errazago, edo organizazio-mailan orientabideak... Adibide bat, bost S-ak, nola aplikatu kalitatean... Baina hor sortutako harremanan ondorioz. (E11, p. 1) 
Adibidez, Bizkaian dagoen enpresa batek esan zigun haiek laborategia eduki ordez, bueno pues, analisiak zuek egingo dituzue, eta hemen egiten dizkiegu guk haiei laborategi-lanak. Eta hilero pasatzen dizkiegu muestrak eta guk egiten duguna, ... edo momentu batean pues bueno, «problema bat daukaguna pues honekin, egin dezakezue holako ikerketa?». (E5, p. 19)

Hemen ditugun makinak ere sektoreari interesatzen zaio puntakoak izatea ze, erakusgarri dira eta hemen ikasten dana gero fabriketan aurkituko da denetik, askoz hurbilago dago eskola askotan baino. Eskola askotan dago makinaria, finanziazio publikoa soilik baldin badago pixkat urrutiago daude ordea. Eskolan dago makina eta gero, makina, tailerretan aurkituko dutena da. Alde hori haundiagoa da hemen aurkitzen dena baino. (E7, p. 2)

La posibilidad de utilizar equipamiento de buen nivel tecnológico, a veces adquirido con ayudas públicas regionales y también, en otras ocasiones, con la colaboración de empresas, es una de las bases de la prestación de servicios de los centros de FP a las empresas y una infraestructura regional relevante para la innovación de las pymes industriales, que generalmente carecen de recursos para la realización de este tipo de actuaciones y quedan alejadas de la interlocución con otros actores como los centros tecnológicos o las universidades.

De acuerdo con los datos de la encuesta efectuada a las pymes industriales vascas, un $18,1 \%$ de las empresas recurren a los centros de FP para utilizar su infraestructura y están muy satisfechas del servicio. Las empresas innovadoras utilizan las instalaciones y los equipamientos de los centros ligeramente con mayor frecuencia (20\% frente a $18,1 \%$ en total), siendo la diferencia en porcentaje de uso de 6,2 puntos porcentuales sobre las empresas no innovadoras $(13,8 \%)$. La media de la valoración de esta experiencia es, una vez más, alta: 7,4/10 puntos, subiendo a 7,54/10 en el caso de las empresas innovadoras.

En la actualidad, los centros quieren formalizar y sistematizar la prestación de ayuda técnica que desde siempre han realizado a las empresas. Con este objetivo han surgido diferentes proyectos ${ }^{16}$ que, contando con distintos actores, persiguen facilitar a las pymes el acceso a

16 El proyecto Goikerri Plus está liderado por Goierri Lanbide Eskola y participan también los centros La Salle Berrozpe de Andoain y Urola Garaiko Lanbide Eskola de Zumarraga y los centros públicos de FP Usurbil, Tolosaldea y Miguel Altuna de Bergara. Goikerri Plus es un proyecto de 3 años de duración (2008-2010) y consta de tres fases. En el primer período los profesores-asesores de los seis centros, tras una formación, han realizado diagnósticos de necesidades de formación en empresas de su comarca. En la segunda fase, y también tras una formación que están realizando ahora, llevarán a cabo diagnósticos tecnológicos de las empresas, al tiempo que tratarán de captar proyectos de carácter tecnológico para su posterior materialización. En suma, se pretende reproducir el «modelo Goikerri de servicios técnicos-tecnológicos a empresas» en cada centro de FP participante. En la tercera fase el objetivo sería captar empresas que estén dispuestas a mejorar su modelo organizativo y de gestión, para ayudarlas en esta labor.

Goikerri Plus es un proyecto en el que se unen intereses comunes de centros de formación profesional públicos y privados para poder alcanzar unos objetivos que han sido determinados entre todos. Estos centros pretenden abrir una brecha, derivada del trabajo en equipo y la consolidación de una relación de colaboración duradera entre los centros, para ofrecer los mejores servicios formativos, técnico-tecnológicos y de asesoría en gestión adaptada a las necesidades de las pequeñas empresas.

Giga es un proyecto piloto de 4 años de duración (2008-2011) en el que colaboran el Instituto de Máquina Herramienta (IMH), la Escuela de Armería de Eibar y el Instituto Meka de Elgoibar, junto con el Departamento de Educación y el Departamento de Industria del Gobierno Vasco, a través de la iniciativa Euskadi Innova. Entre sus objetivos está facilitar a las pymes el acceso a la innovación y la mejora continua de sus procesos clave y ser un referente tecnológico para ellas en la implantación y mejora de la tecnología en un plazo de 4 años, desarrollando una oferta especializada que promueva formaciones avanzadas, servicios técnicos de valor añadido y colaboraciones y proyectos de innovación con empresas y centros de $\mathrm{I}+\mathrm{D}+\mathrm{i}$.

Otros objetivos más inmediatos son: desarrollar e implantar una oferta de servicios tecnológicos en el ámbito de la innovación con las pymes del sector industrial; desarrollar e implantar un catálogo avanzado de formación continua para empresas, profesionales y profesores; organizar jornadas de divulgación y transferencia de las tecnologías y buenas prácticas en procesos tecnológicos; incrementar la oferta de formación continua en los centros de la red; introducir en la formación inicial nuevas tecnologías de forma natural a partir de los cursos de formación continua; y desarrollar un nuevo perfil profesional en los centros participantes que se puede denominar profesor técnico de procesos.

Las prácticas industriales a las que atenderá este proceso son las siguientes: diseño, fabricación, medición, montaje, automatización, mantenimiento, sistemas de unión, ensayos, protección y embellecimiento, y reparación.

A iniciativa de la Viceconsejería de FP del Gobierno Vasco, personal de los centros de FP (los responsables de formación continua) se está formando como diagnosticadores de necesidades de formación (Proyecto DNF - Diagnósticos de Necesidades de Formación). 
la innovación y la mejora continua de sus procesos clave, ofreciéndoles desde los centros apoyo técnico, herramientas, metodologías y formación adecuada a sus necesidades.

Las personas entrevistadas coinciden en afirmar que el nicho de actuación para los centros de formación profesional se encuentra fundamentalmente en las microempresas y pequeñas empresas del entorno comarcal, que son las que cuentan con menores capacidades de innovación y a las que no llega la infraestructura de I+D (universidades y centros tecnológicos). Además, la cooperación con estas empresas no es atractiva para los mencionados agentes tecnológicos, que prefieren trabajar en proyectos con empresas más grandes, con una mayor trascendencia temporal de las colaboraciones en innovación y más atractivos desde el punto de vista de las partidas económicas destinadas y por su mayor contenido técnico. Con estos proyectos se puede constatar que los centros están adoptando una actitud más proactiva en las relaciones que mantienen con las empresas. Asimismo, se considera que esta colaboración centro de FPempresa revierte en la calidad y mejora de la formación que ofrece el centro.

Esta iniciativa nace de ver que hay un espacio para la innovación que la empresa no aborda porque en ocasiones no tiene recursos suficientes para ponerlo en manos, por ejemplo, de centros de investigación, o al centro de investigación no le interesa el proyecto porque, bueno, no llega a los mínimos establecidos que tienen para poder abordar un proyecto. (E9, p. 5)

Enpresa batzuk lan egiten dute zentro teknologikoekin. Guk ez daukagu maila hori. Geurea piska bat bajuagoa da. Zentru teknologikora ez dira iristen txikiagoak direlako, garestiagoa delako beraientzat, edo ez dutelako ondo ikusten. Beraz, bai, ikusten dugu esparrua. Honela empresa txikientzako zerbitzu teknologikoak eskaintzeko gai gara. Txikiak direnez, ez daukatelako igual ofizina bat oso garatua eta guk lagundu diezaiekegu bai gure tresneriarekin, lanbide heziketako tresnarekin edo makinariarekin eta baita ere ezagutzarekin, irakasleak daukan ezagutzarekin. Ikusten dugu bisibilidadea behar dela eta horregatik animatu nahi ditugu empresak, pymeak, mikropymeak animatu nahi ditugu proiektuetan elkarrekin egitera... badago nitxo bat elkarrekin lan egiteko. (E8, p. 17)

Viniendo a los datos de la encuesta efectuada entre las empresas de la CAPV, un 8,1\% de las empresas encuestadas tienen algún centro FP como colaborador en programas de mejora de gestión/organización, siendo la diferencia entre la proporción de empresas que colaboran con centros de $\mathrm{FP}$ en estos proyectos de tres puntos porcentuales entre las empresas innovadoras y las no innovadoras. La valoración que efectúan las empresas de este tipo de colaboración es de 7,19/10 puntos, no existiendo diferencias de valoración promedio entre empresas en función de su carácter innovador o no.

Por otro lado, un $6,7 \%$ de las empresas de esta muestra han realizado algún proyecto formal de innovación técnica con centros de FP, subiendo la proporción al 9,7\% en las empresas innovadoras, que representan el $100 \%$ de las empresas que desarrollan este tipo de colaboración. La valoración que efectúan las empresas sobre esta colaboración es, en este caso, de $6,79 / 10$ puntos.

De esta manera, se trata de ayudar a las empresas a identificar y desarrollar las competencias clave necesarias para mantener o aumentar su competitividad y adecuar formaciones específicas en este sentido. 


\section{Conclusiones}

La CAPV es una región próspera (PIB, renta per cápita, empleo) dentro del contexto español gracias (al igual que sucede en la CFN, aunque con ciertas diferencias que ya se han explicado), en buena medida, a tres elementos: cultura y desarrollo industrial, Gobierno regional activo en la política tecnológico-industrial y alto nivel de cualificación de la población.

En relación con la primera cuestión, cabe señalar que la tradición industrial-metalúrgica de la CAPV se hunde en el tiempo (se conocen yacimientos mineros desde la época romana; la existencia de ferrerías se remonta a la Edad Media; y en el siglo xv se documenta una floreciente industria armamentística y naval). En la actualidad es la región más industrial del Estado (junto con la CFN), estando su actividad industrial fundamentalmente orientada hacia las diferentes ramas industriales de la metalmecánica. Asimismo, cabe señalar que el nivel tecnológico de esta industria, con una representación importante de pymes, es relativamente alto.

En relación con la actuación del Gobierno regional, cabe señalar que ha jugado un papel ininterrumpido, claramente direccionado y decisivo en la promoción de la $\mathrm{I}+\mathrm{D}+\mathrm{i}$ desde el momento en el que la Comunidad Autónoma del País Vasco adquiere competencias derivadas del Estatuto de Gernika (1979).

La cercanía y el papel tractor del Gobierno regional, a través de sus instrumentos de apoyo económico continuado a los proyectos de $\mathrm{I}+\mathrm{D}$ de las empresas - en coordinación con los instrumentos de las diputaciones forales y, en menor medida, con los estatales y europeos-, la creación de una potente red de centros tecnológicos en la región y la creación de organismos de interfaz, generación de infraestructuras e instrumentos de animación de la cooperación han completado el robusto sistema de $\mathrm{I}+\mathrm{D}+\mathrm{i}$ de la CAPV.

La existencia de una importante red de centros de educación e investigación públicos y privados ha posibilitado el poder dar cobertura - fundamentalmente, en las cualificaciones altas y muy altas - a las necesidades de capital humano adecuadamente formado en ámbitos científico-tecnológicos en relación con las necesidades industriales, si bien, y aunque con unas cifras punteras en el ámbito estatal en términos de egresados de FP, las empresas demandan más personal con algunos perfiles intermedios (FP grado superior).

La FP en la CAPV se caracteriza diferencialmente en el ámbito estatal por seis rasgos: a) fuerte apoyo de la Administración y elevados niveles relativos de institucionalización; $b$ ) alta penetración de la enseñanza privada concertada (casi 50\%), que deviene en unas relaciones más estrechas con el mundo industrial; c) alta matriculación de las familias industriales (aprox. 50\%) y muy especialmente en Fabricación Mecánica, Electricidad y Electrónica y Mantenimiento y Servicios a la Producción; d) importante penetración de la FP de grado superior, tanto en ratios de cobertura como en \% de la población activa con techo de estudios en FPGS; e) alta presencia de centros integrales — con capacidad para desarrollar formación para el empleo(40\%) y fuerte participación de estos en la formación continua (50\% de los recursos económicos gestionados a nivel autonómico); y f) importante nivel de adaptación a las necesidades industriales de la región y, muy especialmente en Gipuzkoa — aunque no solo aquí-, al tejido industrial comarcal, que se concentra en comarcas por ramas de actividad ${ }^{17}$. La FP industrial en la CAPV no ha sido ajena a la regresión que se ha producido a nivel estatal en la matriculación, si bien la crisis económica actual ha favorecido su repunte.

17 Por ejemplo: Tolosaldea (papel); Lea-Artibai-Oka (polímeros); Urola Garaia (madera); Deba (M-H); Durangaldea (fundición); Bergara (textil/estampación frío); Bidasoa (química); Goi Herri (elevación); Deba Erdia (armería)... 
Los centros de FP de la CAPV tienen un nivel muy importante de relación con el entorno empresarial regional. El principal nexo a este respecto son las relaciones continuas, en un contexto de cercanía, reciprocidad y confianza, entre los tutores de los centros y los tutores de las empresas. Estas relaciones posibilitan la inserción del capital humano en las empresas y la adaptación del currículo educativo de los centros a las necesidades empresariales. Los centros de FP de la CAPV son, por lo tanto, una estructura clave en la provisión de mano de obra cualificada en la región, siendo muy bien valorados a este respecto por las empresas.

Los centros vascos de FP efectúan una labor considerable y bien valorada por las empresas en el área de formación para el empleo. En el caso específico de la formación de demanda, se demuestra una manera de relación con los centros de FP menos frecuente pero más intensa y con unos niveles de satisfacción por parte de las empresas muy altos. Las empresas innovadoras vascas recurren significativamente más a la formación continua en los centros de FP que las no innovadoras. La CAPV se caracteriza especialmente por la amplia implantación de las fórmulas que implican presencialidad en formación para el empleo y porque la formación para personas con cargos de responsabilidad y niveles medio-altos de cualificación tiene una repercusión alta en la región.

La prestación de servicios de asistencia técnica a las empresas se encuentra, a la luz de la evidencia aportada en este trabajo, menos desarrollada en la CAPV. Cerca del $20 \%$ de las empresas utilizan las instalaciones y la maquinaria de los centros para hacer pruebas y ensayos, y menos de un $10 \%$ de estas recurren a los centros como agentes de innovación para desarrollar proyectos en cooperación. Cabe señalar que existe un movimiento en el que participan los principales centros de la CAPV tendente a institucionalizar y desarrollar este tipo de relación. Los próximos años dirán cuál es su alcance real. Con todo, cabe concluir que el papel de los centros como facilitadores de la innovación en las empresas es, aunque creciente, bastante reducido.

En general, a pesar de que la FP ha jugado un papel importante en el desarrollo económico de la CAPV, en la actualidad se encuentra desligada de las infraestructuras de I+D (centros tecnológicos y universitarios) potenciadas en los últimos años por el Gobierno regional, aunque se están diseñando instrumentos para una mejor imbricación entre estos dos mundos.

\section{Anexos}

\section{Anexo I. Ficha técnica}

El estudio de carácter exploratorio efectuado se basa en la combinación y triangulación de evidencia cualitativa y cuantitativa. Por una parte, se han efectuado 15 entrevistas en profundidad a actores relevantes del sistema: 10 a los directores y los responsables de relaciones con la empresa en centros de $\mathrm{FP}^{18}$; una entrevista en Tknika, Centro de Innovación para la Formación Profesional y el Aprendizaje Permanente; y cuatro a responsables institucionales ${ }^{19}$. A continua-

18 IEFPS Miguel Altuna GBLHI, IEFPS Escuela de Armería GBLHI, IEFPS Bidasoa GBLHI, IES Escuela del Papel BHI, Instituto de Máquina Herramienta (IMH), IES Urola IK. Azkoitia-Azpeitia BHI, Urola Garaiko Lanbide Eskola, CPEIPS La Salle-Berrozpe HLBHIP, Mondragón Eskola Politeknikoa, Goierriko Lanbide Eskola.

19 Viceconsejero de Formación Profesional del Gobierno Tripartito (2006-2009); viceconsejero de Universidades e Investigación Científica del Gobierno Vasco; directora general de Formación Profesional del Gobierno Vasco; director gerente de Hobetuz (Fundación Vasca para la Formación Profesional Continua). 
ción analizamos los aspectos más relevantes del material cualitativo obtenido en estas entrevistas, que se desarrollaron entre mediados de 2009 y comienzos de 2011.

Por otra, se ha realizado una encuesta a pymes industriales para conocer su punto de vista sobre el servicio prestado por los centros de FP y caracterizar los ámbitos de colaboración con los centros de FP. Se ha considerado como población a todas las pymes industriales con domicilio social en el País Vasco.

Se ha seleccionado ${ }^{20}$ una muestra aleatoria $(\mathrm{N}=248)$ de entre la población de empresas que tienen entre 25 y 249 trabajadores (pymes) y que se pueden considerar industriales/ manufactureras (códigos CNAE93 entre 15 y 41). El tamaño de muestra global garantiza la representatividad estadística del colectivo de empresas con un error muestral máximo del 5,7\% para estimaciones a un nivel de confianza del $95,5 \%$ en el supuesto de diversidad más desfavorable $(p=q=0,5)$. La muestra fue estratificada proporcionalmente por territorio y tamaño de la empresa, con selección aleatoria final de unidades en cada estrato.

El cuestionario que se ha utilizado para la realización del trabajo de campo, parte de cuyos resultados se analizan en este artículo, ha sido elaborado por el propio equipo de investigación tomando como referencia los objetivos de la investigación, la literatura analizada, los resultados de la investigación cualitativa efectuada en la primera fase de este proyecto y las limitaciones inherentes a la modalidad de encuesta seleccionada (telefónica).

La encuesta se pasó a responsables de recursos humanos y formación (85\% de los casos), y en el resto de los casos, a gerentes o directores. El trabajo de campo se realizó entre el 10 y el 24 de junio de 2010. A nivel de análisis, y con vistas a favorecer los objetivos de este trabajo, se han considerado separadamente las empresas innovadoras frente a las no innovadoras.

20 Se trata de una muestra sobre una población de 1.295 empresas, la cual estadísticamente se considera una población bastante pequeña. Las condiciones de representatividad asociadas al tamaño son aceptables en la medida en que las poblaciones pequeñas necesitan muestras proporcionalmente muy grandes para reducir el error muestral a los niveles convencionales de diseño para poblaciones grandes. 

CONCLUSIONES GENERALES 



\section{Entorno regional y formación profesional}

Como se ha señalado en el capítulo introductorio de este libro, en esta investigación se ha pretendido dar respuesta a las siguientes preguntas:

- ¿Cómo se relacionan los centros de formación profesional (FP) y las empresas y cuál es el alcance de los distintos tipos de relación?

- ¿Hasta qué punto realizan los centros de FP actividades como la formación para el empleo y el apoyo a la innovación? ¿Qué potencialidades y dificultades existen al respecto?

- Y, en general, ¿cómo incide el entorno regional en la configuración del sistema de formación profesional y en la relación entre este y las empresas?

En los epígrafes siguientes se detallan las respuestas obtenidas respecto a los distintos tipos de relación, principalmente prácticas de formación en centros de trabajo (FCT), actividades de formación para el empleo y servicios técnicos. Asimismo, tanto en este primer epígrafe como en los distintos apartados de estas conclusiones se atiende al papel de las regiones en la configuración del sistema de formación y en su orientación hacia el entorno empresarial.

Dentro del marco normativo sobre el sistema de formación profesional desarrollado recientemente a nivel estatal y de las CC. AA., se busca una mayor orientación del sistema de FP a las necesidades del tejido productivo, así como una mayor integración entre los distintos componentes del sistema de formación (FP reglada y formación para el empleo en sus distintas modalidades: para desempleados y para ocupados, así como formación de demanda). Un aspecto importante de las reformas recientes es la instauración de los centros integrales de FP, que debían ser los nudos dinamizadores del sistema.

Como se ha mencionado en la introducción, el sistema de formación profesional español está regulado básicamente por la Ley Orgánica de las Cualificaciones y de la Formación Profesional (Ley Orgánica, 2002), la cual adopta una perspectiva integrada y trata de considerar a la formación como un sistema. La Ley se ha desarrollado posteriormente en dos reales decretos, que establecen de hecho dos subsistemas. Por una parte, el Real Decreto de 2006 regula la formación inicial en el marco del sistema educativo y depende del Ministerio de Educación. Por otra, el Real Decreto de 2007, que integra la antigua formación ocupacional y la formación continua, regula la formación para el empleo y depende del Ministerio de Trabajo e Inmigración. Así, como ha señalado Homs (2008), aunque existe una voluntad integradora, en la práctica existe una subdivisión entre la formación inicial y la formación para el empleo, con una articulación incompleta entre ambos sistemas. 
En cuanto a la formación para el empleo, como ha señalado este autor (ibidem, p. 60), el traspaso de la gestión a las CC. AA. está siendo bastante complejo, dado que no existe un consenso entre el Gobierno central y los agentes sociales sobre cuál debe ser el papel de los distintos actores en el sistema. En el fondo del desacuerdo se halla el debate sobre dar la prioridad a la proximidad de las necesidades territoriales de formación (en este caso son las comunidades autónomas las que tendrían que asumir plenamente las competencias que los respectivos estatutos de autonomía les otorgan, tal como ha pasado en el subsistema de formación inicial) o bien a la dimensión sectorial y al marco de relaciones laborales (en este caso los agentes sociales y las instituciones sectoriales estatales tendrían que mantener un importante papel regulador $\mathrm{u}$ organizador de la oferta formativa).

Como se puede ver en estas conclusiones, especialmente en el epígrafe dedicado a formación para el empleo, los problemas señalados por Homs han sido en buena medida confirmados en esta investigación, cuyo foco han sido los centros de FP y su relación con el entorno.

En primer lugar, del trabajo realizado en las distintas CC. AA. se desprende que, ante retos similares (el desarrollo e integración del sistema de formación, así como su adaptación al entorno productivo), las regiones han formulado en los últimos años respuestas diferentes. Dos de las CC. AA. han optado por un modelo que podemos denominar «propio» (Cataluña y el País Vasco), mientras que el resto se han decantado por lo que podría denominarse el modelo «general». No obstante, en todas las regiones la configuración e implementación del sistema de formación es un proceso de construcción entre los agentes implicados (áreas de Educación y Empleo de los gobiernos regionales, agentes sociales, centros de formación, en coordinación - mayor o menor - con la Administración y los actores estatales) que admite estructuras, prácticas y estilos diferenciados.

El modelo vasco se caracteriza por una fuerte apuesta de la Administración regional a favor de la FP que se manifiesta en la modernización del equipamiento de los centros, la introducción de sistemas de calidad, la formación del profesorado en centros y empresas y el desarrollo del centro para la innovación en FP Tknika. Otro elemento muy destacable del modelo vasco es el papel que los centros de $\mathrm{FP}$ (centros integrados) vienen jugando en la formación para el empleo (antes llamada continua y ocupacional), una cuestión clave para un mayor desarrollo de las relaciones entre los centros y el tejido empresarial. Puede decirse que el País Vasco es la única región que hasta el momento ha desarrollado sistemáticamente la figura del centro de FP integrado, incluso antes de que se definiera la normativa estatal a este respecto.

En el caso catalán, destaca también la fuerte apuesta de la Administración regional, que se manifiesta en la creación de la red de centros FP.CAT, de ámbito sectorial y territorial e integrada por algunos centros de innovación y formación ocupacional (CIFO) del Servei d'Ocupació de Catalunya (SOC) y algunos institutos de FP, que realizan actividades de innovación pedagógica y formación para el empleo. Dicha red de centros ofrece cursos de FP integrada adaptada a los alumnos independientemente de si estudian formación inicial, ocupacional o continua. Con ello se busca acercar la formación profesional inicial a la formación para el empleo a través de la vía de los certificados de profesionalidad. El objetivo de este proyecto pasa por crear «itinerarios de profesionalidad» para los alumnos (estén estos trabajando o no) entre los diferentes centros ofertantes de este tipo de formación. Por lo tanto, en el modelo catalán no se observa (al contrario que en otros casos) una posición central de los centros tradicionales de FP. Al contrario, el éxito de los CIFO ha sido notable, sobre todo en los de ámbito sectorial y en las comarcas que presentan una mayor articulación territorial de los agentes económicos. Ello ha conllevado, en lo que respecta a los centros de FP, un protagonismo menor que en otros 
casos estudiados debido a la complementariedad con otros centros y, especialmente, a la apuesta del Gobierno regional a favor de los CIFO.

En el resto de regiones los agentes sociales (sindicatos y organizaciones empresariales) juegan un papel mayor en la configuración del sistema de formación, lo que (a día de hoy) redunda en una menor participación de los centros de FP reglada en actividades de formación para el empleo. Destaca el contraste entre el País Vasco y Navarra, regiones con una cultura industrial similar en las que las administraciones regionales han realizado apuestas muy diferentes. También hay que mencionar que, en el caso de Madrid, la Administración regional ha tomado recientemente medidas tendentes a reducir la participación de los agentes sociales en los ámbitos de decisión regionales sobre formación para el empleo.

En todo caso, el estudio realizado confirma que el sistema español de formación presenta importantes problemas de coordinación e integración entre la formación reglada y la formación para el empleo, así como entre las administraciones de Educación y Empleo y los agentes intervinientes en este último ámbito (los agentes sociales).

\section{El papel de las prácticas de formación en centros de trabajo (FCT)}

De la información recogida en las distintas regiones se desprende que las prácticas FCT son el mecanismo fundamental de relación entre centros de FP y empresas. Este instrumento, que fue formalizado en la LOGSE (1990), ha tenido un notable éxito, aunque las regiones de más tradición industrial contaban con una trayectoria de colaboración anterior.

La FCT es un mecanismo fundamental para que las empresas y los centros se conozcan y desarrollen relaciones de confianza. Así las cosas, los tutores del centro de FP visitan las empresas y conocen de cerca su actividad, sus necesidades en materia de formación, así como los niveles de adecuación de los conocimientos de los estudiantes a las necesidades de las empresas. Subsiguientemente, los centros de FP pueden, a través de este mecanismo, captar y canalizar información relativa a los cambios que están sucediendo en el ámbito tecnológico en las empresas. Un resultado muy importante de estas relaciones entre centros de FP y empresas es la adaptación de las enseñanzas y el currículo educativo de los centros a las necesidades de las empresas. En los centros más dinámicos se detectan estos procesos de adaptación del currículo.

De las relaciones regulares entre los tutores de los centros y los instructores de las empresas (no hay que olvidar, además, que estos son en ocasiones antiguos alumnos de los centros) surgen relaciones de cercanía y confianza que derivan en la articulación de un canal de comunicación a través del cual los centros de FP reciben gran cantidad de información y detectan necesidades de las empresas. De la relación entre pymes industriales y centros de FP en torno a las prácticas se derivan resultados como la contratación de estudiantes egresados, adaptaciones en el currículo de la formación reglada y detección de necesidades de formación continua y de necesidades tecnológicas.

En el caso catalán, se detecta una mayor intensidad en las relaciones que rodean a las prácticas FCT en los ámbitos comarcales donde el nivel de organización del tejido empresarial y de articulación territorial es mayor. Este nivel de relación se ha plasmado, en algunos casos (donde, además, existía un cierto nivel de cohesión territorial), en la creación de fundaciones 
donde tienen cabida organizaciones empresariales y sindicales, Administración local y centros formativos. En el País Vasco se detectan también dinámicas similares.

Para el sector industrial y para los centros formativos, las FCT son fundamentales. Se produce una mayor inserción laboral de los egresados debido al creciente nivel de exigencia formativa de las empresas industriales. La mayor especialización que requieren las empresas industriales hace más necesaria la puesta en práctica de estas FCT, al facilitar una mayor probabilidad de inserción futura del alumno en comparación con determinadas familias profesionales del sector servicios.

Además, de alguna manera los centros de FP, a través de las FCT, se configuran como una especie de intermediadores laborales, en el sentido de que consiguen que las empresas conozcan a sus alumnos, lo que facilita unos primeros contactos que, en caso de no existir tales prácticas, los egresados deberían hacer una vez finalizados sus estudios. Así pues, los centros formativos permiten acercar a sus alumnos al «mundo real» de las empresas, pero también permiten un mayor contacto entre ellos, facilitando el contacto y dirigiendo a su alumnado a las empresas del entorno en función de las características formativas y las expectativas laborales de los estudiantes y en función de las demandas y exigencias de las empresas.

En los casos analizados se constata que las relaciones entre tutores de centros de FP y empresas en torno a las prácticas FCT, así como las estancias de profesores en las empresas, son la base de formas más avanzadas de relación como son la impartición de formación continua, la utilización de maquinaria o la prestación de servicios técnicos.

Aquí, en el centro X, participan como tutores de prácticas FCT todos los profesores que imparten clase en el curso. Hay unos que llevan a dos alumnos, otros a tres, otros De tal forma que todo el equipo está en contacto con la empresa Con lo cual quiere decir que todos se enriquecen de ir hacia el exterior $y$ visualizar qué es lo nuclear, qué es lo fundamental, para luego aquí no quedarte con lo accesorio. Y luego, pues ese intercambio, esa puesta en común (NAV-FP3, pp. 5-6)

A la vez que hacen el seguimiento del alumno, van conociendo, pues bueno, los entresijos de la empresa, la tecnología con la que está trabajando actualmente, los programas, las máquinas y tal Y, entonces, pues ahí es donde se ven las necesidades (PV-E4, p. 36)

[...] Aspectos positivos, para nosotros, todos, porque realmente nos hace estar justo dentro de lo que son las necesidades del mercado laboral. Esto ya no se trata de un observatorio de ocupaciones y tal, que es más genérico y demás, sino que esto es la propia empresa, en este caso una empresa potente y otras empresas, las que nos dicenः «Bueno, es que nosotros necesitamos tal cosa; entonces, queremos formar en esto, en eso y en aquello de más allá». ¿De acuerdo? Entonces, para nosotros eso es muy positivo. (AST-Director CIFP)

Las prácticas en empresas aquí la verdad es que desde siempre se han realizado razonablemente bien. En los últimos tiempos sí que hay más dificultades, porque hay empresas que no se atreven o no quieren coger alumnos en prácticas porque están ajustando plantillas. Entonces, claro, queda mal. Y en los últimos tiempos sí que hay algunas dificultades, pero la verdad es que la experiencia nos ha ido demostrando que los alumnos que hacen prácticas en una empresa luego tienen muchísimas probabilidades de quedarse en esa empresa trabajando. (ARAG-AR1)

Nosotros ya teníamos una relación muy estrecha con las empresas por el tema de la formación profesional por las FCT, la formación en centros de trabajo. Este siempre ha sido un centro que se ha caracterizado por que la relación con las empresas las cuida mucho. Entonces, además de llevar a alumnos a prácticas cuando toca, para que acaben sus módulos y sus ciclos, se ha intentado mantener una colaboración estrecha con las empresas y un cuidado de tener una relación durante todo el año. (ARAG-FP1) 
Però, realment, la FCT, a part de per a l'alumne és obrir-li una porta a conèixer què és el món real del treball, també és una molt bona eina de l'empresa per conèixer aquests alumnes de cara a futures incorporacions. (CAT-FP2)

Las necesidades de formación continua de las empresas se detectan a partir de las prácticas y, sobre todo, de las estancias [de profesores en las empresas]. Y son las dos fuentes, básicamente. (NAV-FP10, p. 15)

\section{Formación para el empleo}

Los cursos de formación para el empleo (denominados anteriormente formación continua, para ocupados, y formación ocupacional, para desempleados) son una fuente importante de relación entre los centros de FP y las empresas. Los técnicos de las empresas que acuden a estos cursos tienen la oportunidad de conocer de cerca los centros, los profesores y el equipamiento de que disponen. Asimismo, a través de los técnicos, los profesores conocen los problemas a los que se enfrentan las empresas en su actividad diaria y actualizan su conocimiento de la realidad empresarial.

Como se ha señalado anteriormente, el País Vasco es a día de hoy la única región que ha apostado por una fuerte participación de los centros de FP reglada (denominados integrales) en la formación para el empleo, lo que ha contribuido a elevar el prestigio de la FP entre las empresas del entorno, a la vez que a estrechar lazos con ellas. Desde los centros vascos entrevistados se señala que las necesidades en formación que plantean las empresas frecuentemente se insertan dentro de la formación continua (que ha pasado a denominarse formación para el empleo), si bien estos contenidos van pasando a formar parte del currículo de la formación reglada progresivamente.

Asimismo, las demandas recibidas desde las empresas marcan las prioridades en la adquisición de equipamientos que permitan dar soporte a la formación ofrecida. En el trabajo de Albizu et alii (2011) se muestra que las pymes industriales vascas realizan un nivel importante de formación para el empleo (sobre todo de oferta, pero también de demanda) con los centros de FP y que son las empresas innovadoras las que más formación de este tipo realizan (existe una relación estadísticamente significativa al respecto). Por otro lado, las pymes valoran de una forma muy positiva este tipo de formación.

Esperientzia ona da ikastetxeentzako. Harreman zuzena daukate langile horiekin edo tekniko horiekin. Gero langileek ere ikusten dute batzuetan: «kontxo, honek soluzionatu ahal du...» Asko etortzen dira problema batekin, batzuetan «lantegian ez dugu lortzen hau egitea», batzuetan soluzionatzen zaizkie gauza batzuk. Badago harreman bat nahiko aberatsa, irakasleek, eurek ere, asko ikasten dute, benetako problemak ikusten dituzte, nondik datozten problemak. Orduan horrek ematen die feed back bat oso importantea. (PV-E8, p. 16)

Eta irakasle bat baldin badago bere bizitzako urte guztietan hemen, Ez arautuan parte hartzeke, Arautuan bakarrik, atzeratuta geratzen da. (PV-E3, p. 20)

Por su parte, Cataluña ha dedicado importantes esfuerzos al fomento de la formación para el empleo. Sin embargo, la peculiaridad del caso catalán reside en dos cuestiones. La primera es la concepción amplia de la idea de integración de la formación profesional, entendida esta como una formación que puede ser ofertada por una multiplicidad de agentes: IES, CIFO, 
centros homologados (ayuntamientos, agentes sociales, centros privados...), entre otros; pero, sobre todo, porque la integración parece entenderse como la complementariedad entre centros formativos, de tal manera que la integración de la formación no pasa necesariamente por un solo centro formativo. La segunda cuestión es la existencia desde hace tiempo de los centros de innovación y formación ocupacional (CIFO), que aglutinan parte de la formación para el empleo actual, sea esta de oferta o de demanda. Como consecuencia de todo ello, los centros de FP reglada han tenido una participación limitada en la formación para el empleo.

En el modelo general los centros de FP tienen igualmente una participación limitada, relacionada en este caso con una mayor participación de las organizaciones sindicales y patronales tanto en la configuración como en la impartición de la formación para el empleo. Así las cosas, puede afirmarse que la implantación del concepto de «centro integrado de $\mathrm{FP}$ », una de las novedades de las reformas normativas recientes, no ha tenido hasta el momento el alcance que cabía esperar.

En Aragón los planes de formación profesional incluyen el concepto de centros integrados y, por lo tanto, el progresivo protagonismo de los centros de FP en la formación para el empleo. Respecto a la formación de oferta para desempleados, cabe destacar, dentro de la formación de oferta dirigida prioritariamente a desempleados que establece el Instituto Aragonés de Empleo (INAEM), la creación hace dos años de una partida propia de formación de oferta en centros integrados de FP que, en 2010, ascendió a 504.315 euros, lo que supone un 2,8\% del presupuesto dirigido a dicha formación. Esta partida presupuestaria se reparte entre los cinco centros integrados existentes en función de las propuestas de los centros y de los criterios de selección del INAEM. Antes del establecimiento de esta partida, los centros integrados competían en las mismas condiciones que el resto de ofertantes de formación.

Respecto a la formación de oferta para empleados, el INAEM no permite la participación a los centros de FP. De hecho, el mecanismo que han buscado los centros integrados es ofrecerse a los agentes sociales (a quienes sí se les asignan dichos cursos de formación) como centros con recursos y docentes para la posible realización de sus cursos. Los centros integrados detectan necesidades a partir del contacto continuado con empresas y diseñan un curso que ofrecen a los agentes sociales, a la vez que se ofrecen para cualquier curso de formación planteado por los agentes sociales (siempre en relación con las familias profesionales del centro). Actualmente, hay reticencias por parte del INAEM y de los agentes sociales a la participación de los centros integrados en esta formación. No obstante, este acercamiento de los centros integrados es reconocido por los propios agentes sociales, que consideran los IES como más rígidos y burocratizados que los actuales centros integrados. En algunos centros integrados ya se han hecho cursos con sindicatos y se están manteniendo contactos con organizaciones empresariales.

En el caso de Navarra, en el momento de la realización del trabajo de campo ${ }^{21}$ existía una percepción unánime entre los agentes de FP entrevistados sobre la insuficiencia de los fondos asignados por el Servicio Navarro de Empleo (SNE) para cursos de formación continua en los centros de FP. De hecho, estos fondos fueron eliminados en 2009 debido a las desavenencias entre el Departamento de Educación y los agentes sociales del Consejo de Formación Profesional. Los agentes de FP entrevistados manifiestan que, en comparación con los centros formativos creados por las organizaciones sindicales, su oferta formativa y sus instalaciones se adaptan mejor a las necesidades de las empresas, y que podrían impartir mucha más formación continua de la que imparten en la actualidad (los centros entrevistados imparten por término medio entre 5 y 10 cursos anuales subvencionados por el SNE).

21 Entre abril y noviembre de 2010. 
En Asturias existe coincidencia entre los agentes entrevistados en que falta desarrollar adecuadamente la formación para el empleo y en que el sistema está aún en vías de consolidación, sobre todo en relación con los centros integrados.

En Madrid se señala que la relación con programas formativos de formación para el empleo sufrió una disminución desde que los sindicatos y otros agentes utilizaron sus propios centros para impartirla. Esta se ha retomado en algunos casos puntuales por la reciente aparición de los centros integrados, si bien anteriormente no había prácticamente relación entre los dos tipos de formación. En esta comunidad, la existencia de centros de formación para el empleo impulsados por la Administración regional, así como una creciente oferta desde centros privados, hacen que los centros de FP no jueguen un papel relevante en la formación para el empleo.

[Dentro del convenio con INAEM] solamente entra la parte de desempleados. Entonces la parte de continua lo que estamos empezando a tejer ahora, que no teníamos nada, en continua lo único que teníamos es... La continua se reparte básicamente entre organizaciones sindicales, confederación de empresarios..., agentes sociales en definitiva. Entonces nosotros ahora hemos entrado ahí como una parte muy pequeñita, los centros integrados, y ellos no acaban de tener muy claro cuál es nuestro papel ahí. Entonces nosotros les estamos brindando lo que nosotros vemos o entendemos que debemos hacer. Que es que nosotros tenemos unas instalaciones para poder impartir unas clases y, primero damos reglada, pero tenemos unas horas donde se pueden dedicar esas instalaciones a esa formación continua de empresas. Y tenemos gente preparada que puede darla y tenemos medios para poder darla. Entonces la idea es que los cursos que hasta ahora siempre había que hacer a través de academias o a través de aulas que ellos tienen, que sepan que aquí hay un lugar donde también pueden. ¿Cómo? Ellos solicitan su formación específica a INAEM. Si se la conceden, que sepan que, por un lado, hay instalaciones, profesorado y material para poder impartirla. Y, por otra parte, nosotros tenemos un profesorado activo que propone también cursos que no entran dentro del plan de desempleados. Cursos más innovadores: cosas para dispositivos móviles, cosas de más de dispositivos propios. Cursos cortos, como la formación a demanda que ofrecen las empresas. Nosotros también detectamos necesidades en las empresas cuando vamos. Entonces la idea es decir, bueno, si esa empresa no puede hacerlo, no puede solicitarlo por ella misma porque a lo mejor la única manera que tiene de hacerlo es a través de una formación con compromiso de contratación, por ejemplo, que la empresa no puede asumir. La idea es que si nosotros detectamos que en varias empresas hay esa necesidad, nosotros diseñamos un curso. Se lo ofrecemos a los agentes sociales para que sean ellos los que entren en ese sorteo en que nosotros no podemos entrar. (ARAG-FP1)

A diferencia de la C. A. del País Vasco, aquí en Navarra tienen mucho protagonismo los sindicatos y las organizaciones empresariales. Entonces, de hecho, prácticamente la totalidad de la formación continua va por ese conducto. Y una pequeñísima parte — mínima diría yo- es la que se deriva a los centros de formación profesional. (NAV-FP3, p. 6)

No nos cabe la menor duda de que realmente los que tendríamos la clientela seríamos nosotros, por la especificidad de cada una de las familias profesionales. Merecería la pena que los medios que tenemos estuviesen utilizándose desde las ocho de la mañana hasta las diez de la noche, y cuanto antes se amortizasen y se renovasen, pues todo el mundo saldría beneficiado. Y el hecho de estar en esos mismos centros, pululando los trabajadores y nosotros, pues habría esa ósmosis entre un sistema y el otro que favorecería a todo el mundo. (NAV-FP3, pp. 7-8)

No. No ha habido integración de ningún tipo Los centros integrados no son ni más ni menos que antiguos centros de formación profesional ¡o nuevos! en los que se mete a profesores que ya había, se imparten ciclos que ya había de formación profesional reglada, y, a la vez, se ceden o se ponen las instalaciones para que las fundaciones, por ahí, que nacen al albur de todas estas subvenciones, y de todas estas cosas, tengan sitio para dar esos cursos. ¿Eh? Captando 


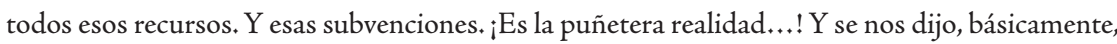
que teníamos que ofertar cursos de ocupacional. Y que esa era la manera de financiarse. Que no había dinero para formación profesional reglada y que si queríamos captar fondos (AST-IES)

Creo que se han confundido las cosas. [Los centros integrados] siguen como estaban. Los mismos profesores, en horario de mañana, y las mismas instalaciones poco utilizadas. Se ha intentado un poco corregir esto, lo de las instalaciones, permitiendo a los centros de FP y los centros integrados hacer cursos del FIP. Lo que han hecho es algo que ambicionan todos los actores en este sistema: meter un bocado grande al presupuesto allí donde hay dinero. (ASTExperto Empleo)

Nosotros estamos dando formación reglada. La formación no reglada..., ahora nosotros no la tenemos. Hubo, sí, un tiempo en que tuvimos relación con el FORCEM, que dependía de sindicatos, sí que tuvimos unos cursos de formación aquí Pero desde hace un tiempo yo creo que los sindicatos se lo guisan y se lo comen. (MAD-Director IES)

[...] la formación reglada no sabe cómo funcionaba formación para el empleo. Entonces, el centro de formación para el empleo colabora con el instituto X para asesorarles [sobre] cómo se seleccionan los alumnos, todo el papeleo que hay que hacer, cómo hay que hacer el seguimiento de los cursos Bueno, en todos los procedimientos, tanto de selección de alumnos como de administración. (MAD- Director centro formación para el empleo)

Además de la cuestión de la asignación de fondos por parte de los agentes sociales y las administraciones regionales, existen también rigideces y limitaciones internas que impiden una mayor participación de los centros de FP en la formación para el empleo, como son la falta de autonomía de los centros, la falta de incentivos a los profesores, los límites legales a la dedicación del profesorado funcionario a estas actividades y la imposibilidad de planificar e integrar la formación continua en los horarios y en la carga lectiva del profesorado titular.

A juicio del agente social entrevistado en Navarra, un problema clave que obstaculiza una mayor financiación para formación continua en los centros de FP, principalmente en los centros integrados, es la falta de autonomía de los centros y su subordinación excesiva al Departamento de Educación. Este problema se refleja en la falta de operatividad de los consejos sociales de dichos centros, donde están representados los agentes empresariales y los sindicales. Estos agentes exigen una mayor participación como condición para vehicular más recursos económicos hacia la formación para el empleo en los centros de FP.

Otras rigideces, señaladas en distintas regiones, tienen que ver con la lentitud de los procesos de selección y financiación de cursos, principalmente en las consejerías de Educación de las administraciones regionales. A este respecto, según las personas entrevistadas, en Asturias el intento de unificar todas las políticas de formación en dicha consejería terminó en fracaso.

Algunos agentes señalan que los cursos tienen un excesivo número de horas o son excesivamente teóricos, dando quizá a entender que los cursos impartidos por centros de formación para el empleo creados por las administraciones regionales (el caso de Madrid), por centros privados o por centros de los agentes sociales tienen una mayor flexibilidad o una orientación más práctica.

En el caso catalán, según algunos entrevistados, los centros de FP resultan más rígidos y menos atractivos para los jóvenes que realizan formación para el empleo que los CIFO, los cuales poseen una estructura más flexible y una formación más práctica y cercana al mundo de la empresa, sobre todo cuando la formación aparece vinculada al ámbito de los certificados de profesionalidad. La estructura más rígida y más académica de los centros de FP puede resultar 
un obstáculo para la demanda de determinados tipos de formación muy específicos (desde el punto de vista del contenido y del tiempo de formación). De hecho, actualmente los CIFO han notado un considerable aumento de jóvenes dentro del perfil de su alumnado.

Los cursos de 2010, solicitados en abril del año pasado, nos los han comunicado la semana pasada [abril de 2010]. Como comprenderán, nos quedan mayo y junio para este trimestre, y luego, septiembre, octubre, noviembre y diciembre para el que viene. Para intentar encajar los once cursos que nos han concedido. Entonces, es muy difícil, y además la única posibilidad de ajustarlo ahí, en el centro, es hacer horas extraordinarias los profesores. Es decir, es el profe el que tiene que coger y decir: «Yo doy ese curso». Entonces, un trabajo extraordinario, cosa que no es lo ideal. Lo ideal sería saber desde el principio la planificación, decir: «Tenéis estos cursos», y te puedes planificar desde los propios departamentos..., puedes tener la planificación de los cursos reglados y los cursos de formación continua u ocupacional. (NAV-FP4, pp. 7-8)

Hombre, yo, lo que veo en los cursos del Plan Nacional de Inserción y Formación Profesional (FIP) es que me parece que tienen muchísimas horas, muchísimas horas, y que están, en cierto modo, un poco desactualizados en cuanto a contenidos, ¿eh? Yo creo que les faltan aspectos Por ejemplo, en temas de gestión, un poco..., la vanguardia de la gestión, no la tienen. Pues porque son programas que están hechos ya desde hace tiempo. Y ahí sí que creo que habría que darle una vuelta de tuerca, ¿eh? Y los certificados de profesionalidad, lo mismo. (AST-Empresa formadora)

[...] necesitamos que los jóvenes, en los períodos de paro, en las distintas transacciones, puedan ir a los cursos. Entonces, estos tienen que ser cortos. ¡ No largos! Porque la prioridad de una persona en desempleo es buscar trabajo. Si le ofrecen un trabajo, de lo que sea, va a dejar el curso. Si tú eres camionero y lo estás pasando mal, y ves que puedes hacer un curso, pero el curso dura 600 horas, y a la hora cien te ofrecen un trabajo, aunque sepas que es muy temprano, vas a dejar el curso. En cambio, si el curso es pequeño, puedes hacer uno y arriesgar con otro. Pero te llevas uno en la mochila. (AST-Experto Empleo)

Porque la formación para el empleo, la formación ocupacional, siempre estuvo en el ámbito del empleo Aquí, en un momento determinado, se hizo una apuesta en Asturias de ser los más innovadores de toda España, y lo que hicimos es coger y meterlo todo en Educación. Mira, yo Al final, lo mismo da que esté todo en Educación que esté todo en Empleo. Si el problema no es dónde esté, sino que es cómo se gestiona. Porque son dos sistemas que tienen que incardinarse uno con el otro. El problema es cuando intentas solapar, o supeditar, uno a otro. ¿Problemas que ha habido en Educación? La burocracia. (AST-Estudios sociales)

Yo creo que es profundamente negativo. Y creo que en Asturias eso ha sido un ejemplo. Después de pasar formación para el empleo a Educación, se consiguió que hubiera cero cursos en la región y cero convocatorias. Y eso es porque la lógica administrativa de la administración de Educación y la lógica administrativa de Empleo son diferentes..., me parece muy bien que los centros de formación profesional, los centros integrados, hagan actividad de formación para el empleo, pero la decisión de formación para el empleo tiene que estar ligada al mundo del empleo y de la actividad económica. Si no, hemos visto aquí que es un error. (AST-Experto Empleo)

Pero en la formación para el empleo, a mi modo de ver, sería lo otro, lo que puede cambiar, lo distinto, lo diferente, lo que es adaptado a unos colectivos concretos, a unos territorios concretos, a unas empresas concretas, con unos proyectos y con unos problemas. Lo que me permita abordar la diferencia, la variedad. Creo que se han confundido las cosas. Porque lo que es muy interesante, en términos de módulos, para la formación profesional, se ha utilizado para dar más rigor teórico — rigor entre comillas - a la formación para el empleo, pero a costa de perder flexibilidad. (AST-Experto Empleo)

Porque uno de los problemas que tienen, y eso ha pasado también, es que no puedes mantener, o no puedes desarrollar, una formación para el empleo con una metodología que venían 
utilizando en la formación inicial, en la reglada. ¡Porque es que la gente que te va a esos cursos han salido rebotados de ese sistema! Es decir, ¿los vuelves a traer al sistema, pero para utilizar o seguir queriendo hacer lo mismo? ¡ No...! La gente busca un aprovechamiento más del tiempo, una rentabilidad... (AST-Estudios sociales)

La formación reglada es una formación formal donde, efectivamente, se dan unos contenidos, se hacen unas prácticas y Aquí [centro de formación para el empleo] la formación profesional está como orientada al empleo. No orientada a tener un título, sino orientada al empleo. De tal manera que los contenidos que se dan son los que verdaderamente necesitan en ese momento en ese puesto de trabajo. Con lo cual es una diferencia abismal Y es que el $80 \%$ es práctico. El $80 \%$ es práctico. Puede haber entre el $70 \%$ y el $80 \%$ práctico, y el resto teoría. (MAD-Director centro formación para el empleo)

Nosotros, aparte de decir «bueno, necesito tal curso, para insertarles», que es a lo que vamos: yo te doy este curso, pero me lo insertas. Vale. Pero nosotros necesitamos material, y las empresas nos lo dan. Que necesitamos normativa, o documentación o contenidos de algo, y las empresas nos lo dan. Que tenemos que elaborar ese programa que tú necesitas. Tú me das los contenidos y yo te elaboro metodológicamente los objetivos y los medios que necesitas, y demás, ¿no? Todo eso es un ten con ten con las empresas. Luego también, a cambio, vienen y les asesoran técnicamente a los alumnos de cualquier cosa, les dan charlas de cómo está el sector, nos dejan visitar las empresas y les dicen cómo funciona todo O sea, todo eso hay, y hay muy buena colaboración. Pero esto es trabajar mucho con las empresas, insistir. (MAD-Director centro formación para el empleo)

La nostra prioritat sempre són els CIFO. De fet, és l’oferta que sempre surt primer. És la que ja està aprovada i funcionant, la dels nostres centres propis. Després és col-lateral, per dir-ho d'alguna manera. No donem preferència als centres de formació. Però, bàsicament, perquè també la nostra població no sempre és carn d'instituts. Nosaltres ara tenim un volum de joves molt important demandants de la nostra formació. Però això és una mica a remolc del fracàs escolar que arrossega Ensenyament. (CAT-AR2)

Flexibilitat, flexibilitat. Pensa que els centres educatius, que els instituts que fan formació professional estan molt limitats per l'organització del sistema educatiu. És més permeable, però és molt poc més permeable. Clar, des del sistema educatiu es veu que és molt permeable, per al que és el sistema educatiu. Però continua sent poc permeable. I et poso un exemple en la contractació d'experts. A formació professional ja es pot contractar experts que no siguin funcionaris, professors per impartir, però és com la cosa rara. M'entens. Llavors, des del sistema educatiu ja es veu que això és un avenç, però faria falta molt més, molt més. (CAT-AS2)

En lo que respecta a la formación de demanda, se detectan también importantes problemas en las CC. AA. estudiadas. En Aragón se está empezando a fomentar este tipo de formación, pero resulta complejo, ya que la pequeña empresa necesita agruparse para poder solicitar este tipo de cursos. Se están realizando algunos cursos de empresas en el propio centro, ofreciendo este los espacios y recursos para ello. Se señala que los centros integrados parecen estar todavía excesivamente burocratizados. En Navarra se detectan barreras similares que impiden una mayor implantación de la formación de demanda. Igualmente, en Asturias los actores entrevistados señalan las dificultades debidas a la complejidad del sistema y a los problemas de adaptación de este al tejido industrial regional, conformado casi en su totalidad por empresas de muy pequeño tamaño.

En Cataluña también se indican las dificultades para que las pymes se agrupen para demandar este tipo de formación. Las experiencias exitosas a este respecto se refieren a fundaciones compuestas por empresas, organizaciones empresariales y sindicales, Administración local y centros de FP del territorio, lo que facilita los canales de comunicación y gestión a la hora de proponer, aprobar y crear formación de demanda, que necesita de una mayor agilidad en su gestión. 
Pues supongo que también porque, al final, los centros integrados son muy burocráticos. Y si somos todos muy burocráticos, pues seguro que CEPYME es más flexible [respecto a la formación de demanda]. Dentro de la burocracia, es más flexible. Dentro de lo que tiene que es una normativa, y seguro que la cumple. Bueno, seguro no, la cumple. Seguro que se adapta más a las necesidades de las empresas. (ARAG-AS1)

Hemos hablado con empresas, pero cuesta. Cuesta porque las opciones que tienen para sacar una formación a demanda es esa. Es a través de juntarse varias empresas. Con las pequeñas empresas sí que tenemos contactos y sí que nos dicen: «Tenemos necesidades de esto o lo otro». Y nosotros les planteamos: «Vale, vamos a diseñar cursos». Pero el camino, de momento, se les hace muy largo. (ARAG-FP1)

Nosotros estamos intentando desde hace años ya apoyar el que pueda realizarse formación de demanda en nuestros centros. Es complejo en maquinarias tan rígidas como las del sistema educativo montar formación de demanda. Pero sí que es cierto que estamos haciendo experiencias, todavía a pequeña escala podríamos decir, de permitir a los centros que puedan realizar ofertas de módulos parciales, de tal manera que puedan ser pactados con empresas en un momento determinado. (ARAG-AR1)

La otra [opción] es que la empresa nos pague a nosotros. Que nos paguen a nosotros el costo de ese curso y ellos se lo deduzcan, nosotros tampoco tenemos problemas. Pero nosotros tenemos una limitación ahí, entre comillas, a la hora de facturar. Por esa pega, porque si yo tuviera aquí la artillería del centro privado X, ¿me explico? Llama a las empresas: «¿Qué cursos? Sí, tenga. Pues yo te facturo tal, y tú te lo descuentas de tal». (NAV-FP4, p. 9)

Claro, nosotros, toda esa colaboración tenemos, pero lo bonito sería que fuese el centro el que facturara, y que luego, bueno, pues cobrase el profesor, o lo que fuese, pero que saliera del centro, que figurara Educación. $Y$ al final, simplemente es una relación a título personal entre el profesor y la empresa. Aunque se realiza todo a través del centro $\mathrm{Al}$ final, pues las personas no pueden facturar, pero siendo profesor, pues hasta unos 3.000 euros o así, cantidades pequeñas, puedes llegar a facturar con el DNI. Pero lo bueno sería que entrase Educación ahí. Porque estás dando un curso, y tienes relación o una colaboración con una empresa. Se podría llegar a un cauce o alguna vía. (NAV-FP8, pp. 8-9)

Hemos empezado ahora. La asociación empresarial comarcal X ha empezado [a fomentar] ese modelo de formación y se lo está enseñando a las empresas, y las empresas lo están utilizando. Desde septiembre hasta mitad, el primer curso. Lo que nos parece, bueno, no nos parece mal, pero nosotros estamos limitados a ese número de horas Y luego tampoco podemos facturar. (NAV-FP8, p. 28)

El problema que tiene la formación de demanda, desde que se creó, es que no llega adecuadamente a un tamaño de empresa determinado: la pyme y la micropyme [ ]. Las micropymes, en muchos casos, no es tanto por el propio sistema, sino por la imposibilidad. Pero yo creo que no es tanto el modelo en sí. (AST-Organización empresarios)

Tenim un sistema de demanda que ja sabíem tots, quan es va instaurar, que tindria un gran problema, que és l'accés a les pimes. Perquè és un sistema que no està pensat ni dissenyat per facilitar l'accés a les pimes. (CAT-AS2)

El sistema d'aquí tenia una cobertura per dalt, però era un sistema des de baix. I és que, clar, la relació amb l'empresa no es decreta. Es construeix des de baix. Per tant..., Lacetània o Garrotxa han creat fundacions fa molts anys. Fa 30 anys que tenen fundacions. $\mathrm{O} 25$ anys que tenen fundacions. Qui hi ha a aquestes fundacions? Hi ha els instituts, hi ha la patronal, hi ha els sindicats, hi ha l'Ajuntament, hi ha el Consell Comarcal. A la del Bages, doncs, està el Consell Comarcal del Bages, però està la Unió Patronal Metal.lúrgica del Bages, està la Cambra de Comerç. És a dir, estan en definitiva els actors locals de la formació professional. (CAT-AR 1) 


\section{Servicios técnicos}

Tal y como se ha señalado en la introducción de este informe, las experiencias internacionales más desarrolladas muestran que los centros de FP pueden jugar un papel nada desdeñable en el apoyo a los procesos de innovación de las empresas, especialmente pymes.

Un primer tipo de relación a este respecto se refiere a la utilización por parte de las empresas de la maquinaria y el equipamiento disponibles en los centros de FP mejor dotados. En el País Vasco los centros de FP entrevistados manifiestan poner a disposición de las empresas equipamiento y personal del que disponen para la solución de problemas tecnológicos de diferente naturaleza (por ejemplo, nuevos elementos de diseño, la fabricación de utillajes, mejoras de procesos, metrologías, pruebas y ensayos de materiales, etc.).

La posibilidad de utilizar equipamiento de buen nivel tecnológico, a veces adquirido con ayudas públicas regionales y también, en otras ocasiones, con la colaboración de empresas, es una de las bases de la prestación de servicios de los centros de FP a las empresas en el País Vasco y constituye una infraestructura regional relevante para la innovación de las pymes industriales, las cuales generalmente carecen de recursos para la realización de este tipo de actuaciones y quedan alejadas de la interlocución con otros actores como los centros tecnológicos o las universidades.

En la actualidad, algunos centros vascos quieren formalizar y sistematizar la prestación de ayuda técnica que desde siempre han realizado a las empresas. Con este objetivo han surgido diferentes proyectos que, contando con distintos actores, persiguen facilitar a las pymes el acceso a la innovación y la mejora continua de sus procesos clave, ofreciéndoles desde los centros apoyo técnico, herramientas, metodologías y formación adecuada a sus necesidades (véase el capítulo referido al País Vasco).

Las personas entrevistadas en esta comunidad autónoma coinciden en afirmar que el nicho de actuación para los centros de formación profesional se encuentra fundamentalmente en las microempresas y pequeñas empresas del entorno comarcal, que son las que cuentan con menores capacidades de innovación y a las que no llega la infraestructura de I+D (universidades y centros tecnológicos). Además, la cooperación con estas empresas no es atractiva para los mencionados agentes tecnológicos, que prefieren trabajar en proyectos con empresas más grandes, con una mayor trascendencia temporal de las colaboraciones en innovación y más atractivos desde el punto de vista de las partidas económicas destinadas y por su mayor contenido técnico. Con estos proyectos se puede constatar que los centros están adoptando una actitud más proactiva en las relaciones que mantienen con las empresas. Asimismo, se considera que esta colaboración centro de FP-empresa revierte en la calidad y mejora de la formación que ofrece el centro.

Fuera de estas experiencias más punteras, que a día de hoy todavía son escasas y se encuentran en proceso de gestación, la realidad en la mayoría de regiones y casos considerados es una extensión limitada de las actividades de apoyo a la innovación en pymes desde los centros de FP.

Así, en Navarra las entrevistas realizadas nos han permitido corroborar la extensión, a día de hoy limitada, de una línea incipiente de apoyo a los proyectos de innovación en centros de FP (en colaboración con empresas) apoyada por la Administración regional. La actual crisis ha contribuido a frenar algunas de estas posibles iniciativas entre las empresas. No obstante, se dan casos exitosos (por ejemplo, el desarrollo de un sistema de visión artificial para una importante empresa de naipes) que pueden servir de modelo de la potencialidad de este tipo de colaboración. 
En Aragón, el trabajo de campo realizado ha permitido constatar una cierta tradición de servicios a las empresas desde los centros de FP. En algunos casos, determinadas empresas han utilizado recursos de los propios centros de FP. Otras veces, los centros integrados ofrecen servicios a empresas, como el programa SiempreFP, que plantea la realización de estudios a empresas para la mejora de algún producto o servicio de la propia empresa. En otras comunidades como Asturias y Madrid no se han detectado experiencias de este tipo.

Con excepción de lo que podríamos denominar experiencias de «campus locales de FP» del País Vasco y Cataluña, relacionadas con agentes económicos y locales del territorio y ligadas a figuras como las fundaciones, la línea de apoyo a la innovación en pymes desde los centros de FP apenas se ha desarrollado hasta el momento en España.

Lo que sí se ha mantenido es la colaboración desde el punto de vista de apoyo técnico, de asesoramiento técnico y de resolución de problemas de la propia empresa. (PV-E9, p. 4)

Adibidez, Bizkaian dagoen enpresa batek esan zigun haiek laborategia eduki ordez, beno ba, analisiak zuek egingo dituzue, eta hemen egiten dizkiegu guk haiei laborategi-lanak. Eta hilero pasatzen dizkiegu muestrak eta guk egiten duguna, ... edo momentu batean ba, «problema bat, honekin daukaguna, egin dezakezue holako ikerketa»? (PV-E5, p. 19)

¿Servicios a la empresa? Hay pequeñas pruebas, que suelen hacer con empresas que no tienen recursos técnicos como para hacer algunos ensayos. Alguna cosilla sí que se ha hecho. Pero, más allá, el planteamiento sería entrar. Claro, las empresas, ya sabes, lo que quieren es hacer una cosa rápida. Y a nosotros más nos interesaría entrar en temas de colaboración en proyectos de innovación. (NAV-FP10, p. 25)

Está pasando en los dos sentidos. Es cierto que hay empresas que ofertan sus instalaciones para determinadas actividades. Pero al revés también. Por ejemplo, en el centro integrado $X$ tenemos una máquina de fabricación mecánica de cinco ejes. Y hay empresas que están yendo allí para fabricar sus prototipos. Entonces, el instituto les cede las instalaciones y la empresa trabaja en el desarrollo de prototipos. Y en el sentido contrario se está planteando, por ejemplo, trabajar conjuntamente entre el centro integrado $\mathrm{X}$ y la Fundación del Hidrógeno para intentar implantar enseñanzas de energías alternativas, que una parte se haría en las instalaciones de la Fundación del Hidrógeno en Walqa, que tienen aerogeneradores, etc., y no haría falta instalarlos en el centro. (ARAG-AR1)

Contactamos con una empresa que se dedicaba a hacer algo de visión. Entonces vino uno, el representante, un poco, el técnico, y yo le dije: «Bueno, a ver, algún problema que tengáis en vista que no se pueda resolver». Y entonces dijo: «Pues tengo este tema de las cartas». Y así empezó el tema. Presentamos un proyecto de innovación y nos lo aceptaron En la cadena de esta empresa tienen puesto el sistema [que desarrollamos] en dos o tres sitios. (NAV-FP12, pp. 17 y 22)

Como se ha mencionado, un aspecto importante relacionado con los servicios técnicos es la disponibilidad de maquinaria avanzada que pueda ser utilizada por las empresas, tal y como se ha detectado en los centros de FP vascos punteros. No obstante, hay que subrayar que la relación al respecto es generalmente bidireccional. Puede decirse que en general es más frecuente que sean las propias empresas quienes transmitan conocimiento relacionado con su maquinaria o tecnología a los centros de FP.

Por medio de instrumentos como las estancias de profesorado o las prácticas en las empresas, muchas veces son los profesores o los alumnos de los centros de FP quienes utilizan el equipamiento más avanzado de que disponen las empresas. En concreto, las estancias de profesorado en las empresas han sido un instrumento impulsado por las distintas administraciones estudiadas y parece que pueden ofrecer resultados muy interesantes. No obstante, se observan 
barreras como un insuficiente impulso de estos programas (por ejemplo, en Madrid se señala que apenas ha tenido incidencia), las reticencias de los profesores (que lo ven como un trabajo «extra») y las dificultades en algunas empresas debidas al desconocimiento mutuo (en un caso se plantea un rechazo procedente de agentes sindicales debido a una posible confusión entre formación y práctica laboral).

En Cataluña las experiencias recogidas en las diferentes entrevistas apuntan a la importancia de determinados sectores (como el sector industrial y, dentro de él, el sector mecánico o electromecánico, el sector químico, etc.). Estos sectores necesitan de recursos importantes (instalaciones, maquinaria) que obligan al acercamiento entre centros de formación profesional especializados en estas familias y empresas o universidades y/o centros tecnológicos. Las razones son varias. La primera es el elevado coste de este tipo de espacios e instrumentos. La segunda razón es la continua necesidad de actualización tecnológica tanto de empresas como de centros formativos (estos en cuanto a los contenidos a trasmitir a sus estudiantes). Cuando existen estas necesidades, el intercambio de profesores y alumnos resulta más fluido. Los primeros a partir de las estancias de profesorado y la realización puntual de formación de demanda para empresas como prestación de servicios a empresas. Los segundos aprovechan las instalaciones de empresas o fundaciones para realizar módulos específicos de los ciclos formativos. Los centros formativos aprovechan las instalaciones y maquinaria más actualizadas de las empresas para realizar determinados módulos. Las empresas, por su parte, aprovechan este trasvase de estudiantes para captar futuros estudiantes en prácticas (FCT), además de futuros trabajadores.

Considero que és un factor molt interessant. Molt del professorat que sol.licita ha pogut fer. I ara, actualment, encara hi ha professors que estan fent estades a l'empresa. Són estades entre $2 \mathrm{i}$ 3 setmanes i el professor està a dedicació completa a l'empresa, formant-se, reciclant-se i, a més, en principi va a l'empresa que el professor demana. Crec que és una eina molt interessant per posar-se al dia i adaptar-nos al que seria la realitat. (CAT-FP2)

Aquí fem dos cicles superiors i cada vegada el nivell tecnològic de la maquinària que tenim a l'institut no està a l'altura del que tenim allà dalt, que l'han comprat les empreses. Per tant, com suplim això? Doncs a través de la col-laboració; els nostres alumnes van allà dalt i fan les classes allà dalt. (CAT-FP1)

Es complicado [las estancias de profesores en empresas] porque vas como un alumno. Tienes que tener un tutor en la empresa que se responsabilice de ti. Tienes que llevar un programa formativo o un proyecto de qué quieres hacer en esas prácticas. No es voy a una empresa para ver cómo funcionan. No. Qué es lo que quiero hacer en esa empresa, en qué quiero profundizar y qué es lo que voy a poder hacer allí. Y, luego, en determinadas empresas es complejo. Yo, por ejemplo, hice una estancia de empresas en X. Pero me costó muchísimo explicarles y que entendieran que no eran unas prácticas laborales. En determinadas entidades están muy alerta de que tú no hagas un trabajo real dentro de tus prácticas. (ARAG-FP1)

Se están haciendo [las estancias de profesores en empresas] y la verdad es que la gente, cuando vas a las prácticas, yo creo que lo ven como algo positivo. Porque ahí sí que se produce intercambio también. Ahí los profesionales primero te ven como un profesor que no tiene ni idea de lo que va a aprender, y luego ven que hay cosas que ellos no conocían o que no las veían así y que tú también les puedes aportar. Se han gestado muchos contactos para dejar de verte como un instituto y poder trabajar juntos en cosas. (ARAG-FP1)

En esto, lo que te he dicho, estamos dos profesores de estancias en empresa. De los 20, es un $10 \%$. El resto no está. Y bueno, aunque vamos pasando a lo largo de los años, pues en los últimos cuatro años igual hemos pasado pues dos, cuatro, seis o siete. Pero claro, el resto aún no ha pasado. (NAV-FP10, p. 24) 
Ha estado puntualmente algún profesor, no es significativo. (NAV-FP12, p. 12)

¿Innovación? Casi prefiero que nos dejen ir a la empresa a trabajar para ver qué está aplicando la empresa. (NAV-FP12, p. 15)

[...] Sí. Realizan estancias formativas en empresas, entre otras cosas, además, vienen reguladas y gestionadas por la propia Consejería de Educación [...]. Pero, además de esto, mediante los seminarios regionales de formación de familias profesionales también se aprovecha para potenciar este tipo de cosas [...]. Es decir, para nosotros, eso..., en formación profesional es fundamental. El profesor, todos los años, no sé, o cada dos años, o más tiempo, pero debería darse una vuelta importante, una estancia, por la empresa y ver cómo se está avanzando para realmente darse cuenta de por dónde van los tiros en el mercado laboral. (AST-Director CIPF)

[...] No, no Ha habido un programa de la Consejería, en el sentido de que se sacan prácticas, de , períodos de estancia..., programas, para que los profesores puedan ir a una empresa, pues..., no sé después en qué se concreta. $Y$ algún profesor de aquí, alguna profesora, evidentemente fue a una empresa Sí, en el mes de julio, y este tipo de cosas. Pero bueno, yo creo que eso era algo experimental, que no cuajó. Y fuera de ahí, pues. (AST-Director IES)

\section{Consideraciones finales}

En este informe se han presentado los resultados de la primera fase del proyecto de investigación «Formación profesional y sistema de innovación: el papel de los trabajadores intermedios en los procesos de innovación de las pymes industriales» (Ministerio de Ciencia e Innovación, hoy Ministerio de Economía y Competitividad, proyecto CSO2011-29410-C03, 2012-2014), donde han participado investigadores de seis universidades o centros de investigación españoles.

El objetivo ha sido indagar sobre los distintos tipos de relación entre los centros de FP y el sistema productivo, con especial atención a la incidencia del entorno regional. Los estudios de caso realizados en las regiones analizadas han mostrado la potencialidad de las relaciones entre los centros educativos y las empresas, así como las principales barreras que impiden un mayor desarrollo de las relaciones entre el sistema formativo y el sistema productivo.

En primer lugar, hay que señalar que la implantación de los módulos de formación en centros de trabajo (FCT) contemplados por la LOGSE, que en las regiones más avanzadas puede verse como una continuación de una trayectoria de relaciones que existían con anterioridad, supone un mecanismo fundamental de relación y transmisión de conocimiento entre centros de FP y empresas. La interrelación continua entre los tutores de los centros y los tutores de las empresas posibilita la capacitación práctica de los alumnos y su posterior inserción profesional, así como una adaptación de los programas formativos de los centros de FP a las necesidades de las empresas de su entorno.

Por otro lado, las prácticas de FCT (así como las estancias de profesores en las empresas) posibilitan la transmisión de conocimiento tecnológico en ambas direcciones. En la medida en que con el paso del tiempo se desarrollan unas relaciones de confianza, los tutores de los centros adquieren información sobre las últimas tecnologías incorporadas a las empresas y los representantes de estas llegan a conocer mejor la oferta formativa de los centros. Las relaciones pueden así encaminarse hacia formas más avanzadas de colaboración como son la realización de formación continua, la utilización de equipamiento avanzado (disponible en los centros) y los servicios técnicos a las empresas. 
La literatura internacional revisada en la introducción de este informe muestra que los centros de FP más avanzados pueden jugar un importante papel en el desarrollo local. No obstante, también se indica que existen importantes barreras que impiden una implicación mayor de estos agentes educativos en el entorno socioeconómico. El estudio realizado en seis CC. AA. españolas ha permitido corroborar e ilustrar buena parte de estos puntos. Entre los factores que impiden una mayor implicación de los centros de FP en misiones hasta ahora consideradas «no tradicionales» se encuentran dimensiones tanto internas como externas al sistema educativo. Entre las primeras cabe destacar la falta de autonomía de los centros, su rigidez burocrática y la falta de implicación o incentivos de los profesores. Entre las barreras externas hay que mencionar el recelo de los agentes sociales, actores clave en la formación para el empleo.

De la investigación realizada en la primera fase de este proyecto cabe concluir que los objetivos de una mayor integración del sistema de formación profesional (formación reglada y formación para el empleo), así como de una mayor orientación del sistema formativo hacia el sistema productivo, recogidos en las últimas reformas normativas realizadas en España, han tenido hasta el momento un grado de cumplimiento bastante limitado. En este sentido, la figura de los centros integrados apenas ha sido desarrollada.

Un aspecto central en la investigación realizada ha sido comprobar la incidencia del entorno regional en la configuración del sistema formativo y en los procesos de relación entre este y el tejido productivo y social, dentro de un contexto de creciente reconocimiento del papel de las regiones en el desarrollo económico y la innovación. El trabajo ha mostrado que, ante retos similares (integración del sistema de formación, orientación hacia el tejido productivo), las regiones analizadas han optado por modelos distintos con características diferenciadas.

Cabe destacar el caso del País Vasco, con un gran desarrollo de las actividades de formación para el empleo (e incluso servicios técnicos) en los centros de FP, dentro de una apuesta regional continuada a favor de la formación profesional (especialmente de grado superior), insertada en una trayectoria de relación entre el sistema formativo y el tejido productivo.

Por su parte, Cataluña también ha realizado una apuesta importante sobre la base de una red de centros propios de ámbito sectorial y territorial, y cuenta con experiencias muy importantes de desarrollo local donde interactúan empresas, centros de formación y Administración local. La potenciación de centros propios como los CIFO ha hecho que el papel de los centros tradicionales de FP haya sido reducido.

El resto de CC. AA. analizadas podrían encuadrarse dentro de un modelo «general», con menos características o impulso político que un modelo «propio». No obstante, en todas estas regiones la configuración del sistema de formación es también el resultado, en buena medida, de procesos de relación y toma de decisión entre agentes clave realizados a nivel regional. Una característica común a estas CC. AA. es, probablemente, un mayor peso de los agentes sociales en el sistema de formación para el empleo.

A la luz de la evidencia recogida, desde el punto de vista de las relaciones entre los centros de FP y las empresas, y partiendo de las grandes potencialidades que se derivan de la institucionalización de las prácticas de FCT, el mayor reto está en este momento en la potenciación de las actividades de formación para el empleo (antes continua y ocupacional) en los centros de FP, así como en una mejor integración de los distintos subsistemas de formación y agentes intervinientes.

En cuanto a los servicios técnicos a las pymes, a día de hoy su extensión es muy limitada, circunscribiéndose a algunos casos de «campus locales de FP» del País Vasco y Cataluña, así como a algunas experiencias aisladas en el resto de regiones. La interrelación entre el siste- 
ma formativo y el «sistema de innovación», entendido como las infraestructuras tecnológicas creadas recientemente en España, ha sido prácticamente inexistente hasta el momento (estas dificultades son previsibles y se han manifestado con anterioridad en otros países, como se ha mencionado en la introducción del informe). También es claramente insuficiente la relación entre los centros de FP y las universidades, a pesar de que un número importante de alumnos que cursan FP superior acceden posteriormente a la universidad.

A la vez que se potencian las relaciones entre los centros de FP y el resto de agentes educativos y de innovación, es importante ampliar la noción de innovación imperante en la sociedad reconociendo el papel que los trabajadores y técnicos cualificados pueden realizar en los procesos de innovación en las empresas, especialmente pymes. Este aspecto será el objetivo de la segunda fase del proyecto de investigación, a la cual nos remitimos. 

ANEXO 



\section{Entorno económico regional}

\subsection{Datos socioeconómicos básicos de referencia y características del tejido productivo}

Tabla 3.1. Indicadores socioeconómicos de España y de las seis regiones (2010)

\begin{tabular}{|l|c|c|c|c|c|c|c|}
\cline { 2 - 8 } \multicolumn{1}{l|}{} & Aragón & Asturias & Cataluña & Madrid & Navarra & $\begin{array}{c}\text { País } \\
\text { Vasco }\end{array}$ & España \\
\hline $\begin{array}{l}\text { Población (miles } \\
\text { de habitantes) }\end{array}$ & $1.346,3$ & $1.081,5$ & $7.539,6$ & $6.489,7$ & 642,1 & $2.184,6$ & $47.190,5$ \\
\hline $\begin{array}{l}\% \text { población } \\
\text { española }\end{array}$ & 2,9 & 2,3 & 16,0 & 13,8 & 1,4 & 4,6 & 100,0 \\
\hline $\begin{array}{l}\text { Producto interior } \\
\text { bruto (PIB) } \\
\text { (millones de euros) }\end{array}$ & $33.252,0$ & $22.704,2$ & $195.286,9$ & $186.630,3$ & $13.121,7$ & $64.464,2$ & $1.051 .342,0$ \\
\hline $\begin{array}{l}\text { \% del PIB total } \\
\text { español }\end{array}$ & 3,2 & 2,2 & 18,6 & 17,8 & 1,7 & 6,1 & 100,0 \\
\hline $\begin{array}{l}\text { PIB per cápita } \\
\text { (miles de euros) }\end{array}$ & 25.322 & 21.477 & 26.675 & 29.351 & 29.197 & 30.152 & 22.819 \\
\hline $\begin{array}{l}\text { PIB per cápita / } \\
\text { media nacional } \\
\text { (=100) }\end{array}$ & 111,0 & 94,1 & 116,9 & 128,6 & 128,0 & 132,1 & 100,0 \\
\hline $\begin{array}{l}\text { Valor añadido } \\
\text { bruto industrial } \\
\text { (VAB) } \\
\text { (millones de euros) }\end{array}$ & $6.327,6$ & $4.313,6$ & $36.688,7$ & $17.538,9$ & $4.839,8$ & $15.152,0$ & $155.191,0$ \\
\hline $\begin{array}{l}\text { \% del VAB total } \\
\text { español }\end{array}$ & 4,1 & 2,8 & 23,6 & 11,3 & 3,1 & 9,8 & 100,0 \\
\hline $\begin{array}{l}\text { \% VAB industrial / } \\
\text { PIB regional }\end{array}$ & 19,0 & 19,0 & 18,8 & 9,4 & 26,7 & 23,5 & 14,8 \\
\hline
\end{tabular}

Fuente: INE 
Tabla 3.2. Peso de los sectores manufactureros de alta y media-alta tecnología en términos de VAB industrial y empleo (2009)

\begin{tabular}{|c|c|c|c|c|c|c|c|}
\hline & Aragón & Asturias & Cataluña & Madrid & Navarra & $\begin{array}{c}\text { País } \\
\text { Vasco }\end{array}$ & España \\
\hline \multicolumn{8}{|c|}{ Sectores manufactureros de alta y media-alta tecnología } \\
\hline $\begin{array}{l}\text { VAB } \\
\text { (miles euros) }\end{array}$ & 1.748 .641 & 425.883 & 4.467 .457 & 10.062 .979 & 1.518 .599 & 4.021 .717 & 32.175 .238 \\
\hline $\begin{array}{l}\% \text { industria } \\
\text { manufacturera }\end{array}$ & 36,3 & 13,7 & 33,6 & 33,7 & 36,7 & 31,7 & 26,6 \\
\hline $\begin{array}{l}\text { Ocupados } \\
\text { (miles) }\end{array}$ & 41,3 & 8,6 & 236,8 & 85,3 & 27,6 & 77,6 & 712,1 \\
\hline $\begin{array}{l}\% \text { ocupados } \\
\text { industria }\end{array}$ & 39,3 & 15,5 & 41,8 & 31,9 & 40,6 & 37,7 & 27,9 \\
\hline \multicolumn{8}{|c|}{ Sectores manufactureros de tecnología alta } \\
\hline $\begin{array}{l}\text { VAB } \\
\text { (miles euros) }\end{array}$ & 171.645 & 7.218 & 1.818 .573 & 2.822 .908 & 268.654 & 499.026 & 6.777 .754 \\
\hline $\begin{array}{l}\% \text { industria } \\
\text { manufacturera }\end{array}$ & 3,6 & 0,2 & 13,7 & 9,5 & 6,5 & 3,9 & 5,6 \\
\hline $\begin{array}{l}\text { Ocupados } \\
\text { (miles) }\end{array}$ & 2,3 & 1,6 & 45,4 & 34 & 1,5 & 8,7 & 132,2 \\
\hline $\begin{array}{l}\text { \% ocupados } \\
\text { industria }\end{array}$ & 2,2 & 2,9 & 8,0 & 12,7 & 2,2 & 4,2 & 5,2 \\
\hline \multicolumn{8}{|c|}{ Sectores manufactureros de tecnología media-alta } \\
\hline $\begin{array}{l}\text { VAB } \\
\text { (miles euros) }\end{array}$ & 1.576 .996 & 418.665 & 2.648 .884 & 7.240 .071 & 1.249 .946 & 3.522 .692 & 25.397 .483 \\
\hline $\begin{array}{l}\% \text { industria } \\
\text { manufacturera }\end{array}$ & 32,8 & 13,5 & 19,9 & 24,3 & 30,2 & 27,8 & 21 \\
\hline $\begin{array}{l}\text { Ocupados } \\
\text { (miles) }\end{array}$ & 39 & 7 & 191,4 & 51,3 & 26,1 & 68,9 & 579,9 \\
\hline $\begin{array}{l}\text { \% ocupados } \\
\text { industria }\end{array}$ & 37,1 & 12,6 & 33,8 & 19,2 & 38,4 & 33,5 & 22,7 \\
\hline
\end{tabular}

Fuente: Indicadores de Alta tecnología, INE

Tabla 3.3. Tasas de actividad, empleo y paro según CC. AA. (2010)

\begin{tabular}{|l|c|c|c|c|c|c|c|}
\cline { 2 - 8 } \multicolumn{1}{c|}{} & Aragón & Asturias & Cataluña & Madrid & Navarra & $\begin{array}{c}\text { País } \\
\text { Vasco }\end{array}$ & España \\
\hline Tasa de actividad & 58,16 & 51,65 & 62,81 & 65,10 & 60,11 & 57,59 & 60,00 \\
\hline Tasa de empleo & 49,57 & 43,40 & 51,66 & 54,63 & 52,99 & 51,52 & 47,96 \\
\hline Tasa de paro & 14,77 & 15,97 & 17,75 & 16,08 & 11,85 & 10,55 & 20,06 \\
\hline
\end{tabular}

Fuente: INE 
Gráfico 3.1. Personas de 25-64 años según nivel educativo alcanzado (\%) en Europa (2010)

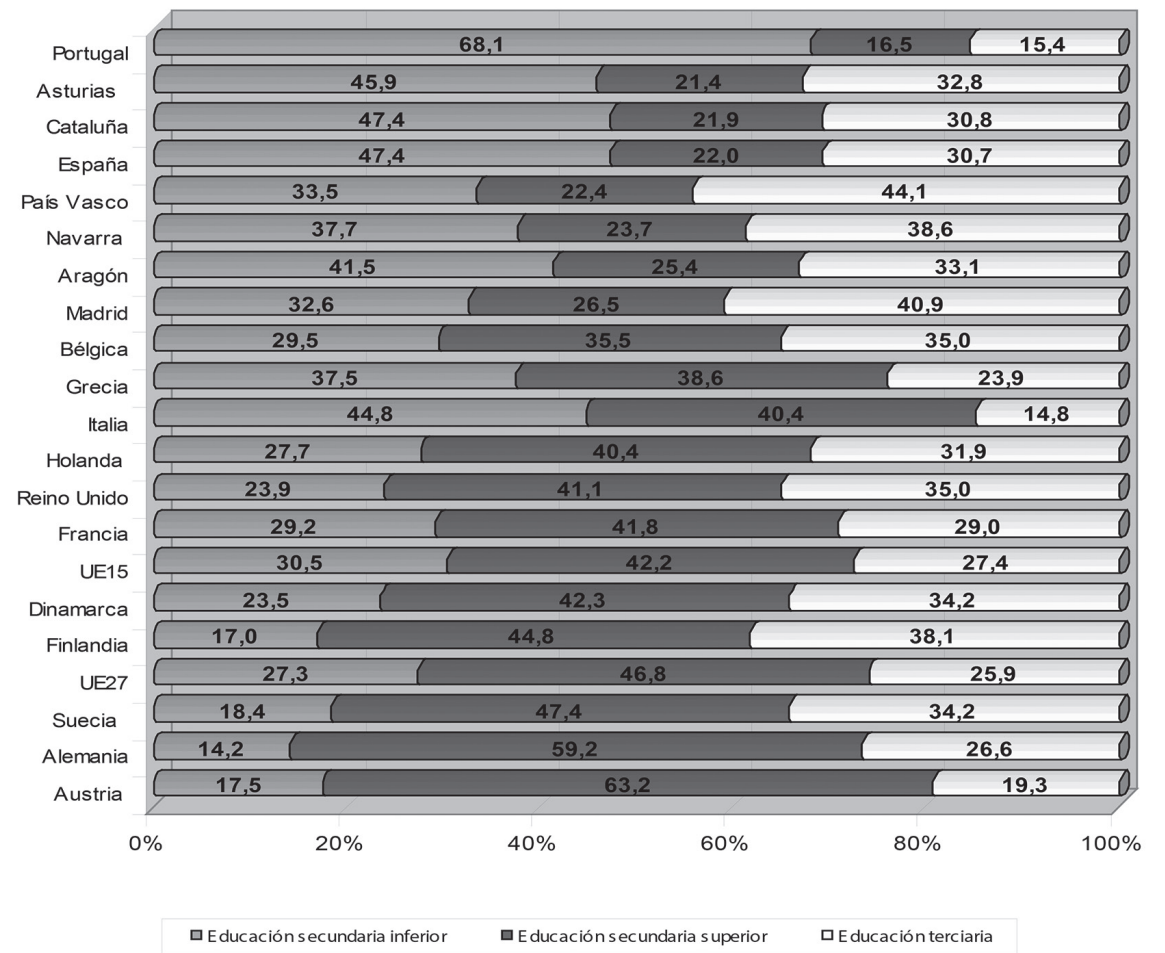

Fuente: Eurostat

Tabla 3.4. Población ocupada según nivel educativo (\%) (2010)

\begin{tabular}{|l|c|c|c|c|c|c|c|}
\cline { 2 - 8 } \multicolumn{1}{c|}{} & Aragón & Asturias & Cataluña & Madrid & Navarra & $\begin{array}{c}\text { País } \\
\text { Vasco }\end{array}$ & España \\
\hline $\begin{array}{l}\text { Analfabetos, sin estudios } \\
\text { y primarios }\end{array}$ & 13 & 10,1 & 17 & 8,7 & 6,5 & 6,3 & 12,8 \\
\hline Bachiller elemental & 22,1 & 24,6 & 22,4 & 18,3 & 23,8 & 20,1 & 26,4 \\
\hline Bachiller superior & 15,7 & 15,1 & 15,7 & 21,1 & 14,0 & 11,0 & 15,3 \\
\hline FPGM & 12,1 & 10,3 & 8,9 & 6 & 11,7 & 11,8 & 8,9 \\
\hline FPGS & 12,1 & 15 & 11,6 & 7,7 & 15,6 & 18,3 & 10,6 \\
\hline Anteriores al superior & 11,5 & 12,4 & 9,5 & 12,3 & 12,9 & 12,9 & 10,9 \\
\hline Superiores & 13,5 & 12,5 & 14,8 & 25,9 & 15,5 & 19,5 & 15,2 \\
\hline TOTAL (miles) & 553,73 & 401,5 & $3,141,56$ & $2,868,51$ & 277,27 & 945,74 & $18.476,8$ \\
\hline
\end{tabular}

FPGM: Formación profesional grado medio

FPGS: Formación profesional grado superior

Fuente: Instituto Valenciano de Investigaciones Económicas 
Tabla 3.5 Población ocupada en la industria según nivel educativo (\%) (2010)

\begin{tabular}{|l|c|c|c|c|c|c|c|}
\cline { 2 - 8 } \multicolumn{1}{c|}{} & Aragón & Asturias & Cataluña & Madrid & Navarra & $\begin{array}{c}\text { País } \\
\text { Vasco }\end{array}$ & España \\
\hline $\begin{array}{l}\text { Analfabetos, sin estudios y } \\
\text { primarios }\end{array}$ & 12,25 & 9,37 & 17,33 & 11,58 & 6,52 & 5,65 & 13,2 \\
\hline Bachiller elemental & 28,93 & 27,53 & 28,02 & 20,25 & 25,54 & 24,16 & 32,2 \\
\hline Bachiller superior & 16,27 & 12,35 & 15,41 & 16,71 & 10,8 & 8,13 & 12,9 \\
\hline FPGM & 13,25 & 10,12 & 9,56 & 7,96 & 16,39 & 14,72 & 10,5 \\
\hline FPGS & 15,1 & 24,57 & 14,71 & 11,49 & 22,67 & 29,47 & 15,4 \\
\hline Anteriores al superior & 7,97 & 8,51 & 4,23 & 9,51 & 9,39 & 7,02 & 6 \\
\hline Superiores & 6,23 & 7,56 & 10,73 & 22,5 & 8,7 & 10,85 & 9,8 \\
\hline TOTAL (miles) & 98,34 & 52,95 & 586,12 & 247,62 & 66,77 & 204,09 & $2.461,5$ \\
\hline
\end{tabular}

FPGM: Formación profesional grado medio

FPGS: Formación profesional grado superior

Fuente: Instituto Valenciano de Investigaciones Económicas

Gráfico 3.2. Evolución del porcentaje de personas ocupadas en la industria con titulación de formación profesional (1985-2010)

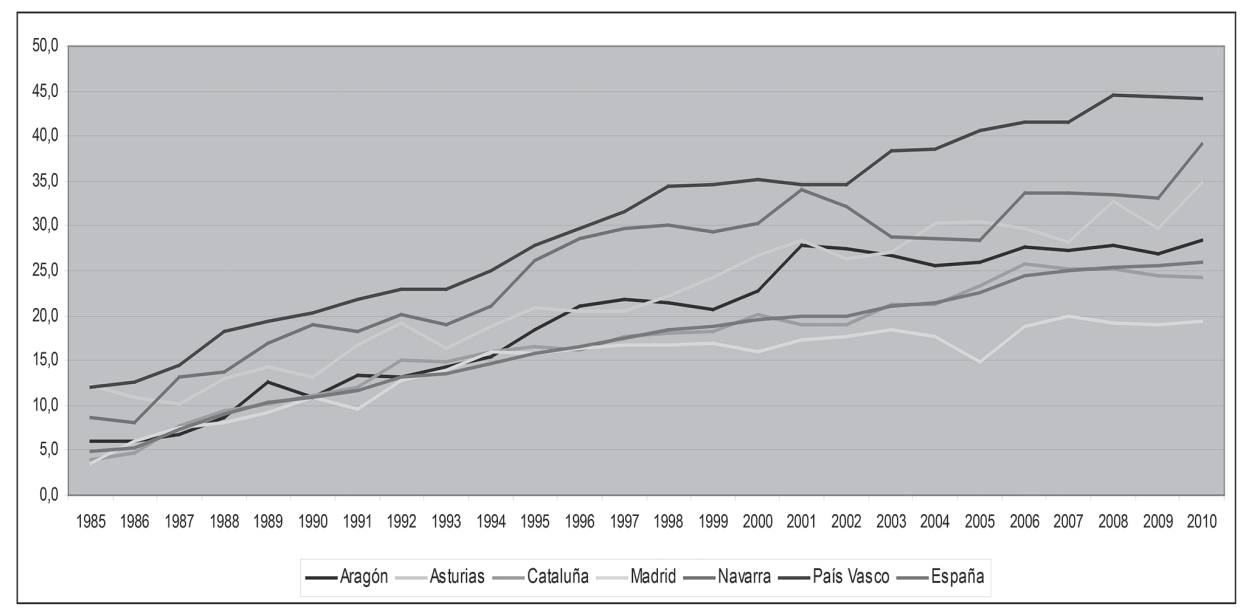

Fuente: Instituto Valenciano de Investigaciones Económicas 
Gráfico 3.3. Formación permanente: porcentaje de personas de 25-64 años que cursa estudios en Europa

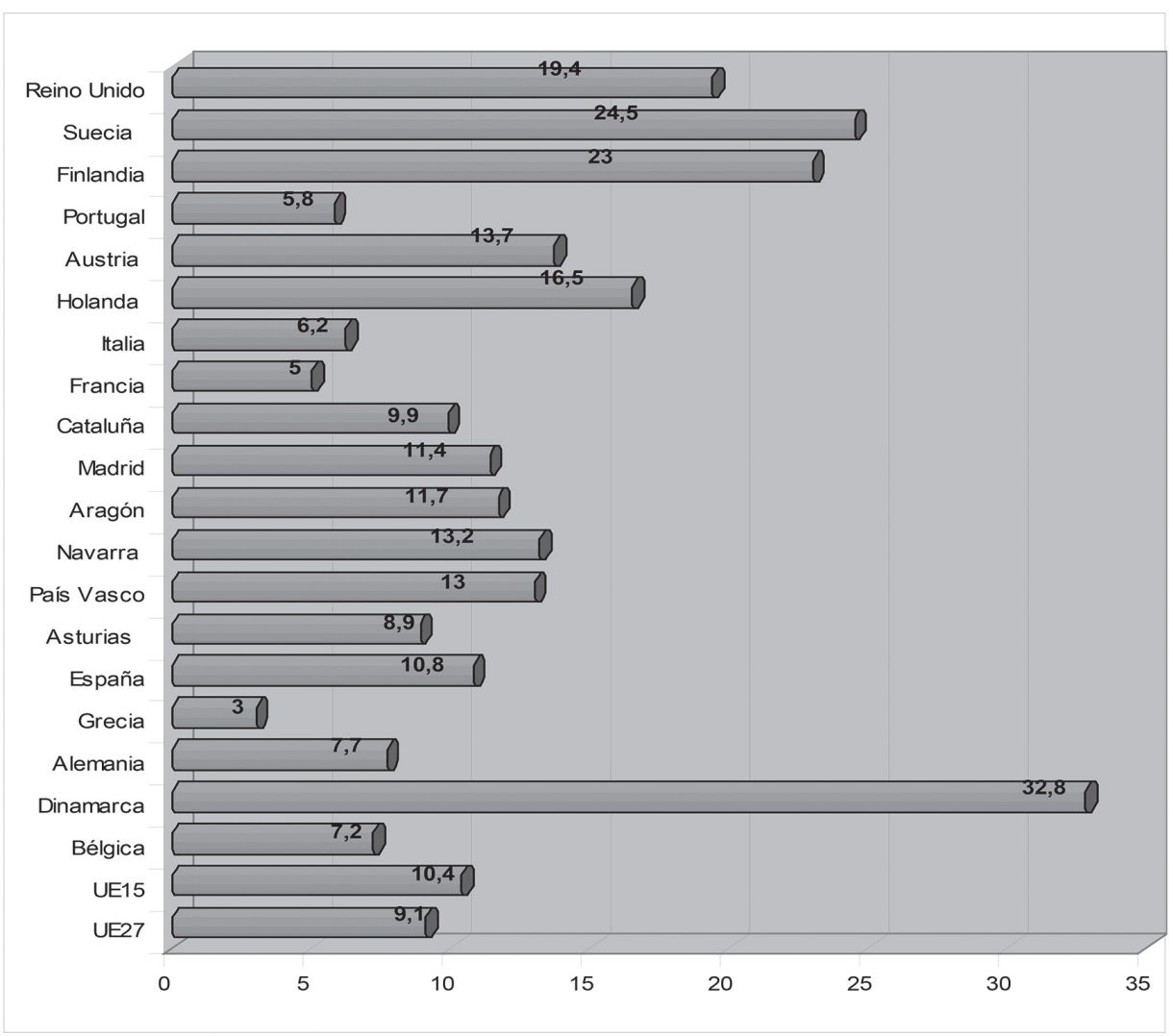

Fuente: Eurostat. Calculado con la metodología establecida por Eurostat basándose en medias anuales de datos trimestrales. Se considera la población de 25 a 64 años, ocupada y no ocupada, que en las cuatro últimas semanas ha cursado algún tipo de estudios, bien en el marco de la empresa/centro de trabajo, bien fuera de él. 


\subsection{Indicadores de investigación, desarrollo e innovación}

Tabla 3.6. Recursos asignados a la I+D por el sistema (2010)

\begin{tabular}{|l|c|c|c|c|c|c|c|c|}
\cline { 2 - 9 } \multicolumn{1}{l|}{} & UE27 & España & Aragón & Asturias & Madrid & Cataluña & Navarra & $\begin{array}{c}\text { País } \\
\text { Vasco }\end{array}$ \\
\hline $\begin{array}{l}\text { Gasto total en } \\
\text { I+D (mill. } € \text { ) }\end{array}$ & $245.673,1$ & $14.588,5$ & 374,2 & 238,1 & $3.854,8$ & $3.227,2$ & 365,7 & $1.305,6$ \\
\hline $\begin{array}{l}\text { Gasto total en } \\
\text { I+D (\% PIB) }\end{array}$ & 2,00 & 1,39 & 1,15 & 1,03 & 2,02 & 1,63 & 1,97 & 1,95 \\
\hline $\begin{array}{l}\text { Personal I+D } \\
\text { (EDP) }\end{array}$ & 2.486 .743 & $222.021,7$ & $7.101,7$ & $3.781,3$ & $54.721,4$ & $46.335,9$ & $5.231,5$ & $16.920,6$ \\
\hline $\begin{array}{l}\text { Personal } \\
\text { I+D (\%o pob. } \\
\text { ocupada) }\end{array}$ & 11,5 & 12,03 & 12,9 & 9,36 & 17,44 & 16,12 & 19,25 & 18,02 \\
\hline $\begin{array}{l}\text { Investigadores } \\
\text { en I+D } \\
\text { (EDP) }\end{array}$ & 1.564 .770 & 134.653 & $4.853,3$ & $2.590,7$ & $31.966,2$ & $27.058,4$ & $3.315,2$ & $10.578,4$ \\
\hline $\begin{array}{l}\text { Investigadores } \\
\text { I+D (\%o pob. } \\
\text { ocupada) }\end{array}$ & 7,2 & 7,3 & 8,81 & 6,41 & 10,19 & 9,41 & 12,2 & 11,27 \\
\hline
\end{tabular}

Fuente: INE, Eurostat y elaboración propia

Gráfico 3.4. Evolución del gasto en I+D sobre el PIB (1997-2010)

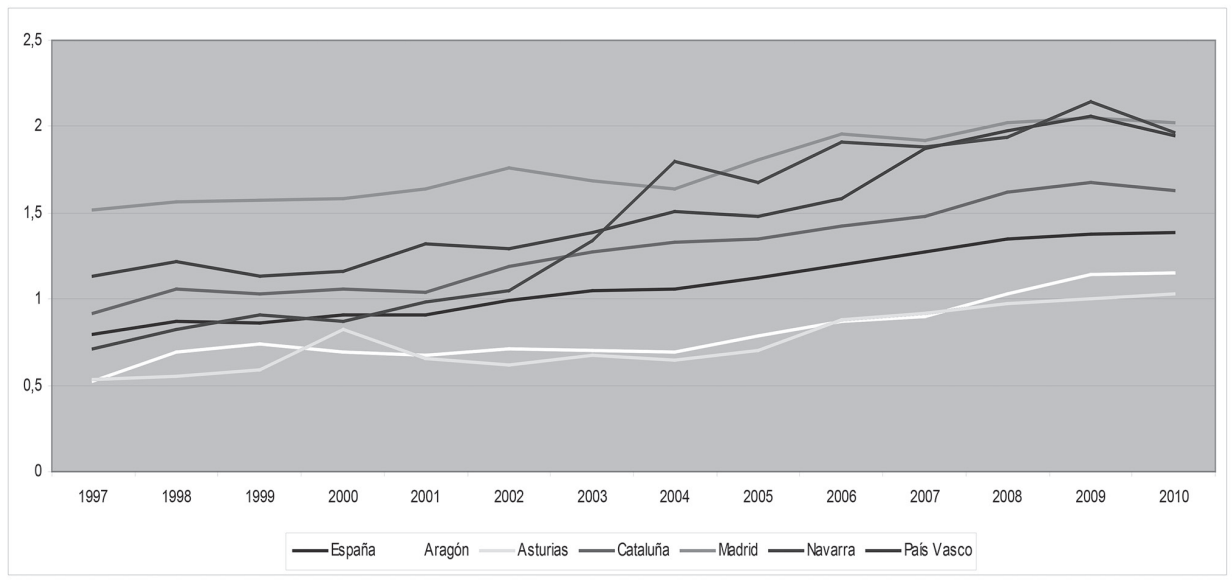

Fuente: INE y elaboración propia 
Tabla 3.7. Gasto en I+D según sectores de ejecución (\%) (2010)

\begin{tabular}{|l|c|c|c|c|c|c|c|}
\cline { 2 - 8 } \multicolumn{1}{c|}{} & Aragón & Asturias & Cataluña & Madrid & Navarra & $\begin{array}{c}\text { País } \\
\text { Vasco }\end{array}$ & España \\
\hline $\begin{array}{l}\text { Empresas e IPSFL } \\
\text { (\% sobre total) }\end{array}$ & 56,5 & 41,2 & 56,8 & 54,6 & 69,4 & 75,5 & 51,6 \\
\hline $\begin{array}{l}\text { Admón. pública } \\
\text { (\% sobre total) }\end{array}$ & 21 & 15,5 & 19,8 & 27,6 & 8,1 & 6 & 20,1 \\
\hline $\begin{array}{l}\text { Enseñanza superior } \\
\text { (\% sobre total) }\end{array}$ & 22,5 & 43,2 & 23,4 & 17,8 & 22,5 & 18,5 & 28,3 \\
\hline $\begin{array}{l}\text { Empresas e IPSFL } \\
\text { (\% sobre PIB) }\end{array}$ & 0,65 & 0,42 & 0,93 & 1,11 & 1,36 & 1,47 & 0,71 \\
\hline $\begin{array}{l}\text { Admón. pública } \\
\text { (\% sobre PIB) }\end{array}$ & 0,24 & 0,16 & 0,32 & 0,56 & 0,16 & 0,12 & 0,28 \\
\hline $\begin{array}{l}\text { Enseñanza superior } \\
\text { (\% sobre PIB) }\end{array}$ & 0,26 & 0,45 & 0,38 & 0,36 & 0,44 & 0,36 & 0,39 \\
\hline
\end{tabular}

Fuente: INE y elaboración propia

Tabla 3.8. Recursos humanos en I+D (2010)

\begin{tabular}{|l|c|c|c|c|c|c|c|}
\cline { 2 - 8 } \multicolumn{1}{l|}{} & España & Aragón & Asturias & Madrid & Cataluña & Navarra & $\begin{array}{c}\text { País } \\
\text { Vasco }\end{array}$ \\
\hline $\begin{array}{l}\text { Personal ocupado I+D } \\
\text { (EDP) }\end{array}$ & $222.021,7$ & $7.101,7$ & $3.781,3$ & $54.721,4$ & $46.335,9$ & $5.231,5$ & $16.920,6$ \\
\hline $\begin{array}{l}\text { Personal I+D } \\
\text { (\%o pob. ocupada) }\end{array}$ & 12,03 & 12,9 & 9,36 & 17,44 & 16,12 & 19,25 & 18,02 \\
\hline $\begin{array}{l}\text { Investigadores en I+D } \\
\text { (EDP) }\end{array}$ & 134.653 & $4.853,3$ & $2.590,7$ & $31.966,2$ & $27.058,4$ & $3.315,2$ & $10.578,4$ \\
\hline $\begin{array}{l}\text { Investigadores I+D } \\
\text { (\%o pob. ocupada) }\end{array}$ & 7,3 & 8,81 & 6,41 & 10,19 & 9,41 & 12,2 & 11,27 \\
\hline Técnicos y auxiliares & $87.368,7$ & $2.248,4$ & $1.190,6$ & $22.755,2$ & $19.277,5$ & $1.916,3$ & $6.342,2$ \\
\hline $\begin{array}{l}\text { Técnicos y auxiliares } \\
\text { (\%o pob. ocupada) }\end{array}$ & 4,7 & 4,1 & 2,9 & 7,3 & 6,7 & 7,1 & 6,8 \\
\hline $\begin{array}{l}\text { Investigadores (\% sobre } \\
\text { personal I+D total) }\end{array}$ & 60,6 & 68,3 & 68,5 & 58,4 & 58,4 & 63,4 & 62,5 \\
\hline $\begin{array}{l}\text { Técnicos y auxiliares } \\
\text { (\% sobre personal I+D } \\
\text { total) }\end{array}$ & 39,4 & 31,7 & 31,5 & 41,6 & 41,6 & 36,6 & 37,5 \\
\hline
\end{tabular}

Fuente: INE, Eurostat y elaboración propia 
Gráfico 3.5. Evolución del personal en I+D sobre la población ocupada (1997-2010)

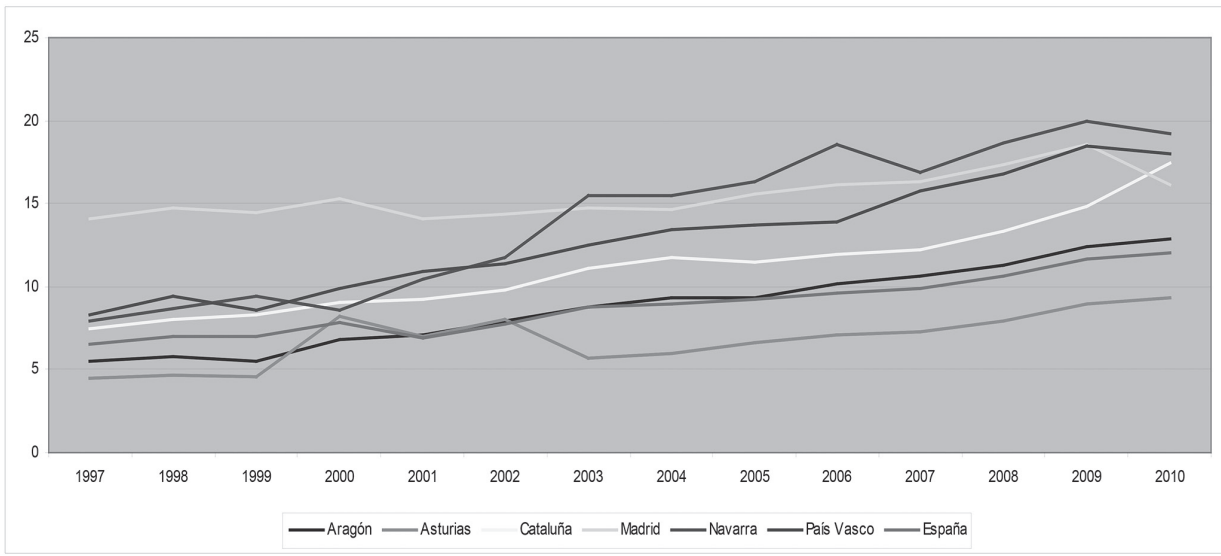

Fuente: INE y elaboración propia

Tabla 3.9. Personal en I+D EDP por sectores de ejecución y CC. AA. (2010)

\begin{tabular}{|l|c|c|c|c|c|c|c|}
\cline { 2 - 8 } \multicolumn{1}{l|}{} & Aragón & Asturias & Cataluña & Madrid & Navarra & $\begin{array}{c}\text { País } \\
\text { Vasco }\end{array}$ & España \\
\hline $\begin{array}{l}\text { Personal I+D EDP } \\
\text { (total) }\end{array}$ & $7.101,7$ & $3.781,3$ & $46.335,9$ & $54.721,4$ & $5.231,5$ & $16.920,6$ & $22.2021,7$ \\
\hline Empresas (\%) & 36,8 & 40,4 & 46,8 & 42,9 & 54,7 & 72,8 & 41,8 \\
\hline Admón. pública (\%) & 19,4 & 17,2 & 20,7 & 29,4 & 7,2 & 6,1 & 20,7 \\
\hline Enseñanza superior (\%) & 43,8 & 42,4 & 32,5 & 27,7 & 38,1 & 21,1 & 37,5 \\
\hline $\begin{array}{l}\text { Investigadores EDP } \\
\text { (total) }\end{array}$ & $4.853,3$ & $2.590,7$ & $27.058,4$ & $31.966,2$ & $3.315,2$ & $10.578,4$ & 134.653 \\
\hline Empresas (\%) & 23,8 & 33,2 & 37,9 & 37,9 & 42,6 & 65,7 & 33,9 \\
\hline Admón. pública (\%) & 15,4 & 12,3 & 21,4 & 23,3 & 7,8 & 5,5 & 18,1 \\
\hline Enseñanza superior (\%) & 60,9 & 54,5 & 40,7 & 38,8 & 49,6 & 28,8 & 48 \\
\hline $\begin{array}{l}\text { Técnicos y auxiliares } \\
\text { EDP }\end{array}$ & $2.248,4$ & $1.190,6$ & $19.277,5$ & $22.755,2$ & $1.916,3$ & $6.342,2$ & $87.368,7$ \\
\hline Empresas (\%) & 64,8 & 56,1 & 59,3 & 49,9 & 75,7 & 84,8 & 53,8 \\
\hline Admón. pública (\%) & 28,1 & 27,7 & 19,9 & 38,0 & 6,0 & 7,0 & 24,8 \\
\hline Enseñanza superior (\%) & 7,1 & 16,1 & 20,9 & 12,1 & 18,3 & 8,3 & 21,4 \\
\hline
\end{tabular}

Fuente: INE y elaboración propia 
Tabla 3.10. Personal EDP en el sector industrial dedicado a actividades en $\mathrm{I}+\mathrm{D}$ por titulación y región $(2010)$

\begin{tabular}{|l|c|c|c|c|c|c|c|}
\cline { 2 - 8 } \multicolumn{1}{c|}{} & Aragón & Asturias & Cataluña & Madrid & Navarra & $\begin{array}{c}\text { País } \\
\text { Vasco }\end{array}$ & España \\
\hline TOTAL & $1.318,9$ & 515,5 & $10.865,1$ & $9.262,4$ & 1.519 & $5.692,5$ & $38.720,8$ \\
\hline Doctores & 3,6 & 5,1 & 7,3 & 6,9 & 4,6 & 2,4 & 5,5 \\
\hline Licenciados & 42,8 & 44,9 & 40,4 & 49,5 & 37,1 & 43,5 & 42,8 \\
\hline Diplomados & 28,6 & 22,4 & 19,5 & 17,4 & 25,9 & 25,9 & 21,3 \\
\hline FP grado superior & 12,1 & 16,5 & 17,6 & 10,8 & 15,4 & 21,2 & 16,1 \\
\hline FP grado medio & 6,5 & 6,1 & 9,2 & 4,8 & 6,9 & 4,9 & 7,2 \\
\hline Otros & 6,4 & 5,0 & 6,0 & 10,6 & 10,2 & 2,1 & 7,2 \\
\hline
\end{tabular}

Fuente: INE y elaboración propia

Tabla 3.11. Aragón. Personal EDP en el sector industrial dedicado a actividades en I+D por titulación y tamaño empresarial (2010)

\begin{tabular}{|c|c|c|c|c|c|c|}
\hline & Total & $0-24$ & $25-74$ & $75-149$ & $150-249$ & 250 y más \\
\hline \multicolumn{7}{|c|}{ ARAGÓN } \\
\hline TOTAL & $1.318,9$ & 186,9 & 345,8 & 190,4 & 185,3 & 410,8 \\
\hline Doctores & 3,6 & 8,6 & 3,8 & 4,3 & 3,4 & 1,0 \\
\hline Licenciados & 42,8 & 44,9 & 48,2 & 46,1 & 35,5 & 38,9 \\
\hline Diplomados & 28,6 & 19,6 & 24,9 & 23,1 & 26,9 & 39,1 \\
\hline FP grado superior & 12,1 & 10,5 & 11,6 & 10,7 & 17,1 & 11,7 \\
\hline FP grado medio & 6,5 & 10,1 & 4,4 & 9,2 & 7,3 & 5,0 \\
\hline Otros & 6,4 & 6,2 & 7,0 & 6,6 & 9,8 & 4,3 \\
\hline \multicolumn{7}{|c|}{ ASTURIAS } \\
\hline TOTAL & 515,5 & 46,3 & 87,6 & 105,9 & 79,9 & 195,6 \\
\hline Doctores & 5,1 & 2,8 & 0,3 & 3,3 & 3,1 & 9,6 \\
\hline Licenciados & 44,9 & 49,2 & 23,7 & 42,3 & 33,8 & 59,4 \\
\hline Diplomados & 22,4 & 24,8 & 27,9 & 30,0 & 25,9 & 13,8 \\
\hline FP grado superior & 16,5 & 9,1 & 25,9 & 22,3 & 15,3 & 11,2 \\
\hline FP grado medio & 6,1 & 11,0 & 11,1 & 1,7 & 12,6 & 2,4 \\
\hline Otros & 5,0 & 3,0 & 11,1 & 0,4 & 9,3 & 3,6 \\
\hline \multicolumn{7}{|c|}{ CATALUÑA } \\
\hline TOTAL & $10.865,1$ & 835,8 & $1.757,0$ & $1.638,3$ & $1.470,6$ & $5.163,8$ \\
\hline Doctores & 7,3 & 5,3 & 5,3 & 6,4 & 7,9 & 8,4 \\
\hline Licenciados & 40,4 & 42,3 & 42,7 & 34,1 & 35,6 & 42,7 \\
\hline Diplomados & 19,5 & 21,6 & 19,9 & 24,2 & 23,2 & 16,5 \\
\hline FP grado superior & 17,6 & 14,8 & 16,7 & 17,2 & 20,0 & 17,8 \\
\hline FP grado medio & 9,2 & 7,2 & 8,5 & 10,9 & 7,4 & 9,7 \\
\hline Otros & 6,0 & 8,8 & 6,9 & 7,2 & 5,8 & 4,8 \\
\hline
\end{tabular}




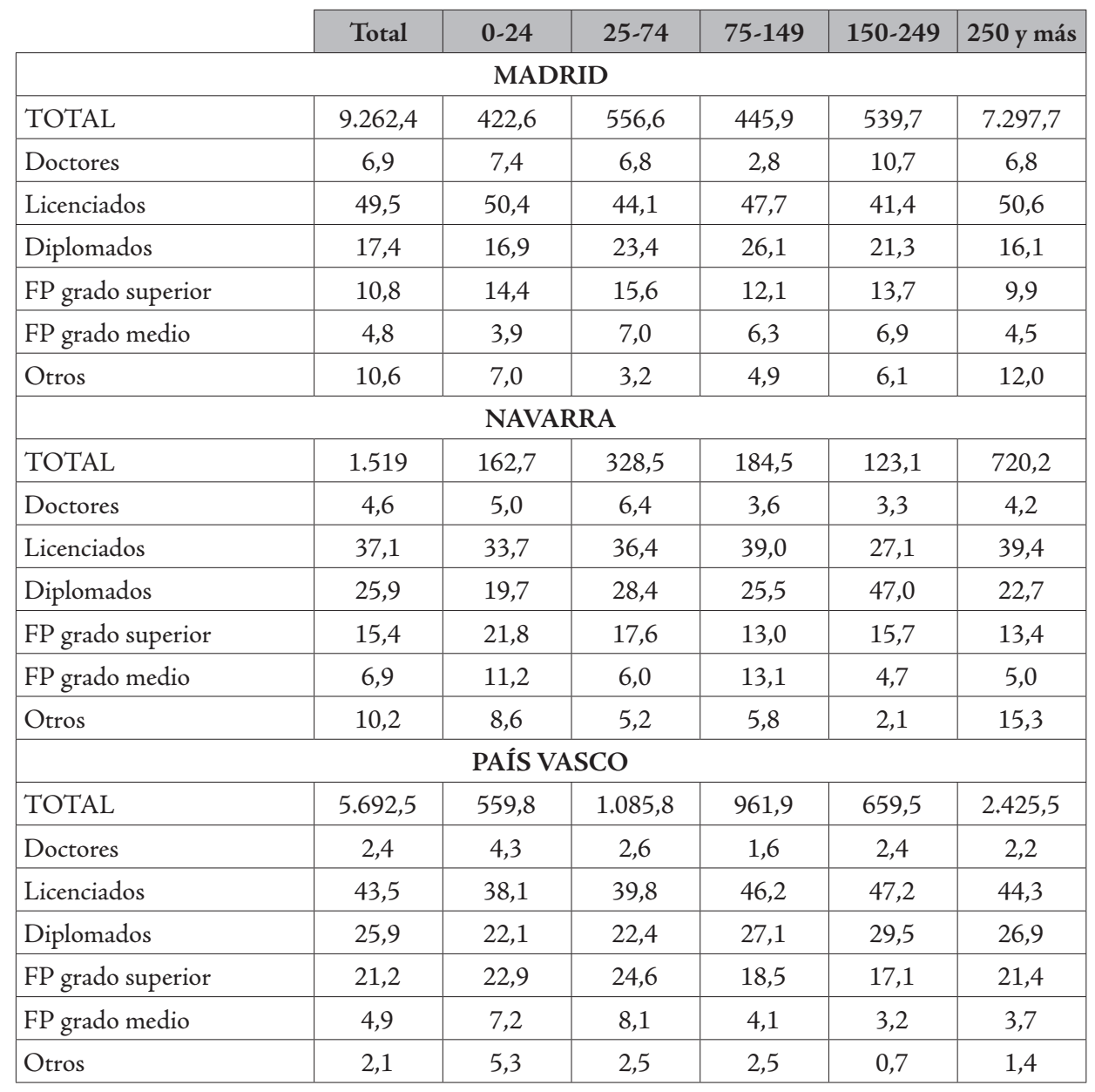

Fuente: INE y elaboración propia 
Tabla 3.12. Distribución (\%) del gasto en innovación en el sector industrial según tipo de actividad y región (2010)

\begin{tabular}{|l|c|c|c|c|c|c|c|}
\cline { 2 - 8 } \multicolumn{1}{l|}{} & Aragón & Asturias & Cataluña & Madrid & Navarra & $\begin{array}{c}\text { País } \\
\text { Vasco }\end{array}$ & España \\
\hline $\begin{array}{l}\text { Total } \\
\text { (miles de euros) }\end{array}$ & 387.104 & 79.049 & 2.325 .950 & 1.903 .490 & 222.458 & 871.166 & 7.499 .395 \\
\hline I+D interna & 26,34 & 46,19 & 42,68 & 55,92 & 63,39 & 58,13 & 46,51 \\
\hline $\begin{array}{l}\text { Adquisición de I+D } \\
\text { (I+D externa) }\end{array}$ & 2,98 & 11,66 & 29,66 & 22,41 & 16,20 & 18,40 & 20,62 \\
\hline $\begin{array}{l}\text { Adquisición de } \\
\text { maquinaria, } \\
\text { equipos y software }\end{array}$ & 11,90 & 26,01 & 16,94 & 13,43 & 14,74 & 15,58 & 19,52 \\
\hline $\begin{array}{l}\text { Adquisición de } \\
\text { conocimientos } \\
\text { externos }\end{array}$ & 55,81 & 0,19 & 2,32 & 0,28 & 0,96 & 1,44 & 5,73 \\
\hline Formación & 0,84 & 0,68 & 0,37 & 0,23 & 0,70 & 1,02 & 0,52 \\
\hline $\begin{array}{l}\text { Introducción de } \\
\text { innovaciones } \\
\text { en el mercado }\end{array}$ & 1,63 & 9,31 & 6,35 & 5,30 & 2,71 & 4,21 & 5,12 \\
\hline $\begin{array}{l}\text { Diseño, otros } \\
\text { preparativos para } \\
\text { producción y/o } \\
\text { distribución }\end{array}$ & 0,49 & 5,97 & 1,68 & 2,42 & 1,30 & 1,23 & 1,99 \\
\hline
\end{tabular}

Fuente: INE y elaboración propia

Tabla 3.13. Obtención de ayudas públicas a la innovación por parte de las empresas industriales según administración financiadora y región (\% de empresas) (2010)

\begin{tabular}{|l|c|c|c|c|c|c|c|}
\cline { 2 - 8 } \multicolumn{1}{c|}{} & Aragón & Asturias & Cataluña & Madrid & Navarra & $\begin{array}{c}\text { País } \\
\text { Vasco }\end{array}$ & España \\
\hline $\begin{array}{l}\text { \% empresas EIN que } \\
\text { han recibido } \\
\text { financiación pública }\end{array}$ & 30,3 & 39,8 & 23,3 & 17,9 & 40,0 & 43,7 & 28,8 \\
\hline $\begin{array}{l}\text { De administraciones } \\
\text { locales }\end{array}$ & 51,1 & 71,7 & 37,3 & 39,0 & 75,9 & 83,6 & 63,5 \\
\hline Admón. del Estado & 64,9 & 46,2 & 73,6 & 72,7 & 58,8 & 46,1 & 52,6 \\
\hline Unión Europea & 6,9 & 7,5 & 4,8 & 14,7 & 6,4 & 8,2 & 7,9 \\
\hline
\end{tabular}

Empresas EIN: empresas innovadoras o con innovaciones en curso o no exitosas

Los porcentajes de la administración financiadora están calculados sobre el total de empresas que reciben subvenciones

Fuente: INE y elaboración propia 
Tabla 3.14. Cooperación con agentes externos por parte de las empresas del sector industrial según partner de cooperación y región (\% de empresas) (2008-2010)

\begin{tabular}{|l|c|c|c|c|c|c|c|}
\cline { 2 - 8 } \multicolumn{1}{l|}{} & Aragón & Asturias & Cataluña & Madrid & Navarra & $\begin{array}{c}\text { País } \\
\text { Vasco }\end{array}$ & España \\
\hline $\begin{array}{l}\text { \% empresas EIN que han } \\
\text { cooperado en innovación }\end{array}$ & 25,2 & 23,7 & 21,1 & 19,9 & 24,8 & 34,4 & 22,1 \\
\hline $\begin{array}{l}\text { Otras empresas de su } \\
\text { mismo grupo }\end{array}$ & 19,3 & 22,2 & 28,4 & 43,0 & 39,7 & 31,3 & 25,9 \\
\hline $\begin{array}{l}\text { Proveedores de equipo, } \\
\text { material o software }\end{array}$ & 39,3 & 47,6 & 53,4 & 42,6 & 52,6 & 50,6 & 47,4 \\
\hline Clientes & 32,4 & 27,0 & 31,5 & 34,4 & 39,7 & 38,5 & 30,0 \\
\hline $\begin{array}{l}\text { Competidores u otras } \\
\text { empresas del sector }\end{array}$ & 20,0 & 17,5 & 18,3 & 21,1 & 9,5 & 15,3 & 16,6 \\
\hline $\begin{array}{l}\text { Consultores, laboratorios } \\
\text { comerciales o institutos } \\
\text { privados de I+D }\end{array}$ & 22,1 & 25,4 & 27,6 & 31,6 & 28,4 & 29,4 & 28,4 \\
\hline $\begin{array}{l}\text { Universidades u otros } \\
\text { centros de enseñanza } \\
\text { superior }\end{array}$ & 41,4 & 50,8 & 38,2 & 43,8 & 25,0 & 24,3 & 34,3 \\
\hline $\begin{array}{l}\text { Organismos públicos de } \\
\text { investigación }\end{array}$ & 22,8 & 17,5 & 17,9 & 28,9 & 17,2 & 13,8 & 17,6 \\
\hline Centros tecnológicos & 35,2 & 49,2 & 33,1 & 25,4 & 35,3 & 51,5 & 38,5 \\
\hline
\end{tabular}

Empresas EIN: empresas innovadoras o con innovaciones en curso o no exitosas

Los porcentajes de partners de cooperación están calculados sobre el total de empresas que cooperan

Fuente: INE y elaboración propia

\section{La FP en el ámbito regional: formación inicial o reglada}

\subsection{Recursos del sistema}

Tabla 3.15. Centros que imparten enseñanzas de formación profesional por grupo de ciclos formativos y región (curso 2009-2010)*

\begin{tabular}{|l|c|c|c|c|c|c|c|}
\cline { 2 - 8 } \multicolumn{1}{l|}{} & Aragón & Asturias & Cataluña & Madrid & Navarra & $\begin{array}{c}\text { País } \\
\text { Vasco }\end{array}$ & España \\
\hline \multicolumn{7}{|c|}{ FP grado medio } \\
\hline N. o de centros & 88 & 70 & 351 & 190 & 25 & 120 & 2.591 \\
\hline \% centros públicos & 67,0 & 68,6 & 67,0 & 64,2 & 76,0 & 52,5 & 73,7 \\
\hline \% centros privados & 33,0 & 31,4 & 33,0 & 35,8 & 24,0 & 47,5 & 26,3 \\
\hline \multicolumn{7}{|c|}{ FP grado superior } \\
\hline N.o de centros & 69 & 61 & 286 & 186 & 23 & 120 & 2.089 \\
\hline \% centros públicos & 69,6 & 75,4 & 67,1 & 66,7 & 73,9 & 54,2 & 76,1 \\
\hline \% centros privados & 30,4 & 24,6 & 32,9 & 33,3 & 26,1 & 45,8 & 23,9 \\
\hline
\end{tabular}

${ }^{*}$ Enseñanza presencial: régimen ordinario y adultos.

Fuente: «Las cifras de la educación en España», Ministerio de Educación, Cultura y Deporte 
Tabla 3.16. Alumnado en enseñanzas de formación profesional por grupo de ciclos formativos (curso 2009-2010)*

\begin{tabular}{|l|c|c|c|c|c|c|c|}
\cline { 2 - 9 } \multicolumn{1}{c|}{} & Aragón & Asturias & Cataluña & Madrid & Navarra & $\begin{array}{c}\text { País } \\
\text { Vasco }\end{array}$ & España \\
\hline \multicolumn{7}{|c|}{ FP grado medio } \\
\hline N. ${ }^{\circ}$ de alumnos & 8.066 & 5.418 & 45.597 & 25.743 & 3.380 & 11.068 & 271.990 \\
\hline \% centros públicos & 71,4 & 75,3 & 74,1 & 72,6 & 76,2 & 59,6 & 75,4 \\
\hline \% centros privados & 28,6 & 24,7 & 25,9 & 27,4 & 23,8 & 40,4 & 24,6 \\
\hline Tasa bruta escolarización & 35,0 & 35,2 & 34,4 & 22,0 & 30,7 & 33,1 & 30,8 \\
\hline \multicolumn{7}{|c|}{ FP grado superior } \\
\hline N. ${ }^{\circ}$ alumnos & 6.751 & 5.555 & 43.563 & 30.016 & 3.035 & 16.579 & 245.354 \\
\hline \% centros públicos & 70,4 & 82,8 & 70,5 & 73,4 & 76,7 & 52,3 & 78,1 \\
\hline \% centros privados & 29,6 & 17,2 & 29,5 & 26,6 & 23,3 & 47,7 & 21,9 \\
\hline Tasa bruta escolarización & 28,1 & 33,5 & 31,8 & 24,5 & 26,8 & 47,7 & 26,4 \\
\hline
\end{tabular}

*Enseñanza presencial: régimen ordinario y adultos.

* «Las tasas brutas de escolarización se calculan como la relación entre el total del alumnado de cualquier edad de la enseñanza considerada y la población del grupo de edad teórica de cursar dicha enseñanza. Las edades teóricas utilizadas han sido las siguientes: Ciclos Formativos de Grado Medio, 16-17 años; Ciclos Formativos de Grado Superior, 18-19 años. Para el cálculo de la tasa bruta de escolarización se ha tenido en cuenta el alumnado de enseñanza presencial: régimen ordinario y adultos».

Fuente: «Las cifras de la educación en España», Ministerio de Educación, Cultura y Deporte

Tabla 3.17. Evolución del alumnado en los ciclos de grado medio en las seis regiones (1998-2010)

\begin{tabular}{|l|c|c|c|c|c|c|c|}
\cline { 2 - 7 } \multicolumn{1}{c|}{} & Aragón & Asturias & Cataluña & Madrid & Navarra & $\begin{array}{c}\text { País } \\
\text { Vasco }\end{array}$ & España \\
\hline $1998-1999$ & 6.200 & 5.089 & 25.527 & 18.658 & 2.045 & 9.254 & 189.096 \\
\hline $1999-2000$ & 5.954 & 5.276 & 22.974 & 15.757 & 2.828 & 10.534 & 161.217 \\
\hline $2000-2001$ & 6.175 & 5.765 & 28.141 & 17.696 & 3.048 & 10.951 & 191.456 \\
\hline $2001-2002$ & 6.534 & 5.677 & 30.370 & 19.485 & 3.266 & 11.023 & 210.750 \\
\hline $2002-2003$ & 6.371 & 5.680 & 32.302 & 20.544 & 3.079 & 11.023 & 224.486 \\
\hline $2003-2004$ & 6.436 & 5.642 & 32.619 & 21.107 & 3.167 & 11.203 & 229.005 \\
\hline $2004-2005$ & 6.541 & 5.538 & 34.131 & 20.698 & 3.249 & 11.050 & 231.317 \\
\hline $2005-2006$ & 6.585 & 5.426 & 34.597 & 20.361 & 3.049 & 11.023 & 230.174 \\
\hline $2006-2007$ & 6.619 & 5.154 & 36.209 & 20.116 & 2.980 & 10.523 & 232.653 \\
\hline $2007-2008$ & 6.851 & 5.011 & 38.007 & 20.896 & 3.037 & 10.266 & 236.489 \\
\hline $2008-2009$ & 7.289 & 5.016 & 41.079 & 22.556 & 3.186 & 10.232 & 249.506 \\
\hline $2009-2010$ & 8.066 & 5.418 & 45.597 & 25.743 & 3.380 & 11.068 & 271.990 \\
\hline
\end{tabular}

Hasta el curso 1999-2000 se incluye el alumnado residual de FPI (formación profesional de I grado)

Fuente: «Las cifras de la educación en España», Ministerio de Educación, Cultura y Deporte 
Tabla 3.18. Evolución del alumnado en los ciclos de grado superior en las seis regiones (1998-2010)

\begin{tabular}{|l|c|c|c|c|c|c|c|}
\cline { 2 - 8 } \multicolumn{1}{c|}{} & Aragón & Asturias & Cataluña & Madrid & Navarra & $\begin{array}{c}\text { País } \\
\text { Vasco }\end{array}$ & España \\
\hline $1998-1999$ & 9.010 & 9.724 & 53.736 & 39.279 & 5.339 & 22.652 & 335.599 \\
\hline $1999-2000$ & 8.168 & 8.594 & 41.276 & 36.052 & 4.190 & 19.768 & 294.422 \\
\hline $2000-2001$ & 7.328 & 8.380 & 32.669 & 33.168 & 2.610 & 19.582 & 256.070 \\
\hline $2001-2002$ & 6.833 & 8.533 & 31.962 & 31.488 & 2.943 & 18.496 & 238.231 \\
\hline $2002-2003$ & 6.714 & 8.259 & 33.212 & 29.567 & 3.271 & 18.626 & 230.614 \\
\hline $2003-2004$ & 6.838 & 7.869 & 34.738 & 29.566 & 3.395 & 18.104 & 229.755 \\
\hline $2004-2005$ & 6.627 & 7.040 & 34.473 & 27.985 & 3.226 & 17.098 & 234.461 \\
\hline $2005-2006$ & 6.307 & 6.219 & 33.783 & 26.366 & 2.946 & 16.345 & 225.964 \\
\hline $2006-2007$ & 6.197 & 5.572 & 34.783 & 25.473 & 2.920 & 15.416 & 217.255 \\
\hline $2007-2008$ & 6.142 & 5.417 & 37.475 & 25.358 & 2.904 & 14.948 & 212.802 \\
\hline $2008-2009$ & 6.100 & 5.282 & 39.641 & 26.878 & 2.918 & 15.098 & 215.052 \\
\hline $2009-2010$ & 6.751 & 5.555 & 43.563 & 30.016 & 3.035 & 16.579 & 233.377 \\
\hline
\end{tabular}

Hasta el curso 2002-2003 se incluye el alumnado residual de FPII (formación profesional de II grado)

Fuente: «Las cifras de la educación en España», Ministerio de Educación, Cultura y Deporte

Tabla 3.19. Evolución de las tasas brutas de escolarización* en ciclos formativos de formación profesional (grado medio)

\begin{tabular}{|l|c|c|c|c|c|c|c|}
\cline { 2 - 7 } \multicolumn{1}{c|}{} & Aragón & Asturias & Cataluña & Madrid & Navarra & $\begin{array}{c}\text { País } \\
\text { Vasco }\end{array}$ & Espańa \\
\hline $1997-1998$ & 5,4 & 8,7 & 2,1 & 3,5 & 3,2 & 2,6 & 4,2 \\
\hline $1998-1999$ & 17,6 & 17,8 & 10,2 & 9,4 & 15,9 & 16,9 & 11,3 \\
\hline $1999-2000$ & 23,2 & 21,9 & 16,0 & 12,5 & 23,1 & 22,7 & 15,6 \\
\hline $2000-2001$ & 25,2 & 25,4 & 20,6 & 14,7 & 26,1 & 25,0 & 19,6 \\
\hline $2001-2002$ & 27,9 & 26,5 & 23,2 & 16,8 & 29,3 & 26,6 & 22,5 \\
\hline $2002-2003$ & 26,7 & 27,5 & 24,7 & 17,2 & 27,8 & 28,3 & 23,9 \\
\hline $2003-2004$ & 27,3 & 28,9 & 25,2 & 17,9 & 29,0 & 29,0 & 24,8 \\
\hline $2004-2005$ & 28,3 & 30,1 & 26,5 & 17,7 & 30,1 & 30,4 & 25,4 \\
\hline $2005-2006$ & 29,0 & 31,1 & 27,0 & 17,6 & 28,4 & 31,5 & 25,6 \\
\hline $2006-2007$ & 28,9 & 30,8 & 27,8 & 17,4 & 27,7 & 30,5 & 25,9 \\
\hline $2007-2008$ & 29,7 & 31,0 & 28,8 & 17,8 & 28,0 & 30,1 & 26,2 \\
\hline $2008-2009$ & 31,5 & 31,9 & 31,0 & 19,1 & 29,2 & 30,4 & 27,8 \\
\hline $2009-2010$ & 35,0 & 35,2 & 34,4 & 22,0 & 30,7 & 33,1 & 30,8 \\
\hline
\end{tabular}

* Las tasas brutas de escolarización se calculan como la relación entre el total de alumnado de cualquier edad de la enseñanza considerada y la población del grupo de edad teórica de cursar dicha enseñanza. Las edades teóricas utilizadas han sido las siguientes: Ciclos Formativos de Grado Medio, 16-17 años; Ciclos Formativos de Grado Superior, 18-19 años.

Fuente: «Las cifras de la educación en España», Ministerio de Educación, Cultura y Deporte 
Tabla 3.20. Evolución de las tasas brutas de escolarización* en ciclos formativos de formación profesional (grado superior)

\begin{tabular}{|l|c|c|c|c|c|c|c|}
\cline { 2 - 7 } \multicolumn{1}{c|}{} & Aragón & Asturias & Cataluña & Madrid & Navarra & $\begin{array}{c}\text { País } \\
\text { Vasco }\end{array}$ & España \\
\hline $1997-1998$ & 4,9 & 9,8 & 4,1 & 6,0 & 3,2 & 6,4 & 4,3 \\
\hline $1998-1999$ & 10,2 & 17,7 & 10,4 & 11,4 & 7,3 & 19,4 & 9,5 \\
\hline $1999-2000$ & 16,0 & 22,4 & 15,0 & 15,4 & 13,8 & 28,9 & 13,2 \\
\hline $2000-2001$ & 21,2 & 29,0 & 20,5 & 19,2 & 20,2 & 36,2 & 17,2 \\
\hline $2001-2002$ & 24,7 & 34,4 & 22,0 & 22,0 & 23,8 & 39,7 & 20,3 \\
\hline $2002-2003$ & 25,7 & 35,3 & 22,8 & 22,2 & 26,5 & 41,7 & 22,4 \\
\hline $2003-2004$ & 27,0 & 35,5 & 24,6 & 22,9 & 28,7 & 42,9 & 23,5 \\
\hline $2004-2005$ & 26,8 & 33,6 & 25,0 & 22,2 & 28,1 & 42,7 & 23,3 \\
\hline $2005-2006$ & 26,0 & 31,5 & 24,9 & 21,3 & 26,1 & 42,7 & 22,8 \\
\hline $2006-2007$ & 25,4 & 29,7 & 25,3 & 20,7 & 26,0 & 41,4 & 22,4 \\
\hline $2007-2008$ & 25,1 & 30,3 & 27,0 & 20,4 & 25,7 & 41,2 & 22,7 \\
\hline $2008-2009$ & 24,9 & 30,8 & 28,7 & 21,6 & 25,6 & 42,7 & 23,7 \\
\hline $2009-2010$ & 28,1 & 33,5 & 31,8 & 24,5 & 26,8 & 47,7 & 26,4 \\
\hline
\end{tabular}

* Las tasas brutas de escolarización se calculan como la relación entre el total de alumnado de cualquier edad de la enseñanza considerada y la población del grupo de edad teórica de cursar dicha enseñanza. Las edades teóricas utilizadas han sido las siguientes: Ciclos Formativos de Grado Medio, 16-17 años; Ciclos Formativos de Grado Superior, 18-19 años.

Fuente: «Las cifras de la educación en España», Ministerio de Educación, Cultura y Deporte

\section{2 Ámbitos de especialización (distribución del alumnado entre las diferen- tes familias profesionales)}

Tabla 3.21. Alumnado matriculado en ciclos formativos, por familia profesional (curso 2009-2010) (grado medio)*

\begin{tabular}{|l|c|c|c|c|c|c|c|}
\cline { 2 - 8 } \multicolumn{1}{c|}{} & Aragón & Asturias & Cataluña & Madrid & Navarra & $\begin{array}{c}\text { País } \\
\text { Vasco }\end{array}$ & $\begin{array}{c}\text { TOTAL } \\
\text { ESTATAL }\end{array}$ \\
\hline Total & 8.207 & 5.756 & 46.741 & 26.422 & 3.409 & 11.068 & 277.925 \\
\hline Act. Agrarias & 4,2 & 0,6 & 1,9 & 0,3 & 3,9 & 1,5 & 2,0 \\
\hline Act. Físicas y Deport. & 1,4 & 1,7 & 2,7 & 1,0 & 3,1 & 1,4 & 1,9 \\
\hline $\begin{array}{l}\text { Act. } \\
\text { Marítimo-Pesquera }\end{array}$ & 0,0 & 0,9 & 0,4 & 0,0 & 0,0 & 0,7 & 0,6 \\
\hline Administración & 20,9 & 13,3 & 13,6 & 22,1 & 17,5 & 9,0 & 19,0 \\
\hline Artes Gráficas & 0,9 & 1,1 & 1,2 & 2,2 & 1,7 & 1,5 & 1,0 \\
\hline Comercio y Marketing & 2,0 & 2,8 & 4,0 & 2,9 & 3,5 & 2,6 & 4,2 \\
\hline $\begin{array}{l}\text { Comunicación, } \\
\text { Imagen y Sonido }\end{array}$ & 1,0 & 1,3 & 0,7 & 2,0 & 0,0 & 0,7 & 1,1 \\
\hline
\end{tabular}




\begin{tabular}{|l|c|c|c|c|c|c|c|}
\cline { 2 - 8 } \multicolumn{1}{l|}{} & Aragón & Asturias & Cataluña & Madrid & Navarra & $\begin{array}{c}\text { País } \\
\text { Vasco }\end{array}$ & $\begin{array}{c}\text { TOTAL } \\
\text { ESTATAL }\end{array}$ \\
\hline $\begin{array}{l}\text { Edificación y } \\
\text { Obra Civil }\end{array}$ & 0,3 & 1,2 & 0,4 & 0,0 & 0,5 & 0,7 & 0,2 \\
\hline $\begin{array}{l}\text { Electricidad y } \\
\text { Electrónica }\end{array}$ & 13,2 & 10,5 & 10,2 & 13,0 & 12,0 & 11,4 & 11,2 \\
\hline Fabricación Mecánica & 5,6 & 8,8 & 3,1 & 2,7 & 11,8 & 16,5 & 4,0 \\
\hline Hostelería y Turismo & 4,7 & 4,4 & 4,7 & 4,1 & 2,9 & 5,2 & 4,5 \\
\hline Imagen Personal & 5,4 & 7,0 & 6,2 & 7,3 & 5,4 & 6,5 & 6,6 \\
\hline $\begin{array}{l}\text { Industrias } \\
\text { Alimentarias }\end{array}$ & 0,9 & 0,8 & 1,1 & 0,4 & 0,6 & 0,7 & 0,8 \\
\hline Informática & 5,6 & 4,4 & 11,1 & 9,9 & 0,0 & 5,3 & 8,0 \\
\hline Madera y Mueble & 0,9 & 1,2 & 1,0 & 0,5 & 2,2 & 2,0 & 0,9 \\
\hline $\begin{array}{l}\text { Manteni. y Servicios a } \\
\text { la Producción }\end{array}$ & 4,9 & 8,4 & 5,0 & 2,5 & 9,9 & 7,6 & 4,1 \\
\hline $\begin{array}{l}\text { Manteni. Vehículos } \\
\text { Autopropulsados }\end{array}$ & 9,5 & 9,1 & 9,3 & 10,4 & 8,7 & 8,9 & 8,8 \\
\hline Química & 0,9 & 1,8 & 1,5 & 0,8 & 1,6 & 0,5 & 1,0 \\
\hline Sanidad & 14,9 & 13,6 & 14,2 & 15,1 & 11,2 & 13,9 & 14,9 \\
\hline $\begin{array}{l}\text { Servicios } \\
\text { Socioculturales } \\
\text { Ya la Comunidad }\end{array}$ & 2,8 & 2,6 & 5,1 & 2,6 & 3,4 & 3,1 & 4,2 \\
\hline Textil, Confecc. y Piel & 0,0 & 0,4 & 0,2 & 0,1 & 0,0 & 0,1 & 0,2 \\
\hline Vidrio y Cerámica & 0,0 & 0,0 & 0,0 & 0,0 & 0,0 & 0,0 & 0,0 \\
\hline Energía y Agua & 0,0 & 0,0 & 0,0 & 0,0 & 0,0 & 0,0 & 0,0 \\
\hline $\begin{array}{l}\text { Sin distribuir por } \\
\text { familia }\end{array}$ & 0,0 & 4,1 & 2,4 & 0,0 & 0,0 & 0,0 & 0,9 \\
\hline & & & & & & & \\
\hline
\end{tabular}

* Incluye el alumnado de enseñanza presencial (regímenes ordinario y de adultos) y enseñanza a distancia, agrupando los ciclos LOGSE y LOE.

Fuente: «Las cifras de la educación en España», Ministerio de Educación, Cultura y Deporte 
Tabla 3.22. Alumnado matriculado en ciclos formativos, por familia profesional (curso 2009-2010) (grado superior)*

\begin{tabular}{|c|c|c|c|c|c|c|c|}
\hline & Aragón & Asturias & Cataluña & Madrid & Navarra & $\begin{array}{l}\text { País } \\
\text { Vasco }\end{array}$ & $\begin{array}{c}\text { TOTAL } \\
\text { ESTATAL }\end{array}$ \\
\hline Total & 6.994 & 6.217 & 47.272 & 30.640 & 3.035 & 16.579 & 259.646 \\
\hline Act. Agrarias & 3,9 & 1,4 & 1,2 & 0,5 & 2,3 & 0,9 & 1,7 \\
\hline Act. Físicas y Deport. & 3,4 & 2,3 & 4,6 & 5,0 & 1,4 & 3,4 & 3,9 \\
\hline $\begin{array}{l}\text { Act. } \\
\text { Marítimo-Pesquera }\end{array}$ & 0,0 & 1,2 & 0,4 & 0,0 & 0,0 & 1,0 & 0,5 \\
\hline Administración & 17,1 & 12,1 & 12,9 & 14,1 & 17,8 & 12,7 & 17,5 \\
\hline Artes Gráficas & 0,8 & 1,3 & 0,7 & 1,4 & 1,0 & 1,7 & 0,7 \\
\hline Comercio y Marketing & 7,8 & 6,5 & 5,5 & 6,1 & 11,7 & 4,9 & 5,6 \\
\hline $\begin{array}{l}\text { Comunicación, Imagen } \\
\text { y Sonido }\end{array}$ & 4,2 & 5,2 & 4,7 & 9,2 & 0,0 & 2,3 & 4,0 \\
\hline $\begin{array}{l}\text { Edificación y Obra } \\
\text { Civil }\end{array}$ & 3,2 & 3,4 & 3,0 & 2,7 & 1,8 & 3,9 & 3,6 \\
\hline $\begin{array}{l}\text { Electricidad y } \\
\text { Electrónica }\end{array}$ & 8,7 & 8,5 & 6,9 & 6,9 & 12,7 & 12,7 & 7,8 \\
\hline Fabricación Mecánica & 3,1 & 5,1 & 2,2 & 1,3 & 5,2 & 11,4 & 2,3 \\
\hline Hostelería y Turismo & 3,6 & 3,9 & 3,5 & 4,6 & 1,5 & 3,6 & 4,4 \\
\hline Imagen Personal & 1,8 & 1,7 & 1,7 & 2,6 & 1,3 & 1,2 & 1,9 \\
\hline $\begin{array}{l}\text { Industrias } \\
\text { Alimentarias }\end{array}$ & 0,5 & 0,4 & 0,5 & 0,3 & 0,4 & 0,1 & 0,4 \\
\hline Informática & 10,2 & 9,7 & 8,4 & 12,6 & 8,3 & 7,1 & 9,7 \\
\hline Madera y Mueble & 0,3 & 0,2 & 0,1 & 0,1 & 0,7 & 0,3 & 0,2 \\
\hline $\begin{array}{l}\text { Manteni. y Servicios a } \\
\text { la Producción }\end{array}$ & 4,4 & 6,0 & 2,9 & 1,2 & 11,4 & 6,9 & 3,9 \\
\hline $\begin{array}{l}\text { Manteni. de Vehículos } \\
\text { Autopropulsados }\end{array}$ & 3,9 & 2,2 & 2,5 & 3,5 & 1,4 & 2,9 & 2,8 \\
\hline Química & 2,3 & 1,9 & 3,4 & 1,4 & 1,4 & 2,8 & 2,0 \\
\hline Sanidad & 12,4 & 16,0 & 10,9 & 12,6 & 7,7 & 7,1 & 11,8 \\
\hline $\begin{array}{l}\text { Servicios } \\
\text { Socioculturales y a la } \\
\text { Comunidad }\end{array}$ & 7,8 & 11,1 & 15,8 & 13,3 & 10,7 & 12,2 & 13,6 \\
\hline Textil, Confecc. y Piel & 0,3 & 0,0 & 0,2 & 0,5 & 0,0 & 0,4 & 0,2 \\
\hline Vidrio y Cerámica & 0,0 & 0,0 & 0,0 & 0,0 & 0,0 & 0,0 & 0,0 \\
\hline Energía y Agua & 0,2 & 0,0 & 0,0 & 0,0 & 1,4 & 0,4 & 0,2 \\
\hline $\begin{array}{l}\text { Sin distribuir por } \\
\text { familia }\end{array}$ & 0,0 & 0,0 & 7,8 & 0,0 & 0,0 & 0,0 & 1,4 \\
\hline
\end{tabular}

* Incluye el alumnado de enseñanza presencial (regímenes ordinario y de adultos) y enseñanza a distancia, agrupando los ciclos LOGSE y LOE.

Fuente: «Las cifras de la educación en España», Ministerio de Educación, Cultura y Deporte 
Tabla 3.23. Evolución del porcentaje de alumnos matriculados en familias del sector industrial respecto al total de alumnos de FP (grado medio) (2000-2010)

\begin{tabular}{|l|c|c|c|c|c|c|c|}
\cline { 2 - 8 } \multicolumn{1}{c|}{} & Aragón & Asturias & Cataluña & Madrid & Navarra & $\begin{array}{c}\text { País } \\
\text { Vasco }\end{array}$ & España \\
\hline $2000-2001$ & 45,2 & 53,1 & 47,8 & 43,7 & 53,6 & 58,4 & 42,3 \\
\hline $2001-2002$ & 44,2 & 53,0 & 49,3 & 44,3 & 56,1 & 58,5 & 42,9 \\
\hline $2002-2003$ & 46,6 & 53,3 & 48,6 & 44,6 & 55,2 & 58,6 & 42,7 \\
\hline $2003-2004$ & 47,1 & 53,3 & 47,5 & 44,0 & 53,4 & 56,7 & 41,6 \\
\hline $2004-2005$ & 44,2 & 50,7 & 44,4 & 42,5 & 53,0 & 54,1 & 39,8 \\
\hline $2005-2006$ & 43,1 & 48,8 & 40,8 & 41,0 & 52,0 & 52,3 & 38,2 \\
\hline $2006-2007$ & 41,0 & 46,7 & 38,8 & 38,3 & 50,3 & 50,3 & 36,4 \\
\hline $2007-2008$ & 38,8 & 45,1 & 36,3 & 35,7 & 48,4 & 49,7 & 34,9 \\
\hline $2008-2009$ & 38,6 & 44,0 & 34,6 & 34,9 & 49,6 & 50,6 & 33,9 \\
\hline $2009-2010$ & 38,2 & 44,5 & 33,6 & 34,7 & 49,1 & 50,7 & 33,3 \\
\hline
\end{tabular}

Se incluyen, siguiendo la clasificación realizada por el Instituto Sindical de Trabajo, Ambiente y Salud (ISTAS-CC. OO.), las siguientes familias: Artes Gráficas; Comunicación, Imagen y Sonido; Edificación y Obra Civil; Electricidad y Electrónica; Fabricación Mecánica; Industrias Alimentarias; Madera y Mueble; Mantenimiento y Servicios a la Producción; Mantenimiento de Vehículos Autopropulsados; Química; Textil, Confección y Piel; Vidrio y Cerámica; Energía y Agua.

Fuente: «Las cifras de la Educación en España», Ministerio de Educación, Cultura y Deporte y elaboración propia

Tabla 3.24. Evolución del porcentaje de alumnos matriculados en familias del sector industrial respecto al total de alumnos de FP (grado superior) (2000-2010)

\begin{tabular}{|l|c|c|c|c|c|c|c|}
\cline { 2 - 8 } \multicolumn{1}{c|}{} & Aragón & Asturias & Cataluña & Madrid & Navarra & $\begin{array}{c}\text { País } \\
\text { Vasco }\end{array}$ & España \\
\hline $2000-2001$ & 35,3 & 29,2 & 34,5 & 30,9 & 27,6 & 47,5 & 30,1 \\
\hline $2001-2002$ & 33,5 & 28,6 & 33,1 & 29,6 & 29,4 & 46,0 & 28,6 \\
\hline $2002-2003$ & 32,1 & 29,7 & 31,9 & 29,2 & 31,0 & 44,8 & 28,0 \\
\hline $2003-2004$ & 33,1 & 32,4 & 32,8 & 30,3 & 34,0 & 45,4 & 28,6 \\
\hline $2004-2005$ & 34,2 & 33,3 & 33,0 & 30,8 & 35,7 & 46,0 & 29,6 \\
\hline $2005-2006$ & 34,7 & 35,6 & 33,6 & 31,1 & 37,0 & 46,8 & 30,5 \\
\hline $2006-2007$ & 34,8 & 36,7 & 33,5 & 31,4 & 35,9 & 47,2 & 31,0 \\
\hline $2007-2008$ & 33,2 & 37,3 & 32,0 & 29,5 & 35,5 & 46,3 & 29,7 \\
\hline $2008-2009$ & 31,8 & 35,7 & 29,5 & 28,7 & 37,6 & 45,9 & 28,8 \\
\hline $2009-2010$ & 31,9 & 34,1 & 27,2 & 28,7 & 37,3 & 45,9 & 28,0 \\
\hline
\end{tabular}

Se incluyen, siguiendo la clasificación realizada por el Instituto Sindical de Trabajo, Ambiente y Salud (ISTAS-CC. OO.), las siguientes familias: Artes Gráficas; Comunicación, Imagen y Sonido; Edificación y Obra Civil; Electricidad y Electrónica; Fabricación Mecánica; Industrias Alimentarias; Madera y Mueble; Mantenimiento y Servicios a la Producción; Mantenimiento de Vehículos Autopropulsados; Química; Textil, Confección y Piel; Vidrio y Cerámica; Energía y Agua.

Fuente: «Las cifras de la educación en España», Ministerio de Educación,

Cultura y Deporte y elaboración propia 


\section{La formación para el empleo (continua y ocupacional) en el ámbito regional}

\subsection{Normativa, políticas y presupuestos}

\subsection{La formación de oferta}

Tabla 3.25. Formación de oferta. Participantes formados según sector de actividad y región (2010)

\begin{tabular}{|l|c|c|c|c|c|c|c|}
\cline { 2 - 8 } \multicolumn{1}{c|}{} & Aragón & Asturias & Cataluña & Madrid & Navarra & País Vasco & España \\
\hline TOTAL & 33.498 & 17.664 & 100.534 & 128.175 & 7.710 & 25.585 & 784.966 \\
\hline Agricultura & 6,7 & 3,7 & 1,0 & 1,1 & 4,9 & 2,6 & 5,1 \\
\hline Industria & 26,8 & 23,0 & 33,4 & 20,3 & 22,9 & 22,4 & 22,7 \\
\hline Construcción & 6,8 & 9,7 & 21,0 & 8,8 & 15,6 & 8,8 & 10,9 \\
\hline Comercio & 15,2 & 10,8 & 13,2 & 8,2 & 10,5 & 15,7 & 13,3 \\
\hline Hostelería & 3,4 & 4,5 & 3,4 & 2,4 & 2,1 & 4,7 & 5,8 \\
\hline Servicios & 19,9 & 31,4 & 22,0 & 37,5 & 17,9 & 22,6 & 26,9 \\
\hline No asignado & 21,1 & 16,8 & 5,9 & 21,8 & 26,2 & 23,3 & 15,3 \\
\hline
\end{tabular}

Fuente: Fundación Tripartita para la Formación en el Empleo

Tabla 3.26. Formación de oferta. Sexo y edad de los participantes formados según región (2010)

\begin{tabular}{|l|c|c|c|c|c|c|c|}
\cline { 2 - 8 } \multicolumn{1}{c|}{} & Aragón & Asturias & Cataluña & Madrid & Navarra & País Vasco & España \\
\hline TOTAL & 33.498 & 17.664 & 100.534 & 128.175 & 7.710 & 25.585 & 784.966 \\
\hline Hombre & 54,4 & 54,5 & 64,5 & 52,2 & 49,5 & 51,5 & 54,2 \\
\hline Mujer & 45,6 & 45,5 & 35,5 & 47,8 & 50,5 & 48,5 & 45,8 \\
\hline 16 a 25 & 10,2 & 7,8 & 8,2 & 9,6 & 9,7 & 6,6 & 10,6 \\
\hline 26 a 35 & 34,3 & 38,4 & 34,5 & 41,2 & 34,3 & 33,0 & 37,6 \\
\hline 36 a 45 & 30,9 & 32,5 & 31,5 & 31,3 & 33,5 & 35,9 & 31,1 \\
\hline 46 a 55 & 19,5 & 16,9 & 19,7 & 14,7 & 18,7 & 19,9 & 16,7 \\
\hline$>55$ & 5,0 & 4,5 & 6,0 & 3,3 & 3,8 & 4,5 & 4,1 \\
\hline
\end{tabular}

Fuente: Fundación Tripartita para la Formación en el Empleo 
Tabla 3.27. Formación de oferta. Categoría profesional de los participantes formados según región (2010)

\begin{tabular}{|l|c|c|c|c|c|c|c|}
\cline { 2 - 8 } \multicolumn{1}{c|}{} & Aragón & Asturias & Cataluña & Madrid & Navarra & $\begin{array}{c}\text { País } \\
\text { Vasco }\end{array}$ & España \\
\hline Total & 33.498 & 17.664 & 100.534 & 128.175 & 7.710 & 25.585 & 784.966 \\
\hline Directivos & 9,9 & 12,8 & 12,4 & 5,5 & 8,9 & 12,0 & 10,2 \\
\hline Mandos intermedios & 5,8 & 6,4 & 7,6 & 9,1 & 12,9 & 13,5 & 6,4 \\
\hline Técnicos & 11,0 & 13,4 & 15,1 & 22,0 & 9,9 & 14,9 & 12,7 \\
\hline Trabajadores cualificados & 43,0 & 37,2 & 44,5 & 38,5 & 34,0 & 33,3 & 38,2 \\
\hline $\begin{array}{l}\text { Trabajadores no } \\
\text { cualificados }\end{array}$ & 30,3 & 30,3 & 20,4 & 24,9 & 34,3 & 26,4 & 32,5 \\
\hline
\end{tabular}

Fuente: Fundación Tripartita para la Formación en el Empleo

\subsection{La formación de demanda}

Tabla 3.28. Formación de demanda. Tasa de cobertura por región y tamaño empresarial (2010)

\begin{tabular}{|l|c|c|c|c|c|c|c|}
\cline { 2 - 8 } \multicolumn{1}{c|}{} & Aragón & Asturias & Cataluña & Madrid & Navarra & $\begin{array}{c}\text { País } \\
\text { Vasco }\end{array}$ & España \\
\hline Total & 21,6 & 27,7 & 18,1 & 19,6 & 22,4 & 24,1 & 24,6 \\
\hline De 1 a 5 & 15,3 & 22 & 11,8 & 13,5 & 14,6 & 16,9 & 18,7 \\
\hline De 6 a 9 & 33 & 42,7 & 27,6 & 27,9 & 29,8 & 33,8 & 36,8 \\
\hline De 10 a 49 & 48,8 & 53,5 & 42,6 & 41,1 & 47,8 & 47,9 & 49,6 \\
\hline De 50 a 249 & 74,2 & 79,7 & 72,9 & 68,3 & 83 & 79 & 74,4 \\
\hline Más de 249 & 91,5 & 87,3 & 90,8 & 87 & 85,9 & 92,7 & 89,7 \\
\hline Plantilla media & 29,4 & 22 & 41,9 & 77,5 & 33,5 & 35,9 & 28,4 \\
\hline $\begin{array}{l}\text { N. }{ }^{\circ} \text { medio de empleados } \\
\text { formados por empresa }\end{array}$ & 7 & 6 & 10 & 14 & 9 & 9 & 7 \\
\hline $\begin{array}{l}\text { Tasa de cobertura } \\
\text { industria manufacturera }\end{array}$ & 31,9 & 37,0 & 25,4 & 25,5 & 37,3 & 33,8 & 32,8 \\
\hline
\end{tabular}

Fuente: Fundación Tripartita para la Formación en el Empleo 
Tabla 3.29. Formación de demanda. Participantes formados según estrato de asalariados de la empresa y región (2010)

\begin{tabular}{|l|c|c|c|c|c|c|c|}
\cline { 2 - 8 } \multicolumn{1}{c|}{} & Aragón & Asturias & Cataluña & Madrid & Navarra & $\begin{array}{c}\text { País } \\
\text { Vasco }\end{array}$ & España \\
\hline Total empresas & 74.107 & 60.108 & 515.171 & 556.840 & 40.986 & 149.816 & 2.771 .069 \\
\hline 1 a 9 & 13,1 & 15,7 & 9,5 & 6,7 & 9,6 & 10,8 & 13,9 \\
\hline 10 a 49 & 18,2 & 15,7 & 16,7 & 10,5 & 17,4 & 20,0 & 17,0 \\
\hline 50 a 99 & 9,5 & 7,6 & 8,4 & 6,1 & 9,4 & 11,6 & 8,0 \\
\hline 100 a 249 & 10,4 & 10,0 & 12,5 & 10,2 & 16,2 & 12,6 & 10,4 \\
\hline$>249$ & 48,8 & 51,1 & 52,9 & 66,5 & 47,2 & 45,0 & 50,7 \\
\hline Empresas manufactureras & 17.495 & 10.830 & 107.297 & 67.522 & 13.285 & 35.747 & 434.450 \\
\hline 1 a 9 & 6,4 & 6,3 & 5,2 & 3,9 & 4,1 & 6,2 & 8,9 \\
\hline 10 a 49 & 18,3 & 17,4 & 16,1 & 10,2 & 14,9 & 22,7 & 20,0 \\
\hline 50 a 99 & 11,7 & 10,0 & 9,8 & 6,2 & 10,3 & 11,4 & 9,8 \\
\hline 100 a 249 & 19,3 & 16,7 & 18,0 & 11,9 & 21,4 & 15,5 & 15,6 \\
\hline$>249$ & 44,4 & 49,6 & 50,8 & 67,7 & 49,3 & 44,2 & 45,7 \\
\hline
\end{tabular}

Fuente: Fundación Tripartita para la Formación en el Empleo

Tabla 3.30. Formación de demanda. Participantes formados según sector empresarial y región (2010)

\begin{tabular}{|l|c|c|c|c|c|c|c|}
\cline { 2 - 8 } \multicolumn{1}{c|}{} & Aragón & Asturias & Cataluña & Madrid & Navarra & $\begin{array}{c}\text { País } \\
\text { Vasco }\end{array}$ & España \\
\hline Total & 74.107 & 60.108 & 515.171 & 556.840 & 40.986 & 149.816 & 2.771 .069 \\
\hline Agricultura & 2,2 & 0,6 & 0,8 & 0,3 & 0,9 & 0,6 & 1 \\
\hline Industria & 26,6 & 24 & 21,8 & 11,6 & 36,9 & 26,2 & 18,7 \\
\hline Construcción & 13 & 10,8 & 8,8 & 7,6 & 11,4 & 10 & 11,4 \\
\hline Comercio & 17,8 & 21,3 & 16,9 & 16 & 10,7 & 11,1 & 17,2 \\
\hline Hostelería & 4,1 & 5,8 & 6,1 & 5,8 & 3,1 & 3,9 & 6,6 \\
\hline Otros servicios & 36,4 & 37,5 & 45,6 & 58,7 & 36,9 & 48,3 & 45,1 \\
\hline
\end{tabular}

Fuente: Fundación Tripartita para la Formación en el Empleo 
Tabla 3.31. Formación de demanda. Sexo y edad de los participantes formados según región (2010)

\begin{tabular}{|l|c|c|c|c|c|c|c|}
\cline { 2 - 8 } \multicolumn{1}{c|}{} & Aragón & Asturias & Cataluña & Madrid & Navarra & $\begin{array}{c}\text { País } \\
\text { Vasco }\end{array}$ & España \\
\hline Total & 74.107 & 60.108 & 515.171 & 556.840 & 40.986 & 149.816 & 2.771 .069 \\
\hline Hombres & 59,8 & 57,9 & 54,6 & 54,6 & 59,5 & 57,3 & 57,6 \\
\hline Mujeres & 40,2 & 42,1 & 45,4 & 45,4 & 40,5 & 42,7 & 42,4 \\
\hline 16 a 25 & 7,3 & 6,2 & 7,9 & 6,8 & 6,6 & 5,4 & 7,6 \\
\hline $26-45$ & 67,4 & 68,1 & 67,4 & 70,0 & 69,7 & 67,6 & 68,5 \\
\hline 46 y más & 25,3 & 25,7 & 24,7 & 23,1 & 23,8 & 27,0 & 23,9 \\
\hline Manufactureras & 17.344 & 11.929 & 100.874 & 49.978 & 13.686 & 34.812 & 434.599 \\
\hline Hombres & 74,9 & 82,0 & 68,9 & 67,1 & 74,6 & 78,0 & 73,1 \\
\hline Mujeres & 25,1 & 18,0 & 31,1 & 32,9 & 25,4 & 22,0 & 26,9 \\
\hline 16 a 25 & 4,7 & 5,2 & 4,4 & 4,3 & 5,8 & 4,2 & 5,4 \\
\hline $26-45$ & 70,9 & 66,4 & 69,5 & 71,4 & 71,4 & 70,0 & 69,9 \\
\hline 46 y más & 24,4 & 28,5 & 26,1 & 24,3 & 22,8 & 25,8 & 24,7 \\
\hline
\end{tabular}

Fuente: Fundación Tripartita para la Formación en el Empleo

Tabla 3.32. Formación de demanda. Categoría profesional de los participantes formados según región (2010)

\begin{tabular}{|l|c|c|c|c|c|c|c|}
\cline { 2 - 8 } \multicolumn{1}{l|}{} & Aragón & Asturias & Cataluña & Madrid & Navarra & $\begin{array}{c}\text { País } \\
\text { Vasco }\end{array}$ & España \\
\hline Total & 74.107 & 60.108 & 515.171 & 556.840 & 40.986 & 149.816 & 2.771 .069 \\
\hline Directivos & 4 & 3 & 3,7 & 4,3 & 5,1 & 4,2 & 3,6 \\
\hline Mandos intermedios & 10,4 & 11,3 & 11,7 & 14,2 & 11,6 & 10,3 & 10,9 \\
\hline Técnicos & 20,1 & 17,1 & 20,2 & 26,2 & 23,6 & 22,9 & 18,7 \\
\hline Trabajadores cualificados & 45,7 & 46,1 & 45,6 & 36,9 & 41,3 & 45,9 & 46 \\
\hline $\begin{array}{l}\text { Trabajadores no } \\
\text { cualificados }\end{array}$ & 19,8 & 22,6 & 18,8 & 18,4 & 18,3 & 16,6 & 20,9 \\
\hline Manufactureras & 17.495 & 10.830 & 107.297 & 67.522 & 13.433 & 35.747 & 434.599 \\
\hline Directivos & 5,1 & 2,6 & 5,2 & 3,9 & 7,9 & 6,0 & 4,8 \\
\hline Mandos intermedios & 14,7 & 12,6 & 14,1 & 13,9 & 13,9 & 12,7 & 12,6 \\
\hline Técnicos & 20,8 & 15,5 & 22,3 & 33,4 & 23,4 & 25,7 & 20,7 \\
\hline Trabajadores cualificados & 39,9 & 44,5 & 42,5 & 36,5 & 35,1 & 40,1 & 43,3 \\
\hline $\begin{array}{l}\text { Trabajadores no } \\
\text { cualificados }\end{array}$ & 19,5 & 24,9 & 15,9 & 12,2 & 19,7 & 15,6 & 18,6 \\
\hline
\end{tabular}

Fuente: Fundación Tripartita para la Formación en el Empleo 
Tabla 3.33. Formación de demanda. Nivel educativo de los participantes formados según región (2010)

\begin{tabular}{|l|c|c|c|c|c|c|c|}
\cline { 2 - 8 } \multicolumn{1}{l|}{} & Aragón & Asturias & Cataluña & Madrid & Navarra & $\begin{array}{c}\text { País } \\
\text { Vasco }\end{array}$ & España \\
\hline Total & 74.107 & 60.108 & 515.171 & 556.840 & 40.986 & 149.816 & 2.771 .069 \\
\hline Sin estudios & 1,9 & 1,8 & 1,7 & 1,5 & 1,7 & 1,4 & 2,1 \\
\hline $\begin{array}{l}\text { Primarios y secundaria } \\
\text { obligatoria }\end{array}$ & 28,3 & 26,1 & 27,7 & 23,1 & 24,9 & 19,9 & 30,1 \\
\hline $\begin{array}{l}\text { Secundarios } \\
\text { postobligatorios }\end{array}$ & 37,2 & 43,7 & 38,8 & 35,8 & 35,1 & 42,1 & 37,0 \\
\hline Universitarios & 31,7 & 27,5 & 30,9 & 38,4 & 37,3 & 35,7 & 29,8 \\
\hline Industria & 19.816 & 14.141 & 109.585 & 59.565 & 15.207 & 37.829 & 499.731 \\
\hline Sin estudios & 1,8 & 0,9 & 1,3 & 0,7 & 2,0 & 2,2 & 1,5 \\
\hline $\begin{array}{l}\text { Primarios y secundaria } \\
\text { obligatoria }\end{array}$ & 26,8 & 27,7 & 26,5 & 17,3 & 20,6 & 17,1 & 29,1 \\
\hline $\begin{array}{l}\text { Secundarios } \\
\text { postobligatorios }\end{array}$ & 35,7 & 45,6 & 43,1 & 35,9 & 40,6 & 47,1 & 39,8 \\
\hline Universitarios & 35,5 & 25,4 & 28,7 & 45,5 & 36,6 & 33,3 & 29,2 \\
\hline
\end{tabular}

Fuente: Fundación Tripartita para la Formación en el Empleo

Tabla 3.34. Permisos individuales de formación según tamaño de la plantilla (2010)

\begin{tabular}{|l|c|c|c|c|c|c|c|}
\cline { 2 - 8 } \multicolumn{1}{c|}{} & Aragón & Asturias & Cataluña & Madrid & Navarra & $\begin{array}{c}\text { País } \\
\text { Vasco }\end{array}$ & España \\
\hline Total & 52 & 38 & 913 & 1,069 & 52 & 132 & 3.335 \\
\hline Micropyme & 9,6 & 7,9 & 1,5 & 0,4 & 0,0 & 4,5 & 3,3 \\
\hline Mediana empresa & 30,8 & 5,3 & 24,9 & 8,2 & 50,0 & 32,6 & 23,3 \\
\hline Gran empresa & 59,6 & 86,8 & 73,6 & 91,4 & 50,0 & 62,9 & 73,4 \\
\hline
\end{tabular}

Fuente: Fundación Tripartita para la Formación en el Empleo

Tabla 3.35. Procedencia de los recursos económicos de la formación profesional para el empleo

\begin{tabular}{|l|c|c|c|c|c|}
\cline { 2 - 6 } \multicolumn{1}{c|}{} & $\mathbf{2 0 0 7}$ & $\mathbf{2 0 0 8}$ & $\mathbf{2 0 0 9}$ & $\mathbf{2 0 1 0}$ & $\mathbf{2 0 1 1}$ \\
\hline Total (miles de euros) & $2.243 .065,1$ & $2.388 .938,5$ & $2.558 .112,6$ & $2.571 .633,1$ & $3.013 .800,7$ \\
\hline Ingreso cuota formación & 79,5 & 82,7 & 85,0 & 83,7 & 65,7 \\
\hline $\begin{array}{l}\text { Dotación Fondo Social } \\
\text { Europeo }\end{array}$ & 19,5 & 14,3 & 9,8 & 9,7 & 3,3 \\
\hline $\begin{array}{l}\text { Mayor recaudación cuota } \\
\text { ejercicio anterior }\end{array}$ & 1,0 & 3,0 & 5,0 & 0,8 & 0,0 \\
\hline Aportación del Estado & 0 & 0 & 0,2 & 5,8 & 31,0 \\
\hline
\end{tabular}

Fuente: Fundación Tripartita para la Formación en el Empleo 
Tabla 3.36. Distribución de los recursos económicos de la formación profesional para el empleo según ámbitos de gestión

\begin{tabular}{|l|c|c|c|}
\cline { 2 - 4 } \multicolumn{1}{c|}{} & $\mathbf{2 0 0 8}$ & $\mathbf{2 0 0 9}$ & $\mathbf{2 0 1 0}$ \\
\hline Total (miles de euros) & $2.388 .938,5$ & $2.558 .112,6$ & $2.571 .633,1$ \\
\hline Fondos de gestión estatal & 48,0 & 49,8 & 51,0 \\
\hline Fondos de gestión autonómica & 52,0 & 50,2 & 49,0 \\
\hline
\end{tabular}

Fuente: Fundación Tripartita para la Formación en el Empleo

Tabla 3.37. Distribución de los recursos económicos de la formación profesional para el empleo según destinatarios

\begin{tabular}{|l|c|c|c|c|c|}
\cline { 2 - 6 } \multicolumn{1}{c|}{} & 2007 & 2008 & 2009 & 2010 & 2011 \\
\hline Total (miles de euros) & $2.243 .065,1$ & $2.388 .938,5$ & $2.558 .112,6$ & $2.571 .633,1$ & $3.013 .800,7$ \\
\hline $\begin{array}{l}\text { Fondos para trabajadores } \\
\text { ocupados }\end{array}$ & 58,1 & 59,8 & 58,9 & 60,1 & 47,5 \\
\hline $\begin{array}{l}\text { Fondos para trabajadores } \\
\text { desempleados }\end{array}$ & 41,6 & 40,2 & 41,1 & 39,9 & 52,5 \\
\hline
\end{tabular}

Fuente: Fundación Tripartita para la Formación en el Empleo 


\section{Índice sistemático}

$\begin{array}{ll}\text { INTRODUCCIÓN } & 7\end{array}$

$\begin{array}{ll}\text { 1. Preguntas de investigación } & 7\end{array}$

2. Entorno regional, formación profesional e innovación: el marco teórico del estudio 8

3. Marco normativo de la formación profesional 11

4. Regiones estudiadas 14

$\begin{array}{ll}\text { Bibliografía } & 17\end{array}$

COMUNIDAD DE ARAGÓN 21

1. Entorno socioeconómico regional 23

1.1 Datos socioeconómicos básicos de referencia y características del tejido productivo 23

1.2 Indicadores de investigación, desarrollo e innovación 24

$\begin{array}{ll}\text { 1.3 Sistema institucional de agentes de } \mathrm{I}+\mathrm{D}+\mathrm{i} & 26\end{array}$

1.4 Política de I+D+i en el ámbito regional 28

2. La FP en el ámbito regional 29

2.1 Formación reglada: recursos del sistema $\quad 29$

2.2 Formación reglada: ámbitos de especialización $\quad 32$

2.3 Formación para el empleo: la formación de oferta 33

2.4 Formación para el empleo: la formación de demanda $\quad 35$

2.5 Política regional en relación con la FP 37

2.6 Prácticas de formación en centros de trabajo (FCT) 43

2.7 Otros tipos de relaciones entre los centros de FP y las empresas.

3. Conclusiones 49

Anexos $\quad 51$

Anexo I. Ficha técnica $\quad 51$

Anexo II. Red de agentes de I+D+i de la Comunidad de Aragón 51

Anexo III. Formación en Aragón 2010: programación y presupuestos 52

PRINCIPADO DE ASTURIAS

1. Entorno socioeconómico regional

1.1 Datos socioeconómicos básicos de referencia y características del tejido productivo $\quad 57$

1.2 Indicadores de investigación, desarrollo e innovación 58 
1.3 Sistema institucional y agentes de I+D+i $\quad 61$

$\begin{array}{ll}1.4 \text { Política de I+D en el ámbito regional } & 61\end{array}$

2. La FP en el ámbito regional 63

$\begin{array}{ll}2.1 \text { Formación reglada: recursos del sistema } & 63\end{array}$

2.2. Formación reglada: ámbitos de especialización 63

2.3 Formación para el empleo: la formación de oferta 65

2.4 Formación para el empleo: la formación de demanda 66

$\begin{array}{ll}2.5 \text { Política regional en relación con la FP } & 67\end{array}$

2.6 Prácticas de formación en centros de trabajo (FCT) 69

2.7 Otros tipos de relaciones entre los centros de FP y las empresas.

$\begin{array}{ll}2.8 \text { Cultura y sociedad } & 79\end{array}$

Conclusiones $\quad 82$

$\begin{array}{ll}\text { Anexos } & 84\end{array}$

Anexo I. Ficha técnica $\quad 84$

Anexo II. Agentes del sistema asturiano de ciencia, tecnología e innovación 84

$\begin{array}{ll}\text { CATALUNA } & 87\end{array}$

1. Entorno socioeconómico regional $\quad 89$

1.1 Datos socioeconómicos básicos de referencia y características del tejido productivo $\quad 89$

1.2 Indicadores de investigación, desarrollo e innovación 90

1.3 Sistema institucional de agentes de $\mathrm{I}+\mathrm{D}+\mathrm{i} \quad 92$

1.4 Política de I+D+i en el ámbito regional 93

2. La FP en el ámbito regional 94

2.1 Formación reglada: recursos del sistema 94

2.2 Formación reglada: ámbitos de especialización $\quad 97$

2.3 Formación para el empleo: la formación de oferta 98

2.4 Formación para el empleo: la formación de demanda 104

$\begin{array}{ll}2.5 \text { Política regional en relación con la FP } & 105\end{array}$

2.6 Prácticas de formación en centros de trabajo (FCT) 110

2.7 Otros tipos de relaciones entre los centros de FP y las empresas.
Papel de los centros de FP en la formación para el empleo

3. Conclusiones 119

$\begin{array}{ll}\text { Anexos } & 121\end{array}$

$\begin{array}{ll}\text { Anexo I. Ficha técnica } & 121\end{array}$

Anexo II. Red de agentes de I+D+I de Cataluña 121

Anexo III. Programas de políticas activas de empleo en Cataluña. 2010

$\begin{array}{ll}\text { MADRID } & 129\end{array}$

1. Entorno socioeconómico regional 131

$\begin{array}{ll}\text { 1.1 Datos económicos básicos de referencia } & 131\end{array}$

1.2 Indicadores de investigación, desarrollo e innovación 132

1.3 Sistema institucional de agentes de I+D+i 134 
1.4 Política de I+D en el ámbito regional

2. La FP en el ámbito regional 137

$\begin{array}{ll}2.1 \text { Formación reglada: recursos del sistema } & 137\end{array}$

$\begin{array}{ll}2.2 \text { Formación reglada: ámbitos de especialización } & 138\end{array}$

2.3 Formación para el empleo: la formación de oferta $\quad 140$

2.4 Formación para el empleo: la formación de demanda $\quad 140$

$\begin{array}{ll}2.5 \text { Política regional en relación con la FP } & 141\end{array}$

2.6 Prácticas de formación en centros de trabajo (FCT) 144

2.7 Otros tipos de relaciones entre los centros de FP y las empresas.

$\begin{array}{ll}\text { Papel de los centros de FP en la formación para el empleo } & 147\end{array}$

3. Conclusiones 150

4. Anexos 152

I Ficha técnica $\quad 152$

II Agentes de I+D+i en la CM 152

Centros de innovación y tecnología de la Comunidad de Madrid 154

$\begin{array}{ll}\text { Estructuras de interfaz de la Comunidad de Madrid } & 154\end{array}$

III Programas, instrumentos y beneficiarios del PRICIT 155

$\begin{array}{ll}\text { 5. Bibliografía } & 158\end{array}$

$\begin{array}{lr}\text { Legislación y normativa } & 159\end{array}$

COMUNIDAD FORAL DE NAVARRA (CFN) 161

1. Entorno socioeconómico regional 163

1.1 Datos socioeconómicos básicos de referencia y características del tejido productivo 163

$\begin{array}{ll}1.2 \text { Indicadores de investigación, desarrollo e innovación } & 164\end{array}$

1.3 Sistema institucional de agentes de I+D+i 166

1.4 Política de I+D+i en el ámbito regional 166

2. La FP en el ámbito regional 167

$\begin{array}{ll}2.1 \text { Formación reglada: recursos del sistema } & 167\end{array}$

2.2 Formación reglada: ámbitos de especialización 168

$\begin{array}{ll}2.3 \text { Formación para el empleo: la formación de oferta } & 170\end{array}$

2.4 Formación para el empleo: la formación de demanda $\quad 170$

$\begin{array}{ll}2.5 \text { Política regional en relación con la FP } & 171\end{array}$

2.6 Prácticas de formación en centros de trabajo (FCT) 172

$\begin{array}{ll}2.7 \text { Otros tipos de relaciones entre los centros de FP y las empresas. } & \\ \text { Papel de los centros de FP en la formación para el empleo } & 175\end{array}$

$\begin{array}{ll}\text { 3. Conclusiones } & 179\end{array}$

$\begin{array}{ll}\text { Anexos } & 181\end{array}$

$\begin{array}{ll}\text { Anexo I. Ficha técnica } & 181\end{array}$

$\begin{array}{ll}\text { Anexo II. Red de agentes institucionales de I+D+i de la CFN } & 181\end{array}$

COMUNIDAD AUTÓNOMA DEL PAÍS VASCO (CAPV) 189

1. Entorno socioeconómico regional 191

1.1 Datos socioeconómicos básicos de referencia y características del tejido productivo 191 
1.2 Indicadores de investigación, desarrollo e innovación

1.3 Política de $\mathrm{I}+\mathrm{D}+\mathrm{i}$ en el ámbito regional

1.4 Sistema institucional de agentes de $\mathrm{I}+\mathrm{D}+\mathrm{i}$

2. La FP en el ámbito regional

2.1 Formación reglada: recursos del sistema

2.2 Formación reglada: ámbitos de especialización

2.3 Formación para el empleo: la formación de oferta

2.4 Formación para el empleo: la formación de demanda

2.5 Política regional en relación con la FP

2.6 Relaciones entre los centros de FP y las empresas

Anexos

Anexo I. Ficha técnica

CONCLUSIONES GENERALES

1. Entorno regional y formación profesional

2. El papel de las prácticas de formación en centros de trabajo (FCT)

3. Formación para el empleo

4. Servicios técnicos

5. Consideraciones finales

1. Entorno económico regional

1.1 Datos socioeconómicos básicos de referencia y características del tejido productivo

1.2 Indicadores de investigación, desarrollo e innovación

2. La FP en el ámbito regional: formación inicial o reglada

2.1 Recursos del sistema

2.2 Ámbitos de especialización

(distribución del alumnado entre las diferentes familias profesionales)

3. La formación para el empleo (continua y ocupacional) en el ámbito regional

3.1 Normativa, políticas y presupuestos

3.2 La formación de oferta

3.3 La formación de demanda 

La formación profesional es un pilar, no suficientemente reconocido, del desarrollo económico y social, además de ser un agente central en el estímulo de la capacidad de innovación empresarial y en la mejora de la productividad. Por esto es importante tener en cuenta el papel de los trabajadores intermedios en los procesos de innovación de las pymes industriales.

Las principales preguntas a las que se responde en este libro son las siguientes:

- ¿Cómo se relacionan los centros de formación profesional y las empresas, y cuál es el alcance de los distintos tipos de relación?

- ¿Hasta qué punto realizan los centros de FP actividades como la formación continua y el apoyo a la innovación? ¿Qué potencialidades y dificultades existen al respecto?

- Y, en general, ¿cómo incide el entorno regional en la configuración del sistema de formación profesional y en la relación entre este y las empresas? 